\title{
VOLATILE TRANSPORT OF METALS IN THE ANDESITIC MAGMATIC-HYDROTHERMAL SYSTEM OF WHITE ISLAND
}

by

Céline Lucie Mandon

\begin{abstract}
A thesis
Submitted to the Victoria University of Wellington In fulfilment of the requirements for the degree of Doctor of Philosophy
\end{abstract}

Victoria University of Wellington

School of Geography, Environment and Earth Sciences

Wellington, New Zealand June 2017 



\section{Abstract}

Volcanic gases observed at active volcanoes originate from the magma at depth. These volatiles exsolve as a result of decompression, crystallization and cooling of the silicate melt. The transport of metals in a magmatic volatile phase arises from complexation with the main volatile species, sulfur and halides. Composition of the magma, temperature, pressure and redox state have thus strong implications on metal mobility in these environments. Moreover, a variety of interactions and phase separations can affect these fluids after exsolution from the parental magma. This thesis aims at constraining the volatile transport of trace metals at White Island, a subduction-related magmatic-hydrothermal system, through a characterization and metal budget of the magmatic reservoir and the different atmospheric discharges.

The metal content of the reservoir, as well as the effects of degassing and magma mixing on the magma are explored through the study of ejecta from the 1976-2000 eruptive cycle. $\mathrm{CO}_{2}$, $\mathrm{SO}_{2}$ and $\mathrm{H}_{2} \mathrm{O}$ are degassing from a mafic melt at $\sim 5 \mathrm{~km}$ depth, regularly feeding a shallower and evolved reservoir at $~ 800 \mathrm{~m}$. Average contents of $164 \mathrm{ppm}$ of $\mathrm{Cu}, 73 \mathrm{ppm}$ of $\mathrm{Zn}, 12 \mathrm{ppm}$ of $\mathrm{Pb}$ and $0.4 \mathrm{ppm}$ of $\mathrm{Au}$ and $\mathrm{Ag}$ were detected in melt inclusions. A fraction of these metals partition into the exsolving aqueous fluid. Onset of magnetite crystallization may trigger exsolution of sulphide melt, found to contain around $30 \mathrm{wt} \%$ of $\mathrm{Cu}$, and as much as $36 \mathrm{wt} \%$ $\mathrm{Ni}, 21 \mathrm{wt} \% \mathrm{Ag}, 0.10 \mathrm{wt} \% \mathrm{Au}$ in small inclusions, representing a considerable source of metals available for an aqueous fluid phase upon resorption.

The volatile transport of metals is indicated by their enrichment in a variety of discharges at the surface. The hyperacidic waters of the crater lake absorb metals from the magmatic gases injected at subaqueous vents. Concentrations of $\sim 12 \mathrm{ppm}$ of As and $\mathrm{Zn}, 6 \mathrm{ppm}$ of $\mathrm{Cu}$ and $\mathrm{Pb}$ were observed. Hydrolysis of the host rock by the reactive waters is responsible for the high cation contents of the fluids. Precipitation of secondary minerals such as silica, anhydrite, gypsum, sulfur and alunite occurs within and underneath the crater lake. The predicted speciation of metals greatly varies, dominated by $\mathrm{Cu}^{\mathrm{I}}$ and $\mathrm{Fe}^{\mathrm{II}}$ chloride complexes in the more reduced environment at the lake bottom, whereas $\mathrm{Cu}^{\mathrm{II}}$ and $\mathrm{Fe}^{\mathrm{III}}$ are stable in the oxidized surficial waters. Arsenic is mainly present as $\mathrm{As}(\mathrm{OH})_{3}$ at depth, with $\mathrm{H}_{3} \mathrm{AsO}_{4}$ dominating at the surface. $\mathrm{Ag}, \mathrm{Pb}$ and $\mathrm{Zn}$ are complexed with chloride, and are not redox dependent. The presence of a body of molten sulfur at the bottom of the lake is indicated by sulfur spherules, both floating at the lake surface and in sediments. Pyrite crystals coat the surface of some globules, and chemical analyses reveal an enrichment in a variety of chalcophile metals ( $\mathrm{Tl}$, $\mathrm{Sb}, \mathrm{Bi}, \mathrm{Au}, \mathrm{As}, \mathrm{Ag}$. Re, $\mathrm{Cu}$ ).

The volcanic gases emitted at fumaroles are enriched in metals compared to the magma. The effective transport of $\mathrm{Se}, \mathrm{Te}, \mathrm{Sb}, \mathrm{B}, \mathrm{Au}, \mathrm{As}$, and $\mathrm{Bi}$ is indicated by enrichment factors larger than 1000. In contrast, $\mathrm{Cu}$ is relatively depleted, suggesting deposition in the subsurface environment. Variations in composition are observed with time, mainly depending on temperature and major composition of the emissions. Values > $100 \mathrm{ppb}$ of $\mathrm{Sb}, \mathrm{Bi}, \mathrm{Ni}, \mathrm{Zn}, \mathrm{As}$ and $\mathrm{Se},>10 \mathrm{ppb}$ of $\mathrm{Te}, \mathrm{Pb}$, and $\mathrm{Cu}$, and up to $8 \mathrm{ppb}$ of $\mathrm{Tl}$ were recorded. Chloride is predicted to be the main ligand responsible for metal transport, even at higher temperature. 
The lack of thermodynamic data for complex solvated metal clusters may nevertheless bias our results. The low temperature of the studied fumaroles (maximum $192.5{ }^{\circ} \mathrm{C}$ ) is in accordance with the small abundance of sulfides in the sublimates, whereas the high proportion of sulfates indicates oxidized conditions.

The volcanic plume is enriched in metals such as $\mathrm{Bi}, \mathrm{Cd}, \mathrm{Tl}, \mathrm{Se}, \mathrm{Te}$ and $\mathrm{Sb}$. The most common particles emitted are sulfates, halides, silicates, sulphuric acid and $\mathrm{Zn} \pm \mathrm{Cu}$ oxides. Metal emission rates are in the range of 1-10 kg/day for As, Se, $\mathrm{Cu}$ and $\mathrm{Zn}, 0.1-1 \mathrm{~kg} / \mathrm{day}$ for $\mathrm{Pb}, \mathrm{Tl}$ and $\mathrm{Bi}$. Emissions of high-temperature magmatic gases are indicated by elevated $\mathrm{SO}_{2} / \mathrm{HCl}$ ratio and the presence of $\mathrm{Au}$ in the particulate phase.

Mass balance calculations in White Island magmatic-hydrothermal system indicate a segregation of around 4900 tons of copper per year, either accumulated from a dense brine at $\sim 500 \mathrm{~m}$ depth, or deposited by low-density vapors on their way to the surface. Metal-rich sulfide blebs trapped in phenocrysts may also retain $\mathrm{Cu}$ at depth. These results thus reinforce the belief that White Island is an actively forming porphyry copper deposit. 


\section{Acknowledgements}

I have learnt a lot during the past three years, both scientifically and personally. None of this would have happened without my supervisors Bruce Christenson and Terry Seward, who I greatly acknowledge for giving me this unique opportunity. Thank you for believing in me from the other side of the world and offering me this amazing project. Thank you also for letting me the freedom of building this PhD project my own way, nevertheless bringing your personal knowledge and guidance along the way. I have learnt a lot from you and had great pleasure being your student.

A huge thank you as well to people from GNS and Vic, helping me throughout the way: students, administrative staff and academics. A special thank for Elliot, showing me the way through lab work and introducing me to life in the SGEES department (and being a great baker!), Di, for supporting your husband's student, Bruce Charlier and Monica Handler for always being here to answer my random methodology questions, Ian for fun talks, amazing drone sampling at White Island, and an unforgettable adventure to Whakatane, and my officemates for good coffee breaks, even better beer sessions on Friday nights and for all the support at the end of this PhD.

I would also like to thank researchers and supervisors that helped me along the way: the geology department in Saint Etienne where it all started, Séverine Moune in ClermontFerrand, Cinzia Federico and Giorgio Capasso in Palermo.

Friends in New Zealand, and especially Rob, Kelly, Eva, Jane, Marcel, and Lu. Thank you for the good fun, the support, making these three years a human adventure full of love, music and parties.

Finally, I would like to say my immense gratitude to my family for letting me live my child dream and become a volcanologist. A long way since I read that book on Le Piton de la Fournaise, dreaming on one day, being the person wearing that weird suit only meters from the lava. I'm there Mum!

And thank you Elisa for your unconditional support and love. Nothing is impossible... 


\section{Table of contents}

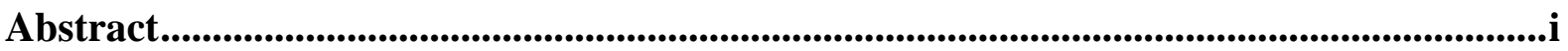

Acknowledgements ............................................................................................................................ iii

Table of contents ...........................................................................................................................................v

List of figures...............................................................................................................................vii

List of tables............................................................................................................................................ix

Chapter 1: Introduction ..............................................................................................................1

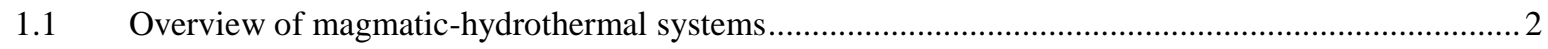

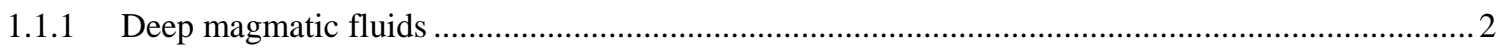

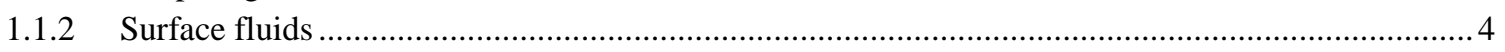

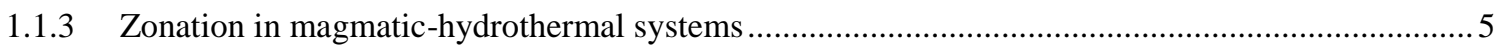

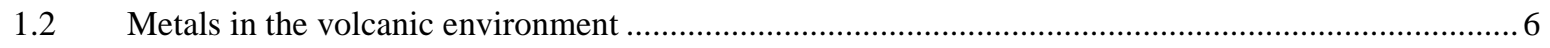

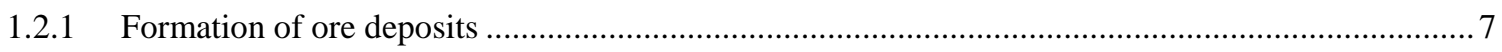

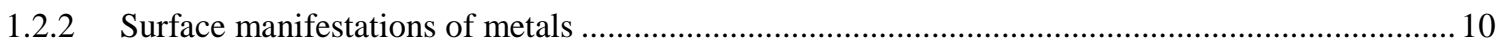

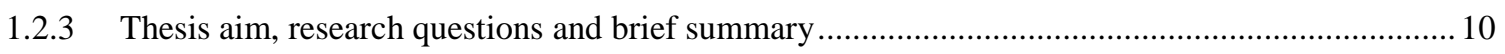

Chapter 2: $\quad$ White Island, an overview ..................................................................................13

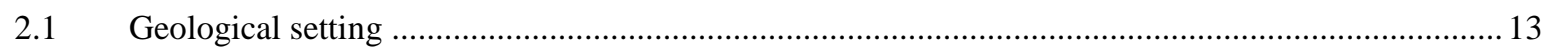

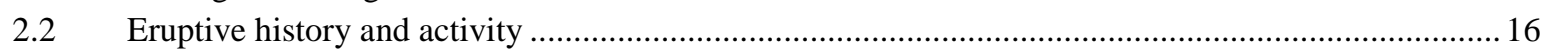

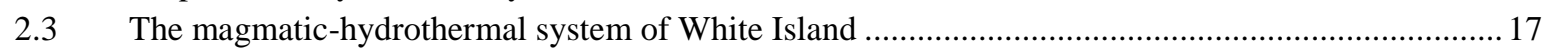

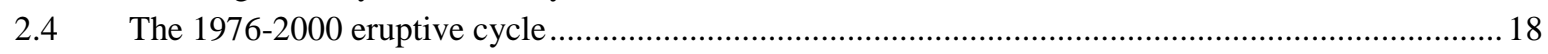

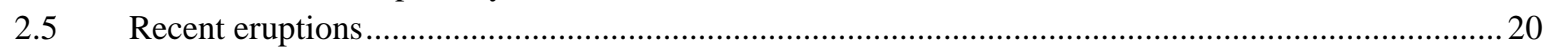

Chapter 3: Magma mixing, volatile degassing and late sulphide saturation:

Insights into the 1976-2000 eruptive sequence at White Island..........................................25

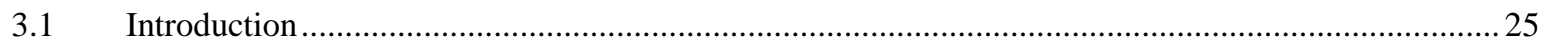

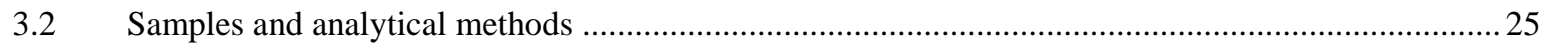

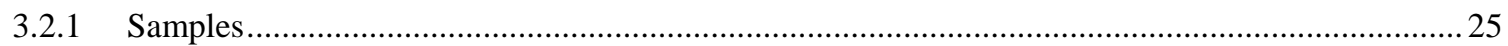

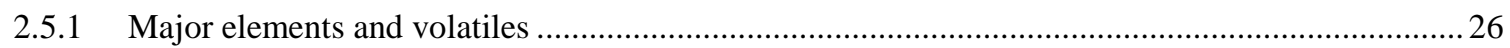

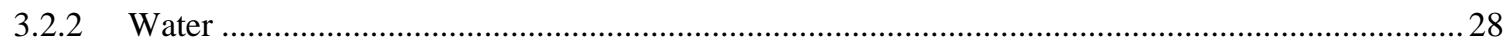

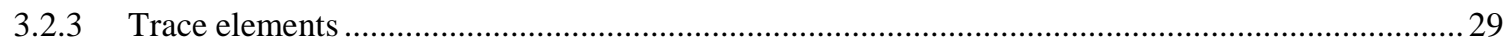

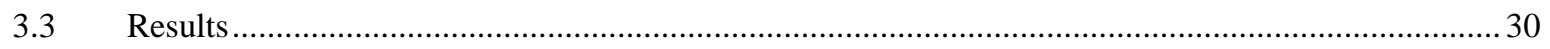

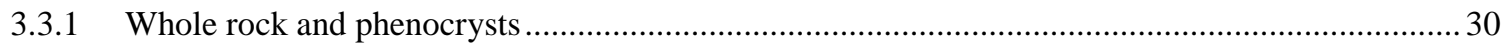

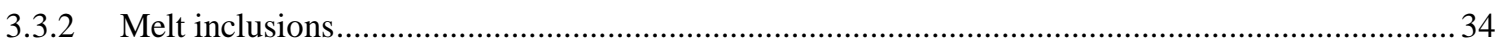

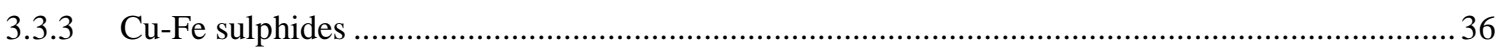

3.4 The role of mafic recharge during the 1976-2000 eruptive sequence ............................................... 42

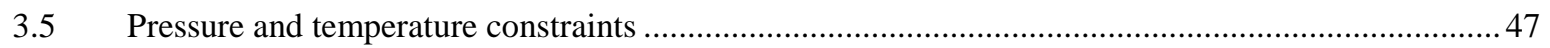

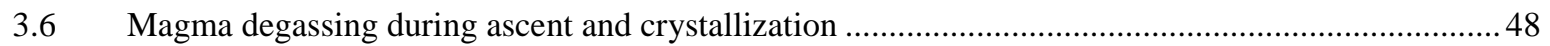

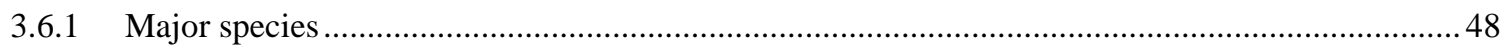

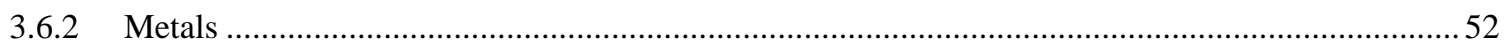

3.7 The occurrence of sulphide melt inclusions and their effect on metals ................................................56

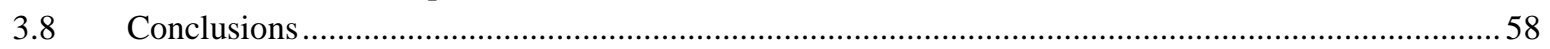

Chapter 4: Hyperacidic crater lake as a sink for metals...........................................661

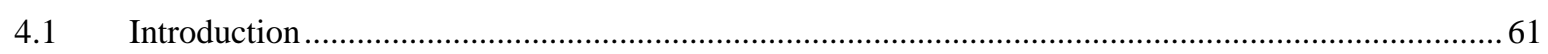

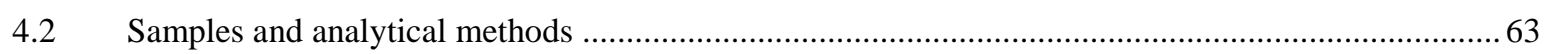

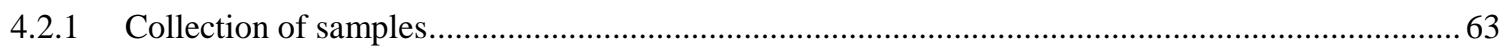

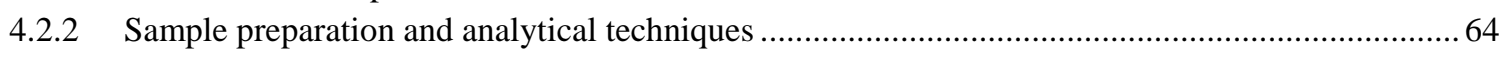




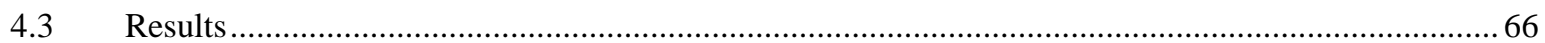

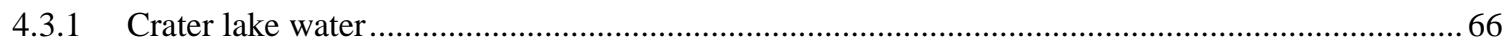

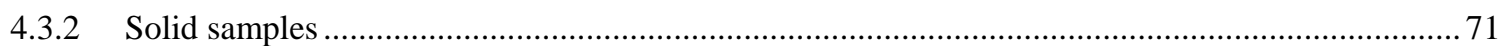

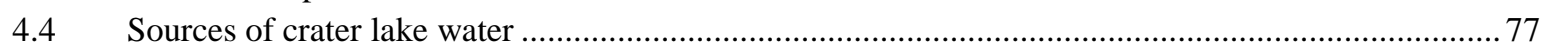

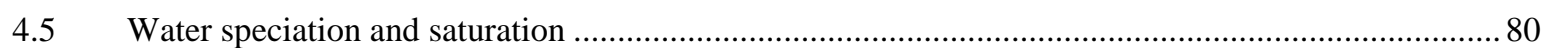

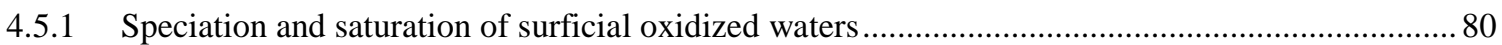

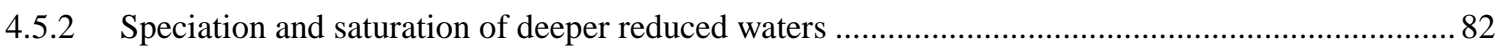

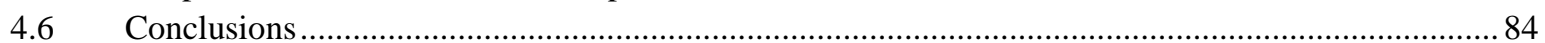

Chapter 5: Transport and deposition of metals by volcanic gases..................................87

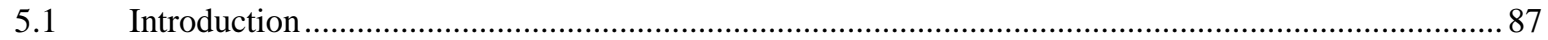

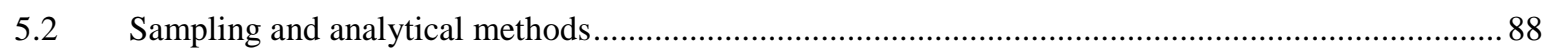

$5.3 \quad$ Variations in metal content of fumarolic condensates..........................................................91

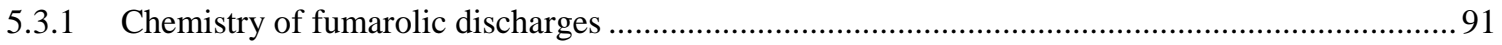

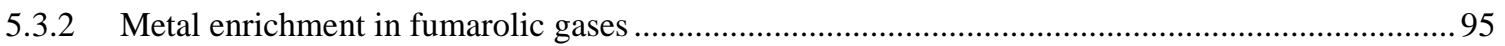

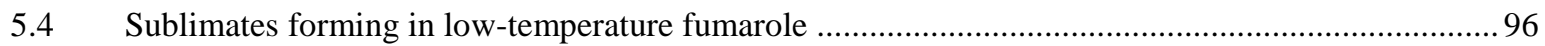

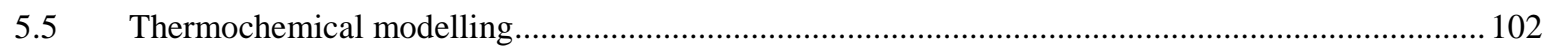

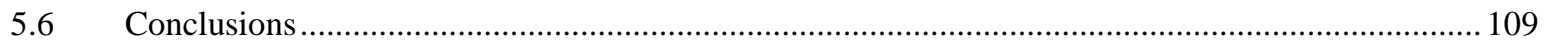

Chapter 6: Metal emissions in volcanic plumes ................................................................113

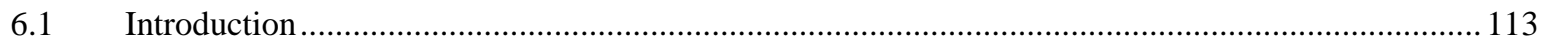

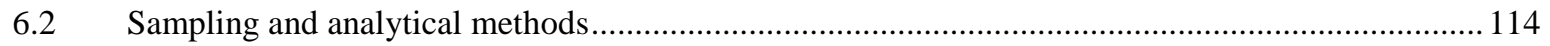

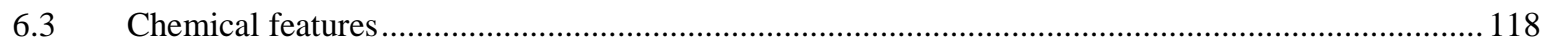

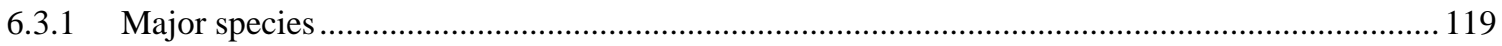

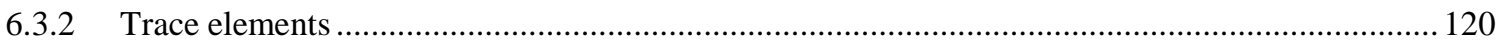

6.3.3 Aerosols from Yasur and Mount Etna volcanoes .................................................................. 122

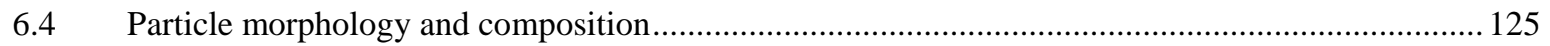

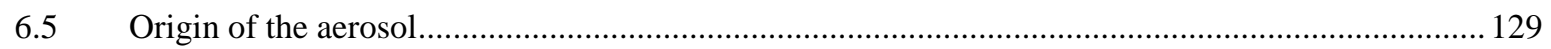

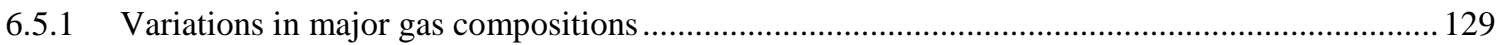

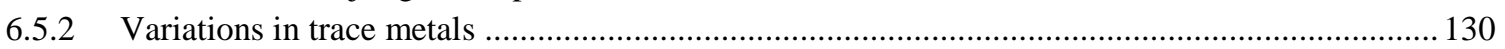

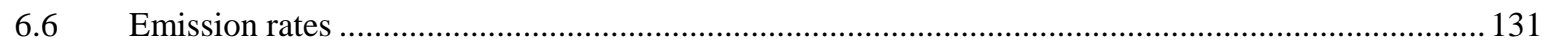

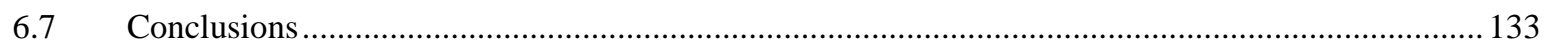

Chapter 7: Mass balance calculations and concluding remarks ...............................135

7.1 The copper budget for White Island magmatic-hydrothermal system .......................................... 135

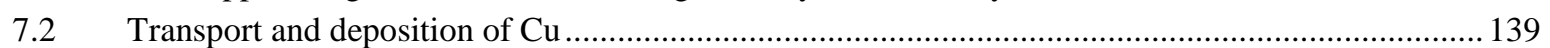

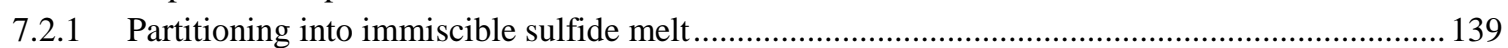

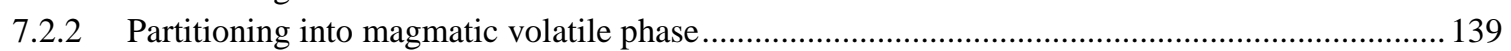

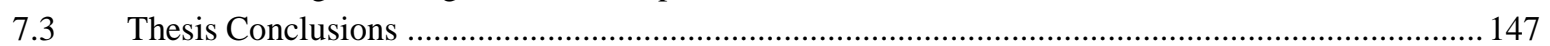

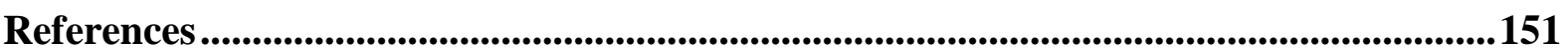

Appendix......................................................................................................................................173

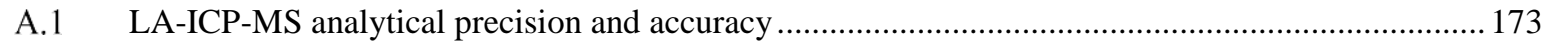

A.2 Melt inclusions and matrix glass compositions .................................................................... 174

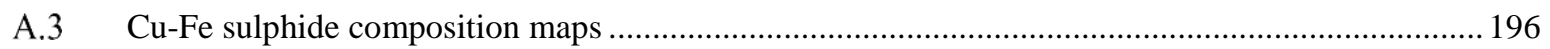

A.4 Sediment core and sulfur globule compositions ..................................................................... 198

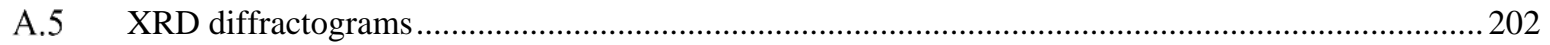

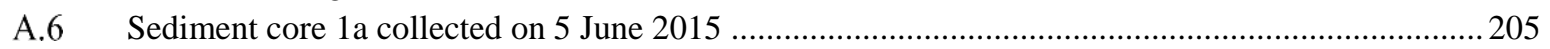

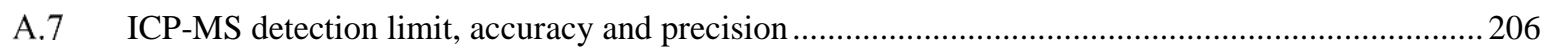

A.8 Plume enrichment factors, rock compositions (White Island, Yasur, Etna) ..................................208

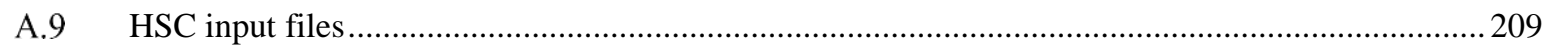




\section{List of figures}

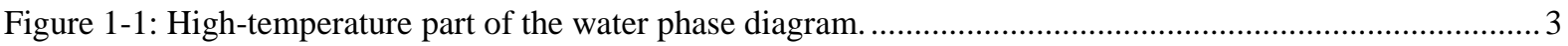

Figure 1-2: Phase diagram of the $\mathrm{H}_{2} \mathrm{O}-\mathrm{NaCl}$ system in T-P-X coordinates.................................................... 4

Figure 1-3: Schematic cross section of a magmatic hydrothermal system. ...................................................6

Figure 1-4: Models for the formation of ore-deposits associated with arc volcanoes........................................ 9

Figure 2-1: Location of White Island with respect to the Taupo Volcanic Zone............................................ 14

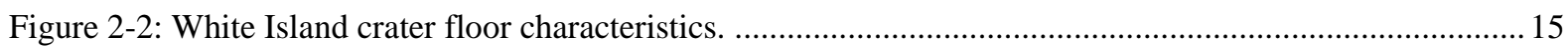

Figure 2-3: Picture of White Island taken from the south showing the breached crater floor ............................. 16

Figure 2-4: Pictures of the 2012-2013 eruptive sequence ....................................................................... 21

Figure 2-5: Picture of the crater floor covered by green-colored ash after the 27 April 2016 phreatic eruption. . 22

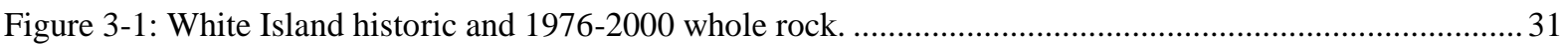

Figure 3-2: Backscattered electron image of olivine Fo76 and olivine Fo92 coexisting in one of the March

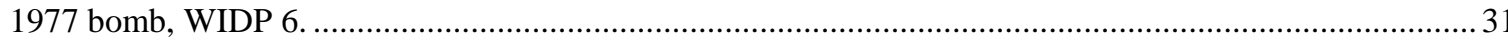

Figure 3-3: $\mathrm{SiO}_{2}$ versus $\mathrm{MgO}$ of melt inclusions and matrix glasses for separate rocks erupted during the

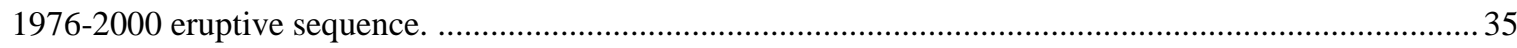

Figure 3-4: Transmitted light image of $\mathrm{Cu}-\mathrm{Fe}$ sulphides in a plagioclase phenocryst in WIDP 13 from

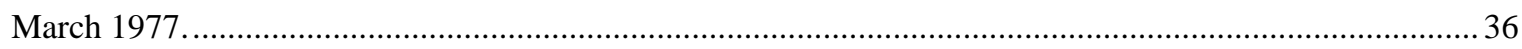

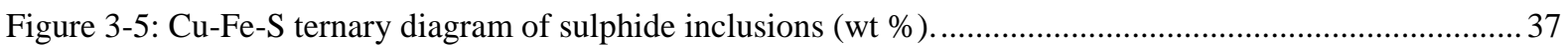

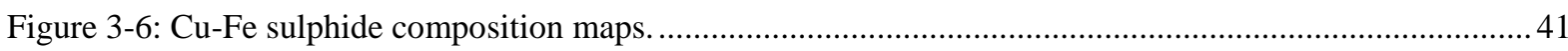

Figure 3-7: U versus As in melt inclusions and matrix glasses of rocks from the 1976-2000 eruptive

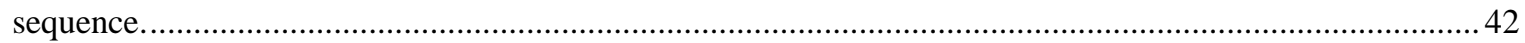

Figure 3-8: Transmitted light image of mingled glasses in the March 1977 block WIDP 6. ...........................43

Figure 3-9: Backscattered electron image of a mafic enclave in the October 1993 bomb WIDP 4...................44

Figure 3-10: Reverse and normal zoning in phenocrysts from the 1976-2000 eruptive sequence. .....................45

Figure 3-11: $\mathrm{CaO}$ versus $\mathrm{S}$ of melt inclusions and matrix glasses from the 1976-2000 eruptive sequence......... 49

Figure 3-12: $\mathrm{CaO}$ versus $\mathrm{Cl}$ of melt inclusions and matrix glasses from the 1976-2000 eruptive sequence........50

Figure 3-13: Cl versus $\mathrm{S}$ of melt inclusions and matrix glasses from the 1976-2000 eruptive sequence. ............51

Figure 3-14: $\mathrm{SiO}_{2}$ versus $\mathrm{Cu}$ of melt inclusions and matrix glasses of rocks from the 1976-2000 eruptive sequence.

Figure 3-15: $\mathrm{SiO} 2$ versus $\mathrm{Zn}$ of melt inclusions and matrix glass for separate rocks of the 1976-2000 eruptive sequence.

Figure 3-16: $\log \mathrm{Cl} / \mathrm{Rb}$ versus $\log \mathrm{Zn} / \mathrm{Rb}$ of melt inclusions and matrix glass for separate rocks of the 19762000 eruptive sequence.

Figure 3-17: Lead behavior with degassing and crystallization............................................................55

Figure 3-18: Backscattered electron image of orthopyroxene phenocrysts in the bomb from July 2000

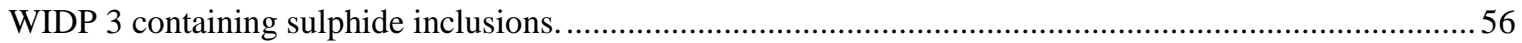

Figure 3-19: Schematic model of White Island magmatic system during the 1976-2000 eruptive sequence.......59

Figure 4-1: Aerial picture showing the sampling locations (source LINZ). ...............................................63

Figure 4-2: Pictures of sulfur spherules floating at the surface of the crater lake..........................................6 66

Figure 4-3: Crater lake time series showing variations in level and temperature. .......................................67

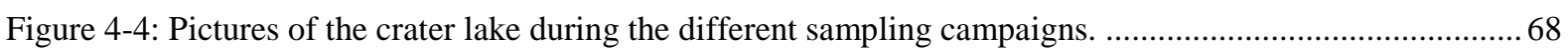

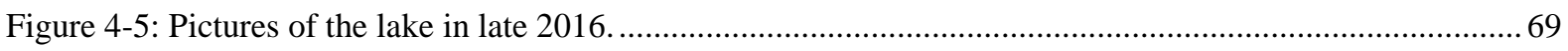

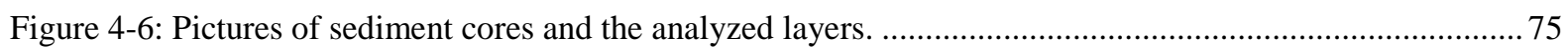

Figure 4-7: Element Transfer Ratio for the crater lake samples and F0 Pool normalized with 1977 andesite. .... 78

Figure 4-8: Ternary diagram $3 * \mathrm{~F}-\mathrm{Al}-3 * \mathrm{Mg}$ showing the composition of the crater lake water since its

formation in 2001 . 


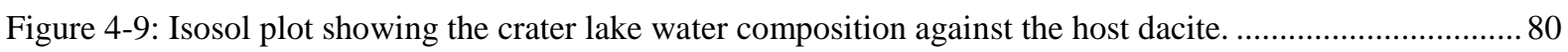

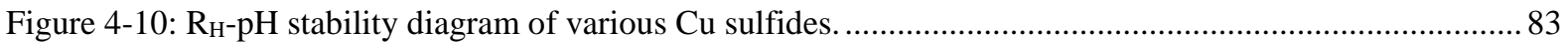

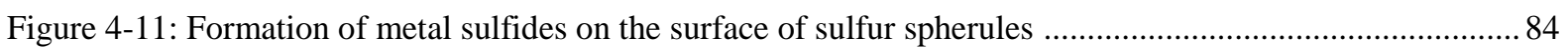

Figure 5-1: Aerial picture showing the locations of the three fumaroles sampled (source LINZ) ......................8 88

Figure 5-2: Sketch of the sampling train, showing the two types of samples collected.................................. 89

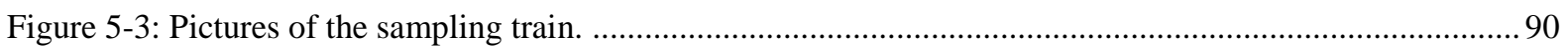

Figure 5-4: $\mathrm{SO}_{2}-\mathrm{CH}_{4} * 100-\mathrm{Ar} * 100$ ternary diagram for $\mathrm{F} 0$ fumarole showing variations between magmatic

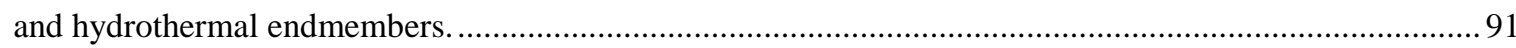

Figure 5-5: Enrichment factors (EF) estimated for the three fumaroles sampled. ...........................................96

Figure 5-6: Description of the mineral species found in the sublimate tubes 1 (June 2015) and 2 (June-

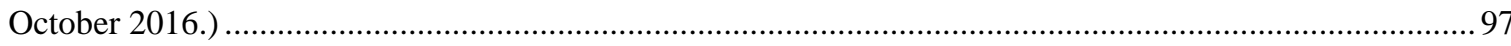

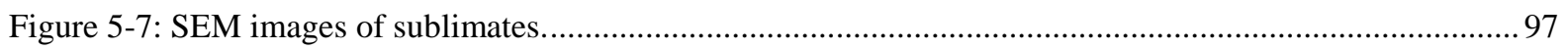

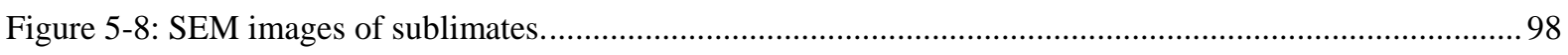

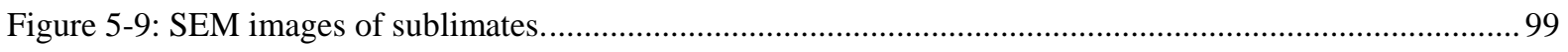

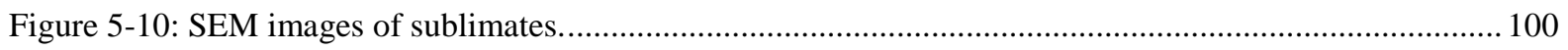

Figure 5-11: Speciation of the most abundant gaseous $\mathrm{Pb}$ species........................................................... 103

Figure 5-12: Speciation of the most abundant gaseous $\mathrm{Cu}$ species. .......................................................... 104

Figure 5-13: Speciation of the most abundant gaseous Zn species............................................................. 105

Figure 5-14: Speciation of the most abundant gaseous Fe species. ........................................................ 106

Figure 5-15: Speciation of the most abundant gaseous As species........................................................... 106

Figure 5-16: Speciation of the most abundant gaseous Bi species. ........................................................ 107

Figure 5-17: Sublimates and condensates formed during cooling. .......................................................... 108

Figure 6-1: Sampling locations and setup at White Island and Yasur volcano, Vanuatu. ............................... 115

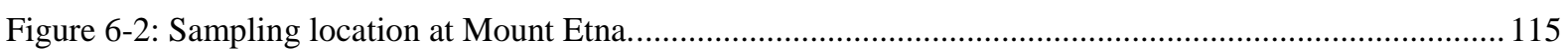

Figure 6-3: Bivariate plots suggesting different sources. ......................................................................... 120

Figure 6-4: Enrichment factors of aerosols from White Island, Mount Etna, and Yasur volcanoes.................. 121

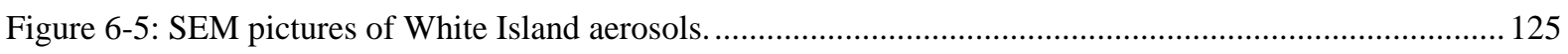

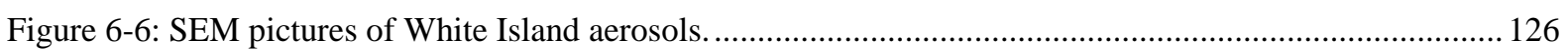

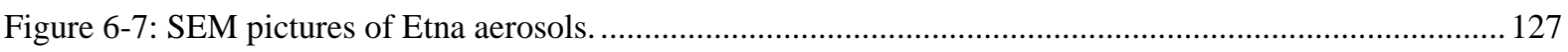

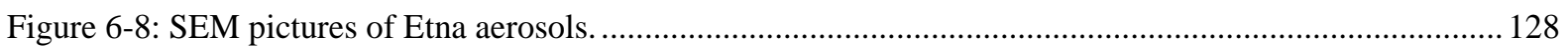

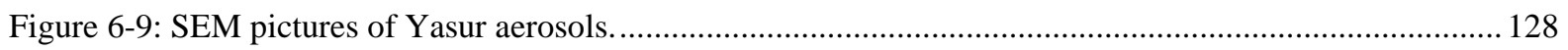

Figure 6-10: Ternary diagram $\mathrm{Cu}-\mathrm{HCl} / 50-\mathrm{SO}_{2} / 100$ for the volcanic plume. ............................................ 130

Figure 7-1: Aerial photos showing acid discharges around White Island................................................... 137

Figure 7-2: Pressure-temperature-salinity relations in the $\mathrm{H}_{2} \mathrm{O}-\mathrm{NaCl}$ system. ........................................... 141

Figure 7-3: Distribution of gaseous $\mathrm{Cu}$ species in high-temperature gases from Kudriavy, Yasur and White

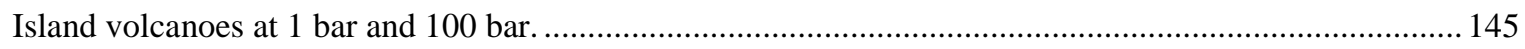

Figure 7-4: Pressure-temperature phase diagram of the $\mathrm{H}_{2} \mathrm{O}-\mathrm{NaCl}$ system.............................................. 146

Figure 7-5: Sketch of White Island magmatic-hydrothermal system. ........................................................ 149

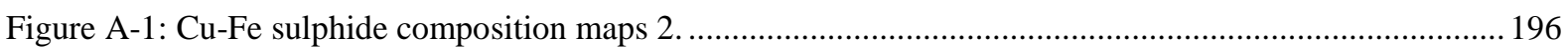

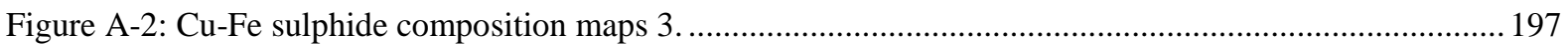

Figure A-3: XRD diffractograms of ash and suspended particles. .......................................................... 202

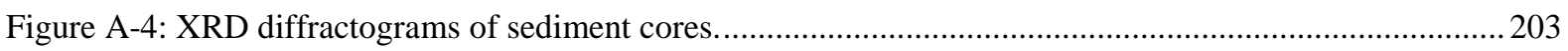

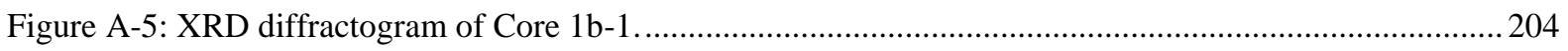

Figure A-6: Picture of one of the core sediments collected on 5 June 2015, Core 1a. ..................................205 


\section{List of tables}

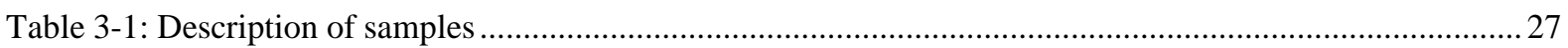

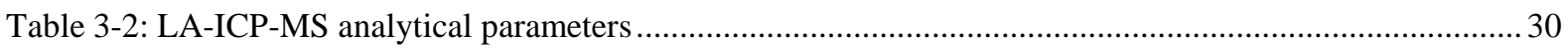

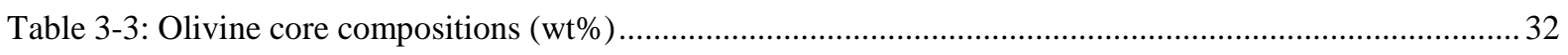

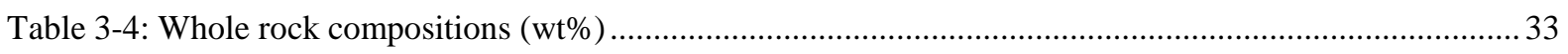

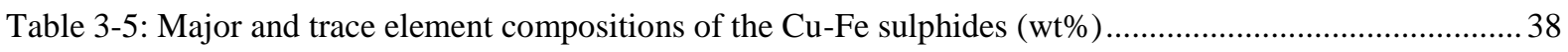

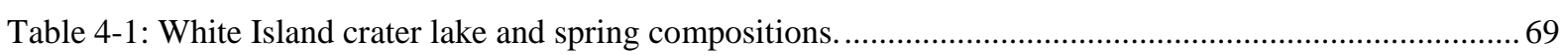

Table 4-2: Composition $\left(\mu \mathrm{g} \cdot \mathrm{g}^{-1}\right)$ of sediments, scum layer, suspended particles, ash, sulfur globules and

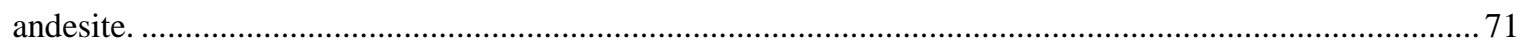

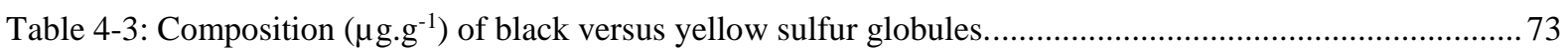

Table 4-4: Composition (ng. $\mathrm{g}^{-1}$ ) of selected layers from the sediment cores................................................74

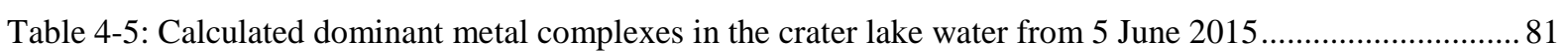

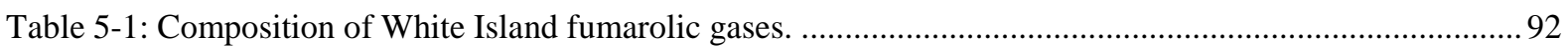

Table 5-2: List of all the observed sulfates in sublimates and natural encrustations. ...................................... 101

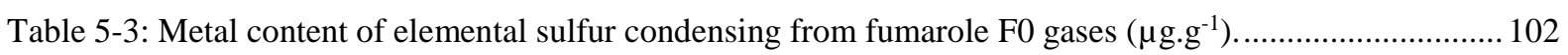

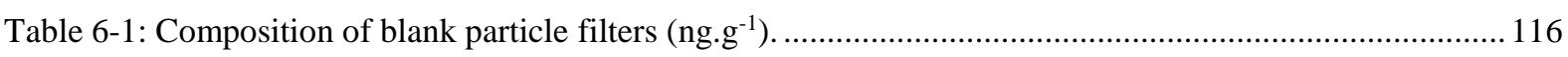

Table 6-2: Acid gases and aerosol compositions of filter packs from White Island plume............................. 118

Table 6-3: Acid gases and aerosol compositions of filter packs from Yasur volcano plume. ........................... 122

Table 6-4: Acid gases and aerosol compositions of filter packs from Mount Etna plume. ............................. 123

Table 6-5: Average emission rates (kg/d, unless specified) for White Island, Yasur and Etna and

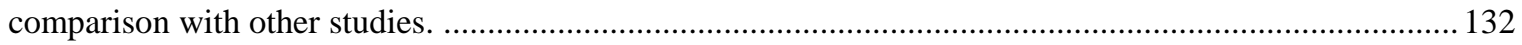

Table 7-1: Mass balance calculations for a selection of metals during periods of low activity (t/y)................ 138

Table A-1: LA-ICP-MS analytical precision ( \pm 1 RSD) and accuracy (bias) estimated with certified reference material GSD-1 for the different spot sizes used............................................................. 173

Table A-2: Melt inclusion and matrix glass compositions. ................................................................... 174

Table A-3: Sediment cores composition, black and yellow sulfur globules composition. ............................... 198

Table A-4: ICP-MS detection limit (3 SD), secondary standards (SLRS-4, JB1, BIR-1) measurement

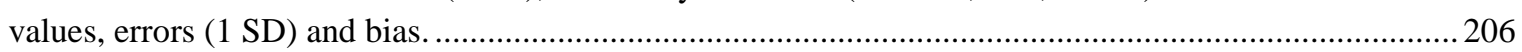

Table A-5: Enrichment factors in the aerosol and rock composition for White Island, Yasur and Etna ...........208

Table A-6: Gas composition in mol\% used as input for HSC thermochemical modeling ...............................209 


\section{Chapter 1: Introduction}

Volcanoes have given birth to many stories and myths throughout history. The term volcano itself comes from the island of Vulcano in the Mediterranean Sea, where the inhabitants used to think the volcano was the chimney of Vulcan's forge, the god of fire in Roman mythology. Every civilization living nearby volcanoes have their myths and legends about the powerful neighbor. In Hawaii, the goddess of volcanoes, Pele, would cause eruptions in her moments of anger (Westervelt, 1916). Her name was given to the thin shards of glass emitted during eruptions, Pele's hair. As it is still the case nowadays, volcanoes fascinated people despite their danger.

In a different manner, metals are fascinating to people too. Materials such as bronze, brass, or iron have long been recognized for their utility in building tools. Nowadays, many metals are found in electronic components due to their remarkable properties, such as conductivity. The US Environmental Protection Agency (EPA) found that $16000 \mathrm{~kg}$ of copper and $34 \mathrm{~kg}$ of gold could be recovered from one million cell phones. Besides their utility, shiny and colorful minerals have also attracted people for their beauty and rarity. First used in art and jewelry, they have acquired an incredible value. They have long been used as a currency and are still a symbol of wealth.

Volcanoes and metals... fascinating and attracting in different ways, but maybe more closely related than one could first think. Volcanoes are considered to be the main natural source of heavy metals in the atmosphere (Lepel et al., 1978; Nriagu, 1989). At the same time, many of the ore deposits on Earth today were formed by magmatic-hydrothermal systems in the past (Burnham, 1979; Henley and Ellis, 1983; Sillitoe and Bonham, 1984; Hedenquist and Lowenstern, 1994; Williams-Jones and Heinrich, 2005; Nadeau et al., 2016). This highlights the source of metals being the magma, but also points to the fact that metals behave differently in the subsurface environment. Not all the metals are released into the atmosphere, some being segregated into what we call ore deposits. We could also argue that not all the metals are segregated into ore deposits, but that some are released into the atmosphere. This brings us to wonder why? What are the processes taking place between the magmatic chamber and the surface, causing metals to partition into a gaseous phase instead of a liquid or solid phase?

Out of the different types of volcanoes present of Earth, andesitic volcanoes are of particular interest, due to several aspects: their high gas content originating from the subducted slab releasing its volatiles (Giggenbach, 1992a), their intermediate viscosity magmas, and their potential to give rise to extensive eruptions. Basaltic volcanoes are known for their effusive activity, during which a large amount of volatiles are released simultaneously with lowviscosity magma. In contrast, rhyolitic volcanoes have too viscous magma to allow volatile separation, thus leading to violent eruptions. At andesitic volcanoes, the large amount of volatiles is able to separate from the melt and often migrates to the surface, leading to passive degassing in quiescent periods. This constant degassing makes arc-volcanoes appropriate places to study volatile metal emissions. The few volcanoes studied thus far, revealed not only differences in the metal species being emitted, but also in their rate of emission. These variations are also observed by economic geologists. Most of the ore deposits on Earth today were formed during the life of a subduction-related volcano (Sillitoe, 1972; Bodnar and 
Beane, 1980; Sawkins, 1984; Hedenquist et al., 1993; Sillitoe, 1995). However, the presence of both ore-bearing and barren systems, with very similar setting, suggests that special conditions are required to form economic ore-bodies. What are these conditions? Why are some elements preferentially concentrated and deposited in a magmatic-hydrothermal system while emitted into the atmosphere at another?

Little is known about the transport of metals after they have escaped from the magma. And as we have seen, a lot happens in the few kilometers separating magmatic chambers from the surface. The subsurface environment of magmatic-hydrothermal systems is probably one of the most challenging areas to study from a geochemical point of view. Temperature sharply decreases by hundreds of degrees, redox conditions are shifted due to mixing with atmospheric gases, and meteoric waters infiltrate and interact with deep sourced fluids. This thesis aims at studying the remarkable environments that are magmatic-hydrothermal systems, by focusing on the example of White Island, in New Zealand.

\subsection{Overview of magmatic-hydrothermal systems}

Inherited from ancient Greek, the term hydrothermal describes the presence and interaction of two key parameters, water (hydros) and heat (thermos), as they circulate in the Earth's crust. In the case of magmatic-hydrothermal systems, energy is supplied dominantly by the shallow underlying magma. In the same manner, we can identify distinct sources for the waters: deep fluids originating from the magma and surface fluids infiltrating the system.

\subsubsection{Deep magmatic fluids}

The major constituent of volcanic gases is water $\left(\mathrm{H}_{2} \mathrm{O}, 40-99 \mathrm{~mol} \%\right)$ followed by carbon dioxide $\left(\mathrm{CO}_{2}, 1-50 \mathrm{~mol} \%\right)$, sulfur dioxide and hydrogen sulfide $\left(\mathrm{SO}_{2}, 0.2-15 \mathrm{~mol} \%\right.$ and $\mathrm{H}_{2} \mathrm{~S}$, 0.1-2 mol\%, respectively) and halogen species hydrogen chloride and hydrogen fluoride ( $\mathrm{HCl}, 0.1-6 \mathrm{~mol} \%$ and HF, < $0.1 \mathrm{~mol} \%$, respectively) (Symonds et al., 1992; Symonds et al., 1994; Wahrenberger et al., 2002). These volatiles originate from the magma, from which they separate due to decompression as the melt rises in the crust (Burnham, 1979, 1997). The timing of exsolution depends on the solubility of the gases as a function of magma composition, pressure and temperature. Carbon dioxide is less soluble in silicate melts, and is therefore released early by the magma at depth, followed by water (Holloway, 1976; Wallace, 2005; Blundy et al., 2010). Due to the acidic nature of magmatic-hydrothermal systems, carbon dioxide gas rises towards the surface without interacting much, similar to a noble gas. In contrast, ascending magmatic water condenses/mixes into hydrothermal fluids under appropriate temperature and pressure conditions. Sulfur and the halogens are more soluble (than $\mathrm{CO}_{2}$ ) in silicate melts and hence, released at shallower levels (in increasing order of solubility $\mathrm{S}<\mathrm{Cl}<\mathrm{F}$, (Carroll and Webster, 1994)). In the case of sulfur, the solubility and relative proportions of $\mathrm{SO}_{2}$ and $\mathrm{H}_{2} \mathrm{~S}$ are strongly dependent on redox conditions and composition of the magma (Haughton et al., 1974; Wallace and Carmichael, 1992; Nilsson and Peach, 1993). Moreover, not only volatile species form, but sulfide and sulfate can precipitate (Carroll and Rutherford, 1985; Luhr, 1990). Regarding chloride, speciation varies 
with pressure, with alkali chlorides $\mathrm{NaCl}$ and $\mathrm{KCl}$ dominating at high pressure in highdensity aqueous fluids and $\mathrm{HCl}$ at low pressure in low-density vapors (Kilinc and Burnham, 1972; Shinohara et al., 1989; Webster, 1992). The dependence of major volatile solubilities on pressure is the basis of volcanic gas monitoring. As mafic magma rises into a volcanic conduit, $\mathrm{CO}_{2}$-rich gas will first be emitted, progressively evolving into low $\mathrm{C} / \mathrm{S}$ ratio mixture.

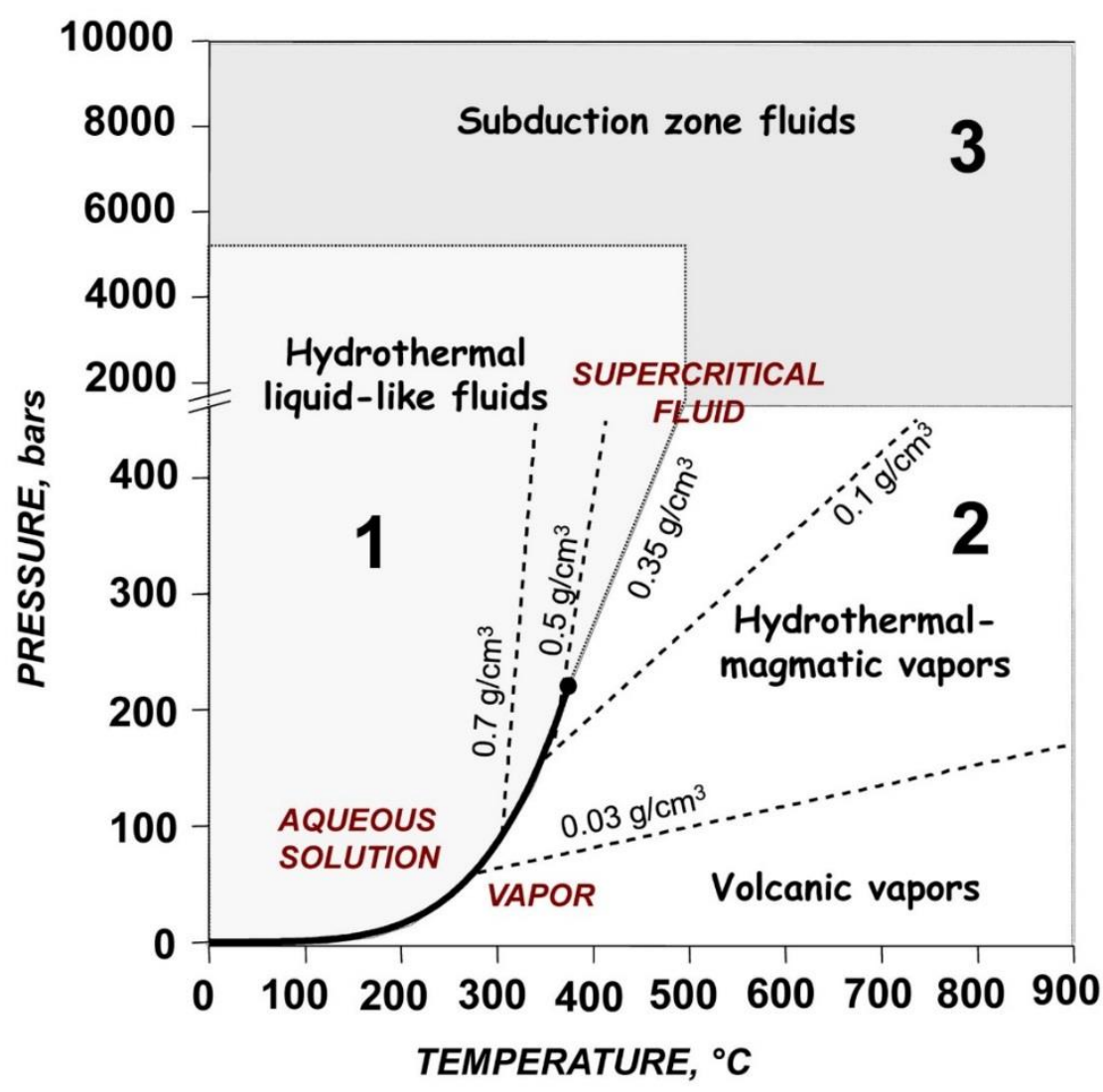

Figure 1-1: High-temperature part of the water phase diagram. The domains of the different aqueous phases (liquid, vapor, supercritical fluid) and three major types of geological fluids are shown, according to their P-T-density parameters and the degree of our knowledge of metal speciation and solubility. From Pokrovski et al. (2013).

Not only the composition of the exsolved phase varies with pressure and temperature, but also its physical state (Figure 1-1). At high pressure, volatiles can exsolve from silicate magmas as supercritical fluids. The critical point in the $\mathrm{NaCl}-\mathrm{H}_{2} \mathrm{O}$ system was estimated to occur between $\sim 100-140 \mathrm{MPa}$ and $600-800^{\circ} \mathrm{C}$ (Sourirajan and Kennedy, 1962; Pitzer and Pabalan, 1986). The decrease in temperature and pressure often leads to separation into a vapor and a high-density hypersaline liquid (Figure 1-2) (Sourirajan and Kennedy, 1962; Bodnar et al., 1985; Pitzer and Pabalan, 1986; Shinohara, 1994; Driesner and Heinrich, 2007). While the low density vapor buoyantly rises towards the surface, the hypersaline liquid tends to remain at depth (Henley and McNabb, 1978). Evidence of these hypersaline liquids are found in fluid inclusions in minerals from many ore deposits (e. g. porphyry copper) (Roedder, 1984; Bodnar, 1995). 


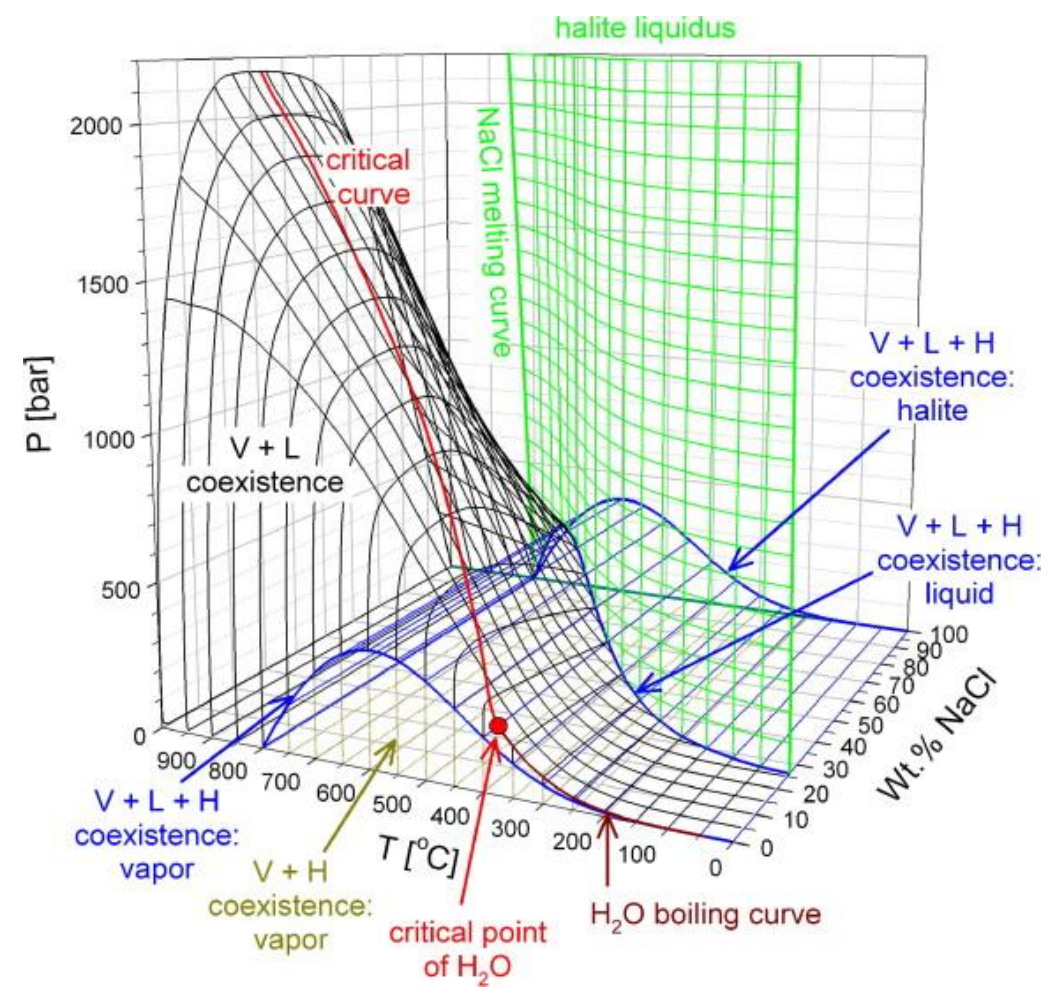

Figure 1-2: Phase diagram of the $\mathrm{H}_{2} \mathrm{O}-\mathrm{NaCl}$ system in T-P-X coordinates. From Driesner and Heinrich (2007).

\subsubsection{Surface fluids}

Surface groundwater, and seawater in the case of volcanic islands (Chiodini et al., 1995; Delmelle et al., 1998; Christenson et al., 2017), infiltrate hydrothermal systems and interact with the ascending gases and/or liquids. Surface waters percolate the system through a network of fissures and cracks and are heated by contact with hot rocks in the deeper part of the system. They also interact with deep volatiles rising from the magma, forming the socalled hydrothermal fluids. Magmatic $\mathrm{SO}_{2}, \mathrm{H}_{2} \mathrm{~S}, \mathrm{HCl}$ and $\mathrm{HF}$ dissolve in aqueous liquids according to the following reactions (Sakai and Matsubaya, 1977; Giggenbach, 1987):

$$
\begin{gathered}
4 \mathrm{SO}_{2(g)}+4 \mathrm{H}_{2} \mathrm{O}=3 \mathrm{H}_{2} \mathrm{SO}_{4(a q)}+\mathrm{H}_{2} \mathrm{O} \\
3 \mathrm{SO}_{2(g)}+2 \mathrm{H}_{2} \mathrm{O}=2 \mathrm{H}_{2} \mathrm{SO}_{4(a q)}+\mathrm{S}^{0} \\
\mathrm{HCl}_{(g)}=\mathrm{H}^{+}+\mathrm{Cl}^{-}
\end{gathered}
$$

At high temperature $\left(>200^{\circ} \mathrm{C}\right.$ and $>300^{\circ} \mathrm{C}$ respectively), the low dipole moment of water results in $\mathrm{HCl}$ and $\mathrm{H}_{2} \mathrm{SO}_{4}$ being mostly associated. It is only at lower temperature that they dissociate, reducing the $\mathrm{pH}$ of the fluid (Quist et al., 1965; Ruaya and Seward, 1987). There, hot and acidic fluids leach the surrounding rock as they circulate through it, bringing cations into solution (Giggenbach and Glasby, 1977). The alteration types vary depending on the composition of the hydrothermal fluids, the temperature, pressure and the rock type. In the presence of highly acidic sulfate-rich fluids, silicic alteration takes place, leaving a residual 
core of vuggy silica after mobilization of the other elements (Ellis and Mahon, 1964; White and Hedenquist, 1990; Hedenquist et al., 2000). This aqueous liquid, although less dense and saline than the brine found at depth, can lead to precipitation of secondary hydrothermal minerals, filling the veins and pores created by intense alteration. A particular case is when the precipitation takes place in the upper part of the hydrothermal system, effectively sealing it from the surface (Browne and Lawless, 2001; Christenson et al., 2007). An example of that process is the 2007 eruption of Ruapehu Crater Lake which arose because of sealing of the system, leading to pressurization and an unexpected phreatic eruption (Christenson et al., 2010).

\subsubsection{Zonation in magmatic-hydrothermal systems}

There are different zones in hydrothermal systems, depending on their temperature and hence on the distance from the underlying magma and volcanic conduit (Figure 1-3). In the vicinity of the latter, the system is said to be single-phase. Further away from the heat source, forming an envelope around the conduit, vapor and liquid coexist as two-phase systems. Hot acidic springs $\mathrm{Cl}$ - and $\mathrm{SO}_{4}$-rich and crater lakes are associated with these. Fumarolic gas discharges are generally separated from the main conduit and interact with the hydrothermal system in this vapor-liquid envelope. This results in both magmatic and hydrothermal contributions to fumarolic fluids (Cioni and D'Amore, 1984; Giggenbach, 1987; Giggenbach and Sheppard, 1989; Taran et al., 1992; Chiodini et al., 1995). High-temperature fumaroles are usually associated with hot acidic springs in areas close to the vent. Crater lakes may form where the hydrology and topography permit (Christenson and Tassi, 2015). In these lakes, magmatic $\mathrm{HCl}-$ and $\mathrm{SO}_{2}$-rich gases dissolve and accumulate (Rowe et al., 1992a; Christenson and Wood, 1993; Symonds et al., 2001). Further from the vent, the heat and acidity are decreasing though water-rock interactions. Neutral hot springs, mudpots and sometimes geysers are the surface features of these distal fluids. The progressive fluid neutralization creates a sequence of alteration facies, from silicic alteration close to the vent where hot and acidic fluids occur, to advanced argillic and intermediate argillic alteration further away from the vent where neutral fluids dominate. Finally, propylitic alteration develops where alkaline-chlorine fluids interact with the host rock (Fulignati et al., 1998; Fulignati et al., 1999). 


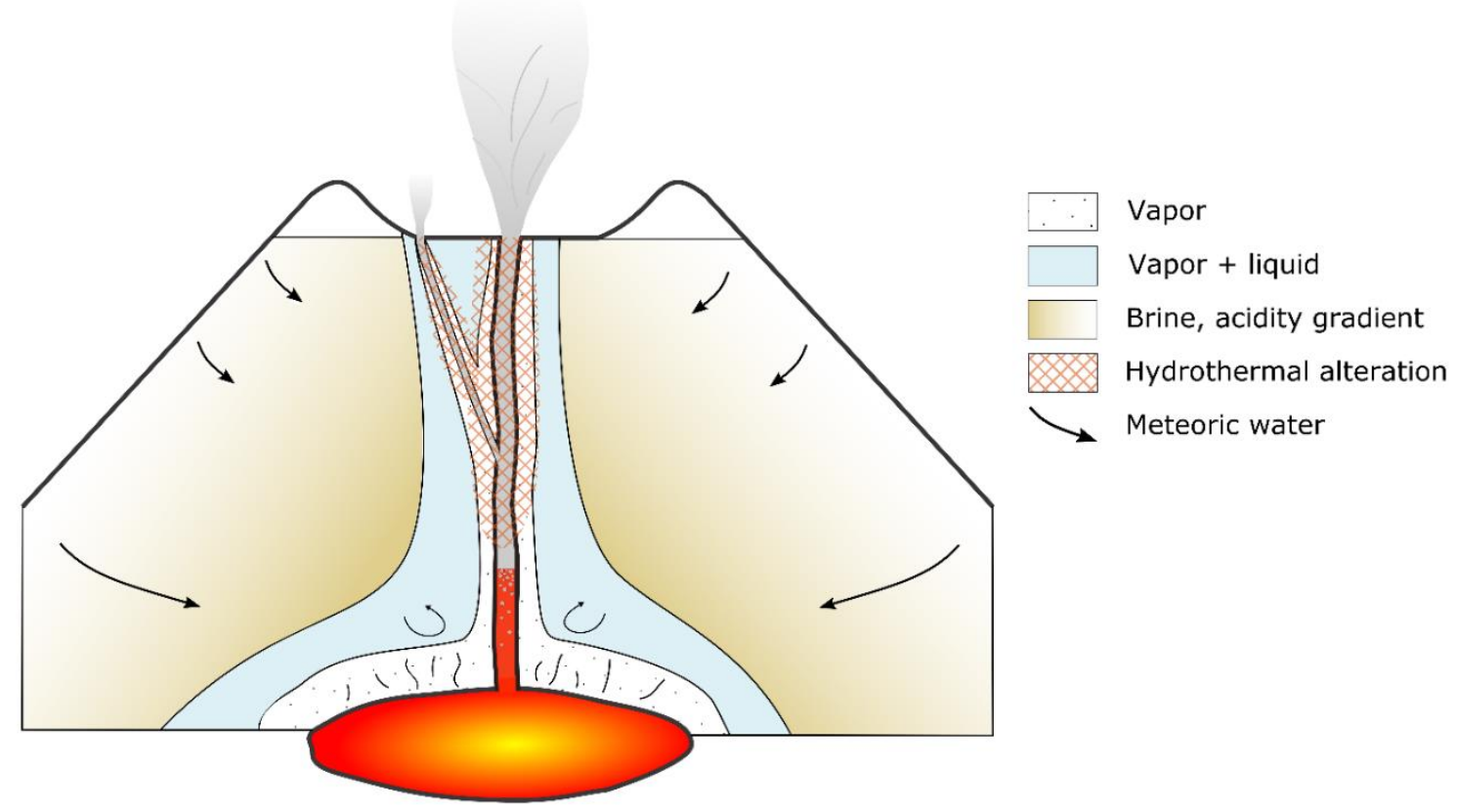

Figure 1-3: Schematic cross section of a magmatic hydrothermal system.

\subsection{Metals in the volcanic environment}

Various metals are reported in diverse forms in and around volcanoes. As an example, 270 tons of mercury are emitted in the volcanic plume of Kilauea every year (Siegel and Siegel, 1987). This is not only a problem locally, as it has been shown that the volcano is the source of the $\mathrm{Hg}$ found $320 \mathrm{~km}$ away, in Oahu (Siegel and Siegel, 1987). Varrica et al. (2000) reported high concentrations of $\mathrm{Br}, \mathrm{Cu}, \mathrm{Zn}$ and $\mathrm{Au}$ in lichens, as a result of volcanic emissions at Vulcano Island.

Menard et al. (2014) reported high levels of B, Li, As and V in a stream flowing down from Lascar volcano into the town of Talabre in Chile. As a comparison, the Talabre river contains $45.4 \mathrm{ppm}$ of arsenic, while the EPA acceptable concentration in drinking water, as of 2001, is $10 \mathrm{ppb}$.

Another proof of the transport of metals by magmatic fluids is the presence of sublimates around high-temperature fumaroles (Symonds et al., 1987; Kavalieris, 1994; Taran et al., 1995; Fulignati et al., 1998; Taran et al., 2001). Appreciable concentrations of As, Cu, Mo, $\mathrm{Pb}, \mathrm{Sn}$ and $\mathrm{W}$ have been reported in sublimates surrounding volcanic vents (Le Guern and Bernard, 1982; Bernard et al., 1990; Africano et al., 2002; Wahrenberger et al., 2002; Zelenski and Bortnikova, 2005). Korzhinsky et al. (1994) showed the existence of a pure rhenium mineral in high-temperature $\left(910{ }^{\circ} \mathrm{C}\right)$ fumaroles at Kudriavy volcano. Only found at trace levels on Earth, this discovery highlights the efficiency of volcanic gases at transporting and concentrating metals.

All these manifestations indicate that metals escape from the magma at depth. Although they are not, as such, volatiles, they behave like volatiles. More strictly speaking, they are volatile molecular metal complexes. The pressure, temperature, and composition of the fluid they are 
carried by constrain their transport towards the surface. Some are retained at depth by hypersaline brines, some are scavenged by waters circulating in the uppermost parts of a volcano, some form sublimation products, and a portion escapes into the atmosphere.

\subsubsection{Formation of ore deposits}

Ore deposits associated with volcanoes are thought to form throughout the lifespan of their host magmatic-hydrothermal system (Hedenquist et al., 1993; Archibald et al., 2001; Williams-Jones and Heinrich, 2005). Their formation requires four different processes to take place: transport and enrichment of metals, alteration and deposition. Moreover, the existence of both barren and ore-bearing intrusions in arc-related environments suggests that the formation of such deposits is not "compulsory", but requires special circumstances to occur.

There are two main types of ore deposits, varying primarily in their mineralogy and their location with respect to the magmatic intrusion. Porphyry deposits are closely overlying the magmatic pluton and often contain elevated concentrations of $\mathrm{Cu}, \mathrm{Mo}, \mathrm{Sn}, \mathrm{W}$ and $\mathrm{Au}$. Epithermal deposits rich in $\mathrm{Au}, \mathrm{Ag},(\mathrm{As}, \mathrm{Cu}, \mathrm{Hg}$ ) are usually more distal and closer to the surface.

It is now widely accepted that fluids exsolving from a shallow emplaced magma are responsible for the transport of ore-forming metals to their deposition site (Burnham, 1967; Drummond and Ohmoto, 1985; Hedenquist and Lowenstern, 1994; Sillitoe and Hedenquist, 2003; Nadeau et al., 2016). The enrichment process takes place by selective partitioning of the metals into the ore forming fluid phase. As stated above, depending on pressure and temperature conditions, this fluid phase can be a supercritical fluid, an aqueous solution or a vapor. Although accepted generally, the role of vapor-liquid separation in segregating ore metals is still poorly understood.

The efficiency of aqueous liquids in transporting metals has long been recognized (Barnes and Kullerud, 1957; Burnham, 1967; Romberger and Barnes, 1970; Bodnar and Beane, 1980; Barnes, 1981; Drummond and Ohmoto, 1985; Shinohara, 1994; Barnes, 1997). Many experimental studies since the 1960's have helped build solubility tables for the most common ore-forming metals in hydrothermal systems (Candela and Piccoli, 1995a; Pokrovski et al., 2013; Seward et al., 2014). The development of melt and fluid inclusion studies have also extended our understanding of fluid-melt partitioning (Bodnar, 1995; Audétat et al., 1998; Heinrich et al., 1999; Heinrich et al., 2003; Lerchbaumer and Audétat, 2013). The most common major species forming complexes with metals, i.e. ligands, in aqueous solutions were found to be chloride and sulfide (Burnham, 1979; Hemley et al., 1992; Burnham, 1997; Yardley et al., 2011).

On the other hand, low-density vapor was first thought to be inefficient in carrying large quantities of metals (Krauskopf, 1957; Krauskopf, 1964) and was left aside until recently. Fluid inclusion studies revealing metal-rich vapor coexisting with high-salinity liquid, led to new experiments in that field (Roedder, 1971; Eastoe, 1978; Henley and McNabb, 1978; Candela, 1989; Lowenstern et al., 1991; Heinrich et al., 1992; Bodnar, 1995; Damman et al., 1996; Audétat et al., 1998; Heinrich et al., 1999; Ulrich et al., 1999; Williams-Jones and Heinrich, 2005; Kouzmanov and Pokrovski, 2012; Migdisov et al., 2014). These studies 
confirm the more important role of the vapor in transporting ore-metals associated with porphyry and higher temperature deposits. The presence of water, hydrochloric acid and sulfur, not taken into account in early volatility studies, accounts for the high transport of $\mathrm{Cu}$, As, Sb, Ag, Mo and Au (Baker et al., 2004; Simon et al., 2005; Simon et al., 2006; Cauzid et al., 2007; Simon et al., 2007; Nagaseki and Hayashi, 2008; Pokrovski et al., 2008; Zajacz and Halter, 2009; Pokrovski et al., 2014).

The paradox of ore deposits resides in the transition from transport to deposition. What changes suddenly reverse the fluid transport capabilities? Cooling, pressure decrease, mixing with another fluid and fluid-rock interaction stand as the most likely processes driving deposition. The very steep thermal gradient between the magma chamber and the surface leads to a drop in fluid temperature as they rise. Cooling reduces the stability of metal complexes leading to saturation. Similarly, as the metal-rich vapors expand into fractures and veins, the drop in pressure can lead to destabilization of the metal complex species and precipitation (Henley and Berger, 2013). Mixing with groundwater has also been reported as a trigger to precipitation through oxidation and/or cooling of the fluids (Vikre, 2007; Leach and Corbett, 2008). Fluid fluxing was suggested by Blundy et al. (2015) in the form of S-rich vapors exsolving from an underlying mafic magma and interacting with metalliferous highsalinity liquids, the increase in sulfide activity leading to metal-sulfide deposition. Finally, interaction of a sulfur-rich vapor with Fe-bearing wall rock can influence transport in two different ways: 1) leads to Fe-sulfide precipitation thus decreasing the solubility of metals transported as sulfide complexes (Williams-Jones and Heinrich, 2005), 2) reduces $\mathrm{SO}_{2}$ to $\mathrm{H}_{2} \mathrm{~S}$ upon cooling thus favoring metal transport as sulfide complexes (Giggenbach, 1992b; Heinrich, 2005). The fluid/rock ratio controls the extent of the previous reactions, with high rock/fluid ratios favoring pyrite deposition, and low rock/fluid ratios favoring transport (Heinrich, 2005).

Figure 1-4 depicts the variation in type and location of ore deposits throughout the life of a magmatic intrusion. The deposition can be seen as a continuous process involving exsolution of fluids from a cooling hydrous magmatic intrusion. Acidic gases of low density and salinity first released by the magma rise towards the surface, mix with meteoric fluids, and produce a halo of alteration. Porphyry deposits form after a carapace has crystallized on the upper part of the magma body. Two different models can explain this type of deposition. The first considers vapor as the transporting phase (Heinrich et al., 2004). Metal-rich vapors of low to intermediate density and salinity ascend from the melt and precipitate ore minerals as they expand through veins and fractures, react with wall rock and cool. The second considers vapor as the trigger for precipitation (Blundy et al., 2015). A metal-rich liquid interacts with sulfur-rich gases rising from an underlying mafic magma chamber leading to sulfide saturation. 


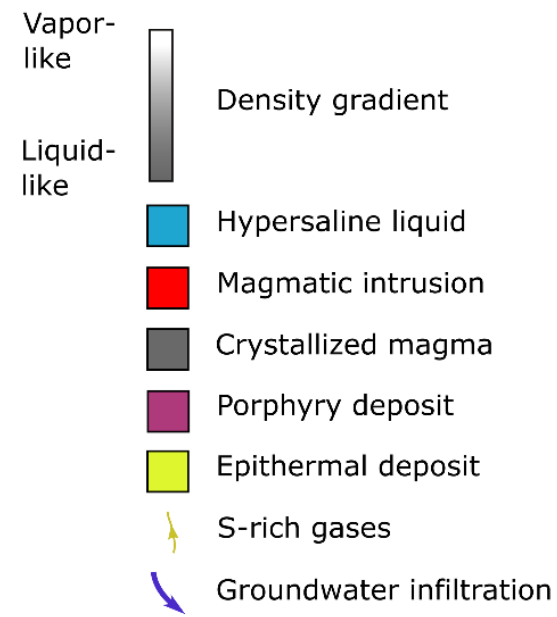

2) Porphyry deposition

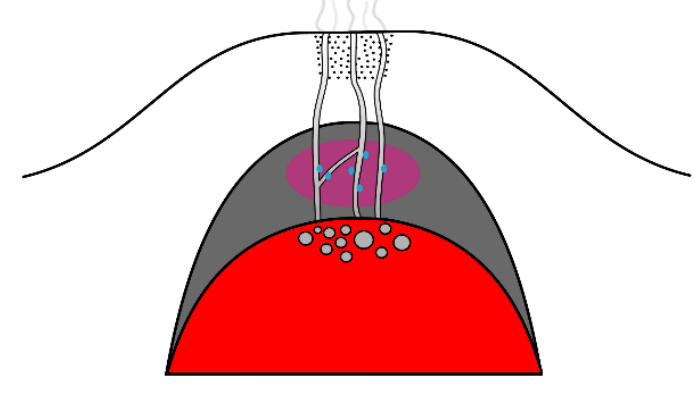

a) Deposition from vapor

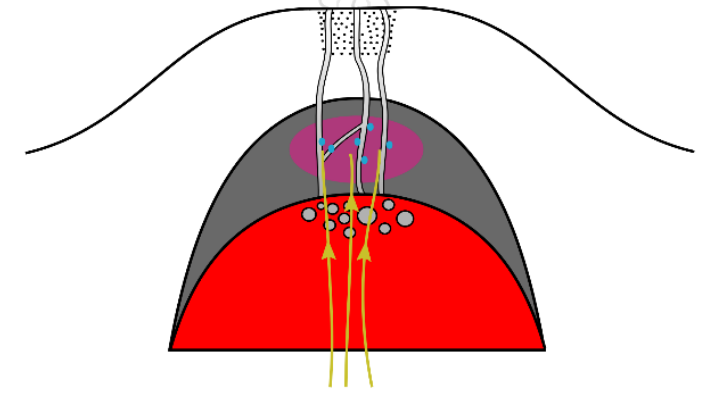

b) Deposition from saline liquid, triggered from S-rich vapor

3) Epithermal deposition

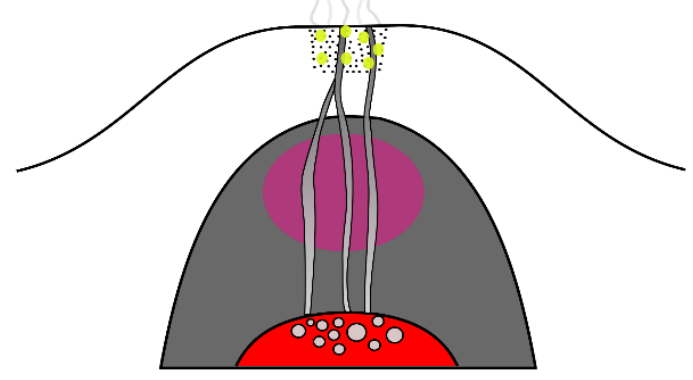

Figure 1-4: Models for the formation of ore-deposits associated with arc volcanoes.

Epithermal deposition occurs later, when most of the intrusion has already crystallized. Low salinity vapors exsolving from the deeper and cooler magma undergo contraction to liquid during ascent, efficiently carrying metals to previously altered rocks at shallow level. There, the loss of sulfide triggers precipitation by either of the following processes: mixing with meteoric water (Stoffregen, 1987; Spycher and Reed, 1989), adiabatic boiling of a metalbearing liquid phase (Drummond and Ohmoto, 1985; Krupp and Seward, 1987; Kouzmanov and Pokrovski, 2012), or reacting with Fe-bearing rocks (Muntean et al., 1990; Kettler et al., 1992). 


\subsubsection{Surface manifestations of metals}

Arc-related volcanoes featuring an active hydrothermal system typically show either signs of volcanic unrest or passive degassing. Despite scrubbing by various fluids at depth, significant quantities of metals are still emitted into the atmosphere. Some studies have estimated an average of 10000 tons of metalloids, metals and trace elements being emitted by quiescently degassing volcanoes per year (Hinkley et al., 1999; Delmelle, 2003). Sublimates deposited around fumarolic vents and waters flowing downslope also comprise part of the surface metal discharge budget.

As stated above, volcanoes contribute greatly to natural emissions of metals into the atmosphere (Zoller et al., 1974; Buat-Ménard and Arnold, 1978; Lepel et al., 1978; Cadle, 1980; Nriagu, 1989). Volcanic plumes are comprised of $\mathrm{H}_{2} \mathrm{O}, \mathrm{CO}_{2}, \mathrm{SO}_{2}, \mathrm{H}_{2} \mathrm{~S}, \mathrm{HCl}, \mathrm{HF}, \mathrm{HBr}$, $\mathrm{H}_{2}$, CO and various particles. The majority of metals is transported as particles, associated with sulfides, halides, oxides and sulfates (Buat-Ménard and Arnold, 1978; Lepel et al., 1978; Vié le Sage, 1983; Varekamp et al., 1986; Gemmell, 1987; Symonds et al., 1987; Pennisi et al., 1988; Quisefit et al., 1989; Hinkley, 1991; Andres et al., 1993; Hinkley et al., 1994; Nho et al., 1996; Stimac et al., 1996; Zreda-Gostynska et al., 1997; Hinkley et al., 1999; Aiuppa et al., 2000; Obenholzner et al., 2003; Mather et al., 2012; Gauthier et al., 2016). As an example, $\mathrm{Cu}, \mathrm{Zn}$ and $\mathrm{Pb}$ emission rates from passively degassing Masaya volcano, Nicaragua, between 2000 and 2001 were estimated at $237-927 \mathrm{~kg} / \mathrm{d}, 49-220 \mathrm{~kg} / \mathrm{d}, 20-38 \mathrm{~kg} / \mathrm{d}$ respectively (Moune et al., 2010). It should be noted that the fluxes of trace metals into the atmosphere increase greatly during eruptive activity (Gauthier and Le Cloarec, 1998; Mather et al., 2003b; Calabrese et al., 2011).

The studies mentioned above highlight the potential hazard of volcanoes in terms of health and environment, both in the vicinity of the vent and further away. Moreover, metal emissions are not only a concern for the atmosphere, but for the hydrosphere and biosphere as well. A fraction of the particles emitted, containing potential harmful species ( $\mathrm{As}, \mathrm{Cd}, \mathrm{Cu}, \mathrm{Se}$, $\mathrm{Sb}, \mathrm{Tl}$ ) is effectively deposited further away from the volcano, affecting the plants and soil and eventually dissolving into the local groundwater (Baxter et al., 1982; Aiuppa et al., 2000; Allen et al., 2000; Delmelle, 2003; Fulignati et al., 2006; Calabrese et al., 2011; Floor et al., 2011; Henley and Berger, 2013).

\subsubsection{Thesis aim, research questions and brief summary}

This thesis aims at understanding the fate of metals in a magmatic-hydrothermal system. From the mafic magma rising to crustal level to exsolution in a fluid phase, interactions with meteoric water, host rock and mixing with the atmosphere, what actually happens to metals? What carriers, if not the magma, are responsible for their mobility? To answer these questions, we will study the metal content and speciation of magmatic-hydrothermal features. First of all, the reservoir of magma, represented by melt inclusions. Then, we will focus on all the discharges into which metals could partition. These include erupted rocks and secondary minerals, hot springs and crater lake, fumarolic gases and volcanic plume. The goal is to constrain the processes occurring in the magmatic-hydrothermal system responsible for such repartition of metals at the surface. By estimating a mass balance between the reservoir and 
the discharges, we also aim at revealing eventual deposition occurring in the sub-surface environment. Finally, monitoring the metal content of volcanic gases throughout this threeyear project might highlight a link between changes in eruptive activity and variations in metal emissions.

The geological background of the area of study, White Island, is given in chapter two. It describes the eruptive history, past and recent, and reports on the current state of knowledge on New Zealand's most active volcano.

The third chapter is a textural, structural and chemical study of a set of ejecta from the 1976-2000 eruptive sequence, in the view of constraining magma dynamics and volatile degassing. We focus on the evolution of the system throughout the eruptive sequence, tracking any changes in the feeding system. We also assess the metal contents of the mafic magma and their behavior during crystallization, degassing and mixing.

In the fourth chapter, we examine the crater lake environment, where scrubbing of magmatic gases and hydrolysis of host rock take place. We assess the speciation of metals through thermodynamic calculations, and compare the predicted saturated phases with minerals observed in sediment cores, suspended particles, and erupted hydrothermal material. We also constrain metal segregation by elemental sulfur present at the lake bottom, and found as sulfur globules floating at the surface of the lake.

The fifth chapter focuses on the metal content of fumarolic gases. Variations in composition of the metal load are compared to changes in major species, the latter being related to volcanic activity. We also describe sublimates precipitated from fumarolic gases and collected in silica tubes. Thermochemical modeling using HSC Chemistry software is also reported, in the view of constraining the nature of gaseous metal complexes and predicting the species likely to precipitate with cooling.

In chapter six, we focus on metal emissions into the atmosphere via aerosols forming in the volcanic plume. The composition and nature of aerosols emitted at White Island are compared to those from the magmatic-hydrothermal plume of Mount Etna (Italy), and the purely magmatic gases of Yasur (Vanuatu). We also explore the existence of a relationship between changes in metal contents of the plume, and variations in volcanic activity. Metal emission rates are estimated for the three volcanoes.

Chapter seven combines results from the previous chapters in the view of constraining the metal transport in White Island magmatic-hydrothermal system. Mass balance calculations are performed in the view of revealing deposition of ore metals in the subsurface environment. 


\section{Chapter 2: White Island, an overview}

White Island has fascinated New Zealanders since their arrival. Maoris refer to it as "Te Puia o Whakaari", or "Whakaari", meaning "The dramatic volcano", and different legends have been reported as to its origin (Luke, 1959). The most popular of them states that it was given birth at the same time as the other volcanoes in the Taupo Volcanic Zone. This tale was reported with other Maori legends by Grey (1853) as follows. Ngatoro-i-rangi, a tohunga or spiritual leader from Arawa, a coastal tribe, decided to go explore the heart of the island. As he reached Lake Taupo, he saw a beautiful mountain to the south. The mountain was so majestic that he could not resist climbing to the summit. He and his slave, Aruhoe, began their climb, and as they were getting higher and higher, the cold affected them, freezing their fingers and toes and stiffening their joints. As they were agonizing, Ngatoro-i-rangi prayed his sisters in Hawaiki to send him fire. The sisters heard the prayer and sent Te Pupu and Te Hoata to rescue their brother. The fire demons travelled underwater towards Aotearoa. They reached the surface at Whakaari to see how far they were, bringing the fire that is still burning nowadays. They reached the surface many times before finding Ngatoro-i-rangi, leaving a trail of steam and thermal activity on their path. They finally brought the fire to the top of the mountain and saved Ngatoro-i-rangi from the cold. He later named it Tongariro, to remember the cold south wind that almost killed him.

The first European to report the island was Captain Cook in 1769. He named it White Island due to the constant cloud of white steam above the island. He nevertheless failed to notice that it was a volcano. It was not until the end of 1826 that people landed on the island. The Williams brothers and Cunningham described steam and smoke in all parts of the crater, as well as several boiling lakes. Captain Drury visited the island in 1848, noting the presence of sulphurous lakes and crystalline sulfur covering the crater floor (Luke, 1959). Sulfur mining started in 1885 and was suspended several times because of eruptions. In 1914, a landslide reaching the crater lake produced a lahar that killed the 11 miners present on the island. The lack of profitability and the bad working conditions led to the end of the mining activity in 1934.

\subsection{Geological setting}

White Island is an andesitic volcano lying on the continental crust, $48 \mathrm{~km}$ off the coast of the North Island in the Bay of Plenty, New Zealand (Figure 2-1). It marks the northern end of the Taupo Volcanic Zone (TVZ), a volcanic arc and back-arc basin due to the westward subduction of the Pacific plate under the Australian plate at the Hikurangi trench, $200 \mathrm{~km}$ east from the TVZ (Cole and Nairn, 1975; Cole and Lewis, 1981; Wright, 1992). Being $200 \mathrm{~km}$ long and $60 \mathrm{~km}$ wide on land, the TVZ extends off shore for another $100 \mathrm{~km}$ as a $45 \mathrm{~km}$ wide graben delineated by the Tauranga Fault Zone to the west and the White Island Fault Zone to the east (Smith et al., 1989; Wright, 1992). The TVZ is characterized by 1 Ma old calcalkaline volcanism and can be divided into three volcanic zones: 1) andesitic volcanoes on the south represented by the Tongariro Volcanic Center, 2) rhyolitic volcanoes in the central part including the Lake Taupo caldera, and 3) andesitic systems on the northern end with 
Edgecumbe, Whale Island and White Island (Figure 2-1) (Cole and Lewis, 1981; Cole, 1990). North-east from White Island is the Tonga-Kermadec arc, a series of volcanic islands and submarine volcanoes associated with the Kermadec-Tonga subduction zone.

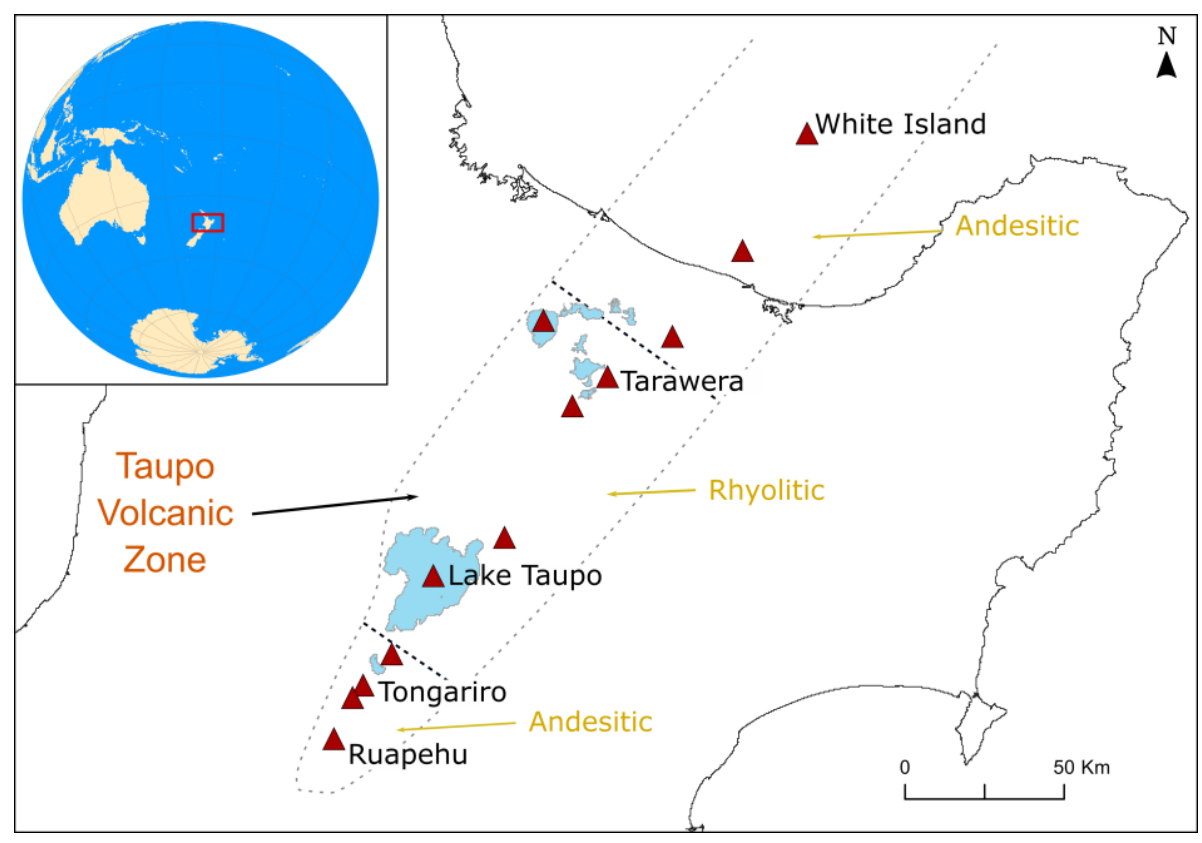

Figure 2-1: Location of White Island with respect to the Taupo Volcanic Zone.

White Island is the subaerial part of an 18 by $16 \mathrm{~km}$ submarine volcano rising from the sea floor 300-400m under the water (Duncan, 1970; Clark and Cole, 1986). The island, around 2 $\mathrm{km}$ in diameter, represents only a small portion of the whole edifice and half its height. Together with the sea stacks Volkner Rocks and Club Rocks, the total volume reaches $78 \mathrm{~km}^{3}$ (Cole et al., 2000). White Island is composed of two overlapping stratocones, the extinct Ngatoro cone on the north-west, and the active Central cone on the south-east (Black, 1970; Duncan, 1970; Cole et al., 2000). Only part of the Ngatoro cone remains, most of it being removed before the construction of the Central cone (Graham and Cole, 1991). The main crater is divided into three subcraters oriented NW-SE (Black, 1970; Duncan, 1970; Nairn and Wood, 1986; Houghton and Nairn, 1989a) as shown in Figure 2-2.

Most of the crater floor is covered by material from the 1914 debris avalanche and is less than 30 meters above sea level. The southeastern crater wall is breached by the sea, giving White Island its peculiar shape (Figure 2-3). The three bays, Crater, Wilson and Shark are thought to have been formed by a large eastward-trending sector collapse that happened in pre-historic times (<3.4 ka) (Moon et al., 2009; Letham-Brake, 2013). 

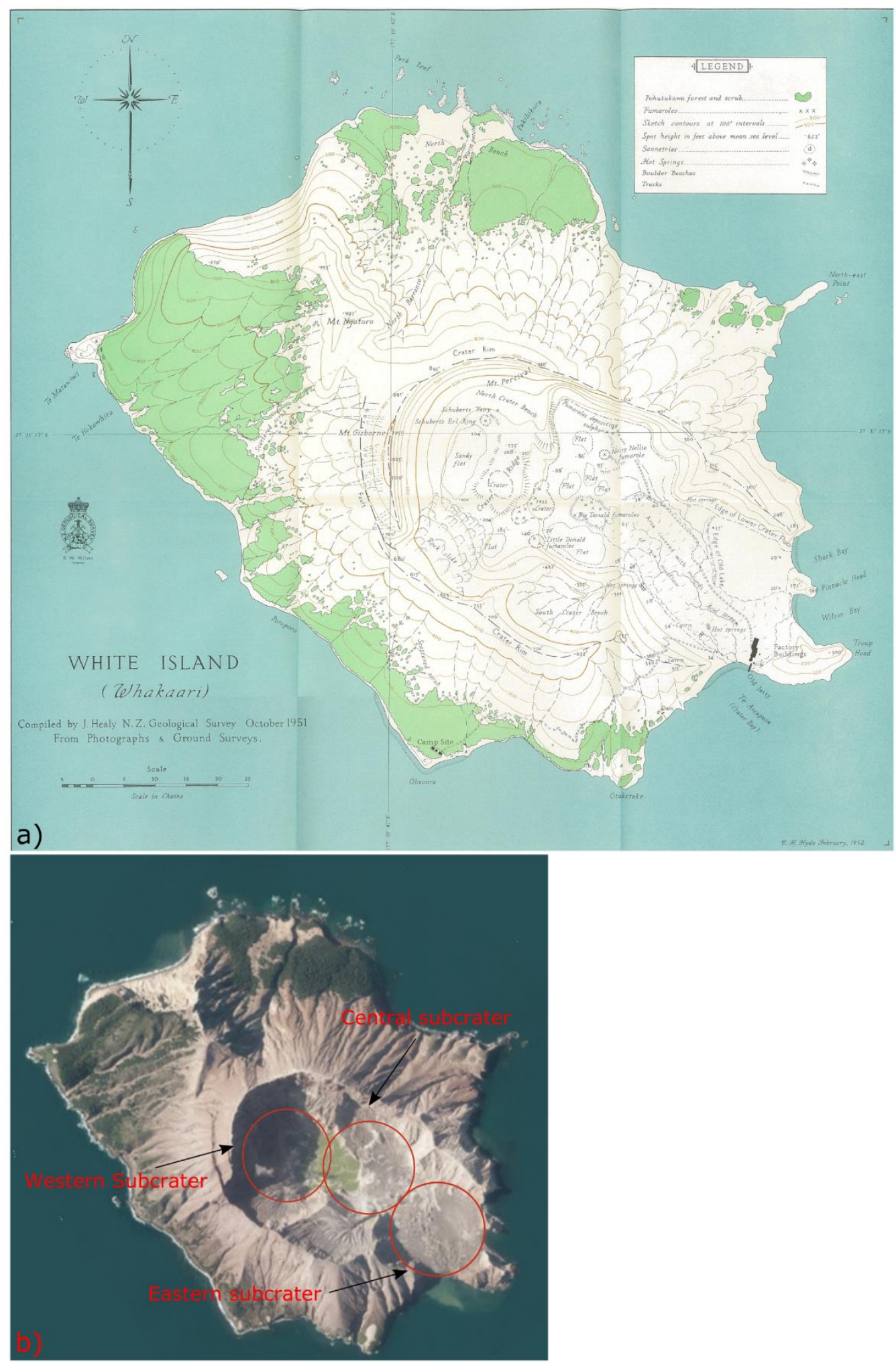

Figure 2-2: White Island crater floor characteristics. a) The first map of White Island compiled by J. Healy from the New Zealand Geological Survey in 1951. b) Aerial photo showing the three subcraters (Source: LINZ). 


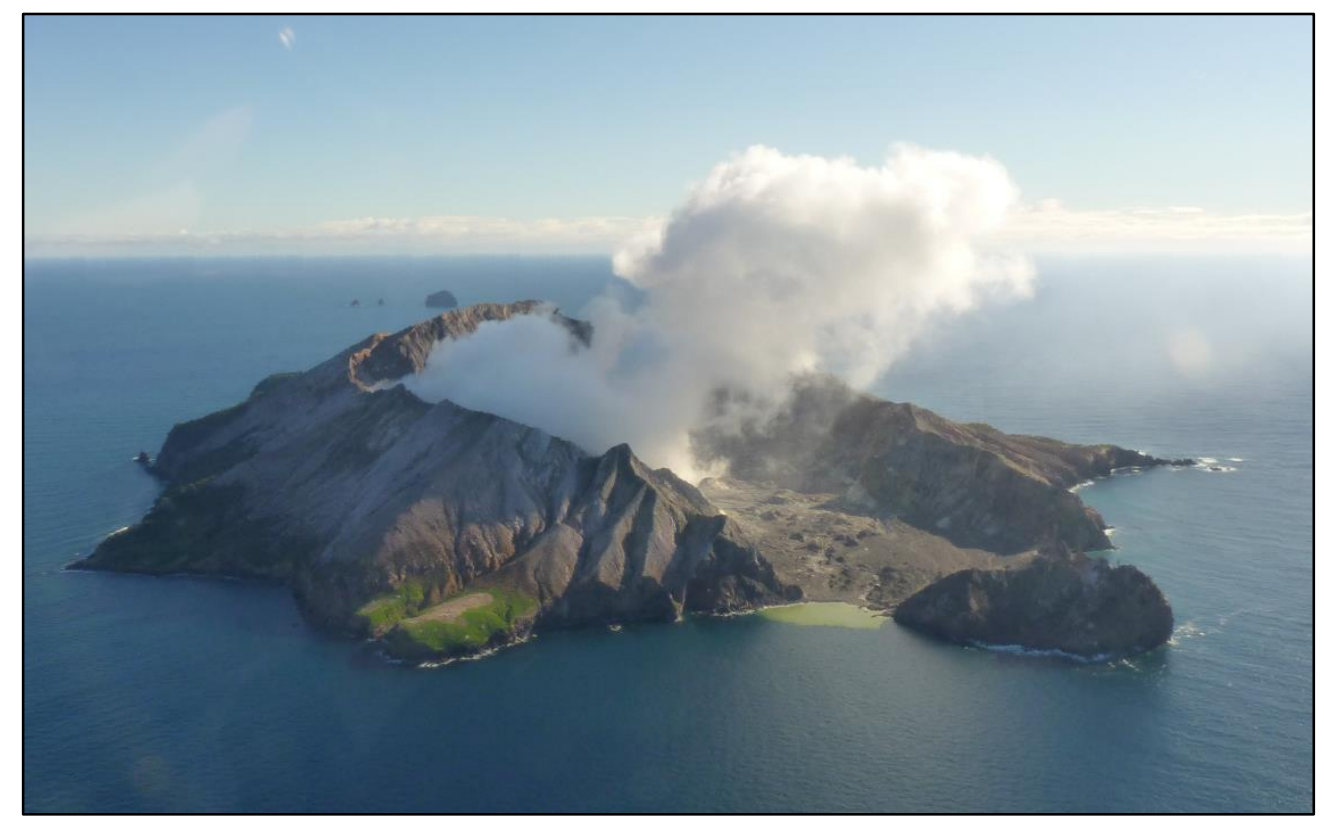

Figure 2-3: Picture of White Island taken from the south showing the breached crater floor (5 June 2015). The acid stream discharging into the sea in Crater Bay gives the yellowish color to the sea.

\subsection{Eruptive history and activity}

White Island is constructed of andesite-dacite lava flows and pyroclastic deposits (Cole and Nairn, 1975; Clark et al., 1979; Cole et al., 2000). The old Ngatoro cone and Troup Head are of andesitic composition, whereas Central cone is dacitic. The eruptive activity appears to be cyclic, with major eruptions of andesite-dacite lava flows alternating with minor basaltandesite explosive eruptions (Cole et al., 2000).

Thirty-four eruptions, mainly phreatic and phreatomagmatic alternating with Strombolian events, have been reported since the arrival of the first settlers in 1826 (Hamilton and Baumgart, 1959; Cole and Nairn, 1975; Smithsonian Institution, 1976-2000; IGNS, 19862001; GeoNet, 2001-2017). White Island has been the most continuously active volcano in New Zealand during the past 40 years, with the longest historic eruptive sequence taking place between December 1976 and September 2000 (Hamilton and Baumgart, 1959; Clark and Cole, 1986; Houghton and Nairn, 1989a; Simkin and Siebert, 1994; Siebert et al., 2010). The last magmatic eruption occurred in August 2012-October 2013 with the formation of a new dome. The volcano is on a state of volcanic unrest since this episode (GeoNet) and small phreatic eruptions have occurred in April and September 2016, ejecting mostly hydrothermally altered material from the conduit.

Magma chambers feeding the eruptions during the last 40 years are thought to be as shallow as $500 \mathrm{~m}$ below the surface (Clark et al., 1979). There is also evidence of deeper chambers beneath the central part of the volcano, at depth between 1-2 km and 2-7 km (Houghton and Nairn, 1989a; Cole et al., 2000). A multi-magma chamber model has been proposed by different studies, involving deep storage of mafic melt and shallower levels of chambers where melt differentiation, mixing and contamination occur to different degrees (Cole et al., 2000). 
The first estimate of $\mathrm{SO}_{2}$ emission rate at White Island was done by Radke (1982) using the treated filter method and yielded to a value of $150 \mathrm{t} / \mathrm{d}$. Soon after, Rose et al. (1986) did the first measurements using airborne correlation spectrometry (COSPEC). They repeated the study three different times, allowing estimates of the long-term emission rate $(\sim 350 \mathrm{t} / \mathrm{d}$ from November 1984 to January 1985) and higher emission rates prior to eruptive activity (1230 $\mathrm{t} / \mathrm{d}$ in November 1983). $\mathrm{CO}_{2}, \mathrm{SO}_{2}$ and $\mathrm{H}_{2} \mathrm{~S}$ emissions have been measured $\sim$ monthly since 2003 (Werner et al., 2008; Christenson et al., 2017).

\subsection{The magmatic-hydrothermal system of White Island}

Giggenbach (1987) described White Island as having a boiling lava surface at varying depth. Magmatic gases exsolving from it either reach the surface in the plume through the main volcanic conduit or discharge from fumaroles after interactions with an envelope of acid brines around the conduit, i.e. the hydrothermal system.

From the study of metal distribution in marine sediments around White Island, Giggenbach and Glasby (1977) concluded that the hydrothermal system must have been active for the past 10 ka. Recent studies (Giggenbach et al., 2003; Bloomberg, 2012; Christenson et al., 2017) have highlighted the presence of a sea water component in subsurface brine composition, thus indicating that the hydrothermal system is not totally isolated from the sea, as was first thought (Stewart and Hulston, 1975; Giggenbach and Sheppard, 1989). The numerous fumaroles and springs found at White Island are the surface expression of the hydrothermal system. The chemistry and temperature of the fumarole discharges have been studied and monitored for more than 40 years (Giggenbach, 1982, 1987; Giggenbach and Sheppard, 1989; Giggenbach and Soto, 1992). From these, Giggenbach and Sheppard (1989) estimated the composition of the magmatic gas phase to be $75 \mathrm{wt} \% \mathrm{H}_{2} \mathrm{O}, 18 \mathrm{wt} \% \mathrm{CO}_{2}, 5 \mathrm{wt} \% \mathrm{SO}_{2}$ and $1.5 \mathrm{wt} \% \mathrm{HCl}$. Temperatures exceeding $770^{\circ} \mathrm{C}$ have been recorded close to the active vents. Studies of the Donald Mound fumarole show cyclic behavior with periods of high temperature emissions (up to $700{ }^{\circ} \mathrm{C}$ ) having a magmatic signature $\left(\mathrm{CO}_{2}, \mathrm{SO}_{2}, \mathrm{H}_{2}\right)$, alternating with cooler gases of hydrothermal composition $\left(\mathrm{H}_{2} \mathrm{~S}, \mathrm{CH}_{4}\right)$. During heating periods, deposited $\mathrm{HCl}, \mathrm{HF}$ and elemental sulfur are remobilized, leading to an increase in their emission until they are exhausted and the gas approaches magmatic composition (Giggenbach and Sheppard, 1989). The fumarolic gases are a mixture of hydrothermal fluids and magmatic gases. Fumaroles with decreasing percentages of magmatic gases with distance from the main active vent delineate the shape of the two-phase hydrothermal envelope. Giggenbach and Sheppard (1989) estimated the volume of magma required to maintain a steady-state degassing of $350 \mathrm{t} /$ day of $\mathrm{SO}_{2}$ on average over the lifetime of the hydrothermal system to be $250 \mathrm{~km}^{3}$. A crater lake intermittently occupies parts of the crater floor. It has been reported as far back as 1826, when settlers first landed on the island (Hamilton and Baumgart, 1959). Werner et al. (2008) and Christenson et al. (2017) showed that, when present, the crater lake is efficient at scrubbing magmatic gases. Such a lake was present at the beginning of the current study in April 2014 and it had completely dried up by the time of writing in February 2017, emphasizing the active character of the magmatic-hydrothermal system at White Island. Fumaroles and hot springs have also been reported on the coastline and underwater on the flanks of the volcano (Grace, 1975; GeoNet, 2001-2017). 
Hydrothermal alteration of rocks is a very fast process due to the presence of acid gases and waters circulating in the sub-surface. Hedenquist et al. (1993) studied altered andesite ejected during eruptions in February 1988. The rocks were free of ash at the time of collection, implying a recent eruption, given the frequent ash emission during that period. However, the samples showed signs of alteration at vesicle margins and in fracture selvages. The fractures were filled with alunite, anhydrite, kaolinite and isolated crystals of pyrite. The rock closely surrounding those veins (few millimeters) was completely altered, recrystallized into cristobalite containing some opal-CT phenocrysts with 2-3 wt $\% \mathrm{Al}_{2} \mathrm{O}_{3}, 0.9-1.8 \mathrm{wt} \% \mathrm{Cl}$, traces of $\mathrm{Fe}$ and $\mathrm{S}$. Alteration is thought to have taken place at around $380{ }^{\circ} \mathrm{C}$, as indicated by S-isotope geothermometry of minerals from the veins.

Only a few data for aerosols are available for White Island. Rose et al. (1986) carried out a study using a cascade impactor to study the mineralogy and size of the particles emitted within the volcanic plume. They showed that the majority of the particles in the plume is less than $1 \mu \mathrm{m}$ in diameter, with the volcanic contribution consisting of $\mathrm{H}_{2} \mathrm{SO}_{4}, \mathrm{FeCl}_{3}$ and $\mathrm{NaCl}$. The likely contribution of sea aerosols in the form of salts was however not quantified. Compared to similar sampling at other volcanoes, the authors found that the proportion of particles at White Island is very low (Casadevall et al., 1984; Chuan et al., 1986). They suggested the scrubbing of gases by hydrothermal fluids, the lower temperature of the vapors, or the higher emission velocity as possible explanations. Since the development of spectroscopic methods, fluxes of major volatile species are now well constrained. The sulfur dioxide emission rate has a low-activity average of $300 \mathrm{t} /$ day and can rise up to $2075 \mathrm{t} / \mathrm{d}$ during eruptive events and unrest (Christenson et al., 2017). The flux of carbon dioxide has been varying between 500 and 2600 t/d since 2004 (Wardell et al., 2001; GeoNet, 2001-2017; Werner et al., 2008). Emission rates of $275 \mathrm{t} / \mathrm{d}$ for $\mathrm{HCl}$ and $<1 \mathrm{t} / \mathrm{d}$ for $\mathrm{HF}$ were reported by Love et al. (2000), higher than the 125-89 t/d, $150 \mathrm{t} / \mathrm{d}$ and 70-80 t/d of $\mathrm{HCl}$ estimated by Christenson et al. (2017), Werner et al. (2008) and Rose et al. (1986) respectively.

Using the average emission rate of $\mathrm{SO}_{2}$, different studies have estimated the trace metal fluxes into the atmosphere. The following emission rates were determined over 16 years using various methods: $\mathrm{Pb}=3-125 \mathrm{~kg} / \mathrm{day}, \mathrm{Bi}=1.5-6 \mathrm{~kg} / \mathrm{day}, \mathrm{As}=11.2-140 \mathrm{~kg} / \mathrm{day}, \mathrm{Sb}=$ 1.6-4 kg/day (Patterson and Settle, 1987; Tedesco and Toutain, 1991; Le Cloarec et al., 1992; Wardell et al., 2008).

\subsection{The 1976-2000 eruptive cycle}

The 1976-2000 cycle is the longest eruptive sequence observed at White Island since the arrival of Europeans. The development of techniques during this period allowed scientists to collect invaluable samples and information throughout the eruptions. This gives us the opportunity to investigate the magmatic processes involved into the injection of fresh mafic magma in the system.

A large body of magma started to rise to the shallow crust beneath White Island in mid-1973. The emplacement, at a depth of around $0.5 \mathrm{~km}$, lasted until 1976 (Clark and Cole, 1989). The eruptive cycle began on 18 December 1976 with phreatic and phreatomagmatic, vent clearing events (Clark et al., 1979; Houghton et al., 1983; Houghton and Nairn, 1989c; Nairn and 
Houghton, 1989). Emissions of ash and steam continued for two months leading to the formation of a crater of $\sim 160 \mathrm{~m}$ diameter and $100 \mathrm{~m}$ depth. Tephras consisted mostly of hydrothermally altered material until 25 January 1977, after which ejecta was mainly juvenile. The first blocks $(<10 \mathrm{~cm})$ were ejected between January 25 and February 15 but it was not until March 12 that vigorous eruptions produced bombs and blocks up to $3 \mathrm{~m}$ length (Clark et al., 1979; Houghton et al., 1983; Houghton and Nairn, 1989c). The strongest explosive activity occurred between March 12 and March 25, before resuming to vigorous incandescent ash emissions until the end of April 1977. Almost continuous eruptions, alternating between strombolian and phreatomagmatic, took place until 1982. A crater of 300 $\mathrm{m}$ diameter and $250 \mathrm{~m}$ deep, later named the 1978 crater complex, resulted from the five years eruption (Houghton and Nairn, 1989a).

The material erupted at the beginning of the cycle in March-April 1977 was characterized by high- $\mathrm{Mg}$ bombs and blocks rich in $\mathrm{Ni}$ and $\mathrm{Cr}$ compared to historic rocks (olivine crystals account for high $\mathrm{Mg}$ and $\mathrm{Ni}$, while chromite crystals in phenocrysts and groundmass glass account for high $\mathrm{Cr}$ ). The isotopic signature also differed, with lower ${ }^{87} \mathrm{Sr} /{ }^{86} \mathrm{Sr}$ ratio and higher ${ }^{143} \mathrm{Nd} /{ }^{144} \mathrm{Nd}$ ratio (Graham and Cole, 1991; Cole et al., 2000). Although erupted at the same time, bombs and blocks slightly differ in composition, mineral assemblage and groundmass texture. The denser material was more mafic ( $\sim 56 \mathrm{wt} \% \mathrm{SiO}_{2}$ against $\sim 58 \mathrm{wt} \%$ $\mathrm{SiO}_{2}$ for bombs), bearing up to 6.2\% forsteritic olivines (Fo90-92 (Clark et al., 1979; Clark and Cole, 1986; Cole and Graham, 1989; Graham and Cole, 1991; Shiraki et al., 1994). Clark et al. (1979) suggested that the bombs may originate from the top of the magma column, highly vesiculated and containing lighter plagioclase crystals. The blocks, however, were from the core of the magma column, containing the heavier olivine and magnetite crystals. Nevertheless, the chemical and isotopic signatures of the bombs and blocks are evidence for a more mafic source for the March-April 1977 eruptions compared to historic rocks. The pyroxene and plagioclase phenocrysts formed in a more evolved melt, suggesting different stages of crystallization, in accordance with the multiple magma chambers model. The reverse zoning exhibited by many pyroxenes and plagioclases reinforces this hypothesis. Shiraki et al. (1994) argued that the 1977 ejecta were the products of mixing of high-Mg basaltic andesite injected prior to the eruption with residual dacite supplying plagioclase and pyroxene phenocrysts. The high-Mg basaltic-andesite magmas are thought to form at or near the slab-mantle wedge interface by hydrous melting of the mantle, metasomatized by fluids from the subducting slab (Cole et al., 2000). After a rapid rise through the mantle and lower crust, they reach shallow (e. g. $300 \mathrm{~m}$ to $7 \mathrm{~km}$ ) chambers where dacite melt is stored. Mixing and crustal contamination can occur, as evidenced by xenoliths (microdiorite, gneiss, quartzose) and magma mingling in some of the ejecta (Graham and Cole, 1991; Shiraki et al., 1994; Cole et al., 2001).

The activity resumed in February 1986, with continuous gas emissions and frequent phreatic, phreatomagmatic and Strombolian events until May 1992. New craters formed within the 1978 crater complex. Similar eruptive cycles, alternating between phreatomagmatic and Strombolian events, crater collapse and clearing events, occurred in 1993-1994, 1998-1999 and 2000. A Strombolian eruption in July 2000 marked the end of the eruptive sequence (Smithsonian Institution, 1976-2000). The total volume erupted between 1976 and 2000 was estimated at $\sim 10^{7} \mathrm{~m}^{3}$ (Houghton and Nairn, 1989b; Scott, 1992) 
Wood and Browne (1996) showed that the juvenile rocks from the 1991-1992 eruptions were not as rich in $\mathrm{Mg}$, Ni and $\mathrm{Cr}$ as the 1977 ejecta, implying differentiation of the mafic melt during the eruptive cycle. The phenocryst assemblage is nevertheless similar, with orthopyroxene, plagioclase and clinopyroxene as major minerals. Olivine is present in most of the rocks in small amounts. Other minor phases include spinel and apatite. Rapien (1998) studied ejecta from 1977, 1988, 1989 and 1991 eruptions. She showed that plagioclases fall in the field of labradorite (An62-68), orthopyroxenes are enstatite (En69-72, Fs23-26, Wo3-5) and clinopyroxenes are augite $\left(\mathrm{En}_{45-46}, \mathrm{Fs}_{14-16}, \mathrm{Wo}_{38-40}\right)$. The groundmass glass is sometimes microlite-free, whereas acicular microcrysts of pyroxene, plagioclase and spinel are present in some samples. $\mathrm{H}_{2} \mathrm{O}, \mathrm{CO}_{2}, \mathrm{~S}$ and $\mathrm{Cl}$ contents of melt inclusions and matrix glass have been reported in different studies. On the basis of melt inclusion studies, fumarolic gas compositions and emission rates, Hedenquist et al. (1993) and Rapien et al. (2003) suggested that White Island has the characteristics to produce a porphyry copper deposit throughout its cooling history.

Melt inclusion studies have led to estimates on depth and temperature of the magma chamber. Wardell et al. (2001) suggested an entrapment pressure of 35 to 70 bars due to the low water content they measured in plagioclase- and clinopyroxene-hosted melt inclusions from the 1986 and 1988 eruptions. This is consistent with the depth of $<500 \mathrm{~m}$ inferred for the shallower magmatic chamber beneath White Island (Clark et al., 1979; Clark and Cole, 1989). However, this study did not consider olivine-hosted melt inclusions, likely to have been trapped deeper in the system. Rapien (1998) estimated a temperature of $\sim 1100{ }^{\circ} \mathrm{C}$ from coexisting pyroxenes (Lindsley and Andersen, 1983) and $1210{ }^{\circ} \mathrm{C}$ from homogenization of melt inclusions from 1991 eruption. Using the rhyolite-MELTS software package (Gualda et al., 2012), Esposito et al. (2014) found a liquidus temperature of $1131{ }^{\circ} \mathrm{C}$. Recently, Kilgour et al. (in prep) estimated crystallization temperatures for the different phenocrysts to be $1210{ }^{\circ} \mathrm{C}$ for olivine, $\sim 1054{ }^{\circ} \mathrm{C}$ for orthopyroxene, $\sim 999{ }^{\circ} \mathrm{C}$ for plagioclase and $\sim 982{ }^{\circ} \mathrm{C}$ for clinopyroxene.

\subsection{Recent eruptions}

A new eruptive episode started on 5 August 2012 with emissions of ash, mud and blocks during a small phreatomagmatic eruption (GeoNet, 2012-2013). The rise of fresh magma within the conduit was later indicated by the growth of a spiny lava dome of about 20-30 m diameter within the active crater (Figure 2-4 a and b). 

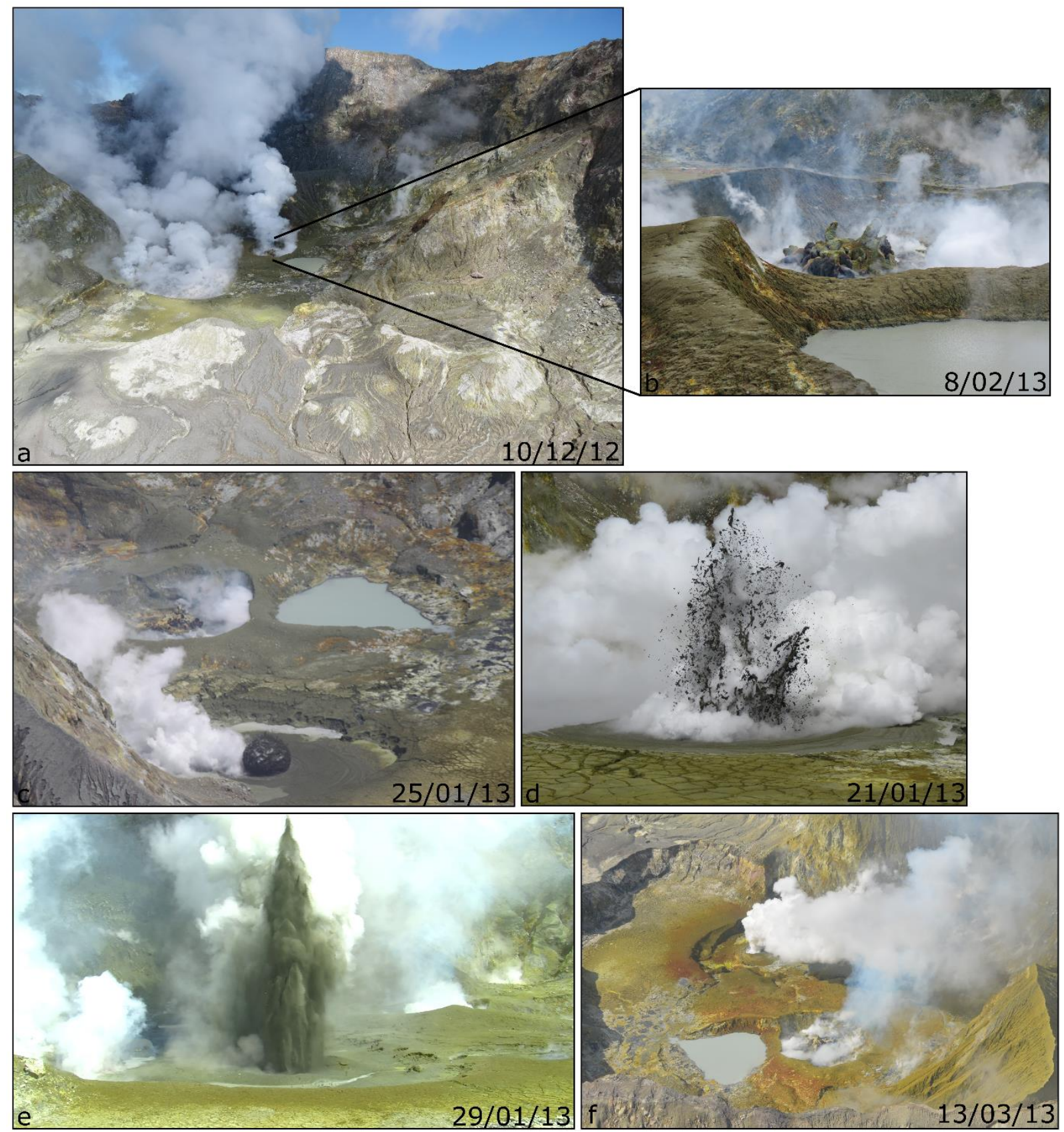

Figure 2-4: Pictures of the 2012-2013 eruptive sequence. a) Aerial pictures of the active crater showing most of the lake had dried by the end of 2012 and a spiny lava dome had formed. b) Close up picture of the lava dome. c) Activity within the south-west pond during January 2013 in the form of expansion and fragmentation of dome-shaped viscous material. d) Dome-shaped viscous liquid during fragmentation and release of steam. e) Vigorous fountaining activity ejecting yellowish material (most likely rich in elemental sulfur) up to $30 \mathrm{~m}$ high. f) Aerial picture of the active crater in March 2013 showing the two different active zones. The vent near the lava dome is emitting a dilute blueish plume whereas the furthest vent emits steam. Photos courtesy of GNS.

This dome is thought to have formed mid-November of 2012, and soon became associated with high temperature gas emissions $\left(>450{ }^{\circ} \mathrm{C}\right)$. This activity was accompanied by changes in the crater lake: the level was high prior to the eruptions in August and rapidly decreased leaving only small ponds distributed across the active crater by the end of 2012. Temperature estimates from late December indicated strong variations between the small lake adjacent to 
the dome and a more distant pond $\left(71{ }^{\circ} \mathrm{C}\right.$ and $\left.35^{\circ} \mathrm{C}\right)$. Gas fluxes measured at the same time were $400 \mathrm{t} / \mathrm{d}$ of $\mathrm{SO}_{2}$ and $1300 \mathrm{t} / \mathrm{d}$ of $\mathrm{CO}_{2}$. These fluxes slightly increased in 2013, with values up $600 \mathrm{t} / \mathrm{d}$ of $\mathrm{SO}_{2}$ and $2000 \mathrm{t} / \mathrm{d}$ of $\mathrm{CO}_{2}$ at the end of January. The activity in early 2013 was focused in one of the ponds, consisting of bursts of dome-shaped, highly viscous liquid (Figure 2-4 c and d) (Christenson et al., 2017). Towards the end of January, it evolved into spectacular fountaining of yellowish material up to $30 \mathrm{~m}$ high (Figure 2-4 e). Similar activity was observed throughout February. The crater lake started reforming in April 2013 following rainfall but disappeared again in June. An eruption occurred on August 20, producing a plume of steam rising up to $4 \mathrm{~km}$. Small lakes soon refilled the crater and persisted until the last eruptions of the sequence in October 2013, depositing mud across the crater floor.

After more than 3 years of unrest, activity resumed in the evening of 27 April 2016 with a phreatic eruption (GeoNet, 2016). The crater floor and parts of the crater walls were covered with green-colored ash, most likely the top of the hydrothermal system consisting of altered andesite (Figure 2-5). No juvenile magma was erupted on that day. Another small phreatic eruption occurred on September 13 of the same year, giving rise to a small ash plume rising from the 2012 lava dome vent.

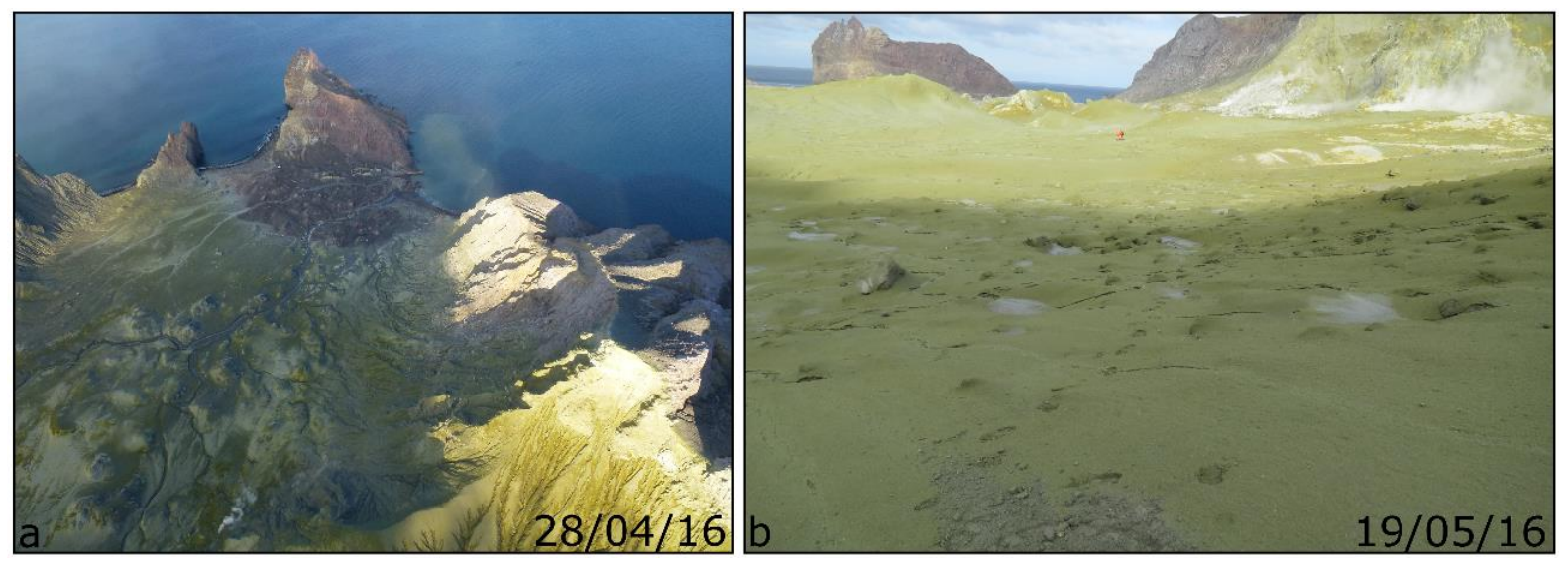

Figure 2-5: Picture of the crater floor covered by green-colored ash after the 27 April 2016 phreatic eruption. a) Aerial picture showing the extent of the deposit, covering almost all the crater floor and crater walls. b) Picture taken from within the crater. Photo courtesy of GNS.

Besides these two unexpected phreatic eruptions in 2016, the activity was reduced to quiescent degassing during the project timeframe, motivating our decision to study metal emissions at Yasur and Etna. The former is located in Tanna Island, in the southern Vanuatu archipelago. The series of volcanic islands extends over $1200 \mathrm{~km}$ following the eastward subduction of the Indo-Australian plate under the Pacific plate. Yasur, a basaltic trachyandesite scoria cone, rises $361 \mathrm{~m}$ above sea level and is part of the larger Siwi caldera (Chen et al., 1995; Métrich et al., 2011). The activity during the past several hundred years has been characterized by persistent degassing coupled with continuous Strombolian and sometimes Vulcanian explosions every 2 to 15 minutes (Firth et al., 2014). The presence of magma only meters below the surface suggests hydrothermal contribution to be minor compared to White Island. 
Mount Etna is a $3330 \mathrm{~m}$ high stratovolcano located in the eastern coast of Sicily in Italy. Being the most active volcano in Europe, Etna is one of the world's largest $\mathrm{SO}_{2}$ emitter owing to the persistent degassing of its volatile-rich alkaline basalts (Metrich and Clocchiatti, 1989; Allard, 1997; Caltabiano et al., 2004).

The knowledge acquired throughout the years on the hydrothermal system of White Island and its link to the volcanic activity sets a starting point for the present study. Focusing on metals, we will refine our understanding of volatile transport in subduction context by:

- Characterizing the magmatic system: what is the parental magma composition in terms of metals, and how degassing and mixing processes affect the repartition between the melt and any fluid phase.

- Studying the metal distribution at the surface through studies of various types of discharges, and constraining the metal speciation in these phases.

- Making a mass balance for the magmatic-hydrothermal system and comparing it to models obtained through thermodynamic calculations to emphasize processes taking place in the subsurface environment. 


\section{Chapter 3: Magma mixing, volatile degassing and late sulphide saturation: Insights into the 1976-2000 eruptive sequence at White Island}

\subsection{Introduction}

The composition of primary magma at depth is an essential parameter controlling the processes happening during the rise and evolution of the melt. It is also one of the most difficult to assess. Volatiles are of special interest due to their role in influencing the eruptive style of a volcano (Wilson, 1980; Woods and Koyaguchi, 1994; Roggensack et al., 1997; Huppert and Woods, 2002; Stock et al., 2016), as well as transporting other species, such as metals (Lowenstern et al., 1991; Williams-Jones et al., 2002; Harris et al., 2003; Foustoukos and Seyfried Jr, 2007; Sherman, 2010; Henley and Berger, 2013; Migdisov et al., 2014). Silicate melt inclusions are small droplets of magma trapped within crystals during their growth. The phenocrysts, due to their incompressible properties, act as pressure vessels and ensure the preservation of inclusions during eruption. Melt inclusions hence provide information on the melt prior to eruption, during the early stages of crystallization at magmatic pressure and temperature (Harris and Anderson, 1983; Roedder, 1984; Anderson et al., 1989; Lowenstern, 1995; Sobolev, 1996; Frezzotti, 2001; Lowenstern, 2003). Inclusions hosted in the first minerals to crystallize, deep in the system (i.e. olivines), are assumed to represent the closest composition to the primary magma. Studies of these archives provide insights into dissolved volatile and metal contents during magma ascent and crystallization (Takenouchi and Imai, 1975; Anderson et al., 1989; Lowenstern, 2003). Combined with petrologic studies, they also highlight the evolution of the magmatic system throughout passive degassing and eruptive activity.

As described in Chapter 2, the December 1976 eruption at White Island was the beginning of a period of eruptive activity that ended in July 2000 (Houghton and Nairn, 1989a). Phreatic, phreatomagmatic and Strombolian events succeeded one another during that time frame. Here, we present results of petrologic and chemical studies of ejecta from the 1976-2000 eruptive sequence.

\subsection{Samples and analytical methods}

\subsubsection{Samples}

The samples used in the study come mainly from the GNS archive, and collections of Prof. Jim Cole and the late Werner Giggenbach. They consist of nine scoria bombs covering the 1976 to 2000 eruptive cycle, and two blocks erupted in March 1977 (Table 3-1). All the samples were collected shortly after eruption, hence minimizing hydrothermal alteration. The precise date of eruption is not known for each sample as the access to the island at that time was limited. Eruptions occurring during clear days were reported by people from the Bay of Plenty but periods of unsettled weather in March 1977 made any visit to the island, and 
inland observation, difficult (Clark et al., 1979). Five of the rocks studied were collected on April $4^{\text {th }}$ and had been erupted over the period from $12^{\text {th }}$ to $25^{\text {th }}$ of March. Strong activity was reported both from land and during flights over the island during that time. There is however a lack of information to constrain the date of eruption of each sample and to assess the relative chronology between the different bombs and blocks. Two samples were collected during a visit on August $3^{\text {rd }} 1977$. The crater was then covered with blocks and bombs up to $1 \mathrm{~m}$ diameter most likely erupted on 29-30 July. Also part of the study is one sample erupted in 1992 and collected by Werner Giggenbach. One of the bombs was collected on October $22^{\text {nd }} 1993$, after the vent clearing, phreatic eruption of October $19^{\text {th }}$. Bombs and blocks of up to $2 \mathrm{~m}$ diameter were erupted during the 17 April 1999 eruptions. One ballistic, collected during a visit on 20 April, was analyzed in this study. The last sample was ejected on July $27^{\text {th }} 2000$, during what was the last eruption of the cycle, and also the largest one in the past 20 years (Smithsonian Institution, 1976-2000; IGNS, 1986-2001).

\subsubsection{Major elements and volatiles}

Polished sections were used for microscopic observations and imaging, as well as chemical analyses. A JEOL JXA-8230 Superprobe was used to determine major and volatile $(\mathrm{Cl}, \mathrm{S}$ and F) element compositions by electron probe microanalysis (EPMA). Melt inclusions and matrix glass were analyzed using $15 \mathrm{kV}, 8.0 \mathrm{nA}$ current and a defocused beam with a spot size of $10 \mu \mathrm{m}$ to minimize Na loss. A bigger spot size was used in matrix glasses containing microlites to encompass the variation in composition due to crystallization. The bulk composition (i.e., residual glass + microlites) was, for these samples, analyzed using a $30 \mu \mathrm{m}$ beam. Analyses were standardized using rhyolitic glass VG-568 for $\mathrm{Si}, \mathrm{Al}$ and $\mathrm{K}$, basaltic glass VGA-99 for $\mathrm{Ca}, \mathrm{Na}, \mathrm{Ti}, \mathrm{Mg}$ and $\mathrm{Fe}$, synthetic pure oxides for $\mathrm{Cr}$ and $\mathrm{Mn}$, Beson apatite for $\mathrm{P}$, fluorite for $\mathrm{F}$, scapolite for $\mathrm{Cl}$ and pyrite for $\mathrm{S}$. On-peak counting times were as follows: 15 s for $\mathrm{Na}, 60 \mathrm{~s}$ for $\mathrm{S}, \mathrm{Cl}$ and F, $30 \mathrm{~s}$ for $\mathrm{Si}, \mathrm{Ca}, \mathrm{K}, \mathrm{Al}, \mathrm{Mg}, \mathrm{Fe}, \mathrm{Ti}, \mathrm{Mn}, \mathrm{Cr}$ and $\mathrm{P}$. $\mathrm{Na}$ was measured first without peak search to minimize volatilization under the beam. Reference glasses VGA-99 and VG-568 (Jarosewich et al., 1980) were used to verify analyses and gave the following uncertainties: $2 \%$ RSD $<8 \%$ for alkalis, $<4 \%$ for $\mathrm{TiO}_{2}$, < $3 \%$ for $\mathrm{Mg}$ and $\mathrm{FeO}_{\mathrm{t}},<2 \%$ for $\mathrm{SiO}_{2}, \mathrm{Al}_{2} \mathrm{O}_{3}, \mathrm{CaO}, 15 \%$ for $\mathrm{Cl}, 21 \%$ for $\mathrm{P}_{2} \mathrm{O}_{5}, 24 \%$ for $\mathrm{MnO}$ and $29 \%$ for $\mathrm{S}$.

Olivine crystals were analyzed using $15 \mathrm{kV}, 20 \mathrm{nA}$ current and a focused beam. Analyses were standardized using San Carlos NMNH-111312-44 (Jarosewich et al., 1980) olivine for $\mathrm{Si}, \mathrm{Mg}$ and $\mathrm{Fe}$, Kakanui augite NMNH-122142 (Jarosewich et al., 1980) for Ca, synthetic oxides for Cr, Mn and Ni. On-peak counting times were $30 \mathrm{~s}$ for all elements. Reference San Carlos NMNH-111312-44 and Springwater olivine USNM-2566 (Jarosewich et al., 1980) were used to verify analyses and gave the following uncertainties: $2 \%$ RSD $<1 \%$ for $\mathrm{SiO}_{2}$, $\mathrm{FeO}_{\mathrm{t}}$ and $\mathrm{MgO}, 8 \%$ for $\mathrm{MnO}$ and $6 \%$ for $\mathrm{NiO}$. 
Table 3-1: Description of samples

\begin{tabular}{|c|c|c|c|c|c|c|c|c|c|c|c|c|c|c|}
\hline Date erupted & $\begin{array}{l}\text { Date } \\
\text { collected }\end{array}$ & Sample & Description & Microlite & $\begin{array}{l}\text { Small } \\
\text { vesicles } \\
\text { Spherical }\end{array}$ & $\begin{array}{l}\text { Big } \\
\text { vesicles } \\
\text { Uneven }\end{array}$ & Olivine & Fo & $\begin{array}{l}\text { Spongy } \\
\text { core } \\
\text { plagioclase }\end{array}$ & $\begin{array}{l}\text { Normal } \\
\text { Zoning }\end{array}$ & $\begin{array}{l}\text { Reverse } \\
\text { zoning }\end{array}$ & Cr-Fe Spinel & $\mathrm{Fe} \pm$ Ti oxides & $\begin{array}{l}\text { Cu-Fe } \\
\text { Sulfide }\end{array}$ \\
\hline \multirow[t]{2}{*}{$12-25 / 3 / 1977$} & $4 / 4 / 1977$ & WIDP 6 & $\begin{array}{l}\text { Dense black block on } \\
\text { edge of crater impact. } \\
\text { Not altered. }\end{array}$ & $\mathrm{Y}++$ & + & + & ++ & $\begin{array}{l}\text { 76-78, } \\
90-93\end{array}$ & $\mathrm{Y}$ & $\mathrm{Y}$ & $\mathrm{N}$ & Gdm, Ol, Px & Gdm, Opx & $\mathrm{N}$ \\
\hline & & $\begin{array}{l}\text { WIDP } 6 \\
\text { dacitic } \\
\text { enclave }\end{array}$ & & $\begin{array}{l}\mathrm{Y}+(\mathrm{Pla} \\
\text { only })\end{array}$ & ++ & + & $\mathrm{N}$ & & $\mathrm{N}$ & $\mathrm{N}$ & $\mathrm{Y}$ & $\mathrm{N}$ & ++ Gdm, Opx & $\mathrm{N}$ \\
\hline $12-25 / 3 / 1977$ & 4/4/1977 & WIDP 18 & Dense black block. & $\mathrm{Y}$ & $\mathrm{Nd}$ & $\mathrm{Nd}$ & ++ & $\sim 90$ & $\mathrm{Nd}$ & $\mathrm{Nd}$ & $\mathrm{Nd}$ & $\mathrm{Nd}$ & $\mathrm{Nd}$ & $\mathrm{Nd}$ \\
\hline $12-25 / 3 / 1977$ & 4/4/1977 & WIDP 10 & $\begin{array}{l}\text { Highly vesiculated } \\
\text { grey scoria. Outside } \\
\text { quite altered. }\end{array}$ & $\mathrm{N}$ & ++ & + & + & $76-78$ & $\mathrm{Y}$ & $\mathrm{N}$ & $\mathrm{Y}$ & Gdm, Ol, Px & $\mathrm{Cpx}$ & $\begin{array}{l}\text { Pla, } \\
\text { Gdm }\end{array}$ \\
\hline $12-25 / 3 / 1977$ & 4/4/1977 & WIDP 11 & $\begin{array}{l}\text { Highly vesiculated } \\
\text { dark grey scoria. } \\
\text { Outside altered. }\end{array}$ & $\mathrm{N}$ & + & ++ & $\mathrm{N}$ & & $\mathrm{Y}$ & $\mathrm{N}$ & $\mathrm{N}$ & Gdm, Px & $\mathrm{N}$ & $\mathrm{N}$ \\
\hline $12-25 / 3 / 1977$ & 4/4/1977 & WIDP 13 & $\begin{array}{l}\text { Highly vesiculated } \\
\text { black scoria. Not } \\
\text { altered. }\end{array}$ & $\mathrm{Y}$ & + & + & + & $76-78$ & $\mathrm{Y}$ & $\mathrm{N}$ & $\mathrm{Y}$ & Px & $\mathrm{Cpx}, \mathrm{Gdm}$ & $\mathrm{Pla}$ \\
\hline 26/7-3/8/1977 & 8/3/1977 & WIDP 9 & $\begin{array}{l}\text { Highly vesiculated } \\
\text { black scoria. Not } \\
\text { altered. }\end{array}$ & $\mathrm{Y}$ & + & ++ & + & $76-78$ & $\mathrm{Y}$ & $\mathrm{N}$ & $\mathrm{Y}$ & Px & $\mathrm{Gdm}$ & $\mathrm{N}$ \\
\hline $26 / 7-3 / 8 / 1977$ & $8 / 3 / 1977$ & WIDP 8 & $\begin{array}{l}\text { Highly vesiculated } \\
\text { dark grey scoria. } \\
\text { Outside altered. }\end{array}$ & $\mathrm{N}$ & $\begin{array}{l}+ \\
\text { (uneven) }\end{array}$ & + & + & $76-78$ & $\mathrm{Y}$ & $\mathrm{N}$ & $\mathrm{Y}$ & $P x$ & Gdm, Pla, Px & $\mathrm{Pla}$ \\
\hline 1992 & 1992 & WIDP 17 & $\begin{array}{l}\text { Highly vesiculated } \\
\text { dark grey scoria. } \\
\text { Outside altered. }\end{array}$ & $\mathrm{N}$ & ++ & ++ & + & $76-78$ & $\mathrm{~N}$ & $\mathrm{~N}$ & $\mathrm{Y}$ & Px & $\mathrm{N}$ & $\mathrm{N}$ \\
\hline 10/19/1993 & $10 / 22 / 1993$ & WIDP 4 & $\begin{array}{l}\text { Dense vesicular fresh } \\
\text { andesite from a } \\
\text { broken bomb. Not } \\
\text { altered. }\end{array}$ & $\mathrm{Y}$ & $\begin{array}{l}+ \\
\text { (uneven) }\end{array}$ & + & ++ & $91-92$ & $\mathrm{Y}$ & $\mathrm{Y}$ & $\mathrm{N}$ & Gdm, Ol, Px & $\mathrm{Gdm}$ & MI \\
\hline 4/17/1999 & 4/20/1999 & WIDP 7 & $\begin{array}{l}\text { Black scoria bomb. } \\
\text { Not altered. }\end{array}$ & $\mathrm{Y}$ & + & + & + & $\begin{array}{l}79-80, \\
91-92\end{array}$ & $\mathrm{Y}$ & $\mathrm{N}$ & $\mathrm{Y}$ & $\mathrm{Gdm}, \mathrm{Ol}$ & $\mathrm{Gdm}$ & $\mathrm{N}$ \\
\hline $7 / 27 / 2000$ & $7 / 31 / 2000$ & WIDP 3 & $\begin{array}{l}\text { Dense dark grey } \\
\text { scoria. Outside } \\
\text { altered. }\end{array}$ & Y (few) & + & + & + & 76 & $\mathrm{Y}$ & $\mathrm{N}$ & $\mathrm{N}$ & Gdm, Ol, Px & $\mathrm{Gdm}$ & Opx \\
\hline
\end{tabular}

Notes: Nd: Not determined. Gdm: Groundmass glass. Ol: Olivine. Px: Pyroxene. Cpx: Clinopyroxene. Opx: Orthopyroxene. Pla: Plagioclase. MI: Melt

Inclusion. Y: Yes. N: No.,+++ : relative abundance. 
Semi-quantitative composition maps of $\mathrm{Cu}-\mathrm{Fe}$ sulphides were acquired using the same instrument, in WDS mode with a beam current of $20 \mathrm{nA}$. For sulphides larger than $10 \mu \mathrm{m}$, maps were done on stage mode, with a pixel size set to $0.2 \mu \mathrm{m}$, and dwell time to $500 \mathrm{~ms}$. For smaller sulphides, the beam mode was used, with a dwell time of $300 \mathrm{~ms}$ and $100 \mathrm{x} 100$ pixels square. The $\mathrm{Cu}-\mathrm{Fe}$ sulphide compositions were measured with a focused beam, $15 \mathrm{kV}$, $20 \mathrm{nA}$, and using pyrite, galena, scapolite and metal standards (pure $\mathrm{Cu}, \mathrm{Ni}, \mathrm{Ag}, \mathrm{Au}, \mathrm{Zn}, \mathrm{Co}$, Mo). Counting time was $30 \mathrm{~s}$ for $\mathrm{Cu}, \mathrm{Fe}$ and $\mathrm{S}$ and $60 \mathrm{~s}$ for all the other elements. The pyrite standard was used to verify analyses yielding to the following uncertainties: $2 \%$ RSD $<2 \%$ for $\mathrm{S}$ and Fe. Unfortunately, no copper sulfide standard was available to assess the accuracy of standardization with metal $\mathrm{Cu}$. The analyses should thus be regarded as semi-quantitative.

\subsubsection{Water}

Phenocrysts from 3 rocks (WIDP 3, WIDP 4 and WIDP 18) were hand-picked from crushed material. Plagioclase, pyroxene and olivine crystals containing melt inclusions apparently unaffected by cracks were mounted separately onto glass slides using Crystalbond ${ }^{\mathrm{TM}} 509$. Crystals were ground using P2500 wet silicon carbide paper until the melt inclusions were exposed. They were then polished with $3 \mu \mathrm{m}$ and $1 \mu \mathrm{m}$ diamond DP-suspension. In order to expose the second side of the inclusions, samples were reheated on a hot plate and the crystals were flipped over. Grinding and polishing of the second side was repeated. Parallel polishing of the crystals was controlled by looking at interference colors under crossedpolarized light. Doubly polished wafers were removed by dissolving the Crystalbond ${ }^{\mathrm{TM}}$ with acetone.

Samples were analyzed by transmission FTIR spectroscopy using a Nicolet 6700 FTIR spectrometer coupled to a Nicolet Continuum FTIR Microscope and OMNIC software at Massey University, Palmerston North, New Zealand. Absorbance at $\sim 3550 \mathrm{~cm}^{-1}$, the fundamental $\mathrm{O}-\mathrm{H}$ stretching vibration, was used to estimate total $\mathrm{H}_{2} \mathrm{O}$ content. Peak heights were measured after applying a linear baseline.

The Beer-Lambert law was used to convert absorbances into $\mathrm{H}_{2} \mathrm{O}$ concentrations (wt $\%$ ):

$$
c=M A / d \rho \varepsilon
$$

where $\mathrm{M}$ is the molar mass of the $\mathrm{H}_{2} \mathrm{O}\left(\mathrm{g} \cdot \mathrm{mol}^{-1}\right)$, $\mathrm{A}$ is the height of the absorbance peak, $\mathrm{d}$ $(\mu \mathrm{m})$ and $\rho\left(\mathrm{g}_{\mathrm{cm}} \mathrm{cm}^{-3}\right)$ are the thickness and density of the melt inclusion, respectively, and $\varepsilon$ $\left(\mathrm{mol}^{-1} \cdot \mathrm{cm}^{-1}\right)$ is the molar absorption coefficient.

The absorption coefficient for the $\sim 3500 \mathrm{~cm}^{-1}$ band was chosen according to the melt inclusion composition. A value of $68 \mathrm{~L} \cdot \mathrm{mol}^{-1} \cdot \mathrm{cm}^{-1}$ was used for dacitic inclusions in plagioclase and pyroxene (Yamashita et al., 1997) whereas $70 \mathrm{~L} \cdot \mathrm{mol}^{-1} \cdot \mathrm{cm}^{-1}$ was used for andesitic inclusions hosted in olivine (King et al., 2002). Three olivine-hosted inclusions were more mafic and the value of $63 \mathrm{~L} \cdot \mathrm{mol}^{-1} \cdot \mathrm{cm}^{-1}$ from Dixon et al. (1988) was used.

The glass densities were estimated following the calculations of Best (2003), as a function of bulk composition, temperature and pressure. The partial molar volumes are from Lange and Carmichael (1990), Lange (1997) and Ochs and Lange (1997). Values range between 2.46 
and $2.82 \mathrm{~g} . \mathrm{cm}^{-3}$. Spacing between interference fringes in the region $2000-2700 \mathrm{~cm}^{-1}$ in reflectance spectrum (Wysoczanski and Tani, 2006) was used to estimate sample thickness. Only one sample showed no interference fringe. We measured its thickness using an Insize micrometer with an accuracy of $\pm 2 \mu \mathrm{m}$. The doubly exposed wafers of olivine-hosted melt inclusions were very fragile. For this reason, we kept the inclusions either partially exposed or unexposed and measured their thickness with the method described by Nichols and Wysoczanski (2007). This method involves two subsequent analyses, one of the unexposed or partially exposed inclusion, and one of the host olivine only. The latter causes peaks in the region between $2000 \mathrm{~cm}^{-1}$ and $1600 \mathrm{~cm}^{-1}$. Given that the peak height at $2000 \mathrm{~cm}^{-1}$ and the amount of olivine in the beam path are proportional, the proportion of the inclusion is calculated by comparing peak heights with and without it. The inclusion thickness is finally derived from the wafer thickness estimated with interference fringe patterns. The refractive index was calculated using the glass composition for the melt inclusions, and the forsterite content for the host olivine. Errors associated with FTIR analysis have been estimated to be \pm $10 \%$ for $\mathrm{H}_{2} \mathrm{O}$ (Dixon et al., 1988; Dixon et al., 1995; Macpherson et al., 1999; Agrinier and Jendrzejewski, 2000; Danyushevsky et al., 2000; Wysoczanski and Tani, 2006; Wysoczanski et al., 2006).

\subsubsection{Trace elements}

Melt inclusions and matrix glass were analyzed for trace elements by Laser Ablation ICP-MS (LA-ICP-MS) at Victoria University of Wellington, using a RESOlution S155-SE, 193nm excimer laser coupled with an Agilent 7500CS quadrupole ICP-MS in dual detector mode. The laser is equipped with a dual volume cell, allowing ablation to take place in a small volume (wash-out time of 5-7 s). Reference material NIST SRM 612 was used to tune the ICP-MS to high sensitivity, keeping low oxide formation ratio $\left(\mathrm{ThO}^{+} / \mathrm{Th}^{+}<5 \%\right)$. The ablation was performed in helium environment to enhance the transport efficiency (Gunther and Heinrich, 1999). Each ablation lasted $40 \mathrm{~s}$ and was preceded by $30 \mathrm{~s}$ of instrument background measurement. Argon and nitrogen were mixed to the carrier gas at the exit of the ablation cell. A $\mathrm{N}_{2}$ flow of $2 \mathrm{~mL} \cdot \mathrm{min}^{-1}$ was found to improve the sensitivity in the higher masses. A spot size of $25 \mu \mathrm{m}$ was used for the majority of samples. For inclusions with a smaller diameter, the spot size was reduced to $20 \mu \mathrm{m}$ or $15 \mu \mathrm{m}$. The analytical parameters are listed in Table 3-2. USGS synthetic basalt glasses were used, GSE-1G for standardization, and GSD-1G to verify the analyses (Jochum et al., 2005). We chose $\mathrm{Si}$ as the internal standard to calculate absolute values. The reproducibility was assessed in inclusions large enough for multiple ablations. Analytical precision for each element (1\% RSD) and deviations of analyzed GSD-1G from preferred values are presented in Appendix A.1. 
Table 3-2: LA-ICP-MS analytical parameters

\begin{tabular}{|c|c|c|c|}
\hline Laser setup & & ICP-MS setup & \\
\hline Laser energy & $5 \mathrm{~mJ}$ & RF Power & $1500 \mathrm{~W}$ \\
\hline Attenuation & $25 \% \mathrm{~T}$ & Carrier gas & $0.91{\mathrm{~L} \times \mathrm{min}^{-1}}^{-1}$ \\
\hline Spot size & $15,20,25 \mu \mathrm{m}$ & Octopole bias & $-8.4 \mathrm{~V}$ \\
\hline Repetition rate & $5 \mathrm{~Hz}$ & $\begin{array}{l}\text { Quadrupole } \\
\text { bias }\end{array}$ & $-6.7 \mathrm{~V}$ \\
\hline Ablation cell gas & $\mathrm{He}, 400 \mathrm{~mL} \times \mathrm{min}^{-1}$ & Dwell times & $10-30 \mathrm{~ms}$ \\
\hline Carrier gas & $\begin{array}{l}\mathrm{N}_{2}, 2 \mathrm{~mL} \times \mathrm{min}^{-1}, \\
\mathrm{Ar}, 910{\mathrm{~mL} \times \mathrm{min}^{-1}}^{2}\end{array}$ & Cones & Aluminum \\
\hline & & Elements & $\begin{array}{l}{ }^{7} \mathrm{Li},{ }^{11} \mathrm{~B},{ }^{29} \mathrm{Si},{ }^{43} \mathrm{Ca},{ }^{45} \mathrm{Sc},{ }^{47} \mathrm{Ti},,{ }^{51} \mathrm{~V},{ }^{53} \mathrm{Cr}, \\
{ }^{55} \mathrm{Mn},{ }^{59} \mathrm{Co},{ }^{60} \mathrm{Ni},{ }^{63} \mathrm{Cu},{ }^{65} \mathrm{Cu} *,{ }^{66} \mathrm{Zn}, \\
{ }^{69} \mathrm{Ga},{ }^{75} \mathrm{As},{ }^{82} \mathrm{Se},{ }^{85} \mathrm{Rb},{ }^{86} \mathrm{Sr},{ }^{88} \mathrm{Sr} *,{ }^{95} \mathrm{Mo}, \\
{ }^{98} \mathrm{Mo},{ }^{107} \mathrm{Ag} *,{ }^{* 09} \mathrm{Ag},{ }^{111} \mathrm{Cd},{ }^{118} \mathrm{Sn} * \\
{ }^{120} \mathrm{Sn},{ }^{121} \mathrm{Sb},{ }^{137} \mathrm{Ba},{ }^{172} \mathrm{Yb},{ }^{182} \mathrm{~W},{ }^{185} \mathrm{Re}, \\
{ }^{197} \mathrm{Au},{ }^{205} \mathrm{Tl},{ }^{208} \mathrm{~Pb},{ }^{209} \mathrm{Bi},{ }^{238} \mathrm{U}\end{array}$ \\
\hline
\end{tabular}

Notes: * Isotope used

\subsection{Results}

\subsubsection{Whole rock and phenocrysts}

All the rocks are glomeroporphyritic andesites with phenocrysts of plagioclase, clinopyroxene and orthopyroxene. A summary of their textural and structural characteristics is presented in Table 3-1. Whole rock compositions for some of the ejecta were analyzed by Peter Wood at GNS, New Zealand (Mike Rosenberg, pers. comm. 2016) and Séverine Moune at the Laboratoire Magmas et Volcans, France (G. Kilgour, pers. comm.) (Table 3-4). Figure 3-1 shows that the 1976-2000 rocks are highly magnesian compared to historic rocks at White Island, as observed by Cole and Graham (1989). Only one scoriaceous block, erupted in October 1991, plots in the dacitic composition. All the other samples are basaltic-andesite and low $\mathrm{SiO}_{2}$ andesite. The combination of the overall small volume erupted during the sequence $\left(10^{7} \mathrm{~m}^{3}\right.$ in 1976-1990, between $10^{4}$ and $10^{5} \mathrm{~m}^{3}$ in 1990-1994 and 1997-2000 (Houghton and Nairn, 1989b; Scott, 1992)) and the basaltic-andesite composition of the ejecta suggests this sequence was a minor explosive eruption following the classification of Clark et al. (1979) and Cole et al. (2000). The rarity of this type of ejecta in historic rocks is explained by the small volume produced as compared to the major andesite-dacite lava-flow eruptions. Concentrating on this sequence thus deprives us of the study of metals evolution through differentiation into more evolved magmas.

Some of the samples present microlite-free matrix glass whereas others contain plagioclase and pyroxene microlites. Bombs are vesicular to highly vesicular ( $40 \%$ to $\sim 70 \%$ vesicles) whereas the 1977 block is denser ( 20\% vesicles). Some samples exhibit large, uneven globular vesicles, evidence of nucleation, growth and coalescence, coexisting with smaller roundish bubbles. The latter are thought to form later, before coalescence can occur. 

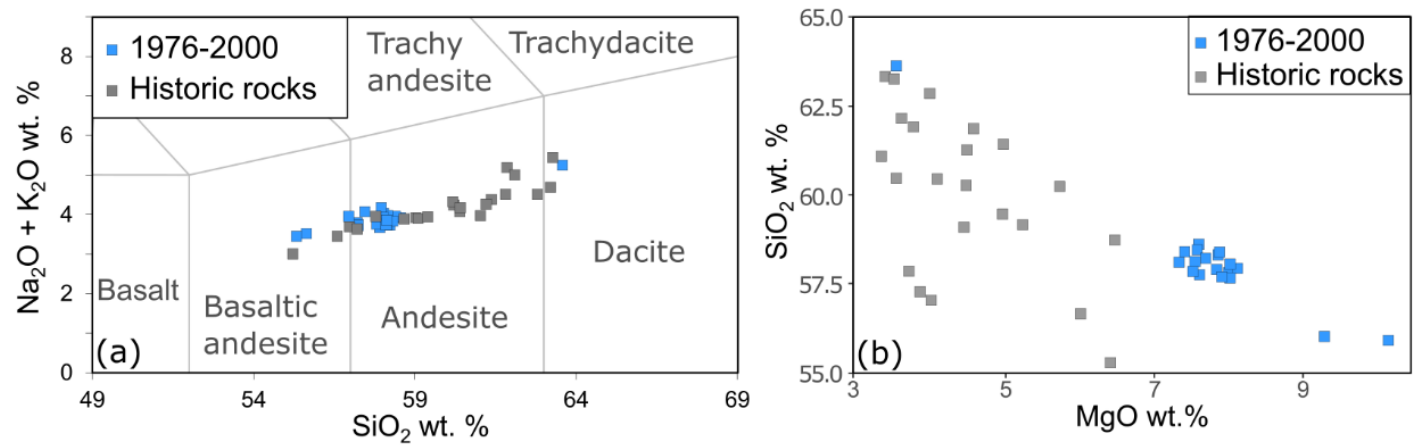

Figure 3-1: White Island historic and 1976-2000 whole rock. a) TAS diagram (Bas et al., 1986). b) $\mathrm{MgO}$ versus $\mathrm{SiO}_{2}$. Data for historic rocks from Cole et al. (2000).

Clinopyroxene and orthopyroxene phenocrysts range in size from $0.5 \mathrm{~mm}$ to $5 \mathrm{~mm}$ and are mostly euhedral to subhedral. Crystal rims with normal and reverse zoning are found in different rocks (Table 3-1). Plagioclase crystals have a similar size range, although two types of crystals are found: 1) subhedral to euhedral crystals with compositional zoning, and 2) subhedral to euhedral crystals with spongy cores, surrounded by rims with compositional zoning. Olivines are present in 9 samples out of 11 as a minor phase $(\leq 1 \%)$. Two distinct populations of olivine were observed, as shown in Figure 3-2.

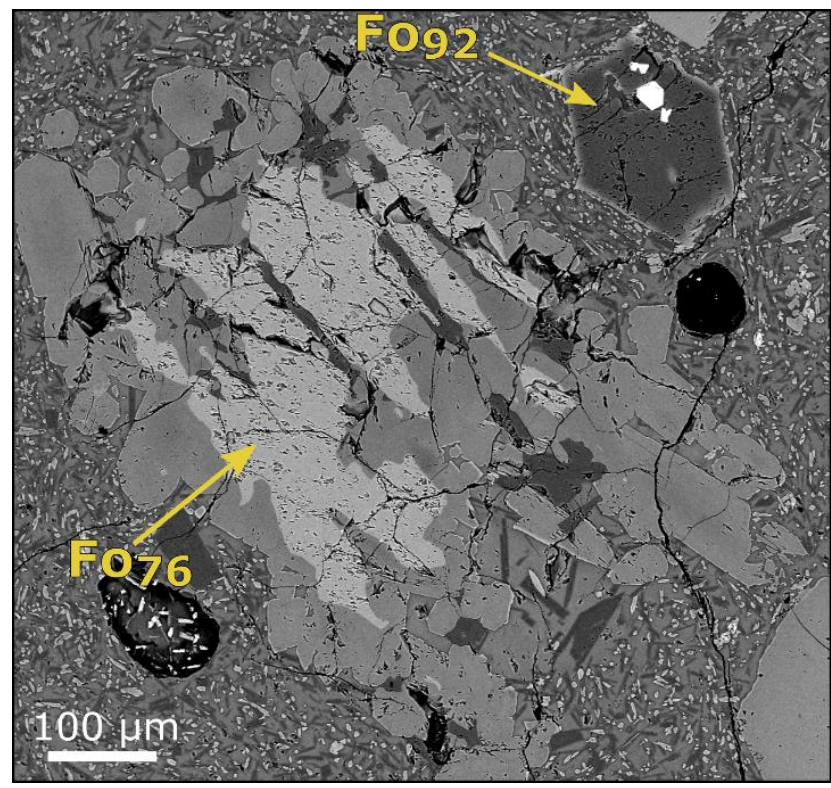

Figure 3-2: Backscattered electron image of olivine Fo76 and olivine Fo92 coexisting in one of the March 1977 bomb, WIDP 6. Note the resorption and recrystallization of orthopyroxene (grey) and plagioclase (dark grey) of the Fo76 olivine. The "white" minerals in the Fo92 olivine are Cr-rich spinel.

The first olivine population, present in only 4 samples, consists of small euhedral to subhedral (100-500 $\mu \mathrm{m})$ crystals, although some larger skeletal phenocrysts (up to $2.5 \mathrm{~mm}$ ) occur, implying a rapid growth rate. Microprobe analyses gave compositions ranging from Fo90 to Fo93 (Table 3-3). These highly magnesian olivines are thought to originate from the 
slab-mantle interface, implying a rapid rise of the magma to the surface to preserve the phenocrysts (Cole et al., 2000). The second population, found in 8 samples, consists of partly resorbed olivine, recrystallized as orthopyroxene and plagioclase. They are less primitive, with composition ranging from Fo76 to Fo80. These differences in composition imply crystallization from melts at different stages of differentiation.

Fe oxides and Fe-Ti oxides are present in the matrix glass of all the rocks apart from WIDP 10, WIDP 11 and WIDP 17 (see Table 3-1). They are also sometimes found as inclusions in pyroxenes or plagioclases. Cr-rich spinels are found in all the rocks, as inclusions in phenocrysts of olivine whenever present, and in pyroxenes. They are also found in the groundmass glass of all the rocks except WIDP 13, WIDP 9 and WIDP 8 from March and July-August 1977 eruptions. A dacitic enclave found in the March 1977 block WIDP 6 contains the largest population of Fe-Ti oxides in the matrix glass and in pyroxenes but is free of Cr-spinel.

Table 3-3: Olivine core compositions (wt $\%$ )

\begin{tabular}{lccccccccc}
\hline Sample & $\mathbf{S i O}_{2}$ & $\mathbf{C r}_{2} \mathbf{O}_{3}$ & $\mathbf{F e O}$ & $\mathbf{M n O}$ & $\mathbf{M g O}$ & $\mathbf{N i O}$ & $\mathbf{C a O}$ & Total & Fo \\
\hline WIDP3_O121 & 38.21 & 0.02 & 21.55 & 0.27 & 38.79 & 0.27 & 0.19 & 99.30 & 76 \\
WIDP4_O107 & 40.34 & 0.30 & 7.77 & 0.13 & 50.37 & 0.24 & 0.18 & 99.34 & 92 \\
WIDP4_O111 & 40.38 & 0.07 & 8.46 & 0.11 & 50.07 & 0.23 & 0.19 & 99.51 & 91 \\
WIDP4_O115 & 40.40 & 0.07 & 8.97 & 0.14 & 49.82 & 0.23 & 0.27 & 99.89 & 91 \\
WIDP4_O118 & 40.68 & 0.15 & 8.28 & 0.12 & 50.15 & 0.25 & 0.20 & 99.81 & 91 \\
WIDP4_O120 & 40.35 & 0.10 & 8.53 & 0.14 & 50.19 & 0.28 & 0.23 & 99.83 & 91 \\
WIDP4_O124 & 40.53 & 0.09 & 8.10 & 0.12 & 50.34 & 0.24 & 0.16 & 99.58 & 92 \\
WIDP4_O125 & 40.60 & 0.11 & 8.30 & 0.14 & 49.99 & 0.26 & 0.18 & 99.58 & 91 \\
WIDP6_O101 & 40.55 & 0.07 & 9.09 & 0.13 & 49.03 & 0.29 & 0.17 & 99.35 & 90 \\
WIDP6_O1 02 & 40.36 & 0.05 & 10.64 & 0.16 & 47.94 & 0.21 & 0.19 & 99.55 & 89 \\
WIDP6_O103 & 40.79 & 0.08 & 8.34 & 0.11 & 50.11 & 0.31 & 0.18 & 99.91 & 91 \\
WIDP6_O104 & 38.61 & 0.01 & 20.38 & 0.29 & 39.50 & 0.26 & 0.17 & 99.22 & 77 \\
WIDP6_O105 & 38.24 & 0.01 & 21.07 & 0.26 & 38.90 & 0.27 & 0.19 & 98.94 & 76 \\
WIDP7_O101 & 38.06 & 0.02 & 18.25 & 0.25 & 40.92 & 0.14 & 0.16 & 97.80 & 80 \\
WIDP7_O102 & 38.02 & 0.05 & 18.51 & 0.26 & 40.64 & 0.16 & 0.15 & 97.79 & 79 \\
WIDP7_O103 & 38.10 & 0.01 & 19.21 & 0.25 & 40.27 & 0.16 & 0.19 & 98.19 & 79 \\
WIDP7_O104 & 40.05 & 0.12 & 8.46 & 0.14 & 49.43 & 0.16 & 0.19 & 98.55 & 91 \\
WIDP7_O105 & 40.39 & 0.17 & 7.70 & 0.13 & 50.10 & 0.17 & 0.17 & 98.83 & 92 \\
WIDP10_O124 & 38.47 & 0.02 & 20.35 & 0.28 & 40.43 & 0.22 & 0.18 & 99.95 & 78 \\
WIDP18_O103 & 40.21 & 0.12 & 6.99 & 0.12 & 51.73 & 0.29 & 0.18 & 99.64 & 93 \\
WIDP18_O120 & 40.60 & 0.01 & 7.33 & 0.11 & 50.74 & 0.21 & 0.23 & 99.23 & 92 \\
WIDP18_O119 & 40.00 & 0.08 & 8.18 & 0.12 & 50.82 & 0.21 & 0.20 & 99.60 & 92 \\
WIDP18_O110 & 40.45 & 0.09 & 7.39 & 0.12 & 50.51 & 0.29 & 0.17 & 99.03 & 92 \\
\hline
\end{tabular}


Table 3-4: Whole rock compositions (wt\%)

\begin{tabular}{|c|c|c|c|c|c|c|c|c|c|c|c|c|c|c|}
\hline Eruption & Type & Sample & $\mathrm{SiO}_{2}$ & $\mathrm{TiO}_{2}$ & $\mathrm{Al}_{2} \mathrm{O}_{3}$ & $\mathrm{Fe}_{2} \mathrm{O}_{3}$ & $\mathrm{FeO}$ & MnO & MgO & $\mathrm{CaO}$ & $\mathrm{Na}_{2} \mathrm{O}$ & $\mathrm{K}_{2} \mathrm{O}$ & $\mathrm{P}_{2} \mathrm{O}_{5}$ & Total \\
\hline March 1977 & Andesite block & P41600 & 55.84 & 0.63 & 13.24 & 1.76 & 5.73 & 0.14 & 10.12 & 8.94 & 2.39 & 1.14 & 0.07 & 100.00 \\
\hline March 1977 & Andesite block & 26592 & 55.95 & 0.61 & 13.48 & 8.40 & - & 0.11 & 9.26 & 8.63 & 2.30 & 1.19 & 0.07 & 100.00 \\
\hline March 1977 & Scoria bomb & P41599 & 57.84 & 0.65 & 13.95 & 1.52 & 5.51 & 0.12 & 7.81 & 8.50 & 2.57 & 1.45 & 0.08 & 100.00 \\
\hline March 1977 & Scoria bomb & 26589 & 57.63 & 0.60 & 13.80 & 7.88 & - & 0.17 & 7.88 & 8.10 & 2.44 & 1.38 & 0.11 & 99.99 \\
\hline July-August 1977 & & 26595 & 58.55 & 0.63 & 14.04 & - & 6.86 & 0.12 & 7.57 & 8.21 & 2.50 & 1.42 & 0.10 & 100.00 \\
\hline May 1979 & & 7905JWC & 58.39 & 0.63 & 13.55 & - & 7.27 & 0.14 & 7.55 & 8.39 & 2.49 & 1.46 & 0.13 & 100.00 \\
\hline 1986 & & 860210 & 57.45 & 0.62 & 13.72 & 7.65 & - & 0.13 & 7.23 & 8.02 & 2.64 & 1.43 & 0.08 & 98.98 \\
\hline 1988 & & 880210 & 57.24 & 0.6 & 13.73 & 7.73 & - & 0.13 & 7.42 & 8.38 & 2.41 & 1.34 & 0.08 & 99.06 \\
\hline 1989 & & 891129 & 57.24 & 0.62 & 13.43 & 7.98 & - & 0.14 & 7.94 & 8.23 & 2.36 & 1.36 & 0.09 & 99.38 \\
\hline August 1991 & & $23411 \mathrm{~A}$ & 58.01 & 0.57 & 13.68 & 7.79 & 0.00 & 0.13 & 7.81 & 8.21 & 2.35 & 1.36 & 0.09 & 100.00 \\
\hline August 1991 & & $23142 \mathrm{~A}$ & 58.29 & 0.62 & 13.86 & 7.57 & 0.00 & 0.13 & 7.38 & 8.08 & 2.54 & 1.44 & 0.10 & 100.00 \\
\hline October 1991 & Scoriaceous block & $911023 \mathrm{~B}$ & 63.58 & 0.68 & 14.75 & 6.34 & - & 0.09 & 3.50 & 5.68 & 3.06 & 2.19 & 0.12 & 99.99 \\
\hline November 1991 & Scoria bomb & 911128 & 58.01 & 0.57 & 13.53 & 7.83 & - & 0.14 & 7.80 & 8.29 & 2.38 & 1.35 & 0.09 & 99.99 \\
\hline December 1991 & Scoria bomb & $911206 \mathrm{~A}$ & 57.70 & 0.58 & 13.84 & 7.66 & - & 0.13 & 7.58 & 8.29 & 2.79 & 1.36 & 0.08 & 100.01 \\
\hline January 1992 & Scoria bomb & 920100 & 57.95 & 0.57 & 14.00 & 7.60 & - & 0.13 & 7.50 & 8.35 & 2.44 & 1.36 & 0.09 & 99.99 \\
\hline February 1992 & Scoria bomb & 920220 & 57.63 & 0.57 & 13.64 & 7.80 & - & 0.14 & 7.96 & 8.27 & 2.54 & 1.36 & 0.10 & 100.01 \\
\hline 1992 & & 920512 & 57.91 & 0.63 & 13.43 & 7.75 & - & 0.13 & 7.63 & 8.34 & 2.26 & 1.41 & 0.09 & 99.58 \\
\hline 1994 & Scoria bomb & WI16c* & 57.82 & 0.62 & 13.76 & 8.49 & - & 0.13 & 7.65 & 8.32 & 2.45 & 1.31 & 0.10 & 100.65 \\
\hline July 2000 & Scoria bomb & 000731A & 57.60 & 0.60 & 13.72 & 7.79 & - & 0.13 & 8.05 & 8.31 & 2.36 & 1.35 & 0.09 & 100.00 \\
\hline July 2000 & Scoria bomb & 000731B & 57.69 & 0.62 & 13.66 & 7.77 & - & 0.13 & 7.95 & 8.27 & 2.46 & 1.37 & 0.09 & 100.00 \\
\hline July 2000 & Scoria bomb & WI-18c* & 56.63 & 0.62 & 13.14 & 8.87 & - & 0.14 & 9.54 & 8.46 & 2.28 & 1.15 & 0.09 & 100.92 \\
\hline July 2000 & Scoria bomb & WI1c* & 56.95 & 0.62 & 13.29 & 8.76 & - & 0.14 & 8.26 & 8.46 & 2.67 & 1.28 & 0.10 & 100.53 \\
\hline
\end{tabular}

Notes: Data from Clark et al. (1979) and Peter Wood (M. Rosenberg, pers. comm.), besides * = data from Severine Moune (G. Kilgour, pers. comm.) 


\subsubsection{Melt inclusions}

Melt inclusions are common in phenocrysts, ranging in size from $5 \mu \mathrm{m}$ to $>100 \mu \mathrm{m}$. A total of 204 melt inclusions were analyzed for major, volatiles (S and $\mathrm{Cl}$ ) and trace elements. Olivine-hosted melt inclusions were corrected for post-entrapment crystallization (Sobolev and Danyushevsky, 1994) by incrementally adding $(0.1 \%)$ olivine back into the melt inclusion until equilibrium with the host was reached. Given the low $\mathrm{H}_{2} \mathrm{O}$ content of the melt inclusions, we used an exchange coefficient $\left(\mathrm{K}_{\mathrm{D}}\right)$ value of 0.3 (Roeder and Emslie, 1970). Clark et al. (1979) analyzed the $\mathrm{FeO}$ and $\mathrm{Fe}_{2} \mathrm{O}_{3}$ content in a bomb and a block from the March 1977 eruptions. We used their average $\mathrm{Fe}^{3+} / \mathrm{Fe}_{\text {tot }}$ value of 0.216 for the postentrapment crystallization correction. The corrected melt inclusion compositions as well as the matrix glass compositions are shown in Appendix A.2.

Inclusions have $\mathrm{SiO}_{2}$ content ranging from $48.20 \mathrm{wt} \%$ to $71.55 \mathrm{wt} \%$, whereas matrix glasses range from $61.44 \mathrm{wt} \%$ to $67.68 \mathrm{wt} \%$. The dacitic enclave in the March 1977 sample exhibits the highest $\mathrm{SiO}_{2}$ content in the matrix glass, with $73.22 \mathrm{wt} \%$. The continuous composition from mafic to more evolved melts (Figure 3-3) suggests a similar source of magma during the 1976-2000 eruptive sequence. Differentiation of mafic magma through crystallization of olivine, pyroxene, and plagioclase seems to explain the range of $\mathrm{SiO}_{2}$ content observed. Olivine-hosted inclusions are the most primitive, while inclusions hosted in plagioclase and pyroxenes are more evolved.

The matrix glass in WIDP 13 (erupted in March 1977), WIDP 8 and 9 (erupted in JulyAugust 1977) is more evolved than melt inclusions, as expected for differentiation through crystallization. In contrast, all the other rocks have matrix glass more mafic than previously trapped inclusions (Figure 3-3), implying that mixing with a more mafic magma occurred after melt inclusions entrapment. WIDP 7, erupted in April 1999, contains melt inclusions with the most evolved compositions (up to $71.55 \mathrm{wt} \% \mathrm{SiO}_{2}$ ). These trapped silicate melts are in the same range as the dacitic enclave found in the March 1977 block. This is consistent with the long break in activity within the sequence, the last sizeable eruption occurring in 1994. The unerupted magma left in the reservoir had time to differentiate, attaining these felsic compositions. The matrix glass has a markedly more primitive signature $(64.36 \mathrm{wt} \%$ $\mathrm{SiO}_{2}$ ), further suggesting the occurrence of magma mixing.

The sulfur content ranges from $16 \mathrm{ppm}$ to $1332 \mathrm{ppm}$ in melt inclusions and from $41 \mathrm{ppm}$ to $105 \mathrm{ppm}$ in matrix glasses. These values are greater than the maximum of $384 \mathrm{ppm}$ reported by Rapien (1998); Wardell et al. (2001); Esposito et al. (2014), in accordance with their analyses of inclusions hosted in plagioclase and pyroxene only. $\mathrm{Cl}$ ranges from $410 \mathrm{ppm}$ to 4388 ppm with most of the melt inclusions between 1000-2000 ppm, and matrix glass between $429 \mathrm{ppm}$ and $1918 \mathrm{ppm}$. F was below detection limit $(\sim 420 \mathrm{ppm})$ in all the melt inclusions and matrix glasses. SIMS analyses by Rapien (1998) and Esposito et al. (2014) of melt inclusions from White Island ejecta $(1977,1986,1988,1991)$ resulted in F contents of 400-800 ppm and 163-169 ppm respectively. 

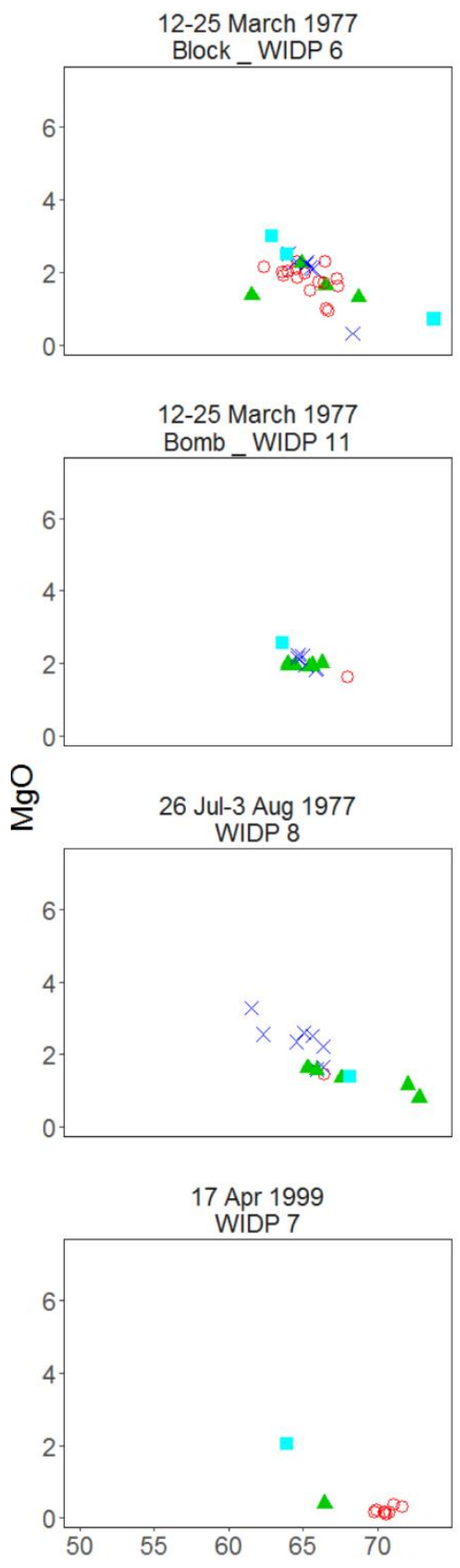
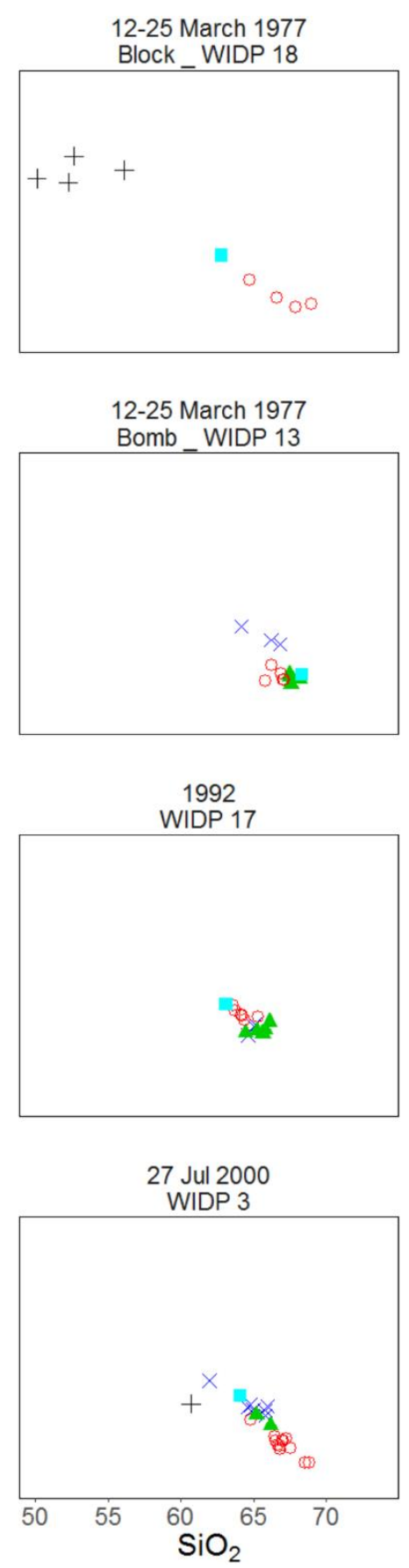
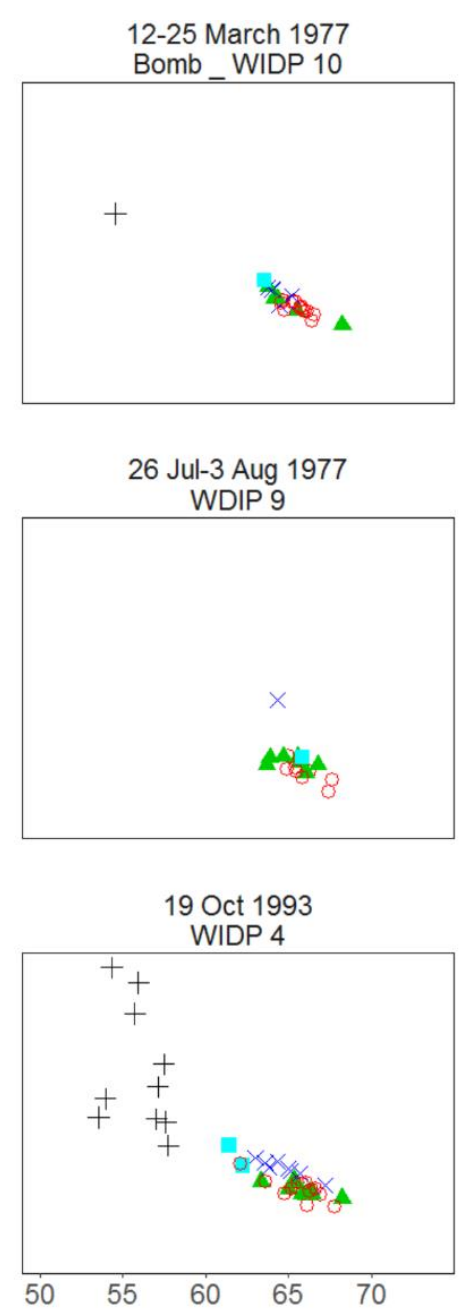

Melt inclusion host

+ Olivine

Orthopyroxene

$\Delta$ Clinopyroxene

$\times$ Plagioclase

Matrix Glass

Figure 3-3: $\mathrm{SiO}_{2}$ versus $\mathrm{MgO}$ of melt inclusions and matrix glasses for separate rocks erupted during the 1976-2000 eruptive sequence.

Water content is available for only 23 melt inclusions, three of them being hosted in olivine phenocrysts, ranging from $0.21 \mathrm{wt} \%$ to $0.97 \mathrm{wt} \%$. These low concentrations $\left(<1 \mathrm{wt} \% \mathrm{H}_{2} \mathrm{O}\right)$ are consistent with earlier findings (Rapien, 1998; Wardell et al., 2001; Esposito et al., 2014). The rarity of olivine crystals and the difficulty of finding melt inclusions larger than $10 \mu \mathrm{m}$ without bubbles or daughter crystals made it challenging to obtain $\mathrm{H}_{2} \mathrm{O}$ data for the deep crystallizing magma. The water content of melt inclusions hosted in olivines from the 1977 block WIDP 18 are very low and most likely reflect difficulties in analyzing melt inclusions smaller than $10 \mu \mathrm{m}$ with FTIR (Nichols and Wysoczanski, 2007). Five other olivine-hosted 
melt inclusions were analyzed, giving the highest observed water contents (1.01-2.25 wt\%). Their major element compositions were however affected by crystallization of daughter minerals after entrapment. As we did not proceed to homogenization of such inclusions containing shrinkage bubble and/or daughter minerals, these results were not included. They nevertheless witness higher water content for the most primitive melt, as we would expect.

No $\mathrm{CO}_{2}$ was detected in any of the melt inclusions. Behrens et al. (2004) reported the difficulties in analyzing $\mathrm{CO}_{2}$ with FTIR in intermediate magmas and recommended the use of SIMS. Previous studies of White Island rocks used the latter technique (Rapien, 1998; Esposito et al., 2014) showing $\mathrm{CO}_{2}$ contents of 39 to 3508 ppm (mostly < $200 \mathrm{ppm}$ ) in melt inclusions hosted in plagioclase and pyroxene. The presence of a shrinkage bubble in olivinehosted inclusions might also explain the very low concentration of dissolved $\mathrm{CO}_{2}$ in the glass (Cervantes and Wallace, 2003; Wallace et al., 2015).

\subsection{3 $\mathrm{Cu}$-Fe sulphides}

$\mathrm{Cu}$ - and Fe-rich sulphides were observed in 5 different samples: two bombs from March 1977, WIDP 10 and WIDP 13, one of the August-July 1977 bombs WIDP 8, the dense vesicular bomb from October 1993 WIDP 4, and WIDP 3 from the last eruption of the sequence in July 2000. These sulphide inclusions have a size range of 4-20 $\mu \mathrm{m}$ and they are found in a variety of hosts: five of these inclusions were found in plagioclase, two within melt inclusions hosted in orthopyroxene, one in an orthopyroxene, and one in the matrix glass. The plagioclase hosting one of the sulphides in WIDP 13 contains many other similar inclusions, as shown in Figure 3-4.

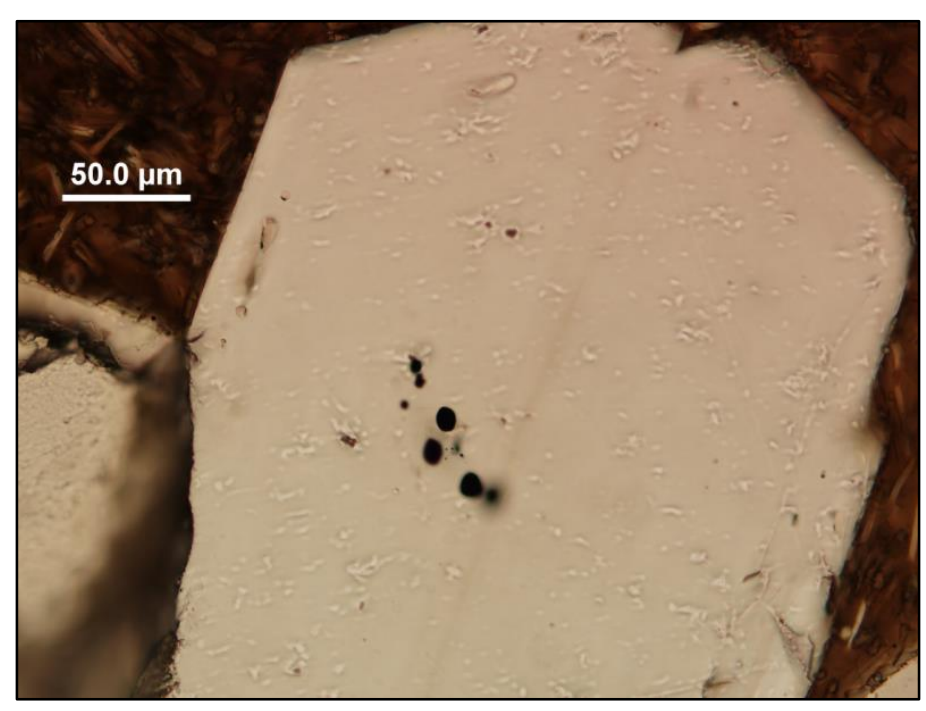

Figure 3-4: Transmitted light image of $\mathrm{Cu}-\mathrm{Fe}$ sulphides in a plagioclase phenocryst in WIDP 13 from March 1977. All the black features in the plagioclase core correspond to $\mathrm{Cu}-\mathrm{Fe}$ sulphides trapped at different depths within the crystal. A total of 8 inclusions were observed, although only one is exposed at the surface (Sulphide 2). 
Qualitative WDS maps show interesting zoning of these unaltered sulphides (Figure 3-6, Appendix A.3). The distribution of the three main constituents, $\mathrm{S}, \mathrm{Fe}$ and $\mathrm{Cu}$, is not uniform. The highest concentrations of sulfur and iron generally coincide with each other, and are associated with low $\mathrm{Cu}$ content. The highest copper concentrations, conversely, usually exhibit lower sulfur and iron contents. Results of point analyses in $\mathrm{S}$ - and Fe-rich zones give 28-34 wt $\% \mathrm{~S}, 24-33 \mathrm{wt} \% \mathrm{Fe}$ and 24-40 wt $\% \mathrm{Cu}$. In the Cu-rich zones, we measured similar S contents (24-33 wt \%) but as low as $6 \mathrm{wt} \%$ for Fe. The highest $\mathrm{Cu}$ content analyzed was 52 wt $\%$. The results of point analyses are presented in Table 3-5. The distribution of compositions in the $\mathrm{Cu}-\mathrm{Fe}-\mathrm{S}$ system (Figure 3-5) suggests exsolution from a precursor intermediate solid solution (iss), forming $\mathrm{Cu}$-rich sulfides towards the bornite endmember and Fe-rich sulfides trending towards pyrite.

Moreover, we observed Fe-rich and S-poor clusters in two different sulphides, having composition of $56 \mathrm{wt} \% \mathrm{Fe}, 10 \mathrm{wt} \% \mathrm{~S}$ and $6 \mathrm{wt} \% \mathrm{Cu}$ for the inclusion in WIDP 10 (Figure 3-6 a, c and Figure 3-5). These may reflect the release of sulfur and copper associated with sulfide oxidation, as reported in other studies (Keith et al., 1997; Larocque et al., 2000; Halter et al., 2002; Nadeau et al., 2010).

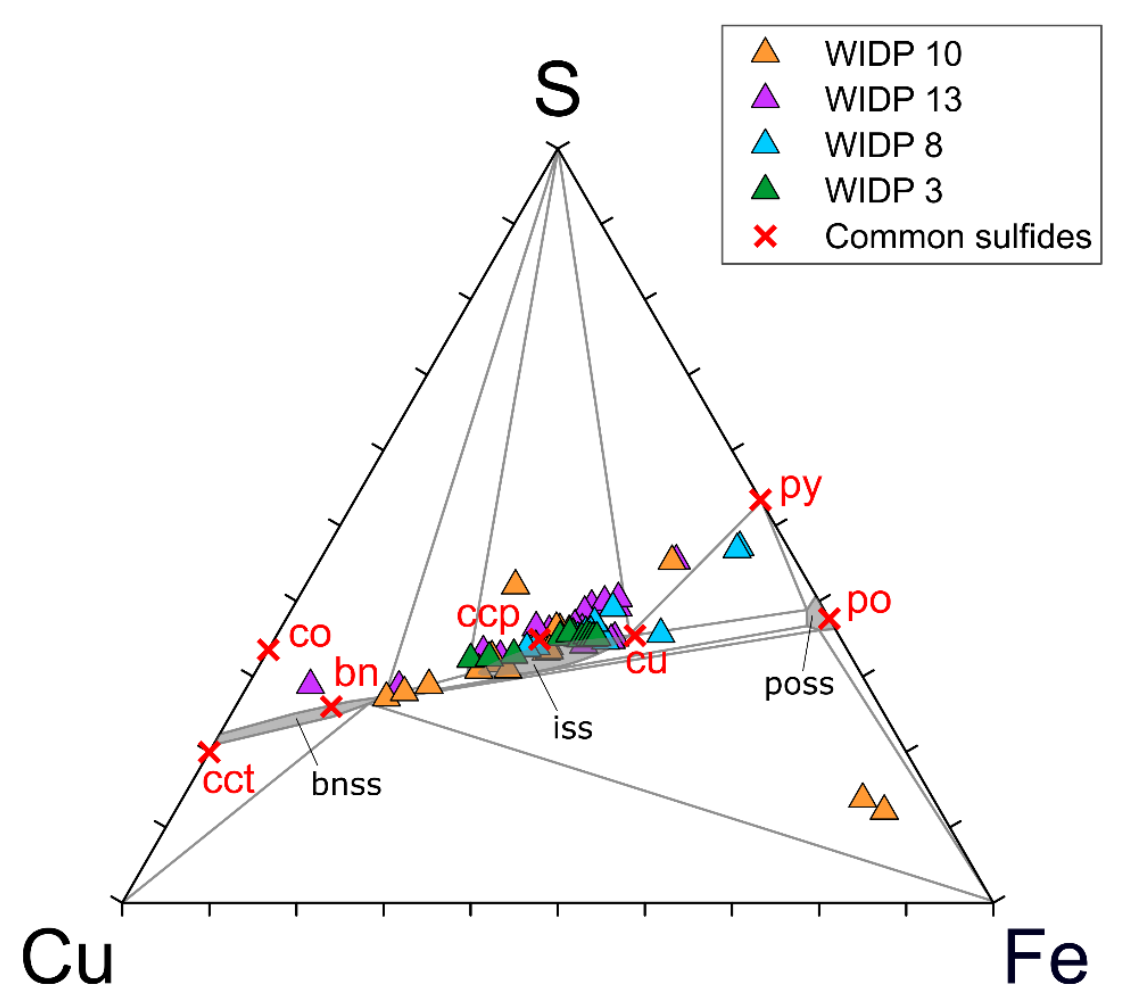

Figure 3-5: $\mathrm{Cu}-\mathrm{Fe}-\mathrm{S}$ ternary diagram of sulphide inclusions (wt \%). Also plotted, the composition of some common $\mathrm{Cu}-\mathrm{Fe}$ sulphides. bn: bornite, ccp: chalcopyrite, cct: chalcocite, co: covellite, cu: cubanite, po: pyrrhotite, py: pyrite. Phase data from Yund and Kullerud (1966) showing solid solution fields at $700{ }^{\circ} \mathrm{C}$. bnss: bornite solid solution, iss: intermediate solid solution, poss: pyrrhotite solid solution. 
Table 3-5: Major and trace element compositions of the $\mathrm{Cu}-\mathrm{Fe}$ sulphides (wt\%)

\begin{tabular}{|c|c|c|c|c|c|c|c|c|c|c|c|c|c|c|c|c|}
\hline & $\begin{array}{l}\text { WIDP3 } \\
\text { Sulf2- } \\
01 \\
\end{array}$ & $\begin{array}{l}\text { WIDP3 } \\
\text { Sulf2- } \\
02 \\
\end{array}$ & $\begin{array}{l}\text { WIDP3 } \\
\text { Sulf2- } \\
03 \\
\end{array}$ & $\begin{array}{l}\text { WIDP3 } \\
\text { Sulf2- } \\
05 \\
\end{array}$ & $\begin{array}{l}\text { WIDP3 } \\
\text { Sulf2- } \\
06 \\
\end{array}$ & $\begin{array}{l}\text { WIDP3 } \\
\text { Sulf2- } \\
07 \\
\end{array}$ & $\begin{array}{l}\text { WIDP3 } \\
\text { Sulf2- } \\
08 \\
\end{array}$ & $\begin{array}{l}\text { WIDP3 } \\
\text { Sulf3- } \\
01 \\
\end{array}$ & $\begin{array}{l}\text { WIDP3 } \\
\text { Sulf3- } \\
02\end{array}$ & $\begin{array}{l}\text { WIDP3 } \\
\text { Sulf3- } \\
03 \\
\end{array}$ & $\begin{array}{l}\text { WIDP3 } \\
\text { Sulf3- } \\
04\end{array}$ & $\begin{array}{l}\text { WIDP3 } \\
\text { Sulf3- } \\
05 \\
\end{array}$ & $\begin{array}{l}\text { WIDP3 } \\
\text { Sulf3- } \\
06 \\
\end{array}$ & $\begin{array}{l}\text { WIDP8 } \\
\text { Sulf1- } \\
02 \\
\end{array}$ & $\begin{array}{l}\text { WIDP8 } \\
\text { Sulf1- } \\
04 \\
\end{array}$ & $\begin{array}{l}\text { WIDP8 } \\
\text { Sulf3- } \\
01 \\
\end{array}$ \\
\hline$S$ & 30.23 & 30.81 & 30.96 & 32.07 & 33.11 & 32.99 & 33.15 & 33.18 & 33.16 & 33.50 & 33.78 & 33.59 & 33.83 & 28.54 & 30.60 & 30.65 \\
\hline Mo & 0.40 & 0.39 & 0.39 & 0.40 & 0.43 & 0.41 & 0.40 & 0.44 & 0.42 & 0.41 & 0.45 & 0.42 & 0.46 & 0.36 & 0.39 & 0.36 \\
\hline $\mathrm{Fe}$ & 22.33 & 26.74 & 24.67 & 29.70 & 31.49 & 33.10 & 31.12 & 33.31 & 33.35 & 34.35 & 35.24 & 34.95 & 35.49 & 31.36 & 37.78 & 30.76 \\
\hline $\mathrm{Zn}$ & 0.05 & 0.07 & 0.04 & 0.05 & 0.05 & 0.07 & 0.04 & 0.05 & 0.01 & 0.01 & 0.02 & 0.07 & 0.08 & 0.03 & 0.03 & - \\
\hline $\mathrm{Ni}$ & 1.33 & 1.55 & 1.22 & 1.68 & 2.61 & 1.73 & 2.87 & 1.73 & 3.88 & 1.20 & 1.05 & 1.16 & 1.08 & 0.21 & 1.09 & 36.31 \\
\hline Co & 0.43 & 0.52 & 0.28 & 0.51 & 0.64 & 0.65 & 0.90 & 0.65 & 0.66 & 0.62 & 0.89 & 0.67 & 0.68 & 0.81 & 0.68 & 1.22 \\
\hline $\mathrm{Pb}$ & - & 0.00 & - & 0.05 & - & - & - & 0.10 & 0.03 & 0.02 & 0.06 & 0.01 & 0.03 & 0.07 & 0.02 & 0.14 \\
\hline $\mathrm{Ag}$ & 0.02 & - & - & 0.02 & - & - & 0.02 & - & 0.03 & 0.01 & - & - & 0.00 & 0.00 & - & 0.23 \\
\hline $\mathrm{Cu}$ & 41.05 & 36.18 & 39.63 & 29.20 & 28.35 & 28.12 & 28.59 & 28.09 & 27.08 & 27.28 & 27.13 & 27.17 & 26.84 & 22.33 & 17.48 & 3.59 \\
\hline $\mathrm{Au}$ & 0.01 & - & 0.02 & 0.02 & 0.00 & 0.01 & - & 0.01 & 0.03 & - & 0.03 & - & - & - & 0.01 & - \\
\hline $\mathrm{Cl}$ & 0.02 & 0.02 & 0.02 & 0.02 & 0.02 & 0.02 & 0.02 & 0.03 & 0.02 & 0.03 & 0.02 & 0.03 & 0.03 & 0.08 & 0.04 & 0.04 \\
\hline Total & 95.86 & 96.27 & 97.21 & 93.69 & 96.68 & 97.07 & 97.09 & 97.54 & 98.66 & 97.39 & 98.66 & 98.05 & 98.47 & 83.70 & 88.08 & 103.27 \\
\hline
\end{tabular}

Table 3-5 (continued)

\begin{tabular}{|c|c|c|c|c|c|c|c|c|c|c|c|c|c|c|c|c|}
\hline & $\begin{array}{l}\text { WIDP8 } \\
\text { Sulf3- } \\
02\end{array}$ & $\begin{array}{l}\text { WIDP8 } \\
\text { Sulf3- } \\
03\end{array}$ & $\begin{array}{l}\text { WIDP8 } \\
\text { Sulf3- } \\
04\end{array}$ & $\begin{array}{l}\text { WIDP8 } \\
\text { Sulf3- } \\
05 \\
\end{array}$ & $\begin{array}{l}\text { WIDP8 } \\
\text { Sulf3- } \\
06\end{array}$ & $\begin{array}{l}\text { WIDP8 } \\
\text { Sulf3- } \\
07 \\
\end{array}$ & $\begin{array}{l}\text { WIDP8 } \\
\text { Sulf3- } \\
08\end{array}$ & $\begin{array}{l}\text { WIDP8 } \\
\text { Sulf3- } \\
09\end{array}$ & $\begin{array}{l}\text { WIDP10 } \\
\text { Sulf1-01 } \\
\end{array}$ & $\begin{array}{l}\text { WIDP10 } \\
\text { Sulf1-02 } \\
\end{array}$ & $\begin{array}{l}\text { WIDP10 } \\
\text { Sulf1-03 } \\
\end{array}$ & $\begin{array}{l}\text { WIDP10 } \\
\text { Sulf1-04 }\end{array}$ & $\begin{array}{l}\text { WIDP10 } \\
\text { Sulf1-05 } \\
\end{array}$ & $\begin{array}{l}\text { WIDP10 } \\
\text { Sulf1-06 } \\
\end{array}$ & $\begin{array}{l}\text { WIDP10 } \\
\text { Sulf1-07 }\end{array}$ & $\begin{array}{l}\text { WIDP10 } \\
\text { Sulf1-08 } \\
\end{array}$ \\
\hline S & 31.34 & 30.51 & 30.57 & 29.42 & 28.89 & 31.30 & 29.84 & 31.38 & 26.78 & 28.46 & 31.32 & 31.63 & 30.16 & 27.49 & 9.86 & 29.40 \\
\hline Mo & 0.41 & 0.38 & 0.42 & 0.36 & 0.36 & 0.37 & 0.40 & 0.38 & 0.36 & 0.39 & 0.40 & 0.38 & 0.37 & 0.38 & 0.11 & 0.36 \\
\hline $\mathrm{Fe}$ & 31.56 & 28.75 & 29.42 & 26.38 & 25.34 & 30.82 & 29.48 & 31.27 & 22.27 & 22.75 & 29.00 & 30.07 & 26.95 & 24.35 & 55.91 & 27.72 \\
\hline $\mathrm{Zn}$ & 0.03 & 0.03 & 0.02 & 0.04 & 0.03 & 0.05 & 0.04 & 0.07 & 0.05 & - & 0.08 & 0.05 & 0.01 & 0.09 & 0.03 & - \\
\hline $\mathrm{Ni}$ & 35.05 & 17.54 & 8.50 & 0.89 & 0.44 & 0.41 & 0.33 & 0.41 & 1.28 & 0.88 & 1.70 & 1.84 & 28.16 & 6.20 & 0.53 & 1.35 \\
\hline Co & 1.24 & 1.03 & 0.85 & 0.54 & 0.40 & 0.63 & 0.34 & 0.65 & 0.39 & 0.24 & 0.26 & 0.49 & 0.73 & 0.34 & 0.49 & 0.42 \\
\hline $\mathrm{Pb}$ & 0.12 & 0.10 & 0.09 & 0.08 & 0.03 & 0.02 & 0.02 & 0.03 & - & - & - & 0.03 & 0.02 & 0.06 & 0.02 & 0.06 \\
\hline $\mathrm{Ag}$ & 0.23 & 0.09 & 0.07 & - & 0.02 & - & 0.02 & 0.00 & 0.04 & 0.02 & 0.02 & - & 0.28 & 0.81 & 0.01 & 0.04 \\
\hline $\mathrm{Cu}$ & 4.00 & 18.85 & 22.45 & 30.73 & 31.39 & 25.19 & 25.59 & 24.69 & 35.38 & 35.92 & 26.73 & 26.96 & 9.47 & 23.98 & 5.79 & 29.40 \\
\hline $\mathrm{Au}$ & 0.02 & 0.03 & - & 0.03 & - & 0.02 & 0.02 & 0.01 & 0.03 & 0.02 & 0.02 & - & 0.04 & 0.06 & 0.03 & 0.10 \\
\hline $\mathrm{Cl}$ & 0.04 & 0.06 & 0.03 & 0.02 & 0.02 & 0.02 & 0.03 & 0.02 & 0.06 & 0.06 & 0.12 & 0.10 & 0.04 & 0.02 & 0.01 & 0.05 \\
\hline Total & 104.02 & 97.30 & 92.39 & 88.46 & 86.90 & 88.79 & 86.07 & 88.89 & 86.59 & 88.67 & 89.52 & 91.44 & 96.18 & 83.75 & 72.77 & 88.85 \\
\hline
\end{tabular}


Table 3-5 (continued)

\begin{tabular}{|c|c|c|c|c|c|c|c|c|c|c|c|c|c|c|c|c|}
\hline & $\begin{array}{l}\text { WIDP10 } \\
\text { Sulf1-09 }\end{array}$ & $\begin{array}{l}\text { WIDP10 } \\
\text { Sulf1-10 }\end{array}$ & $\begin{array}{l}\text { WIDP10 } \\
\text { Sulf1-11 }\end{array}$ & $\begin{array}{l}\text { WIDP10 } \\
\text { Sulf2-01 }\end{array}$ & $\begin{array}{l}\text { WIDP10 } \\
\text { Sulf2-02 }\end{array}$ & $\begin{array}{l}\text { WIDP10 } \\
\text { Sulf2-03 }\end{array}$ & $\begin{array}{l}\text { WIDP10 } \\
\text { Sulf2-04 }\end{array}$ & $\begin{array}{l}\text { WIDP10 } \\
\text { Sulf2-05 }\end{array}$ & $\begin{array}{l}\text { WIDP10 } \\
\text { Sulf2-06 }\end{array}$ & $\begin{array}{l}\text { WIDP10 } \\
\text { Sulf2-07 }\end{array}$ & $\begin{array}{l}\text { WIDP13 } \\
\text { Sulf1-01 }\end{array}$ & $\begin{array}{l}\text { WIDP13 } \\
\text { Sulf1-02 } \\
\end{array}$ & $\begin{array}{l}\text { WIDP13 } \\
\text { Sulf1-04 }\end{array}$ & $\begin{array}{l}\text { WIDP13 } \\
\text { Sulf1-05 }\end{array}$ & $\begin{array}{l}\text { WIDP13 } \\
\text { Sulf1-06 }\end{array}$ & $\begin{array}{l}\text { WIDP13 } \\
\text { Sulf1-07 }\end{array}$ \\
\hline S & 20.99 & 30.88 & 8.57 & 28.28 & 28.57 & 31.51 & 31.48 & 25.46 & 26.20 & 27.20 & 23.54 & 24.00 & 31.47 & 32.69 & 31.84 & 28.88 \\
\hline Mo & 0.25 & 0.37 & 0.12 & 0.35 & 0.39 & 0.42 & 0.38 & 0.34 & 0.33 & 0.37 & 0.29 & 0.30 & 0.38 & 0.38 & 0.39 & 0.37 \\
\hline $\mathrm{Fe}$ & 12.04 & 26.81 & 57.33 & 26.38 & 23.59 & 30.34 & 30.42 & 15.71 & 17.33 & 19.61 & 5.87 & 14.63 & 31.99 & 32.29 & 31.31 & 23.93 \\
\hline $\mathrm{Zn}$ & 0.01 & 0.02 & 0.01 & 0.08 & 0.07 & 0.08 & 0.11 & 0.07 & 0.09 & 0.10 & 0.07 & 0.06 & 0.04 & 0.05 & 0.04 & 0.02 \\
\hline $\mathrm{Ni}$ & 1.46 & 1.97 & 0.33 & 1.50 & 0.69 & 1.61 & 1.77 & - & - & 0.07 & - & 0.22 & 0.95 & 1.06 & 0.97 & 0.71 \\
\hline Co & 0.29 & 0.41 & 0.43 & 0.27 & 0.39 & 0.57 & 0.42 & 0.26 & 0.26 & 0.15 & 0.13 & 0.11 & 0.55 & 0.53 & 0.66 & 0.46 \\
\hline $\mathrm{Pb}$ & 0.11 & 0.00 & 0.01 & - & 0.00 & 0.06 & - & - & - & - & 0.04 & - & - & 0.05 & 0.05 & - \\
\hline $\mathrm{Ag}$ & 21.10 & 0.46 & 0.02 & 0.03 & 0.02 & 0.02 & 0.02 & 0.03 & 0.02 & 0.01 & 0.06 & 0.02 & - & 0.01 & - & - \\
\hline $\mathrm{Cu}$ & 16.87 & 27.04 & 4.53 & 36.83 & 40.36 & 32.89 & 32.21 & 52.55 & 50.43 & 47.49 & 52.19 & 45.17 & 25.21 & 25.01 & 26.12 & 35.59 \\
\hline $\mathrm{Au}$ & 0.02 & 0.02 & 0.03 & 0.01 & - & 0.01 & - & - & - & - & - & - & - & 0.01 & - & 0.00 \\
\hline $\mathrm{Cl}$ & 0.03 & 0.04 & 0.01 & 0.02 & 0.01 & 0.01 & 0.01 & 0.01 & 0.01 & 0.01 & 0.08 & 0.06 & 0.03 & 0.03 & 0.03 & 0.03 \\
\hline Total & 73.15 & 88.00 & 71.37 & 93.73 & 94.10 & 97.52 & 96.81 & 94.42 & 94.65 & 94.98 & 82.18 & 84.52 & 90.59 & 92.07 & 91.38 & 89.96 \\
\hline
\end{tabular}

Table 3-5 (continued)

\begin{tabular}{|c|c|c|c|c|c|c|c|c|c|c|c|c|c|c|c|c|}
\hline & $\begin{array}{l}\text { WIDP13 } \\
\text { Sulf1-08 }\end{array}$ & $\begin{array}{l}\text { WIDP13 } \\
\text { Sulf1-09 }\end{array}$ & $\begin{array}{l}\text { WIDP13 } \\
\text { Sulf1-10 }\end{array}$ & $\begin{array}{l}\text { WIDP13 } \\
\text { Sulf1-11 }\end{array}$ & $\begin{array}{l}\text { WIDP13 } \\
\text { Sulf1-12 }\end{array}$ & $\begin{array}{l}\text { WIDP13 } \\
\text { Sulf1-13 }\end{array}$ & $\begin{array}{l}\text { WIDP13 } \\
\text { Sulf1-14 }\end{array}$ & $\begin{array}{l}\text { WIDP13 } \\
\text { Sulf2-02 }\end{array}$ & $\begin{array}{l}\text { WIDP13 } \\
\text { Sulf2-03 }\end{array}$ & $\begin{array}{l}\text { WIDP13 } \\
\text { Sulf2-04 }\end{array}$ & $\begin{array}{l}\text { WIDP13 } \\
\text { Sulf2-05 }\end{array}$ & $\begin{array}{l}\text { WIDP13 } \\
\text { Sulf2-06 }\end{array}$ & $\begin{array}{l}\text { WIDP13 } \\
\text { Sulf2-07 }\end{array}$ & $\begin{array}{l}\text { WIDP13 } \\
\text { Sulf2-08 }\end{array}$ & $\begin{array}{l}\text { WIDP13 } \\
\text { Sulf2-09 }\end{array}$ & $\begin{array}{l}\text { WIDP13 } \\
\text { Sulf2-10 }\end{array}$ \\
\hline S & 29.83 & 31.71 & 30.29 & 30.90 & 30.28 & 31.70 & 30.61 & 28.79 & 27.82 & 27.93 & 29.33 & 30.78 & 30.05 & 29.06 & 29.08 & 29.66 \\
\hline Mo & 0.38 & 0.40 & 0.37 & 0.39 & 0.40 & 0.39 & 0.41 & 0.35 & 0.35 & 0.35 & 0.38 & 0.38 & 0.35 & 0.36 & 0.38 & 0.40 \\
\hline $\mathrm{Fe}$ & 31.29 & 30.31 & 33.60 & 27.88 & 33.69 & 29.52 & 26.59 & 25.56 & 25.35 & 24.50 & 25.27 & 29.47 & 27.51 & 21.62 & 23.34 & 27.14 \\
\hline $\mathrm{Zn}$ & 0.05 & 0.02 & 0.02 & 0.01 & 0.05 & 0.06 & 0.02 & 0.05 & 0.05 & 0.08 & 0.07 & 0.03 & 0.09 & 0.06 & 0.06 & 0.07 \\
\hline $\mathrm{Ni}$ & 0.84 & 14.63 & 4.13 & 28.84 & 2.50 & 4.57 & 16.60 & 10.67 & 12.09 & 7.77 & 2.07 & 1.33 & 1.52 & 0.44 & 0.74 & 1.08 \\
\hline Co & 0.64 & 0.54 & 0.44 & 1.01 & 0.47 & 0.46 & 0.83 & 0.57 & 0.59 & 0.53 & 0.35 & 0.45 & 0.40 & 0.15 & 0.54 & 0.37 \\
\hline $\mathrm{Pb}$ & - & 0.04 & 0.01 & 0.03 & 0.02 & - & 0.02 & - & 0.02 & 0.04 & - & 0.02 & 0.02 & - & - & - \\
\hline $\mathrm{Ag}$ & - & 0.05 & 0.02 & 0.15 & 0.02 & 0.02 & 0.04 & 0.18 & 0.34 & 0.23 & 0.07 & 0.01 & 0.04 & - & 0.02 & 0.01 \\
\hline $\mathrm{Cu}$ & 26.11 & 19.07 & 22.29 & 9.34 & 23.02 & 24.20 & 20.54 & 17.78 & 15.77 & 20.02 & 26.87 & 24.68 & 24.25 & 36.54 & 27.30 & 23.97 \\
\hline $\mathrm{Au}$ & 0.01 & - & - & - & 0.00 & - & - & 0.01 & 0.03 & - & - & 0.01 & - & 0.01 & - & 0.02 \\
\hline $\mathrm{Cl}$ & 0.02 & 0.02 & 0.02 & 0.02 & 0.02 & 0.02 & 0.03 & 0.03 & 0.03 & 0.03 & 0.03 & 0.03 & 0.03 & 0.03 & 0.03 & 0.03 \\
\hline Total & 89.16 & 96.77 & 91.17 & 98.53 & 90.44 & 90.92 & 95.66 & 83.95 & 82.40 & 81.42 & 84.40 & 87.16 & 84.22 & 88.23 & 81.45 & 82.71 \\
\hline
\end{tabular}

Note: - not determined. 
The sulphide trapped in the matrix glass in WIDP 10 is richer in $\mathrm{Cu}$ than any other sulphides, with values of $32 \mathrm{wt} \%$ to $53 \mathrm{wt} \%$. This is also the only sulphide found in the matrix glass, probably suggesting a later formation than the other sulphides trapped in phenocrysts. These concentrations are extremely high and demonstrate the efficiency of sulphide melts in concentrating chalcophile metals.

A variety of trace elements were observed in the different sulphides, usually concentrated in clusters rather than distributed uniformly. This is the case for $\mathrm{Ni}$, with concentrations up to 36 wt\% in one of the sulphides in WIDP 8 from late July 1977 (Appendix A.3, Figure A-1 c). These Ni-rich areas are usually $\mathrm{Cu}$-poor, highlighting stability of a Ni-S-Fe phase. The other notable trace elements forming clusters are $\mathrm{Ag}$ and $\mathrm{Au}$. One of the clusters in sulphide 1 from WIDP 10 has elevated silver content (21 wt\%) (Figure 3-6 a). The other Ag-rich clusters usually exhibit contents in thousands of ppm. The highest concentration of gold observed is $1000 \mathrm{ppm}$ in the same sulphide from WIDP 10 (Figure 3-6 a). Clusters rich in zinc are less common. One of the sulfides from WIDP 13 nevertheless exhibits a concentration of 880 ppm. The highest contents for zinc are observed in the sulphide hosted in the matrix glass from WIDP 10, with values up to $1140 \mathrm{ppm}$, which is also the most concentrated in copper. The concentration of Mo is quite uniform in all the sulphides, ranging from $3000 \mathrm{ppm}$ to $4500 \mathrm{ppm}$. Co shows more variability and notably the highest concentrations of up to $1 \mathrm{wt} \%$ associated with Ni-rich clusters. All the sulphides have low $\mathrm{Pb}$ concentrations, the highest being found with $\mathrm{Ni}$ - and Ag-rich clusters, at around $1000 \mathrm{ppm}$.

The composition of these metal-rich sulfides is in agreement with the experimentally determined partition coefficients between sulphide and silicate melts: $250-1300$ for $\mathrm{Cu}, 790$ 5500 for $\mathrm{Au}, 300-19000$ for $\mathrm{Ag}, 210-4400$ for Ni, 18-164 for Co, 3-200 for Mo, 0.28-130 for $\mathrm{Zn}$ and 7-48 for $\mathrm{Pb}$ (Peach et al., 1990; Lodders and Palme, 1991; Gaetani and Grove, 1997; Ripley et al., 2002; Mengason et al., 2006; Mengason et al., 2011; Li and Audétat, 2012). In spite of the wide range of partition coefficients obtained due to varying silicate melt composition, fugacity of oxygen and sulfur during experiments, all of the metals besides $\mathrm{Zn}$ show a compatible behavior. It is interesting to note that $\mathrm{Cl}$ is present in the sulphides, even up to concentrations of $1160 \mathrm{ppm}$ in small cluster found in the plagioclase-hosted sulphide in WIDP 10 (Figure 3-6 a). 
a) WIDP 10 _ 12-25 March 1977 _ Sulfide 1

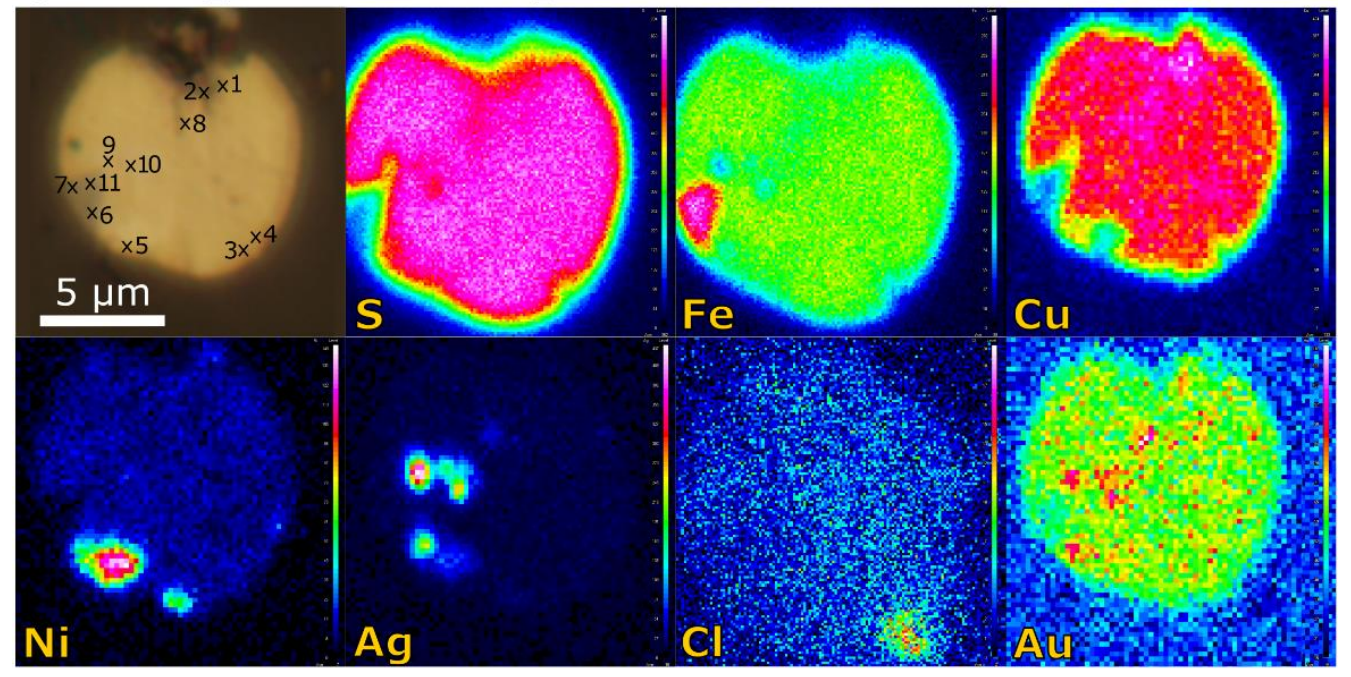

b) WIDP 10 _ $12-25$ March 1977 _ Sulfide 2

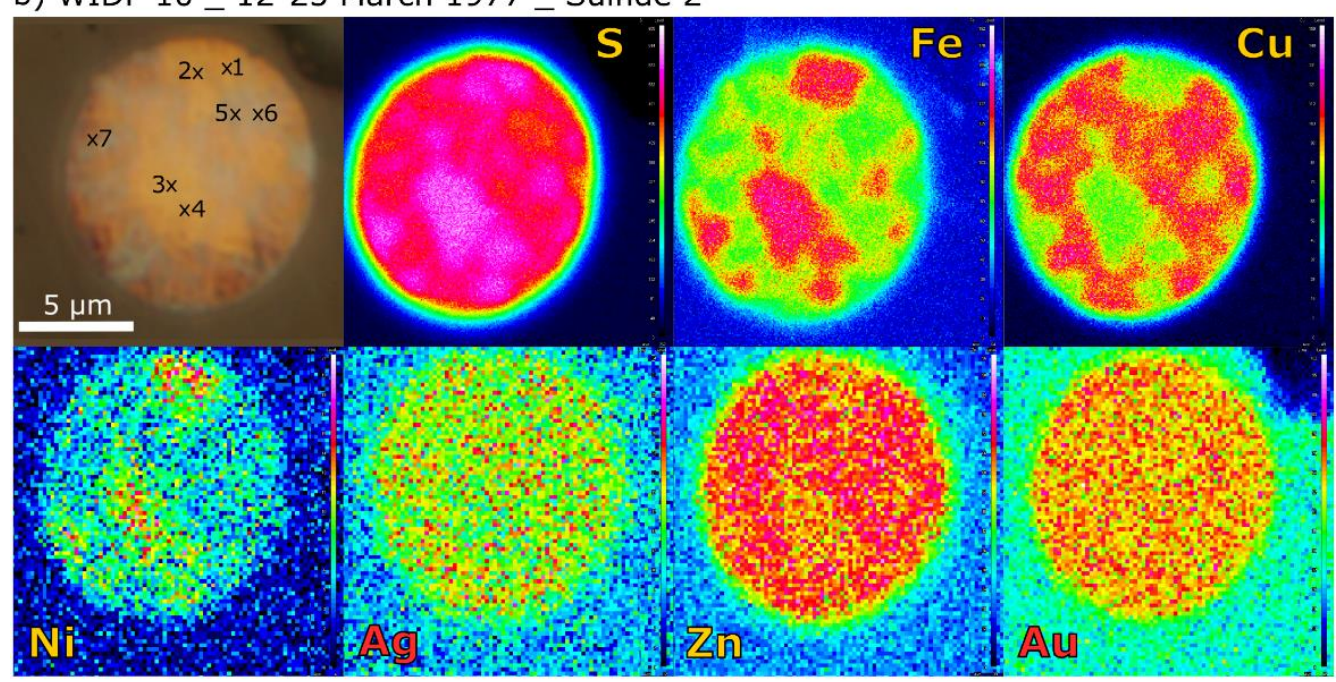

c) WIDP 13 _ 12-25 March 1977 _ Sulfide 1

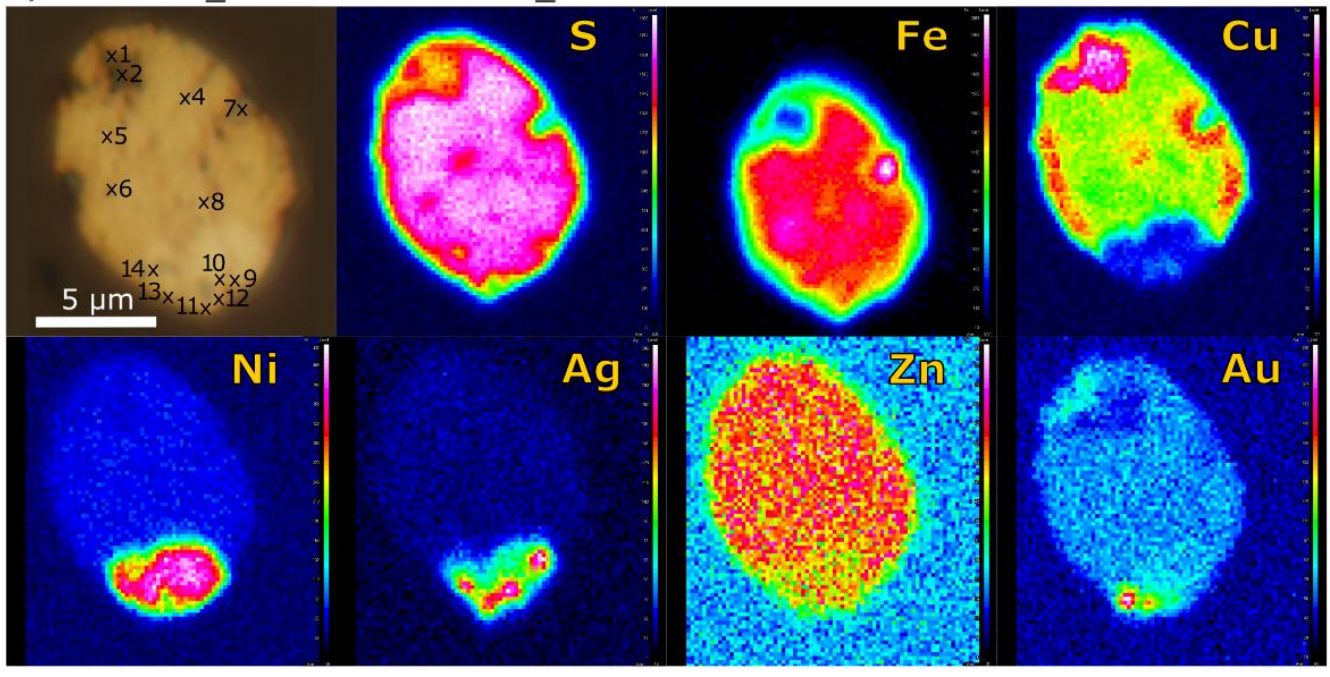

Figure 3-6: Cu-Fe sulphide composition maps. The reflected light image on top left corner shows the position of quantitative point analyses. The other images are composition maps acquired using WDS detectors and show the distribution of each species within the sulphide. a) Sulphide in plagioclase phenocryst from WIDP 10, March 1977. b) Sulphide in matrix glass from WIDP 10, March 1977. c) Sulphide in plagioclase phenocryst from WIDP 13, March 1977. 
Arsenic was below detection limit in almost all the sulphides. Figure 3-7 however shows that the latter behaves incompatibly during crystallization. The lack of As in sulphides might be explained by preferential partitioning into a volatile phase. The high concentrations observed in fumarolic gases (123-1090 ppm, cf. Chapter 5) support the idea of arsenic degassing.

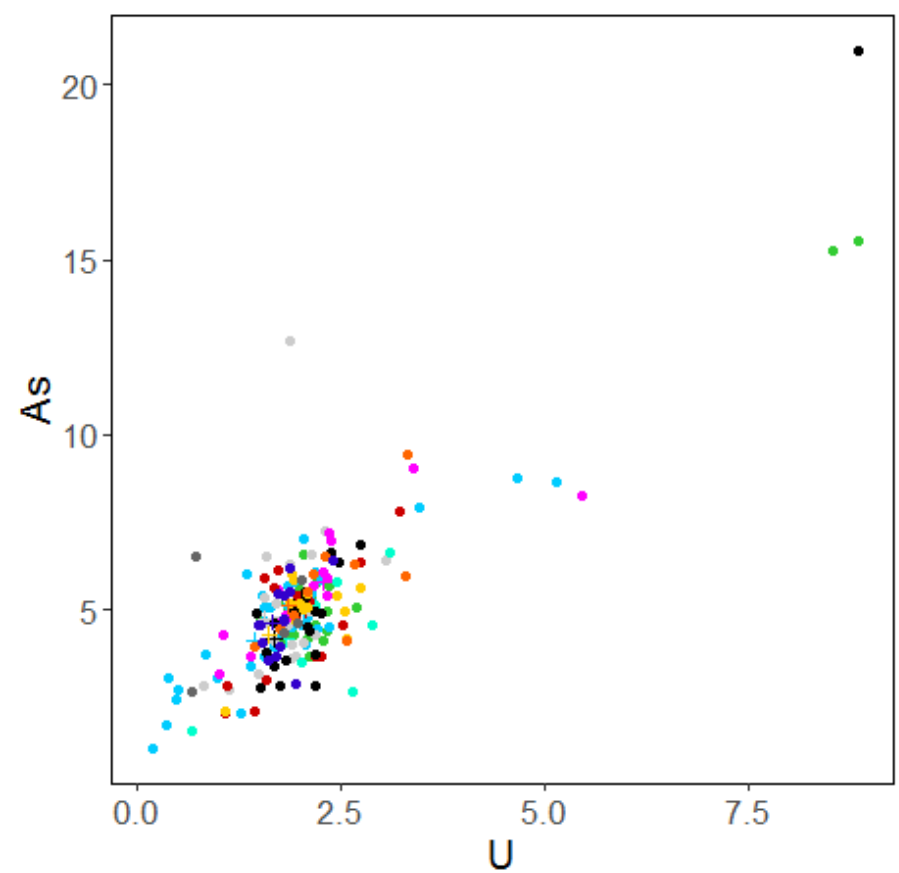

\section{Eruption}

12-25 March 1977 _ Block _ WIDP 6

- 12-25 March 1977 _ Bomb _ WIDP 18

- 12-25 March 1977 _ Bomb _ WIDP 10

- 12-25 March 1977 _ Bomb _ WIDP 11

- 12-25 March 1977 _ Bomb_ WIDP 13

- 26 Jul-3 Aug 1977 _ WDIP 9

- 26 Jul-3 Aug 1977 _ WIDP 8

- 1992 _WIDP 17

- 19 Oct 1993 _ WIDP 4

- 17 Apr 1999 _ WIDP 7

- 27 Jul 2000 _ WIDP 3

Melt

- Melt inclusions

+ Matrix Glass

Figure 3-7: U versus As in melt inclusions and matrix glasses of rocks from the 1976-2000 eruptive sequence.

\subsection{The role of mafic recharge during the 1976-2000 eruptive sequence}

Magma mixing is suggested by enclaves of different compositions. The mingled glass in WIDP 6 (erupted in March 1977) is a dacitic enclave with a high silica content $(73.22 \mathrm{wt} \%$ $\mathrm{SiO}_{2}$ ) compared to the matrix of the block (62.99 wt\% $\left.\mathrm{SiO}_{2}, \mathrm{Mix} 1\right)$ (Figure 3-8). The matrix glass of Mix 2 has a similar silica content (63.51 wt\% $\mathrm{SiO}_{2}$ ) as Mix 1, although they exhibit slightly different textures. Glass 1 contains a lot of acicular microlites up to $30 \mu \mathrm{m}$, whereas microlites in glass 2 are rarely exceeding $10 \mu \mathrm{m}$ in size. These two melts might represent a different mixing ratio between the mafic and dacitic magmas, with more dacitic component in Mix 2. Variation in degassing could also explain such a difference, given the effects of degassing on microlite crystallization (Cashman, 1992; Hammer et al., 1999; Szramek et al., 2006; Johnson et al., 2008). 


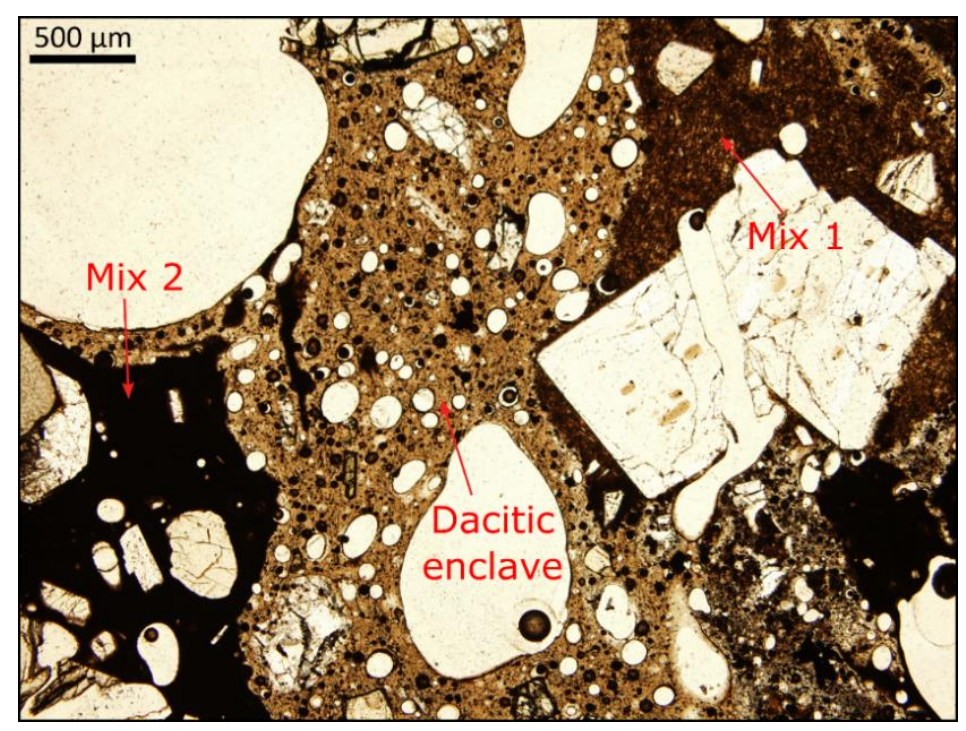

Figure 3-8: Transmitted light image of mingled glasses in the March 1977 block WIDP 6. Three different glasses are present, Mix 1, Mix 2 and Dacitic enclave.

We suggest the dacitic enclave arises from a shallow stored chamber that had undergone crystallization, and was incorporated by magma on the move. The uplift seen prior to the eruptive sequence in 1973-1976 and thought to be associated with emplacement of a magma body at $\sim 500 \mathrm{~m}$ depth, indicates crystallization in this shallow reservoir (Clark and Cole, 1989; Houghton and Nairn, 1989b). The mafic recharge probably mixes with the bottom part of the differentiated magma, leaving the upper zone unmixed. As mentioned by several authors (Reubi and Blundy, 2009; Kent et al., 2010), the majority of magmas erupted at arc volcanoes where mixing is a recognized process, are of intermediate composition. Only a small portion of the two endmembers, mafic and felsic, is erupted. Kent et al. (2010) showed that volcanoes erupting andesites with constant composition through time, are the ones relying the most on mafic recharge and magma mixing to erupt.

Another enclave was found in WIDP 4. It contains a $2.4 \mathrm{~mm}$ skeletal Fo90 olivine phenocryst, suggesting a mafic origin, and is isolated from the rest of the rock by a crystallized clinopyroxene border (Figure 3-9). The composition of the glass within the pocket is slightly more evolved and Cl-rich, in contrast to what would be expected for a mafic enclave. This might be explained by crystallization of microlites within the isolated, small volume of melt, after crystallization of the clinopyroxene border. The inset in Figure 3-9 shows different clinopyroxene composition on either side of the border, supporting crystallization from different melts, the enclave being isolated from the rest of the magma. 

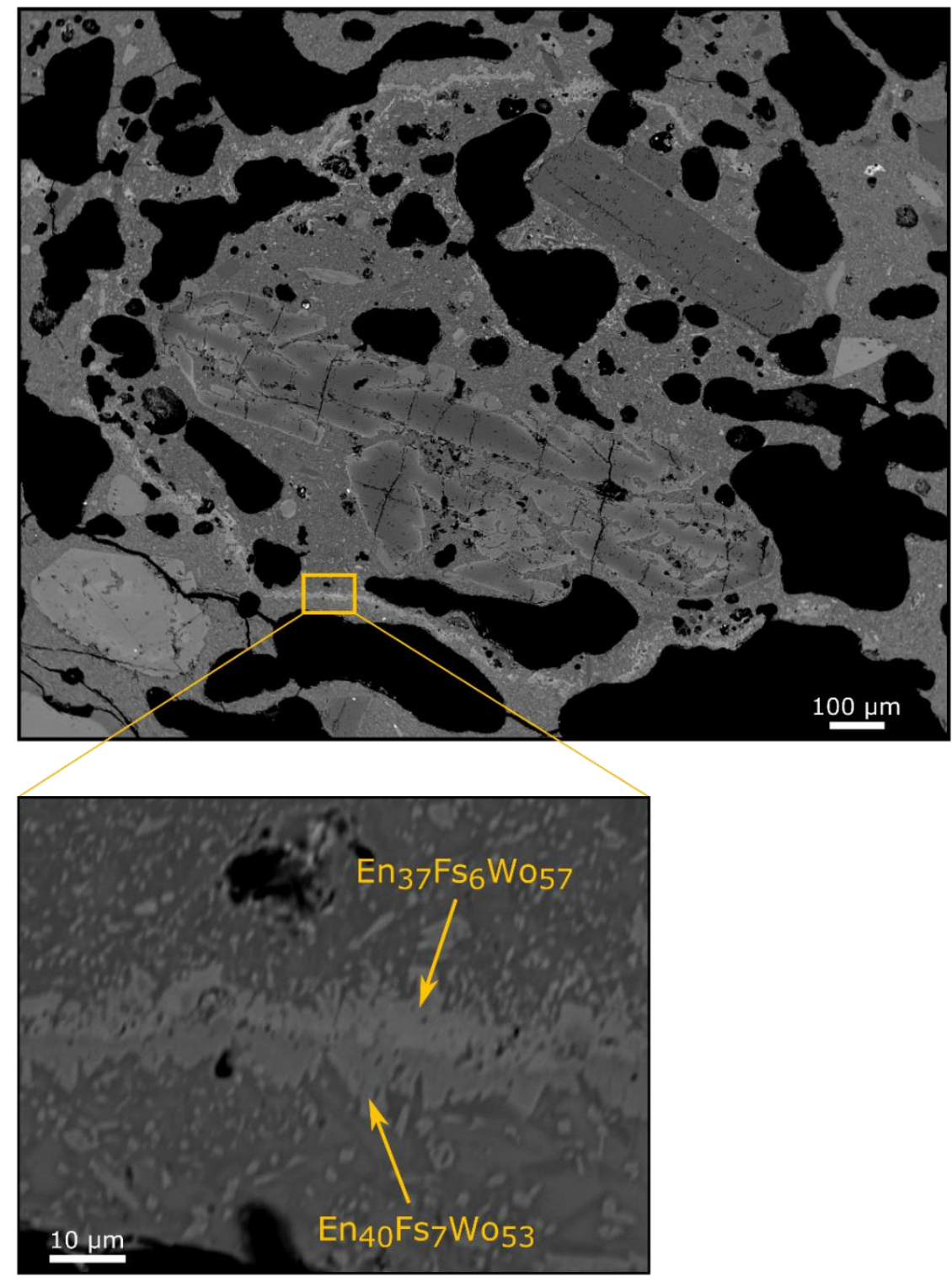

Figure 3-9: Backscattered electron image of a mafic enclave in the October 1993 bomb WIDP 4. Skeletal olivine and surrounded glass isolated from the rest of the melt by a border of clinopyroxene. Zooming into the border reveals two distinct pyroxene compositions in and out of the enclave.

Magma mixing is further supported by zoned crystals. When recharge occurs, the phenocrysts crystallizing in the felsic melt end up surrounded by a more primitive magma. This results in disequilibrium textures (Eichelberger, 1975; Sakuyama, 1981; Gerlach and Grove, 1982), observed as reverse zoning in some of the crystals. Figure 3-10 shows such a zonation in rocks erupted in March 1977, October 1993 and April 1999. In contrast, in the WIDP 6 dacitic enclave where no mixing occurred (Figure 3-10 a), orthopyroxene phenocrysts exhibit normal zoning, reflecting fractional crystallization of the magma. The same normally zoned rims are observed in magnesian olivines formed at depth in the mafic melt (Figure 3-10 a and c). 


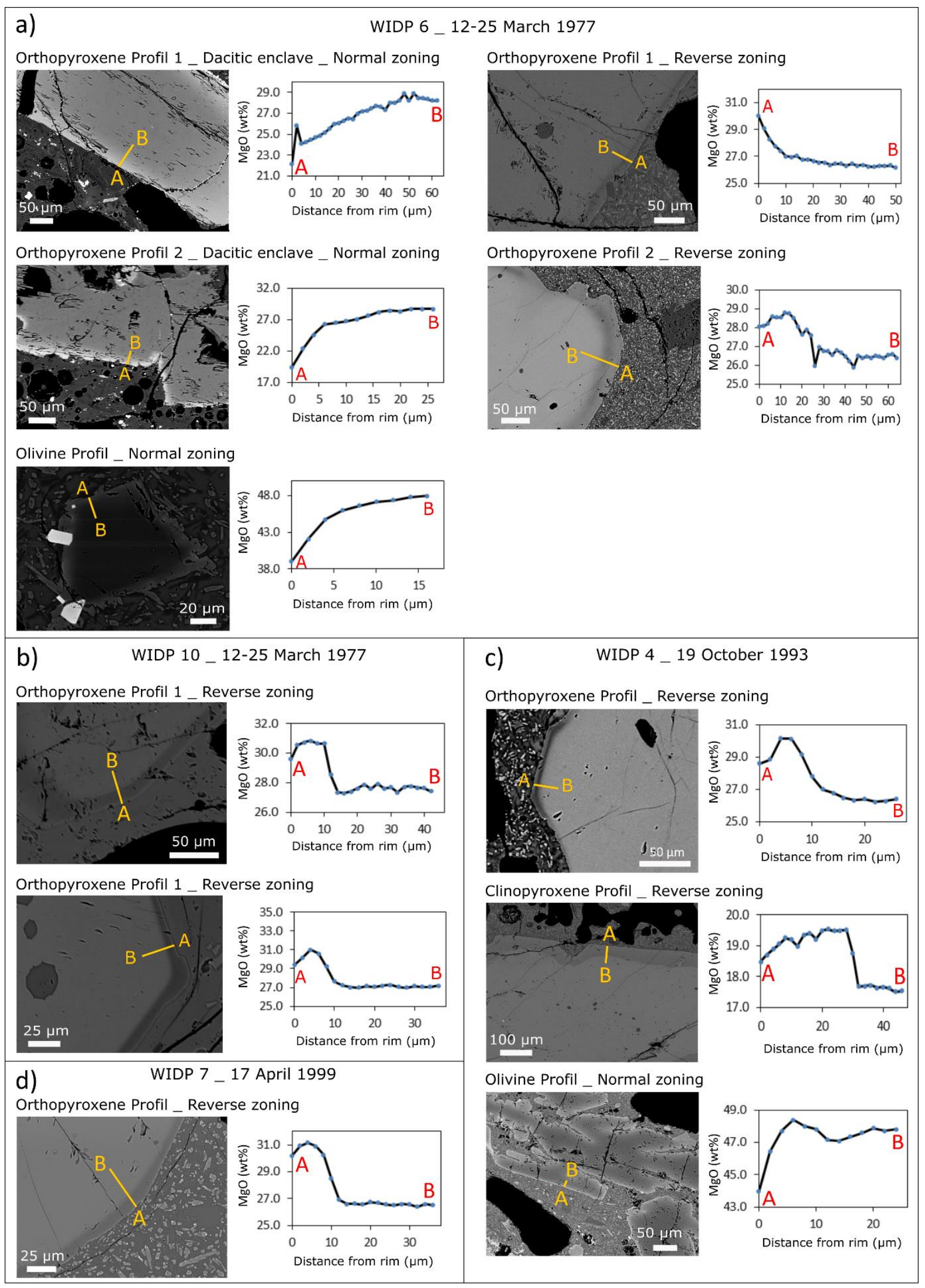

Figure 3-10: Reverse and normal zoning in phenocrysts from the 1976-2000 eruptive sequence. All images are backscattered electron images. a) Block erupted in March 1977, WIDP 6. Normal zoning in orthopyroxenes from the dacitic enclave and in a magnesian olivine from the block. Reverse zoning in orthopyroxenes from the block. b) Bomb erupted in March 1977, WIDP 10. Reverse zoning in an 
orthopyroxene phenocryst and in an orthopyroxene overgrowth in a resorbed olivine. c) Bomb erupted on 19 October 1993, WIDP 4. Reverse zoning in orthopyroxene and clinopyroxene, normal zoning in magnesian olivine. d) Bomb erupted on 17 April 1999. Reverse zoning in orthopyroxene.

The presence of normally zoned, stable mafic olivine next to resorbed, less magnesian olivine, indicates repeated recharge events (Figure 3-2). Zellmer et al. (2016) showed that such resorption results from uptake in a silicic magma. Fe enrichment of the crystal rim and dissolution continue until a microlite isolates the mineral from the melt. The resorption process then stops, and growth of the microlite (orthopyroxene or plagioclase) is favored. Isolation before complete dissolution preserves the core of the olivine, as observed in our samples. The growth of orthopyroxene from the rim indicates that no eruption closely followed the mafic injection. In contrast, the magnesian Fo92 olivine shows Fe-enrichment of the rim but no resorption, implying the residence time in the felsic magma after injection was short (i.e. eruption occurred shortly after mixing). This time constraint is also supported by matrix glass being more mafic than trapped inclusions in most of our samples (Figure 3-3). A prolonged residence time would allow crystallization to proceed, leading to an evolved matrix glass composition.

As no diffusion study was done, we could not assess whether the observed forsteritic content of the resorbed olivine is primary or not. The different size of crystals from the two populations nevertheless suggests different sources. Repeated injections from these more mafic reservoirs into a shallow felsic chamber would then lead to the observed assemblage. Mafic recharge can lead to eruption due to: 1) increase of material into a fixed-volume chamber, 2) exchange of heat and volatiles between the two melts leading to volatile solubility modifications, 3) formation of a new magma with different physical properties, 4) depressurization of the chamber due to fracturing of the overlying rocks (Anderson, 1976; Sparks et al., 1977; Eichelberger, 1980; Sparks and Marshall, 1986; Watts et al., 1999). Such a magma mixing hypothesis has already been suggested by different authors (Graham and Cole, 1991; Shiraki et al., 1994; Cole et al., 2001). Moreover, it is a well known process, recognized as one of the mechanisms triggering eruptions at subduction-related volcanoes (Anderson, 1976; Sparks et al., 1977; Eichelberger, 1980; Murphy et al., 1998; Watts et al., 1999; Kent et al., 2010).

The composition of matrix glass and melt inclusions shows that mixing was closely followed by eruption for 8 samples out of 11 . The 3 rocks (WIDP 13, 8, 9) having more evolved matrix glass than melt inclusions contain resorbed Fo76-78 olivines, suggesting that recharge events occurred but did not lead to eruption, enabling the melt to evolve towards more felsic composition again. Two silicic melt inclusions (70.21 wt $\%$ and $71.47 \mathrm{wt} \% \mathrm{SiO}_{2}$ ) in WIDP 8 support long residence time in the shallow chamber. A low mixing ratio with such felsic melt could also explain the more evolved composition of WIDP 8 and 9, erupted in late July 1977. It is interesting to note the high $\mathrm{Cl}$ contents (1477 and $1593 \mathrm{ppm}$ respectively) and low $\mathrm{S}$ and $\mathrm{Cu}$ contents (99 and 77 ppm, 85 and 38 ppm respectively) of these two felsic inclusions.

To summarize, ejecta from the 1976-2000 eruptive sequence highlight mixing of an evolved shallow stored melt with a more mafic component shortly before eruption, in the form of: 1) enclaves with different composition than the host rock, 2) stable magnesian olivines coexisting with resorbed less primitive olivines, 3) matrix glass less evolved than melt 
inclusions hosted in phenocrysts. Such mixing was observed for most of the eruptions during the sequence, suggesting a potential role in triggering eruptions.

\subsection{Pressure and temperature constraints}

Some mineral-melt thermometry was carried out on the same samples by Geoff Kilgour and co-workers (pers. comm., 2016). They estimated the melt temperature at which olivine, orthopyroxene, clinopyroxene and plagioclase phenocrysts were crystallizing. Their results are in agreement with our findings, indicating higher temperature for the olivines as compared to the rest of the phenocrysts. The former crystallized in melts with temperature ranging between $1183{ }^{\circ} \mathrm{C}$ and $1270{ }^{\circ} \mathrm{C}$. The latter show a broader range of temperature, 965 ${ }^{\circ} \mathrm{C}$ to $1082{ }^{\circ} \mathrm{C}$ for plagioclase, $903{ }^{\circ} \mathrm{C}$ to $1077^{\circ} \mathrm{C}$ for clinopyroxene, and $949{ }^{\circ} \mathrm{C}$ to $1176{ }^{\circ} \mathrm{C}$ for orthopyroxene. This is also consistent with differentiation of the cooler magma in the shallow chamber, and varying degrees of mixing between the mafic and dacitic melts.

Entrapment pressures were estimated using the $\mathrm{H}_{2} \mathrm{O}-\mathrm{CO}_{2}$-melt solubility model of Papale et al. (2006). Calculations were performed for melt inclusions hosted in each of the phenocryst phases to assess different depths of crystallization, using the temperatures reported above (G. Kilgour, pers. comm., 2016). For melt inclusions in WIDP 4 (ejected October 1993), we used the average temperature for orthopyroxene $\left(1026{ }^{\circ} \mathrm{C}\right)$, clinopyroxene $\left(945{ }^{\circ} \mathrm{C}\right)$ and plagioclase $\left(978{ }^{\circ} \mathrm{C}\right)$ determined in the same rock. For the melt inclusion in WIDP 3 from July 2000, we used the average temperature for orthopyroxene $\left(1103{ }^{\circ} \mathrm{C}\right)$ determined in the same rock. For melt inclusions from WIDP 18 from March 1977, we used the average temperature for olivine $\left(1209{ }^{\circ} \mathrm{C}\right)$ determined in WIDP 6 . For each inclusion, we calculated the $\mathrm{Fe}_{2} \mathrm{O}_{3}$ and $\mathrm{FeO}$ contents using the $\mathrm{Fe}^{3+/} \mathrm{Fe}_{\text {tot }}=0.216$ ratio for White Island whole rock from Clark et al. (1979), measured in bombs and blocks from the 1977 eruptions. Esposito et al. (2014) and Rapien (1998) reported $\mathrm{CO}_{2}$ contents from SIMS analyses of 39-3508 ppm in melt inclusions hosted in plagioclase and pyroxene phenocrysts. Given that $\mathrm{CO}_{2}$ was not detected in our samples and that the majority of their results were $<200 \mathrm{ppm}$, we performed our calculations with values of 0 and $100 \mathrm{ppm}$ of $\mathrm{CO}_{2}$ for melt inclusions hosted in these phenocrysts.

Our results yield entrapment pressures of 15.0-21.7 $\mathrm{MPa}\left(\right.$ no $\left.\mathrm{CO}_{2}\right)$ and 14.2-46.4 $\mathrm{MPa}(100$ ppm $\mathrm{CO}_{2}$ ) for orthopyroxene-hosted inclusions from October 1993 (500-700 $\mathrm{m}$ and 470-1550 $m$ respectively) with $\mathrm{SiO}_{2}$ contents ranging from 62.53 to $67.31 \mathrm{wt} \%$. The pressures estimated from clinopyroxene-hosted inclusions without and with $\mathrm{CO}_{2}$ were $18.4 \mathrm{MPa}$ and 29.7 $\mathrm{MPa}$ respectively (i.e. depths of $600 \mathrm{~m}$ and $1000 \mathrm{~m}$ ), and 12.6 $\mathrm{MPa}$ and 23.5 MPa (420 $\mathrm{m}$ and $780 \mathrm{~m}$ ) for inclusions in plagioclase. We obtained similar results from melt inclusions hosted in orthopyroxene from the July 2000 eruption, 13.3 MPa and $26.4 \mathrm{MPa}(440 \mathrm{~m}$ and $880 \mathrm{~m})$. Our estimates are in agreement with the values of 21.5 to $32 \mathrm{MPa}(720-1100 \mathrm{~m})$ obtained by Esposito et al. (2014) using the same model, a temperature of $1100{ }^{\circ} \mathrm{C}$ and $\mathrm{Fe}^{3+/} \mathrm{Fe}_{\text {tot }}=0.2$.

These pressures correspond to depths of about $420-1550 \mathrm{~m}$, thus confirming crystallization in the shallow environment. The higher pressures might reflect onset of crystallization during ascent in the conduit, or crystallization in intermediate chambers/accumulation zones along 
with olivine Fo76-80. This is consistent with the higher sulfur content of some of these inclusions, reaching $535 \mathrm{ppm}$, reflecting deeper entrapment during $\mathrm{SO}_{2}$ degassing. Given the range in pressure estimated, a model with multiple accumulation zones of small volume in the shallow environment $(420$ to $880 \mathrm{~m}$ ) and maybe deeper ones (at 1000-1500 $\mathrm{m}$ depth) seems more realistic than a single, voluminous magmatic chamber.

For the olivine-hosted inclusions, we used the estimate of $500 \mathrm{ppm} \mathrm{CO}_{2}$ from Werner et al. (2008) for a magma at a depth of $7 \mathrm{~km}$ and $1 \mathrm{wt} \% \mathrm{H}_{2} \mathrm{O}$. We obtained entrapment pressures of 142.3 $\mathrm{MPa}$ and 82.8 $\mathrm{MPa}$ for two different melt inclusions $(60.2 \mathrm{MPa}$ and $63.1 \mathrm{MPa}$ respectively using $\mathrm{CO}_{2}=100 \mathrm{ppm}$ ). These values correspond to much greater depths of 2.7 $\mathrm{km}$ to $4.7 \mathrm{~km}$, supporting deeper crystallization of the olivines from the mafic magma. The high $\mathrm{CO}_{2}$ contents (up to 3508 ppm) obtained by Rapien (1998) and Esposito et al. (2014) in plagioclase- and pyroxene-hosted silicate inclusions suggest our estimates are minimum depths of entrapment. Moreover, the extremely magnesian nature of the olivines, as noted above, suggests a source at the crust/mantle boundary. We thus assume that the more mafic reservoir is at a minimum depth of $5 \mathrm{~km}$ depth.

\subsection{Magma degassing during ascent and crystallization}

\subsubsection{Major species}

Figure 3-11 and Figure 3-12 show degassing of sulfur and chlorine as the melt crystallizes. The few olivine-hosted melt inclusions allow us to look at the sulfur and chlorine contents of the primary melt. The highest concentrations recorded, in crystal-free melt inclusions, are $1020 \mathrm{ppm}$ for $\mathrm{S}$ and $4388 \mathrm{ppm}$ for $\mathrm{Cl}$ (Appendix A.2). The inclusions hosted in olivine Fo76 and Fo78 exhibit the highest $\mathrm{Cl}$ contents (WIDP3-IN21, WIDP10-IN26) but have only intermediate $\mathrm{CaO}$ concentrations. These high $\mathrm{Cl}$ contents resemble the paralava described by Wood and Browne (1996) and might reflect regassing of the samples. The mafic enclave of WIDP 4 also exhibits really high $\mathrm{Cl}$ content, possibly due to similar regassing. On the other hand, the highest $\mathrm{S}$ contents are found in the most primitive olivines Fo90-93 (Figure 3-11). 


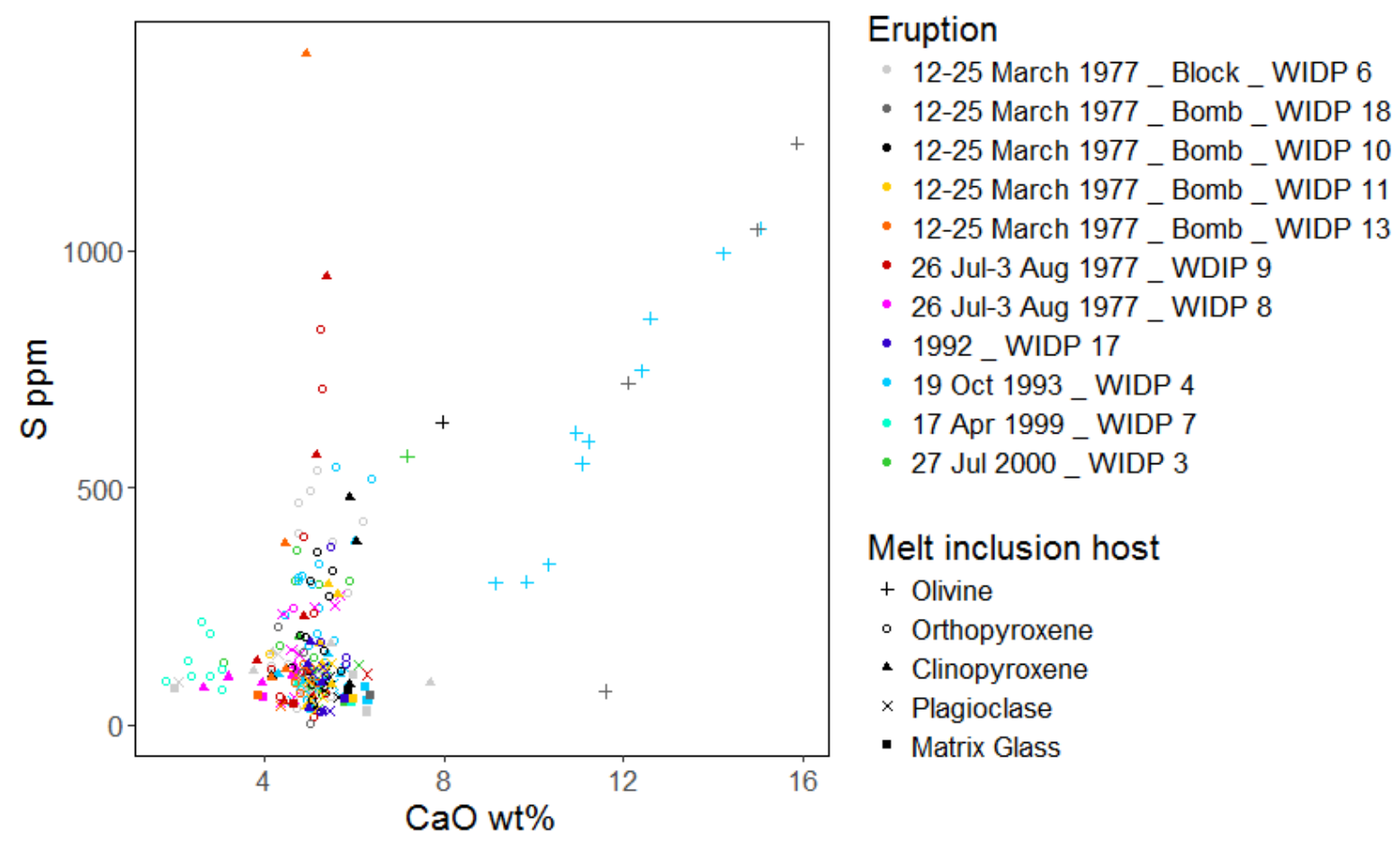

Figure 3-11: $\mathrm{CaO}$ versus $\mathrm{S}$ of melt inclusions and matrix glasses from the 1976-2000 eruptive sequence.

This is consistent with the earlier hypothesis that the two populations of olivines are produced at different depths by more and less differentiated magmas. Sulfur is less soluble in silicate melts than $\mathrm{Cl}$ and thus starts exsolving earlier as the magma rises and crystallizes (Carroll and Webster, 1994; Aiuppa et al., 2002; Spilliaert et al., 2006). The entrapment pressures determined above suggest most of the $\mathrm{S}$ exsolves at depth between 4.7 and $2.7 \mathrm{~km}$, with the majority of inclusions hosted in plagioclase and pyroxene already degassed. This is consistent with the findings of Werner et al. (2008), indicating that degassing of $\mathrm{CO}_{2}$ and $\mathrm{SO}_{2}$ occurs at depth greater than $300 \mathrm{~m}$. Experimental results on the partitioning of sulfur between a silicate melt (basalt to basaltic andesite) and aqueous fluids also supports efficient degassing, with $\mathrm{D}_{\mathrm{s}}^{\mathrm{v}}{ }^{\mathrm{v}}$ between 6 and $>1000$, the highest values reached as pressure decreases to $25 \mathrm{MPa}$ (Moune et al., 2009; Lesne et al., 2011; Webster and Botcharnikov, 2011). The less magnesian olivines trapped melt that has already lost some of its sulfur and is $\mathrm{CaO}$-poor, indicating a depth in the lower range (i.e. $\leq 2.7 \mathrm{~km}$ ), potentially as an intermediate magma chamber.

Some inclusions hosted in plagioclase and pyroxene show higher S contents (Figure 3-11). Onset of crystallization of these minerals in the deeper reservoir(s) might explain entrapment of less degassed melt, although regassing of magma in the shallow chamber through fluxing of S-rich vapors should not be ruled out. The S-rich melt inclusion in WIDP 13 (1391 ppm) is also the most evolved and $\mathrm{Cu}$-rich of the samples, pointing to possible destabilization of $\mathrm{Cu}$ Fe sulfide bleb responsible for such enrichment.

In contrast, the behavior of chlorine in pyroxene- and plagioclase-hosted inclusions is not as marked as for S, broadly ranging from 600 to 1700 ppm, without a clear trend (Figure 3-12). The estimated entrapment pressures indicate a depth in the range of 420-880 m. Experimental 
work on basalts from Mt. Etna by Alletti et al. (2009) indicates that the partition coefficient of chlorine between a hydrous vapor and a basaltic melt changes from 6 at $200 \mathrm{MPa}$, to 11-14 at $1 \mathrm{MPa}$ and $25 \mathrm{MPa}$ at $\mathrm{NNO}$, supporting partitioning of chlorine into a $\mathrm{H}_{2} \mathrm{O}$-rich vapor phase at low depth. Degassing is nevertheless not as efficient as for $\mathrm{S}$, with the more evolved inclusions in WIDP 8 and WIDP 7 having high $\mathrm{Cl}$ contents, possibly reflecting diffusionlimited degassing (Watson, 1991; Alletti et al., 2007; Balcone-Boissard et al., 2009).
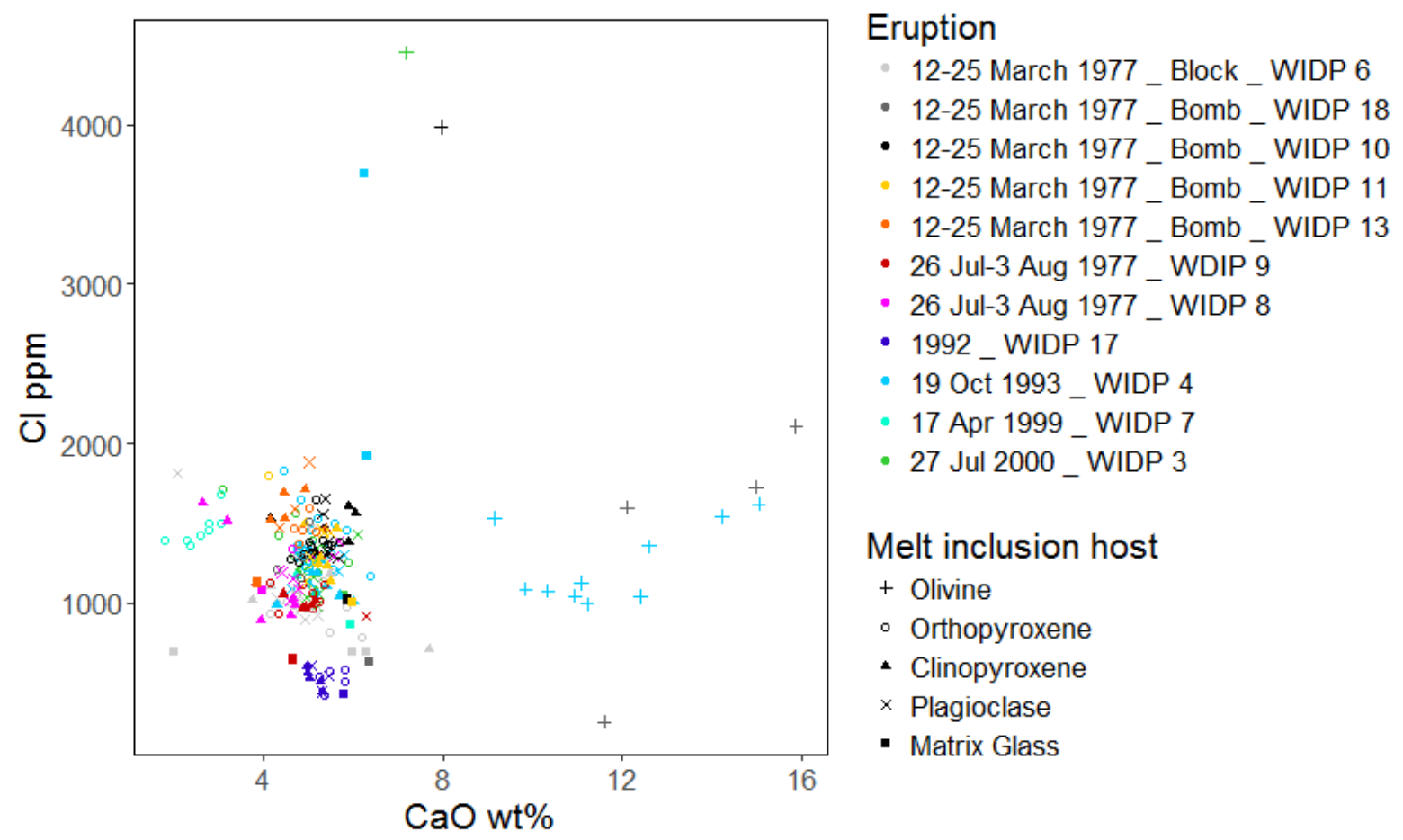

Melt inclusion host

+ Olivine

- Orthopyroxene

- Clinopyroxene

$\times$ Plagioclase

- Matrix Glass

Figure 3-12: $\mathrm{CaO}$ versus $\mathrm{Cl}$ of melt inclusions and matrix glasses from the 1976-2000 eruptive sequence.

Figure 3-13 supports efficient degassing of $\mathrm{S}$ compared to $\mathrm{Cl}$, pointing towards a balance between degassing and incompatible behavior of $\mathrm{Cl}$ in the magma. Similar degassing was reported at Stromboli, where $>75 \%$ of the sulfur is exsolved between 6 and $2 \mathrm{~km}$ (Métrich et al., 2010). It also highlights the multiple injections of mafic melt described earlier, with the absence of a degassing pattern throughout the eruptive sequence.

The dacitic enclave in WIDP 6 contains many small spherical bubbles whereas the rest of the block has mainly big uneven globular vesicles (Figure 3-8). As shown by Schipper et al. (2017), as much as 99\% of the vesicles are interconnected in the April 1999 ejecta (WIDP 7), providing a path for the deeply exsolved volatiles to escape the magma under open-system conditions. We interpret volatile degassing to occur in three stages: 1) early exsolution of less soluble $\mathrm{CO}_{2}, \mathrm{H}_{2} \mathrm{O}$ and $\mathrm{SO}_{2}$ at depth with effective coalescence, building the network of vesicles observed, 2) exsolution of $\mathrm{Cl}$ in $\mathrm{H}_{2} \mathrm{O}$-rich vapor in the shallow chamber as described by Métrich et al. (2010) under open-system conditions, and 3) late exsolution of residual $\mathrm{H}_{2} \mathrm{O}$ and $\mathrm{HCl}$ during ascent to the vent (Metrich and Rutherford, 1992) without possibility to coalesce. The observed trends for chlorine and sulfur are qualitatively consistent with the 
fluxes of $\mathrm{SO}_{2}$ and $\mathrm{HCl}$ emitted at the surface: 171-1230 t/d of $\mathrm{SO}_{2}$ between 1983 and present (Rose et al., 1986; Love et al., 2000; Wardell et al., 2001; GeoNet, 2001-2017), 89-275 t/d of $\mathrm{HCl}$ (Love et al., 2000; Werner et al., 2008; Christenson et al., 2017).

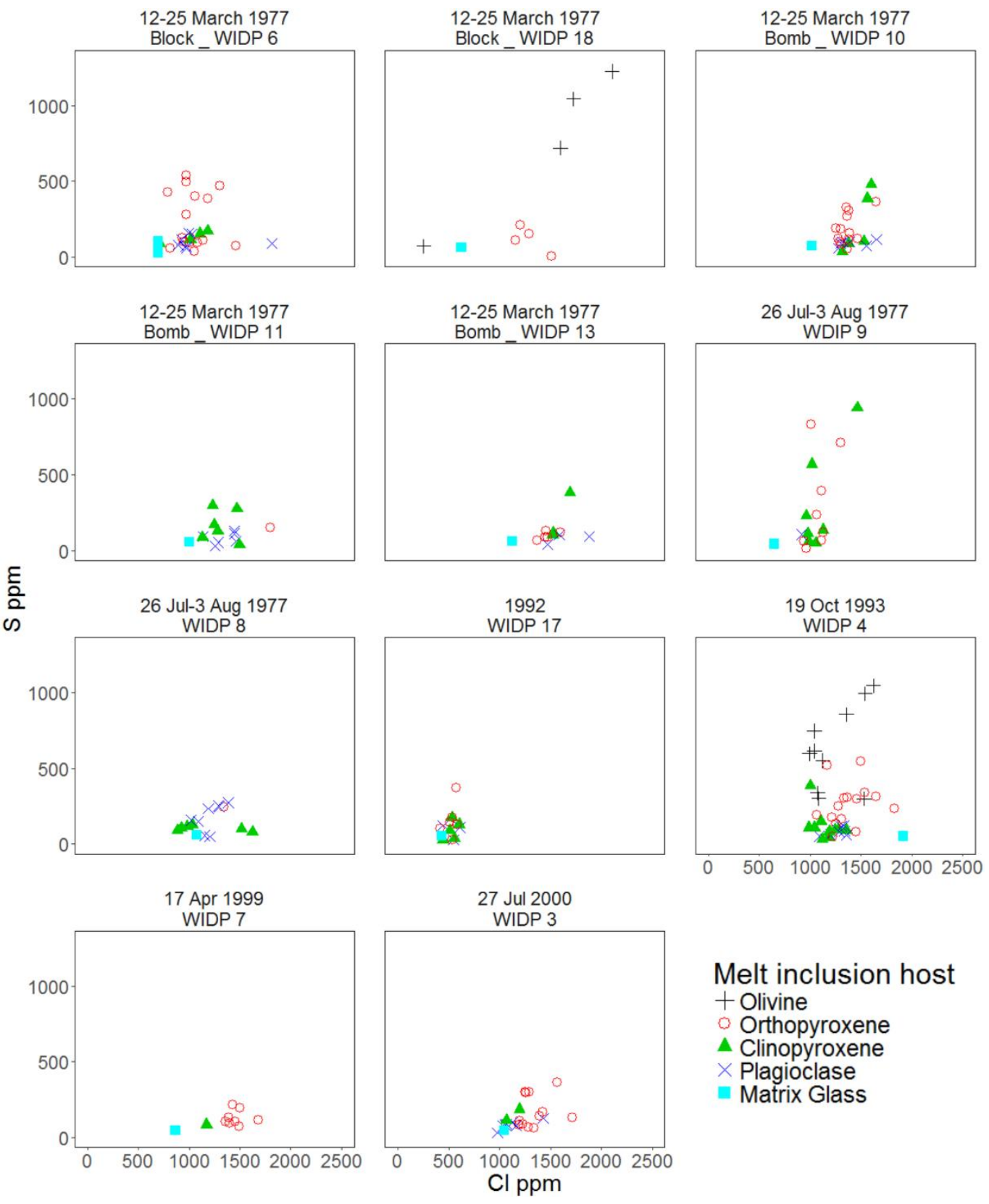

Figure 3-13: $\mathrm{Cl}$ versus $\mathrm{S}$ of melt inclusions and matrix glasses from the 1976-2000 eruptive sequence.

Despite the persistent degassing observed at White Island, only a very small volume of magma has been erupted throughout the whole sequence. We propose convection within the deep magmatic reservoir $(2.7$ to $4.7 \mathrm{~km})$ to explain such consistent flow of gases. This process was first introduced by Kazahaya et al. (1994) to explain excess degassing at IzuOshima volcano, Japan. It implies overturn of dense degassed magma with less dense, gasrich melt, within a vertical conduit overlying a magmatic chamber. Their model has since 
been refined and suggested to be the driver of persistent degassing at many others volcanoes (Tazieff, 1994; Shinohara et al., 1995; Allard, 1997; Stevenson and Blake, 1998; Kazahaya et al., 2002; Witter et al., 2005). In the case of White Island, convection within the deep reservoir, and potentially, extended to the overlying conduit, would explain the more or less constant flux of $\mathrm{CO}_{2}, \mathrm{SO}_{2}$ and $\mathrm{H}_{2} \mathrm{O}$ observed at the surface. As shown above, $\mathrm{Cl}$ most likely exsolves at shallower level, probably due to second boiling in the crystallizing dacitic magma at a depth of $420-880 \mathrm{~m}$.

\subsubsection{Metals}

Copper content of silicate melt inclusions from the 1976-2000 sequence varies between 2 ppm and 1004 ppm, with the majority of them containing less than 300 ppm (Figure 3-14). $\mathrm{Cu}$ content first increases with crystallization, until the melt reaches a silica content of $\sim 60$ wt $\%$, at which point the $\mathrm{Cu}$ content starts to decrease. A dozen melt inclusions in the March 1977 block WIDP 6 and in one of the late July 1977 bombs WIDP 9, have copper concentrations much greater. This enrichment might reflect breakdown of a $\mathrm{Cu}$-rich sulphide melt following fluxing of the shallow environment with deep-derived $\mathrm{SO}_{2}$-rich gas (Hattori, 1993). This argument is reinforced by the absence of such sulfide in both samples, whereas WIDP 8, erupted in the same period, does not show such $\mathrm{Cu}$ enrichment and contains sulphides. It should be noted that the most evolved inclusions in WIDP 8 have low $\mathrm{S}$ and $\mathrm{Cu}$ contents, supporting depletion in $\mathrm{Cu}$ with differentiation due to degassing and/or sulfide melt formation.

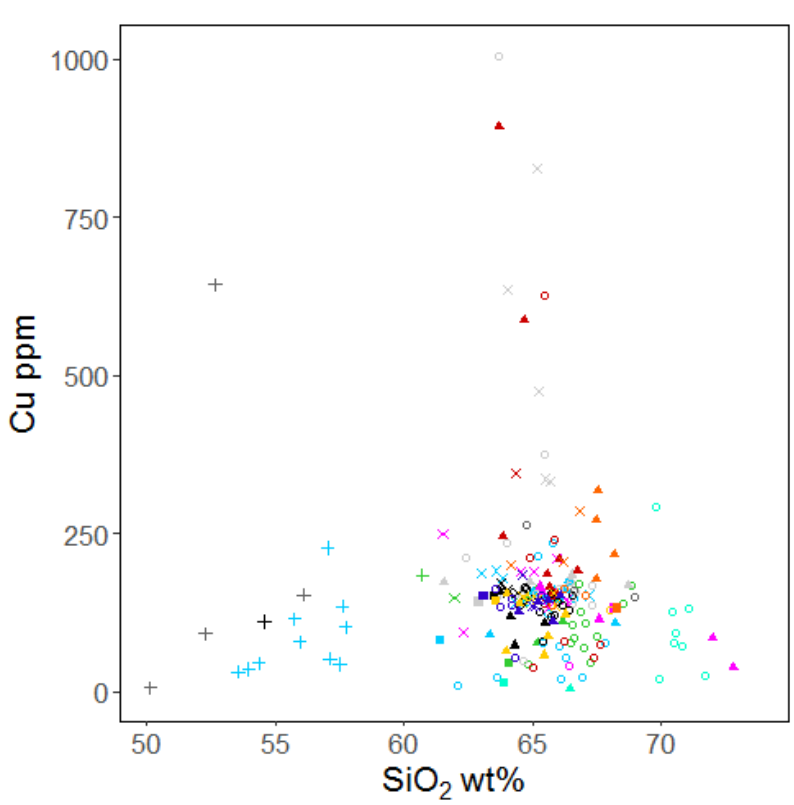

\section{Eruption}

- 12-25 March 1977 _ Block _ WIDP 6

- 12-25 March 1977 _ Bomb_ WIDP 18

- 12-25 March 1977 Bomb WIDP 10

- 12-25 March 1977 _ Bomb _ WIDP 11

- 12-25 March 1977 _ Bomb _ WIDP 13

- 26 Jul-3 Aug 1977 _WDIP 9

- 26 Jul-3 Aug 1977 _ WIDP 8

- 1992 _ WIDP 17

- 19 Oct 1993 _WIDP 4

- 17 Apr 1999 _ WIDP 7

- 27 Jul 2000 _ WIDP 3

Melt inclusion host

+ Olivine

- Orthopyroxene

- Clinopyroxene

$\times$ Plagioclase

- Matrix Glass

Figure 3-14: $\mathrm{SiO}_{2}$ versus $\mathrm{Cu}$ of melt inclusions and matrix glasses of rocks from the 1976-2000 eruptive sequence. 
Partitioning of copper into a magmatic vapor phase $\left(\mathrm{D}_{\mathrm{Cu}}{ }^{\mathrm{v} / \mathrm{m}}\right.$ varies from 10 to 20 but can reach up to 2700) and the role of $S$ as a ligand are well known (Giggenbach and Matsuo, 1991; Candela and Piccoli, 1995b; Harris et al., 2003; Halter et al., 2005; Zajacz et al., 2008; Johnson and Canil, 2011). This is in agreement with the composition of fumarolic gases at White Island, containing 5-93 ppb of copper (cf. Chapter 5). The presence of sulphide inclusions in some of the rocks, as mentioned above, should also be considered as a sink for chalcophile metals.
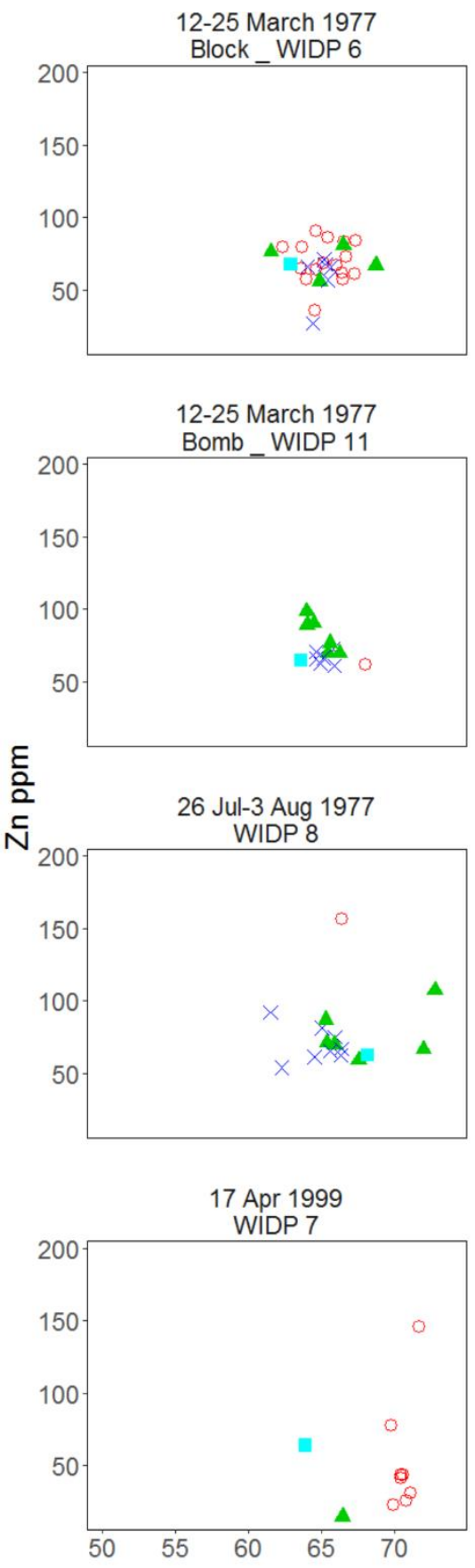

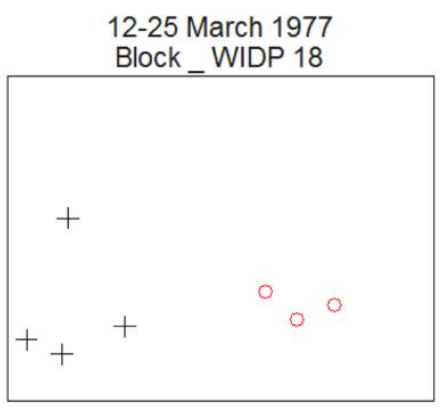

12-25 March 1977
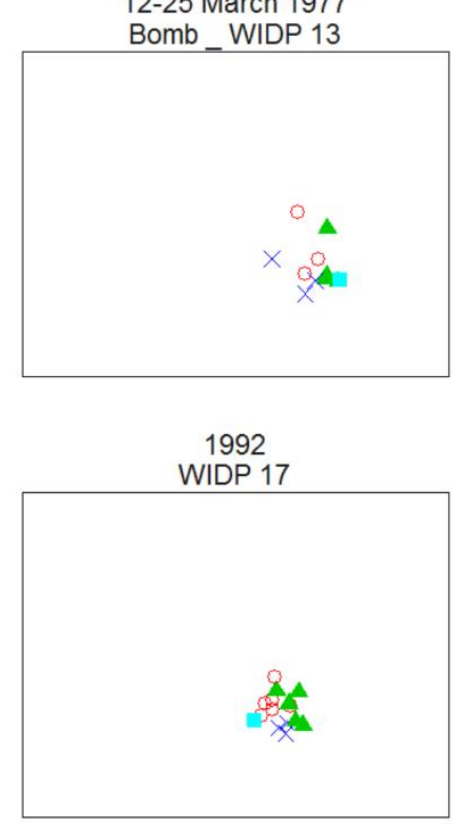

27 Jul 2000

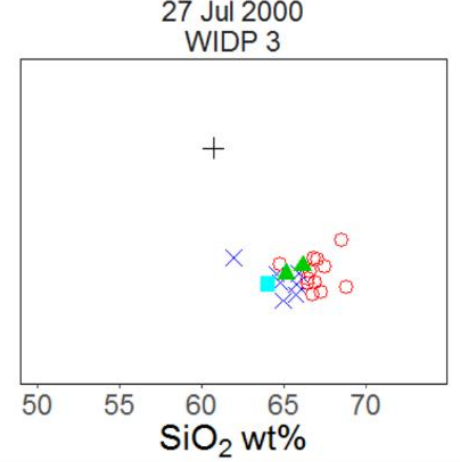

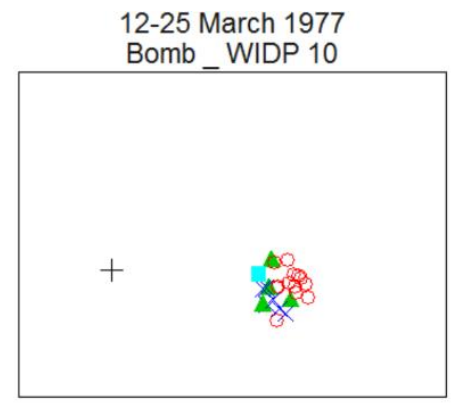
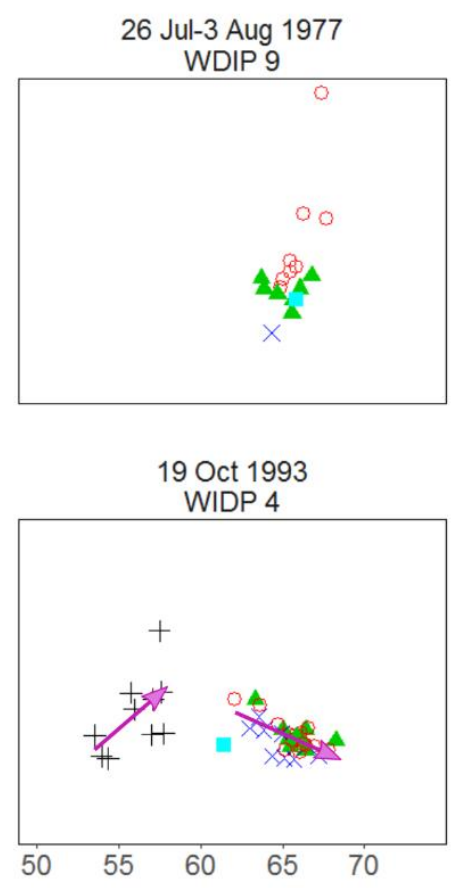

Melt inclusion host

+ Olivine

Orthopyroxene

Clinopyroxene

$\times$ Plagioclase

Matrix Glass

Figure 3-15: $\mathrm{SiO} 2$ versus $\mathrm{Zn}$ of melt inclusions and matrix glass for separate rocks of the 1976-2000 eruptive sequence. 
Melt inclusions have zinc contents of 22-196 ppm. The numerous olivine-hosted melt inclusions in WIDP 4 from October 1993 allow us to see the behavior of $\mathrm{Zn}$ through crystallization. Figure 3-15 shows that $\mathrm{Zn}$ first behaves incompatibly during olivine crystallization at depth, and then decreases in the magma in the shallow environment. It has been shown that zinc is compatible in ferromagnesian minerals such as orthopyroxenes and in some oxides (Core et al., 2005; Johnson et al., 2013). Given that we did not analyze $\mathrm{Zn}$ in such phases, we cannot rule out that the decreasing content in WIDP 4 is due to partitioning into these minerals. This late compatibility is however absent in many of the other rocks, pointing to different behavior of zinc.
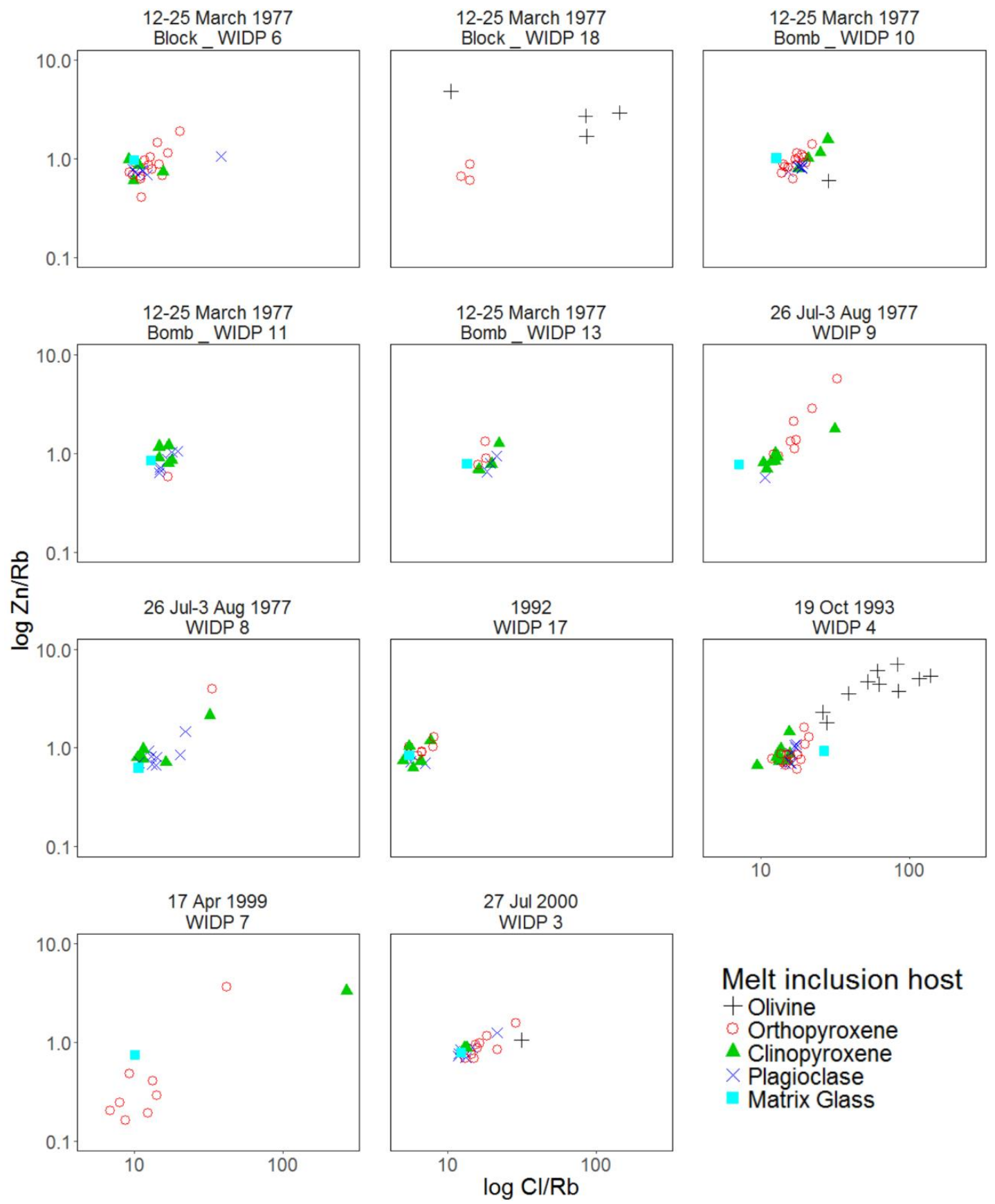

\section{Melt inclusion host}

+ Olivine

Orthopyroxene

$\Delta$ Clinopyroxene

$\times$ Plagioclase

- Matrix Glass

Figure 3-16: $\log \mathrm{Cl} / \mathrm{Rb}$ versus $\log \mathrm{Zn} / \mathrm{Rb}$ of melt inclusions and matrix glass for separate rocks of the 1976-2000 eruptive sequence. 
When plotting $\mathrm{Zn} / \mathrm{Rb}$ and $\mathrm{Cl} / \mathrm{Rb}$ ratios, the effect of crystallization on both species is removed, due to the incompatible behavior of $\mathrm{Rb}$ in silicate magmas (Griffin and Rama Murthy, 1969). We now see in Figure 3-16 that zinc and chlorine are positively correlated. This suggests zinc partitions into crystallizing phases and/or magmatic vapor phase. Zinc degassing is observed at the surface, with fumarolic gases containing 8-250 ppb (cf. Chapter 5 ), and supported by experimental estimates of the partition coefficient between magmatic vapor phase and silicate melt $\left(\mathrm{D}_{\mathrm{Zn}}{ }^{\mathrm{v} / \mathrm{m}}\right.$ varies from 7.6 to 44 , (Candela, 1989; Candela and Piccoli, 1995b; Keppler, 1996)).
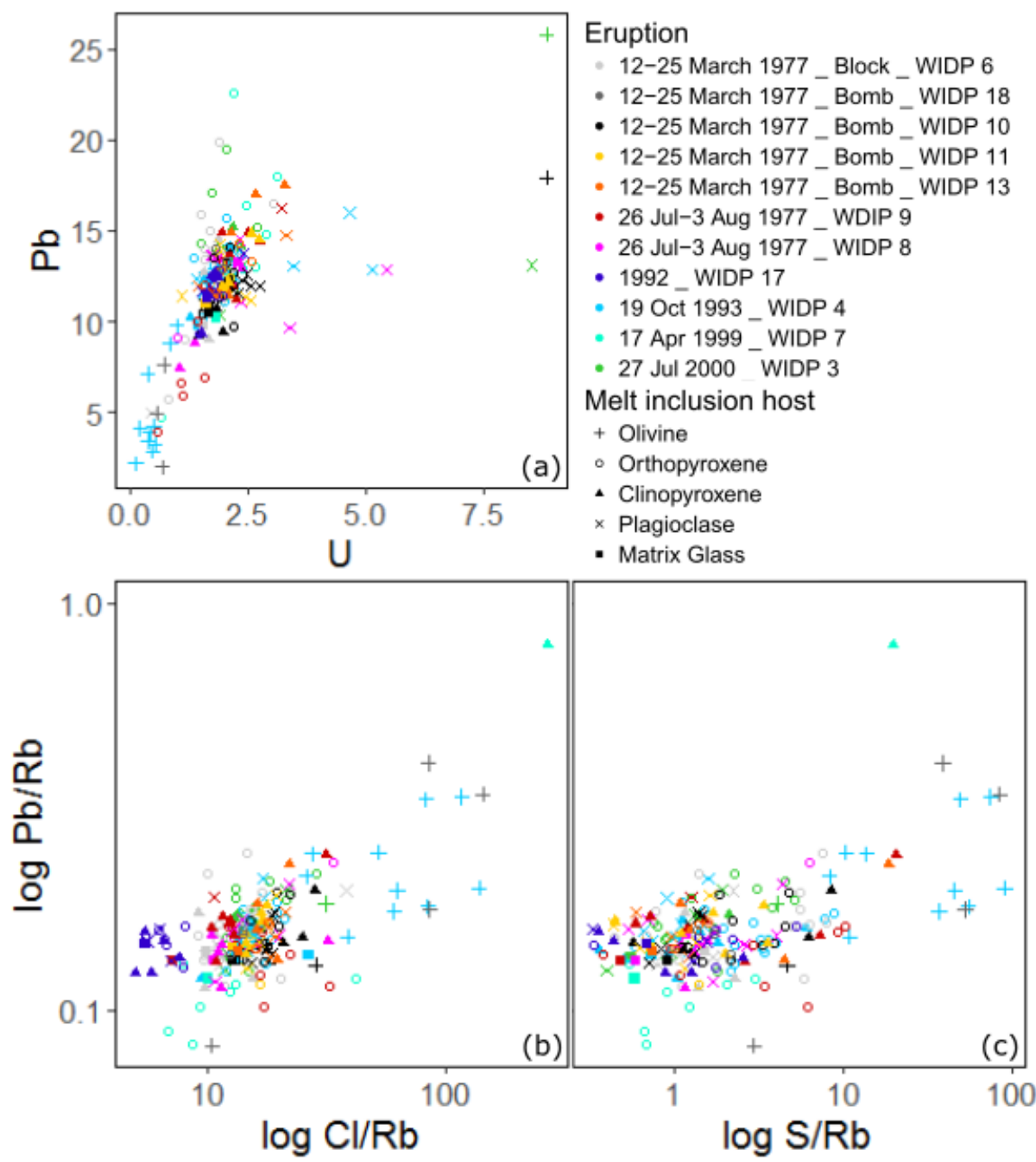

Figure 3-17: Lead behavior with degassing and crystallization. $\mathrm{U}$ versus $\mathrm{Pb}$. b) $\log \mathrm{Cl} / \mathrm{Rb}$ versus $\log$ $\mathrm{Pb} / \mathrm{Rb}$. C) $\log \mathrm{Cl} / \mathrm{Rb}$ versus $\log \mathrm{Pb} / \mathrm{Rb}$.

Lead content varies from $2 \mathrm{ppm}$ to $23 \mathrm{ppm}$. These concentrations are much lower than for $\mathrm{Cu}$ and $\mathrm{Zn}$. Magnesian olivines have low values, and Figure 3-17 shows an increase with differentiation, with the magma progressively becoming enriched. We observe a slight decrease of $\mathrm{Pb}$ with decreasing $\mathrm{S}$ and $\mathrm{Cl}$. Again, the composition of fumaroles at the surface supports lead degassing, with $1 \mathrm{ppb}$ to $23 \mathrm{ppb}$ in the volatile phase. Partition coefficients between magmatic vapor phase and silicate melt for $\mathrm{Pb}$ is also consistent with $\mathrm{Pb}$ degassing $\left(\mathrm{D}_{\mathrm{Pb}}{ }^{\mathrm{v} / \mathrm{m}}\right.$ varies from 4.2 to 20, (Urabe, 1987; Candela, 1989; Keppler, 1996)). 
To summarize, this study of melt inclusions from the 1976-2000 eruptive sequence indicates efficient degassing of the least soluble species $\mathrm{CO}_{2}, \mathrm{H}_{2} \mathrm{O}$ and $\mathrm{SO}_{2}$ before the magma reaches the shallow environment $(420-880 \mathrm{~m})$. The interconnected network formed through coalescence allows volatiles to escape the magma and degas at the surface. Convection within the deeper reservoir and/or overlying conduit $(2.7$ to $4.7 \mathrm{~km})$ is a potential process to explain the persistent degassing of White Island despite the very low volume of magma erupted. $\mathrm{HCl}$ is more soluble and starts exsolving in the shallow environment ( 420 to $880 \mathrm{~m}$ ), augmented by crystallization. The repeated mafic injections bring volatiles and heat to the shallow crystallizing dacitic magma. Metals such as $\mathrm{Cu}, \mathrm{Zn}, \mathrm{Pb}$ behave incompatibly, progressively enriching the residual magma through crystallization. Correlations with $\mathrm{S}$ and $\mathrm{Cl}$ nevertheless suggest degassing of these metals, and/or segregation by a sulphide melt.

\subsection{The occurrence of sulphide melt inclusions and their effect on metals}

The sulphide hosted in the matrix glass in one of the 1977 bombs, WIDP 10, exhibits a perfectly spherical shape (Figure 3-6 b). Minimizing surface tension during mixing of two immiscible liquids results in the least abundant species to adopt a shape with minimum surface area for a given volume (i.e. a sphere). This physical process implies that the sulfide was trapped as an immiscible melt within a liquid silicate melt.

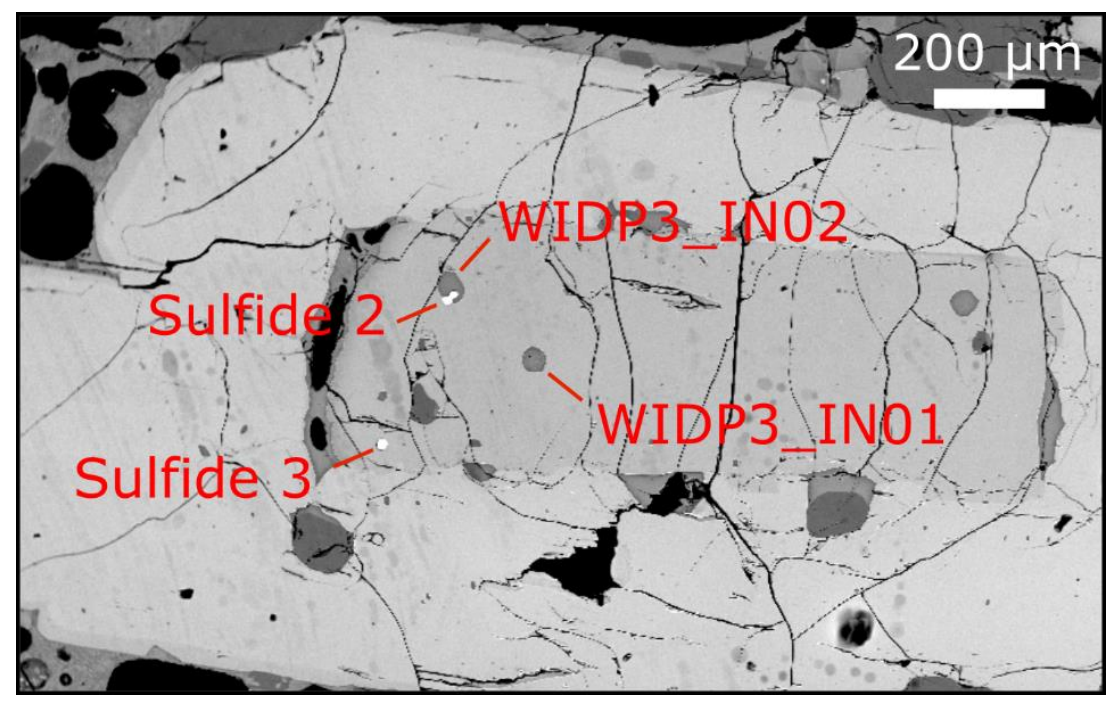

Figure 3-18: Backscattered electron image of orthopyroxene phenocrysts in the bomb from July 2000 WIDP 3 containing sulphide inclusions. The silicate melt inclusion containing one the sulphides (WIDP3_IN02), and a close by inclusion (WIDP3_IN01) were analyzed for their volatile content.

In order to constrain the sulfur content at sulfide saturation, we analyzed silicate melt inclusions containing sulphides or hosted in phenocrysts containing sulphides. In WIDP 3, the inclusion containing one of the sulphides (IN02) and a nearby inclusion (IN01), have sulfur contents of $359 \mathrm{ppm}$ and $299 \mathrm{ppm}$ respectively (Figure 3-18). In WIDP 4, the small sulphide phase is hosted in a melt inclusion containing $310 \mathrm{ppm}$ of sulfur. Entrapment pressure of this silicate inclusion was estimated following the $\mathrm{H}_{2} \mathrm{O}-\mathrm{CO}_{2}$-melt solubility 
model of Papale et al. (2006) as described above, using $100 \mathrm{ppm} \mathrm{CO}_{2}$ from Esposito et al. (2014). The resulting pressure of $21 \mathrm{MPa}$ is in agreement with the proposed late saturation, after the magma has reached depth of $\sim 600 \mathrm{~m}$.

The absence of sulphide in olivine phenocrysts suggests late saturation with respect to a sulphide melt. Given the low (<1332 ppm) sulfur content of olivine-hosted melt inclusions (typically 900-2500 ppm S in arc magmas (Wallace and Edmonds, 2011)), an oxidized mafic magma at $\sim 1200{ }^{\circ} \mathrm{C}$ will most likely become saturated with sulfur due to decompression, at depths where a magmatic volatile phase is present $\left(\mathrm{CO}_{2}\right.$ and most likely $\mathrm{H}_{2} \mathrm{O}$ already saturated), favoring exsolution of $\mathrm{S}$ into the aqueous fluid phase instead of formation of an immiscible sulfide liquid. This is in accordance with the composition of gases emitted by Donald Mound fumarole in 1988 of about $92 \mathrm{~mol} \% \mathrm{H}_{2} \mathrm{O}, 6 \mathrm{~mol} \% \mathrm{CO}_{2}, 1 \mathrm{~mol} \% \mathrm{SO}_{2}$ and 0.2 mol\% $\mathrm{HCl}$ (Giggenbach and Matsuo, 1991). It also agrees with the onset of sulfur exsolution from mafic melts into a vapor phase at pressures around 140-100 MPa observed in natural systems (Spilliaert et al., 2006; Johnson et al., 2010), determined experimentally (Webster and Botcharnikov, 2011), and calculated with models (Scaillet and Pichavant, 2005). Further rise of this magma into the shallow $(\sim 420-880 \mathrm{~m})$ accumulation zones and mixing with cooler, partly crystallized dacitic magma induces cooling and decompression. The effects of both these processes have been determined experimentally and tend to decrease sulfur solubility in hydrous silicate melts (Carroll and Rutherford, 1985; Poulson and Ohmoto, 1990; Mavrogenes and O’Neill, 1999; Holzheid and Grove, 2002).

Additionally, crystallization taking place in the shallow reservoirs will reduce the total volume of residual melt, thus increasing the sulfur content ( $\mathrm{S}$ incompatible in crystallizing phases). Experimental studies have shown that sulfur solubility is also dependent on $\mathrm{FeO}$ content of the silicate melt and oxygen fugacity $f_{\mathrm{O}_{2}}$ (Carroll and Rutherford, 1985; Luhr, 1990; Wallace and Carmichael, 1992; Metrich and Clocchiatti, 1996; Jugo, 2009). The dacitic enclave in WIDP 6 contains more Fe-oxides than any other rocks of the eruptive sequence, suggesting increased crystallization in the felsic melt. Onset of crystallization of such phases would not only reduce the total Fe content of the melt, but would also lower $f_{\mathrm{O}_{2}}$, by decreasing the $\mathrm{Fe}^{3+} / \mathrm{Fe}^{2+}$ ratio. This, in turn, would convert the highly soluble sulphate $\left(\mathrm{S}^{6+}\right)$ into less soluble sulphide ( $\mathrm{S}^{2-}$ ) (Carroll and Rutherford, 1988). Jenner et al. (2010) showed that crystallization of magnetite at $\mathrm{SiO}_{2}>60 \mathrm{wt} \%$ acts as a trigger to sulphide saturation by reducing the silicate melt (i.e. decreasing $f_{\mathrm{O}_{2}}$ ). All of these processes (i.e. cooling, crystallization, shift in redox conditions) lead to formation of an immiscible sulphide melt.

The small amount of magnetite crystallizing in White Island magma may not be sufficient to trigger sulphide saturation on its own, but might be efficient when coupled with the processes described previously. It may also promote sulphide saturation on a local scale, as suggested by Bacon (1989). Late sulphide saturation in arc settings has been proposed by several authors, supported by silicic magmas saturated with a sulphide melt whereas their mafic counterparts are not (Larocque et al., 2000; Luhr, 2008; Parat et al., 2011). Timing of sulphide saturation is a critical parameter in the formation of ore deposits (Keith et al., 1997; Halter et al., 2002; Halter et al., 2005; Nadeau et al., 2010; Richards, 2011; Wilkinson, 2013). Jenner et al. (2010) and Park et al. (2015) showed that late sulphide saturation is not a barrier to the formation of ore-bearing systems. On the contrary, fractional crystallization permits 
enrichment of the silicate melt in incompatible metals $(\mathrm{Au}, \mathrm{Cu}, \mathrm{Zn})$ efficiently segregated into the sulphide melt upon saturation.

Destabilization of this sulphide phase by volatile exsolution would provide metals to newly formed hydrothermal fluids. Resorption of the sulphide melt before complete crystallization of the melt thus prevents small blebs of metal-rich sulphides to be disseminated in a large volume of magma. Various authors have explored processes leading to destabilization of an immiscible sulphide phase, including, 1) oxidation through fluxing of $\mathrm{SO}_{2}$-rich magmatic volatile phase rising from underlying mafic magmas (Hattori, 1993; Blundy et al., 2015), 2) oxidation through volatile exsolution (Keith et al., 1997; Larocque et al., 2000; Halter et al., 2002; Halter et al., 2005), and 3) pressure decrease (Keith et al., 1997). In the case of White Island, deep $\mathrm{SO}_{2}$-rich fluids and ongoing volatile exsolution within the shallow environment would promote oxidation of the sulfide blebs. Nevertheless, the importance of such processes in generating ore-forming fluids inevitably depends on the amount of immiscible sulfide melt exsolved from the magma.

\subsection{Conclusions}

This study of ejecta from the 1976-2000 eruptive sequence revealed textural, structural and chemical evidence for magma mixing in a shallow environment, between a crystallizing dacitic melt and mafic recharge. The estimated entrapment pressure indicates that the shallow reservoir is at $\sim 400$ to $800 \mathrm{~m}$ depth, probably in the form of multiple accumulation zones interacting together and mixing with the mafic melt. The source of this more primitive magma is deeper than $5 \mathrm{~km}$ depth, probably at the crust-mantle interface as suggested by the extremely magnesian olivines. The presence of intermediate reservoir(s) between 1-2 km, in which Fo76-78 olivines and some of the pyroxenes crystallize, is suggested. A schematic view of the magmatic system of White Island is proposed in Figure 3-19. Mafic injections are frequent and do not always lead to eruption. Short residence times of mafic minerals into more evolved melt nevertheless suggest these recharge events might act as a triggering mechanism in some instances. The repeated injections of magma lead to zonation within the shallow magmatic chambers, indicated by enclaves of different composition in erupted material.

The persistent flux of gases observed at White Island is mainly due to degassing of the less soluble species $\mathrm{CO}_{2}, \mathrm{H}_{2} \mathrm{O}$ and $\mathrm{SO}_{2}$ from the deepest reservoir. Magma convection within a large chamber and/or within the overlying conduit might be responsible for overturn of dense degassed magma with less dense gas-rich melt. Efficient degassing is then possible without erupting large volumes of magma. More soluble chlorine degasses in the shallow reservoirs, most likely through second boiling. 


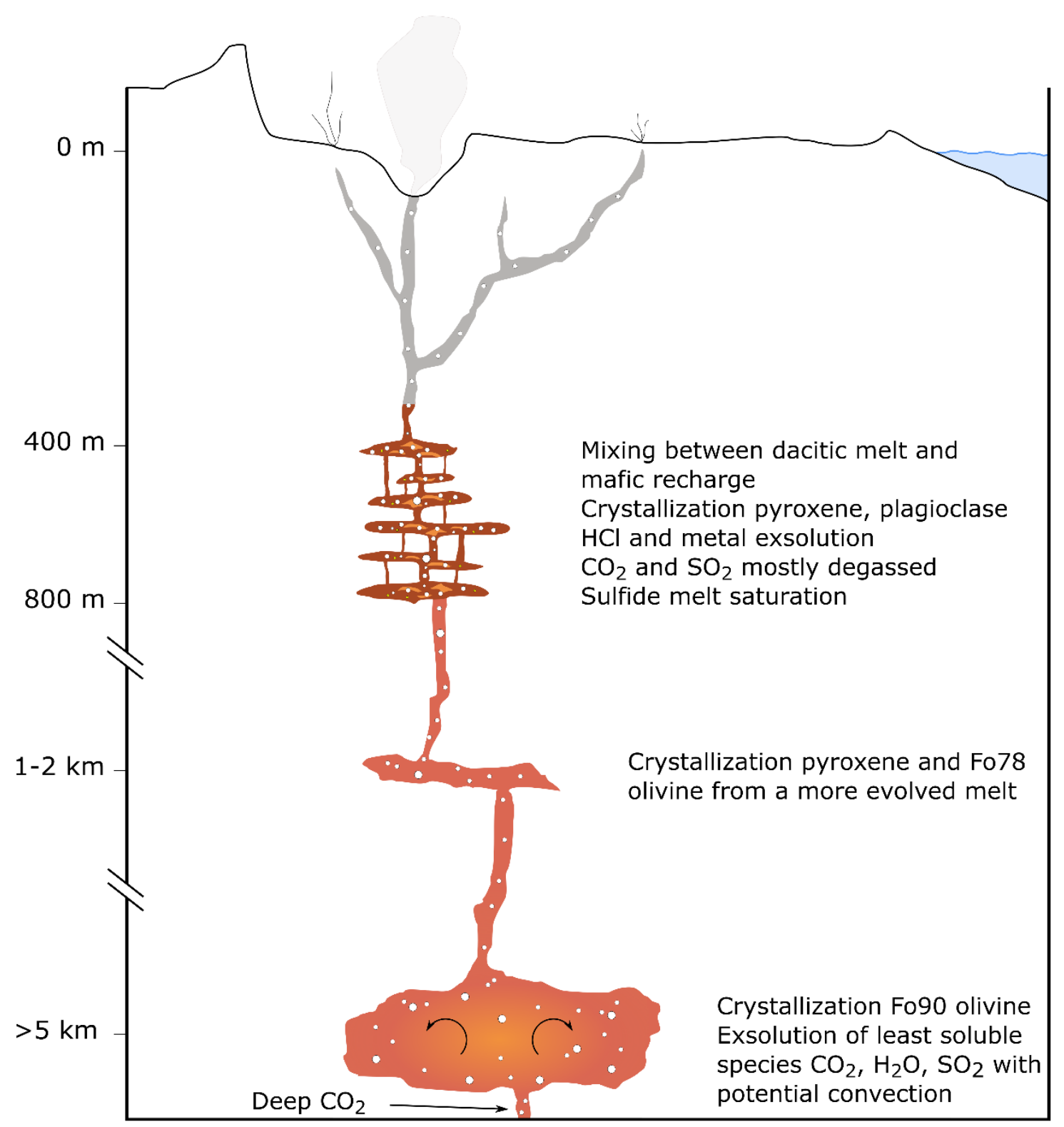

Figure 3-19: Schematic model of White Island magmatic system during the 1976-2000 eruptive sequence.

Metals exhibit an incompatible behavior in the mafic melt yielding an enriched magma through crystallization. Degassing occurs in the shallow environment favoring volatile transport of $\mathrm{Cu}$ and $\mathrm{Pb}$, although partitioning into crystallizing phases cannot be ruled out in the case of zinc. The presence of $\mathrm{Cu}-\mathrm{Fe}$ sulphides rich in $\mathrm{Ag}$, $\mathrm{Au}$ and $\mathrm{Zn}$ implies saturation of an immiscible sulphide phase, potentially triggered by magnetite crystallization in the dacitic melt. Destabilization of these sulfides would act as an additional source of metal-rich fluids, assuming remobilization within a magmatic volatile phase. 


\section{Chapter 4: Hyperacidic crater lake as a sink for metals}

\subsection{Introduction}

In the last chapter, we explored the metal content of the magma responsible for volcanic activity at White Island. We saw that many of the metals are being exsolved along with the major volatile species, sulfur and chlorine. Here, we follow these fluids on their path towards the uppermost part of the system, where they encounter accumulating and infiltrating, cooler meteoric water.

Of all the Holocene or younger volcanoes worldwide, around $16 \%$ of them feature a crater lake (Delmelle and Bernard, 2000). These lakes can be subdivided into two categories: hot, mineralized acidic waters, and cooler and diluted, slightly acidic to neutral waters. The former are usually associated with active volcanoes releasing high fluxes of magmatic gases, whereas the latter generally sit on top of dormant volcanoes where deep-seated magma releases less gas (Delmelle and Bernard, 2000; Rouwet et al., 2014; Christenson et al., 2015). Scientific interest was first driven by the risk associated with these systems. In spite of the harmless characteristics of the cool and neutral crater lakes at first glance, a hidden hazard arises from them: the accumulation of carbon dioxide at the bottom of the stratified waters suddenly released in a deadly asphyxiating gas cloud. Such an event occurred in Cameroun at the now famous Lake Nyos in 1986, killing the population and livestock living nearby (Kling et al., 1987; Sigurdsson et al., 1987; Kusakabe et al., 1989). In the case of active volcanoes, additional hazard arises from the presence of a crater lake. Drainage of these waters following eruption or rim/flank collapse can generate lahars (Simkin and Siebert, 1994; Delmelle and Bernard, 2000; Delmelle et al., 2015; Manville, 2015). Another potential risk is associated with pollution of the local groundwater by seepage or overflow of the acidic and mineralized waters, as observed for instance at Kawah Ijen, Poas or Copahue volcanoes (Rowe et al., 1992a; Simkin and Siebert, 1994; Rowe et al., 1995; Sriwana et al., 1998; Delmelle and Bernard, 2000; Varekamp et al., 2001; Löhr et al., 2005; van Hinsberg et al., 2010a; Manville, 2015). In addition, phreatic eruptions are frequent, and usually unheralded, at volcanoes where a lake occupies the crater. They are often associated with sealing of the hydrothermal system by secondary precipitation of mineralized fluids (Browne and Lawless, 2001; Christenson et al., 2007; Christenson et al., 2010).

The interest in crater lakes also arises from their chemical "scrubbing" capabilities, making them potential tools to monitor the volcanic activity. Indeed, changes in water chemistry, temperature and/or color have been observed preceding and following eruptions at different volcanoes (Giggenbach, 1974; Giggenbach and Glover, 1975; Takano, 1987; Brown et al., 1989; Takano and Watanuki, 1990; Brown et al., 1991; Rowe et al., 1992b; Christenson and Wood, 1993; Oppenheimer, 1993; Badrudin, 1994; Christenson, 2000; Martínez et al., 2000; Ohba et al., 2000; Varekamp et al., 2001; Ohba et al., 2008; Bani et al., 2009; Christenson et al., 2010; Rouwet and Tassi, 2011; Rouwet et al., 2014).

Hyperacidic crater lakes $(\mathrm{pH}<2)$ are rare and remarkable environments, which contain the most acidic natural waters on Earth. They occupy craters of active volcanoes where the hydrology and geomorphology allow ponding of meteoric waters and condensation of rising volcanic vapors from the underlying conduit (Symonds et al., 2001; Christenson and Tassi, 
2015). Their hyperacidic nature arises from scrubbing of magmatic gases, notably $\mathrm{HCl}$ and $\mathrm{SO}_{2}$, and their subsequent dissolution (Sakai and Matsubaya, 1977; Giggenbach, 1987; Rye et al., 1992; Kusakabe et al., 2000) as described by the reactions:

$$
\begin{gathered}
\mathrm{HCl}_{(g)}=\mathrm{H}^{+}+\mathrm{Cl}^{-} \\
4 \mathrm{SO}_{2(g)}+4 \mathrm{H}_{2} \mathrm{O}=3 \mathrm{H}_{2} \mathrm{SO}_{4(a q)}+\mathrm{H}_{2} \mathrm{~S}_{(a q)} \\
3 \mathrm{SO}_{2(g)}+2 \mathrm{H}_{2} \mathrm{O}=2 \mathrm{H}_{2} \mathrm{SO}_{4(a q)}+\mathrm{S}^{0}
\end{gathered}
$$

Such disproportionation of magmatic gases leads to strong enrichment in sulfate and chloride in crater lake waters, as well as the formation of elemental sulfur. These reactive waters promote hydrolysis of the host rock, enriching the lake in cations resulting in high total dissolved solids (Henley and Berger, 2011). Such extensive alteration results in silicaenriched residual rock beneath and around volcanic lakes (Rowe and Brantley, 1993; Wood, 1994; Christenson et al., 2010; van Hinsberg et al., 2010b). At Kawah Ijen, Delmelle and Bernard (1994) reported incongruent dissolution leading to residual rock with as much as 85 $\mathrm{wt} \% \mathrm{SiO}_{2}$.

Crater lakes thus represent perfect environments to study water/gas/rock interactions in magmatic-hydrothermal systems. The metal load of acidic crater lakes has mostly been ignored at the expense of sulfur and chlorine species in the past studies. It nevertheless represents a potential hazard in terms of water pollution in inhabited areas. Moreover, crater lakes have been shown to act as metal sinks, in the same way as they scrub gaseous $\mathrm{HCl}$ and $\mathrm{SO}_{2}$ (Henley, 2015). The study of metal behaviour in such environments will thus help us understand metal segregation in hydrothermal systems.

The presence of a lake occupying portions of the crater floor at White Island has been reported as far back as 1826, by the first settlers to visit the island (Luke, 1959). It nevertheless appears to be ephemeral, and linked to the activity of the volcano. No lake was present during the 1976-2000 eruptive sequence, but water accumulation in the eruption crater complex started as soon as the activity stopped in mid-2000. It was not until 2003 that a crater lake as such filled the western subcrater. The volume at the overflow level has been estimated at $\sim 2.5 \times 10^{6} \mathrm{~m}^{3}$ (Christenson et al., 2017). Three complete cycles of filling and evaporation took place since the lake's re-appearance in 2003 (Werner et al., 2008; Christenson et al., 2017). Its composition is characteristic of hyperacidic lakes, with chloride and sulfate contents of $35-150 \mathrm{~g} / \mathrm{L}$ and $5-45 \mathrm{~g} / \mathrm{L}$ respectively, $\mathrm{pH}$ of -1 to 1.5 , and temperatures ranging from $31{ }^{\circ} \mathrm{C}$ to $78.8{ }^{\circ} \mathrm{C}$ (GeoNet, 2001-2017). The lake dried again at the end of 2016, and remains absent at the time of writing.

This study aims to constrain the behaviour of metals in White Island's hyperacidic crater lake, from magmatic-gas injection at the bottom of the lake, to elemental sulfur scrubbing, secondary mineral deposition and evaporation. 


\subsection{Samples and analytical methods}

\subsubsection{Collection of samples}

The crater lake samples were collected from the southern shore (Figure 4-1) using a polyethylene bottle attached to a sampling pole. The temperature of the lake was measured during collection with a thermocouple. Three different water samples were collected each time: 1) rubber seal bottle, removing any head space, for the analysis of $\mathrm{pH}$ and $\mathrm{H}_{2} \mathrm{~S}, 2$ ) filtered $(0.45 \mu \mathrm{m}$ Millipore and $0.45 \mu \mathrm{m}$ Whatman) for anions and trace elements (Nalgene and Teflon bottle respectively), 3) filtered $(0.45 \mu \mathrm{m})$ and acidified $\left(7 \mathrm{M} \mathrm{HNO}_{3}\right)$ for major cations and $\mathrm{Cu}$ (Nalgene bottle). The suspended particles collected onto one of the filters $(0.45 \mu \mathrm{m}$ Whatman) were kept for X-ray powder diffraction (XRD) and bulk analysis. The acidity of the lake and hazard due to the unpredictable nature of phreatic eruptions, prevented collection of water samples further from the shore and at deeper levels.

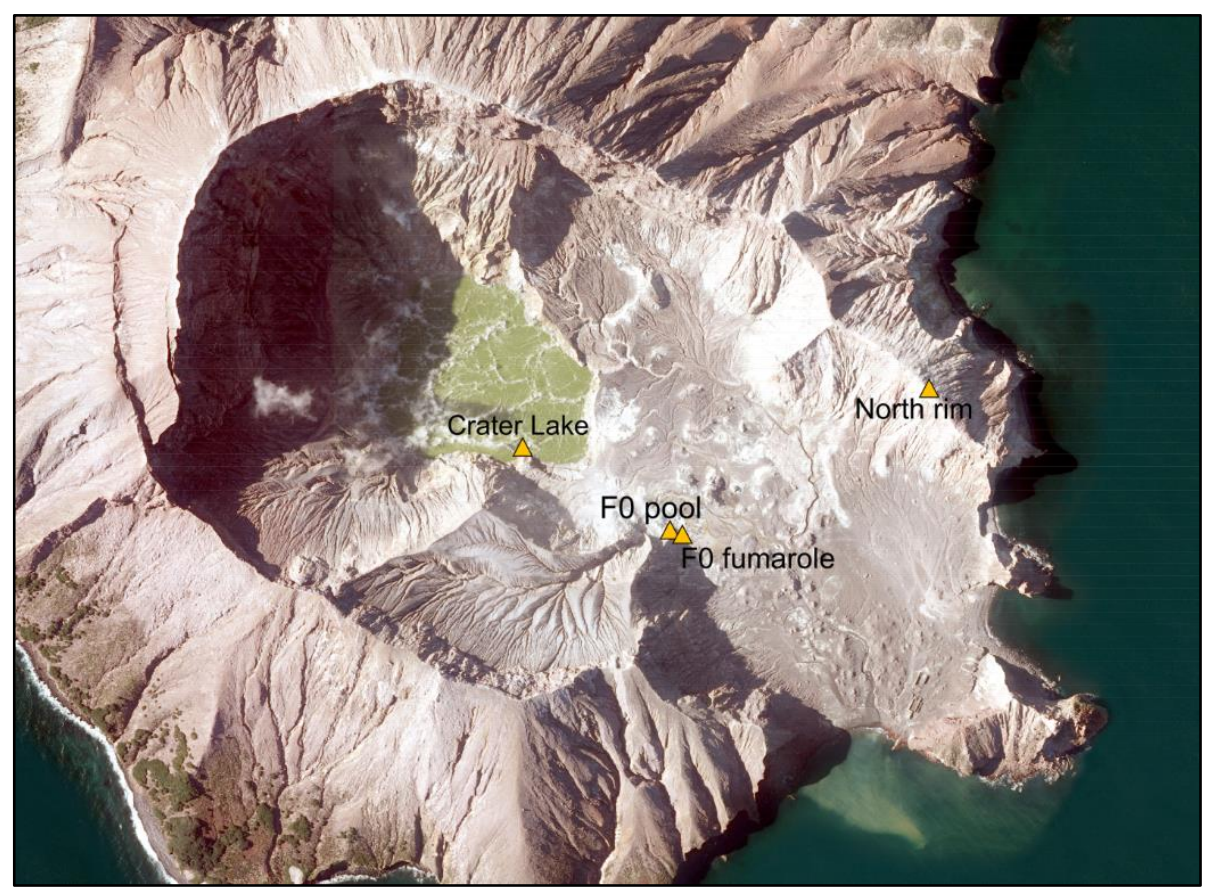

Figure 4-1: Aerial picture showing the sampling locations (source LINZ). North rim is where the ashes from the 27 April 2016 eruption were collected.

Sediments were collected from the bank and lake bottom at the shore line. Cores were also taken near the shore, at shallow levels. A cleaned plastic tube was hammered into the bottom of the lake and carefully removed with its sediment core. The tube was closed with two lids and later allowed to dry in a desiccator in the laboratory. During one of the sampling visits, a greenish foamy layer containing elemental sulfur spherules was floating at the surface of the lake. Some of this material was collected in a bottle and subsequently dried in a desiccator.

Another sample used for this study comprised ejecta of the phreatic eruption of 28 April 2016. Most of the crater floor and part of the rim was covered with greenish wet ash during the event (cf. Chapter 2). The sample was collected the day after the eruption, with no rain 
occurring since deposition, by Michael Rosenberg from GNS Science. As no juvenile material was erupted during this phreatic blast, we assume the ash to represent material altered and /or deposited by the hydrothermal system underneath the lake.

We also sampled a spring discharging in the crater floor, F0 Pool, and the active fumarole F0 located close by (Figure 4-1). The water was collected using a $0.5 \mathrm{~L}$ Nalgene bottle to fill our small Teflon vessels. Two samples of fumarolic gases were also collected: a condensate, using a glass condenser connected to a silica tube inserted into the fumarole; a Giggenbach flask, using a titanium tube inserted into the fumarole (cf. 5.2). The major and minor species are analysed by gas chromatography and wet chemistry, as part of the GeoNet volcanic hazards monitoring. The trace metal content of fumarolic gases was retrieved from ICP-MS analysis of the condensate.

\subsubsection{Sample preparation and analytical techniques}

All chemical treatments for trace elements analysis by ICP-MS were done using SeaStar ${ }^{\mathrm{TM}}$ ultra-pure acids and Milli-Q water. All the sample preparations were done in a class 100 clean room at Victoria University of Wellington.

\subsubsection{Water samples}

The $\mathrm{pH}$ and major element analyses were done by GeoNet scientists at Wairakei (New Zealand), as part of an on-going volcanic hazards monitoring program. $\mathrm{pH}$ and $\mathrm{H}_{2} \mathrm{~S}$ were measured in the laboratory as soon as possible after collection. Flow injection analysers were used for $\mathrm{H}_{2} \mathrm{~S}$ and $\mathrm{NH}_{3} . \mathrm{SO}_{4}{ }^{2-}, \mathrm{Br}^{-}$and the cations were measured by ion chromatography. The high concentration of $\mathrm{Cl}^{-}$makes titration analysis more suitable than ion chromatography. $\mathrm{F}^{-}$ was measured by ion selective electrode.

The trace elements were analysed at Victoria University of Wellington with a Thermo Scientific Element2 sector-field ICP-MS. As some precipitates formed after collection, the samples had to be analysed as bulk samples. They were weighed using a high precision balance $( \pm 0.00001 \mathrm{~g})$. We first dried down the samples and subsequently digested them in 5 $\mathrm{mL} 15 \mathrm{M} \mathrm{HNO}_{3}+5 \mathrm{~mL} 12 \mathrm{M} \mathrm{HCl}$ at $120{ }^{\circ} \mathrm{C}$ in Teflon beakers. In some cases, a white residue remained in solution which was then digested by addition of $0.1 \mathrm{~mL}$ of $36 \mathrm{M} \mathrm{HF}$. After complete dissolution, the samples were evaporated again to near dryness, refluxed in $15 \mathrm{M}$ $\mathrm{HNO}_{3}$ and finally taken up in $30 \mathrm{~mL}$ of $3 \mathrm{M} \mathrm{HNO}_{3}$. Fumarolic condensates were treated the same way.

Samples were analysed with different dilution factors in order to determine major and trace elements. The final dilution was done using $1 \% \mathrm{HNO}_{3}$. A synthetic solution was used to calibrate the ICP-MS, running 4 different dilutions to obtain a calibration curve. Instrument background was assessed by running $1 \% \mathrm{HNO}_{3}$ blank solution every 2 samples. The detection limit was taken as 3 standard deviations of the acid blank, whereas the limit of quantification was 6 standard deviations. SLRS-4 reference material (Yeghicheyan et al., 2001) was run to determine precision and accuracy of the analyses (Appendix A.7). In 
addition, we ran JB1 and BIR-1 standards (Jochum et al., 2016) to verify rock and sediment analyses.

\subsubsection{Solid samples}

The cellulose $0.45 \mu \mathrm{m}$ Whatman filter used for collection of suspended particles was weighed before and after sampling, along with the water bottle for which the filter was used. We could then recover a mass fraction of suspended particles per kilogram of water. The filter and suspended particles were digested in a Teflon beaker at $120{ }^{\circ} \mathrm{C}$ in a mixture of $5 \mathrm{~mL} 15 \mathrm{M}$ $\mathrm{HNO}_{3}+5 \mathrm{~mL} 12 \mathrm{M} \mathrm{HCl}+1 \mathrm{~mL} 36 \mathrm{M} \mathrm{HF}$. The samples were evaporated after complete dissolution and taken up in $5 \mathrm{~mL} 6 \mathrm{M} \mathrm{HCl}$ to ensure no solid remained. After drying, the

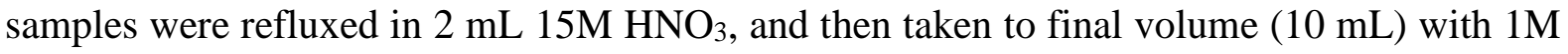
$\mathrm{HNO}_{3}$. The composition of the Whatman cellulose filter was assessed by digesting 10 weighed blank filters following a similar procedure. Another filter used to collect suspended particles was dried in a desiccator and kept for XRD analysis.

Sediment cores were pushed out of the sampling tube in a half tube using a plastic plunger. The core was then cut in half with a clean fishing line. Different layers within the core were observed and aliquots of each layer taken for ICP-MS analysis. The material was first dried in a desiccator, crushed using an agate mortar and pestle, and $0.05 \mathrm{~g}$ of each layer was precisely weighed. The digestion was performed in $0.5 \mathrm{~mL}$ of $15 \mathrm{M} \mathrm{HNO}+2 \mathrm{~mL}$ of $36 \mathrm{M} \mathrm{HF}$. After dissolution, the samples were dried to near dryness to prevent the formation of insoluble salts and refluxed in $15 \mathrm{M} \mathrm{HNO}_{3}$. After complete evaporation, $5 \mathrm{~mL}$ of $6 \mathrm{M} \mathrm{HCl}$ were added to ensure no solid remained and the samples were dried again. We then refluxed them in $15 \mathrm{M}$ $\mathrm{HNO}_{3}$ and finally dissolved them in $10 \mathrm{~mL} 1 \mathrm{M} \mathrm{HNO}_{3}$. A block of sediment collected on 6 June 2015 from the bottom of the lake had the same thin black layer surrounded by sulfurrich yellow precipitates as in the sediment cores (Figure 4-6). We powered an aliquot of both the black and the yellow layers and analysed it by XRD to assess the mineral phases present.

The foamy layer collected from the surface of the lake was dried in a desiccator and digested using the same protocol as the sediments. The sulfur spherules it contained were also analysed separately to assess the metals scavenged by elemental sulfur. The globules are usually spherical, although some of them present flattened surfaces. Contrary to many sulfur spherules found at other lakes (e.g., Poas, Ruapehu, Santa Ana, Kawah Ijen, Kawah Puti, Keli Mutu, Kusatsu-Shirane (Giggenbach, 1974; Takano and Watanuki, 1990; Rowe et al., 1992b; Delmelle and Bernard, 1994; Pasternack and Varekamp, 1994; Sriwana et al., 2000; Martínez et al., 2002; Colvin et al., 2013), the samples at White Island were rarely hollow. Most of them exhibit a hole but their interior is mostly solid. Their size ranges from $0.5 \mathrm{~mm}$ to $2 \mathrm{~mm}$. The color varied from bright yellow to shiny, metallic-like black, most likely due to the presence of trace metals compounds (Figure 4-2).

Spherules of different colors were picked for analysis in order to ascertain the differences in composition between metal-poor and metal-rich spherules. $0.05 \mathrm{~g}$ of the scum and spherules were precisely weighed and digested in Teflon beakers at $120^{\circ} \mathrm{C}$. A mixture of $1 \mathrm{~mL} 15 \mathrm{M}$ $\mathrm{HNO}_{3}+1 \mathrm{~mL} 12 \mathrm{M} \mathrm{HCl}+0.5 \mathrm{~mL} 36 \mathrm{M} \mathrm{HF}$ was added to the foam sample. The solution was dried to incipient dryness after complete dissolution to prevent for the formation of insoluble salts. After reflux in $15 \mathrm{M} \mathrm{HNO}_{3}, 5 \mathrm{~mL}$ of $6 \mathrm{M} \mathrm{HCl}$ was added to the sample. It was dried 
down after couple of hours, refluxed in $15 \mathrm{M} \mathrm{HNO}_{3}$ and finally taken up in $10 \mathrm{ML} 1 \mathrm{M} \mathrm{HNO}$. The sulfur spherules were treated similarly although they did not require HF during the dissolution procedure due to the absence of silicates.

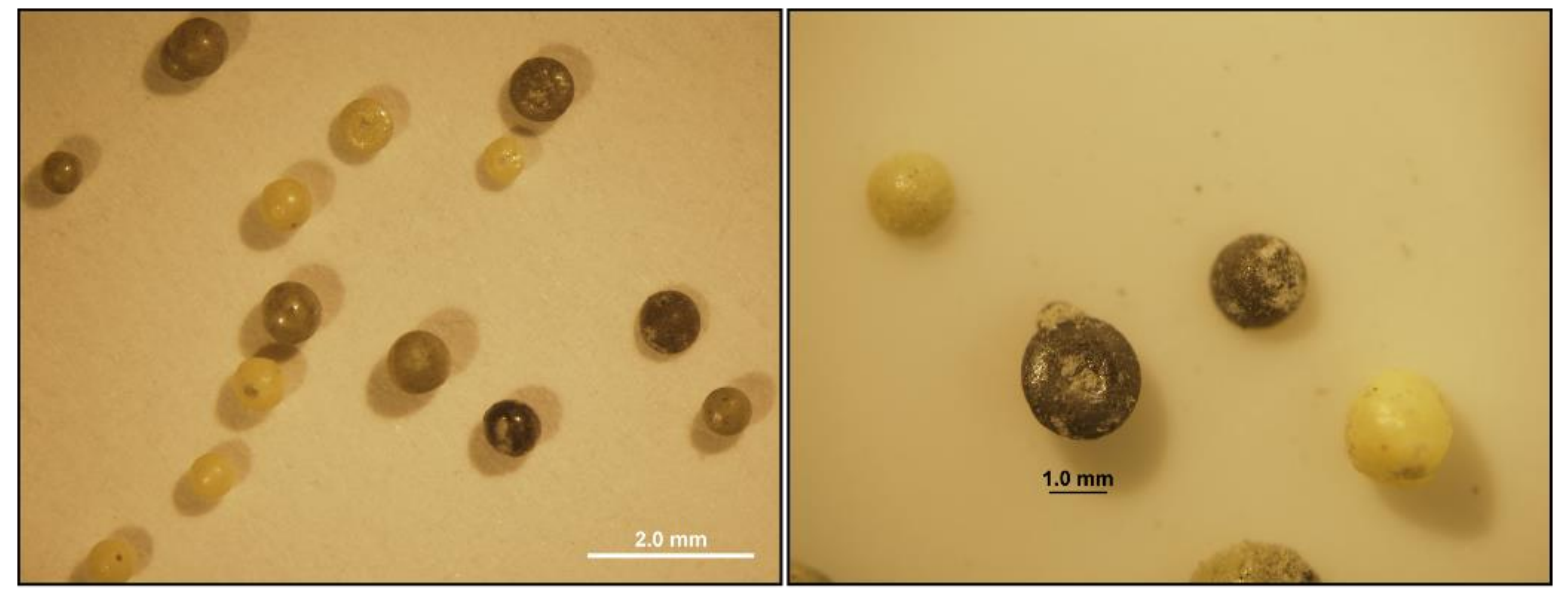

Figure 4-2: Pictures of sulfur spherules floating at the surface of the crater lake.

The ash from the 28 April 2016 eruption was powdered using an agate mortar and pestle. We also crushed part of a bomb erupted during the 12-25 March 1977 active period. The sample was first crushed using a Boyd crusher at Victoria University of Wellington, then powdered using an agate ball mill. We precisely weighed an aliquot of $0.05 \mathrm{~g}$ for each sample and digested them following the same protocol as for the sediments. The major elements were analysed by XRF by SpectraChem Analytical, CRL Energy Limited, Lower Hutt, New Zealand. BIR-1 was analysed to determine accuracy of the analysis $\left(<4 \%\right.$ bias for $\mathrm{Na}_{2} \mathrm{O},<$ $2 \%$ for $\mathrm{Fe}_{2} \mathrm{O}_{3},<1 \%$ for $\mathrm{SiO}_{2}, \mathrm{Al}_{2} \mathrm{O}_{3}, \mathrm{MgO}, \mathrm{CaO}$ ).

Samples for XRD analysis (sediments, suspended particles and ash) were analysed with a PANalytical X-Pert Pro Multi-Purpose Diffractometer (Victoria University of Wellington), using copper $\mathrm{K}$ alpha $(\mathrm{K}=1.54187 \AA$ ) radiation, with a beam intensity of $45 \mathrm{kV}$ and $40 \mathrm{~mA}$.

The lake sediments, including the thin black layer in the core from 5 June 2015, along with the April 2016 ash, sulphur spherules and suspended particles were imaged and analysed using a JEOL JSM-53000LV SEM coupled with EDS detector at Victoria University of Wellington. The analyses were performed with an acceleration voltage of $20 \mathrm{kV}$, a spot size of 57 , and a load current of $69-72 \mu \mathrm{A}$.

\subsection{Results}

\subsubsection{Crater lake water}

The crater lake was sampled on three occasions between October 2014 and December 2015. Changes in lake level (Figure 4-3) and color were also observed throughout this period. The level on 24 October 2014 was $~ 3.6$ meters above the reference level, slowly rising after 
complete dry-down during the 2012-2013 eruptive activity. The lake had a temperature of 68 ${ }^{\circ} \mathrm{C}$ and consisted of a main uniform pool, of light greyish green color reflecting the amount of particles in suspension (Figure 4-4 a). Smaller pools without signs of convection were observed on the sides. Evaporation from the lake surface is evident on Figure 4-4-a. Bubbling was also observed, indicating direct gas escape in addition to evaporation.

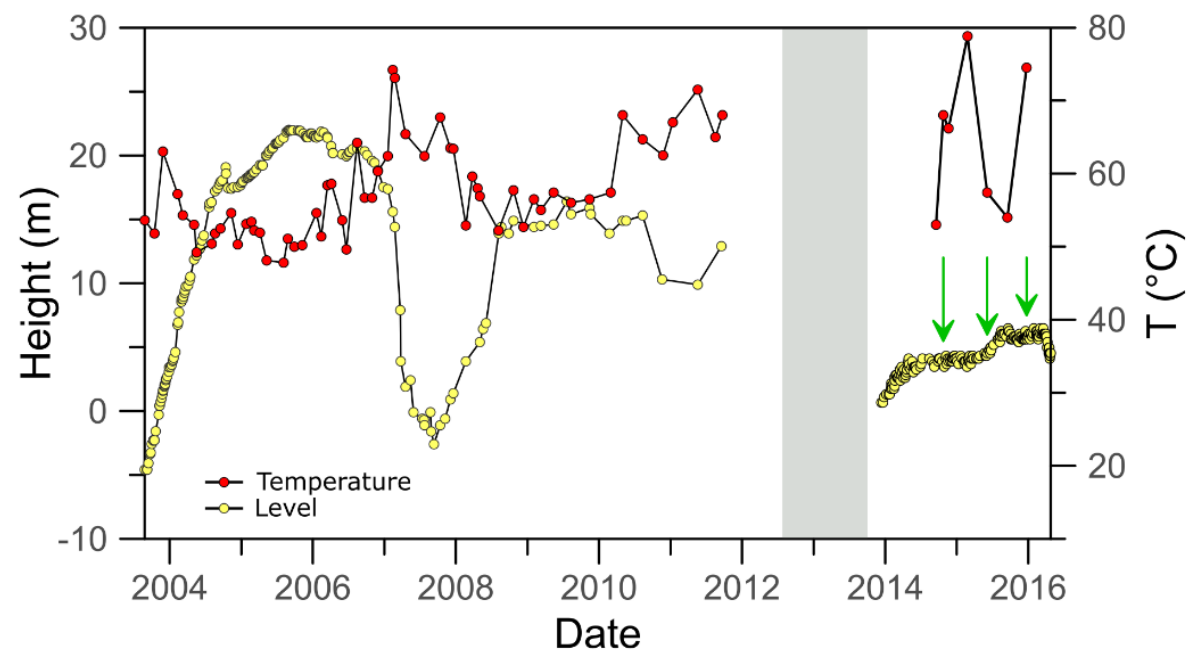

Figure 4-3: Crater lake time series showing variations in level and temperature. Green arrows represent the three sampling campaigns. The grey area delineates the 2012-2013 eruptive sequence, during which the crater lake disappeared.

The level had slightly increased on 5 June 2015, accompanied by a decrease in temperature down to $57.4{ }^{\circ} \mathrm{C}$. A scum layer containing sulfur globules was floating at the surface of the lake (Figure 4-4 c). As noted in October 2014, Figure 4-4-c shows that evaporation and bubbling were still taking place. The lake was not as uniform as during the first visit, with various colors of grey and yellowish green observed at the surface (Figure 4-4 b), indicating that convection was not sufficient to completely homogenize the system.

The lake level had increased again on 23 December 2015. Despite this rise, the shore at the sampling site consisted of a thick layer (at least $30 \mathrm{~cm}$ ) of smooth, unpacked mud-like sediments, emphasizing drying and precipitation of this portion of the lake (Figure 4-4 d). The temperature had risen to $74.5^{\circ} \mathrm{C}$. The warming of the system was also observed around fumarole 0, where hot springs and mud pools had dried. Despite the lake looking more uniform than during the previous visit, pools of different colors were still observed. Overall, the grey coloration of the lake indicates stronger convection, in accordance with the rise in temperature. Such a grey pool was present at the sampling site, where water and suspended particles were collected. 

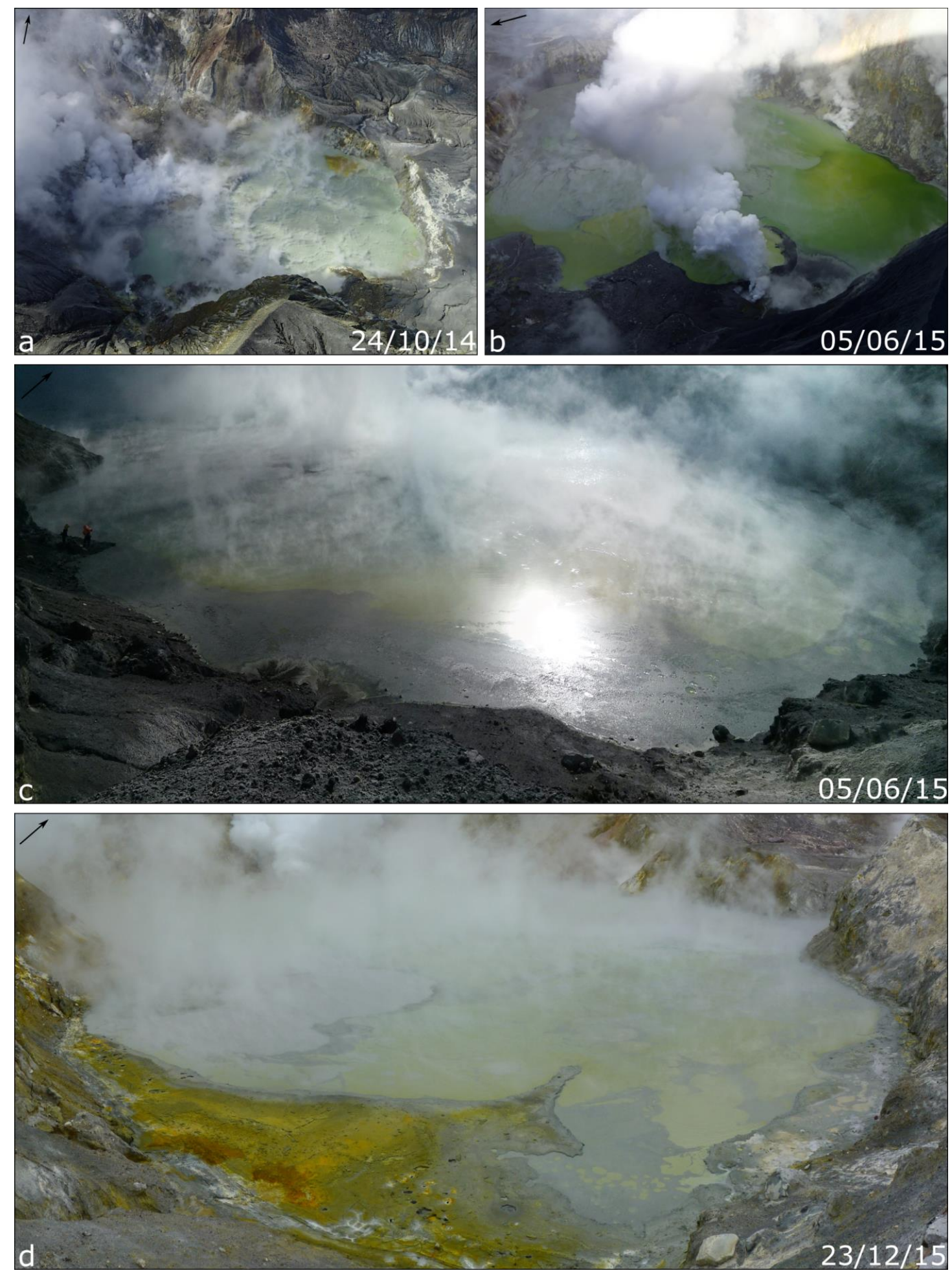

Figure 4-4: Pictures of the crater lake during the different sampling campaigns. a) Photo taken from the helicopter on 24/10/14 showing a mostly uniform lake (looking north). Small pools with different colors are seen only on the sides. Many fumaroles are visible at the back of the lake. b) Picture taken from the western rim on 5/06/15 showing different pools in the lake, varying in color from bright green to pale greyish green. The vigorous fumarole at the back of the lake is well exposed. c) Photo taken from the crater floor on 5/06/15. The scum layer rich in sulfur globules is the darker layer close to the shore. Note the two persons at the sampling location on the left for scale. d) Picture taken from the crater floor on 23/12/15 showing the thick smooth layer of dried sediments extending from the shore. A zone with a grey color is present on the left side of the lake. Note the black arrow indicating north. Pictures: Celine Mandon, GeoNet. 
The lake level kept on rising until early 2016, when a rapid decrease began, preventing further water sampling. It consisted of a shallow pool in June and October 2016, which had completely disappeared by December (Figure 4-5).

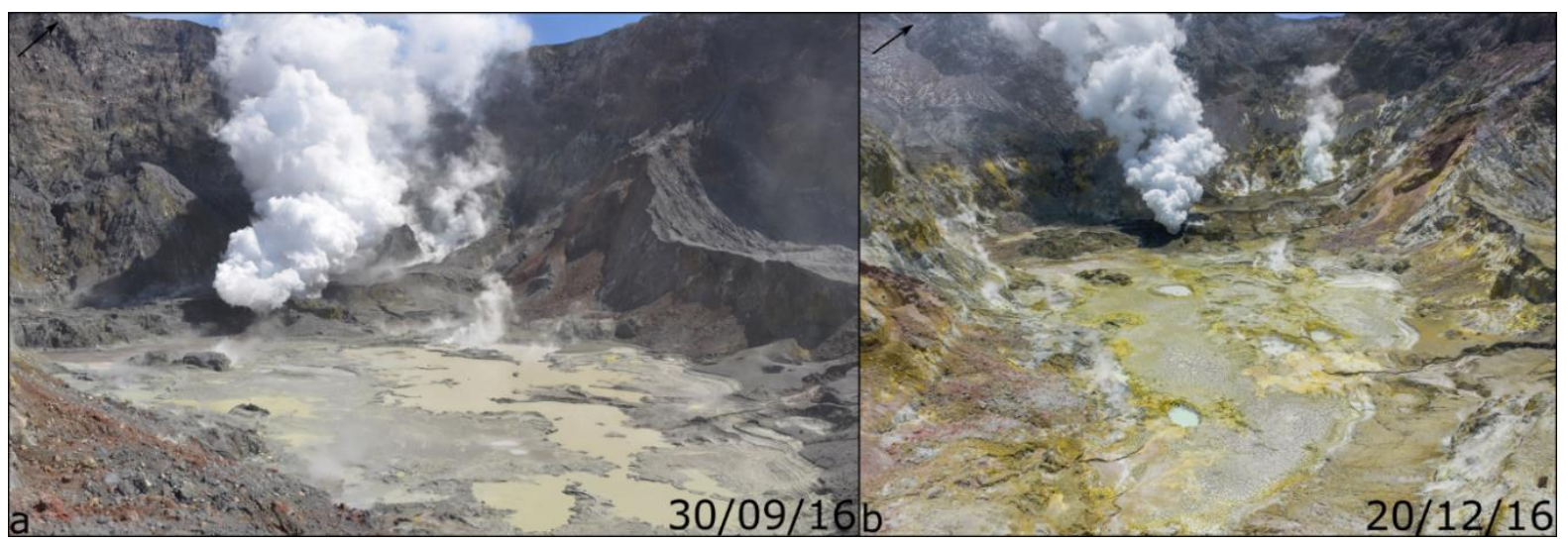

Figure 4-5: Pictures of the lake in late 2016. a) Photo taken from the crater floor on 30/09/16 showing the almost dried lake, with only small pools remaining. b) Picture of the dried lake on 20/12/16 taken from the crater floor (drone). Photo courtesy of GeoNet.

In terms of chemistry, White Island crater lake has a composition similar to those of other hyperacidic lakes, with average contents of $140335 \mathrm{mg} . \mathrm{L}^{-1}$ for chlorine and $27075 \mathrm{mg} . \mathrm{L}^{-1}$ for sulfate over the studied period. The $\mathrm{pH}$ is negative, fluctuating between -0.71 to -0.87 and the total dissolved solids (TDS) is around $200000 \mathrm{mg} . \mathrm{L}^{-1}$. Some trace metals are very concentrated: $6.3-8.6 \mu \mathrm{g} . \mathrm{g}^{-1}$ of $\mathrm{Cu}, 10.6-17.2 \mu \mathrm{g} . \mathrm{g}^{-1}$ of $\mathrm{Zn}, 6.7-18 \mu \mathrm{g} . \mathrm{g}^{-1}$ of $\mathrm{Pb}, 11.6-12.7$ $\mu \mathrm{g} . \mathrm{g}^{-1}$ of As, $0.3-1.3 \mu \mathrm{g} . \mathrm{g}^{-1}$ of $\mathrm{Hg}, 3.0-7.5 \mu \mathrm{g} . \mathrm{g}^{-1}$ of Tl. The complete analyses of the water are presented in Table 4-1.

Table 4-1: White Island crater lake and spring compositions.

\begin{tabular}{lrrrrr}
\hline & Crater Lake & Crater Lake & Crater Lake & F0 Pool & F0 Pool \\
\hline Sampling date & $24 / 10 / 14$ & $5 / 06 / 15$ & $23 / 12 / 15$ & $5 / 06 / 15$ & $15 / 10 / 15$ \\
\hline $\mathrm{T}\left({ }^{\circ} \mathrm{C}\right)$ & 68.0 & 57.4 & 74.5 & 99.3 & 101.2 \\
$\mathrm{pH}$ & -0.77 & -0.83 & -0.85 & -0.84 & -0.8 \\
$\mathrm{Major}$ and minor elements $\left(\mu \mathrm{gg} \cdot \mathrm{g}^{-1}\right)$ & & & & \\
$\mathrm{Cl}$ & 142454 & 153300 & 134198 & 142285 & 141313 \\
$\mathrm{SO}{ }_{4}$ & 27209 & 27337 & 28147 & 1410 & 1218 \\
$\mathrm{~B}$ & 282 & 316 & 259 & 134 & 587 \\
$\mathrm{Na}$ & 7372 & 6401 & 4829 & 27 & 26 \\
$\mathrm{Ca}$ & 4417 & 5305 & 5619 & 48 & 49 \\
$\mathrm{Mg}$ & 4076 & 3292 & 2687 & 34 & 37 \\
$\mathrm{Al}$ & 9492 & 7902 & 6766 & 89 & 89 \\
$\mathrm{Fe}$ & 4678 & 3879 & 3046 & 198 & 460 \\
$\mathrm{~K}$ & 2716 & 2425 & 1850 & 27 & 29 \\
$\mathrm{As}$ & 11.60 & 12.30 & 14.30 & 36 & 64 \\
\hline
\end{tabular}




\begin{tabular}{|c|c|c|c|c|c|}
\hline & Crater Lake & Crater Lake & Crater Lake & F0 Pool & F0 Pool \\
\hline Sampling date & $24 / 10 / 14$ & $5 / 06 / 15$ & $23 / 12 / 15$ & $5 / 06 / 15$ & $15 / 10 / 15$ \\
\hline $\mathrm{Li}$ & 9.9 & 8.6 & 6.1 & 0.03 & 0.05 \\
\hline Si & 39 & 41 & 43 & 51 & 45 \\
\hline $\mathrm{H}_{2} \mathrm{~S}$ & $<0.01$ & 0.22 & 0.20 & 0.13 & 0.17 \\
\hline $\mathrm{Br}$ & 455 & 465 & 600 & 3.1 & 16.3 \\
\hline $\mathrm{F}$ & 3067 & 1793 & 1470 & 1.2 & 2.2 \\
\hline $\mathrm{NH}_{3}$ & 277 & 275 & 236 & 0.38 & 0.41 \\
\hline $\mathrm{Rb}$ & 11.81 & 5.81 & 5.50 & 0.08 & 0.09 \\
\hline $\mathrm{Sr}$ & 28.82 & 20.78 & 21.17 & 0.25 & 0.23 \\
\hline $\mathrm{Zr}$ & 1.67 & 1.99 & 1.88 & 0.48 & 0.68 \\
\hline Sn & 1.14 & 0.79 & 0.69 & 0.01 & 0.02 \\
\hline $\mathrm{Sb}$ & 1.67 & 1.49 & 1.60 & 0.69 & 2.36 \\
\hline $\mathrm{Ba}$ & 32.81 & 2.49 & 2.20 & 0.95 & 2.44 \\
\hline $\mathrm{Tl}$ & 7.53 & 3.32 & 3.02 & 0.01 & 0.02 \\
\hline $\mathrm{Pb}$ & 18.00 & 7.68 & 6.70 & 0.03 & 0.08 \\
\hline $\mathrm{Bi}$ & 5.74 & 2.64 & 2.68 & 0.01 & 0.01 \\
\hline Sc & 2.81 & 2.29 & 2.37 & 0.05 & 0.04 \\
\hline $\mathrm{Ti}$ & 54.10 & 41.98 & 48.30 & 24.57 & 45.13 \\
\hline V & 25.98 & 20.84 & 19.25 & 0.37 & 0.43 \\
\hline $\mathrm{Cr}$ & 41.93 & 23.95 & 19.36 & 0.89 & 2.09 \\
\hline $\mathrm{Mn}$ & 172.0 & 100.1 & 82.29 & 0.92 & 1.27 \\
\hline Co & 1.99 & 1.55 & 1.35 & 0.23 & 0.31 \\
\hline $\mathrm{Ni}$ & 7.07 & 5.04 & 5.19 & 0.62 & 1.39 \\
\hline $\mathrm{Cu}$ & 5.70 & 5.80 & 6.00 & 2.50 & 2.28 \\
\hline $\mathrm{Zn}$ & 17.24 & 10.62 & 12.50 & 0.13 & 0.28 \\
\hline $\mathrm{Ga}$ & 1.74 & 1.33 & 1.16 & 0.03 & 0.02 \\
\hline \multicolumn{6}{|c|}{ Trace elements $\left(n g . g^{-1}\right)$} \\
\hline Mo & 81.68 & 439.9 & 89.27 & 30.22 & 36.97 \\
\hline $\mathrm{Ag}$ & 41.10 & 34.05 & 36.05 & 5.20 & 7.24 \\
\hline $\mathrm{Cd}$ & 253.5 & 138.6 & 95.18 & 1.04 & 2.04 \\
\hline In & 165.9 & 101.0 & 72.14 & 0.37 & 0.78 \\
\hline $\operatorname{Re}$ & 0.52 & 0.36 & 0.29 & 0.07 & 0.10 \\
\hline $\mathrm{Au}$ & 2.07 & 1.36 & 0.58 & 0.11 & 0.33 \\
\hline $\mathrm{Hg}$ & 584.0 & 270.1 & 1281 & 43.55 & 34.31 \\
\hline
\end{tabular}

Reproducibility (1 RSD): Hg \pm 110\%; Te $\pm 71 \%$; Sn \pm 61\%; Se, Tl, Au, W, Ag, Na < $\pm 40 \%, \mathrm{~B}, \mathrm{Cd}$, $\mathrm{Sb}, \mathrm{Re}, \mathrm{Pb}, \mathrm{Bi}, \mathrm{Mg}, \mathrm{Sc}, \mathrm{Ti}, \mathrm{Cr}, \mathrm{Zn}, \mathrm{K}< \pm 20 \%$; $< \pm 10 \%$ for the rest of the elements (Appendix A.7).

Bubbling at the surface of the lake provides evidence of fumarolic discharge at the bottom. The numerous vents observed at lower lake levels also confirm direct gas discharge into the lake. These gases are responsible for the highly acidic nature of the lake through disproportionation of $\mathrm{HCl}$ and hydrolytic reaction of $\mathrm{SO}_{2}$ (Christenson et al., 2017). They also maintain the lake temperature due to enthalpy loss during steam condensation (e.g. Brown et al., 1989). 


\subsubsection{Solid samples}

\subsubsection{Suspended particles}

The suspended particles are rich in $\mathrm{Ti}, \mathrm{Ba}$ and $\mathrm{Ag}$ compared to the lake water (Table 4-2). The sample collected in June 2015 is richer in As, Ba, B and Tl than the later sample from December 2015. Collection in December led to an estimate of $14 \mathrm{~g}$ of suspended particles per kilogramme of water. Calcium sulfate (gypsum and/or anhydrite), barite, $\mathrm{SiO}_{2}, \mathrm{TiO}_{2}$ and $\mathrm{Al}-$ $\mathrm{K}$ sulfate (most likely alunite) were observed by SEM in the suspended particles. This is consistent with the results from X-ray powder diffraction, highlighting the presence of anhydrite, gypsum and cristobalite, with minor amounts of alunite, halite and quartz (Appendix A.5). Halite, instead of being saturated in the lake water, most likely formed after collection, by evaporation of residual water on the filter. The proportion of barite and $\mathrm{TiO}_{2}$ is too small to be detected by XRD. Moreover, we observe a broad hump in the XRD spectra at $2 \theta=20-22.5$ (Appendix A.5), probably highlighting the presence of amorphous silica. Particulate amorphous silica has in fact been reported as abundant in the suspended solids of Kawah Ijen crater lake (Delmelle and Bernard, 1994).

Table 4-2: Composition $\left(\mu \mathrm{g} \cdot \mathrm{g}^{-1}\right)$ of sediments, scum layer, suspended particles, ash, sulfur globules and andesite.

\begin{tabular}{|c|c|c|c|c|c|c|c|}
\hline & Sediments & Scum & $\begin{array}{c}\text { Suspended } \\
\text { particles }\end{array}$ & $\begin{array}{l}\text { Suspended } \\
\text { particles }\end{array}$ & Ash & S globules & Andesite \\
\hline Sampling & $5 / 06 / 15$ & $5 / 06 / 15$ & $5 / 06 / 15$ & $23 / 12 / 15$ & $28 / 04 / 16$ & $5 / 06 / 15$ & $4 / 04 / 77$ \\
\hline $\mathrm{Na}$ & 7334 & 9013 & 21404 & 27389 & 12945 & 105.5 & 16988 \\
\hline $\mathrm{Ca}$ & 53932 & 57915 & 25706 & 18117 & 48276 & 211.8 & 57819 \\
\hline $\mathrm{Mg}$ & 4193 & 4247 & 8700 & 10247 & 4776 & 47.0 & 48185 \\
\hline $\mathrm{Al}$ & 22240 & 8503 & 21401 & 19573 & 37334 & 104.8 & 69966 \\
\hline $\mathrm{Fe}$ & 15306 & 19095 & 8296 & 9605 & 20762 & 18679 & 56096 \\
\hline K & 6760 & 2585 & 6170 & 6563 & 10329 & 35.7 & 11871 \\
\hline B & 26.47 & 17.40 & 339.5 & 194.7 & nd & 0.21 & 25.12 \\
\hline $\mathrm{Rb}$ & 30.75 & 10.25 & 25.64 & 24.09 & 33.76 & 0.08 & 46.89 \\
\hline $\mathrm{Sr}$ & 171.0 & 96.79 & 108.7 & 87.69 & 683.9 & 0.61 & 161.0 \\
\hline $\mathrm{Zr}$ & 91.30 & 16.68 & 59.30 & 46.38 & 93.83 & 0.31 & 97.84 \\
\hline Mo & 1.33 & 2.04 & 1.46 & 1.22 & 1.52 & 0.85 & 1.01 \\
\hline $\mathrm{Ba}$ & 631.9 & 108.0 & 132.5 & 50.54 & 610.0 & 7.07 & 509.8 \\
\hline $\mathrm{TI}$ & 5.73 & 5.37 & 19.67 & 9.93 & 2.85 & 1.11 & 0.19 \\
\hline $\mathrm{Pb}$ & 12.69 & 11.40 & 15.04 & 14.52 & 7.69 & 2.66 & 7.73 \\
\hline $\mathrm{Bi}$ & 1.87 & 4.66 & 6.52 & 7.93 & 1.40 & 1.23 & 0.76 \\
\hline Sc & 8.75 & 5.75 & 8.22 & 9.17 & 13.77 & 0.07 & 30.43 \\
\hline $\mathrm{Ti}$ & 3522 & 1000 & 3203 & 2507 & 3902 & 26.44 & 3701 \\
\hline V & 68.16 & 28.09 & 67.96 & 71.57 & 113.6 & 0.76 & 211.3 \\
\hline $\mathrm{Cr}$ & 74.96 & 35.35 & 63.50 & 66.44 & 119.3 & 5.90 & 355.8 \\
\hline $\mathrm{Mn}$ & 123.2 & 102.5 & 211.1 & 254.5 & 197.9 & 2.47 & 1059 \\
\hline Co & 9.09 & 22.28 & 4.57 & 5.57 & 18.53 & 21.00 & 31.81 \\
\hline $\mathrm{Ni}$ & 22.64 & 52.56 & 12.42 & 16.89 & 43.70 & 49.78 & 114.3 \\
\hline $\mathrm{Cu}$ & 55.69 & 91.01 & 30.30 & 29.11 & 84.41 & 80.94 & 81.29 \\
\hline
\end{tabular}




\begin{tabular}{|c|c|c|c|c|c|c|c|}
\hline & Sediments & Scum & $\begin{array}{c}\text { Suspended } \\
\text { particles }\end{array}$ & $\begin{array}{c}\text { Suspended } \\
\text { particles }\end{array}$ & Ash & S globules & Andesite \\
\hline $\mathrm{Zn}$ & 13.41 & 16.14 & 28.76 & 39.28 & 18.91 & 0.86 & 46.67 \\
\hline Ga & 5.45 & 1.81 & 4.73 & 4.98 & 7.47 & 0.04 & 12.95 \\
\hline As & 26.33 & 762.5 & 309.0 & 92.31 & 46.70 & 291.2 & 4.76 \\
\hline $\mathrm{Se}$ & 31.39 & 314.7 & nd & nd & 39.18 & 938.3 & nd \\
\hline $\mathrm{Ag}$ & 0.89 & 0.23 & 0.66 & 0.63 & 0.89 & 0.08 & 0.04 \\
\hline $\mathrm{Cd}$ & 0.13 & 0.16 & 0.37 & 0.31 & 0.18 & 0.02 & 0.05 \\
\hline In & 0.06 & 0.11 & 0.23 & 0.26 & 0.06 & 0.01 & 0.05 \\
\hline Sn & 1.36 & 1.06 & 2.88 & 2.57 & 7.37 & 0.06 & 1.47 \\
\hline $\mathrm{Sb}$ & 2.16 & 1.96 & 5.66 & 6.00 & 1.80 & 0.27 & 0.19 \\
\hline $\mathrm{Te}$ & 3.34 & 42.62 & 0.36 & 0.40 & 3.78 & 142.99 & 0.001 \\
\hline Sm & 2.20 & 0.77 & 0.98 & 0.82 & 2.14 & 0.01 & 2.39 \\
\hline $\mathrm{Yb}$ & 0.90 & 0.27 & 0.67 & 0.57 & 1.36 & 0.004 & 1.99 \\
\hline W & 0.87 & 0.38 & 0.74 & 0.51 & 1.07 & 0.08 & 1.25 \\
\hline $\mathrm{Re}$ & 0.05 & 0.22 & 0.05 & 0.05 & 0.15 & 0.17 & 0.001 \\
\hline $\mathrm{Au}$ & 0.09 & 0.10 & 0.06 & 0.06 & 0.06 & 0.19 & 0.0001 \\
\hline
\end{tabular}

Notes: nd: Below detection limit.

\subsubsection{Sulfur spherules}

The composition of mixed color sulfur globules is presented in Table 4-2. They are enriched in various elements such as $\mathrm{Se}\left(\sim 900 \mu \mathrm{g} \cdot \mathrm{g}^{-1}\right)$, As $\left(\sim 300 \mu \mathrm{g} \cdot \mathrm{g}^{-1}\right), \mathrm{Te}\left(\sim 150 \mu \mathrm{g} \cdot \mathrm{g}^{-1}\right), \mathrm{Cu}(\sim 80$ $\left.\mu \mathrm{g} \cdot \mathrm{g}^{-1}\right)$, Co $\left(\sim 21 \mu \mathrm{g} \cdot \mathrm{g}^{-1}\right)$, Re $\left(\sim 169 \mathrm{ng} \cdot \mathrm{g}^{-1}\right)$, and Au $\left(\sim 189 \mathrm{ng} \cdot \mathrm{g}^{-1}\right)$. This partly explains the enrichment of the sediments in the latter species. Pyrite crystals up to $20 \mu \mathrm{m}$ were observed with the SEM at the surface and in cavities of black sulfur globules, as reported at other crater lakes (Delmelle and Bernard, 1994). This is also in agreement with the findings of Takano et al. (1994), who reported native sulfur with a black color to contain $\sim 10 \%$ of pyrite. ICP-MS analyses of black and yellow globules showed that the former are richer in metals (

Table 4-3 and Appendix A.4). The high metal contents in the dark globules may be explained by the presence of metal sulfides, as observed on the surface of sulfur spherules at Kawah Ijen (Delmelle and Bernard, 1994; Henley, 2015). 
Table 4-3: Composition $\left(\mu \mathrm{g} \cdot \mathrm{g}^{-1}\right)$ of black versus yellow sulfur globules.

\begin{tabular}{ccc}
\hline & $\begin{array}{c}\text { Sulfur globules } \\
\text { yellow }\end{array}$ & $\begin{array}{c}\text { Sulfur globules } \\
\text { black }\end{array}$ \\
\hline $\mathrm{Fe}$ & 442.1 & 20582 \\
$\mathrm{Tl}$ & 0.17 & 1.31 \\
$\mathrm{~Pb}$ & 0.35 & 3.30 \\
$\mathrm{Bi}$ & 0.15 & 1.71 \\
$\mathrm{Co}$ & 0.20 & 27.14 \\
$\mathrm{Ni}$ & 0.34 & 62.20 \\
$\mathrm{Cu}$ & 0.79 & 98.97 \\
$\mathrm{Zn}$ & 0.51 & 1.37 \\
$\mathrm{Se}$ & 305.8 & 701.2 \\
$\mathrm{Ag}$ & 0.009 & 0.096 \\
$\mathrm{Cd}$ & 0.007 & 0.032 \\
$\mathrm{Te}$ & 186.982 & 128.643 \\
$\mathrm{Re}$ & 0.003 & 0.294 \\
$\mathrm{Au}$ & 0.010 & 0.124 \\
$\mathrm{Hg}$ & $\mathrm{nd}$ & 0.059 \\
\hline $\mathrm{Ne}$
\end{tabular}

Note: nd: Below detection limit.

\subsubsection{Sediments}

SEM observations and EDS analyses of the sediments collected on the lake bottom on $5 / 06 / 15$ revealed the presence of barite, $\mathrm{TiO}_{2}, \mathrm{SiO}_{2}$, altered silicates, gypsum/anhydrite, AlNa sulfate and pyrite.

Cores from June 2015 (Core 1a and 1b) have a crystalline yellow layer at the top, most likely formed by evaporation during crater lake level fluctuations (Figure 4-6 and Appendix A.6). As the cores were sampled close to the shore, a small variation in lake level would result in drying of the shallow parts. This is consistent with the variation in chemistry of the sediments (Appendix A.4). XRD analysis of this crystalline layer (Core 1b-1) revealed that it is mostly composed of gypsum, with small amounts of anhydrite, cristobalite and halite (Appendix A.5). It is also enriched in Sr, Sc, As, Cd and In (Table 4-4). On the other hand, we note that $\mathrm{Ba}$ is depleted in the evaporite material. The dark thin layer (Figure 4-6) observed in the upper section arises from the presence of black sulfur spherules within the gypsum crystals. As previously noted, the black globules are covered with small crystals of pyrite. 
Table 4-4: Composition (ng.g $\left.{ }^{-1}\right)$ of selected layers from the sediment cores.

\begin{tabular}{|c|c|c|c|c|c|c|c|}
\hline & Core $1 b-1$ & Core $1 b-6$ & Core $1 b-9$ & Core 2-1 & Core 2-6 & Core $2-10$ & Core $2-13$ \\
\hline Date & $5 / 06 / 15$ & $5 / 06 / 15$ & $5 / 06 / 15$ & $23 / 12 / 15$ & $23 / 12 / 15$ & $23 / 12 / 15$ & $23 / 12 / 15$ \\
\hline $\mathrm{Na}$ & 9516 & 3614 & 5596 & 3525 & 4445 & 4498 & 3512 \\
\hline $\mathrm{Ca}$ & 137766 & 39832 & 35178 & 22008 & 30663 & 4224 & 8999 \\
\hline $\mathrm{Mg}$ & 4795 & 3672 & 4006 & 1842 & 2232 & 2153 & 1863 \\
\hline Al & 13335 & 8227 & 24378 & 5785 & 11878 & 16298 & 10833 \\
\hline $\mathrm{Fe}$ & 6887 & 9792 & 13100 & 15594 & 8695 & 12747 & 8984 \\
\hline K & 4266 & 2757 & 7115 & 1570 & 2953 & 4543 & 2499 \\
\hline Sr & 264.8 & 75.94 & 131.2 & 285.0 & 492.1 & 147.5 & 186.0 \\
\hline $\mathrm{Ba}$ & 120.8 & 225.1 & 508.4 & 300.8 & 563.6 & 384.6 & 597.1 \\
\hline $\mathrm{Tl}$ & 6.28 & 1.93 & 2.32 & 3.10 & 3.81 & 4.48 & 3.22 \\
\hline $\mathrm{Pb}$ & 14.71 & 5.15 & 10.52 & 5.43 & 5.29 & 5.73 & 3.83 \\
\hline $\mathrm{Bi}$ & 5.19 & 1.63 & 1.30 & 3.01 & 2.39 & 2.08 & 1.89 \\
\hline Sc & 20.25 & 4.13 & 8.66 & 2.48 & 4.81 & 4.91 & 3.52 \\
\hline $\mathrm{Ti}$ & 753.3 & 1097 & 3474 & 967.1 & 3006 & 3269 & 3196 \\
\hline $\mathrm{Cr}$ & 49.50 & 35.33 & 71.99 & 23.28 & 29.02 & 26.99 & 25.17 \\
\hline Co & 3.48 & 6.54 & 5.87 & 13.20 & 5.99 & 9.72 & 6.17 \\
\hline $\mathrm{Ni}$ & 10.33 & 17.12 & 14.34 & 34.35 & 14.40 & 24.48 & 14.98 \\
\hline $\mathrm{Cu}$ & 17.16 & 27.47 & 36.30 & 76.18 & 37.73 & 54.41 & 47.88 \\
\hline $\mathrm{Zn}$ & 24.11 & 7.43 & 12.09 & 18.43 & 10.78 & 12.35 & 9.27 \\
\hline $\mathrm{Ga}$ & 2.90 & 1.72 & 5.27 & 1.21 & 2.06 & 2.88 & 1.77 \\
\hline As & 52.26 & 138.4 & 21.07 & 549.5 & 333.3 & 86.11 & 238.2 \\
\hline $\mathrm{Se}$ & nd & 296.3 & 29.61 & 540.4 & 169.3 & 227.1 & 202.6 \\
\hline $\mathrm{Ag}$ & 0.18 & 0.23 & 0.80 & 0.21 & 0.64 & 0.97 & 0.70 \\
\hline $\mathrm{Cd}$ & 0.23 & 0.07 & 0.13 & 0.09 & 0.10 & 0.13 & 0.09 \\
\hline In & 0.15 & 0.04 & 0.05 & 0.07 & 0.08 & 0.06 & 0.06 \\
\hline Sn & 0.98 & 0.48 & 0.88 & 0.87 & 8.85 & 1.29 & 1.11 \\
\hline $\mathrm{Sb}$ & 2.25 & 1.02 & 1.82 & 1.21 & 1.75 & 1.73 & 1.62 \\
\hline Te & nd & 1.23 & 0.15 & 52.97 & 15.10 & 21.51 & 16.76 \\
\hline $\mathrm{Re}$ & 0.01 & 0.03 & 0.02 & 0.22 & 0.12 & 0.11 & 0.12 \\
\hline $\mathrm{Au}$ & 0.04 & 0.03 & 0.10 & 0.02 & 0.03 & 0.05 & 0.03 \\
\hline
\end{tabular}

Note: nd: Below detection limit

One of the cores (Core 1b) contained a second layer of yellowish crystalline material (Figure 4-6), the composition of which is similar to the one at the top (Core 1b-1, see Table 4-4). This most likely reflects an earlier episode of evaporation that did not occur at the location of the other sediment core. Underneath this layer is a horizon (Core 1b-6) very rich in sulfur spherules, with high Se and Te contents $\left(296 \mu \mathrm{g} . \mathrm{g}^{-1}\right.$ and $1.2 \mu \mathrm{g} \cdot \mathrm{g}^{-1}$ respectively, see Table 4-4). The lower part of both cores is quite uniform, made of coarse grey to whitish particles. It also contains larger clasts, up to $5 \mathrm{~cm}$ in length, probably from blocks falling into the lake. Yellow sulfur globules are visible in some of the horizons. XRD results show gypsum, alunite, sulfur and Al-rich silicate to be the main components, with minor amounts of pyrite (Appendix A.5). Two broad humps are also visible on the spectra, at around 2 $\theta=11-14$ and 
$2 \theta=20-23.5$, corresponding to altered silicates and amorphous silica, respectively. Small dark particles are found in the bottom layers, consisting of glassy silica with holes filled with white milky crystals (most likely sulfates).

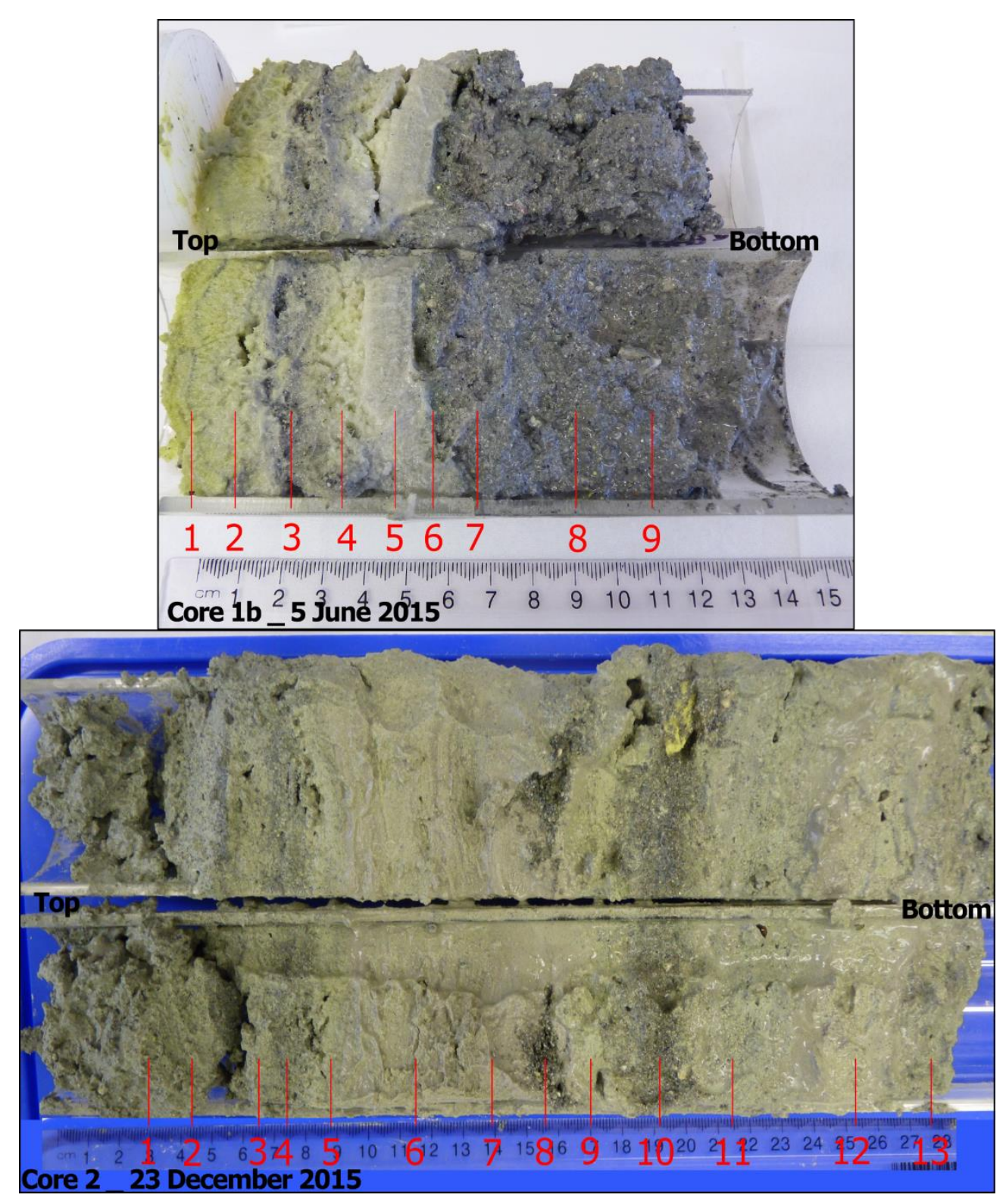

Figure 4-6: Pictures of sediment cores and the analyzed layers. Core 1b was sampled on 6 June 2015. Note a very thin black layer in the top yellow layer. Core 2 was sampled on 23 December 2015.

The sediment core collected in December 2015 (core 2) is very different. It consists of soft sediments, mud-like, from the dried accessible shore, in which we were sinking by more than twenty centimetres at each step. The coarser horizon at the bottom of core $1 \mathrm{~b}$ is not present, in agreement with a formation by evaporation rather than sedimentation and/or alteration of silicates falling into the lake. The absence of a crystalline layer as seen in June implies different conditions of evaporation. 
The most striking difference between horizons in Core 2 arises from the presence or absence of sulfur spherules. Sediments are darker and coarser when sulfur spherules are present (Layers 1, 2, 3, 4, 5, 8, 10), whereas layers without globules appear greener and are comprised of smaller particles (Figure 4-6) similar to the suspended material collected on the cellulose filter. This is reflected in the composition (Table 4-4 and Appendix A.4), with high Fe and Te contents in the first five layers, as well as in layers 2-8, and 2-10 (dark and coarse).

XRD analysis reveals that the pale greenish thin horizons at the middle of the core (e.g. Core 2-6) consist of anhydrite and sulfur, with minor amounts of cristobalite and gypsum (Appendix A.5). The high contents of sulfur and anhydrite is responsible for the cement-like aspect of the sediments in these horizons. The broad hump at $2 \theta=11-14$ is visible on the diffractogram, pointing to the probable presence of altered silicates. Pale greenish layers at the bottom (e.g. 2-13) are similar to the analysed layer 2-6 (Table 4-4 and Appendix A4), although their composition point to a higher sulfur to anhydrite ratio, given the lower $\mathrm{Ca}$ content. The very high content of calcium in layers 2-1 and 2-2 most likely corresponds to observed gypsum crystals. It is interesting to note that layer 2-13 is enriched in $\mathrm{Ag}(0.70$ $\left.\mu \mathrm{g} . \mathrm{g}^{-1}\right)$ compared to the top $\left(0.21 \mu \mathrm{g} . \mathrm{g}^{-1}\right.$ in Core $\left.2-1\right)$, which is rich in sulfur spherules. Core 2 is very different from the sediments sampled in June 2015, highlighting sedimentation of gypsum and sulfur spherules at times, changing to sulfur and anhydrite.

The differences observed in the sediment cores indicate changes in precipitating minerals with time, switching from gypsum, alunite, sulfur and Al-rich silica as main components in June 2015, to sulfur and anhydrite in December 2015 (Appendix A.5). The overall composition of sediments and suspended particles is similar to what has been reported at other hyperacidic crater lakes (Wood, 1977; Brantley et al., 1987; Delmelle and Bernard, 1994). Sulfur spherules in such lakes are thought to originate from molten sulfur present at the bottom, through which gases are injected, forming these spherical, sometimes hollow globules (Rowe et al., 1992b; Delmelle and Bernard, 1994; Pasternack and Varekamp, 1994). The presence of such a sulfur body has also been inferred by Christenson et al. (2017), to explain the sulfur-rich eruptions witnessed in 2013 (cf. Chapter 2). The sporadic presence of sulfur globules in the lake sediments suggests differences in the gas discharge regime (bubbling) as well as convection within the lake itself as a function of time. It might also reflect variations in water level, with deposition occurring only on the lake shore due to their low densities.

\subsubsection{Ash}

The ash ejected during the April 2016 phreatic eruption represents material from deeper within the hydrothermal system. It is thus not surprising to find abundant anhydrite and alunite, detected by SEM and XRD. In lesser amount, cristobalite, gypsum, pyrite and quartz were also identified (Appendix A.5), with altered silicates and traces of a Fe- and Cr-rich compound. This mineralogy is similar to that in the suspended particles and sediments from the crater lake, as well as the altered assemblage described by Hedenquist et al. (1993). This highlights recirculation of lake fluids in the upper part of the hydrothermal system. It is worth noting that the pyrite/anhydrite assemblage can also result from gas-rock interactions. Henley et al. (2015) showed that $\mathrm{SO}_{2}$-rich gases may react with Ca-bearing silicates producing $\mathrm{Ca}$ sulfate and $\mathrm{H}_{2} \mathrm{~S}$, the latter efficiently capturing Fe from the gas to form iron sulfides. 
Precipitation of secondary minerals in the residual porous rock beneath the lake is of importance as it reduces permeability (Heap et al., 2017). Anhydrite and alunite might indeed be responsible for the sealing of the system, leading to overpressure and phreatic eruption, as reported at other volcanoes (Christenson and Wood, 1993; Wood, 1994; Christenson et al., 2007; Christenson et al., 2010). This process was most likely responsible for the phreatic eruption that occurred in April 2016 without warning. ICP-MS analyses indicate that the bulk $\mathrm{Cu}$ content of the ash is higher than that of the andesite (Table 4-2). This suggests deep precipitation of $\mathrm{Cu}$-rich minerals, probably as halides or sulfides, subliming from the hightemperature gases (Bernard, 1985; Symonds et al., 1987). It may also occur through saturation of deep brines scrubbing volatile metals from the gas phase. Silver is very concentrated in the ash and sediments compared to the andesite, although no silver containing particles were observed with SEM nor XRD.

The presence of $\mathrm{SiO}_{2}$, gypsum/anhydrite, alunite, pyrite and barite in suspended particles and ash indicates that the sediments filling the eruption crater complex at White Island are partly comprised of secondary minerals. Andesite falling from the lake rim and subsequently altered by the acidic waters is another source of material, as evidenced by the coarser particles found on the shore and the Si-rich grains. Finally, elemental sulfur is present at the lake bottom, most likely in a molten form, and appears to be effective at sequestering chalcophile elements such as $\mathrm{Fe}, \mathrm{Se}, \mathrm{Te}, \mathrm{As}, \mathrm{Cu}, \mathrm{Co}, \mathrm{Au}$ and $\mathrm{Re}$. This body of molten sulfur is thought to form through disproportionation of $\mathrm{SO}_{2}$, oxidation of $\mathrm{H}_{2} \mathrm{~S}$ and polythionates (Takano and Watanuki, 1990; Rowe, 1994). The presence of pyrite on the sulfur spherules suggests a more reduced environment close to subaqueous vents, where the $\mathrm{H}_{2} \mathrm{~S}$-bearing gases meet metalrich waters and form sulfides.

\subsection{Sources of crater lake water}

As previously discussed in the introduction, hyperacidic crater lakes derive their extremely low $\mathrm{pH}$ by accumulation or scrubbing of magmatic vapors. The strong enrichment in $\mathrm{Cl}^{-}$and $\mathrm{SO}_{4}{ }^{2-}$ observed in White Island crater lake manifests such a magmatic input. The sulfur content is controlled by several reactions. For example, the elemental sulfur and sulfates observed in the sediments have an impact on the $S$ content of the water, lowering it by precipitating and increasing it during remobilization of previously crystallized phases. On the other hand, $\mathrm{Cl}$ is conservative and only affected by variations in magmatic input and evaporation/dilution processes (Giggenbach, 1974). Rock-water interactions between the reactive, acidic fluid and the host andesite are responsible for the high total dissolved solids (TDS) values.

The element transfer ratio (ETR), introduced by Pasternack and Varekamp (1994), highlights the three processes occurring in hyperacidic crater lakes: 1) magmatic gas input, 2) rock dissolution (constant $\mathrm{HCl}$ input enables on-going titration of the host rock), 3) precipitation of secondary minerals. The ETR is defined as:

$$
\text { ETR }=(X / M g)_{\text {water }} /(X / M g)_{\text {andesite }}
$$


where $(\mathrm{X} / \mathrm{Mg})_{\text {water }}$ is the ratio of element $\mathrm{X}$ to magnesium in the water and $(\mathrm{X} / \mathrm{Mg})_{\text {andesite }}$ is the same ratio in the andesite. We use $\mathrm{Mg}$ as a reference element, as it is considered to remain in solution in acidic fluids (i.e. it does not form secondary minerals) (Giggenbach, 1974). The calculated ETR are presented in Figure 4-7. Three groups of elements are observed: 1) elements with ETR 1 showing a similar dissolution from the andesite as $\mathrm{Mg} ; 2$ ) elements with ETR > 1 showing an enrichment due to either dissolution of earlier precipitated minerals, and/or input through magmatic gases; 3) elements with ETR $<1$ reflecting limited dissolution, and/or precipitation of secondary minerals.

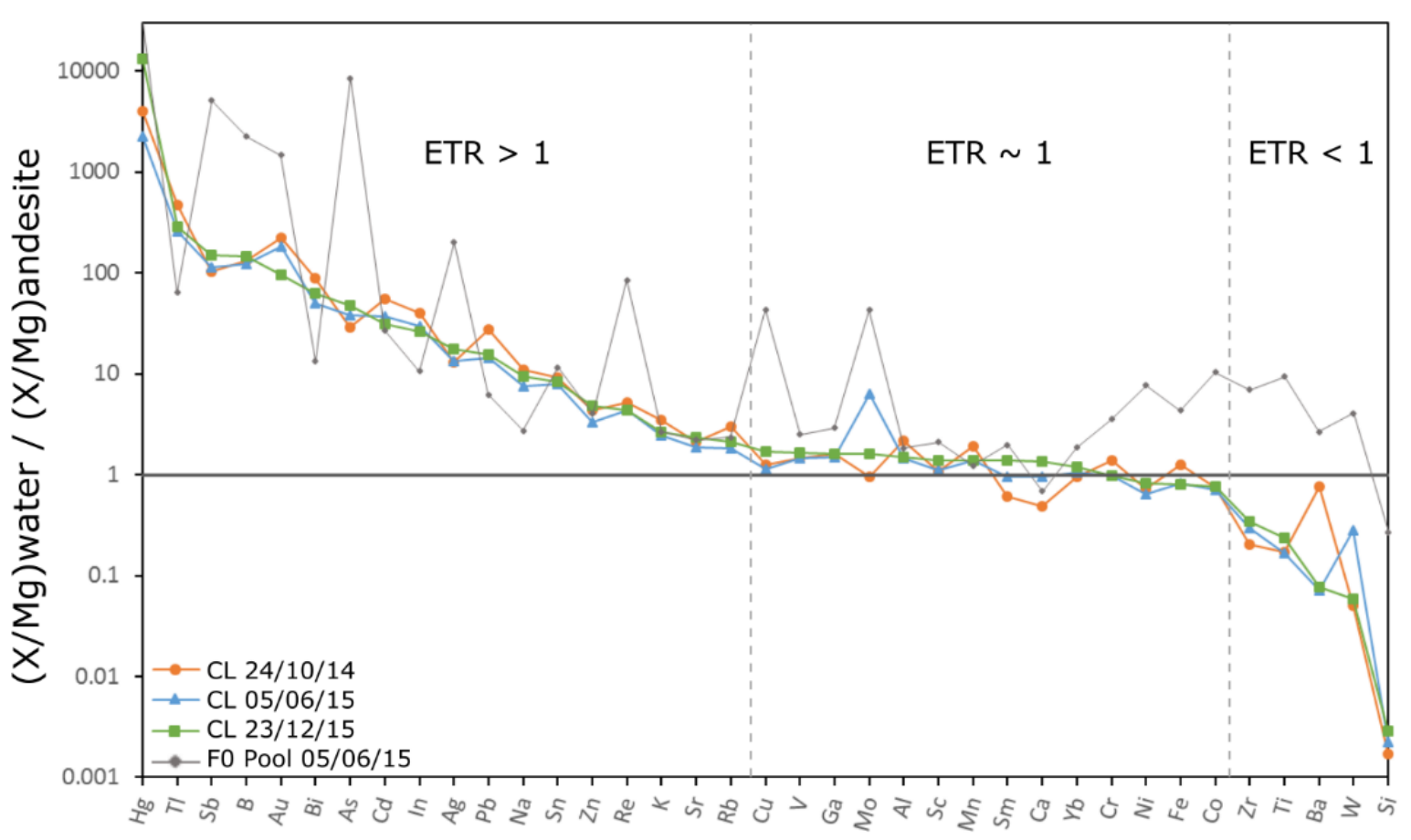

Figure 4-7: Element Transfer Ratio for the crater lake samples and F0 Pool normalized with 1977 andesite.

The phases observed in lake sediments (i.e., $\mathrm{BaSO}_{4}, \mathrm{TiO}_{2}, \mathrm{SiO}_{2}$ ) suggest that precipitation of secondary minerals explains the ETR $<1$ for $\mathrm{Ba}$, Ti and $\mathrm{Si}$. In the case of silica, limited dissolution may also be responsible for the low ETR, as indicated by Si-rich residual rocks found underneath crater lakes. Calcium has an ETR $\sim 1$ despite its presence as sulfate in the suspended particles and sediments. In contrast, the enrichment of elements on the left side is most likely due to gaseous input at the lake bottom. Most of these species are in fact transported by volcanic gases (Lambert et al., 1985; Rose et al., 1986; Varekamp et al., 1986; Symonds et al., 1987; Quisefit et al., 1989; Symonds et al., 1992; Hinkley et al., 1994; Cheynet et al., 2000). Enrichment of $\mathrm{Hg}, \mathrm{Tl}, \mathrm{Sb}, \mathrm{B}, \mathrm{Au}, \mathrm{Bi}, \mathrm{As}, \mathrm{Cd}$ and In is particularly high, as reported at other hyperacidic crater lakes (Delmelle and Bernard, 1994; Pasternack and Varekamp, 1994; Sriwana et al., 2000; Varekamp et al., 2009; van Hinsberg et al., 2010a). It is interesting to note the low enrichment factor for $\mathrm{Cu}$, as previously reported in brines from White Island (Giggenbach et al., 2003) and interpreted to reflect enargite precipitation at depth by Hedenquist et al. (1993). 
Figure 4-8 shows the relative abundances of $\mathrm{F}, \mathrm{Mg}$ and $\mathrm{Al}$ of the water since the lake formation in 2001. The dacite is the average composition of historic dacitic rocks from Graham and Cole (1991), whereas andesite is one of the 1977 ejecta. We clearly see the influence of both dissolution of the rock, mostly dacite, and magmatic gases on the composition of the water. The enrichment of $\mathrm{Mg}$ relative to $\mathrm{Al}$ emphasizes precipitation of Al-rich secondary minerals, compared to the conservative nature of magnesium. The rock endmember is closer to the dacitic composition than andesite, in agreement with the findings of Cole et al. (2000), reporting dacite as the product of major eruptions.

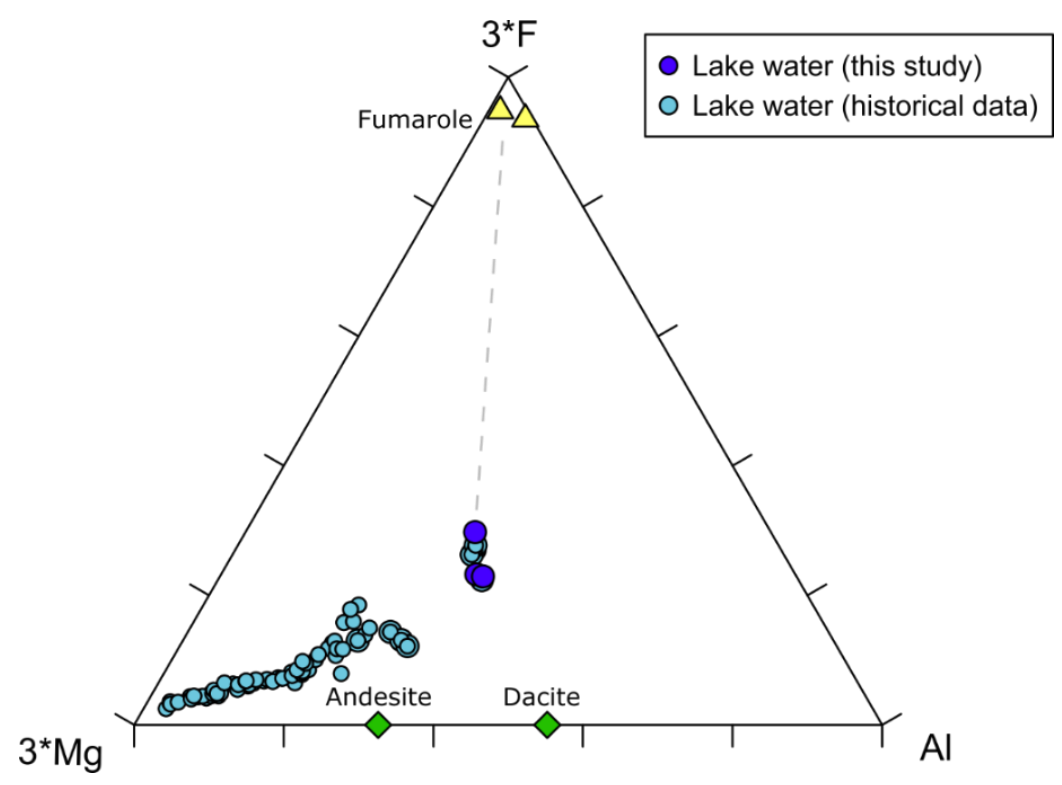

Figure 4-8: Ternary diagram $3 * \mathrm{~F}-\mathrm{Al}-3 * \mathrm{Mg}$ showing the composition of the crater lake water since its formation in 2001. The historical data is from GeoNet. Also shown are the composition of the host rocks, both andesite and dacite, and the composition of fumarolic gases on 23/12/14 and 05/06/15.

The ETR for F0 Pool is plotted for a comparison in Figure 4-7. Values near 1 for rockforming elements ( $\mathrm{Ca}$, alkali metals, $\mathrm{Mn}, \mathrm{Sm}, \mathrm{Sr}, \mathrm{Rb}$ ) emphasize the extent of rock dissolution in this hot and acidic spring. Differences in Ag and B might be explained by precipitating phases rich in these elements in the lake, as shown by their greater concentration in the sediments, ash and suspended particles in comparison to the lake water and andesite (Table 4-2). Similarly, the higher abundances of chalcophile $\mathrm{Au}, \mathrm{As}, \mathrm{Re}, \mathrm{Cu}$ and $\mathrm{Mo}$ in the acid spring might reflect scavenging by elemental sulfur at the bottom of the lake. Only $\mathrm{Si}$ has a negative ETR, emphasizing that most of the secondary minerals precipitating in the crater lake (i.e., $\mathrm{BaSO}_{4}, \mathrm{TiO}_{2}$ ) are not saturated in $\mathrm{F} 0$ pool. Overall, the similarities between crater lake water and F0 pool support the findings of Christenson et al. (2017), suggesting comparable source components resulting from water-rock-magmatic gas interactions.

The isosol plot (Figure 4-9) shows that a congruent dissolution of $100 \mathrm{~g}$ of dacite per liter of water explains the observed composition for most of the elements. This value is slightly higher than the one reported by Delmelle and Bernard (1994) for the crater lake at Kawah Ijen and Christenson and Wood (1993) for Ruapehu crater lake. Si and Ba are depleted in the lake water, in agreement with the ETR plot and the observed secondary minerals in the sediments. 


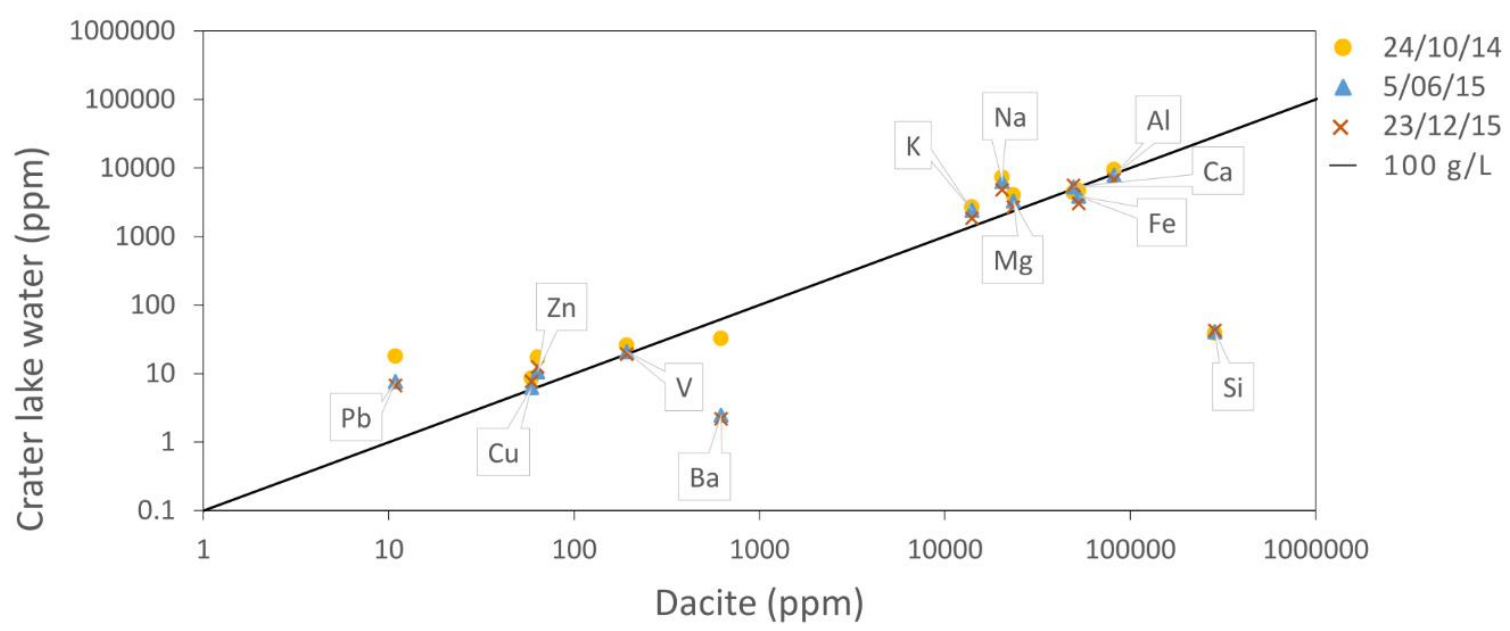

Figure 4-9: Isosol plot showing the crater lake water composition against the host dacite. The dacite composition was taken from Graham and Cole (1991).

\subsection{Water speciation and saturation}

Thermodynamic calculations performed to constrain the speciation and saturation of natural waters assume a system in equilibrium. White Island crater lake, as we have demonstrated earlier, is a very active system: magmatic gases are continually injected at the bottom of the lake, where elemental sulfur forms. In contrast, surficial waters are in contact with the cooling and oxidizing atmosphere. Pools of various colors indicate convection and mixing of fluids within the lake. The varying secondary minerals in sediment cores moreover reflect changes in temperature and/or redox and/or composition with time. In summary, an evolving thermal gradient, as well as a redox gradient, exist between the bottom and surface of White Island crater lake, at odds with the equilibrium state assumed for calculations. Our approach to overcome the complexity of this natural system for thermodynamic modelling, is to consider two systems with redox conditions representative of the bottom and the surface of the lake respectively. The lake water is likely to be reduced at depth where magmatic gases are injected (Delmelle and Bernard, 1994) and more oxidized at the surface.

Calculations were performed using the SpecE8 module within The Geochemist's Workbench software (Bethke, 2007). Activity coefficients applicable to the electrolyte solution of the crater lake are derived using the extended Debye-Hückel expression of Helgeson (1969) and the B-dot deviation function. Given no major changes were observed between different water samples from the crater lake, we only report results from the June 2015 sample. Speciation and saturation calculations were also performed for the June 2015 F0 pool sample. The LLNL database (Delany and Lundeen, 1989) was used for calculations, allowing variations of $\mathrm{pH}$ to satisfy charge balance.

\subsubsection{Speciation and saturation of surficial oxidized waters}

We first estimated the speciation in the surficial waters, assumed to be in equilibrium with the atmosphere. The redox state was thus controlled by $f_{\mathrm{O}_{2}}$ in air (i.e. $\log f_{\mathrm{O}_{2}}=-0.68$ ). The following results are all computed results. $\mathrm{HSO}_{4}{ }^{-}$is the dominant sulfur species, as expected 
in these acidic waters, more than two orders of magnitude higher than $\mathrm{H}_{2} \mathrm{SO}_{4}$ and $\mathrm{SO}_{4}{ }^{2-}$. Free $\mathrm{Cl}^{-}$is dominant, associated $\mathrm{HCl}$ being 5 orders of magnitude lower. Free ions are also expected to be the dominant species for the major cations $\mathrm{Na}^{+}, \mathrm{Al}^{3+}$ and $\mathrm{K}^{+}$. Complexes are nevertheless quite stable, as indicated by the high molalities of $\mathrm{AlF}^{2+}, \mathrm{NaCl}, \mathrm{KCl}$ and $\mathrm{AlSO}_{4}{ }^{+}$, less than an order of magnitude lower than the free ions. The stability of $\mathrm{AlF}^{2+}$ reflects the high concentration of $\mathrm{F}$ in the crater lake (i.e. $1793 \mu \mathrm{g} \cdot \mathrm{g}^{-1}$ ). The dominant $\mathrm{Ca}$ species is found to be $\mathrm{CaCl}^{+}$, followed by $\mathrm{Ca}^{2+} \cdot \mathrm{MgCl}^{+}$and $\mathrm{Mg}^{2+}$ dominate in the case of $\mathrm{Mg}$. The oxidized $\mathrm{Fe}^{(\mathrm{III})}$ species are stable in the surficial waters, dominated by $\mathrm{FeCl}_{2}{ }^{+}, \mathrm{FeCl}_{3}$ and $\mathrm{FeCl}^{2+}$. Ionic complexes are the most stable species concerning trace metals (Table 4-5). $\mathrm{CuCl}^{+}$, followed by $\mathrm{CuCl}_{2}$ and $\mathrm{Cu}^{2+}$, are the most abundant $\mathrm{Cu}$ species. Complexes with $\mathrm{Cl}$ ligands are also dominant for $\mathrm{Zn}$ and $\mathrm{Pb}$, as $\mathrm{ZnCl}_{4}{ }^{2-}$ and $\mathrm{PbCl}_{4}{ }^{2-}$. Calculations suggest $\mathrm{H}_{3} \mathrm{AsO}_{4}\left(\mathrm{As}^{\mathrm{V}}\right)$ is the dominant arsenic species in the crater lake.

Table 4-5: Calculated dominant metal complexes in the crater lake water from 5 June $2015(\Sigma \mathrm{Cl}=$ $5.93 \mathrm{~mol} / \mathrm{kg})$ under oxidized $\left(\log f_{\mathrm{O}_{2}}=-0.68\right)$ and reduced $\left(\mathrm{R}_{\mathrm{H}}=-3.5\right.$, equivalent to $\left.\log f_{\mathrm{O}_{2}}=-65\right)$ conditions.

\begin{tabular}{|c|c|c|c|}
\hline & $\begin{array}{l}\text { Eelement } \\
\text { (molarity) }\end{array}$ & $\begin{array}{l}\text { Oxidized surficial environment } \\
\text { Dominant complexes (molarity) }\end{array}$ & $\begin{array}{l}\text { Reduced deep environment } \\
\text { Dominant complexes (molarity) }\end{array}$ \\
\hline $\mathrm{Ag}$ & $4.02 \mathrm{E}-07$ & $\mathrm{AgCl}_{4}{ }^{3-}(4.00 \mathrm{E}-7), \mathrm{AgCl}_{3}{ }^{2-}(2.24 \mathrm{E}-9)$ & $\mathrm{AgCl}_{4}{ }^{3-}(4.00 \mathrm{E}-7), \mathrm{AgCl}_{3}{ }^{2-}(2.38 \mathrm{E}-9)$ \\
\hline As & $2.10 \mathrm{E}-04$ & $\mathrm{H}_{3} \mathrm{AsO}_{4}(2.09 \mathrm{E}-4)$ & $\mathrm{As}(\mathrm{OH})_{3}(2.09 \mathrm{E}-4)$ \\
\hline $\mathrm{Cu}$ & $1.17 \mathrm{E}-04$ & $\begin{array}{l}\mathrm{CuCl}^{+}(5.73 \mathrm{E}-5), \mathrm{CuCl}_{2}(3.70 \mathrm{E}-5), \mathrm{Cu}^{2+} \\
(1.32 \mathrm{E}-5), \mathrm{CuCl}_{3}^{-}(7.14 \mathrm{E}-6)\end{array}$ & $\mathrm{CuCl}_{3}{ }^{2-}(1.14 \mathrm{E}-4), \mathrm{CuCl}_{2}^{-}(2.87 \mathrm{E}-6)$ \\
\hline $\mathrm{Fe}$ & 8.87E-02 & $\begin{array}{l}\mathrm{FeCl}_{2}^{+}(5.23 \mathrm{E}-2), \mathrm{FeCl}_{3}(1.78 \mathrm{E}-2), \mathrm{FeCl}^{2+} \\
(1.47 \mathrm{E}-2), \mathrm{FeCl}_{4}^{-}(1.95 \mathrm{E}-3), \mathrm{FeHSO}_{4}{ }^{2+} \\
(1.63 \mathrm{E}-3)\end{array}$ & $\begin{array}{l}\mathrm{FeCl}_{2}(4.39 \mathrm{E}-2), \mathrm{FeCl}^{+}(3.99 \mathrm{E}-2), \mathrm{Fe}^{2+} \\
(4.86 \mathrm{E}-3)\end{array}$ \\
\hline $\mathrm{Pb}$ & $4.73 \mathrm{E}-05$ & $\mathrm{PbCl}_{4}^{2-}(4.38 \mathrm{E}-5), \mathrm{PbCl}_{3}^{-}(2.75 \mathrm{E}-6)$ & $\begin{array}{l}\mathrm{PbCl}_{4}^{2-}(4.35 \mathrm{E}-5), \mathrm{PbCl}_{3}^{-}(2.91 \mathrm{E}-6), \\
\mathrm{PbCl}_{2}(7.31 \mathrm{E}-7)\end{array}$ \\
\hline $\mathrm{Zn}$ & $2.07 E-04$ & $\mathrm{ZnCl}_{4}{ }^{2-}(1.91 \mathrm{E}-4), \mathrm{ZnCl}_{3}^{-}(1.30 \mathrm{E}-5)$ & $\mathrm{ZnCl}_{4}{ }^{2-}(1.90 \mathrm{E}-4), \mathrm{ZnCl}_{3}^{-}(1.37 \mathrm{E}-5)$ \\
\hline
\end{tabular}

In addition, the saturation index (SI) for a number of minerals was determined using the expression:

$$
S I=\log Q / K
$$

where $\mathrm{Q}$ and $\mathrm{K}$ are the activity quotient and the equilibrium formation constant of the respective mineral. Values equal to 0 indicate saturation with respect to a mineral whereas SI $>0$ and $\mathrm{SI}<0$ reflect supersaturation and undersaturation respectively.

In surficial waters in equilibrium with the atmosphere, barite and silica phases (quartz, tridymite, chalcedony, cristobalite and amorphous silica) are calculated to be slightly supersaturated. We nevertheless favor the presence of cristobalite, following the XRD results of the sediments and the altered assemblage reported by Hedenquist et al. (1993). In both cases, anhydrite and gypsum are computed slightly undersaturated. We calculated SI at 30 
${ }^{\circ} \mathrm{C}, 100{ }^{\circ} \mathrm{C}, 200{ }^{\circ} \mathrm{C}$ and $300{ }^{\circ} \mathrm{C}$ to assess the effect of temperature on the precipitating phases. No change occur at $30{ }^{\circ} \mathrm{C}$ and $100{ }^{\circ} \mathrm{C}$. At $200{ }^{\circ} \mathrm{C}$, only quartz, tridymite and chalcedony are supersaturated. Quartz remains the only saturated phase at $300{ }^{\circ} \mathrm{C}$. It should be noted that Albearing minerals such as diaspore, boehmite and gibbsite, as well as alunite, show SI tending towards 0 , following their retrograde solubility. This is an important fact, confirming the assumption that alunite plays a role in sealing the system at depth, where these higher temperatures exist. Natroalunite saturation at lake temperature is observed in the sediments and suspended particles, although not confirmed due to lack of thermodynamic data.

Calculations show that F0 pool is supersaturated with silica (quartz, tridymite, chalcedony, cristobalite and amorphous silica), with all the sulfates predicted close to saturation in crate lake water far from saturation $(\log \mathrm{Q} / \mathrm{K}<1.8)$. This is in line with the ETR calculated above, showing Si only to be precipitating.

\subsubsection{Speciation and saturation of deeper reduced waters}

When modelling the speciation at the lake bottom, we used $\mathrm{R}_{\mathrm{H}}\left(\mathrm{R}_{\mathrm{H}}=\log \left(f \mathrm{H}_{2} / f \mathrm{H}_{2} \mathrm{O}\right) \approx \log \right.$ $\left(x_{\mathrm{H}_{2}} / x_{\mathrm{H} 2 \mathrm{O}}\right)$, (Giggenbach, 1987)) measured in White Island fumarolic gases to control the redox state. We took an average value of $\mathrm{R}_{\mathrm{H}}=-3.5$ from fumarole $\mathrm{F} 0$ gases. The computed speciation of chloride and most of the major cations is not affected greatly by changes in redox state. In contrast, the distribution of sulfur species changes drastically, with $\mathrm{H}_{2} \mathrm{~S}_{(\mathrm{aq})}$ becoming the dominant phase. The dominant $\mathrm{Fe}^{(\mathrm{III})}$ species in oxidized waters are replaced by $\mathrm{Fe}^{(\mathrm{II})}$ species, as shown in Table 4-5. This table also shows that $\mathrm{Ag}, \mathrm{Zn}$ and $\mathrm{Pb}$ speciation is not affected by changes in redox state, in contrast to $\mathrm{Cu}, \mathrm{Fe}$ and $\mathrm{As}$. $\mathrm{As}^{(\mathrm{V})}$ species are replaced by $\mathrm{As}^{(\mathrm{III})}$ arsenous acid $\left(\mathrm{As}(\mathrm{OH})_{3}\right.$, whereas $\mathrm{Cu}^{(\mathrm{I})}$ chloride complexes become the dominant species.

The predicted saturated species in the more reduced environment present at the lake bottom vary greatly, with precipitation of various metal sulfides. Orpiment and realgar are highly supersaturated, with SI of 28 and 12 respectively. These really high values suggest that additional minerals such as arsenolite or arsenate, not taken into account in our calculations, may be saturated. Pyrite, bornite and covellite are supersaturated (SI of 2.7, 1.8 and 1.4 respectively), chalcopyrite and chalcocite are slightly supersaturated (SI of 0.5 and 0.4 respectively), whereas galena, sphalerite and pyrrhotite and undersaturated (SI < -3). Elemental sulfur is also predicted to be precipitating $(\mathrm{SI}=0.3)$ under these conditions, in agreement with the observed sulfur globules.

The results from these thermodynamic calculations generally agree with the minerals observed in the suspended particles and sediments. We should note the absence of Ag-rich minerals in the calculations despite the high enrichment in both the sediments and ash. Sulfur and alunite are other species observed in sediments and suspended particles (alunite only) that are not predicted in the computations. This disagreement might reflect incorrect thermodynamic database. It may also emphasize the active character of the crater lake, with different redox and temperature conditions with depth, ignored in our modelling. It is worth noting that Na-bearing alunite (i.e. natroalunite) may also be forming instead of the pure phase. The chemistry of sulfur in hyperacidic crater lakes is rather complex and has been detailed in several studies (Takano, 1987; Takano and Watanuki, 1990; Takano et al., 1994; 
Delmelle and Bernard, 2015). Elemental sulfur is thought to form through deposition reactions involving magmatic $\mathrm{SO}_{2}$ and $\mathrm{H}_{2} \mathrm{~S}$, and/or intermediate sulfur species such as polythionates, polysulfides and thiosulfate (see Figure 4-11).

The presence of pyrite in the ash erupted in April 2016 and on the sulfur globules reflects reducing environment underneath the lake. Pyrite precipitation in reduced environment has been shown to incorporate various metals as minor elements (Fleischer, 1955; Craw et al., 2003; Yamaguchi and Ohmoto, 2006; Berner et al., 2013), and might explain the strong enrichment of the $\mathrm{Tl}, \mathrm{Pb}, \mathrm{Bi}, \mathrm{Co}, \mathrm{Ni}$, $\mathrm{Cu}, \mathrm{Ag}, \mathrm{Cd}, \mathrm{Re}$ and $\mathrm{Au}$ in the dark globules (

Table 4-3). The absence of any other metal sulfides may reflect pyrite precipitation at temperatures slightly over $250{ }^{\circ} \mathrm{C}$, at which $\mathrm{FeS}_{2}$ becomes less soluble in contrast to other sulfides, which solubility increases (Reed and Palandri, 2006). It is also possible that we did not observe sulfides other than pyrite due to their low amount. This is especially relevant given that $\mathrm{Fe}$ concentration in the lake water is more than two orders of magnitude higher than that of $\mathrm{Cu}$ and $\mathrm{Pb}$ (Table 4-1).

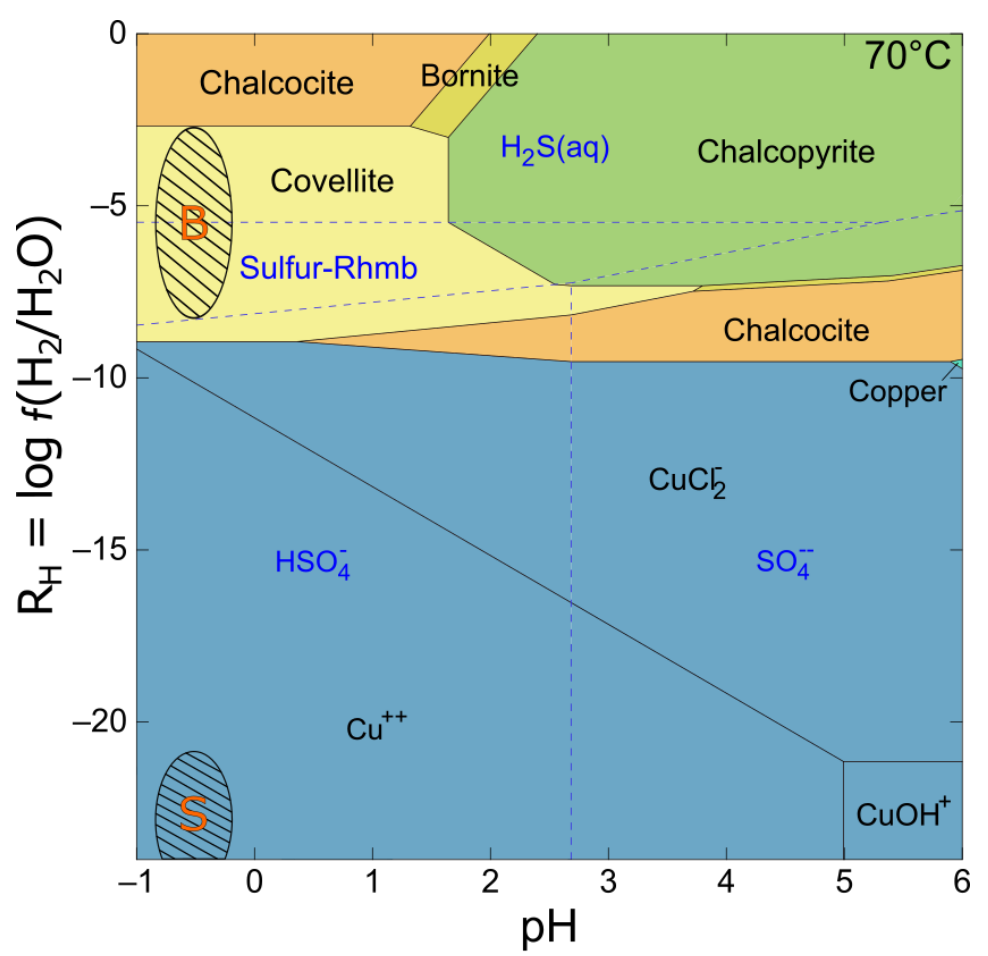

Figure 4-10: $\mathrm{R}_{\mathrm{H}} \mathrm{pH}$ stability diagram of various $\mathrm{Cu}$ sulfides. The fields representing the oxidized surficial waters (S) and the reduced environment at the lake bottom (B) are shown. The stability of sulfur species is also represented to emphasize coprecipitation of sulfides and elemental sulfur.

The elevated metal concentrations of sulfur spherules and the predicted precipitation of sulfides in reduced environment nevertheless highlights removal of metals from these fluids deeper in the system. Figure 4-10 shows the stability field of $\mathrm{Cu}$ sulfides as a function of the redox and acidity of the crater lake. Covellite is the stable mineral in the reduced environment at the lake bottom, coprecipitating with elemental sulfur. In contrast, sulfide minerals are not stable in the oxidized surficial waters. 
Another potential mechanism (Figure 4-11) responsible for the metal enrichment of elemental sulfur arises from the properties of sulfur in aqueous solutions. In fact, given the point of zero charge (pzc) of sulfur at $\mathrm{pH}=2.3$ (Garcia and Druschel, 2014, and references therein), the surface of sulfur molecules will be positively charged in the highly acidic crater lake waters. Adsorption of neutral and negatively charged metal chloride complexes, predominant at the bottom of the lake, is thus promoted. Considering that hydrolysis of elemental sulfur is an ongoing reaction (although slow at $\mathrm{T}<150{ }^{\circ} \mathrm{C}$, (Ellis and Giggenbach, 1971)), small amounts of $\mathrm{H}_{2} \mathrm{~S}$ will be present in the vicinity of elemental sulfur (i.e. at the sulfur-water interface). Metal sulfides are formed through reaction of the adsorbed metals and the $\mathrm{H}_{2} \mathrm{~S}$ produced.

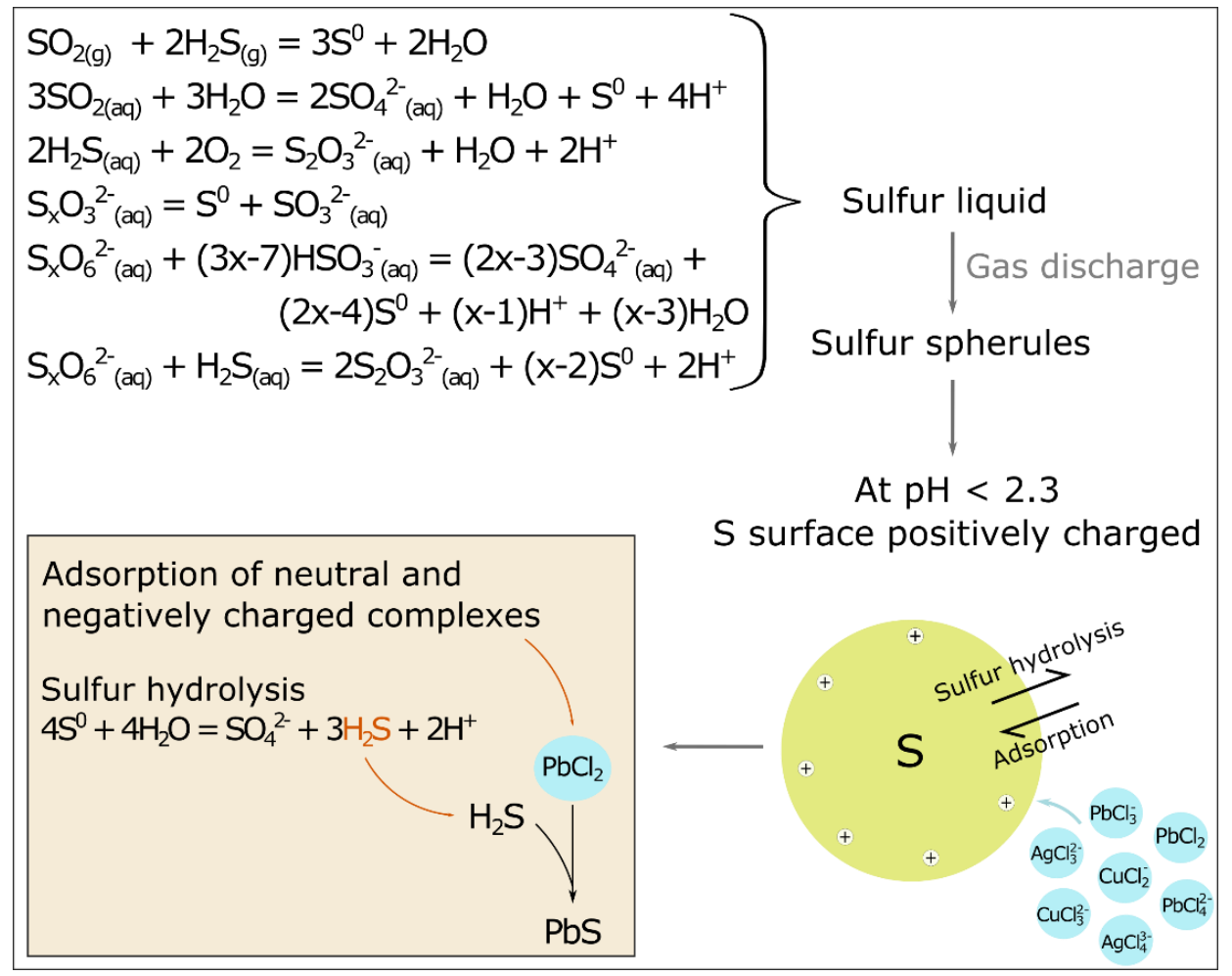

Figure 4-11: Formation of metal sulfides on the surface of sulfur spherules

\subsection{Conclusions}

The chemistry of the crater lake waters indicates that high-temperature magmatic volatile input is responsible for their strong acidity, in turn leading to water-rock interactions with the host rock. Congruent dissolution of $\sim 100 \mathrm{~g}$ of dacite per liter of water explains the major cation concentrations in solution. It is also responsible for the formation of residual vuggy silica associated with hyperacidic crater lakes (Christenson and Wood, 1993; Rowe and Brantley, 1993; Wood, 1994; van Hinsberg et al., 2010b). Species such as B, As, Hg, Tl, Au, $\mathrm{Bi}, \mathrm{Sb}, \mathrm{As}, \mathrm{Zn}$ are enriched in the lake waters through magmatic gas input.

The magmatic gases injected at subaqueous vents favor the formation and accumulation of a body of molten sulfur at the bottom of the lake, effectively scavenging chalcophile elements ( $\mathrm{Te}, \mathrm{Se}, \mathrm{Cu}, \mathrm{As}, \mathrm{Ag}, \mathrm{Cd}, \mathrm{Sb}, \mathrm{Re}, \mathrm{Au}$ ). Reduced conditions in this deep environment are 
responsible for sulphide precipitation, as evidenced by pyrite crystals on sulfur spherules. Adsorption of metal chloride complexes on the surface of positively charged sulfur spherules and subsequent reactions with $\mathrm{H}_{2} \mathrm{~S}$ could also explain the elevated metal content.

Saturated phases in the oxidized surficial waters determined by thermodynamic modelling are in agreement with the observed minerals in suspended particles and sediments. Silica, most likely in the form of cristobalite, anhydrite, gypsum and barite are saturated at the observed temperature. Saturation of alunite occurs deeper in the system, at higher temperature, as evidenced in the April 2016 ash. Precipitation of anhydrite and alunite/natroalunite from fluids recirculating within the porous rocks beneath the lake is an efficient mechanism for sealing the system, with implications on generating phreatic eruptions.

Sulfur is predicted to precipitate in the deeper, more reduced environment, together with metal sulfides. The low enrichment factor of copper in the lake waters and the saturation of bornite, covellite, chalcocite and chalcopyrite in this more reduced environment strongly suggest precipitation at depth. Together with the assemblage alunite-cristobalite-pyrite and the intense alteration of the host rock, the predicted copper precipitation is reminiscent of conditions occurring around "high sulfidation" ore depositing environments (Stoffregen, 1987; White and Hedenquist, 1990; Izawa, 1991; Hedenquist et al., 1993; Hedenquist et al., 1994b). 


\section{Chapter 5: Transport and deposition of metals by volcanic gases}

\subsection{Introduction}

After highlighting the role of magmatic gases in enriching crater lake waters and hydrothermal fluids in metals, we now focus on the gaseous phase itself. In this chapter, we follow the path of magmatic gases throughout the hydrothermal system and out to the surface as fumaroles. Which metals are present, at what concentration, and which ligand are they complexed with? We also explore the effects of mixing with the cool and oxidized atmosphere.

The path of magmatic gases after their exsolution from the magma is rather chaotic: they make their way through porous fractured rock, hot and acidic brine, mix with cool meteoric water, each time a little altered by such interactions. All of these processes are imprinted in the composition of the volcanic gases emitted at the surface. Fumaroles have long been of interest to volcanologists, as they carry valuable information on the magma at depth. Sadao Matsuo, a Japanese pioneer gas geochemist, described volcanic gases as "a telegram from the Earth's interior". The development of sampling and analytical methods enables complete gas analyses: from major elements to minor and trace, organic species and even isotopes (Giggenbach, 1975a, 1982; Tassi et al., 2005; Vaselli et al., 2006; Tassi et al., 2009). This provides a snapshot of the state of the magma at depth, together with a picture of the hydrothermal system encountered by the gases on their way to the surface. Some volcanoes, such as Etna, Vulcano, and White Island, have been extensively studied over the past few decades. The long trend datasets enable scientists to discern a certain link between volcanic activity and gas composition (Giggenbach, 1975b, 1983; Capasso et al., 1992; Chiodini et al., 1993; Chiodini et al., 1995; Capasso et al., 1999). Magmatic components $\left(\mathrm{CO}_{2}, \mathrm{CO}, \mathrm{H}_{2}, \mathrm{SO}_{2}\right)$ were identified, as opposed to their hydrothermal counterparts $\left(\mathrm{CH}_{4}, \mathrm{H}_{2} \mathrm{~S}\right)$. Variations of elemental ratios (e.g., $\mathrm{SO}_{2} / \mathrm{H}_{2} \mathrm{~S}, \mathrm{CO}_{2} / \mathrm{CH}_{4}$ ) thus highlight predominance of either endmember. Based on the pressure dependence of elements' solubility (Carroll and Webster, 1994), we can also follow the path of magma as it rises into a volcanic conduit. $\mathrm{CO}_{2}$ and $\mathrm{H}_{2} \mathrm{O}$ are the first species to exsolve from the melt, followed by sulfur and the halogens as pressure decreases. Monitoring volcanic gases at the surface thus tells us about magma movements at depth (Tassi et al., 2005; Aiuppa et al., 2007; Tassi et al., 2009).

Pressure, temperature and redox variations as the gases arrive at the surface lead to mineral deposition in the form of sublimates. Such encrustations found around high-temperature fumaroles are of importance as they provide clues about metal transport by volcanic gases (Le Guern and Bernard, 1982; Symonds et al., 1987; Quisefit et al., 1989; Bernard et al., 1990; Symonds et al., 1992; Getahun et al., 1996; Cheynet et al., 2000; Africano et al., 2002; Wahrenberger et al., 2002; Zelenski and Bortnikova, 2005). These studies reveal the existence of exotic minerals, found exclusively in these environments, and emphasizing the role of major ligands in forming complexes with metals.

Despite their trace concentrations, many of these metal species are toxic, and as we saw in the last chapter, enriched in the gas phase. Furthermore, ancient dissected volcanoes show us that extreme deposition of economically valuable metals $(\mathrm{Cu}, \mathrm{Au}, \mathrm{Ag}, \mathrm{Mo})$ is taking place at depth, over magmatic systems' lifetime (Henley and Berger, 2013). 
In this chapter, we characterize the volatile transport of metals at White Island, focusing on fumarolic gases emitted across the crater floor. We determine the metal content of fumarolic discharges and how it is affected by variations of the major species with time. We also describe minerals precipitating from these gases and perform thermodynamic calculations to constrain the speciation of gaseous metal species.

\subsection{Sampling and analytical methods}

Three different fumaroles located across the crater floor as shown in Figure 5-1, were sampled during the study. Fumarole F9a, also called Noisy Nellie, is an old vent, in which the temperature and flow were previously much higher in the 1970's and 1980's. The flow is currently very low with a temperature around boiling point. F13a is also an old fumarole, which temperature has been fluctuating between $100^{\circ} \mathrm{C}$ and $120^{\circ} \mathrm{C}$ since the 1980 's. F0, the youngest fumarole, first appeared in 2005 during the first cycle of crater lake growth (Christenson et al., 2017). It also had the highest temperature amongst the accessible fumaroles, at around $160{ }^{\circ} \mathrm{C}$ at the beginning of the study, rising to $\sim 190{ }^{\circ} \mathrm{C}$ in June 2016 . Despite their similar distance from the main vent, F0 has a stronger magmatic component, highlighting preferential pathway from the main conduit (Christenson et al., 2017). Sublimates were exclusively collected from this vent, due to its higher temperature and flux.

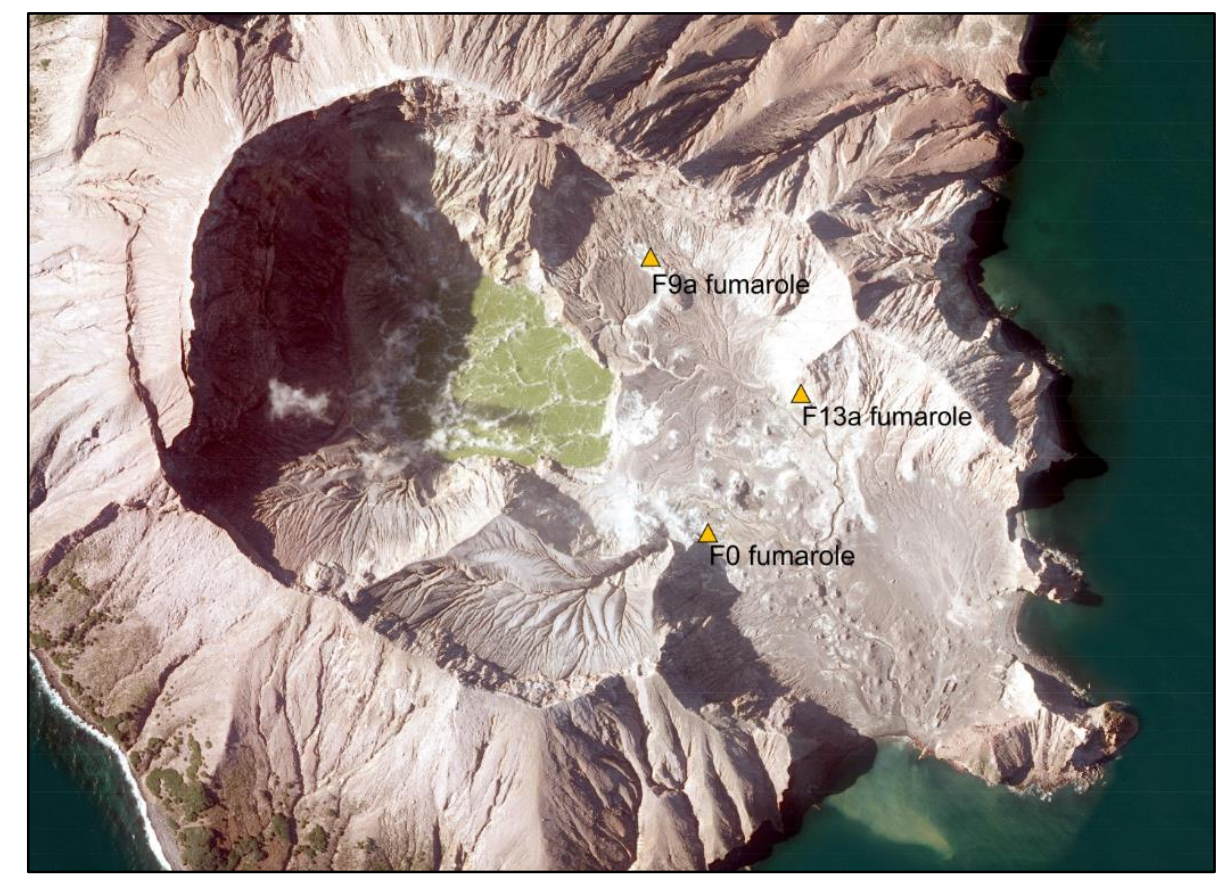

Figure 5-1: Aerial picture showing the locations of the three fumaroles sampled (source LINZ).

Two different types of samples were collected in order to obtain the bulk composition as well as the trace element concentrations. A Giggenbach flask is used to collect the former, whereas condensates allow determination of the latter (Figure 5-2). Prior to a collecting trip, the Giggenbach bottles are filled with a known volume of $6 \mathrm{~N} \mathrm{KOH}$ and subsequently 
evacuated. During sampling, soluble and acidic species (including $\mathrm{H}_{2} \mathrm{O}$ ) react with the caustic solution, thus increasing the liquid fraction. The non-soluble and non-reactive species $(\mathrm{CO}$, $\mathrm{H}_{2}, \mathrm{CH}_{4}, \mathrm{He}, \mathrm{N}_{2}$ ) occupy the head-space. The gaseous fraction is analyzed by gas chromatography whereas water and reactive species contents are determined by wet chemistry and ion chromatography. These analyses are done at GNS Science, Lower Hutt, as part of the GeoNet volcanic hazards monitoring. Condensates were sampled using a glass condenser, immersed in ice-water to ensure efficient condensation. After $\sim 30 \mathrm{~mL}$ of condensate was collected, the liquid was transferred to acid-cleaned Teflon bottles. The temperatures were measured at the fumarole outlet with a thermocouple. Elemental sulfur droplets deposited on the sampling train during collection were collected and analyzed following the procedure described in 4.2.2.2.
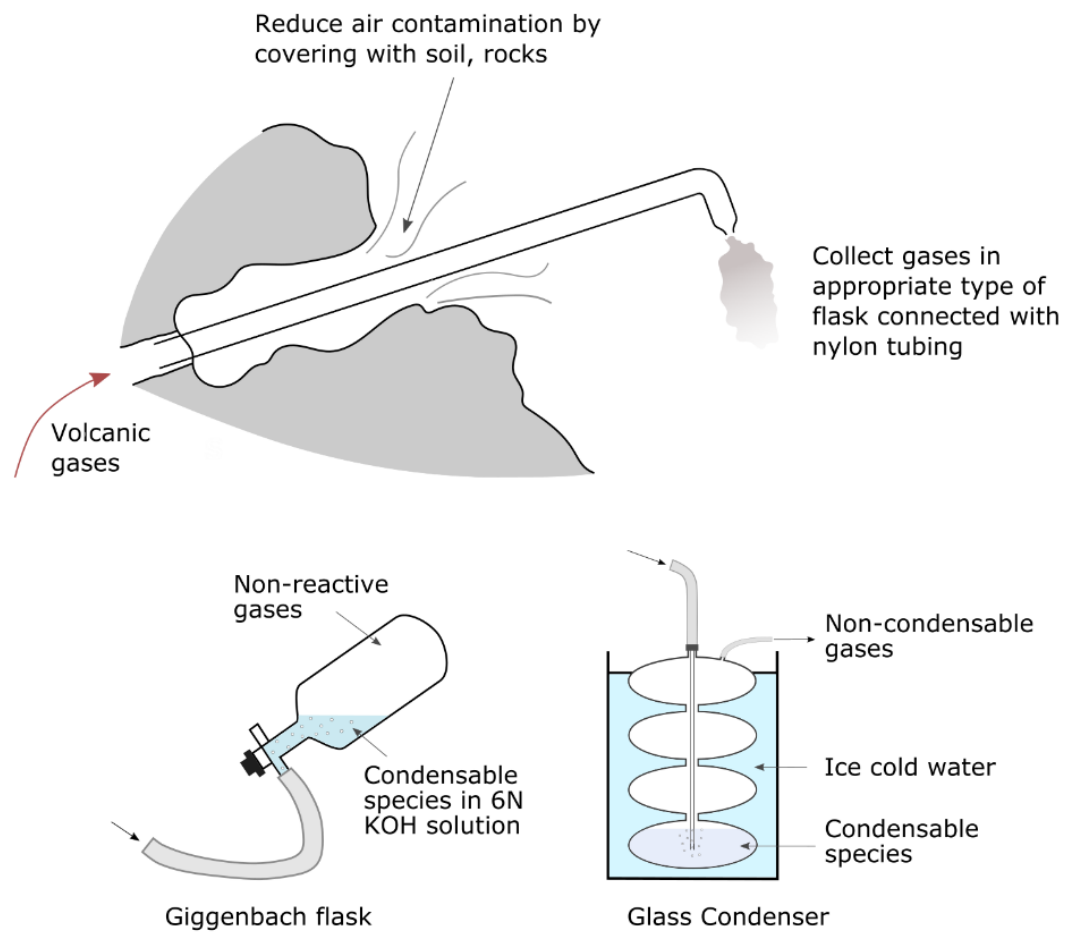

Figure 5-2: Sketch of the sampling train, showing the two types of samples collected.

The sampling train consists of a tube, made of titanium for bulk composition and silica for trace metals, inserted into the fumarole in one end, and connected to the collecting device with nylon tubing on the other end (Figure 5-2 and Figure 5-3 a). For fumaroles with a low gas flow, we dug into the fumarole to insert the tube, and covered with soil and rocks to minimize atmospheric contamination. The $\mathrm{N}_{2} / \mathrm{Ar}$ ratio is used to identify likely atmospheric contamination.

The condensates were weighed $( \pm 0.00001 \mathrm{~g})$, dried at $120{ }^{\circ} \mathrm{C}$ and subsequently digested in a

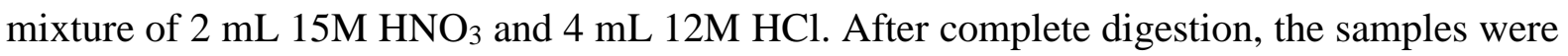
dried, refluxed in $15 \mathrm{M} \mathrm{HNO}_{3}$ and finally taken up in $10 \mathrm{~mL} 1 \mathrm{M} \mathrm{HNO}_{3}$. Appropriate dilutions for both minor and trace elements were made using $1 \% \mathrm{HNO}_{3}$. The analyses were done with 
a Thermo Scientific Element2 sector-field ICP-MS at Victoria University of Wellington, following the procedures described in 4.2.3.1.

Sublimates were collected in a silica tube inserted into fumarole F0 (Figure 5-3 b) as described by Le Guern and Bernard (1982). The tubes were $130 \mathrm{~cm}$ long, $2.1 \mathrm{~cm}$ inner diameter, with a bent section finished with a narrow mouth on the upper end. The first tube was left 20 days in the fumarole. The temperature at the inlet was $160{ }^{\circ} \mathrm{C}$ on 5 June 2015 and $168{ }^{\circ} \mathrm{C}$ on 25 June when it was collected. The second tube was inserted into the fumarole for almost 4 months, starting on 17 June 2016 (temperature inlet: $189.6{ }^{\circ} \mathrm{C}$, temperature outlet: $112.0^{\circ} \mathrm{C}$ ) and collected on 14 October (temperature inlet: $192.5^{\circ} \mathrm{C}$ ). The tube had broken, causing the small upper section to fall lower into the fumarole. The bent upper part was clogged with elemental sulfur, forming a plug of around $3 \mathrm{~cm}$ in length. The last tube (only $75 \mathrm{~cm}$ long) was put into the fumarole on 14 October 2016 and left for 2 months. During a visit on 9 November, we noticed that the thin opening on the upper part was clogged up with precipitated elemental sulfur. We broke the narrow mouth and ensured the gases were flowing freely. The temperature was $191.6^{\circ} \mathrm{C}$. We took the tube out on 20 December 2016. The temperature $\left(182^{\circ} \mathrm{C}\right)$ was measured using an infrared pyrometer, usually yielding values 2 to $10{ }^{\circ} \mathrm{C}$ lower than with a thermocouple (Brad Scott, pers. comm.). The tubes were sealed with Parafilm $\mathrm{M}^{\circledR}$ after collection to reduce contact with air. The last tube had liquid inside when opened in the laboratory, due to minor condensation after collection.

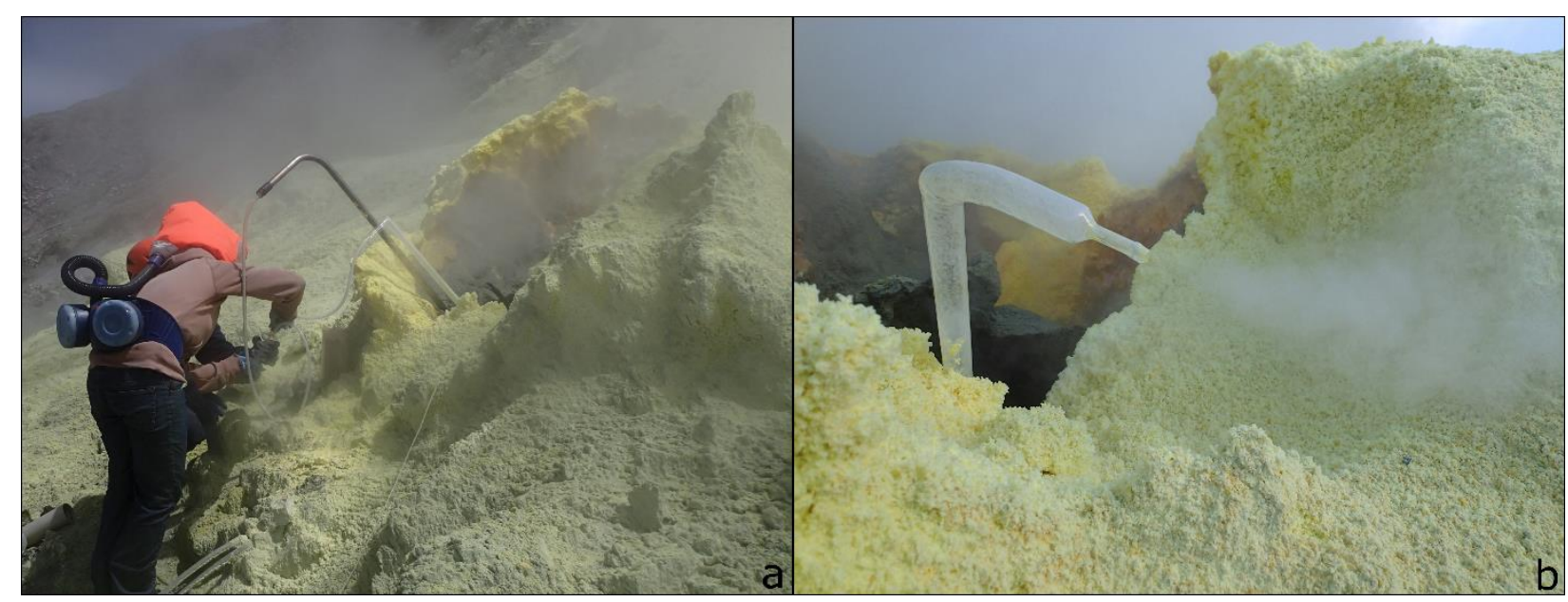

Figure 5-3: Pictures of the sampling train. a) Collection of condensate at fumarole F0 using the silica tube inserted into the vent. Note the presence of the titanium tube used to collect Giggenbach flasks. b) Silica tube inserted in F0 for sublimate collection. Photo Courtesy of GNS.

Each tube was cut into 5 to $10 \mathrm{~cm}$ sections and subsequently halved. All the cutting was done without water, using a diamond cutter to pre-cut sections, gently broken afterwards. Crystals from the tube walls were transferred onto a stub for subsequent SEM observations, using the same instrument and analytical conditions as described in 4.2.3.3.

We also collected natural incrustations by breaking a large block hanging over the fumarole outlet. These incrustations were also observed and analyzed by SEM and EDS. 


\subsection{Variations in metal content of fumarolic condensates}

\subsubsection{Chemistry of fumarolic discharges}

The composition of major species in F0 condensates highlights variations in magmatic and hydrothermal contributions (Table 5-1 and Figure 5-4). Fumarolic gases from 23 December 2014 indicates high hydrothermal contribution. This is illustrated by low sulfur oxidation state of $-0.95\left(\mathrm{~S}_{\mathrm{n}}\right.$ varies from -2 (for $\mathrm{S}^{2-}$ in $\left.\mathrm{H}_{2} \mathrm{~S}\right)$ to 4 (for $\mathrm{S}^{+4}$ in $\left.\mathrm{SO}_{2}\right)$ ), low $\mathrm{CO}_{2} / \mathrm{H}_{2} \mathrm{~S}$ and high $\mathrm{CH}_{4}$ content.

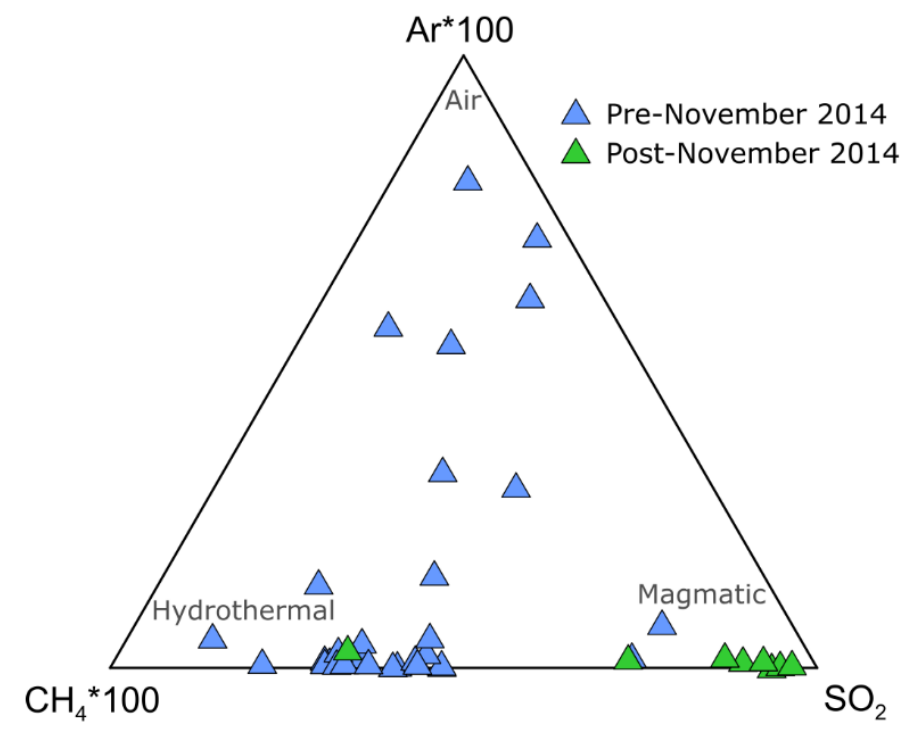

Figure 5-4: $\mathrm{SO}_{2}-\mathrm{CH}_{4} * 100-\mathrm{Ar}^{*} 100$ ternary diagram for $\mathrm{F} 0$ fumarole showing variations between magmatic and hydrothermal endmembers. The post-November 2014 sample with hydrothermal signature is the 23 December 2014 sample.

A shift towards more magmatic signature commenced in June 2015, with $S_{n}$ of 2.64, showing that $\mathrm{SO}_{2}$ was becoming the dominant sulfur species. This trend was confirmed in September and October of the same year, with $\mathrm{S}_{\mathrm{n}}>3.3$. The concurrent decrease in $\mathrm{CO}_{2} / \mathrm{SO}_{2}$ ratio may reflect less hydrothermal scrubbing, allowing a greater proportion of soluble $\mathrm{SO}_{2}$ to escape to the atmosphere. At high temperature, such "scrubbing" is due to the reactivity of $\mathrm{SO}_{2}$ according to (Kusakabe et al., 2000),

$$
4 \mathrm{H}_{2} \mathrm{O}_{(l)}+4 \mathrm{SO}_{2(a q)}=\mathrm{H}_{2} \mathrm{~S}_{(a q)}+3 \mathrm{H}^{+}+3 \mathrm{HSO}_{4}^{-}
$$

At low temperature and elevated redox potentials, the $\mathrm{SO}_{2}$ hydrolysis may proceed as,

$$
3 \mathrm{H}_{2} \mathrm{O}_{(l)}+3 \mathrm{SO}_{2(a q)}=2 \mathrm{HSO}_{4}^{-}+\mathrm{S}^{0}+2 \mathrm{H}^{+}
$$

June 2015 was also the beginning of a heating period, with gas temperature rising above the average $160{ }^{\circ} \mathrm{C}$ measured over the previous year. This continued to a maximum of $192.5{ }^{\circ} \mathrm{C}$ 
in October 2016. A rapid shift towards hydrothermal signature was nevertheless observed. The November 2016 sample has a $\mathrm{S}_{\mathrm{n}}$ value of 0.94 indicating increasing $\mathrm{H}_{2} \mathrm{~S}$ content, despite the elevated temperature of $191.6{ }^{\circ} \mathrm{C}$. We should note that the crater lake was drying out during the same period. The increasing hydrothermal signature may thus reflect evaporation of the hydrothermal system due to increasing heat input, rather than a decrease in the magmatic contribution. Remobilization of elemental sulfur during heating, for example, would increase $\mathrm{H}_{2} \mathrm{~S}$ content of the gases at the expense of $\mathrm{SO}_{2}$ following (Mizutani and Sugiura, 1966):

$$
3 S^{0}+H_{2} \mathrm{O}=2 \mathrm{H}_{2} \mathrm{~S}_{(g)}+\mathrm{SO}_{2(g)}
$$

Two moles of $\mathrm{H}_{2} \mathrm{~S}$ for one mole of $\mathrm{SO}_{2}$ result from this reaction, leading to gases with a hydrothermal signature despite increasing input of hotter magmatic gases.

Table 5-1: Composition of White Island fumarolic gases.

\begin{tabular}{|c|c|c|c|c|c|c|c|c|c|c|c|}
\hline Vent & Fo & FO & FO & FO & F0 & Fo & FO & $\begin{array}{l}\text { Donald } \\
\text { Mound* }\end{array}$ & F9a & F9a & F13a \\
\hline \multirow{2}{*}{ Date } & $23 \mathrm{Dec}$ & 5 Jun & 30 Sep & 15 Oct & $23 \mathrm{Dec}$ & 14 Oct & $9 \mathrm{Nov}$ & 1988 & $23 \mathrm{Dec}$ & $9 \mathrm{Nov}$ & $9 \mathrm{Nov}$ \\
\hline & 2014 & 2015 & 2015 & 2015 & 2015 & 2016 & 2016 & & 2014 & 2016 & 2016 \\
\hline $\mathrm{T}^{\circ} \mathrm{C}$ & 160.7 & 160 & 174 & 174 & 178.6 & 192.5 & 191.6 & 495 & 100.3 & 99.7 & 103.8 \\
\hline \multicolumn{12}{|c|}{ Major elements (mol\%) } \\
\hline $\mathrm{H}_{2} \mathrm{O}$ & 92.22 & 89.18 & 85.47 & 83.12 & 87.88 & 89.39 & 90.33 & 94.44 & - & - & - \\
\hline $\mathrm{CO}_{2}$ & 6.18 & 8.78 & 12.34 & 13.53 & 9.85 & 8.52 & 7.82 & 4.00 & - & - & - \\
\hline $\mathrm{SO}_{2}$ & 0.074 & 0.82 & 1.47 & 1.28 & 0.81 & 0.71 & 0.42 & 0.59 & - & - & - \\
\hline $\mathrm{H}_{2} \mathrm{~S}$ & 0.35 & 0.24 & 0.12 & 0.15 & 0.35 & 0.32 & 0.44 & 0.17 & - & - & - \\
\hline St & 0.42 & 1.06 & 1.59 & 1.43 & 1.15 & 1.03 & 0.86 & 0.75 & - & - & - \\
\hline Sn & -0.95 & 2.64 & 3.55 & 3.38 & 2.2 & 2.15 & 0.94 & - & - & - & - \\
\hline $\mathrm{HCl}$ & 0.82 & 0.80 & 0.52 & 1.73 & 1.04 & 0.97 & 0.93 & 0.60 & - & - & - \\
\hline $\mathrm{HF}$ & $3.6 \mathrm{E}-04$ & $1.4 \mathrm{E}-04$ & $6.1 \mathrm{E}-04$ & 8.9E-04 & $1.0 \mathrm{E}-03$ & $5.0 \mathrm{E}-04$ & $1.3 \mathrm{E}-03$ & $9.8 \mathrm{E}-03$ & - & - & - \\
\hline $\mathrm{H}_{2}$ & $3.2 \mathrm{E}-01$ & $1.0 \mathrm{E}-01$ & 5.3E-05 & $1.1 \mathrm{E}-01$ & $1.8 \mathrm{E}-04$ & $2.0 \mathrm{E}-04$ & $1.3 \mathrm{E}-04$ & $2.5 \mathrm{E}-02$ & - & - & - \\
\hline $\mathrm{N}_{2}$ & $3.3 \mathrm{E}-02$ & 7.7E-02 & $8.4 \mathrm{E}-02$ & $8.4 \mathrm{E}-02$ & 7.7E-02 & 8.6E-02 & $6.0 \mathrm{E}-02$ & 1.7E-02 & - & - & - \\
\hline $\mathrm{CH}_{4}$ & $1.5 \mathrm{E}-03$ & $9.0 \mathrm{E}-04$ & $7.5 \mathrm{E}-04$ & 4.1E-04 & $6.0 \mathrm{E}-04$ & $9.9 \mathrm{E}-04$ & $1.5 \mathrm{E}-03$ & 4.6E-04 & - & - & - \\
\hline $\mathrm{CO}$ & $5.8 \mathrm{E}-03$ & $2.5 \mathrm{E}-06$ & 4.2E-06 & $1.8 \mathrm{E}-06$ & - & - & - & $1.5 \mathrm{E}-04$ & - & - & - \\
\hline $\mathrm{He}$ & $3.3 \mathrm{E}-07$ & 4.1E-05 & $5.4 \mathrm{E}-05$ & 5.1E-05 & 4.1E-05 & 3.7E-05 & $2.4 \mathrm{E}-05$ & $1.4 \mathrm{E}-05$ & - & - & - \\
\hline $\mathrm{O}_{2}$ & - & $1.6 \mathrm{E}-03$ & $1.4 \mathrm{E}-03$ & $1.4 \mathrm{E}-03$ & - & - & - & - & - & - & - \\
\hline $\mathrm{Ar}$ & 7.7E-05 & $1.3 \mathrm{E}-04$ & $1.2 \mathrm{E}-04$ & $1.2 \mathrm{E}-04$ & $1.3 \mathrm{E}-04$ & $1.8 \mathrm{E}-04$ & 1.1E-04 & - & - & - & - \\
\hline $\mathrm{HBr}$ & 4.9E-05 & $1.2 \mathrm{E}-04$ & $2.4 \mathrm{E}-04$ & $4.8 \mathrm{E}-04$ & $4.0 \mathrm{E}-04$ & $5.3 \mathrm{E}-03$ & $3.8 \mathrm{E}-04$ & - & - & - & - \\
\hline \multicolumn{12}{|c|}{ Minor and trace elements (ng.g ${ }^{-1}$ ) } \\
\hline B & 32440 & 31549 & 16536 & 23102 & 19005 & 19702 & 11527 & 35100 & 6.65 & 2.40 & 176 \\
\hline $\mathrm{Na}$ & 77.13 & 206.1 & 1989 & 1277 & 21253 & 20642 & 514.5 & 870 & - & - & - \\
\hline $\mathrm{Ca}$ & 1409 & 1197 & 1757 & 1706 & 19811 & 21136 & 724.6 & - & 94.6 & - & - \\
\hline $\mathrm{Rb}$ & 0.06 & 0.05 & 1.98 & 1.34 & 17.17 & 12.65 & 0.78 & 2 & 0.13 & 0.37 & nd \\
\hline $\mathrm{Sr}$ & 0.26 & 0.63 & 11.36 & 8.28 & 84.35 & - & - & - & 0.19 & - & - \\
\hline $\mathrm{Zr}$ & 0.21 & 0.36 & 1.62 & 1.33 & 10.14 & 53.37 & 1.81 & - & 0.03 & 0.06 & 0.91 \\
\hline Mo & 0.16 & 0.10 & 0.59 & 1.48 & 0.59 & 0.86 & 0.76 & 3 & 0.02 & 0.11 & nd \\
\hline
\end{tabular}




\begin{tabular}{|c|c|c|c|c|c|c|c|c|c|c|c|}
\hline Vent & F0 & F0 & F0 & F0 & F0 & F0 & F0 & $\begin{array}{l}\text { Donald } \\
\text { Mound* }\end{array}$ & F9a & F9a & F13a \\
\hline Date & $\begin{array}{c}23 \mathrm{Dec} \\
2014\end{array}$ & $\begin{array}{l}5 \text { Jun } \\
2015\end{array}$ & $\begin{array}{c}30 \text { Sep } \\
2015\end{array}$ & $\begin{array}{c}15 \text { Oct } \\
2015\end{array}$ & $\begin{array}{c}23 \mathrm{Dec} \\
2015\end{array}$ & $\begin{array}{c}14 \text { Oct } \\
2016\end{array}$ & $\begin{array}{l}9 \text { Nov } \\
2016\end{array}$ & 1988 & $\begin{array}{c}23 \mathrm{Dec} \\
2014\end{array}$ & $\begin{array}{l}9 \text { Nov } \\
2016\end{array}$ & $\begin{array}{l}9 \text { Nov } \\
2016\end{array}$ \\
\hline $\mathrm{Ag}$ & 0.05 & 0.07 & 0.19 & 0.33 & 0.40 & 0.38 & 0.08 & nd & 0.01 & 0.01 & 0.18 \\
\hline $\mathrm{Cd}$ & 0.01 & 0.01 & 0.10 & 0.18 & 0.21 & 0.28 & 0.04 & 2 & 0.003 & 0.01 & 0.14 \\
\hline In & 0.00 & 0.00 & 0.03 & 0.01 & 0.26 & 0.79 & 0.03 & - & nd & nd & 0.00 \\
\hline Sn & 5.32 & 7.10 & 31.36 & 18.13 & 45.69 & 241.1 & 52.01 & - & 0.02 & 0.04 & 0.48 \\
\hline $\mathrm{Sb}$ & 97.49 & 285.3 & 114.8 & 133.2 & 90.09 & 392.8 & 205.9 & 80 & 0.04 & 0.19 & 2.67 \\
\hline $\mathrm{Te}$ & 10.08 & 3.52 & 1.10 & 3.13 & 15.97 & 6.93 & 46.11 & 60 & 0.56 & 2.96 & 10.4 \\
\hline $\mathrm{Ba}$ & 1.50 & 0.85 & 97.21 & 37.67 & 186.6 & 508.4 & 97.29 & - & 0.83 & 2.96 & 16.6 \\
\hline Sm & 0.00 & nd & 0.08 & 0.06 & 0.68 & 0.95 & 0.05 & - & nd & 0.001 & 0.01 \\
\hline $\mathrm{Yb}$ & 0.00 & nd & 0.04 & 0.03 & 0.37 & 0.57 & 0.02 & - & nd & 0.001 & 0.01 \\
\hline W & 0.13 & 0.16 & 0.14 & 0.32 & 0.13 & 0.13 & 0.16 & - & 0.02 & 0.02 & 0.04 \\
\hline $\mathrm{Au}$ & 0.05 & nd & 0.02 & 0.03 & 0.02 & 0.03 & 0.04 & nd & 0.01 & 0.02 & 0.04 \\
\hline $\mathrm{Tl}$ & 0.01 & 0.01 & 0.21 & 0.22 & 1.68 & 8.15 & 0.34 & 70 & 0.01 & 0.02 & 0.03 \\
\hline $\mathrm{Pb}$ & 0.96 & 1.51 & 22.67 & 2.56 & 16.49 & 24.64 & 3.28 & 180 & 0.79 & 0.46 & 6.04 \\
\hline $\mathrm{Bi}$ & 0.37 & 0.59 & 5.23 & 3.20 & 18.99 & 165.0 & 3.49 & 70 & 0.02 & 0.02 & 0.06 \\
\hline $\mathrm{Mg}$ & 24.41 & 47.72 & 664.8 & 621.5 & 6428 & 5914 & 178.3 & 460 & 20.7 & 11.3 & 76.2 \\
\hline $\mathrm{Al}$ & 579.1 & 52.95 & 3747 & 2163 & 29154 & 14922 & 2192 & 3460 & 52.9 & 18.1 & 150 \\
\hline Sc & 0.02 & 0.01 & 0.79 & 0.74 & 8.15 & 7.50 & 0.57 & 10 & 0.002 & 0.01 & 0.04 \\
\hline $\mathrm{Ti}$ & 332.0 & 5.13 & - & - & - & - & - & - & - & - & - \\
\hline V & 0.20 & 0.06 & 26.77 & 10.82 & 111.4 & 59.17 & 29.61 & 70 & 0.04 & 0.05 & 0.42 \\
\hline $\mathrm{Cr}$ & 1.73 & 0.35 & 37.50 & 114.0 & 104.6 & 68.27 & 10.50 & 30 & 0.18 & 0.69 & 1.18 \\
\hline $\mathrm{Mn}$ & 0.98 & 0.22 & 18.61 & 30.21 & 157.0 & 277.4 & 8.73 & - & 0.64 & 2.95 & 1.38 \\
\hline $\mathrm{Fe}$ & 60.18 & 8.81 & 555.3 & 849.9 & 2769 & 5064 & 383.2 & 950 & 75.46 & 68.4 & 155 \\
\hline Co & 0.05 & 0.02 & 0.27 & 2.24 & 0.83 & 3.76 & 0.42 & - & 0.02 & 0.05 & 0.09 \\
\hline $\mathrm{Ni}$ & 3.41 & 1.21 & 18.11 & 206.7 & 10.32 & 40.22 & 10.46 & 20 & 0.42 & 3.10 & 2.86 \\
\hline $\mathrm{Cu}$ & 4.95 & 4.22 & 92.58 & 54.42 & 11.79 & 19.18 & 38.83 & 30 & 0.82 & 1.49 & 13.0 \\
\hline $\mathrm{Zn}$ & 49.39 & 8.42 & 250.4 & 82.50 & 97.27 & 66.16 & 15.09 & 1200 & 7.56 & 9.78 & 20.70 \\
\hline $\mathrm{Ga}$ & 1.20 & 0.82 & 7.98 & 3.78 & 53.20 & 261.5 & 6.84 & - & nd & 0.02 & 0.06 \\
\hline K & 29.71 & 20.19 & 1236 & 980.1 & 8853 & 1064 & 854.7 & - & 23.5 & 97.9 & 92.4 \\
\hline As & 123.1 & 1090 & 469.7 & 125.0 & 221.2 & 131.8 & 340.5 & 2700 & 3.19 & 3.82 & 53.2 \\
\hline $\mathrm{Se}$ & 75.31 & 26.04 & 16.60 & 68.03 & 97.28 & 21.50 & 191.6 & 330 & 3.27 & 16.5 & 38.9 \\
\hline
\end{tabular}

Notes: nd: Below detection limit. -: Not analyzed. St: Total sulfur. Sn: Sulfur oxidation state.

*: From Tedesco and Toutain (1991)

Reproducibility (1 RSD): $\mathrm{Hg} \pm 110 \%, \mathrm{Te} \pm 71 \%, \mathrm{Sn} \pm 61 \%$, Se, $\mathrm{Tl}, \mathrm{Au}, \mathrm{W}, \mathrm{Ag}, \mathrm{Na}< \pm 40 \%$; B, Cd, $\mathrm{Sb}, \mathrm{Re}, \mathrm{Pb}, \mathrm{Bi}, \mathrm{Mg}, \mathrm{Sc}, \mathrm{Ti}, \mathrm{Cr}, \mathrm{Zn}, \mathrm{K}< \pm 20 \%$; $< \pm 10 \%$ for the rest of the elements (Appendix A.7).

These variations in major gas composition emphasize the active character of White Island magmatic-hydrothermal system, and especially changes in the spatial distribution of the twophase hydrothermal envelope described by Giggenbach (1987).

The composition of fumarolic gases of higher temperature sampled in February 1988 at Donald Mound fumarole are presented for a comparison (Table 5-1). This vent reached the highest temperature ever recorded at White Island in October $1987,730{ }^{\circ} \mathrm{C}$, but had cooled down to $495{ }^{\circ} \mathrm{C}$ at the time of sampling (Giggenbach and Matsuo, 1991). The sample 
collected in February 1988, despite different absolute compositions, show similarities to F0 gases from June and September 2015 in terms of $\mathrm{CO}_{2} / \mathrm{SO}_{2}, \mathrm{SO}_{2} / \mathrm{HCl}$ and $\mathrm{SO}_{2} / \mathrm{H}_{2} \mathrm{~S}$ ratios. Contrastingly, the sample from December 2014 has very different composition, with more $\mathrm{HCl}$ than $\mathrm{SO}_{2}$, and $\mathrm{H}_{2} \mathrm{~S}$ dominating over $\mathrm{SO}_{2}$ (Table 5-1), reflecting a greater contribution from the hydrothermal system. The oxygen fugacity $\mathrm{fO}_{2}$ of some samples was estimated using:

$$
C O_{(g)}+0.5 O_{2(g)}=C O_{2(g)}
$$

and

$$
H_{2(g)}+0.5 O_{2(g)}=H_{2} O_{(g)}
$$

and thermodynamic data from Robie and Hemingway (1995). The similar $\mathrm{fO}_{2}$ values (see Appendix A.9) obtained with the two methods for the high temperature $\left(495{ }^{\circ} \mathrm{C}\right)$ gases of Donald Mound suggest that they are in equilibrium, slightly above the Nickel-Nickel Oxide $(\mathrm{NNO})$ buffer $\left(\Delta \mathrm{NNO}=+2.56\right.$ using $\mathrm{CO} / \mathrm{CO}_{2}$ and $\Delta \mathrm{NNO}=+2.35$ using $\left.\mathrm{H}_{2} / \mathrm{H}_{2} \mathrm{O}\right)$. Contrastingly, the obtained $\mathrm{fO}_{2}$ values from $\mathrm{CO} / \mathrm{CO}_{2}$ and $\mathrm{H}_{2} / \mathrm{H}_{2} \mathrm{O}$ for fumarole $\mathrm{F} 0$ gases differ by up to $4 \log$ units. Disequilibrium is however expected in such low temperature gases. F0 sample from December 2014 is more reducing $(\triangle \mathrm{NNO}=-4.90$ and $\triangle \mathrm{NNO}=-0.62$ using $\mathrm{CO} / \mathrm{CO}_{2}$ and $\mathrm{H}_{2} / \mathrm{H}_{2} \mathrm{O}$ respectively) than the samples from June $2015(\Delta \mathrm{NNO}=+2.25$ and $\Delta \mathrm{NNO}=+0.36)$ and September $2015(\Delta \mathrm{NNO}=+2.32$ and $\Delta \mathrm{NNO}=+6.91)$.

Some metals show variations following that of the major species, with $\mathrm{Cu}, \mathrm{Zn}, \mathrm{Ga}, \mathrm{Pb}, \mathrm{Bi}$, $\mathrm{Ag}, \mathrm{Cd}$ having higher contents in the more magmatic samples. In contrast, the metalloids As, $\mathrm{Se}, \mathrm{Te}$ and $\mathrm{Sb}$ show more erratic variations, with a quite high content in the November 2016 sample, indicating different behavior during volatilization of the hydrothermal system. Copper varies between 4.2 and $92.6 \mathrm{ng} . \mathrm{g}^{-1}$, As between 123.1 and $1090 \mathrm{ng} \cdot \mathrm{g}^{-1}$ and $\mathrm{Zn}$ between 8.4 and $250.4 \mathrm{ng}^{-\mathrm{g}^{-1}}$ (Table 5-1). We notice that As maximum corresponds to $\mathrm{Cu}$ and $\mathrm{Zn}$ minima, in the June 2015 sample. These concentrations are in the same range as those reported in high temperature fumaroles at Merapi and Vulcano (Cheynet et al., 2000; Nadeau, 2011). The content of $\mathrm{Pb}$ is, in contrast, quite low (1.0-24.6 ng. $\left.\mathrm{g}^{-1}\right)$ compared to the 8000 ng. $\mathrm{g}^{-1}$ at Merapi and $3200 \mathrm{ng} \cdot \mathrm{g}^{-1}$ at Vulcano. The only previous metal data available for White Island gases is from Tedesco and Toutain (1991), who sampled Donald Mound fumarole in February 1988 (Table 5-1). The reported $\mathrm{Pb}, \mathrm{Tl}$, As and $\mathrm{Zn}$ contents were almost one order of magnitude higher (180 ng.g $\mathrm{g}^{-1}, 70 \mathrm{ng} \cdot \mathrm{g}^{-1}, 2700 \mathrm{ng} \cdot \mathrm{g}^{-1}$ and $1200 \mathrm{ng} \cdot \mathrm{g}^{-1}$ respectively), whereas $\mathrm{Cu}$ was in the same range (30 ng. $\left.\mathrm{g}^{-1}\right)$. This suggests that less $\mathrm{Pb}, \mathrm{Tl}$, $\mathrm{Zn}$ and $\mathrm{As}$ is lost in the subsurface environment in the $495{ }^{\circ} \mathrm{C}$ fumarolic gases. In contrast, the similar $\mathrm{Cu}$ concentration in the current low-temperature gases and the $495{ }^{\circ} \mathrm{C}$ gases from Donald Mound, suggests that it is deposited at $\mathrm{T}>500{ }^{\circ} \mathrm{C}$. Comparing with lower temperature fumaroles (Table 5-1), we observe that F13a is an order of magnitude more concentrated than $\mathrm{F} 9 \mathrm{a}$ in $\mathrm{Cu}, \mathrm{Pb}$ and $\mathrm{As}$ and many other metals. It is nevertheless almost 10 times lower than fumarole F0, reflecting its hydrothermal nature. 


\subsubsection{Metal enrichment in fumarolic gases}

Enrichment factors are used to emphasize preferential partitioning into gaseous phase compared to the residual magma (Zoller et al., 1974; Lepel et al., 1978). The enrichment factor, $\mathrm{EF}$, of an element $i$ is defined as follows:

$$
E F_{i}=\left(C_{i} / C_{R}\right)_{\text {gas }} /\left(C_{i} / C_{R}\right)_{\text {rock }}
$$

where $\left(C_{i} / C_{R}\right)$ is the ratio of concentrations of the element $i$ to a reference element $\mathrm{R}$ in the gas, divided by the same ratio in the host rock. The reference element is a major non-volatile species, $\mathrm{Al}$ in this case. We used the composition of the andesite (Appendix A.8) erupted in 1977 to calculate the EF.

Enrichment factors are shown in Figure 5-5. Elements with EF $>1$ are mainly volatiles and chalcophiles, in accordance with their enrichment in volcanic gases. As expected, all the refractory elements have $\mathrm{EF} \sim 1$. We nevertheless observe quite a wide range in enrichment factor for a single element with time, probably linked to changes in major composition. Antimony for example, varies from 4 orders of magnitude from June to December 2015. It is also interesting to note the highest $\mathrm{EF}$ for the sample from June 2015, despite its quite low temperature $\left(160{ }^{\circ} \mathrm{C}\right)$. Interestingly, F9a and F13a, which have lower concentrations compared to F0, have similar enrichment factors. For some elements such as $\mathrm{Au}, \mathrm{Tl}, \mathrm{Cu}$ and $\mathrm{Zn}$, they are even in the high range. Given these fumaroles are most likely originating from boiling of the hydrothermal envelope (Giggenbach, 1987), these high EF's values may reflect the refractory character of $\mathrm{Al}$, partitioning strongly in the brine during phase separation, or preferential partitioning of the metals into the vapor. It might also represent efficient deposition occurring in the conduit of F0. Despite the higher general concentrations of hotter gases from Donald Mound, the enrichment factors are comparable to the present day gases. We note high enrichment for $\mathrm{Tl}, \mathrm{Pb}$ and $\mathrm{Zn}$, emphasizing the magmatic origin of these species and their volatile behavior. $\mathrm{Cu}$, in contrast, has an enrichment factor similar to the average found in this study. We should note the $\mathrm{EF} \sim 1$ for $\mathrm{Cu}$ in $\mathrm{F} 0$ condensates from December 2015 and October 2016. 


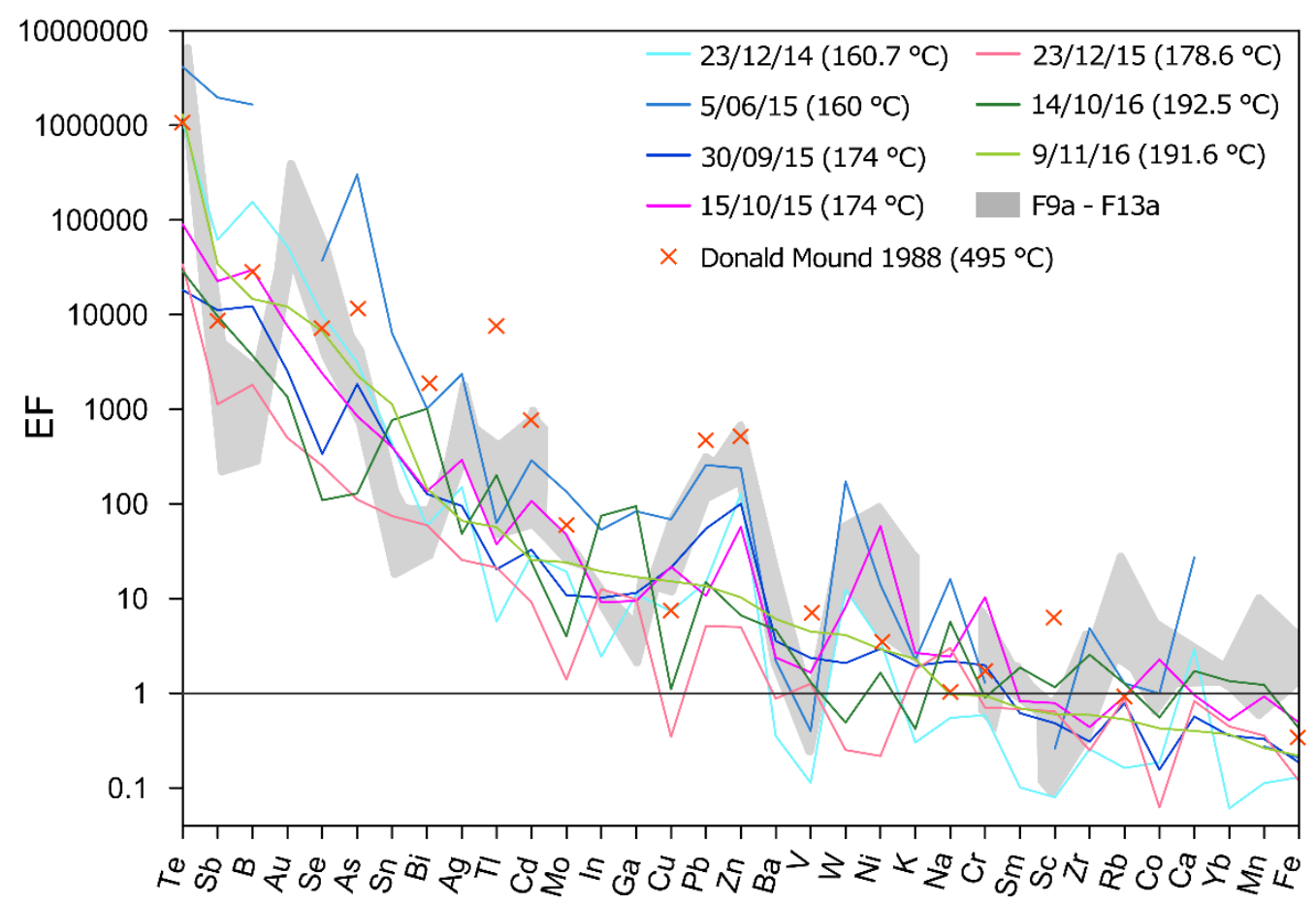

Figure 5-5: Enrichment factors (EF) estimated for the three fumaroles sampled. Data from Donald Mound are from Tedesco and Toutain (1991). The Se value of $0.92 \mathrm{ppm}$ in White Island andesite was taken from Wells (1967).

\subsection{Sublimates forming in low-temperature fumarole}

Despite F0 being the hottest accessible fumarole, its temperature is still low compared to vents usually chosen for sublimate studies (i.e. > $400{ }^{\circ} \mathrm{C}$ ) (Garavelli et al., 1997; Cheynet et al., 2000; Africano et al., 2002; Wahrenberger et al., 2002; Zelenski and Bortnikova, 2005). A sketch of the tubes and zones of the commonly observed minerals collected in them is shown in Figure 5-6.

Salammoniac $\left(\mathrm{NH}_{4} \mathrm{Cl}\right)$ is common in tube 2, from June-October 2016, as colorless arborescent euhedral crystals, sometimes rounded, displaying an adamantine luster (Figure 5-7 a, b). Small heavy (i.e. bright in backscattered image) crystals and euhedral in form, were commonly found on large salammoniac crystals. We could unfortunately not analyze them due to their very small size requiring high magnification, causing volatilization of the salammoniac host. Vapor deposited $\mathrm{SiO}_{2}$ is very common in the silica tubes. Some euhedral crystals were observed having a morphology similar to cristobalite, along with aggregates of spheres that could either be cristobalite or opal. Some silica crystals are rich in Al, and a few Ti-rich and Sn-rich particles were observed. 
Sublimate tube 1

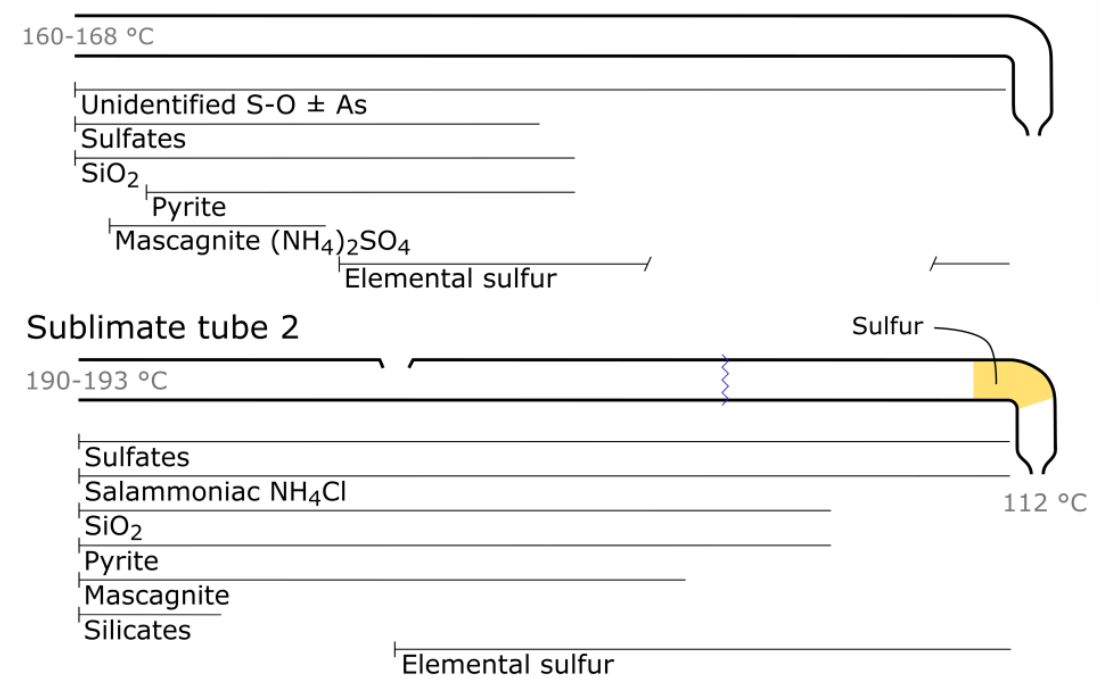

Figure 5-6: Description of the mineral species found in the sublimate tubes 1 (June 2015) and 2 (JuneOctober 2016.) The second tube was broken at $38 \mathrm{~cm}$ from the top and had a hole of around $8 \mathrm{~cm}$ length at $40 \mathrm{~cm}$ from the bottom. The bent section was clogged with elemental sulfur.

Elemental sulfur is present in the form of solidified droplets from 37 to $75 \mathrm{~cm}$ and $113 \mathrm{~cm}$ to the top in tube 1 and from $45 \mathrm{~cm}$ to the top in tube 2 (Figure 5-6). This is in accordance with the condensation of sulfur reported to occur at $\mathrm{T}<200{ }^{\circ} \mathrm{C}$ (Le Guern, 1988; Quisefit et al., 1989; Cheynet et al., 2000; Africano et al., 2002). The zone between 75 and $113 \mathrm{~cm}$ in tube 1 contains almost no sublimate at all.

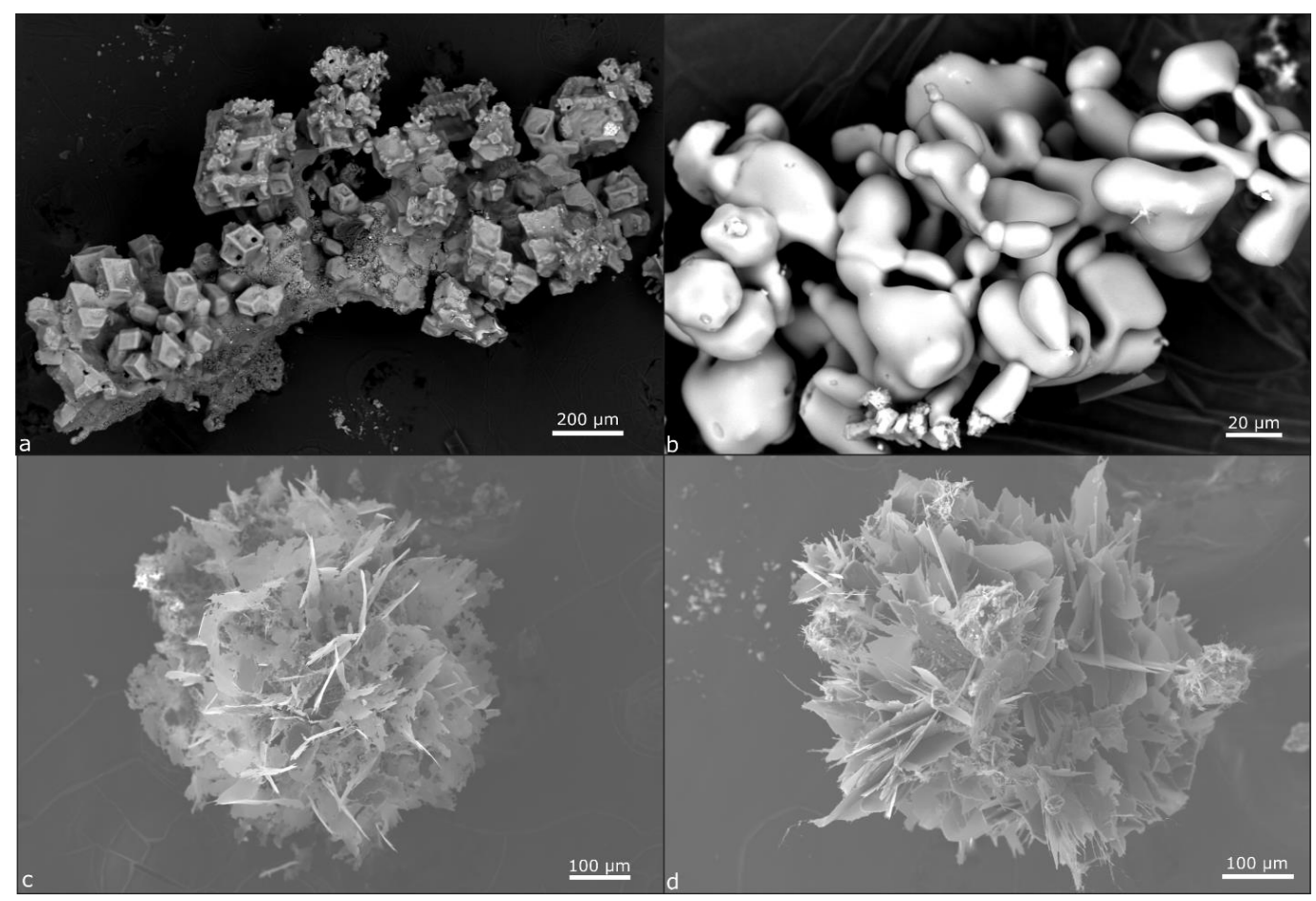

Figure 5-7: SEM images of sublimates. Salammoniac crystals showing both rounded (b) and cubic shape (a) in tube 2 and incrustations respectively (Backscattered electron (BSE) images). Thin plates of $\mathrm{S}$ and $\mathrm{N}$ in tube 2 thought to be mascagnite (c and d) (Secondary electron (SE) images). 


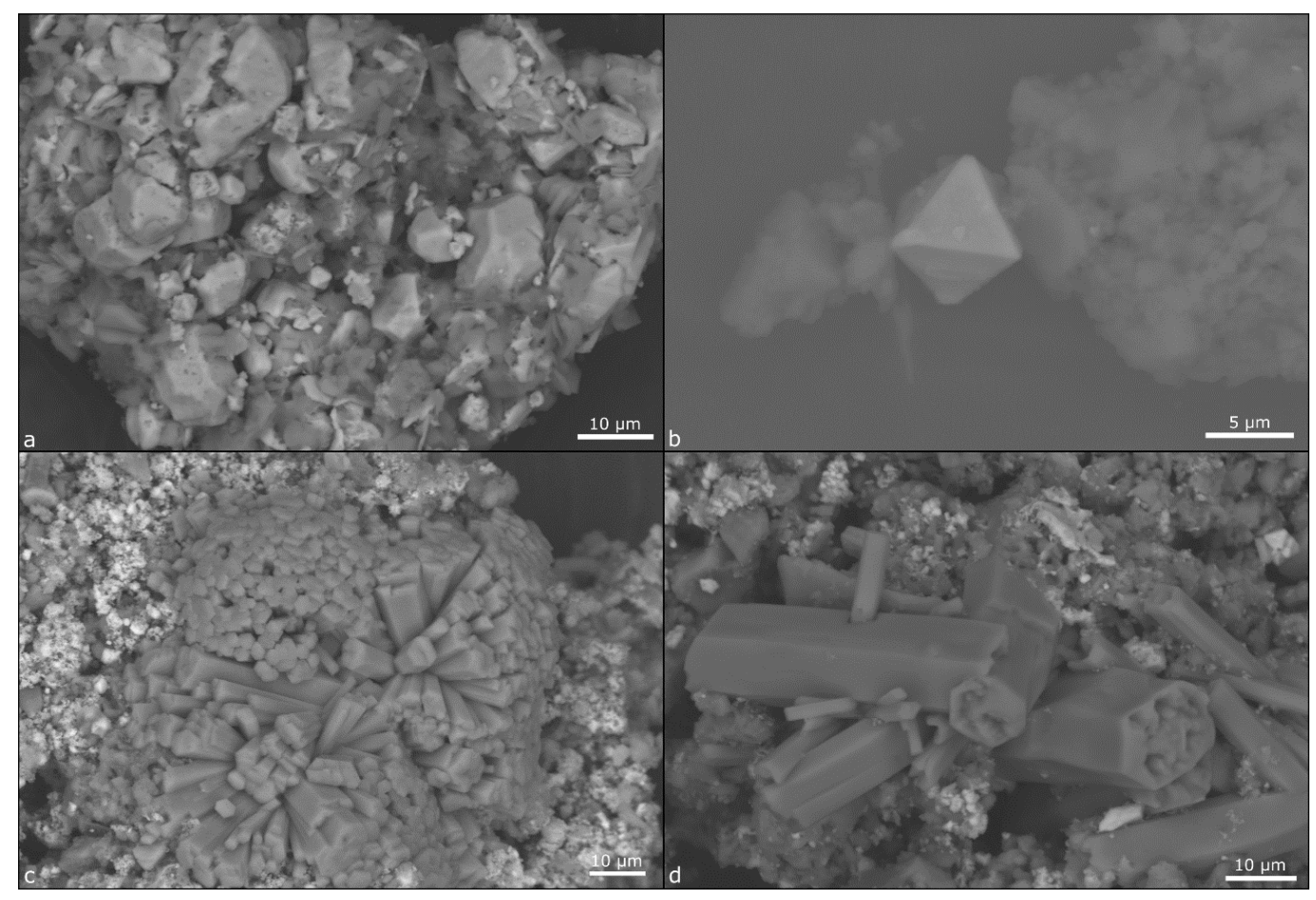

Figure 5-8: SEM images of sublimates. Pyrite crystals covering entire surfaces in tube 2 (a) or occurring as single octahedral crystals in tube 3 (b). Iron ammonium sulfates thought to be pyracmonite in tube 1 (c and d). All BSE images.

Pyrite is the only identified sulfide, occurring as euhedral grains up to $15 \mu \mathrm{m}$ in size (Figure $5-8 \mathrm{a}, \mathrm{b})$. It is found in the three tubes, from 0 to $80 \mathrm{~cm}$ in tube 1 and as far as $105 \mathrm{~cm}$ in tube 2. Prismatic crystals of ammonium iron sulfate, thought to be pyracmonite $\left(\left(\mathrm{NH}_{4}\right)_{3} \mathrm{Fe}\left(\mathrm{SO}_{4}\right)_{3}\right.$ (Demartin et al., 2010) were found in tube 1 (Figure 5-8 c, d). Mascagnite $\left(\left(\mathrm{NH}_{4}\right)_{2} \mathrm{SO}_{4}\right.$ ) occurs as thin plates growing on top of existing crystals, giving them the appearance of white balls (Figure 5-7 c, d). We are not certain whether the mascagnite crystals formed within the fumarole or later on, during reactions with condensed gases. This uncertainty arises from observation of sections of tube coated with mascagnite, weeks after opening and cutting segments.

Barite is present in all the tubes as euhedral crystals up to $20 \mu \mathrm{m}$ in size, between 10 and 35 $\mathrm{cm}$ in tube 1 and 0 to $80 \mathrm{~cm}$ in tube 2. Some barite crystals in the second tube were $\mathrm{Sr}$-rich according to EDS analysis. A wide variety of sulfates were present as euhedral crystals and are reported in Table 5-2. Some of them displayed an adamantine luster (Al sulfates) and others a vitreous luster (Ca sulfates).

We observed a common unidentified phase in tubes 1 and 3 (Figure 5-9 a, b and c), displaying a euhedral arborescent shape, although quite rounded, translucent and pale yellow in color, with adamantine luster. The only detected species in EDS were S and O. They appear very different compared to elemental sulfur droplets under the SEM, dark and almost translucent in backscattered images (Figure 5-9 a, b, c). This suggests the likely presence of light elements (H, B, N, F), hardly detected by EDS. 


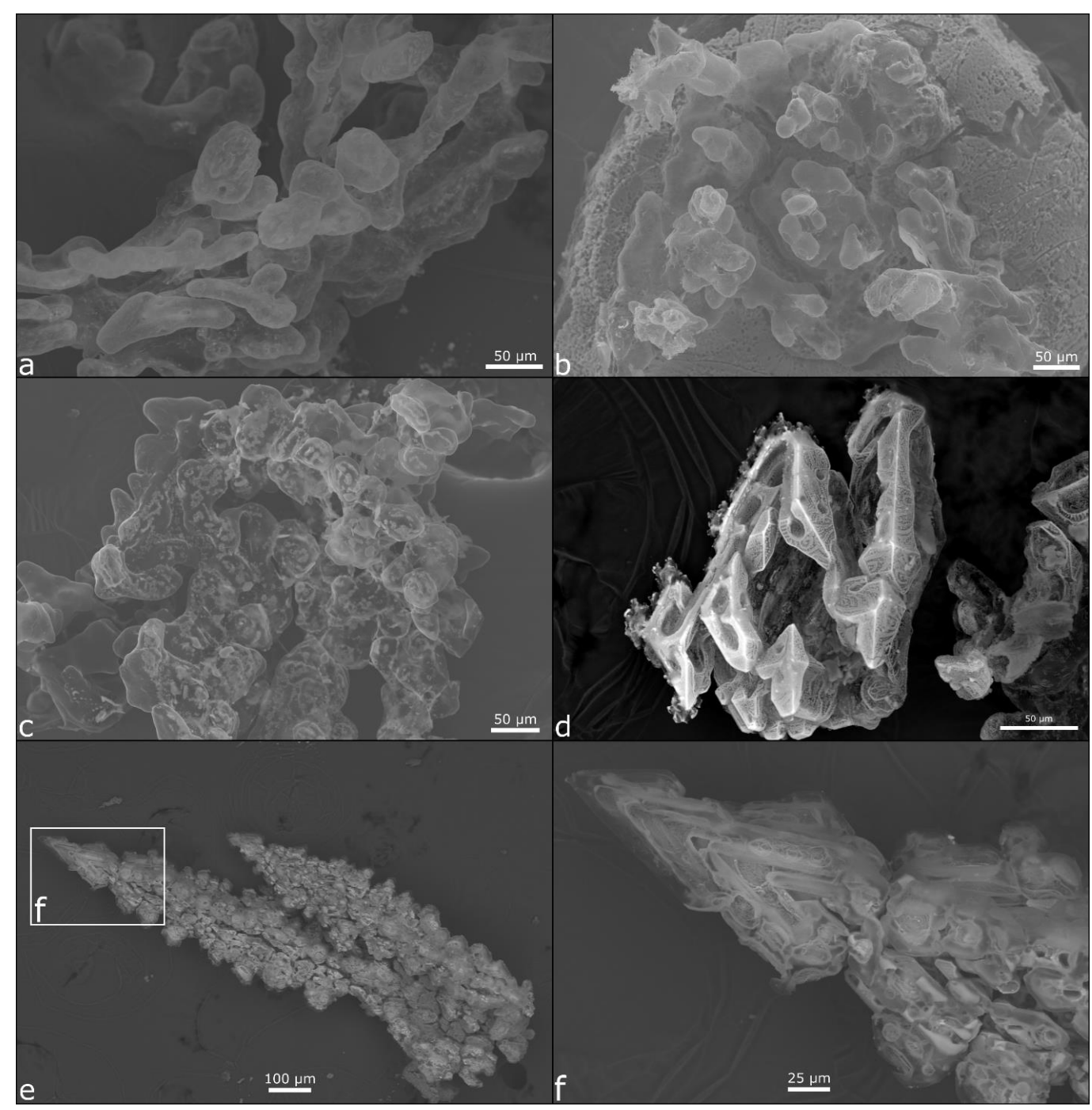

Figure 5-9: SEM images of sublimates. Unidentified compounds in tube 1 bearing $\mathrm{S}$ and $\mathrm{O}$, pale yellow (a, b, c) and dark bright yellow (d, e, f). a) Euhedral rounded arborescent crystals with bright spots containing up to $16 \%$ As. b) Euhedral rounded arborescent crystals (up to 2.5\% As) on top of an elemental sulfur droplet. c) Euhedral rounded arborescent crystals with bright spots containing up to $5 \% \mathrm{Hg}, 2 \% \mathrm{As}, 0.7 \% \mathrm{Cu}$ and $0.5 \% \mathrm{Sb}$. d) Euhedral skeletal crystals with bright blobs containing up to $18 \%$ As. e, f) Euhedral skeletal crystal bearing up to $11 \%$ As). All SE images expect BSE image for d. As and $\mathrm{Hg}$ contents are qualitative.

In some of these crystals, small blobs appearing brighter in backscattered images contain metals and/or metalloids. Arsenic is the most common element, up to $16 \%$ in qualitative EDS analyses, corresponding to the yellower parts. Higher up in the tube $(75-80 \mathrm{~cm}$ and $125-130$ $\mathrm{cm}$ ), the same minerals were found with similar bright spots, rich in As (up to $18 \%$ ), $\mathrm{Hg}$ (up to $5 \%$ ), $\mathrm{Cu}$ (up to $0.7 \%$ ) and $\mathrm{Sb}$ (up to $0.5 \%$ ). These were found in a thin layer of euhedral crystals, completely covering the inside of the tube. Translucent to pale yellow crystals only contain $\mathrm{S}$ and $\mathrm{O}$, whereas the darker yellow crystals are rich in As. The Hg-rich blobs, in contrast, were dark with a metallic luster. Cinnabar precipitation was predicted by thermodynamic calculations during cooling of White Island fumarolic gas (Christenson and Mroczek, 2003) supporting our observations. 
Similar crystals were observed in the bottom part of tube 3. Again, only the yellow crystals contained As (up to 10\%), while the translucent parts are composed of S and O. There is only one occurrence of a similar phase in tube 2, at around $25 \mathrm{~cm}$ from the bottom. The small blobs contain up to $12 \% \mathrm{As}$, and less than $1 \% \mathrm{Cu}$. A similar type of mineral was observed in tube $1(0-15 \mathrm{~cm}$ and $75-80 \mathrm{~cm}$ ), also containing $\mathrm{S}, \mathrm{O}$ and As (up to 18\%), although exhibiting euhedral skeletal morphology, a bright yellow color and adamantine luster (Figure 5-9 d, e, f). The distribution of arsenic is not quite uniform, and appears as bright blobs in the cooler specimen.

Some unidentified phases were observed in tube 1: Ti-S-K-Si between 10 and $15 \mathrm{~cm}$ (Figure 5-10 c), Fe-Cr-Ni crystal (35-40 cm), Cl-Fe-Ca-S compound at 50-55 cm and a dark red plate made of Fe-Cl-P-Zn-Br (Figure 5-10 b).

Sublimate tube 2 contained platy minerals, made of light elements only, at $15-20 \mathrm{~cm}$ and thought to be sassolite $\left(\mathrm{B}(\mathrm{OH})_{3}\right)$, a common mineral around fumaroles at Vulcano (Garavelli et al., 1997). A variety of unidentified phases was found: small blue particles with an ellipsoidal shape containing $\mathrm{S}$ with minor Si-Cl-As-Al between 30 and $52 \mathrm{~cm}$. Some compounds rich in $\mathrm{Cl}$ and $\mathrm{Fe}$ and bearing $\mathrm{Cr}, \mathrm{Ni}$, As with trace amounts of $\mathrm{Cu}$, as well as a crystal containing $\mathrm{S}-\mathrm{Cr}-\mathrm{Fe}$ were observed at $74-85 \mathrm{~cm}$. We observed more compounds bearing $\mathrm{Cl}-\mathrm{S}-\mathrm{Al}$ in the upper part of the tube that had fallen into the fumarole after breaking, as well as a shiny translucent Al-S-Si-Ca crystal, and a white ball made of small plates of STi-Fe.

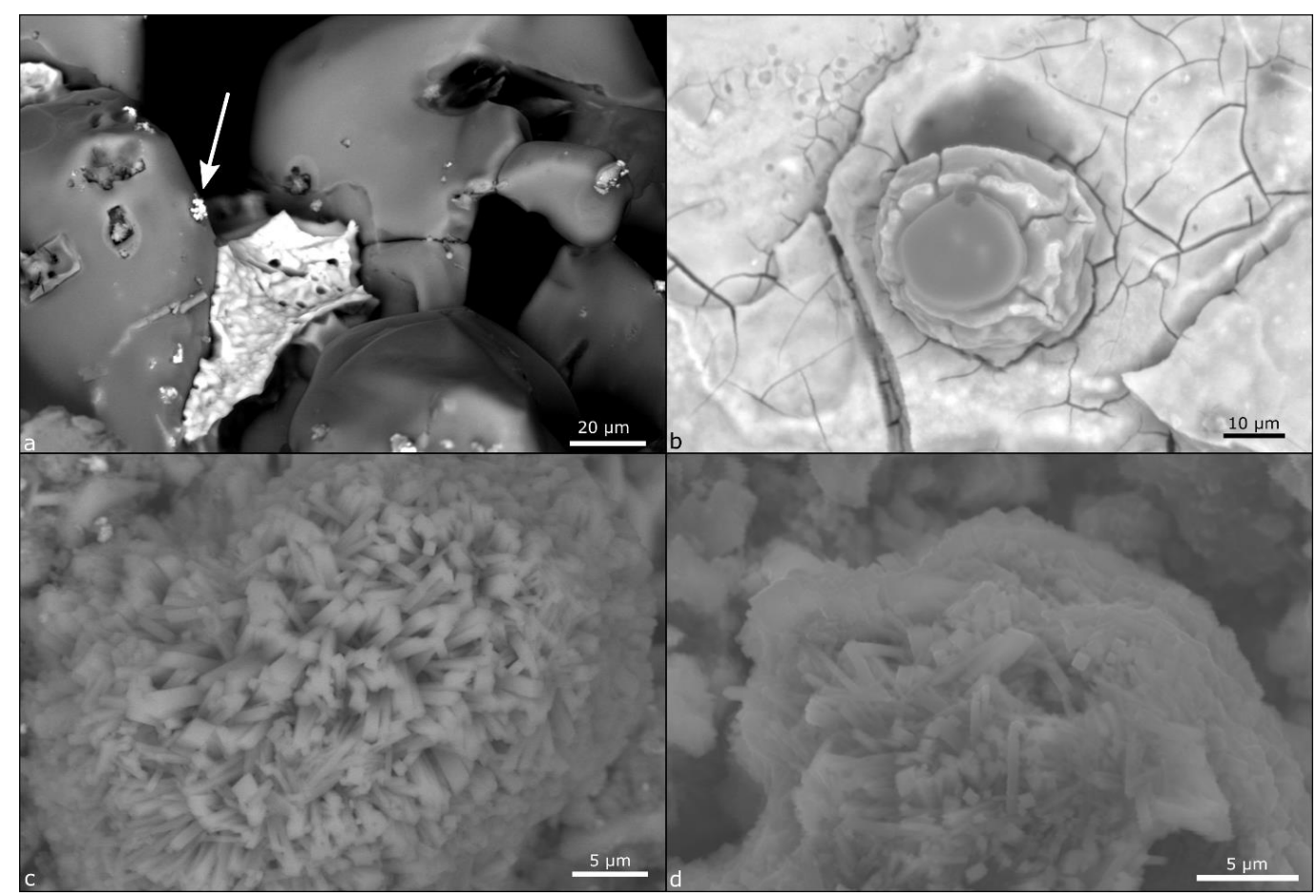

Figure 5-10: SEM images of sublimates. a) Aggregate of unidentified Sn-S compounds on salammoniac in natural incrustations. The bright leaf in the middle is elemental sulfur. b) Unidentified dark red plate containing Fe-Cl-P-Zn-Br in tube 1. c) Unidentified euhedral crystals of S-Ti-K-Si in tube 1. d) Unidentified euhedral crystals bearing Ti-S-O in tube 1. a and b are BSE images, c and d are SE images. 
Table 5-2: List of all the observed sulfates in sublimates and natural encrustations.

\begin{tabular}{llll}
\hline Tube 1 & Tube 2 & Tube 3 & Encrustations \\
\hline Mg sulfate & Mg-Fe sulfate & Mg sulfate & Fe-Mg sulfate \\
Barite & Barite (crystal with 2\% Sr) & Barite & Barite \\
Al sulfate (crystal with 0.8\% Ga) & Al sulfate & Al sulfate & Al sulfate \\
Ca sulfate & Ca sulfate & Ca sulfate & Ca sulfate \\
Fe-N sulfate & Fe-N sulfate & & Fe-N sulfate \\
K-Ca-N sulfate & Ca-K sulfate & Ca-K sulfate \\
Mg-N sulfate & Fe-Na-N sulfate & Ca-K-Fe sulfate \\
Al-Fe sulfate & Na-Fe sulfate & Fe-K-N sulfate \\
Al-Mg-Fe sulfate & Na-K-Fe-Ti sulfate & Mg-Fe-Al sulfate \\
& & & Al-Na-K sulfate \\
\hline
\end{tabular}

The third tube was quite wet when we opened it in the lab, suggesting dissolution reactions may have occurred after collection. We only analyzed crystals from the first $10 \mathrm{~cm}$ and found salammoniac, silica, a lot of silicate particles most likely dragged from the conduit by the gases, mascagnite, pyrite and the unidentified compound bearing S, O and As. A variety of sulfates was also observed and is detailed in Table 5-2.

Sulfur is a ubiquitous phase around fumaroles, as evidenced by the yellow color of the sublimate chimneys and sulfur flows leaking away from them. The slab of fumarole wall collected was covered with natural incrustations. The top of the block was coated with colorless to pale yellow euhedral arborescent crystals of salammoniac up to 2 to $3 \mathrm{~mm}$ long. Some were also covered with elemental sulfur. Small crystals had grown on the salammoniac, such as tiny spheres of silica, radiant acicular aggregates of $\mathrm{S}-\mathrm{Fe}-\mathrm{Ga}-\mathrm{Cu}$ compounds, needles containing $\mathrm{Cl}-\mathrm{S}-\mathrm{Br}-\mathrm{Al}-\mathrm{Na}-\mathrm{Sn}$ and $\mathrm{Bi}$, euhedral plate $(4 \mu \mathrm{m})$ containing $\mathrm{Sn}-\mathrm{S}-\mathrm{Si}-\mathrm{Al}-\mathrm{Ti}$, cubes of sylvite up to $10 \mu \mathrm{m}$, pyrite, and small spheres of unidentified $\mathrm{S}-\mathrm{Sn}$ compounds (Figure 5-10 a). An area on the side of the block was covered by dull pink filamentous crystals most likely made of $\mathrm{B}, \mathrm{H}, \mathrm{N}$ and/or $\mathrm{F}$ given the dark color in backscattered images. We found tiny grains of W-Cl-Na-Al-K-Ca, S-Fe-Cu-As, pyrite and sylvite in these pink crystals. The sides and bottom of the block was covered with grey amorphous silica, forming cavities in which minerals had crystallized. A variety of crystals were found such as acicular gypsum, orange platy anhydrite, pyrite and a variety of other sulfates (Table 5-2). Silica occurs as different colors and structures, such as orange vitreous crystals ( $1 \mathrm{~mm}$ in length) similar to opal, euhedral crystals up to $50 \mu \mathrm{m}$ with the morphology of cristobalite, dark vitreous amorphous silica thought to be opal, red amorphous silica comparable to jasper.

Sulfates are the most common sublimates both in the tubes and in natural incrustations, suggesting quite oxidized conditions, as reported by Bernard (1985) and Taran et al. (2001) and modelled by Africano et al. (2002). The oxidizing nature of White Island lowtemperature fumarolic gases is the likely consequence of elemental sulfur precipitation in the conduit (Christenson et al., 2010). The latter may also explain the rarity of sulfides, owing to the elevated metal contents measured in elemental sulfur (Table 5-3). Values of $\sim 1 \mathrm{ppm}$ for $\mathrm{Cu}, \mathrm{Pb}$ and $\mathrm{Bi}$ were reported, two orders of magnitude higher than in the condensate, suggesting high solubility of metals in liquid sulfur. 
Table 5-3: Metal content of elemental sulfur condensing from fumarole F0 gases $\left(\mu \mathrm{g} \cdot \mathrm{g}^{-1}\right)$.

\begin{tabular}{lrrr}
\hline \multicolumn{4}{c}{ F0 elemental sulfur } \\
\hline $\mathrm{Mo}$ & 0.11 & $\mathrm{~Pb}$ & 1.27 \\
$\mathrm{Ag}$ & 0.05 & $\mathrm{Bi}$ & 1.29 \\
$\mathrm{Cd}$ & 0.005 & $\mathrm{Co}$ & 0.27 \\
$\mathrm{Sn}$ & 2.93 & $\mathrm{Ni}$ & 0.75 \\
$\mathrm{Sb}$ & 0.16 & $\mathrm{Cu}$ & 1.68 \\
$\mathrm{Te}$ & 387.3 & $\mathrm{Zn}$ & 4.38 \\
$\mathrm{Re}$ & 0.001 & $\mathrm{Ga}$ & 2.93 \\
$\mathrm{Au}$ & 0.0005 & $\mathrm{As}$ & 103.3 \\
$\mathrm{Hg}$ & 0.43 & $\mathrm{Se}$ & 640.5 \\
$\mathrm{Tl}$ & 0.10 & $\mathrm{Cr}$ & 2.27 \\
\hline
\end{tabular}

Of the previous studies of this kind, the majority was realized in very high temperature fumaroles (usually $>500{ }^{\circ} \mathrm{C}$ ) resulting in a variety of sulfides, sulfosalts and metal chlorides to be observed (Korzhinsky et al., 1994; Garavelli et al., 1997; Cheynet et al., 2000; Africano et al., 2002; Wahrenberger et al., 2002; Zelenski and Bortnikova, 2005; Garavelli et al., 2013). As noted by several studies, many metals such as $\mathrm{Cu}, \mathrm{Bi}$ and $\mathrm{Sn}$ are not as volatile as $\mathrm{Tl}$, As or $\mathrm{B}$ and tend to deposit at temperature $>350{ }^{\circ} \mathrm{C}$ by chemical vapor deposition (Symonds et al., 1987; Bernard et al., 1990; Symonds et al., 1990). The relative absence of minerals containing $\mathrm{Cu}$ and their overall low concentrations in the fumarolic condensates suggest that deposition might occur deeper in the subsurface, as the gases cool and expand on their way to the surface (Henley and Berger, 2013). Conversely, As and Sb are quite concentrated in the gases yet no major phase is reported in the sublimates. This points to unfavorable conditions for deposition, as was observed in similar studies (Symonds et al., 1992; Getahun et al., 1996).

\subsection{Thermochemical modelling}

Gas speciation was calculated using the software HSC Chemistry (version 9.1.1, Outotec Research Oy, Finland), based on Gibbs free energy minimization calculations. Modeling was facilitated using measured mole $\%$ gas compositions at 1 bar, in a 15 element system $(\mathrm{H}, \mathrm{O}$, $\mathrm{C}, \mathrm{S}, \mathrm{Cl}, \mathrm{F}, \mathrm{N}, \mathrm{Br}, \mathrm{Cu}, \mathrm{Zn}, \mathrm{Pb}, \mathrm{As}, \mathrm{Fe}, \mathrm{Bi}, \mathrm{Tl}$ ). The lack of $\mathrm{HBr}$ data for Donald Mound sample (Tedesco and Toutain, 1991) prevented us from comparing it with the other gases. The input files are reported in Appendix A.9. We also added gas, liquid and solid phases expected to be present in the volcanic gases or form during cooling. We assumed a constant gas flow, and therefore modeled deposition in closed-system conditions. Such an assumption is supported by results from Africano et al. (2002), who showed that closed-system conditions reproduced more closely the observed assemblage than an open-system in Satsuma-Iwojima fumarolic gases. The use of solids as pure phases ignores both solid solutions and the presence of trace elements in minerals, and thus deviates from real conditions. Gases were assumed to mix ideally. Equilibrium calculations were first performed at the sampling temperature to assess gaseous speciation. Cooling was then modeled by incrementally decreasing the temperature down to $50{ }^{\circ} \mathrm{C}$, by $10{ }^{\circ} \mathrm{C}$ steps. 
Samples collected at fumarole F0 on 23 December 2014, 5 June 2015 and 30 September 2015 were used for modeling, as well as the higher temperature $\left(495^{\circ} \mathrm{C}\right)$ gas from Donald Mound fumarole collected in 1988 by Tedesco and Toutain (1991). As described above, the fumarolic gases from F0 collected in December 2014 are more reducing, and have a $\mathrm{SO}_{2} / \mathrm{H}_{2} \mathrm{~S}$ ratio < 1 (see Table 5-1). F0 gases from June and September 2015, as well as Donald Mound sample from 1988 are more oxidized, $\mathrm{SO}_{2}$ being the dominant sulfur species.
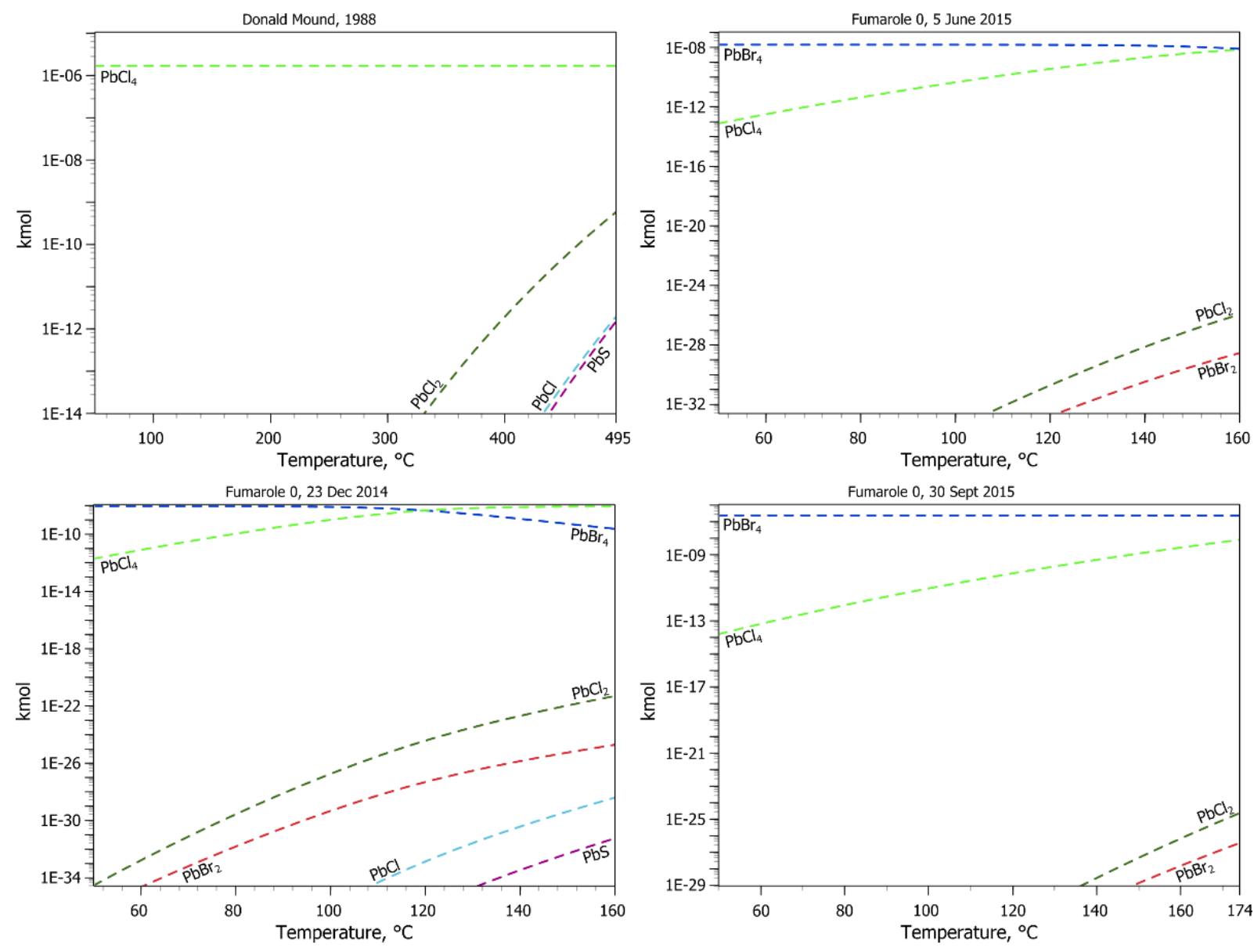

Figure 5-11: Speciation of the most abundant gaseous $\mathrm{Pb}$ species.

The distribution of $\mathrm{Pb}$ amongst gaseous species is shown in Figure 5-11 and emphasizes the role of chloride and bromide complexes in transporting lead. $\mathrm{PbBr}_{4}$ and $\mathrm{PbCl}_{4}$ are the dominant species even at low temperature, indicating $\mathrm{Pb}^{(\mathrm{IV})}$ is the most stable in the gas. Stability of $\mathrm{PbCl}_{4(\mathrm{~g})}$ at $\mathrm{T}<800{ }^{\circ} \mathrm{C}$ was reported in gases from Erta Ale, Kudriavy and Merapi (Symonds et al., 1987; Wahrenberger et al., 2002; Renggli et al., 2017). $\mathrm{PbCl}_{2}, \mathrm{PbBr}_{2}, \mathrm{PbCl}$ and the sulfide complex $\mathrm{PbS}$ are the second most abundant species.

The speciation of $\mathrm{Cu}$ amongst gaseous species is depicted in Figure 5-12. $\mathrm{Cu}^{\mathrm{I}} \mathrm{Cl}$ dominates at high temperature in Donald Mound gases, replaced by the dichloride complex $\mathrm{Cu}^{\mathrm{II}} \mathrm{Cl}_{2}$ at $\mathrm{T}<$ $300{ }^{\circ} \mathrm{C}$. Similar distribution is observed in the 2015 samples from F0, although we see that bromide complexes $\mathrm{CuBr}$ and $\mathrm{CuBr}_{2}$ are also quite stable. $\mathrm{Cu}_{4} \mathrm{Br}_{4}$ becomes more stable at $\mathrm{T}<$ $100{ }^{\circ} \mathrm{C}$. The more reduced sample from December 2014 shows a slightly different 
distribution, with the bromide complex dominating at the sampling temperature, and similar abundances for $\mathrm{CuCl}$ and $\mathrm{CuCl}_{2}$. It is interesting to note that the general abundance of gaseous copper species is very low compared to $\mathrm{Pb}$. In the $\mathrm{F} 0$ samples, $\mathrm{PbCl}_{4}$ had an equilibrium amount between $10^{-6}$ and $10^{-8} \mathrm{kmol}$, whereas $\mathrm{CuCl}_{2}$ is at most $10^{-17} \mathrm{kmol}$. This depletion in the gas phase is likely to reflect loss by deposition of solid species.
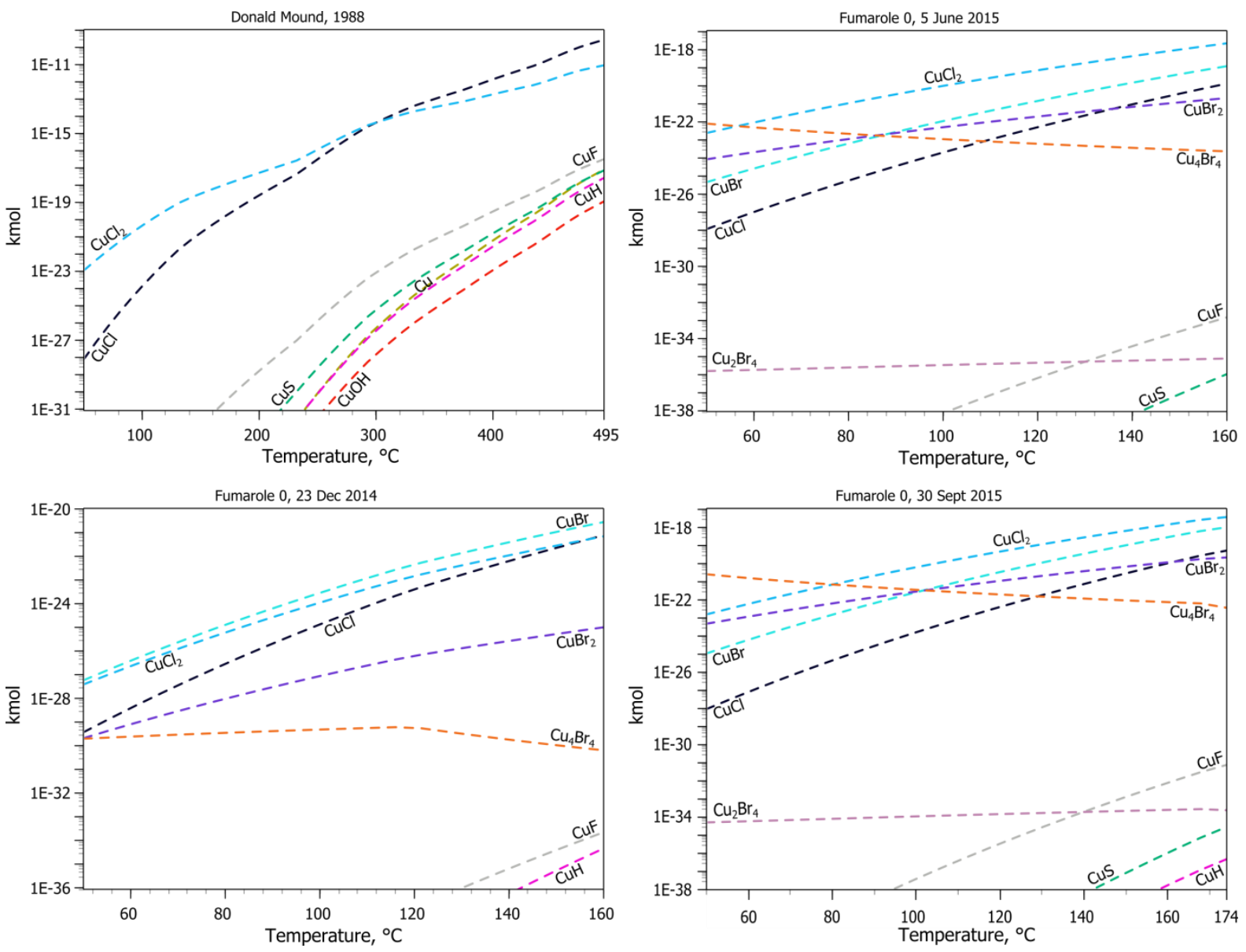

Figure 5-12: Speciation of the most abundant gaseous $\mathrm{Cu}$ species.

The predominance of chloride complex prevails for $\mathrm{Zn}$ as well, with $\mathrm{ZnCl}_{2}$ being the most abundant species in all the samples (Figure 5-13). The bromide complex $\mathrm{ZnBr}_{2}$ is orders of magnitude less abundant whereas other species such as $\mathrm{Zn}_{2} \mathrm{Br}_{4}, \mathrm{Zn}(\mathrm{OH})_{2}, \mathrm{ZnF}_{2}, \mathrm{ZnCl}$ and $\mathrm{Zn}$ are very low.

$\mathrm{Fe}^{\mathrm{II}} \mathrm{Cl}_{2}$ is the most stable species in the high temperature gas of Donald Mound (Figure 5-14), replaced by $\mathrm{Fe}^{\mathrm{III}} \mathrm{Cl}_{3}$ at $\mathrm{T} \leq 170{ }^{\circ} \mathrm{C}$. This shift in redox state of iron is observed in the 2015 gases from $\mathrm{F} 0$, where $\mathrm{FeCl}_{3}$ and $\mathrm{FeCl}_{2}$ have similar abundances at the sampling temperature, the former becoming more important with cooling. In contrast, the more hydrothermal sample from 2014 indicates greater stability of $\mathrm{FeCl}_{2}$ at all temperatures. The hydroxide complex, $\mathrm{Fe}(\mathrm{OH})_{2}$, is predicted to be quite abundant at high temperature, rapidly decreasing in cooler gases, where $\mathrm{FeF}_{3}$ becomes increasingly stable, in accordance with a shift in redox state. Bromide complexes in $\mathrm{F} 0$ samples somewhat lowers the overall abundance of $\mathrm{FeF}_{3}$. 

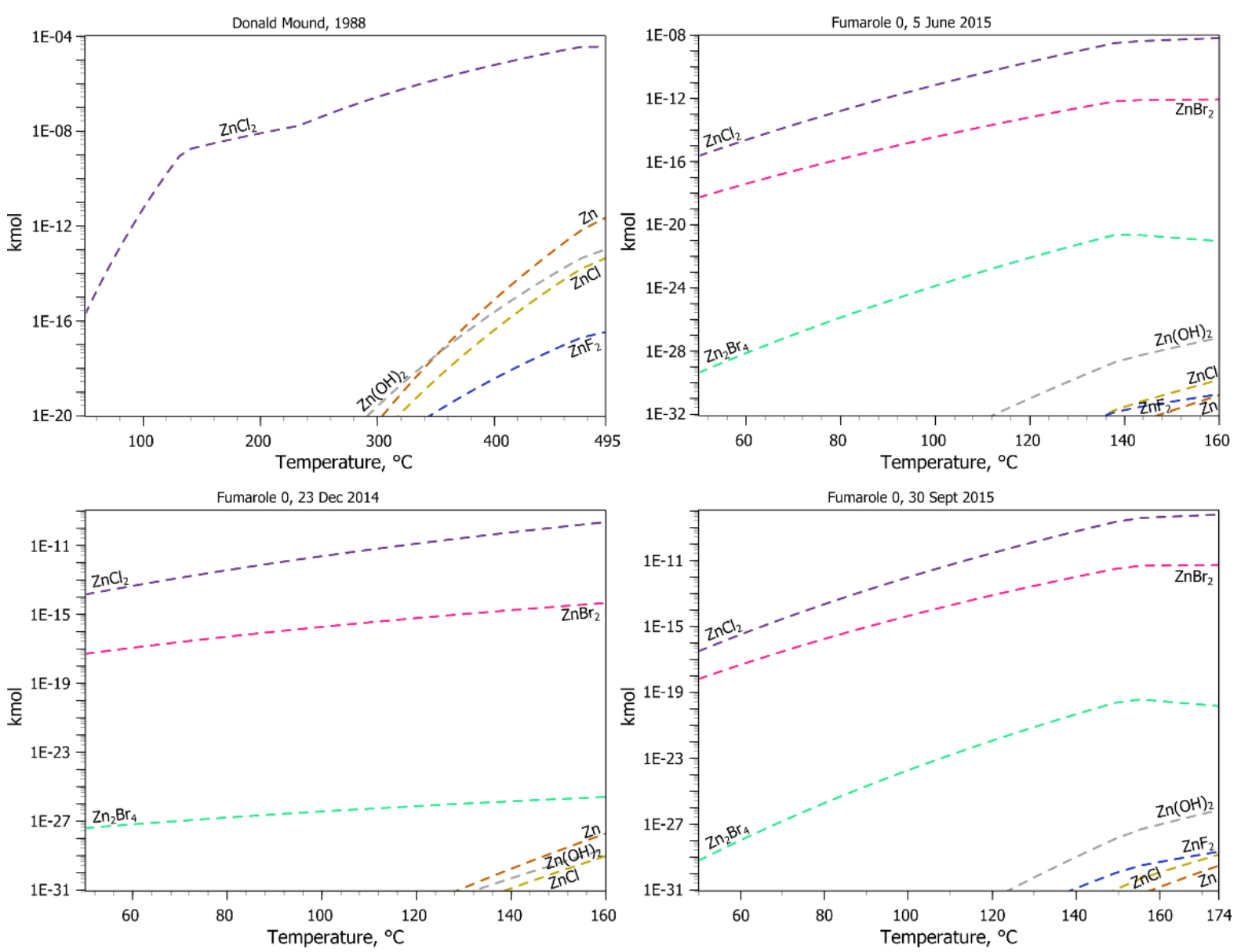

Figure 5-13: Speciation of the most abundant gaseous $\mathrm{Zn}$ species.

As and $\mathrm{Tl}$ are the only species predicted to be mainly transported as volatile oxide species. $\mathrm{As}_{4} \mathrm{O}_{6}$ is only stable until $\sim 240{ }^{\circ} \mathrm{C}$ and with further cooling is replaced by the chloride complex, $\mathrm{AsCl}_{3}$ (Figure 5-15). The valence is the same in the two species, indicating the lower stability of the molecular $\mathrm{As}_{4} \mathrm{O}_{6}$ species at lower temperatures. All of the gaseous species show a marked decrease at that same temperature $\left(\sim 240{ }^{\circ} \mathrm{C}\right)$, related with removal of As from the gas phase by condensation of AsS (see below). The presence of $\mathrm{AsBr}_{3}$ in the 2015 F0 samples increases the stability of $\mathrm{As}_{4} \mathrm{O}_{6}$ over $\mathrm{AsF}_{3}$, as predicted from cooling of Donald Mound discharge gas to $\sim 160{ }^{\circ} \mathrm{C}$. The sulfide complex, AsS, is also quite abundant at high temperature. Once again, we observe discrepancies in the 2014 sample from F0. $\mathrm{AsCl}_{3}$ is still the most abundant complex, followed by $\mathrm{As}_{4}$ and $\mathrm{AsH}_{3}$ in these more reduced and $\mathrm{HCl}$-rich gases. In the case of $\mathrm{Tl}, \mathrm{TlO}$ dominates at all temperatures and even in the more reduced sample (F0 fumarole, December 2014), with $\mathrm{TlCl}$ the second most abundant gaseous species. $\mathrm{TlCl}$ was found to be the dominant complex in fumarolic gases from Vulcano (Cheynet et al., 2000) and Kudriavy (Wahrenberger, 1997). The distribution of $\mathrm{Bi}$ is divided between $\mathrm{Bi}(\mathrm{OH})_{2} \mathrm{Cl}$ and $\mathrm{BiCl}_{3}$ in the four samples studied. The sulfide complex $\mathrm{BiS}$ is predicted to be quite stable in the higher temperature gas of Donald Mound, similar to what was observed for $\mathrm{As}$ and $\mathrm{Pb}$. 

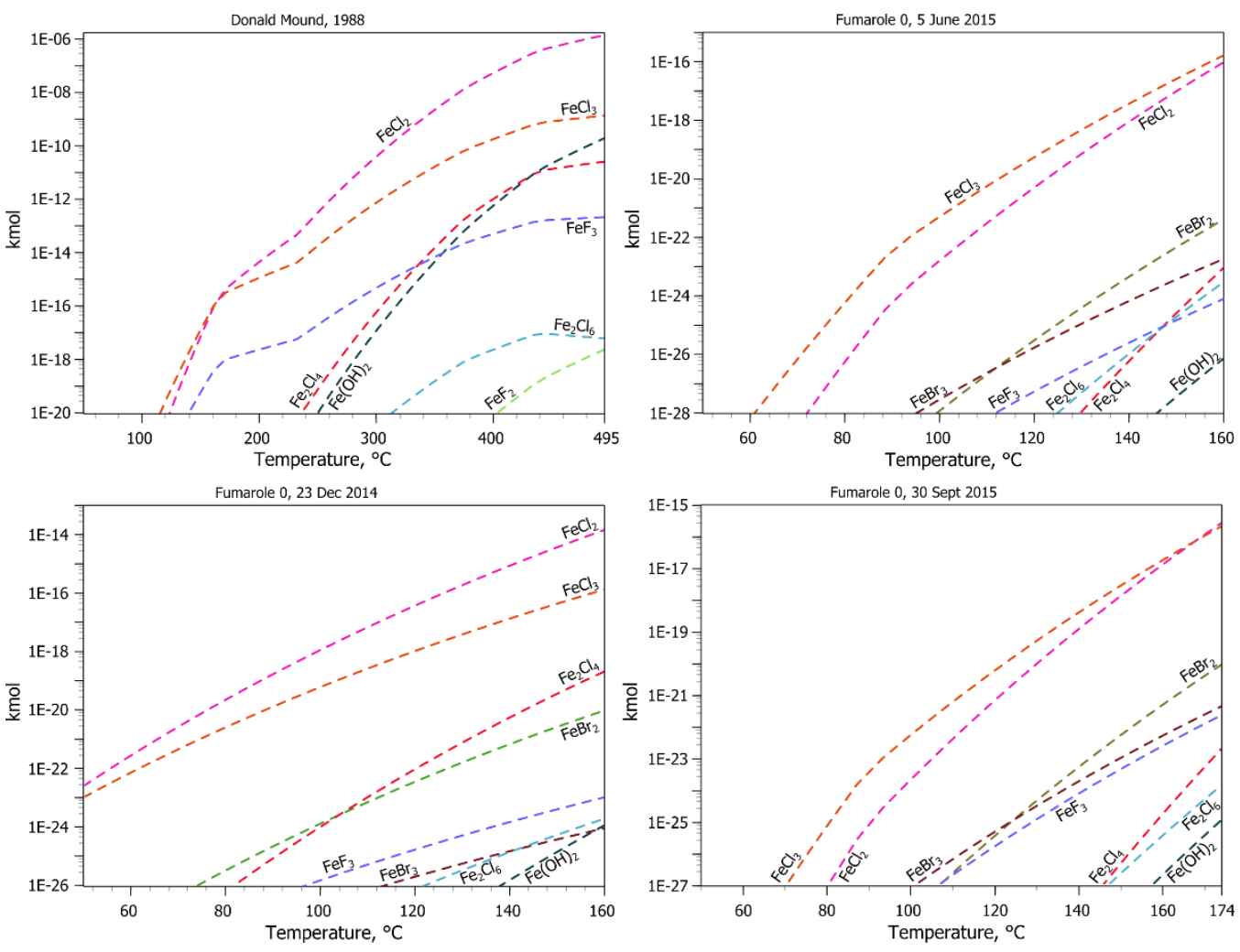

Figure 5-14: Speciation of the most abundant gaseous Fe species.
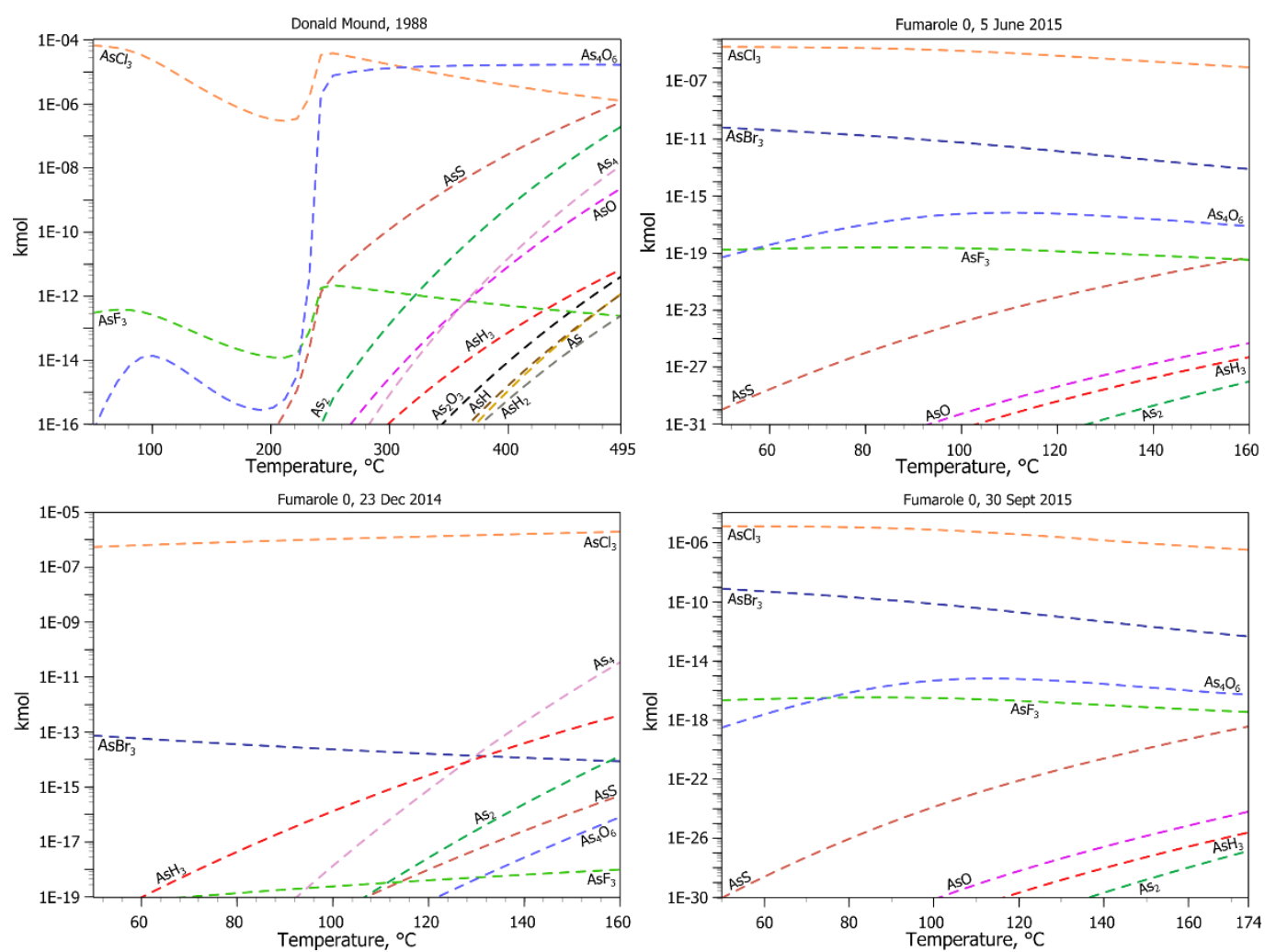

Figure 5-15: Speciation of the most abundant gaseous As species. 

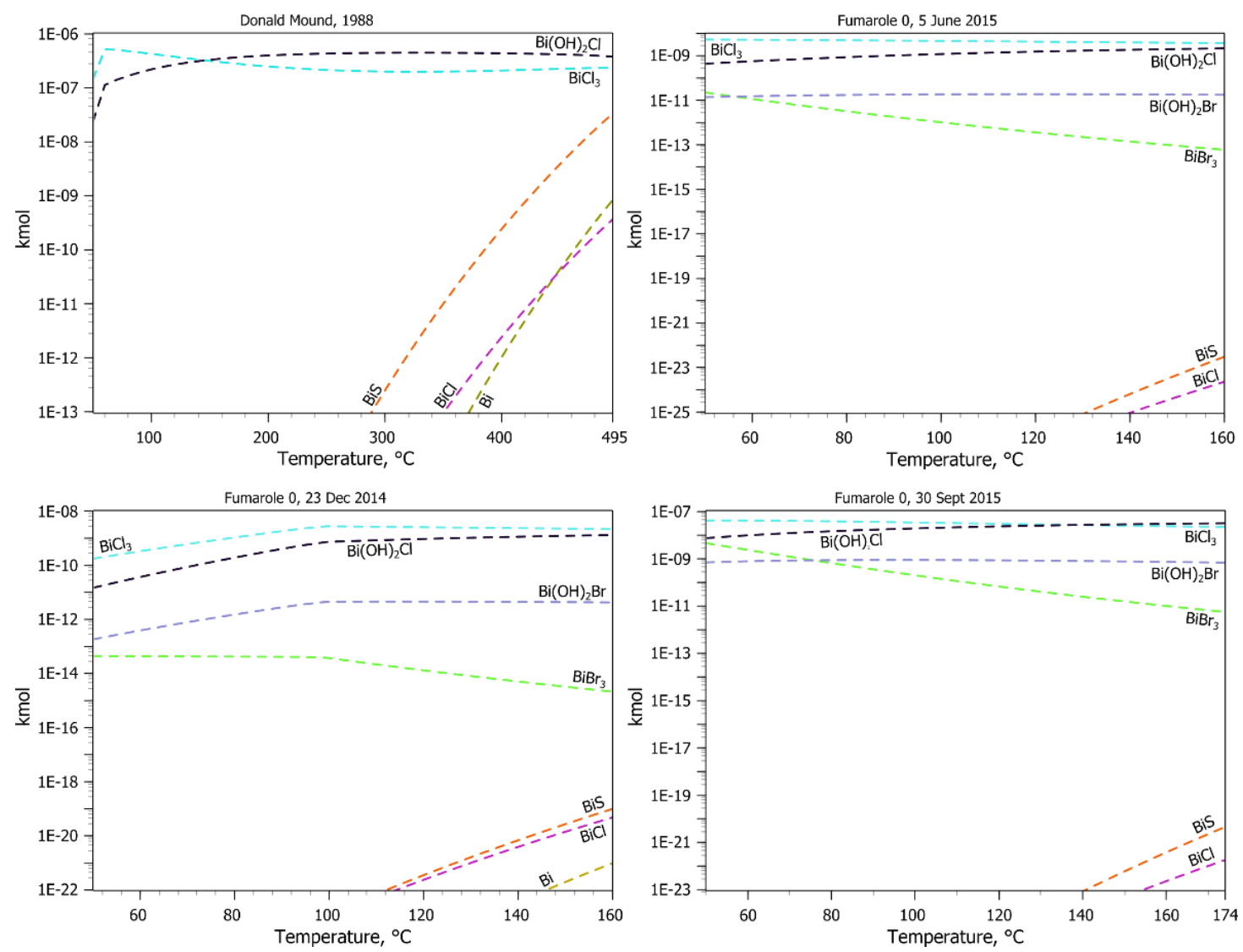

Figure 5-16: Speciation of the most abundant gaseous Bi species.

In addition to speciation in the gas phase, we modeled solid and liquid phases depositing as the gas is cooled to $50{ }^{\circ} \mathrm{C}$. Figure 5-17 shows the species predicted to form during such a process. The most noticeable result is the near absence of chloride minerals, in contrast with the abundance of gaseous chloride complexes. Molysite $\left(\mathrm{FeCl}_{3}\right)$ and lafossaite $(\mathrm{TlCl})$, for instance, may occur in volcanic sublimates (Menyaylov et al., 1983; Getahun et al., 1996; Zelenski and Bortnikova, 2005; Roberts et al., 2006). The results from Donald Mound show a deposition sequence of minerals containing $\mathrm{Fe}, \mathrm{Cu}, \mathrm{As}, \mathrm{Zn}$ and $\mathrm{Bi}$, from high to low temperature. The stable phases tend to be sulfides at high temperature, replaced by sulfates with cooling. We observe magnetite deposition at the highest temperature, supplanted by pyrite $\left(\mathrm{FeS}_{2}\right)$, and finally hydrated iron sulfates at $\mathrm{T}<160{ }^{\circ} \mathrm{C}$. At high temperature, the $\mathrm{Cu}-$ containing minerals are iron or arsenic sulfosalts, whereas covellite is precipitating at $\mathrm{T}<180$ ${ }^{\circ} \mathrm{C}$. The only chloride mineral is $\mathrm{BiCl}_{3}$, depositing at very low temperature. We also observe condensation of liquid phases, elemental sulfur and AsS, commencing at $\sim 240{ }^{\circ} \mathrm{C}$. Elemental sulfur is known to condense at $\mathrm{T}<350^{\circ} \mathrm{C}$, following (Matsuo, 1962; Mizutani and Sugiura, 1966):

$$
2 \mathrm{H}_{2} \mathrm{~S}_{(g)}+\mathrm{SO}_{2(g)}=3 \mathrm{~S}^{0}+2 \mathrm{H}_{2} \mathrm{O}
$$

This is in agreement with our observations of solidified droplets of elemental sulfur in the sublimate tubes at temperature $<160{ }^{\circ} \mathrm{C}$. Condensation of AsS is likely to be responsible for the drop in As gaseous species stability discussed above. 
As expected from the cooling of Donald Mound gases, the calculations show that the 2015 F0 samples have low-temperature mineral assemblages. $\mathrm{ZnSO}_{4}$ replaces sphalerite at $\mathrm{T}<155$ ${ }^{\circ} \mathrm{C}$, whereas hydrated iron sulfates are precipitating at all temperature. Pyrite is not predicted to deposit at $\mathrm{T}<171{ }^{\circ} \mathrm{C}$, although it was observed in the two tubes at temperature lower than $160{ }^{\circ} \mathrm{C}$. Covellite, however, deposits over the whole temperature range in the computation. The lack of minerals containing $\mathrm{Cu}$ and $\mathrm{Zn}$ in our observations may reflect their segregation by elemental sulfur, owing to the elevated metal content in the condensing liquid (see Table 5-3). $\mathrm{ZnSO}_{4}$ is also very soluble in water, which is likely to be present at $\mathrm{T}<100{ }^{\circ} \mathrm{C}$. Condensation of liquid sulfur and AsS is predicted in the two F0 samples from 2015. It is worth noting that AsS liquid might be at the origin of the unidentified As bearing crystals observed in the tubes, solidifying after condensation. The predominance of sulfates in the model is in agreement with minerals observed both in the sublimate tubes and in the natural incrustations.
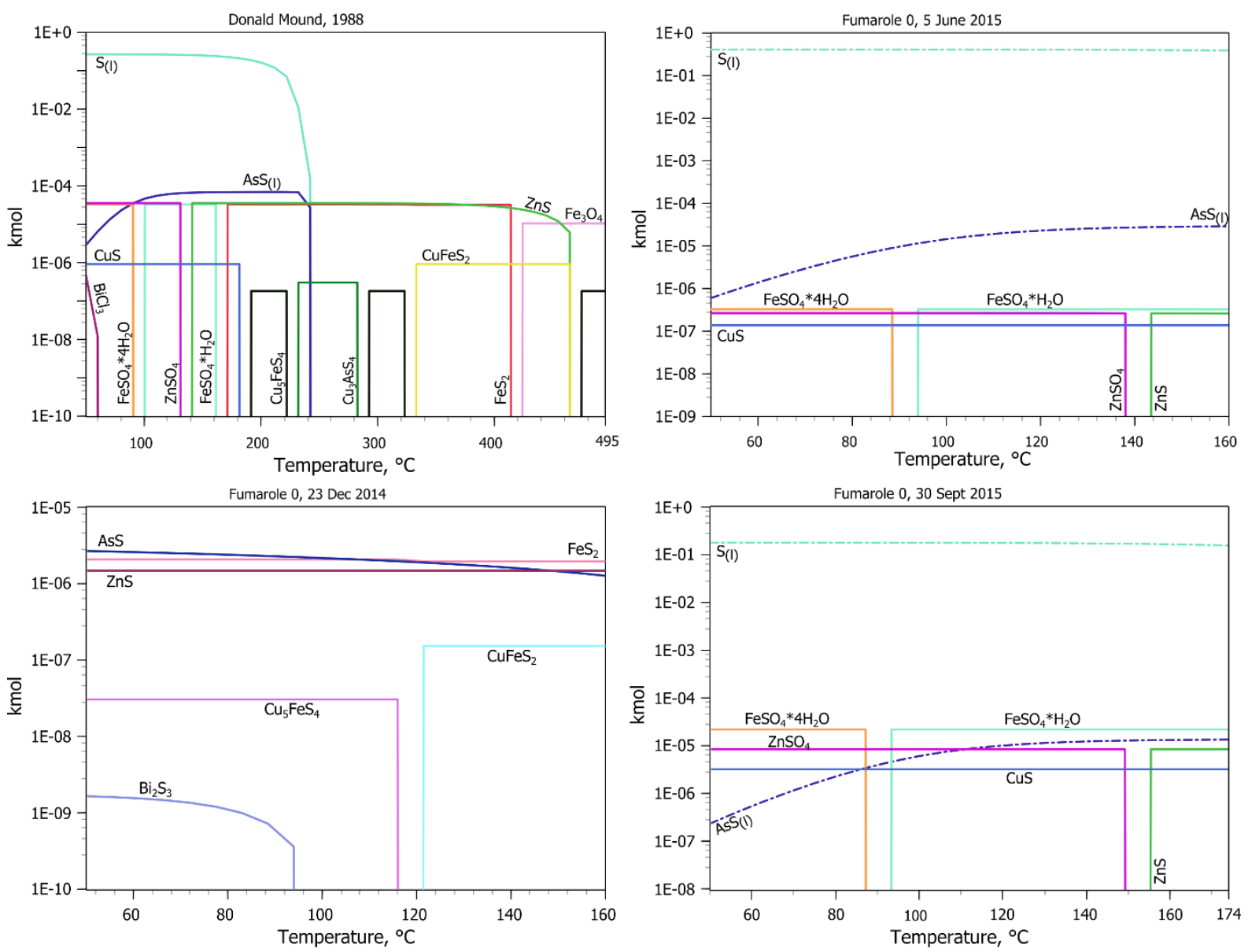

Figure 5-17: Sublimates and condensates formed during cooling.

The modeled assemblage depositing from the more hydrothermal gases from December 2014 differs greatly from the three other gases (Figure 5-17). Sulfides and sulfosalts are the only minerals precipitating, as would be expected from reduced gases. The absence of elemental sulfur may arise from the low total sulfur content of the gas $(0.42 \mathrm{~mol} \%)$. 
We modeled the effect of mixing with oxidized atmospheric air by incrementally adding $\mathrm{N}_{2}$ and $\mathrm{O}_{2}$ to the F0 June 2015 sample. The speciation of gaseous species is mostly unchanged, with predominance of chloride and bromide complexes. Changes arise for bismuth, with $\mathrm{Bi}(\mathrm{OH})_{2} \mathrm{Cl}_{(\mathrm{g})}$ becoming more abundant than $\mathrm{BiCl}_{3(\mathrm{~g})}$. $\mathrm{AsCl}_{3(\mathrm{~g})}$ remains the most stable phase until high $f_{\mathrm{O}_{2}}$, when it is replaced by $\mathrm{As}_{4} \mathrm{O}_{10(\mathrm{~g})}$. The modeled depositing phases, in contrast, reflect oxidation, with a shift to $\mathrm{CuSO}_{4}, \mathrm{ZnSO}_{4}, \mathrm{Fe}_{2}\left(\mathrm{SO}_{4}\right)_{3}$ and $\mathrm{As}_{2} \mathrm{O}_{5}$ depositing at $160{ }^{\circ} \mathrm{C}$. Such oxidizing conditions are likely to occur during deposition of the natural incrustations on the fumarole walls. Minerals observed in natural incrustations from fumarole F0 were mainly sulfates, in accordance with mixing with atmosphere. We however noted the presence of pyrite crystals, not predicted to deposit at such low temperature and high $f_{\mathrm{O}_{2}}$.

No $\mathrm{Pb}$-bearing minerals are predicted to deposit. $\mathrm{PbS}$ (galena) and $\mathrm{PbCl}_{2}$ (cotunnite) are the most common species reported in sublimates from reduced gases at $\mathrm{T}<400{ }^{\circ} \mathrm{C}$ (Stoiber and Rose, 1974; Bernard, 1985; Symonds et al., 1987; Quisefit et al., 1989; Cheynet et al., 2000; Africano et al., 2002; Wahrenberger et al., 2002). Sulfosalts of Bi, Pb, and As are also often observed (Le Guern, 1988; Quisefit et al., 1989; Garavelli et al., 1997; Cheynet et al., 2000; Africano et al., 2002; Zelenski and Bortnikova, 2005). Lead sulfate (anglesite) is common in more oxidized gases (Taran et al., 2001). As we did not detect Pb-containing sublimates, we cannot be sure that the lack of predicted solid species reflects reality and that it is not due to incomplete thermodynamic data. No Tl mineral is predicted to deposit, suggesting most of it is dispersed into the atmosphere. However, as noted above, thallium-containing minerals such as lafossaite $(\mathrm{TlCl})$, steropesite $\left(\mathrm{Tl}_{3} \mathrm{BiCl}_{6}\right)$ and hephaistosite $\left(\mathrm{TlPb}_{2} \mathrm{Cl}_{3}\right)$ have recently been found in fumarole sublimates at Vulcano (e.g. Roberts et al., 2006), whereas Nataliyamalikite (TII) was discovered at Avacha volcano, in Kamchatka (Okrugin et al., 2017).

To summarize, chloride appears to be the main ligand responsible for metal transport in the gas phase. This result supports findings from Chapter 2, suggesting correlation between $\mathrm{Cl}$ and metals during degassing of the magma, and exsolution from the shallow dacitic chamber. Despite the low abundance of $\mathrm{HBr}$ in volcanic gases $(\mathrm{HCl} / \mathrm{HBr}>2000)$, bromide complexes are extremely stable, especially at lower temperature, as reported in gases from Kudriavy and Vulcano (Wahrenberger, 1997). The role of sulfur is minor in this context. Metal sulfide complexes appear to be stable only at high temperature $\left(\mathrm{T}>500{ }^{\circ} \mathrm{C}\right)$. However, the presence of sulfur in the gas phase, and its oxidation state, strongly influence the metal speciation. This emphasizes the indirect control of sulfur on metal transport and deposition.

\subsection{Conclusions}

Rapid changes in fumarolic gas composition and temperature are observed at White Island, in response to changes in the magmatic feeding system. Giggenbach (1987) ascribed such variations to an evolving two-phase hydrothermal envelope surrounding the conduit. Cooling periods are reflected by invading liquids, reflected at the surface by emissions with a hydrothermal signature (e.g. $\mathrm{H}_{2} \mathrm{~S}, \mathrm{CH}_{4}$ ). In contrast, periods of higher activity are characterized by fumarolic gases of magmatic composition, indicating expansion of the single-phase vapor envelope. During heating period, the two-phase envelope is volatilized, retracting further away from the conduit. 
This study has demonstrated that metals are enriched in volcanic gases and that they respond similarly to interactions with the hydrothermal system. The lower metal concentrations in gases with hydrothermal signature emphasize metal "scrubbing" in shallow aquifers. Moreover, we observed a link with changes in magmatic activity. More $\mathrm{Tl}, \mathrm{Pb}, \mathrm{Bi}, \mathrm{Zn}$ and $\mathrm{Ag}$ are transported by high-temperature magmatic gases, suggesting that these species are deposited and/or scrubbed at temperatures $<495{ }^{\circ} \mathrm{C}$. In contrast, the copper load of gases at $<$ $200{ }^{\circ} \mathrm{C}$ and $495{ }^{\circ} \mathrm{C}$ is very similar, emphasizing efficient deposition at $\mathrm{T}>495{ }^{\circ} \mathrm{C}$, deeper within the system.

The oxidized nature of low-temperature fumarolic gases is reflected by the predominance of sulfate minerals precipitating around the vent. This assemblage may greatly differ during emissions of reduced gases with high hydrothermal contribution, dominated by precipitation of various sulfide and sulfosalt minerals. Pyrite is the only sulfide mineral observed, likely reflecting the higher abundance of iron compared to other metals. The absence of the predicted phases $\mathrm{CuS}, \mathrm{ZnS}$ and sulfosalts in the sublimate tubes may be due to the very low metal concentrations in the discharging gas. In addition, uptake of chalcophile elements into condensing elemental sulfur at $\mathrm{T}<240{ }^{\circ} \mathrm{C}$ may prevent sulfide precipitation. Lead and thallium show very volatile behavior, with no solid phases precipitating according to thermodynamic calculations. Sulfur removal by condensation of elemental sulfur is a very efficient process, as observed in the field. Several compounds rich in $\mathrm{As}$ or $\mathrm{Hg}$ are associated with sulfur, most likely forming through solidification of condensed liquids. The predicted formation of $\mathrm{AsS}_{(1)}$ at $\mathrm{T}<240{ }^{\circ} \mathrm{C}$ supports this interpretation. The results from thermodynamic modelling show an overall good agreement with species observed in nature, especially when considering oxidation following atmospheric mixing.

Thermochemical modelling emphasizes the role of chloride and bromide complexes in transporting $\mathrm{Pb}, \mathrm{Cu}, \mathrm{Zn}, \mathrm{Bi}$ and $\mathrm{Fe}$. In contrast, oxide complexes are dominant in the case of $\mathrm{Tl}$, and As at high temperature. The role of $\mathrm{S}$ as a ligand appears to be minor, with increasing importance for $\mathrm{Bi}, \mathrm{As}$ and $\mathrm{Pb}$ as temperature increases. However, sulfur remains a critical species given the control it exerts on the redox conditions of volcanic gases, themselves influencing metal transport. 


\section{Chapter 6: Metal emissions in volcanic plumes}

\subsection{Introduction}

The white cloud which sits over White Island, and for which the island is named, is the last piece of our puzzle. Having studied the metal composition of the magma itself, the crater lake and springs and the fumaroles, we now turn our attention to the plume.

Volcanoes represent a significant natural source of metals in the atmosphere by way of the plumes emitted both during eruptions and quiescent activity (Nriagu, 1989; Hinkley et al., 1999). The gas species of interest are similar to the fumarolic ones and include $\mathrm{SO}_{2}, \mathrm{H}_{2} \mathrm{~S}$, $\mathrm{HCl}, \mathrm{HF}$ (minor $\mathrm{HBr}$ and $\mathrm{HI}$ ), as well as some highly volatile trace components such as $\mathrm{Hg}$ (Kyle et al., 1990; Christenson and Mroczek, 2003; Delmelle, 2003; Mather et al., 2003b; Nriagu and Becker, 2003; Pyle and Mather, 2003; Bagnato et al., 2007; Witt et al., 2008; Bagnato et al., 2011). In addition to gaseous species, volcanic plumes also contain aerosols. These particles have various origins: 1) silicates swept up from the volcanic conduit and/or resulting from magma fragmentation, 2) condensation of droplets, 3) gas-to-particle conversion. The last two processes are responsible for the formation of $\mathrm{H}_{2} \mathrm{SO}_{4}$, halides, sulfates, sulfides, elemental sulfur and oxides in the particulate aerosols. Trace metals $(\mathrm{Cu}$, $\mathrm{Cr}, \mathrm{As}, \mathrm{Zn}, \mathrm{Se}, \mathrm{Cd}, \mathrm{Sn}, \mathrm{Sb}, \mathrm{Pb}, \mathrm{Tl}$ and $\mathrm{Bi}$ ) are concentrated in such aerosols as a result of strong partitioning into the particulate phase during cooling and dilution of the plume (Hinkley, 1991; Aiuppa et al., 2000; Allard et al., 2000; Obenholzner et al., 2003; Moune et al., 2010; Martin et al., 2012; Menard et al., 2014; Allard et al., 2015; Calabrese and D'Alessandro, 2015). The particle size in volcanic plumes ranges from $<0.01$ to $>25 \mu \mathrm{m}$, with most of the solids smaller than $2 \mu \mathrm{m}$ originating from gas-to-particle conversion within the plume (Hobbs et al., 1982; Vié le Sage, 1983; Rose et al., 1986; Allard et al., 2000; Watson and Oppenheimer, 2000; Martin et al., 2009a).

The impact of volcanic clouds on the environment and human health arises from the acidic gases and the heavy metals they carry. Not only are they a threat locally through gravity deposition and rain remobilization (Fulignati et al., 2006; Martin et al., 2009b; Calabrese et al., 2011; Floor et al., 2011; Calabrese and D'Alessandro, 2015), but also at a global scale due to their capacity to be dispersed into the troposphere (Siegel and Siegel, 1987; Delmelle, 2003).

The common method used to simultaneously collect the gas and particle fractions of a plume is by the use of filter packs. This technique was first introduced by Naughton et al. (1975) and further improved by Finnegan et al. (1989). The main advantages are the possibility to sample volcanic plumes from distance (both ground-based and airborne), thus allowing collection even during periods of higher activity. In conjunction with $\mathrm{SO}_{2}$ fluxes measured by remote sensing techniques (DOAS, COSPEC, UV camera), it also provides estimates of metal emission rates. The discrete character of collection however neglects the spatial and temporal variations of a plume. It also leaves behind any species transported in a different form than particle or acid gas, such as $\mathrm{H}_{2} \mathrm{O}$ and $\mathrm{Hg}$.

Many volcanoes are difficult or dangerous to access, leaving the filter pack technique as the only means to assess acidic gases and trace element emissions. As such, it has been widely 
used and improved over the years (Zoller et al., 1974; Varekamp et al., 1986; Pennisi et al., 1988; Finnegan et al., 1989; Kyle et al., 1990; Zreda-Gostynska et al., 1997; Gauthier and Le Cloarec, 1998; Allard et al., 2000; Allen et al., 2000; Aiuppa et al., 2003; Mather et al., 2003a; Martin et al., 2008; Moune et al., 2010; Calabrese et al., 2011; Martin et al., 2012; Mather et al., 2012; Zelenski et al., 2013; Menard et al., 2014; Allard et al., 2015; Gauthier et al., 2016).

The aim at White Island has been to estimate the amount of metals released by the superheated vent located at the back of the crater lake, at the root of the volcanic plume. The output flow suggests these gases are being discharged through the main conduit, most likely bearing a more magmatic signature compared to the other fumarolic discharges. We also compare the signature of White Island plume to magmatic-hydrothermal emissions from Mt Etna (Italy), and purely magmatic plume from Yasur (Vanuatu).

\subsection{Sampling and analytical methods}

Collection of plume material at White Island was performed from the western crater rim (Figure 6-1 a-b). The gases, entrained by the wind, rise as a vortex along the crater wall. Care was taken not to sample fumarolic gases emitted from the walls underneath. This setup relies on the wind direction to be constant. For this matter, the last sampling campaign was performed with a drone (Figure 6-1 c). All the equipment was mounted on the flying device and flown into the plume. The flight time, limited by the battery lifetime, was around 5 minutes. Background air samples for White Island were collected at Maketu, in the Bay of Plenty $\left(-37.75051^{\circ} \mathrm{S}, 176.46285^{\circ} \mathrm{E}\right)$.

In addition to White Island, we also sampled acidic gases and aerosols at Yasur volcano, in Vanuatu, and at Mount Etna in Italy. At Yasur, the trade winds commonly blow from the southeast, giving rise to the ash plain at the north west of the volcano. We installed our equipment on the western rim (Figure 6-1 d), at the margin of the volcanic plume (due to safety reasons). Background sample was collected from the southeast coast of Tanna island, close to the village of Manuapen $\left(-19.54838^{\circ} \mathrm{S}, 169.47821^{\circ} \mathrm{E}\right)$.

The samples from Mt Etna were collected on 3 August 2016 during the Etna International Training School of Geochemistry, from the southeast rim of Bocca Nuova crater (Figure 6-2). The eruption that took place in May of the same year resulted in the crater being filled with lava, hence depriving Etna from its usual plume. We sampled what was thought to be the plume making its way through the lava, emitted along a fissure in the south east sector of the Bocca Nuova crater $\left(37.74957^{\circ} \mathrm{S}, 14.99561^{\circ} \mathrm{E}\right)$. 


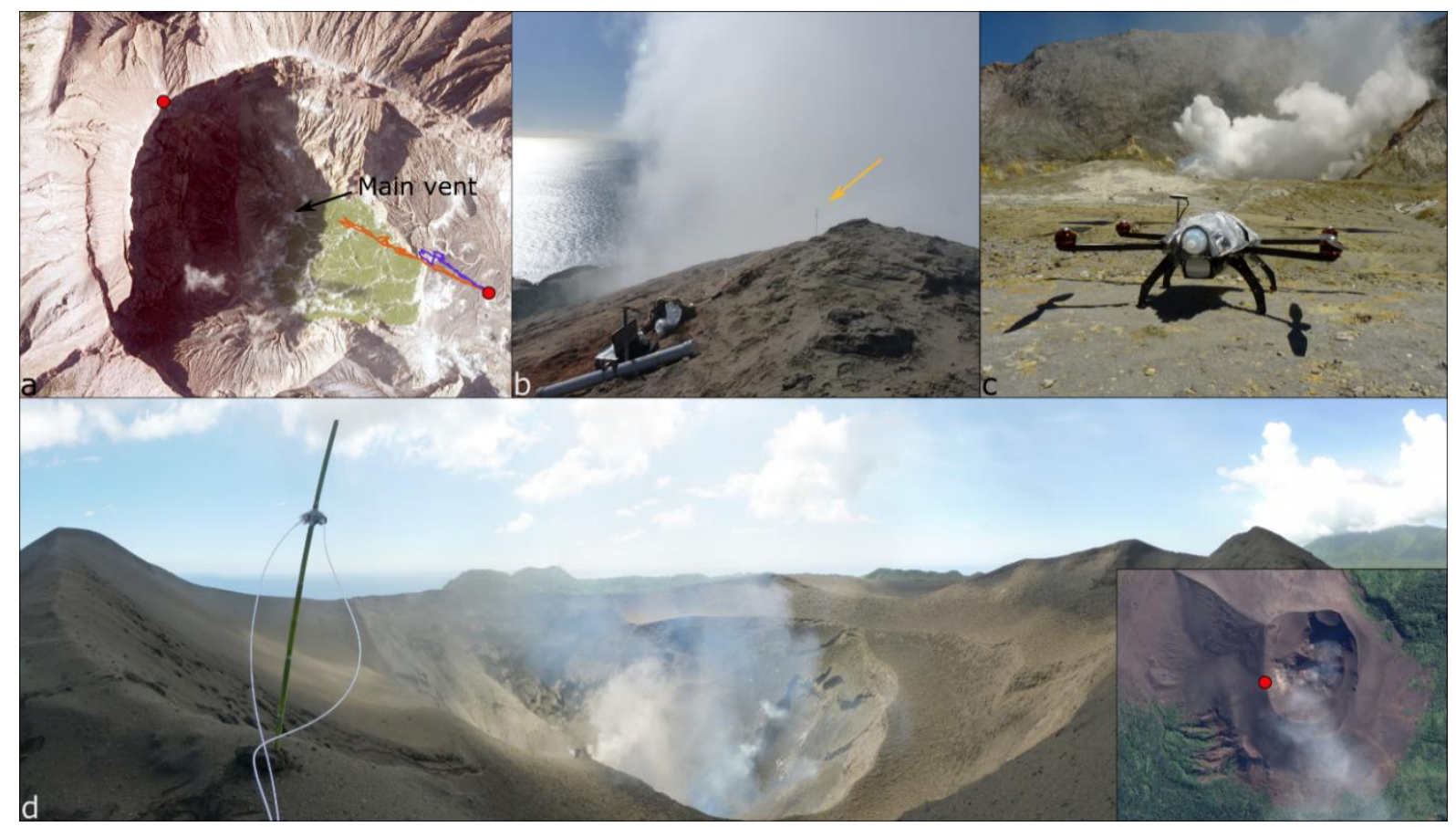

Figure 6-1: Sampling locations and setup at White Island and Yasur volcano, Vanuatu. a) Aerial picture (source: LINZ) showing the sampling location on the western rim and the two flight paths of the drone on 20 December 2016. The first flight is drawn in blue (sample WI S1), the second in red (sample WI S4). It should be kept in mind that the lake was dried during drone sampling in December 2016 (see Figure 4-5), with mainly the superheated vent emitting. b) Picture of the sampling settings on the western rim. Note the pole holding the filter packs in the middle of the plume. c) Picture of the flying device used for sampling. The filter pack is mounted at the front of the flying device. d) Picture of the sampling settings at Yasur volcano on the western rim. The inset (source: Google Earth) shows the location of sampling. The ash plain extends to the northwest.

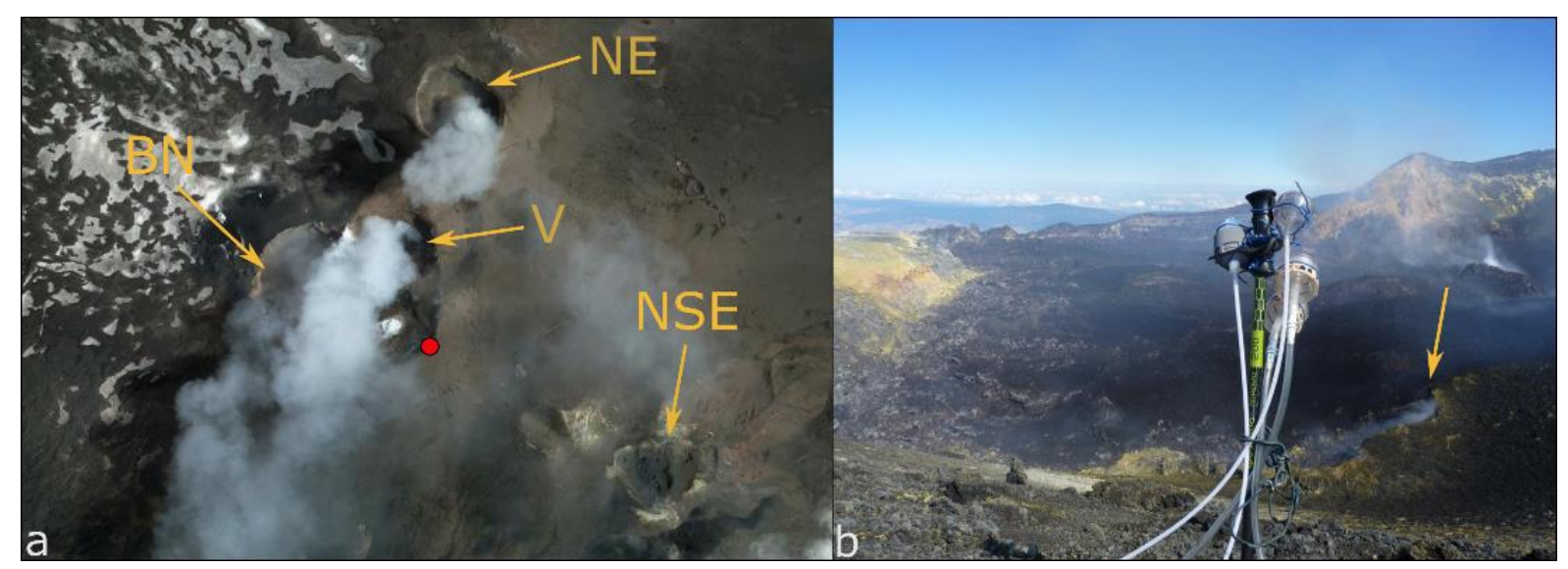

Figure 6-2: Sampling location at Mount Etna. a) Aerial picture (source Google Earth) showing the sampling location on the southeast rim of Bocca Nuova (BN). NE: Northeast crater. NSE: New southeast crater. V: Voragine. b) Picture of the pole holding the filter packs in front of the now filled Bocca Nuova crater. The arrow points to the fissure from which the plume is thought to escape. 
Filter pack sampling was done by pumping the plume through a PFA filter holder containing 4 filters in series. The first filter is a membrane collecting the particulate phase. On June 2016, we used two different types of membrane, a Millipore AAWP mixed cellulose esters membrane filter (diameter $47 \mathrm{~mm}$, pore size: $0.8 \mu \mathrm{m}$ ) and a Whatman ${ }^{\circledR}$ PTFE membrane (diameter $47 \mathrm{~mm}$, pore size $2 \mu \mathrm{m}$ ). The sampling campaigns in June and December 2016 at White Island, as well as Etna and Yasur, were done using Pall ${ }^{\circledR}$ Zefluor membranes (diameter $47 \mathrm{~mm}$, pore size $1 \mu \mathrm{m}$ ). In December 2016, we also sampled using a Sterlitech $\odot$ membrane (diameter $47 \mathrm{~mm}$, pore size $0.1 \mu \mathrm{m}$ ) to collect particles smaller than $1 \mu \mathrm{m}$. This particle membrane is followed by three paper filters (Whatman ${ }^{\circledR}$, ashless grade 41 , diameter $47 \mathrm{~mm}$ ) impregnated with a solution of $1 \mathrm{M} \mathrm{KOH}+5 \%$ Glycerol (Finnegan et al., 1989). The $\mathrm{KOH}$ solution reacts with the acid gases $\left(\mathrm{SO}_{2}, \mathrm{HCl}, \mathrm{HF}\right)$ in the plume. The sampling flow and duration were monitored in order to avoid saturation of the impregnated filters with respect to $\mathrm{SO}_{2}$. Such saturation results in non-quantifiable $\mathrm{S}$ measurements and was assessed by the total amount on the last (final) filter to be $<5 \%$ of the total amount. At White Island, we sampled for 20 to 30 minutes at a flow of 5-10 L. $\mathrm{min}^{-1}$. The range used at Yasur volcano was 8-40 $\mathrm{min}$ at 8-13 L. $\mathrm{min}^{-1}$. The flow and duration were reduced to $41 . \mathrm{min}^{-1}$ and 15-20 min at Etna due to the much higher $\mathrm{SO}_{2}$ flux. The flow rates and total volume of air pumped were measured by Bronkhorst ${ }^{\circledR}$ Mass View digital mass flow meters. The Zefluor membrane used at White Island in December 2016 and at Yasur were pre-washed with a dilute $\mathrm{HCl}$ solution to reduce the amount of background trace metals. Filter blanks for the different types of membrane are presented in Table 6-1.

As the amount of aerosol collected with the filter pack is limited (to avoid saturation of impregnated filters), we also used a single-stage holder with a PTFE filter (Pall@ Zefluor) to collect particles for trace elements analysis. Samples for SEM analysis were collected on polycarbonate filters (Nuclepore ${ }^{\circledR}$, diameter $25 \mathrm{~mm}$ ). In this case, air was drawn at a flow of 12-15 L. $\mathrm{min}^{-1}$ for 20 to $40 \mathrm{~min}$.

Table 6-1: Composition of blank particle filters (ng. $\left.\mathrm{g}^{-1}\right)$.

\begin{tabular}{lrrrrr}
\hline & $\begin{array}{r}\text { Sterlitech } \\
0.1 \mu \mathrm{m}\end{array}$ & $\begin{array}{r}\text { Pall } \\
1 \mu \mathrm{m}\end{array}$ & $\begin{array}{r}\text { Pall pre- } \\
\text { washed }\end{array}$ & $\begin{array}{r}\text { Whatman } \\
2 \mu \mathrm{m}\end{array}$ & $\begin{array}{r}\text { Millipore } \\
\text { Cellulose }\end{array}$ \\
\hline $\mathrm{B}$ & 10.7 & 29.3 & 8.35 & 34.8 & 31.9 \\
$\mathrm{Na}$ & 18.2 & 381.2 & 33.6 & $\mathrm{na}$ & na \\
$\mathrm{Ca}$ & 365.8 & $\mathrm{na}$ & 168.0 & 167.2 & 5556.4 \\
$\mathrm{Rb}$ & 0.04 & 0.04 & 0.01 & 0.003 & 4.1 \\
$\mathrm{Sr}$ & $\mathrm{na}$ & 0.91 & 1.71 & 0.12 & 32.2 \\
$\mathrm{Zr}$ & 0.34 & 2.29 & 0.29 & 0.06 & 0.21 \\
$\mathrm{Mo}$ & 0.12 & 0.29 & 0.29 & 0.08 & 2.0 \\
$\mathrm{Ag}$ & 0.08 & 0.14 & 0.01 & 0.01 & 0.46 \\
$\mathrm{Cd}$ & 0.09 & 0.03 & 0.01 & 0.001 & 0.13 \\
$\mathrm{In}$ & 0.001 & 1.28 & 1.35 & $\mathrm{nd}$ & 0.16 \\
$\mathrm{Sn}$ & 3.70 & 406.6 & 499.8 & 0.14 & 51.9 \\
$\mathrm{Sb}$ & 0.08 & 0.07 & 0.11 & $\mathrm{na}$ & 0.64 \\
$\mathrm{Te}$ & - & - & - & 0.02 & 0.08 \\
$\mathrm{Ba}$ & 1.27 & 1.62 & 0.39 & 0.05 & 21.5 \\
\hline
\end{tabular}




\begin{tabular}{lrrrrr}
\hline & $\begin{array}{r}\text { Sterlitech } \\
0.1 \mu \mathrm{m}\end{array}$ & $\begin{array}{r}\text { Pall } \\
1 \mu \mathrm{m}\end{array}$ & $\begin{array}{r}\text { Pall pre- } \\
\text { washed }\end{array}$ & $\begin{array}{r}\text { Whatman } \\
2 \mu \mathrm{m}\end{array}$ & $\begin{array}{r}\text { Millipore } \\
\text { Cellulose }\end{array}$ \\
\hline $\mathrm{Sm}$ & 0.01 & 0.003 & 0.003 & - & 0.05 \\
$\mathrm{Yb}$ & 0.003 & 0.002 & 0.001 & - & 0.02 \\
$\mathrm{~W}$ & - & 0.02 & 0.02 & 0.09 & 4.0 \\
$\mathrm{Re}$ & - & 0.002 & 0.001 & - & 0.001 \\
$\mathrm{Au}$ & 0.04 & 1.36 & 0.46 & 0.004 & 0.01 \\
$\mathrm{Tl}$ & 0.15 & 0.01 & 0.01 & 0.004 & 0.03 \\
$\mathrm{~Pb}$ & 0.09 & 0.23 & 0.11 & 0.02 & 12.9 \\
$\mathrm{Bi}$ & 0.01 & 0.01 & 0.003 & 0.003 & 0.04 \\
$\mathrm{Mg}$ & 6.91 & 46.7 & 11.0 & 5.16 & 1376 \\
$\mathrm{Al}$ & 94.4 & 74.4 & 37.4 & 16.6 & 31.3 \\
$\mathrm{Sc}$ & 0.02 & 0.01 & 0.002 & - & 0.01 \\
$\mathrm{Ti}$ & 3.04 & 2.02 & 40.2 & 0.46 & 16.0 \\
$\mathrm{~V}$ & 0.08 & 0.14 & 0.07 & 0.002 & 0.16 \\
$\mathrm{Cr}$ & 17.8 & 4.78 & 2.08 & 5.81 & 316.0 \\
$\mathrm{Mn}$ & 0.25 & 15.6 & 0.23 & na & na \\
$\mathrm{Fe}$ & 10.3 & 50.8 & 16.6 & 7.84 & 115.6 \\
$\mathrm{Co}$ & 0.005 & 0.06 & 0.02 & 0.02 & 0.17 \\
$\mathrm{Ni}$ & 0.19 & 2.89 & 0.66 & 0.80 & 9.4 \\
$\mathrm{Cu}$ & 0.90 & 0.87 & 0.55 & 0.10 & 130.3 \\
$\mathrm{Zn}$ & 12.8 & 18.2 & 5.34 & 1.80 & 148.9 \\
$\mathrm{Ga}$ & 0.03 & 0.03 & 0.01 & 0.01 & 0.01 \\
$\mathrm{~K}$ & 8.28 & 99.5 & 40.3 & 1.99 & 2857 \\
$\mathrm{As}$ & 0.36 & - & - & 0.10 & 2.1 \\
$\mathrm{Se}$ & 2.15 & - & - & 0.31 & 3.4 \\
\hline $\mathrm{Notes}:$ & na: Not analyzed. & - Below detection limit. \\
& & & & &
\end{tabular}

The filter cassettes were prepared and taken apart in a class 100 clean lab, in a fume hood and using nitrile gloves. Filters were handled using polypropylene or Teflon tweezers. The packs were transported in doubly sealed bags, and, when possible, were stored at $-18{ }^{\circ} \mathrm{C}$ until analysis. Impregnated filters were extracted in $30 \mathrm{~mL}$ of distilled de-ionized water, to which a drop of $\mathrm{H}_{2} \mathrm{O}_{2}$ was added to oxidize any sulfide into sulfate. The solutions were analyzed after a week by ion chromatography (Dionex ICS-3000, GNS Science, Lower Hutt, New Zealand) for $\mathrm{F}^{-}, \mathrm{Cl}^{-}$and $\mathrm{SO}_{4}{ }^{2-}$. Interferences created by the paper filters in the region of $\mathrm{F}^{-}$prevented quantification of the low amount present in White Island samples. $\mathrm{SO}_{2}, \mathrm{HCl}$ and $\mathrm{HF}$ abundances in the plume were derived from the sulfate and halide ions concentrations. Dionex seven anion standard solution was used for calibration, with a reproducibility of $7 \%$ (1 RSD).

Aerosol components on the PTFE membranes were digested in PTFE beakers with a solution of $3 \mathrm{~mL} 8 \mathrm{M} \mathrm{HNO}_{3}+3 \mathrm{~mL} 6 \mathrm{M} \mathrm{HCl}$ and left on a hot plate at $120{ }^{\circ} \mathrm{C}$. After two days, the filters were rinsed with $2 \mathrm{M} \mathrm{HNO}_{3}$ and removed from the beaker. The solutions were then dried down, refluxed in $15 \mathrm{M} \mathrm{HNO}_{3}$ and dried down again. Finally, the samples were taken up in $10 \mathrm{~mL}$ of $1 \% \mathrm{HNO}_{3}$ and analyzed by double focusing magnetic sector field ICP-MS (Element $2^{\mathrm{TM}}$, Thermo Fisher Scientific) at Victoria University of Wellington following the 
procedure described in 4.2.3.1. A synthetic solution was used to calibrate the ICP-MS. Acid blanks and certified reference material SLRS-4 (Yeghicheyan et al., 2001) were run throughout the analysis. The accuracy, as the deviation from the certified value in percent, is as follows: $97 \%$ for $\mathrm{Ag}$ and Te, $70 \%$ for $\mathrm{Zn},<30 \%$ for $\mathrm{Na}, \mathrm{Zr}, \mathrm{Cd}, \mathrm{Sb}, \mathrm{W}, \mathrm{Tl}, \mathrm{V}, \mathrm{Mn}, \mathrm{Co}, \mathrm{Ga}$, As, Se and less than $10 \%$ for the other elements (Appendix A.7).

A round section of the polycarbonate filters was cut for observation with the SEM. EDS analyses, despite being semi-quantitative, suggests the nature of the particles.

\subsection{Chemical features}

The results are presented in Table 6-2 for White Island. All the results were corrected for the contribution of the filter, by subtracting the respective background content presented in Table 6-1. The great variability of the results reflects spatial and temporal variations of volcanic plumes (e. g. density), as well as changes in wind directions in some cases (Aiuppa et al., 2002).

Table 6-2: Acid gases and aerosol compositions of filter packs from White Island plume.

\begin{tabular}{|c|c|c|c|c|c|c|c|c|c|c|}
\hline & WI S4 & WI S2 & WI S3 & WI P5 & WI S2 & WI S3 & WI P & $\mathrm{WI} \mathrm{S1}^{*}$ & WI S4* & Maketu \\
\hline \multirow[t]{2}{*}{ Date } & 26 Jun & 26 Jun & 26 Jun & 26 Jun & 17 Jun & 17 Jun & 17 Jun & $20 \mathrm{Dec}$ & $20 \mathrm{Dec}$ & $4 \mathrm{Mar}$ \\
\hline & 2015 & 2015 & 2015 & 2015 & 2016 & 2016 & 2016 & 2016 & 2016 & 2017 \\
\hline Vol. $\left(m^{3}\right)$ & 0.102 & 0.141 & 0.055 & 0.529 & 0.154 & 0.148 & 0.289 & 0.012 & 0.013 & \\
\hline $\mathrm{SO}_{2}$ (t/day) & 343 & 343 & 343 & 343 & 246 & 246 & 246 & 402 & 402 & \\
\hline \multicolumn{11}{|c|}{ Acid gases $\mu \mathrm{g} \cdot \mathrm{m}^{-3}$} \\
\hline $\mathrm{HCl}$ & 4414 & 3940 & 4546 & & 11159 & 8885 & & 2521 & 484 & 414 \\
\hline $\mathrm{SO}_{2}$ & 20175 & 19308 & 18894 & & 20986 & 17764 & & 4519 & 5138 & 247 \\
\hline $\mathrm{SO}_{2} / \mathrm{HCl}$ & 4.57 & 4.90 & 4.16 & & 1.88 & 2.00 & & 1.79 & 10.61 & \\
\hline \multicolumn{11}{|c|}{ Aerosols ng.m ${ }^{-3}$} \\
\hline B & 796.4 & 352.2 & 2864 & 61.1 & na & na & na & 2285 & 1948 & - \\
\hline $\mathrm{Na}$ & na & na & na & na & 303.5 & - & - & 199.0 & 1640 & 25750 \\
\hline $\mathrm{Ca}$ & 31059 & 16931 & 25347 & 3201 & 1382 & 3750 & 1011 & 107583 & 11266 & 70505 \\
\hline $\mathrm{Rb}$ & 2.5 & 4.8 & 11.1 & 1.3 & 0.48 & 0.41 & 0.21 & 5.1 & 1.0 & 1.9 \\
\hline Sr & 12.3 & 48.6 & 74.6 & 7.4 & na & na & na & na & na & na \\
\hline $\mathrm{Zr}$ & 3.0 & 12.7 & 16.4 & 1.6 & - & - & - & 69.2 & 31.8 & 71.3 \\
\hline Mo & 42.8 & 1.6 & 2.7 & 1.0 & - & - & - & - & 24.0 & 0.81 \\
\hline $\mathrm{Ag}$ & - & 1.9 & 4.3 & 1.2 & - & - & - & - & 7.0 & 0.56 \\
\hline $\mathrm{Cd}$ & 0.92 & 0.82 & 0.88 & 0.65 & 1.2 & 0.16 & 0.07 & - & - & 0.12 \\
\hline $\ln$ & - & 0.31 & 0.32 & 0.30 & - & - & - & - & - & - \\
\hline Sn & - & 14.0 & 20.6 & 7.1 & na & na & na & na & na & na \\
\hline $\mathrm{Sb}$ & 26.1 & 20.3 & 60.6 & 10.4 & 16.9 & 14.1 & 8.4 & 26.9 & - & 0.63 \\
\hline Te & 31.5 & 46.9 & 31.1 & 39.4 & 13.5 & 9.2 & 2.9 & - & - & 0.29 \\
\hline $\mathrm{Ba}$ & 1.9 & 97.7 & 120.1 & 15.6 & 53.5 & 22.3 & 3.1 & 496.0 & 76.7 & 274.4 \\
\hline $\mathrm{Sm}$ & 0.12 & 0.26 & 0.31 & 0.04 & 0.01 & 0.05 & 0.01 & 2.7 & 0.73 & 2.0 \\
\hline $\mathrm{Yb}$ & 0.05 & 0.13 & 0.14 & 0.02 & 0.01 & 0.03 & 0.01 & 0.80 & 0.18 & 0.59 \\
\hline W & 54.2 & 0.2 & - & 0.16 & - & 0.03 & - & - & - & 1.5 \\
\hline $\operatorname{Re}$ & 0.22 & 0.09 & 0.16 & 0.02 & - & - & - & - & - & - \\
\hline $\mathrm{Au}$ & 0.62 & 1.9 & 5.5 & 0.05 & - & - & - & - & 0.62 & - \\
\hline TI & 54.7 & 42.6 & 35.5 & 37.5 & 9.2 & 4.5 & 9.9 & 10.5 & - & 0.28 \\
\hline
\end{tabular}




\begin{tabular}{|c|c|c|c|c|c|c|c|c|c|c|}
\hline & WI S4 & WI S2 & WI S3 & WI P5 & WI S2 & WI S3 & WI P & WI S1 ${ }^{*}$ & WI S4 ${ }^{*}$ & Maketu \\
\hline $\mathrm{Pb}$ & 79.9 & 87.1 & 102.4 & 74.0 & 31.3 & 28.3 & 18.3 & 11.1 & 9.5 & 7.9 \\
\hline $\mathrm{Bi}$ & 37.2 & 24.8 & 21.7 & 22.9 & 2.4 & 1.5 & 1.1 & - & 5.4 & 0.14 \\
\hline Mg & 75.5 & 2792 & 6288 & 487.4 & 153.2 & 327.7 & 83.4 & 1656 & 501.9 & 3248 \\
\hline $\mathrm{Al}$ & 3755 & 20185 & 44345 & 4531 & 442.9 & 959.8 & 137.7 & 49105 & 10407 & 34088 \\
\hline Sc & 0.85 & 2.8 & 4.2 & 0.36 & 0.12 & 0.18 & 0.04 & 6.5 & 1.1 & 3.4 \\
\hline $\mathrm{Ti}$ & - & 431.6 & 844.7 & 78.9 & 19.8 & 43.9 & 4.1 & - & 272.3 & 1097 \\
\hline V & 8.0 & 25.9 & 44.2 & 4.0 & 1.7 & 1.1 & 1.1 & 14.4 & 5.5 & 18.4 \\
\hline $\mathrm{Cr}$ & - & 2333 & 5068 & 589.0 & - & - & - & - & 2153 & 15.7 \\
\hline $\mathrm{Mn}$ & - & - & - & - & - & - & - & 5.5 & 47.4 & 20.1 \\
\hline $\mathrm{Fe}$ & 1518 & 5243 & 9303 & 1142 & 254.7 & 169.1 & - & 448.0 & 1722 & 810.7 \\
\hline Co & 0.36 & 1.2 & 2.5 & 0.38 & 0.31 & - & - & - & 0.81 & 1.0 \\
\hline $\mathrm{Ni}$ & - & 14.2 & 21.8 & 3.0 & - & - & - & - & 53.0 & 5.3 \\
\hline $\mathrm{Cu}$ & - & 47.3 & 469.9 & 11.3 & 7.5 & 15.9 & 3.8 & - & 109.8 & 1.3 \\
\hline $\mathrm{Zn}$ & - & 248.6 & 549.1 & 83.7 & - & - & 628.8 & - & - & 37.7 \\
\hline Ga & 0.90 & 3.7 & 7.4 & 0.79 & 0.38 & 0.45 & 0.24 & 12.5 & 2.7 & 7.2 \\
\hline K & & 2451 & 4262 & 509.1 & 924.6 & 87.1 & 109.7 & & 1125 & 1488 \\
\hline As & 572.8 & 277.7 & 312.2 & 270.4 & 230.8 & 236.6 & 97.4 & 44.0 & - & 2.8 \\
\hline $\mathrm{Se}$ & 189.8 & 98.0 & 208.5 & 91.1 & 318.3 & 307.2 & 259.0 & & - & \\
\hline
\end{tabular}

Notes: - Below detection limit. na: Not analyzed.

$\mathrm{SO}_{2}$ (t/day) is the $\mathrm{SO}_{2}$ flux measured by GeoNet with airborne COSPEC.

*: Samples collected with a drone.

The particle filters WI P5 and WI P only collected the particulate phase (no acid gases).

Background air sampled on mainland at Maketu.

Reproducibility (1 RSD): Te $\pm 71 \%$; $\mathrm{Sn} \pm 61 \%$; Se, Tl, Au, W, Ag, Na < $\pm 40 \%$; B, Cd, Sb, Re, Pb, $\mathrm{Bi}, \mathrm{Mg}, \mathrm{Sc}, \mathrm{Ti}, \mathrm{Cr}, \mathrm{Zn},< \pm 20 \%$; $< \pm 10 \%$ for the rest of the elements (Appendix A.7).

The atmospheric background for White Island was measured on the beach in Maketu, in the Bay of Plenty. The strong wind on that day was most likely carrying droplets of sea water, indicated by very high values in major elements, $\mathrm{Ba}$ and $\mathrm{Zr}$ compared to background in Vanuatu (see Table 6-3). In White Island samples, many elements are nevertheless well above atmospheric background, emphasizing a volcanic origin.

\subsubsection{Major species}

The $\mathrm{SO}_{2}$ and $\mathrm{HCl}$ contents of the volcanic plume are 4.8-19.1 mg. $\mathrm{m}^{-3}$ and $1.5-10.0 \mathrm{mg} . \mathrm{m}^{-3}$ respectively. The $\mathrm{SO}_{2} / \mathrm{HCl}$ ratio in June 2016 is low compare to June 2015 (1.94 and 4.54 respectively) suggesting either a change in the magmatic settings, or variations of response from the hydrothermal system. It is possible that the $27^{\text {th }}$ April phreatic eruption induced changes in the surficial vent environment. The increase in temperature observed at fumarole F0 (from $\sim 160{ }^{\circ} \mathrm{C}$ in June 2015 to $\sim 190{ }^{\circ} \mathrm{C}$ in June 2016, cf. Chapter 5) might also be linked to this variation in $\mathrm{SO}_{2} / \mathrm{HCl}$ ratio. This ratio is very different in the two samples from December 2016, ranging from 1.79 to 10.61 . The sampling time was drastically reduced during drone sampling, and might explain these variations (less time to average temporal variations in the plume). During the second flight, we approached the vent more closely and flew at lower altitude, potentially collecting a greater proportion of the main vent compared to neighboring fumaroles. The higher $\mathrm{SO}_{2} / \mathrm{HCl}$ ratio might thus represent gases less affected by hydrothermal interactions. Overall, our understanding of the system is limited by the small 
number of sampling campaigns and the absence of direct comparison between drone and ground-based samples on the same day.

\subsubsection{Trace elements}

The most abundant elements in the volcanic plume are $\mathrm{B}, \mathrm{Na}, \mathrm{Ca}, \mathrm{Mg}, \mathrm{Al}, \mathrm{Ti}, \mathrm{Cr}, \mathrm{Fe}, \mathrm{K}$, with concentrations $>1000 \mathrm{ng} \cdot \mathrm{m}^{-3}$ in some occasions, besides Ti exhibiting a maximum of 845 ng. $\mathrm{m}^{-3}$. Arsenic and selenium are often higher than $100 \mathrm{ng} \cdot \mathrm{m}^{-3}$, whereas $\mathrm{Ba}, \mathrm{Pb}, \mathrm{Cu}$ and $\mathrm{Zn}$ sometimes exceed this value. The rest of the elements have contents $<100 \mathrm{ng} . \mathrm{m}^{-3}$, and less than 15 ng.m ${ }^{-3}$ for Rb, Ag, Cd, In, Re, Au, Sc, Co, Ga and Rare Earth Elements (Sm and Yb).
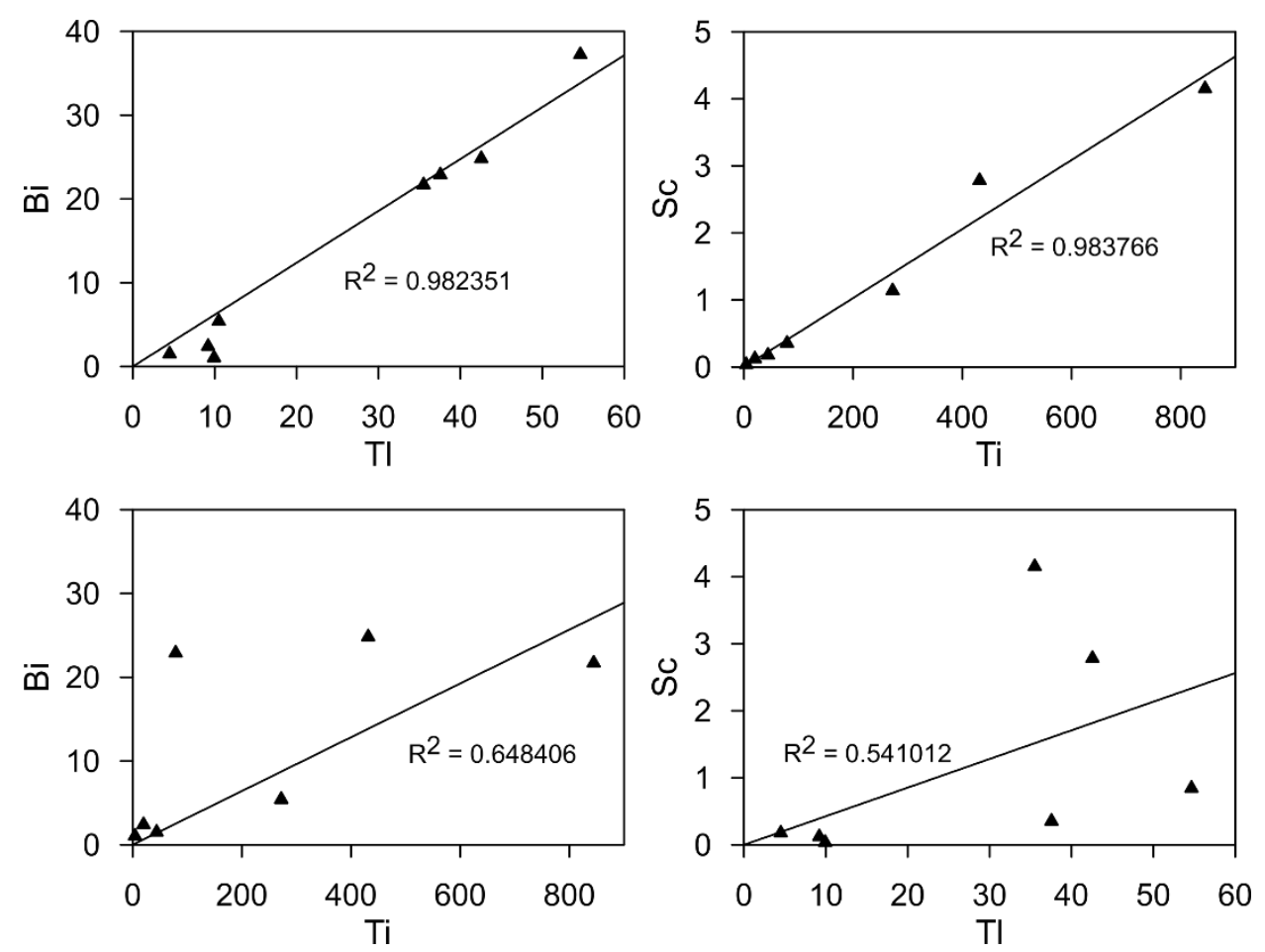

Figure 6-3: Bivariate plots suggesting different sources. The constant ratio between thallium and volatile elements such as $\mathrm{Bi}$ indicates they originate from a similar magmatic volatile phase. In contrast, the constant ratio between titanium and lithophile elements such as Sc suggests silicate nanoparticles as the common source. Conversely, Bi does not correlate with $\mathrm{Ti}$, nor does $\mathrm{Sc}$ with $\mathrm{Tl}$.

We observe a correlation between some chalcophile elements (e. g. $\mathrm{Cd}, \mathrm{Te}, \mathrm{Pb}, \mathrm{Bi}$ ) and highly volatile Tl (cf. Chapter 5 (Patterson and Settle, 1987; Hinkley et al., 1994; Baker et al., 2009)), whereas lithophile elements (e. g. Cr, Sc, Al, Sm, Yb, Ba) correlate with Ti (Figure 6-3). These correlations suggest two different sources for the particles within the plume. Lithophile elements are transported by solid nano-particles, either formed through magma fragmentation or swept up from the conduit walls. Chalcophile elements, in contrast, are transported by a magmatic volatile phase.

The contents of $\mathrm{Pb}, \mathrm{Bi}$ and $\mathrm{Tl}$ show strong variations with time, around one order of magnitude higher in June 2015 (Table 6-2). Arsenic shows a strong decrease during the 
studied period, from $358 \mathrm{ng} \cdot \mathrm{m}^{-3}$ in June 2015 to $44 \mathrm{ng} \cdot \mathrm{m}^{-3}$ in December 2016. Most elements are notably less concentrated in the June 2016 plume, with the exception of Se, Zn, $\mathrm{Ni}$, and $\mathrm{Ba}$. Samples collected closer to the source with the drone contain more lithophile elements ( $\mathrm{Zr}, \mathrm{Ba}, \mathrm{Yb}, \mathrm{Sm}, \mathrm{Mn})$, suggesting that silicate particles from the conduit wall settle before the plume reaches the crater rim.

Enrichment factors (Lepel et al., 1978; Vié le Sage, 1983) were calculated by dividing each element in the aerosol by the concentration of the same element in the host rock, both divided by a reference element. We chose $\mathrm{Al}$ for the latter as it is refractory and abundant in both aerosols and rocks. The rock composition used for White Island is the 1977 andesite, a lava reported by Aiuppa et al. (2003) for Etna and ash erupted during sampling at Yasur (Appendix A.8). Elements with EF $\sim 1$ are transported as silicate whereas species with EF > 1 are volatile, transported in aerosols formed through gas-to-particle conversion (Vié le Sage, 1983).

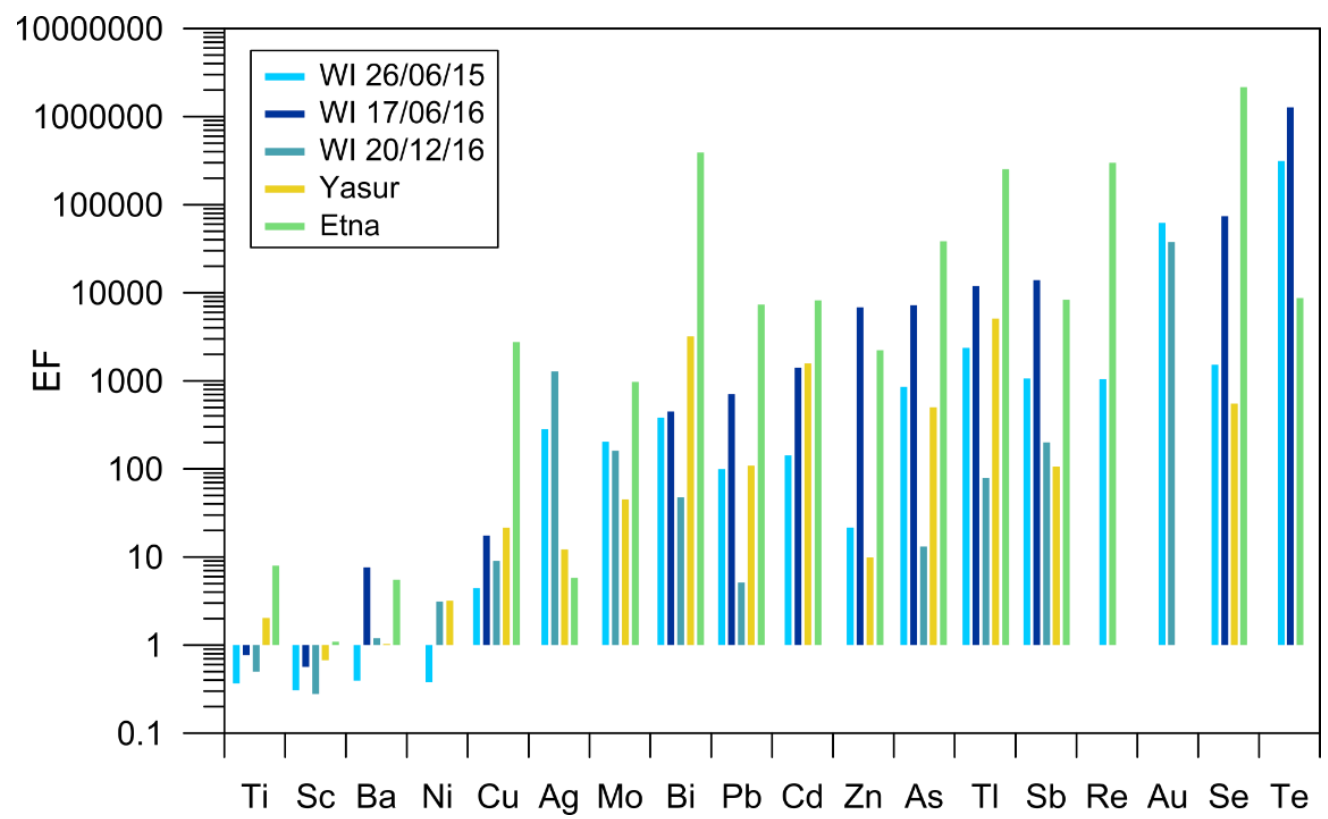

Figure 6-4: Enrichment factors of aerosols from White Island, Mount Etna, and Yasur volcanoes. The andesite from 1977 eruption was used for White Island, with Se content of $0.92 \mu \mathrm{g} \cdot \mathrm{m}^{-3}$ from Wells (1967). We used ash collected during sampling for Yasur and composition of lava from Etna reported by Aiuppa et al. (2003).

The results presented in Figure 6-4 show lithophile elements (Sc, Ba) with EF 1, in accordance with the correlation with Ti reported above. On the other hand, chalcophile and siderophile elements show volatile to extremely volatile behavior, with EF > 10000 for Se, Te and Au, similar to what was observed in fumarolic gases (cf. Chapter 5) and at other volcanoes (Aiuppa et al., 2003; Moune et al., 2010; Menard et al., 2014; Gauthier et al., 2016). Volatile elements with lower EF in December 2016 are likely reflecting the higher proportion of silicates in the aerosols sampled with the drone. 


\subsubsection{Aerosols from Yasur and Mount Etna volcanoes}

Results from the filter pack studies at Yasur and Etna volcanoes are presented in Table 6-3 and Table 6-4 respectively. Despite the short collection time at Etna, the two filter packs were saturated with respect to $\mathrm{SO}_{2}$, with $25 \%$ and $30 \%$ of the total sulfate present on the last filter. Such saturation indicates that we cannot quantify the total amount of $\mathrm{SO}_{2}$, leading to underestimated concentration of the latter species.

At Etna, our results indicate mean values of $60.4 \mathrm{mg} \cdot \mathrm{m}^{-3}, 7.2 \mathrm{mg} \cdot \mathrm{m}^{-3}$ and $0.13 \mathrm{mg} \cdot \mathrm{m}^{-3}$ for $\mathrm{SO}_{2}$, $\mathrm{HCl}$ and $\mathrm{HF}$ respectively, with a $\mathrm{SO}_{2} / \mathrm{HCl}$ ratio of 8.4 . These results are within the range previously measured by Calabrese et al. (2011) and Aiuppa et al. (2002), despite underestimation of $\mathrm{SO}_{2}$. At Yasur, average concentrations of $7.5 \mathrm{mg} \cdot \mathrm{m}^{-3}$ of $\mathrm{SO}_{2}, 0.7 \mathrm{mg} . \mathrm{m}^{-3}$ of $\mathrm{HCl}$ and $75 \mu \mathrm{g} \cdot \mathrm{m}^{-3}$ of $\mathrm{HF}$ respectively were measured, with a $\mathrm{SO}_{2} / \mathrm{HCl}$ molar ratio of 7.7. FTIR measurements of Yasur emissions reported by Oppenheimer et al. (2006) show $\mathrm{SO}_{2} / \mathrm{HCl}$ molar ratio of $\sim 2$ during passive degassing, whereas the same ratio rises to $\sim 30$ during Strombolian eruptions. Our value of 7.7 agrees with these previous estimates, as it represents average ratio of both types of emission (sampling time 8 to 40 minutes).

Table 6-3: Acid gases and aerosol compositions of filter packs from Yasur volcano plume.

\begin{tabular}{|c|c|c|c|c|c|c|c|c|c|}
\hline & S2 & S3 & S4 & S5 & S6 & S7 & N1 & $P$ & Manuapen \\
\hline Vol. $\left(\mathrm{m}^{3}\right)$ & 0.221 & 0.282 & 0.158 & 0.066 & 0.176 & 0.077 & 0.130 & 0.153 & \\
\hline \multicolumn{10}{|c|}{ Acid gases $\mu \mathrm{g} \cdot \mathrm{m}^{-3}$} \\
\hline HF & 52 & 23 & 54 & 123 & 38 & 161 & - & & - \\
\hline $\mathrm{HCl}$ & 582 & 205 & 904 & 721 & 423 & 2036 & 142 & & - \\
\hline $\mathrm{SO}_{2}$ & 6541 & 3000 & 7850 & 13759 & 5110 & 17756 & 2801 & & 17 \\
\hline $\mathrm{SO}_{2} / \mathrm{HCl}$ & 11.23 & 14.61 & 8.69 & 19.09 & 12.09 & 8.72 & 19.77 & & - \\
\hline \multicolumn{10}{|c|}{ Aerosols ng.m ${ }^{-3}$} \\
\hline $\mathrm{Na}$ & 6507 & 3007 & 65025 & 2106 & 66993 & 2947 & 1713 & 4607 & 1235 \\
\hline $\mathrm{Ca}$ & 10402 & 2785 & 86322 & 313.7 & 132431 & 25259 & 2409 & 4812 & 1042 \\
\hline $\mathrm{Rb}$ & 7.0 & 2.9 & 55.5 & 3.4 & 66.7 & 4.9 & 4.2 & 11.2 & 0.10 \\
\hline $\mathrm{Zr}$ & 13.0 & 5.0 & 148.5 & - & 179.6 & 1.6 & 9.8 & 2.2 & 0.20 \\
\hline Mo & 10.5 & - & 22.4 & - & 12.7 & - & 9.1 & 12.8 & 2.9 \\
\hline $\mathrm{Ag}$ & 0.4 & 0.22 & 2.3 & 0.21 & 2.3 & 0.59 & 0.26 & 1.1 & 0.06 \\
\hline $\mathrm{Cd}$ & 6.1 & 3.2 & 8.2 & 9.3 & 3.2 & 12.9 & 4.9 & 22.3 & 0.02 \\
\hline In & 7.2 & 15.4 & 50.9 & - & 49.2 & - & 20.0 & 25.6 & - \\
\hline $\mathrm{Sb}$ & 11.8 & 0.05 & 3.1 & - & 0.72 & 0.02 & - & - & 0.03 \\
\hline $\mathrm{Te}$ & 12.4 & 0.92 & 13.6 & 0.59 & 7.0 & 1.4 & 6.3 & 16.7 & 0.16 \\
\hline $\mathrm{Ba}$ & 110.4 & 37.2 & 1151 & 5.8 & 1431 & 35.0 & 36.0 & 28.6 & 3.4 \\
\hline Sm & 0.92 & 0.31 & 9.4 & 0.02 & 12.4 & 0.20 & 0.37 & 0.23 & 0.02 \\
\hline $\mathrm{Yb}$ & 0.52 & 0.18 & 5.2 & 0.01 & 7.0 & 0.08 & 0.21 & 0.10 & 0.02 \\
\hline W & 0.42 & - & 0.49 & - & 2.8 & - & 2.9 & - & - \\
\hline $\operatorname{Re}$ & 0.56 & 0.26 & 0.63 & 1.0 & 0.3 & 1.2 & 0.28 & 1.5 & - \\
\hline $\mathrm{TI}$ & 10.6 & 5.1 & 11.4 & 10.8 & 4.5 & 17.9 & 6.8 & 31.3 & 0.16 \\
\hline $\mathrm{Pb}$ & 51.4 & 26.8 & 79.3 & 77.2 & 59.3 & 99.9 & 26.6 & 119.7 & 0.12 \\
\hline $\mathrm{Bi}$ & 6.6 & 1.0 & 7.2 & 0.04 & 4.6 & 0.47 & 3.9 & 17.2 & 0.03 \\
\hline
\end{tabular}




\begin{tabular}{|c|c|c|c|c|c|c|c|c|c|}
\hline & S2 & S3 & S4 & S5 & S6 & S7 & N1 & $P$ & Manuapen \\
\hline $\mathrm{Mg}$ & 2952 & 1117 & 39367 & 13468 & 38630 & 877.8 & 917.5 & 767.6 & 234.4 \\
\hline Al & 17107 & 4599 & 153258 & 3074 & 205838 & 3751 & 6986 & 4363 & 462.9 \\
\hline Sc & 3.5 & 1.1 & 32.7 & 0.10 & 50.1 & 0.47 & 1.3 & 0.68 & 0.08 \\
\hline $\mathrm{Ti}$ & 1037.3 & 733.3 & 9877.0 & - & 11635.6 & - & 1526.3 & 112.3 & 3.5 \\
\hline V & 51.5 & 14.1 & 439.0 & 0.42 & 597.1 & 6.9 & 23.7 & 15.0 & 1.0 \\
\hline $\mathrm{Cr}$ & 0.65 & 3.1 & 42.2 & - & 33.9 & - & - & 0.08 & 0.02 \\
\hline Mn & 235.7 & 80.7 & 2775.9 & 7.3 & 3156.2 & 21.1 & 86.1 & 55.3 & 6.1 \\
\hline $\mathrm{Fe}$ & 11045 & 3535 & 122761 & 786.0 & 138772 & 1312 & 3711 & 3490 & 253.1 \\
\hline Co & 3.6 & 1.3 & 49.4 & 0.10 & 46.9 & 0.33 & 1.2 & 1.3 & 0.09 \\
\hline $\mathrm{Ni}$ & 0.77 & - & 86.3 & - & 34.7 & 2.9 & 8.3 & 2.5 & 0.78 \\
\hline $\mathrm{Cu}$ & 238.4 & 113.3 & 841.0 & 348.3 & 928.3 & 394.8 & 142.0 & 646.4 & 3.1 \\
\hline $\mathrm{Zn}$ & 51.5 & 10.2 & 200.3 & 12.0 & 198.7 & 66.2 & - & 136.6 & - \\
\hline Ga & 3.7 & 1.1 & 35.0 & 0.46 & 44.8 & 1.0 & 1.8 & 0.90 & 0.10 \\
\hline K & 5873 & 1859 & 45571 & 2156 & 49119 & 2683 & 2186 & 6023 & 236.4 \\
\hline As & 172.7 & 40.5 & 146.9 & 17.7 & 53.3 & 67.7 & 43.7 & 233.6 & 0.83 \\
\hline Se & 18.9 & 16.9 & 24.9 & - & - & - & - & 58.2 & 47.1 \\
\hline Ash\% & 2.5 & 1.9 & 23.2 & 0.04 & 39.6 & 0.08 & 2.3 & 1.5 & \\
\hline
\end{tabular}

Notes: - Below detection limit.

Background air sampled at Manuapen.

The particle filter P only collected the particulate phase (no acid gases).

Ash\%: Estimated assuming Mn originates from silicates only and using Yasur ash composition.

We notice high $\mathrm{Cu}$ concentrations with average content of $327 \mathrm{ng} \cdot \mathrm{m}^{-3}$ and $457 \mathrm{ng} \cdot \mathrm{m}^{-3}$ at Etna and Yasur respectively, against average of $176 \mathrm{ng} \cdot \mathrm{m}^{-3}, 9 \mathrm{ng} \cdot \mathrm{m}^{-3}$ and $110 \mathrm{ng} \cdot \mathrm{m}^{-3}$ (see Table 6-2) during the three sampling campaigns at White Island. This is in accordance with the results from the previous chapters, reporting overall low $\mathrm{Cu}$ contents in White Island emissions. Given the temperature dependence of $\mathrm{Cu}$ solubility in vapor, the lower temperature of White Island plume is likely to explain the lesser amount of $\mathrm{Cu}$ transported (Symonds et al., 1987). It is worth noting that the $\mathrm{Cu}$ concentration reported by Calabrese et al. (2011) at Etna from 2004 to 2007 is one order of magnitude higher $\left(\sim 2200 \mathrm{ng} \cdot \mathrm{m}^{-3}\right)$.

Table 6-4: Acid gases and aerosol compositions of filter packs from Mount Etna plume.

\begin{tabular}{|c|c|c|c|c|}
\hline & Etna S3 & Etna S4 & Etna $\mathrm{P}$ & Etna $N^{*}$ \\
\hline Vol. $\left(m^{3}\right)$ & 0.082 & 0.070 & 0.455 & Blank \\
\hline \multicolumn{5}{|c|}{ Acid gases $\mu \mathrm{g} \cdot \mathrm{m}^{-3}$} \\
\hline $\mathrm{HF}$ & 102 & 159 & & - \\
\hline $\mathrm{HCl}$ & 7351 & 7056 & & 2 \\
\hline $\mathrm{SO}_{2}$ & 68025 & 52803 & & 12 \\
\hline $\mathrm{SO}_{2} / \mathrm{HCl}$ & 9.25 & 7.48 & & 5.30 \\
\hline \multicolumn{5}{|c|}{ Aerosols ng.m ${ }^{-3}$} \\
\hline $\mathrm{Na}$ & - & - & 1975.0 & 39.4 \\
\hline $\mathrm{Rb}$ & 10.4 & 7.5 & 19.8 & 0.02 \\
\hline $\mathrm{Zr}$ & 26.6 & - & - & 0.20 \\
\hline Mo & 3.1 & - & 6.0 & - \\
\hline
\end{tabular}




\begin{tabular}{|c|c|c|c|c|}
\hline & Etna S3 & Etna S4 & Etna $\mathrm{P}$ & Etna $\mathrm{N}^{*}$ \\
\hline $\mathrm{Ag}$ & - & - & 0.004 & - \\
\hline $\mathrm{Cd}$ & 5.5 & 3.0 & 11.6 & 0.01 \\
\hline $\mathrm{Sb}$ & 1.9 & 0.88 & 1.7 & 0.07 \\
\hline $\mathrm{Te}$ & - & - & 13.9 & - \\
\hline $\mathrm{Ba}$ & - & - & 3.1 & 0.23 \\
\hline $\mathrm{Sm}$ & 0.41 & 0.01 & 0.03 & 0.001 \\
\hline $\mathrm{Yb}$ & 0.12 & - & 0.01 & 0.001 \\
\hline $\operatorname{Re}$ & 0.06 & 0.04 & 0.20 & - \\
\hline TI & 16.3 & 14.6 & 38.0 & 0.12 \\
\hline $\mathrm{Pb}$ & 55.2 & 52.4 & 98.1 & 0.09 \\
\hline $\mathrm{Bi}$ & 2.4 & 0.73 & 13.1 & \\
\hline $\mathrm{Al}$ & 5538 & - & 80.5 & 33.6 \\
\hline Sc & 0.71 & 0.01 & 0.03 & 0.01 \\
\hline $\mathrm{Ti}$ & 289.3 & 51.8 & 80.0 & 1.3 \\
\hline V & 6.1 & 3.9 & 5.3 & 0.07 \\
\hline $\mathrm{Mn}$ & - & - & 0.39 & 1.6 \\
\hline $\mathrm{Fe}$ & - & - & 249.8 & 90.1 \\
\hline Co & - & - & 0.64 & 0.11 \\
\hline $\mathrm{Cu}$ & 236.1 & 334.3 & 411.2 & 0.90 \\
\hline $\mathrm{Zn}$ & - & - & 205.3 & 6.1 \\
\hline $\mathrm{Ga}$ & 1.4 & - & 0.07 & 0.02 \\
\hline K & 1960 & 515.8 & 3278 & 24.5 \\
\hline As & 9.9 & 9.9 & 64.4 & - \\
\hline $\mathrm{Se}$ & 93.3 & 96.2 & 179.8 & - \\
\hline
\end{tabular}

Notes: - Below detection limit.

The particle filter Etna P only collected the particulate phase (no acid gases). *: Field blank in ug. $\mathrm{g}^{-1}$ and ng. $\mathrm{g}^{-1}$

Enrichment factors for Mount Etna, and especially for volatile elements (Se, $\mathrm{Re}, \mathrm{Tl}, \mathrm{As}, \mathrm{Cd}$, $\mathrm{Pb}, \mathrm{Bi}$ ), are higher than those for White Island (Figure 6-4). Different magma compositions may be responsible for these discrepancies. However, the greater concentrations of volatile elements at Etna might also reflect a more important magmatic contribution. In fact, discrete eruptions occurred in the evening following sampling, emphasizing the proximity of the magma. In contrast, the last magmatic eruption at White Island occurred in 2013. Moreover, the low temperature of emissions (plume and fumarolic gases) measured at White Island suggests that the two-phase envelope surrounding the conduit (Giggenbach, 1987) is well developed. Cooling of the metal-transporting vapors on their way to the surface is likely to trigger metal precipitation (Bernard, 1985; Symonds et al., 1987; Bernard et al., 1990) explaining the lower $\mathrm{EF}$ for White Island. Note the really high enrichment in $\mathrm{Bi}(\mathrm{EF}=390$ 000) in Mount Etna plume, in agreement with the bismuth iodide particles observed on the polycarbonate filter (see below).

Enrichment factors of volatile elements at Yasur are, on the other hand, in the same range as those at White Island. The Strombolian eruptions occurring every 2-10 minutes at Yasur are likely to be responsible (dilution effect), owing to the ash emitted during such events and collected onto the filters. The amount of ash on each filter was assessed by assuming Mn to 
be solely of silicate origin, and using the ash composition $\left(\mathrm{Mn}=1285 \mu \mathrm{g} \cdot \mathrm{g}^{-1}\right.$, Appendix A.8). The high concentration of aluminum in the aerosol fraction due to the presence of silicates, lowers the enrichment factors for volatile elements, depleted in the juvenile magma. Despite this dilution effect, $\mathrm{Bi}, \mathrm{Cd}$ and $\mathrm{Tl}$ show substantial enrichment. These values are similar to those reported at Ambrym, another volcano of the Vanuatu volcanic archipelago (Allard et al., 2015).

\subsection{Particle morphology and composition}

Single particles in White Island aerosols consist of euhedral sulfates, larger than $2 \mu \mathrm{m}$ in size (Figure 6-5 a). Two types of sulfates were observed, Ca sulfate and Al-K sulfate. Euhedral crystals of halite of up to $10 \mu \mathrm{m}$ were also found (Figure 6-6 a).

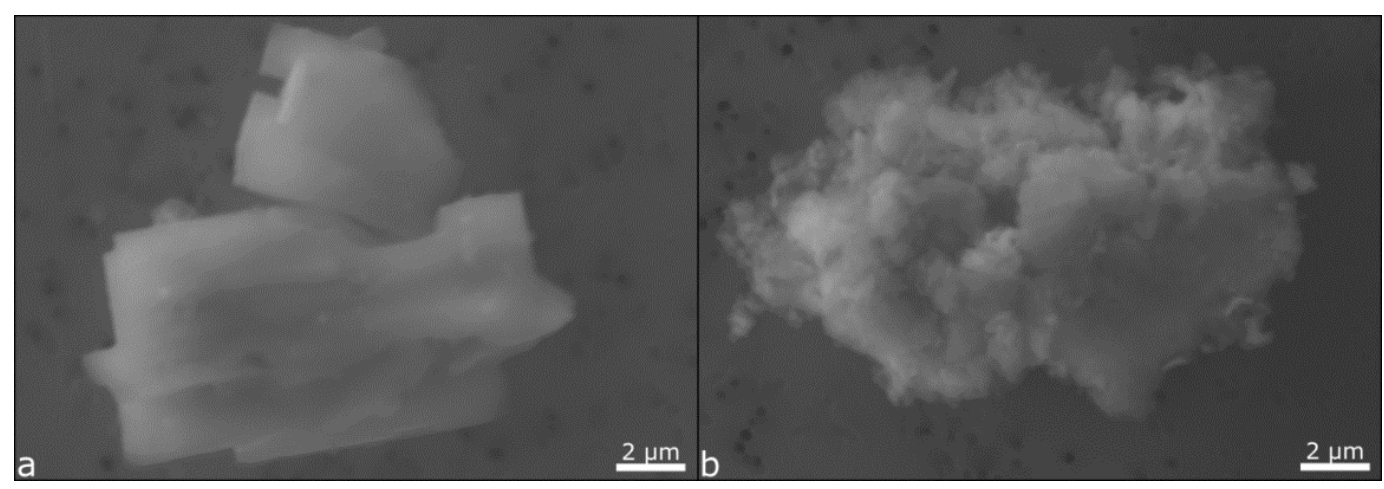

Figure 6-5: SEM pictures of White Island aerosols. a) Euhedral crystal of Ca sulfate. b) Zn oxide with minor amount of $\mathrm{Al}, \mathrm{Cu}, \mathrm{Al}$ and $\mathrm{S}$. All SE images. 
Figure 6-6: SEM pictures of White Island aerosols. a) Euhedral crystals of halite. b) Particle containing Si-S-O thought to be silica coated with sulfur. c) Aggregate of particles, coated with S, showing a round shape suggesting drying of a $\mathrm{H}_{2} \mathrm{SO}_{4}$ droplet. Particles include silicates, pyrite and euhedral $\mathrm{SiO}_{2}$. d) Unidentified $\mathrm{Cl}, \mathrm{S}, \mathrm{P}, \mathrm{Al}$ round particle. Note the presence of dried material next to the particle assumed to be $\mathrm{H}_{2} \mathrm{SO}_{4}$. All SE images.

Numerous particles are rich in $\mathrm{Si}$, with minor amounts of $\mathrm{Al}-\mathrm{K}-\mathrm{Fe}-\mathrm{Mg}-\mathrm{Na}$ indicating that they are silicates, likely originating from conduit wall erosion. Their shape is often irregular and they usually contain sulfur. Some of them have a smoother surface and are comprised almost exclusively of $\mathrm{Si}$, suggesting they might be silica particles forming by gas-to-particle conversion (Chuan et al., 1986; Lefevre et al., 1986; Toutain et al., 1995; Moune et al., 2010). A thin shard more than $10 \mu \mathrm{m}$ long was observed (Figure 6-6 b), containing Si and S, suggesting it might be coated with sulfur. We found three unidentified rounded particles, with similar appearance and composition (Figure 6-6 d). EDS analyses revealed Cl, S, P, Al and/or $\mathrm{Na}$, with minor $\mathrm{Br}$. They easily volatilize under the beam. The presence of $\mathrm{H}_{2} \mathrm{SO}_{4}$ is indicated by dried material on the filter (Figure 6-6 c, d) and aggregate of particles all containing $\mathrm{S}$ and deposited with a circular shape. The aggregate in Figure 6-6-c is mainly composed of small fragments of silicates coated with sulfuric acid, although a grain of pyrite $(\sim 2 \mu \mathrm{m})$ was found. Elemental sulfur particles were also detected by EDS.

The second most common type of particles after silicates was $\mathrm{Zn} \pm \mathrm{Cu}$ oxides (Figure 6-5 b). The majority of them contained more than $50 \% \mathrm{Zn}$, with smaller amount of $\mathrm{Cu}$. Only one particle was $\mathrm{Cu}$-dominant, and another had equal proportions (37\% $\mathrm{Zn}, 33 \% \mathrm{Cu}$ and $30 \% \mathrm{O}$ ). The morphology differs, with particles appearing as aggregates of small grains whereas others look uniform and smooth. Their sizes range from $0.5 \mu \mathrm{m}$ to $6 \mu \mathrm{m}$. Rose et al. (1982) reported the occurrence of $\mathrm{Zn} \pm \mathrm{Cu}$ oxides in the non 
cooling and reacting with the atmosphere to form oxides. Similarly, Toutain et al. (1995) reported unidentified particles containing major $\mathrm{Cu}$ and $\mathrm{Zn}$ in the plume of Mount Etna.

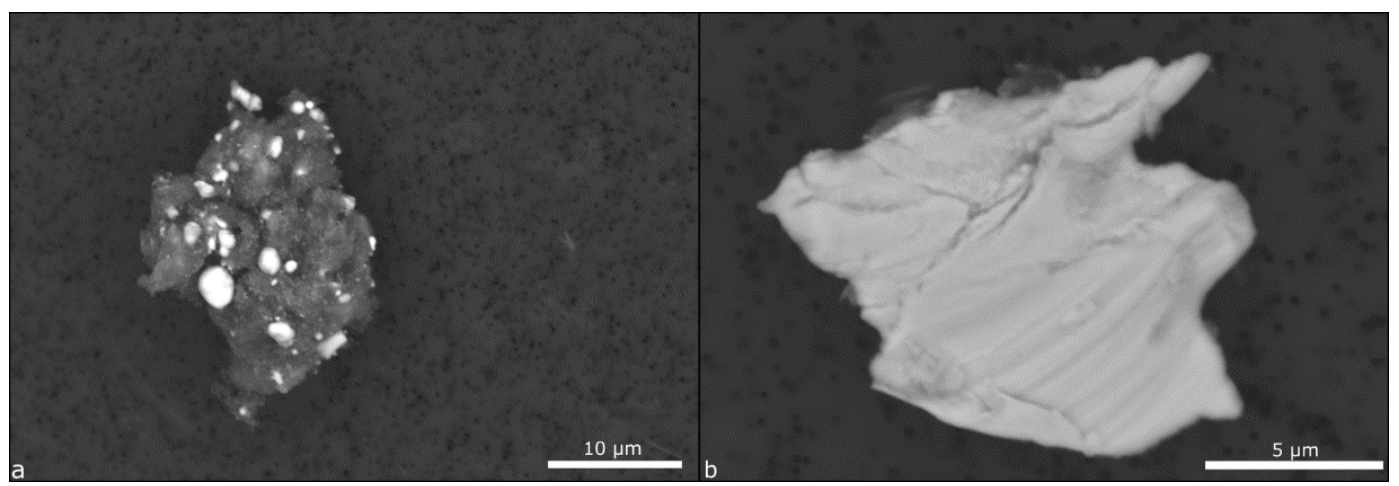

Figure 6-7: SEM pictures of Etna aerosols. a) Small crystals of Zn (93\%) on a particle. b) Metallic plate containing $72 \% \mathrm{Cu}$ and $27 \% \mathrm{Zn}$. All BSE images.

Comparable $\mathrm{Zn} \pm \mathrm{Cu}$ oxides were found in the particulates from Mount Etna plume. A number of zinc- and copper-rich grains apparently do not contain oxygen, suggesting they might be pure metals. One of them (Figure 6-7 b) is a $10 \mu \mathrm{m}$ long plate which contains $72 \%$ $\mathrm{Cu}$ and $27 \% \mathrm{Zn}$, which corresponds to a compound with formula $\mathrm{Cu}_{2.9} \mathrm{Zn}_{1.1}$. This is very similar to $\alpha$-Brass $\left(\mathrm{Cu}_{3} \mathrm{Zn}\right)$, observed as inclusions in plagioclase from Miyake volcanic island (Japan) (Li et al., 1989). Small roundish grains of Zn (93\%) were also observed on a sulfur particle (Figure 6-7 a). Moreover, we found elongated euhedral rosette crystals of zinc sulfate, absent in the plume of White Island (Figure 6-8 a).

The presence of $\mathrm{H}_{2} \mathrm{SO}_{4}$ is highlighted by similar dried material on the polycarbonate filter surrounding particles of $\mathrm{SiO}_{2}$ and silicate (Figure 6-8 b). A round aggregate of Ca sulfate crystals also suggests presence of liquid droplets (Figure 6-8 d). Interesting irregular masses of $\mathrm{Bi}$ iodide were present on the filter (Figure 6-8 c).

The filter collected at Yasur contained mainly ash. These had a very smooth surface under the SEM, and a variety of shapes reflecting magma fragmentation (Figure 6-9 c). Fe-Cr-Ni oxide was observed, as well as comparable $\mathrm{Zn} \pm \mathrm{Cu}$ oxides than the ones found at White Island and Etna (Figure 6-9 a). Euhedral crystals of Ca sulfate and halite were also observed (Figure 6-9 d). 


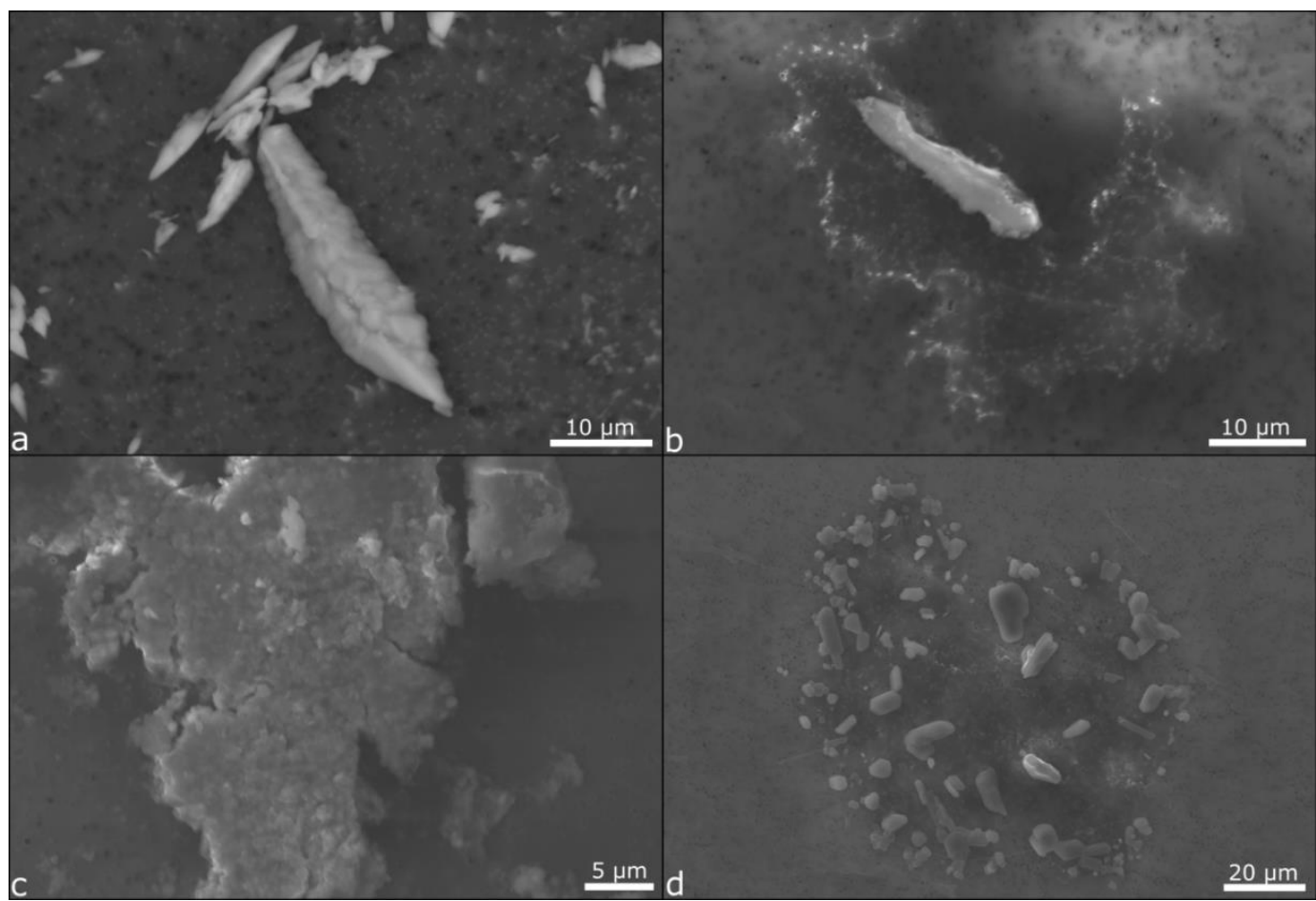

Figure 6-8: SEM pictures of Etna aerosols. a) Zn sulfate rosette. b) Silica in a $\mathrm{H}_{2} \mathrm{SO}_{4}$ droplet. c) Aggregate of bismuth iodide. d) Round aggregate composed of Ca sulfate and thought to have been transported in a droplet of liquid. All SE images.

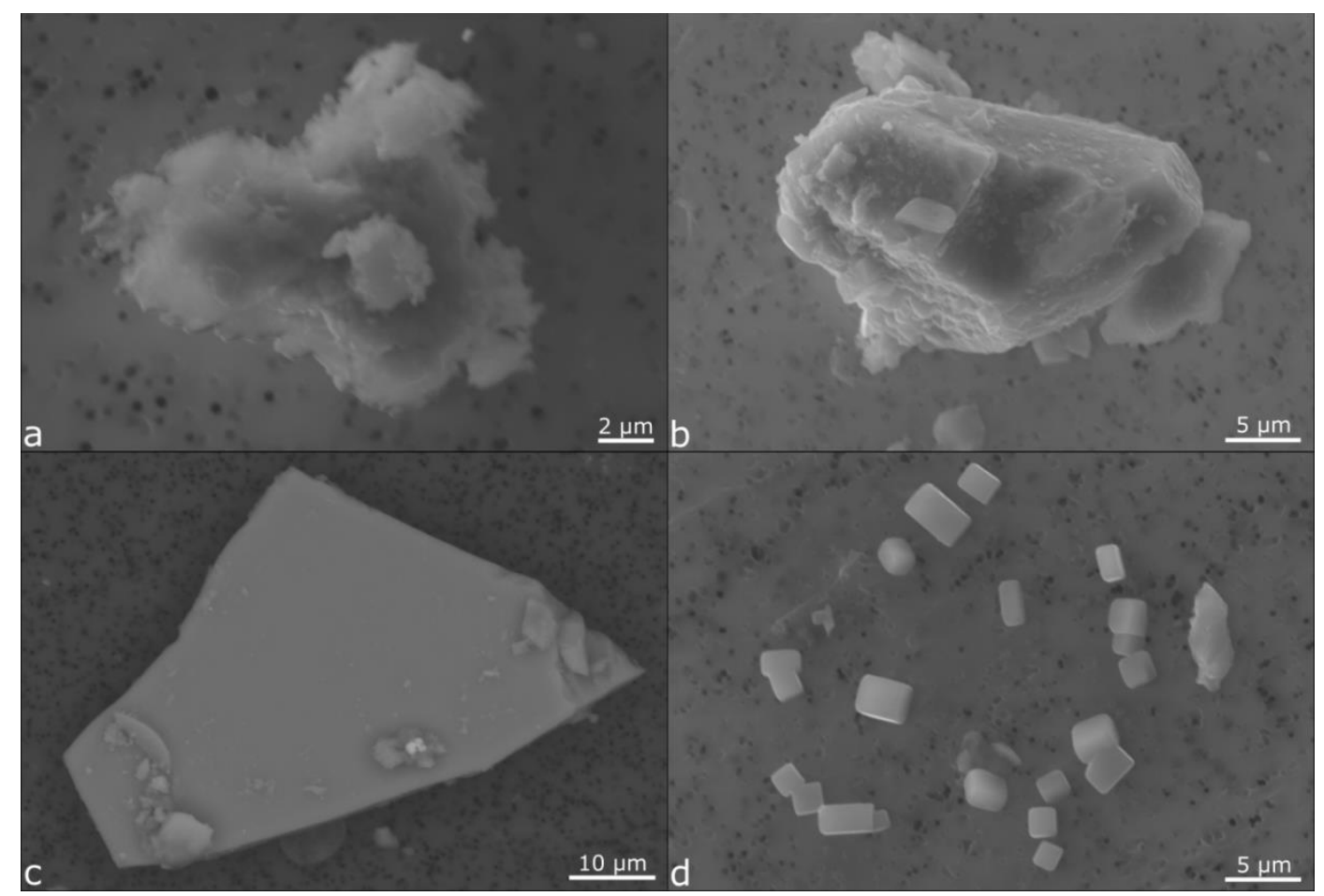

Figure 6-9: SEM pictures of Yasur aerosols. a) Zn oxide with minor amount of $\mathrm{Al}, \mathrm{Cu}, \mathrm{S}, \mathrm{Cl}, \mathrm{Ca}$. b) Silicate. c) Ash. d) Halite. All SE images except BSE image for b.

To summarize, silicates are ubiquitous in the aerosols, resulting from conduit erosion and magma fragmentation in the case of Yasur. Sulfates are also found in the particulate phase of 
the three volcanoes, as well as $\mathrm{Zn}$ oxides $( \pm \mathrm{Al}-\mathrm{Cu})$. The only chloride particulate found is halite, in the plume of White Island and Yasur. The presence of this compound at the two volcanic islands could suggest a marine origin. However, $\mathrm{NaCl}$ was previously observed at Etna (Andres et al., 1993; Toutain et al., 1995; Calabrese and D'Alessandro, 2015) and the mineral is common in fumarolic sublimates (Quisefit et al., 1989; Bernard et al., 1990; Africano et al., 2002; Wahrenberger et al., 2002; Zelenski and Bortnikova, 2005) emphasizing a magmatic origin as well. Sulfur is present in small amounts in many particles at White Island, indicating possible coating. Moreover, the presence of sulfuric acid is suggested by dried droplets containing $S$, as reported in the past by Rose et al. (1986). Formation of sulfuric acid is likely occurring after $\mathrm{SO}_{2}$ emission into the atmosphere and subsequent oxidation in water droplets (Eatough et al., 1994).

\subsection{Origin of the aerosol}

\subsubsection{Variations in major gas compositions}

As previously noted, we observed variations in the $\mathrm{SO}_{2} / \mathrm{HCl}$ ratio of White Island plume between the three sampling campaigns, with values around 4.5 in June 2015 dropping to around 1.9 in June 2016. The two samples collected in December 2016 vary greatly, from 1.8 to 10.6. For a comparison, values of the same ratio in Yasur and Etna plumes are 13.5 and 8.4 respectively, showing that magmatic signature is indicated by high $\mathrm{SO}_{2} / \mathrm{HCl}$ ratios.

The composition of plume emissions measured by GeoNet during flight surveys are used to constrain the nature of the changes observed. Variations in $\mathrm{CO}_{2} / \mathrm{SO}_{2}, \mathrm{CO}_{2} / \mathrm{H}_{2} \mathrm{~S}$ and $\mathrm{SO}_{2} / \mathrm{HCl}$ are the result of both changes in the magmatic feeding system and varying contribution from the hydrothermal system. Increase in $\mathrm{CO}_{2}$ indicates rise of mafic magma within the conduit. $\mathrm{SO}_{2}$ is also of magmatic origin, although it is easily scrubbed by the hydrothermal system (cf. Chapter 4). $\mathrm{H}_{2} \mathrm{~S}$ mainly arises from the hydrothermal system, whereas $\mathrm{HCl}$ is a combination of both magmatic and hydrothermal contributions (see Symonds et al., 2001).

Emission rates measured during flights in the plume show increase in $\mathrm{CO}_{2} / \mathrm{SO}_{2}$ from 4.8 (on 16 June 2015) to 8.2 (on 2 June 2016) whereas $\mathrm{CO}_{2} / \mathrm{H}_{2} \mathrm{~S}$ decreases from 115 to 33 (GeoNet, 2016). The $\mathrm{SO}_{2}$ emissions decrease while $\mathrm{H}_{2} \mathrm{~S}$ increases. A process than can explain such variations is the remobilization of sulfur dissolved in the hydrothermal system as $\mathrm{H}_{2} \mathrm{~S}_{(\mathrm{g})}$ following heating. Because of scrubbing into a two-phase hydrothermal envelope, $\mathrm{SO}_{2}$ emissions are likely to stay low until complete vaporization. These variations are similar to the dry-out process described by Symonds et al. (2001). The parallel decrease in $\mathrm{SO}_{2} / \mathrm{HCl}$ ratio between June 2015 and June 2016 (Table 6-2) may also indicate increasing $\mathrm{HCl}$ emissions due to the vaporization of hydrothermal fluids. The rise in temperature observed in fumarolic gases (cf. Chapter 5) over the same period further supports this assumption.

Contrastingly, the average $\mathrm{CO}_{2} / \mathrm{SO}_{2}$ ratio decreases from 8.2 in June 2016 to 3.8 in December 2016, back into the field of magmatic vapors described by Christenson et al., 2017 (molar $\mathrm{C} / \mathrm{S}$ of 3 to 6), suggesting only minor $\mathrm{SO}_{2}$ scrubbing. The accompanying increase in $\mathrm{CO}_{2} / \mathrm{H}_{2} \mathrm{~S}$ ratio from 33 to 68.1 also supports low contribution from the hydrothermal system. 
The contrasting $\mathrm{SO}_{2} / \mathrm{HCl}$ ratio (1.8 and 10.6) measured in December 2016 (Table 6-2) indicates collection of very different gases. The $\mathrm{SO}_{2} / \mathrm{HCl}$ ratio of 10.6 is similar to magmatic values reported at Etna and Yasur, whereas the lower ratio of 1.8 reflects hydrothermal contribution. Such disparity may either reflect rapid changes in emission with time (the sample with a ratio $=10.6$ could be a burst of magmatic gases), or greater contribution from the crater lake evaporation and/or low-temperature fumaroles with changing wind conditions to explain the lower $\mathrm{SO}_{2} / \mathrm{HCl}$ ratio. Collection closer to the high-temperature vent at the back of the crater lake (see Figure 6-1) during the second drone flight $\left(\mathrm{SO}_{2} / \mathrm{HCl}=10.6\right)$ further suggests sampling of gases of magmatic origin.

\subsubsection{Variations in trace metals}

Partitioning of gold into the gas phase at magmatic conditions was reported by several experimental studies (Heinrich, 2005; Simon et al., 2005; Simon et al., 2007; Frank et al., 2011). Elevated Au concentrations are also observed in high-temperature fumarolic gases (Symonds et al., 1987; Quisefit et al., 1989; Hedenquist et al., 1994a; Kavalieris, 1994; Taran et al., 1995; Taran et al., 2000; Yudovskaya et al., 2006; Yudovskaya et al., 2008). The presence of $\mathrm{Au}$ in the samples with high $\mathrm{SO}_{2} / \mathrm{HCl}$ only (Table 6-2) is an indicator of their magmatic origin. Considering that the ability of volcanic vapors to transport gold decreases with cooling, the temperature of the plume sampled in June 2016 must have been too low to efficiently carry gold complexes, explaining its absence in the particulate phase. The presence of $\mathrm{Au}$ in White Island aerosols thus appears as indicative of high-temperature magmatic gases emitted from the inaccessible vent at the back of the currently active crater.

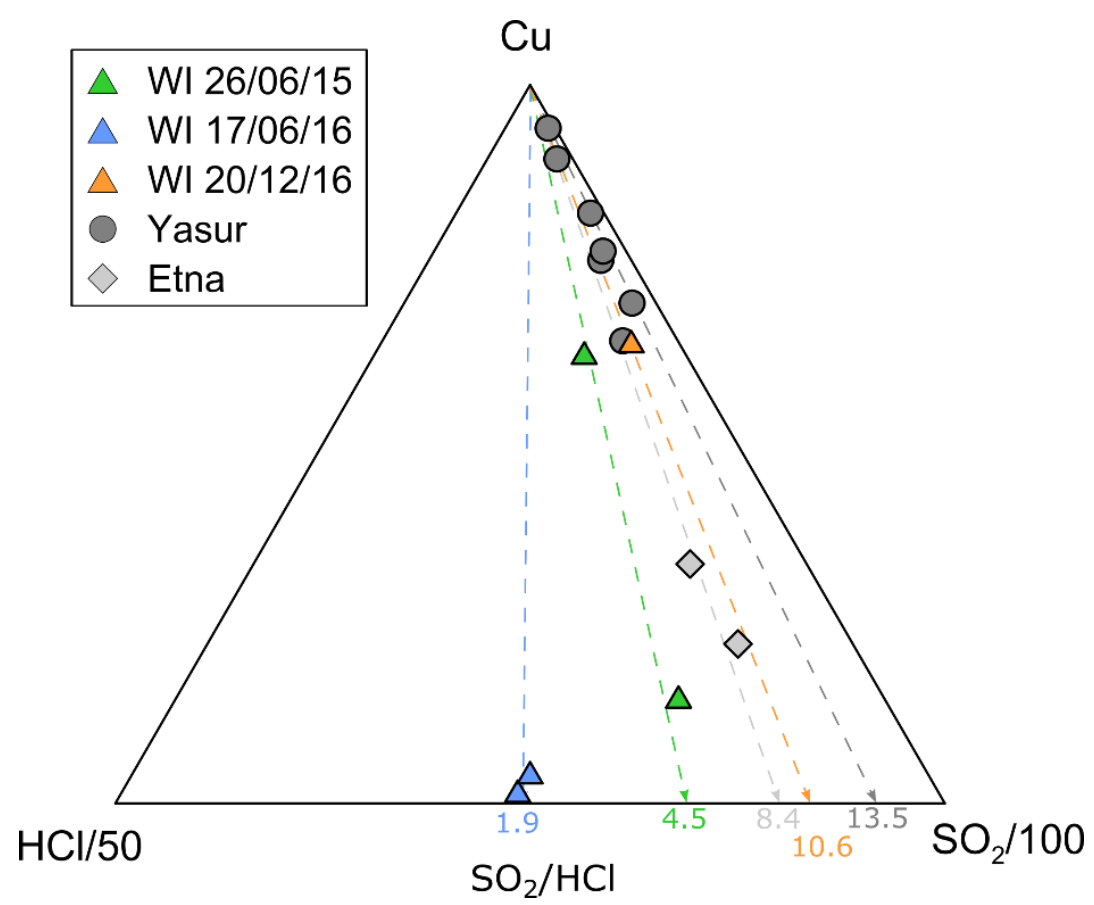

Figure 6-10: Ternary diagram $\mathrm{Cu}-\mathrm{HCl} / 50-\mathrm{SO}_{2} / 100$ for the volcanic plume. 
Similar behavior is observed for $\mathrm{Cu}$, as shown in Figure 6-10. Samples from June 2015 and December 2016 with higher $\mathrm{SO}_{2} / \mathrm{HCl}$ ratios contain more copper than was carried by the plume in June 2016. It is interesting to note that increasing $\mathrm{Cu}$ content with increasing $\mathrm{HCl}$ could also be expected, given the predominance of $\mathrm{Cu}$ chloride complexes predicted by thermodynamic calculations in fumarole F0 gases (cf. Chapter 5). The opposite trend observed however seems to indicate the more important control of temperature on copper transport by volcanic vapors.

\subsection{Emission rates}

Combination of $\mathrm{SO}_{2}$ flux measured independently and filter pack studies allow estimate of halogens and metal emission rates through:

$$
X_{f l u x}=X / S_{2} * S O_{2} \text { flux }
$$

where $\mathrm{X}_{\text {flux }}$ and $\mathrm{SO}_{2 \text { flux }}$ are the flux of element $\mathrm{X}$ and $\mathrm{SO}_{2}$ respectively, and $\mathrm{X} / \mathrm{SO}_{2}$ is the concentration ratio of element $\mathrm{X}$ to $\mathrm{SO}_{2}$. The flux of $\mathrm{SO}_{2}$ is measured at White Island as part of the GeoNet volcanic hazards monitoring, with an airborne COSPEC instrument. The $\mathrm{SO}_{2}$ emissions have ranged from 50 to $500 \mathrm{t} / \mathrm{d}$ in periods of low activity in the last 14 years and rising as high as $2075 \mathrm{t} / \mathrm{d}$ during the 2012-2013 eruption (Christenson et al., 2017).

In order to estimate the trace metal emission rates for the three sampling campaigns at White Island, we used the $\mathrm{SO}_{2}$ flux measured within the same month as aerosol collection. $343 \mathrm{t} / \mathrm{d}$ of $\mathrm{SO}_{2}$ were emitted on 16 June 2015, $246 \mathrm{t} / \mathrm{d}$ on 2 June 2016, and $402 \mathrm{t} / \mathrm{d}$ in November 2016-January 2017 (Table 6-2).

For Yasur, Bani and Lardy (2007) measured an average flux of 683 t/d between April 2004 and November 2005, while Métrich et al. (2011) reported daily emissions of 940 tons and 620 tons on 20-21 and 29-30 October 2007 respectively. The measured flux on the day of sampling was higher than average, with a value of $1683 \mathrm{t} / \mathrm{d}( \pm 530)$ (Benjamin Simons, pers. comm., 2017). The latter flux of $1683 \mathrm{t} / \mathrm{d}$ was used in our calculations.

The average emission rate at Etna during 1987-2000 was estimated by Caltabiano et al. (2004) at $\sim 5560 \mathrm{t} / \mathrm{d}$ and at $~ 3530 \mathrm{t} / \mathrm{d}$ from 2005-2008 by Salerno et al. (2009). We used the rate of $3530 \mathrm{t} / \mathrm{d}$ in our calculations, taking into consideration that lava filling the Bocca Nuova crater during the May 2016 eruption would have reduced the total emission. 
Table 6-5: Average emission rates ( $\mathrm{kg} / \mathrm{d}$, unless specified) for White Island, Yasur and Etna and comparison with other studies.

\begin{tabular}{lcrrrrrrrr}
\hline & $\begin{array}{l}\text { White } \\
\text { Island }\end{array}$ & Yasur & Etna & White Island & Etna & Erta Ale $^{\mathrm{e}}$ & Lascar $^{\mathrm{f}}$ & Masaya $^{\mathrm{g}}$ & Ambrym $^{\mathrm{h}}$ \\
\hline $\mathrm{r}$ & \multicolumn{2}{c}{ This study } & & Other studies & & & & & \\
$\mathrm{HCl}(\mathrm{t} / \mathrm{d})$ & 106.2 & 161.7 & 420.9 & & & & & & \\
$\mathrm{HF}(\mathrm{t} / \mathrm{d})$ & - & 17.0 & 7.6 & & & & & & \\
$\mathrm{Cu}$ & 3.62 & 103.11 & 19.12 & $300^{\mathrm{b}}$ & $657^{\mathrm{d}}$ & 0.7 & 16.9 & 582 & 1300 \\
$\mathrm{As}$ & 4.58 & 21.91 & 2.11 & $11.2^{\mathrm{a}}$ & $85^{\mathrm{d}}$ & 0.4 & 80.3 & & 300 \\
$\mathrm{~Pb}$ & 1.07 & 15.25 & 4.01 & $23.3^{\mathrm{a}}, 125^{\mathrm{b}}, 12^{\mathrm{c}}$ & $85^{\mathrm{d}}$ & 0.17 & 7.7 & 29.1 & 90 \\
$\mathrm{Se}$ & 3.15 & 6.71 & 7.19 & $1.3^{\mathrm{a}}$ & $52^{\mathrm{d}}$ & 0.8 & 125.2 & & 360 \\
$\mathrm{Bi}$ & 0.34 & 1.16 & 0.31 & $6^{\mathrm{b}}, 55^{\mathrm{c}}$ & $26^{\mathrm{d}}$ & 0.058 & 1.4 & 9.8 & 32 \\
$\mathrm{Tl}$ & 0.53 & 2.78 & 1.34 & $11^{\mathrm{c}}$ & $107^{\mathrm{d}}$ & 0.037 & 1.9 & 33.8 & 160 \\
$\mathrm{Zn}$ & 6.16 & 21.79 & 12.00 & & $246^{\mathrm{d}}$ & 0.68 & 50.1 & 135 & 350 \\
$\mathrm{Sb}$ & 0.63 & 0.71 & 0.09 & $1.6^{\mathrm{a}}$ & $24^{\mathrm{d}}$ & 0.0014 & 0.91 & 0.9 & \\
$\mathrm{Te}$ & 0.43 & 1.66 & 0.81 & & & 0.59 & 1.28 & 17.2 & \\
$\mathrm{Cd}$ & 0.04 & 1.98 & 0.39 & $9^{\mathrm{b}}$ & $36^{\mathrm{d}}$ & 1 & 0.17 & 22 & 46 \\
$\mathrm{Au}$ & 0.12 & - & - & & & & & & \\
\hline
\end{tabular}

Notes: - Below detection limit.

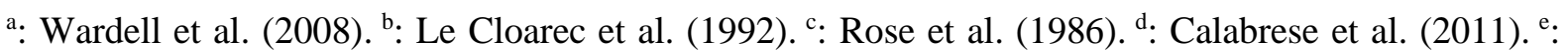

Zelenski et al. (2013). ${ }^{\mathrm{f}}$ : Menard et al. (2014). g: Moune et al. (2010), ${ }^{\text {h: }}$ : Allard et al. (2015).

The average emission rates for White Island, Yasur and Etna are presented in Table 6-5. The flux of $\mathrm{HCl}$ at White Island estimated from filter pack study is $\sim 106 \mathrm{t} / \mathrm{d}$, in agreement with previous estimates of 70-80 t/d, $150 \mathrm{t} / \mathrm{d}$ and 89-125 t/d from Rose et al. (1986), Werner et al. (2008) and Christenson et al. (2017) respectively. In terms of trace metals, our results show emission rates of $\sim 4 \mathrm{~kg} / \mathrm{d}$ of $\mathrm{Cu}, \mathrm{As}, \mathrm{Se}, \sim 6 \mathrm{~kg} / \mathrm{d}$ of $\mathrm{Zn}$, and $\leq 1 \mathrm{~kg} / \mathrm{d}$ of $\mathrm{Pb}, \mathrm{Bi}, \mathrm{Tl}, \mathrm{Sb}, \mathrm{Te}$, $\mathrm{Au}$ and $\mathrm{Cd}$ during quiescent degassing at White Island. Besides Se and $\mathrm{Sb}$, these values are one to two orders of magnitude lower than reported in previous studies (see Table 6-5).

The daily emissions at Yasur are $~ 162$ tons of $\mathrm{HCl}$ and $\sim 17$ tons of $\mathrm{HF}$, close to the filter packs estimates of $164 \mathrm{t} / \mathrm{d}$ and $23 \mathrm{t} / \mathrm{d}$ respectively, reported by Métrich et al. (2011). Trace metal emission rates are higher at Yasur than at White Island, with up to $\sim 100 \mathrm{~kg} / \mathrm{d}$ of $\mathrm{Cu}, 22$ $\mathrm{kg} / \mathrm{d}$ of As and $\mathrm{Zn}, 15 \mathrm{~kg} / \mathrm{d}$ of $\mathrm{Pb}$ and $\sim 2 \mathrm{~kg} / \mathrm{d}$ of $\mathrm{Tl}$ and $\mathrm{Cd}$. These values are nevertheless substantially lower than those reported at Ambrym, the second largest volcano of the Vanuatu archipelago (Allard et al., 2015).

Metal emission rates from Etna are likely to be overestimated due to saturation of the filters with respect to $\mathrm{SO}_{2}$. Results in Table 6-5 show that they are slightly higher than at White Island. In contrast, they are an order of magnitude lower than previous estimates, as expected after the decrease in plume emissions following the May 2016 eruption.

Comparison with other volcanoes (Table 6-5) emphasizes the relatively low trace metal emissions at White Island measured during the quiescent activity encompassing this study. Results from the thermodynamic calculations in Chapter 5 exhibited a drop of four orders of magnitude in the $\mathrm{Cu}, \mathrm{Fe}$ and $\mathrm{Zn}$ contents of Donald Mound fumarolic gases between $500{ }^{\circ} \mathrm{C}$ and $300{ }^{\circ} \mathrm{C}$. Moreover, the stability of all metal sulfur complexes rapidly decreased as the 
temperature fell below $500{ }^{\circ} \mathrm{C}$. The lower fluxes of metals recorded at White Island are thus likely the result of contrasting emission temperatures. Thermal images of the superheated vent giving rise to the volcanic plume at White Island using a FLIR camera, revealed temperatures ranging from $142{ }^{\circ} \mathrm{C}$ to $337{ }^{\circ} \mathrm{C}$ (mean of $255^{\circ} \mathrm{C}$ ), between June 2015 and November 2016 (Bruce Christenson, pers. comm.). The temperatures inside the fumarole vent are probably appreciably higher. In contrast, fumarolic gas discharges in excess of 300 ${ }^{\circ} \mathrm{C}$ were recorded at Mount Etna on the day of sampling, suggesting higher temperature for the volcanic plume. The elevated temperature of gas emissions at Yasur are obvious, owing to the proximity of the magma, only meters below the surface. Métrich et al. (2011) estimated the silicate melt to be $\sim 1107{ }^{\circ} \mathrm{C}$ at a shallow depth $(<4 \mathrm{~km})$, suggesting plume temperature above $900{ }^{\circ} \mathrm{C}$. The more elevated trace metal emissions at these two volcanoes is thus explained by the currently higher temperature of emissions, favoring transport of metal complexes. In fact, metal fluxes from White Island reported by Le Cloarec et al. (1992), Wardell et al. (2008) and Rose et al. (1986) are about an order of magnitude or more higher (Table 6-5). These three studies were conducted during the 1976-2000 eruptive sequence, when emission temperatures were much higher than presently.

\subsection{Conclusions}

To summarize, this study showed that $\mathrm{Bi}, \mathrm{Cd}, \mathrm{Tl}, \mathrm{Se}, \mathrm{Te}, \mathrm{Au}$ and $\mathrm{Sb}$ are the most enriched trace metals and metalloids in volcanic plumes. Despite its enrichment at Etna and Yasur, $\mathrm{Cu}$ is not very concentrated in White Island plume, once again emphasizing the importance of temperature in volatile transport of metals. The most common observed particles at the three volcanoes are silicates, sulfates, halite, $\mathrm{SiO}_{2}$, sulfuric acid droplets, and most interestingly $\mathrm{Zn}$ $\pm \mathrm{Cu}$ oxides.

Three main sources for volcanic aerosols are: 1) the magmatic contribution, represented by volatile elements emitted directly from the magma, 2) silicate contribution, as particles originating from magma fragmentation, or dragged from the conduit during wall erosion, 3) hydrothermal contribution, important when a well-developed, two-phase hydrothermal system is present in the subsurface. The variations in aerosol composition reflect changes in the relative contributions of these three endmembers, and is linked to changes in volcanic activity. The presence of $\mathrm{Au}$ in the plume of White Island, for instance, indicates emission of magmatic gases of high temperature. Further study, and especially during higher activity at White Island, is required to constrain the variations in metal content induced by injection of mafic magma. The development of technology, and especially of drones, should greatly improve aerosol sampling, by removing the dependence on wind direction and allowing collection in remote and dangerous locations.

Metal emission rates were estimated, yielding to values in the range of 0.1 to $10 \mathrm{~kg} / \mathrm{d}$ of $\mathrm{Cu}$, $\mathrm{As}, \mathrm{Se}, \mathrm{Zn}, \mathrm{Pb}, \mathrm{Bi}, \mathrm{Tl}, \mathrm{Sb}$ and $\mathrm{Te}$ at White Island. These emissions are not negligible and should be taken into consideration where populations are living nearby volcanoes. The case of Yasur is of importance, where as much as $100 \mathrm{~kg}$ of $\mathrm{Cu}$ and $10-20 \mathrm{~kg}$ of $\mathrm{As}, \mathrm{Pb}$ and $\mathrm{Zn}$ are emitted daily in the volcanic plume, in an area where populations rely on local water and food supply. 


\section{Chapter 7: Mass balance calculations and concluding remarks}

In the previous chapters, we provided detailed analyses of different features from the White Island magmatic-hydrothermal system, focusing on the distribution and speciation of metals. Melt inclusions and erupted rocks enable determination of the effects of crystallization and degassing on metals present in the magma. Analysis of volatiles discharging at the surface helped us in constraining metal degassing and revealed interactions with the active hydrothermal system.

Exsolution of aqueous fluid from magma residing at depth is at the root of hydrothermal systems in volcanic environments (Burnham, 1979). What happens to this fluid subsequently is the focus of this concluding chapter: does it separate into a low-density vapor (observed at passively degassing volcanoes) and a high-density brine, and if so, at what depth and temperature. What is the relative role of each phase in transporting metals? Here, we constrain the transport of metals in the subsurface environment, after volatile exsolution from the magma. Using our results and data from past studies at White Island, we also estimate the copper budget for the magmatic-hydrothermal system.

\subsection{The copper budget for White Island magmatic-hydrothermal system}

White Island has been depicted in different studies as a favorable system for the formation of a porphyry copper deposit (Hedenquist et al., 1993; Rapien et al., 2003). The data collected during this project enables us to undertake mass balance calculations for copper within the magmatic-hydrothermal system and to highlight potential deposition occurring in the subsurface environment.

First, we need to estimate the volume of magma that degasses over a period of time at White Island. The $\mathrm{SO}_{2}$ flux is routinely measured by GeoNet (since 2003), using airborne COSPEC (GeoNet, 2003-2017). Christenson et al. (2017) determined a molar C/S ratio between 3 and 6 to represent the magmatic vapor. The main assumption in estimating the volume of degassed magma is that the $\mathrm{SO}_{2}$ measured at the surface represents all the sulfur exsolved from the silicate melt. We therefore used only $\mathrm{SO}_{2}$ fluxes measured on days when scrubbing was minimal (i.e. molar $\mathrm{C} / \mathrm{S}$ ratio between 3 and 6). The $\mathrm{SO}_{2}$ emission rate obtained is $\sim 423$ $\mathrm{t} / \mathrm{d}$, similar to the average flux of $430 \mathrm{t} / \mathrm{d}$ measured during a period of higher activity (19861999) by Wardell et al. (2001). The original S content of White Island magma is taken as that of olivine-hosted melt inclusions, $1200 \mathrm{ppm}$, whereas erupted dacite containing $100 \mathrm{ppm}$ (Giggenbach, 1996) represents the final S content. The amount of magma required to produce the observed flux of $\mathrm{SO}_{2}$ is $\sim 190000 \mathrm{t} / \mathrm{d}$, or $\sim 7 \times 10^{7}$ tons every year. Considering that magma has a density of $2700 \mathrm{~kg} / \mathrm{m}^{3}$, it corresponds to $0.026 \mathrm{~km}^{3}$ of silicate melt degassing annually. This volume is in the range of previous estimates from Werner et al. (2008) and Giggenbach and Sheppard (1989) of $\sim 0.022 \mathrm{~km}^{3} / \mathrm{y}$ and $\sim 0.025 \mathrm{~km}^{3} / \mathrm{y}$ respectively.

The average $\mathrm{Cu}$ content of olivine-hosted melt inclusions, $128 \mathrm{ppm}$, is thought to represent the amount of copper in the magma before degassing. Considering the $7 \times 10^{7}$ tons of magma degassed annually, this corresponds to a total of 9010 tons of $\mathrm{Cu}$ per annum. Taking the $\mathrm{Cu}$ 
content of White Island dacite of $58 \mathrm{ppm}$ determined by Graham and Cole (1991), it implies that $45 \%$ of the total $\mathrm{Cu}$ stays in the silicate melt, amounting to 4083 tons. Consequently, the other $55 \%$, corresponding to 4927 tons of $\mathrm{Cu}$, escapes from the magma.

It is important to consider all the potential sinks for $\mathrm{Cu}$ in order to obtain realistic mass balance estimate. In the case of White Island, we have defined them as follows:

- Gas discharges

- Spring discharges

- Elemental sulfur scrubbing/sequestration

- Sulfide melt scrubbing/sequestration

- Cu-rich mineral deposition

The copper content of most of these components was determined and reported in previous chapters or in past studies. For the mass calculation, an estimate of emission/formation rate for each of the potential sinks is required.

The gaseous emissions at White Island have been detailed in Chapter 6 and resulted in $\mathrm{Cu}$ emission rates of $\sim 4.65 \mathrm{~kg} / \mathrm{d}$ during low, quiescent activity, corresponding to $1.7 \mathrm{t} / \mathrm{y}$. Le Cloarec et al. (1992) collected aerosols from White Island in 1988, during a period of higher volcanic activity. They estimated the temperature of the gases to be $\sim 1000{ }^{\circ} \mathrm{C}$. Their results yield a flux of copper in the range of $300 \mathrm{~kg} / \mathrm{d}$, or $110 \mathrm{t} / \mathrm{y}$. Despite this value being two orders of magnitude higher than our current estimate, it is still very low compared to the $4927 \mathrm{t}$ of $\mathrm{Cu}$ leaving the magma every year.

Acidic springs are discharged into the sea at various locations around the island. The discolored plume resulting from precipitation of various hydroxides after mixing with sea water makes them easily identifiable (Figure 7-1). Acid Stream drains waters within the crater floor, flowing southeastward and discharging in Crater Bay (Figure 7-1 a and d). The flow has been regularly monitored by GeoNet over the period 2004-2015, with an average value of 2765 t/d (GeoNet, 2004-2015). Its $\mathrm{Cu}$ content was reported by Giggenbach and Glasby (1977) at $\sim 0.2 \mathrm{ppm}$, leading to $\sim 0.20$ tons of copper discharged every year. The flow and composition of the other discharges observed in Figure 7-1 have not been studied. The minor discharges observed in the southeastern bays are attributable to Acid Stream, discharging beneath the tide line (Bruce Christenson, pers. comm.). Two major seepages exist on the northwest coast of the island (Figure 7-1 b and c). We estimated their total discharge to equal that of Acid Stream by comparing the size of discolored plume they produce after mixing with sea water. Considering the same $\mathrm{Cu}$ content of $0.2 \mathrm{ppm}$, the annual flow of copper from spring discharges corresponds to $2 \mathrm{x}$ Acid Stream emission rate, or about 0.40 $\mathrm{t} / \mathrm{y}$. 


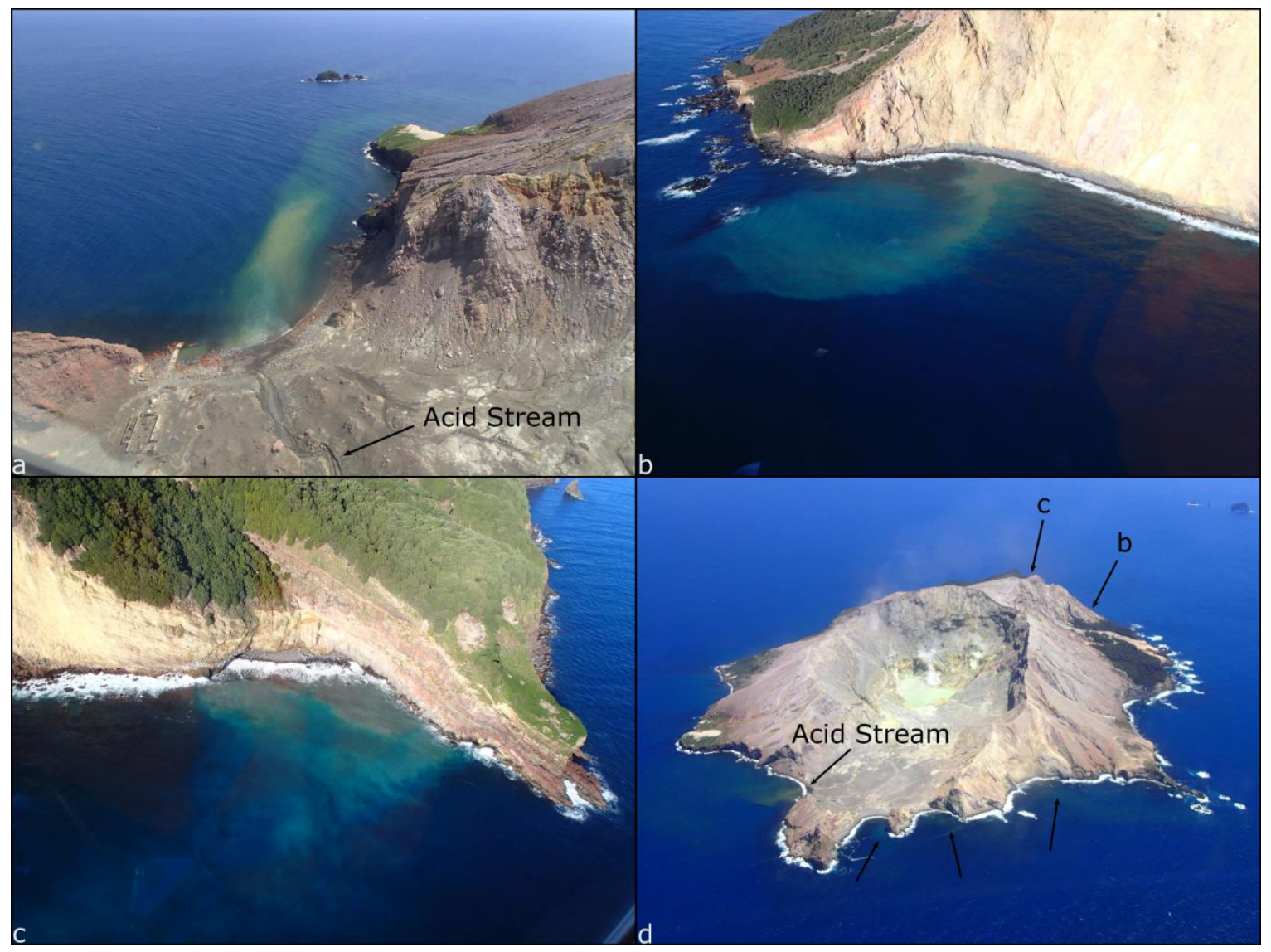

Figure 7-1: Aerial photos showing acid discharges around White Island. Photo: courtesy of GNS.

The crater lake that periodically floods the main crater, despite its ephemeral nature, has been present most of the time since its reappearance in 2003. The occurrence of similar features has also been reported in the past (Luke, 1959), indicating that sulfur scrubbing of metals in the lake should be considered in our calculations. The formation of elemental sulfur in the crater lake environment may be described by the hydrolysis mediated redox reaction,

$$
3 \mathrm{SO}_{2(\mathrm{~g})}+2 \mathrm{H}_{2} \mathrm{O}=\mathrm{S}^{0}+2 \mathrm{H}_{2} \mathrm{SO}_{4(a q)}
$$

as well as reaction between sulfur gaseous species during expansion and cooling,

$$
\mathrm{SO}_{2(g)}+2 \mathrm{H}_{2} \mathrm{~S}_{(g)}=3 \mathrm{~S}^{0}+2 \mathrm{H}_{2} \mathrm{O}
$$

and through the simple oxidation of $\mathrm{H}_{2} \mathrm{~S}$ by atmospheric oxygen,

$$
\mathrm{H}_{2} S_{(g)}+1 / 2 \mathrm{O}_{2(g)}=S^{0}+\mathrm{H}_{2} \mathrm{O}
$$

Christenson et al. (2017) estimated the rate of formation of elemental sulfur during the 20032006 lake cycle by looking at the $\mathrm{SO}_{2}$ deficit due to reaction (7.1). Difficulties in constraining $\mathrm{S}$ loss through reactions (7.2) and (7.3) implies these estimates are minimum values. Their results show that at least 44000 tons of elemental sulfur deposited during that time frame, 
corresponding to $\sim 14000$ t/y. For comparison, rates of deposition have been estimated at $11500 \mathrm{t} / \mathrm{y}$ at Poas volcano (Rowe et al., 1992a) and $20880 \mathrm{t} / \mathrm{y}$ at Copahue volcano (Varekamp et al., 2001). Taking an average $\mathrm{Cu}$ content of $80 \mathrm{ppm}$ in sulfur globules (cf. Chapter 4) leads to 1.12 tons of copper sequestered by elemental sulfur in the crater lake every year.

Mass balance calculations were performed according to:

$$
X_{S e q}=X_{P M}-\left(X_{D M}+X_{P}+X_{A S}+X_{E S}\right)
$$

where $\mathrm{X}_{\text {Seq }}$ is the amount of element $\mathrm{X}$ sequestered at depth annually, $\mathrm{X}_{\mathrm{PM}}$ is the amount of $\mathrm{X}$ in the primary magma degassing every year estimated from concentration in olivine-hosted melt inclusions, $\mathrm{X}_{\mathrm{DM}}$ is the amount of $\mathrm{X}$ that stays in the silicate melt estimated from concentration in erupted dacite (Graham and Cole, 1991) for $\mathrm{Cu}$ and $\mathrm{Zn}$ and andesite for $\mathrm{Au}$ and $\mathrm{Ag}, \mathrm{X}_{\mathrm{P}}$ is the amount of $\mathrm{X}$ discharged in the aerosol annually, $\mathrm{X}_{\mathrm{AS}}$ is the amount of $\mathrm{X}$ discharged by acid springs annually, and $\mathrm{X}_{\mathrm{ES}}$ is the amount of $\mathrm{X}$ scavenged every year by elemental sulfur depositing at the bottom of the crater lake. Results from these calculations are presented in Table 7-1.

Table 7-1: Mass balance calculations for a selection of metals during periods of low activity ( $t / y)$.

\begin{tabular}{lrrrr}
\hline Element & $\begin{array}{c}\text { Initial amount } \\
\text { in magma }\left(X_{P M}\right)\end{array}$ & $\begin{array}{c}\text { Final content in } \\
\text { silicate rock }\left(X_{\text {DM }}\right)\end{array}$ & $\begin{array}{c}\text { Discharged at } \\
\text { the surface* }\end{array}$ & $\begin{array}{c}\text { Sequestered } \\
\text { at depth }\left(X_{\text {Seq }}\right)\end{array}$ \\
\hline $\mathrm{S}$ & 84471 & 7039 & 77431 & 0 \\
$\mathrm{Cu}$ & 9010 & 4083 & 3.22 & 4924 \\
$\mathrm{Zn}$ & 5843 & 4505 & 3.68 & 1334 \\
$\mathrm{Ag}$ & 65 & 21 & 0.11 & 44 \\
$\mathrm{Au}$ & 62 & 23 & 0.02 & 39 \\
\hline
\end{tabular}

* Total discharge at the surface $=$ gas discharge $\left(X_{\mathrm{P}}\right)+$ spring discharge $\left(\mathrm{X}_{\mathrm{AS}}\right)+$ elemental sulfur scrubbing $\left(X_{E S}\right)$.

Gaseous and liquid emissions, together with elemental sulfur deposition at the lake bottom are the main copper discharges at White Island. They add up to $\sim 3$ tons of $\mathrm{Cu}$ released per year during passive degassing periods when a crater lake floods the upper portion of the conduit. During more active periods when no crater lake is present, $110 \mathrm{t} / \mathrm{y}$ are discharged. This value is very small compared to the 4927 tons of $\mathrm{Cu}$ escaping the magma each year, implying most of it is trapped within the subsurface environment. Giggenbach and Glasby (1977) estimated that White Island magmatic-hydrothermal system has been active for the last 10000 years. If we consider a constant flow of magmatic gases over the lifetime of the system, this corresponds to deposition of $\sim 50$ megatons of $\mathrm{Cu}$. This is a considerable amount, and within the range of porphyry copper deposits presently mined. The Bingham Canyon and El Teniente porphyry deposits for example, contain $30 \mathrm{Mt}$ and $94 \mathrm{Mt}$ of $\mathrm{Cu}$ respectively (Hattori and Keith, 2001; Cooke et al., 2005). The common copper-containing ore minerals are chalcopyrite $\left(\mathrm{CuFeS}_{2}\right)$, bornite $\left(\mathrm{Cu}_{5} \mathrm{FeS}_{4}\right)$, chalcocite $\left(\mathrm{Cu}_{2} \mathrm{~S}\right)$, covellite $(\mathrm{CuS})$ and enargite $\left(\mathrm{Cu}_{3} \mathrm{AsS}_{4}\right)$, emphasizing the role of sulfur in forming such deposits. The 
formation of porphyry copper deposits of economic grade (>1 wt $\% \mathrm{Cu})$, relies on efficient metal transport and deposition, which we will try to constrain for White Island.

\subsection{Transport and deposition of $\mathrm{Cu}$}

We have determined that around 4900 tons of copper are sequestered in White Island hydrothermal system every year. Given that this copper leaves the magma, two possibilities arise: 1) $\mathrm{Cu}$ is segregated into an immiscible sulfide melt, and/or 2) $\mathrm{Cu}$ partitions into an exsolving magmatic volatile phase.

\subsubsection{Partitioning into immiscible sulfide melt}

Droplets of sulfide melt were observed in some of the ejecta from the 1976-2000 eruptive cycle, containing on average $30 \mathrm{wt} \% \mathrm{Cu}$. Given the rarity of these phases, if we assume the sulfide melt represents $0.01 \%$ of the magma degassing per year, we obtain a total of 7039 tons of sulfide melt, containing 2112 tons of $\mathrm{Cu}$. This estimate drops to 1056 tons of $\mathrm{Cu}$ sequestered by sulfide melt if we assume sulfide melt is only $0.005 \%$ of the total magma. As already mentioned in Chapter 3, late sulfide saturation has been reported as a factor promoting porphyry copper deposit formation (Jenner et al., 2010; Park et al., 2015). Sulfides that are not trapped into phenocrysts are likely to be destabilized during crystallization and degassing of the silicate melt, being replaced by iron oxides (Candela and Holland, 1986; Hattori, 1993; Keith et al., 1997; Halter et al., 2005; Audetat and Pettke, 2006; Nadeau et al., 2010). The most efficient process linked with sulfide removal appears to be related to oxidation following degassing (Candela and Holland, 1986; Candela, 1989; Halter et al., 2005; Stavast et al., 2006; Di Muro et al., 2008), although Hattori (1993) postulated that $\mathrm{SO}_{2-}$ rich gas fluxing could also lead to sulfide oxidation.

The cases of Bingham Canyon and Tintic District in Utah are particularly interesting. Larocque et al. (2000) showed that more than $90 \%$ of the original magmatic sulfides were removed in slowly cooled rocks associated with porphyries, by degassing and oxidation. In contrast, dykes emplaced at high pressure preventing degassing, contained a higher proportion of preserved sulfide blebs. Following these arguments, rapid ascent and cooling experienced by the sulfide inclusions found in White Island ejecta would inhibit their resorption. However, given the low total volume of magma erupted, we can assume that the majority of sulfide melt formed in the dacitic magma experiences slow cooling and degassing, favoring resorption. In the likely presence of an aqueous fluid, the metals released from the sulfide melt $(\mathrm{Cu}, \mathrm{Zn}, \mathrm{Ni}, \mathrm{Ag}, \mathrm{Au})$ would partition into the aqueous phase, given their preferential partitioning into an aqueous fluid over silicate melt (Candela, 1989; Candela and Piccoli, 1995b; Keppler, 1996; Harris et al., 2003; Simon et al., 2006, 2007; Pokrovski et al., 2008; Simon et al., 2008; Zajacz et al., 2008; Johnson and Canil, 2011). 


\subsubsection{Partitioning into magmatic volatile phase}

A critical step in porphyry copper deposit formation is the exsolution of $\mathrm{Cu}$ into a volatile phase, and the nature of the latter (i.e. a supercritical fluid, a low-density vapor, or a highdensity aqueous fluid) (Hedenquist and Lowenstern, 1994; Burnham, 1997; Candela and Piccoli, 2005; Williams-Jones and Heinrich, 2005; Simon and Ripley, 2011). We determined in Chapter 3 that $\mathrm{Cu}$ exsolves from the shallow magmatic chamber. Despite the bulk of $\mathrm{S}$ degassing occurring at depth greater than $800 \mathrm{~m}$, plagioclase- and pyroxene-hosted melt inclusions entrapped in shallow storage, contain up to $500 \mathrm{ppm} \mathrm{S}$, indicating only minor sulfur degassing from the dacitic melt. In contrast, due to its greater solubility, $\mathrm{Cl}$ degasses mainly from the shallow magmatic reservoir. Moreover, the deeper $\mathrm{CO}_{2}$ - and $\mathrm{S}$-rich magmatic volatile phase is likely to be fluxing the shallow chamber (Wallace and Edmonds, 2011), suggesting that a $\mathrm{Cl}$ - and S-bearing magmatic volatile $\left( \pm \mathrm{CO}_{2}\right)$ phase is present in the shallow dacitic chamber.

Metrich and Rutherford (1992) and Shinohara (1994) showed that the exsolution of an aqueous fluid from a silicate magma at conditions below the critical point of the $\mathrm{H}_{2} \mathrm{O}-\mathrm{NaCl}$ system (i.e. at $800{ }^{\circ} \mathrm{C}$ and pressure lower than $1.3 \mathrm{kbar}$ ) is a two-step process:

- The first step is the exsolution of a homogeneous aqueous fluid from the magma.

- With further crystallization and cooling, fluid phase exsolution occurs but with simultaneous exsolution of both vapor and a liquid.

Of course, the continuously exsolving homogeneous aqueous fluid accumulates, cools and decompresses until the pressure-temperature conditions of the solvus are encountered. Separation then occurs with the formation of a saline fluid with liquid-like density and a less dense, volatile-rich, more gas-like phase.

Sowat, a program kindly provided by Thomas Driesner, allows estimation of the state of a fluid in the $\mathrm{H}_{2} \mathrm{O}-\mathrm{NaCl}$ system. Under the pressure and temperature conditions determined for the shallow dacitic magma chamber $\left(\sim 900{ }^{\circ} \mathrm{C}, 800 \mathrm{~m}\right.$ depth, that is 240 bar $)$, the volatile phase exsolving from the silicate magma is a two-phase fluid (vapor + liquid). Considering an initial salinity of $5 \mathrm{wt} \% \mathrm{NaCl}$ (typically $4-10 \mathrm{wt} \%$ in porphyry $\mathrm{Cu}$ environments) (Burnham, 1979; Cline and Bodnar, 1991; Shinohara and Hedenquist, 1997; Ulrich et al., 2001; Klemm et al., 2007; Rusk et al., 2008; Pudack et al., 2009; Landtwing et al., 2010), at

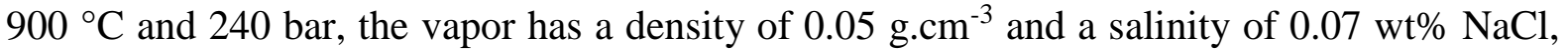
whereas the liquid has a density of $1.4 \mathrm{~g} . \mathrm{cm}^{-3}$ and contains $94.6 \mathrm{wt} \% \mathrm{NaCl}$ (see Figure 7-2). This suggests that both a low-density vapor and a saline liquid are exsolving from the shallow dacitic melt, the former containing both chlorine and sulfur. 


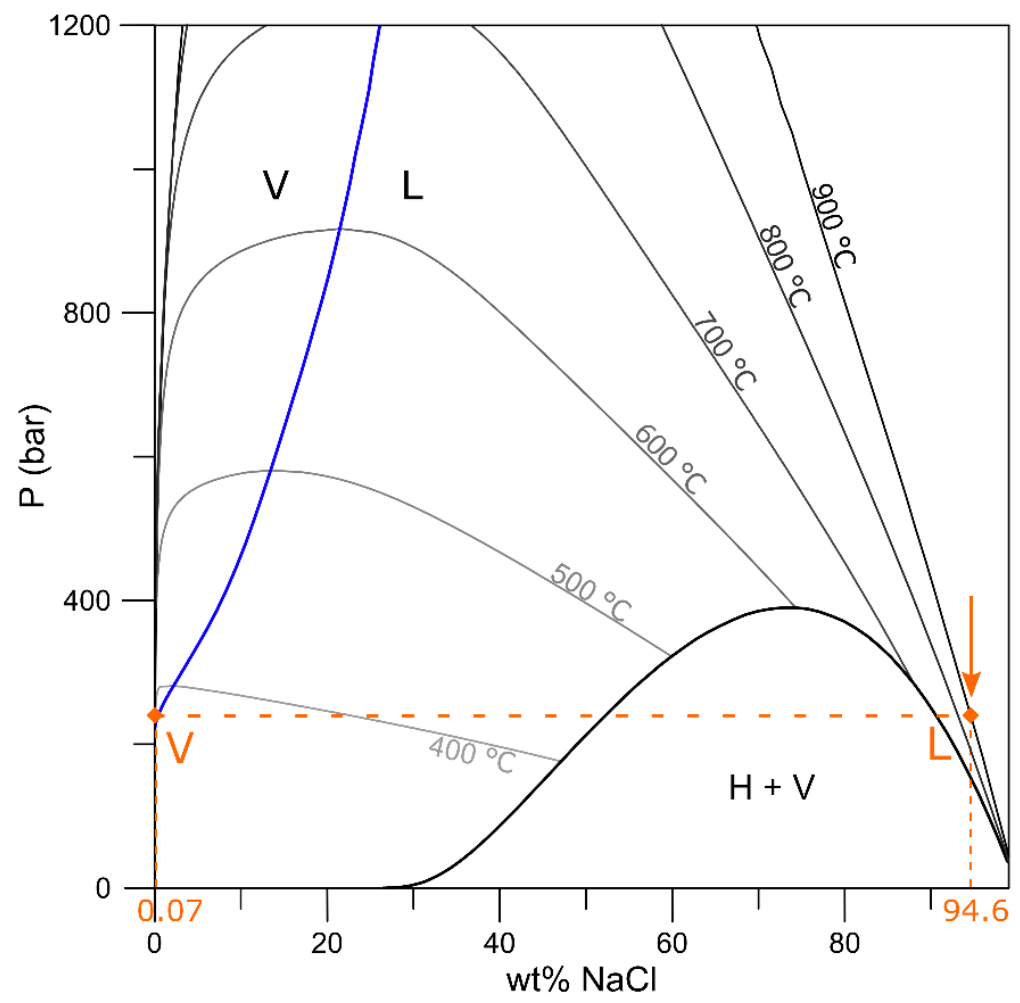

Figure 7-2: Pressure-temperature-salinity relations in the $\mathrm{H}_{2} \mathrm{O}-\mathrm{NaCl}$ system. At the low pressure of exsolution (240 bar), the volatile phase is in the two-phase field at $900{ }^{\circ} \mathrm{C}$. It changes into halite + vapor with decreasing temperature and pressure. The blue line represents the critical curve. Constructed using Sowat program and data from Driesner (2007).

Fluid inclusion studies have reported high concentrations of $\mathrm{Cu}$ (Lowenstern et al., 1991; Heinrich et al., 1992; Lowenstern, 1993; Cauzid et al., 2007) in the vapor phase that cannot be explained by chloride complexes alone. In fact, experimental and fluid inclusion studies have shown the role of sulfur in transporting ore metals such as $\mathrm{Cu}$ and $\mathrm{Au}$ in a low-density vapor phase (Heinrich et al., 1999; Simon et al., 2006, 2007; Seo et al., 2009; Zajacz and Halter, 2009; Etschmann et al., 2010; Zajacz et al., 2011). Moreover, recent studies indicated the effect of hydration in transporting considerable amounts of copper in low-density vapor, in the form of solvated cluster-like species (Archibald et al., 2002; Zajacz et al., 2011; Migdisov et al., 2014). In terms of partition coefficient between aqueous vapor and liquid, Simon et al. (2006) reported $\mathrm{D}_{\mathrm{Cu}}{ }^{\mathrm{v} / 1}=0.69 \pm 0.16$ at $800{ }^{\circ} \mathrm{C}, 140 \mathrm{MPa}$ and S- and Cl-bearing system. At lower pressure (100 MPa), Frank et al. (2011) reported $\mathrm{D}_{\mathrm{Cu}}{ }^{\mathrm{v} / 1}$ values from $0.14 \pm$ 0.5 to $0.01 \pm 0.025$. Experiments at 600 and $800{ }^{\circ} \mathrm{C}$, and 70 and $130 \mathrm{MPa}$ (Lerchbaumer and Audétat, 2012), yielded $\mathrm{D}_{\mathrm{Cu}}^{\mathrm{v} / 1}$ in the range of $0.11 \pm 0.04$ to $0.15 \pm 0.04$. The highest partition coefficient obtained experimentally is 1.0 in the presence of $\sim 1 \mathrm{wt} \%$ total $\mathrm{S}$ for temperature $350{ }^{\circ} \mathrm{C}$ and $500{ }^{\circ} \mathrm{C}$ (Pokrovski et al., 2008). These studies suggest that, despite growing evidence for the capabilities of low-density vapor to transport metals, our current knowledge favors preferential partitioning of $\mathrm{Cu}$ into the high-density and salinity liquid. Given the complexity of real systems and the difficulties related to experiments on hightemperature vapors, we consider the two case scenarios in our discussion. This choice is further supported by the results of Pokrovski et al. (2005), who showed that even using metal partition coefficients favoring the dense liquid, boiling of $90 \%$ of a metal-bearing sulfur-poor 
brine at $600{ }^{\circ} \mathrm{C}$, would result in more than half of the total amount of $\mathrm{Cu}$ extracted into the vapor.

\subsubsection{Cu partitioning into high-density saline liquid}

Partitioning of metals into dense saline liquids relies on efficient chloride complexing and is supported by fluid inclusion analyses, and the aforementioned experimental studies (Barnes and Kullerud, 1957; Burnham, 1967; Roedder, 1971; Henley and McNabb, 1978; Candela and Holland, 1986; Hemley et al., 1992; Bodnar, 1995; Candela and Piccoli, 1995b). Considering that a vapor phase is predicted to exsolve simultaneously with a brine, any sulfur, $\mathrm{CO}_{2}$ and $\mathrm{H}_{2}$ left in the shallow emplaced dacitic magma, would partition into the vapor. This results in the brine containing predominantly metal chloride complexes, with minor sulfur complexes. The high density $\left(1.4 \mathrm{~g} . \mathrm{cm}^{-3}\right)$ predicted for the aqueous liquid prevents it from rising to shallower levels (Henley and McNabb, 1978; Bodnar et al., 1985; Shinohara, 1994). Instead, it may accumulate at the depth of formation, retaining metals underneath the solidifying magmatic carapace (Williams-Jones and Heinrich, 2005). The shift from accumulation to deposition can be induced by different mechanisms, related to changes in pressure, temperature and composition (i.e. concentration of metals and ligands, redox conditions, $\mathrm{pH}$ ).

Water-rock interaction is an efficient mechanism associated with ore deposition. As detailed in Chapter 3, andesite-dacite lava is the most common rock at White Island, containing plagioclase, orthopyroxene, and minor olivine, magnetite and chromite. Phenocryst compositions were reported by Cole et al. (2000) showing Fe-rich orthopyroxenes and Carich clinopyroxenes. Alteration products on andesite blocks ejected in February 1988 consist of veins bearing alunite, anhydrite, and Al-rich chlorite (Hedenquist et al., 1993). Some crystals of pyrite were also reported in contact with alunite. The host rock adjacent to the veins was completely altered, with cristobalite replacing all primary minerals. In contrast, porous tuff ejected during the same eruptive event contained disseminated cristobalite, alunite, anhydrite and pyrite (Hedenquist et al., 1993). The authors estimated that alteration occurred at $\sim 380{ }^{\circ} \mathrm{C}$.

Two different processes are related to water-rock interactions. The first one is enrichment through selective dissolution of minerals, whereas the second involves precipitation due to variations in the fluid chemistry along specific reaction pathways (e.g. $\mathrm{pH}$, composition). The relative proportions of fluid and rock is also of importance, with high and low water-rock ratios inducing different changes in fluid composition and mineral dissolution/precipitation (Reed, 1997). Reactions with Fe-bearing rocks described by Hemley et al. (1992) would, for instance, increase the $\mathrm{pH}$ and $\mathrm{Fe}^{2+}$ of the fluid, favoring precipitation of chalcopyrite. Dissolution of White Island Fe-rich orthopyroxenes would thus promote sulfide precipitation.

Besides water-rock interactions, a pressure-related mechanism is often thought to be responsible for ore deposition. The thermal contraction of the solidified carapace overlying the accumulating dense saline liquid results in the creation of a network of fractures and cracks. Assuming that hydrostatic pressure controls the fluids above the carapace (Fournier, 1999), the transition from lithostatic to hydrostatic regime would induce boiling of the highsalinity metal-rich liquid, with exsolution of a low-density vapor. The volatile species (i.e. 
$\mathrm{CO}_{2}, \mathrm{H}_{2} \mathrm{~S}, \mathrm{H}_{2}, \mathrm{HCl}, \mathrm{SO}_{2}$ ) partition in the vapor phase, whereas $\mathrm{NaCl}$ and $\mathrm{KCl}$ stay in the liquid (Ellis, 1979; Drummond and Ohmoto, 1985). The effects of boiling on the remaining liquid are diverse and include: 1) rise in $\mathrm{pH}$ due to partitioning of $\mathrm{CO}_{2}$ and $\mathrm{H}_{2} \mathrm{~S}$ into the vapor, 2) decrease in S ligand concentration, and 3) concentration of species remaining in the liquid. Any metal complexed with reduced sulfur (i.e. $\mathrm{Au}$ and $\mathrm{Cu}$ ) in the aqueous liquid would become oversaturated with the loss of $\mathrm{H}_{2} \mathrm{~S}$ and precipitate. Drummond and Ohmoto (1985) demonstrated that the saturation state before boiling is critical, with only species already close to saturation actually precipitating during boiling.

Saturation of gangue minerals (quartz, anhydrite, pyrite) is the result of both water-rock reactions and boiling, due to increasing activity of certain elements in the aqueous fluid. Changes in mineral solubility are also efficiently promoted by cooling, especially in the case of mixing with another liquid. In this regard, infiltration of cool and oxidized meteoric water within the volcanic edifice could influence ore deposition. In fact, oxidation results in a drop in reduced sulfur activity as well as a change in $\mathrm{pH}$, both of which would destabilize metal sulfide complexes. The meteoric fluids are also likely to be cooler, which, as mentioned above, can lower the solubility of some metals (Seward, 1981).

To summarize, the most important processes affecting ore deposition from a high-density, high-salinity liquid appear to be changes in the fluid composition (i.e. redox state, $\mathrm{pH}$, activities) and cooling, induced by a variety of mechanisms such as fluid-rock interaction, mixing with meteoric fluids or boiling.

\subsubsection{Cu partitioning into low-density vapor}

We know from fumarolic gas compositions that a $\mathrm{Cl}$ - and $\mathrm{S}$-bearing fluid is exsolving from the magma. Such a low-density vapor would also be formed by a boiling dense saline liquid, as discussed above. Assuming that some metals, such as $\mathrm{Cu}$, partition into this vapor phase, we will try to constrain the mechanisms affecting transport and deposition.

Thermodynamic modeling showed that $\mathrm{Cu}$ is mainly transported as a chloride complex in fumarolic gases from White Island. Copper chloride $\mathrm{CuCl}$ dominates at high temperature (300-495 ${ }^{\circ} \mathrm{C}$ ) whereas the dichloride species $\mathrm{CuCl}_{2}$ is more abundant with decreasing temperature. Many experimental studies nevertheless emphasize the role of sulfur complexes in transporting $\mathrm{Cu}$ (Simon et al., 2006; Seo et al., 2009; Zajacz et al., 2011). We thus modelled volcanic gases at higher magmatic temperatures to constrain speciation of gaseous $\mathrm{Cu}$ species. Yasur was chosen for calculations as the magma is only meters below the surface, insuring that minimal hydrothermal interaction occurs. The major gas composition was taken from MulltiGas and filter pack data collected by Métrich et al. (2011). The same authors estimated the temperature of Yasur basaltic trachyandesite to be around $1107{ }^{\circ} \mathrm{C}$, and we used the trace metal contents from our filter pack campaign in October 2016 (cf. Chapter 6) in these calculations. The second case study uses the $984{ }^{\circ} \mathrm{C}$ gas composition reported by Wahrenberger et al. (2002) from Kudriavy volcano. We also modelled the major gas composition of high-temperature $\left(772{ }^{\circ} \mathrm{C}\right)$ fumarolic gases from White Island collected in February 1984 (Giggenbach and Sheppard, 1989), and the trace metal contents from lower temperature $\left(495^{\circ} \mathrm{C}\right)$ emissions (Tedesco and Toutain, 1991). The gas compositions used for input are reported in Appendix A.9. 
HSC modelling shows that chloride complexes are responsible for $\mathrm{Cu}$ transport at these higher temperatures (Figure 7-3). For the three volcanic gases, the content of the dominant complex $\mathrm{CuCl}$ is almost constant with cooling until a certain temperature is reached, after which it starts decreasing. This temperature, indicating onset of $\mathrm{Cu}$-containing minerals deposition, is slightly over $700{ }^{\circ} \mathrm{C}$ for Yasur and White Island gases, and $\sim 800{ }^{\circ} \mathrm{C}$ for Kudriavy gases (see Figure 7-3). The mineral predicted to precipitate in White Island gases at $\mathrm{T}<700{ }^{\circ} \mathrm{C}$ is bornite $\left(\mathrm{Cu}_{5} \mathrm{FeS}_{4}\right)$, replaced by chalcopyrite $\left(\mathrm{CuFeS}_{2}\right)$ at temperature between $570{ }^{\circ} \mathrm{C}$ and $\sim 370{ }^{\circ} \mathrm{C}$. Formation of enargite $\left(\mathrm{Cu}_{3} \mathrm{AsS}_{4}\right)$ is restricted to temperature between $340{ }^{\circ} \mathrm{C}$ to $\sim 310{ }^{\circ} \mathrm{C}$.

Simulation for higher pressure (100 bar) affects only slightly the speciation of $\mathrm{Cu}$ gaseous species, increasing $\mathrm{CuCl}_{2}$ stability. Increasing the metal content to $0.001 \mathrm{~mol} \%$ does not change the speciation of gaseous copper species. The minor role of $\mathrm{S}$ in transporting $\mathrm{Cu}$ might reflect the lack of thermodynamic data compared to the complexity of natural systems: many studies showed the importance of water in increasing metal transport through the formation of hydrated complexes (Pokrovski et al., 2008; Zajacz et al., 2011), for which no thermodynamic data are available. Moreover, complexes such as $\mathrm{CuHS}\left(\mathrm{H}_{2} \mathrm{~S}\right), \mathrm{CuHS}$, $\mathrm{Na}(/ \mathrm{K}) \mathrm{Cu}(\mathrm{HS})_{2}, \mathrm{Na}(/ \mathrm{K}) \mathrm{ClCuHS}$ are associated with $\mathrm{Cu}$ transport in experimental studies (Seo et al., 2009; Zajacz et al., 2011), although not considered in our calculations due to the lack of thermodynamic data. 

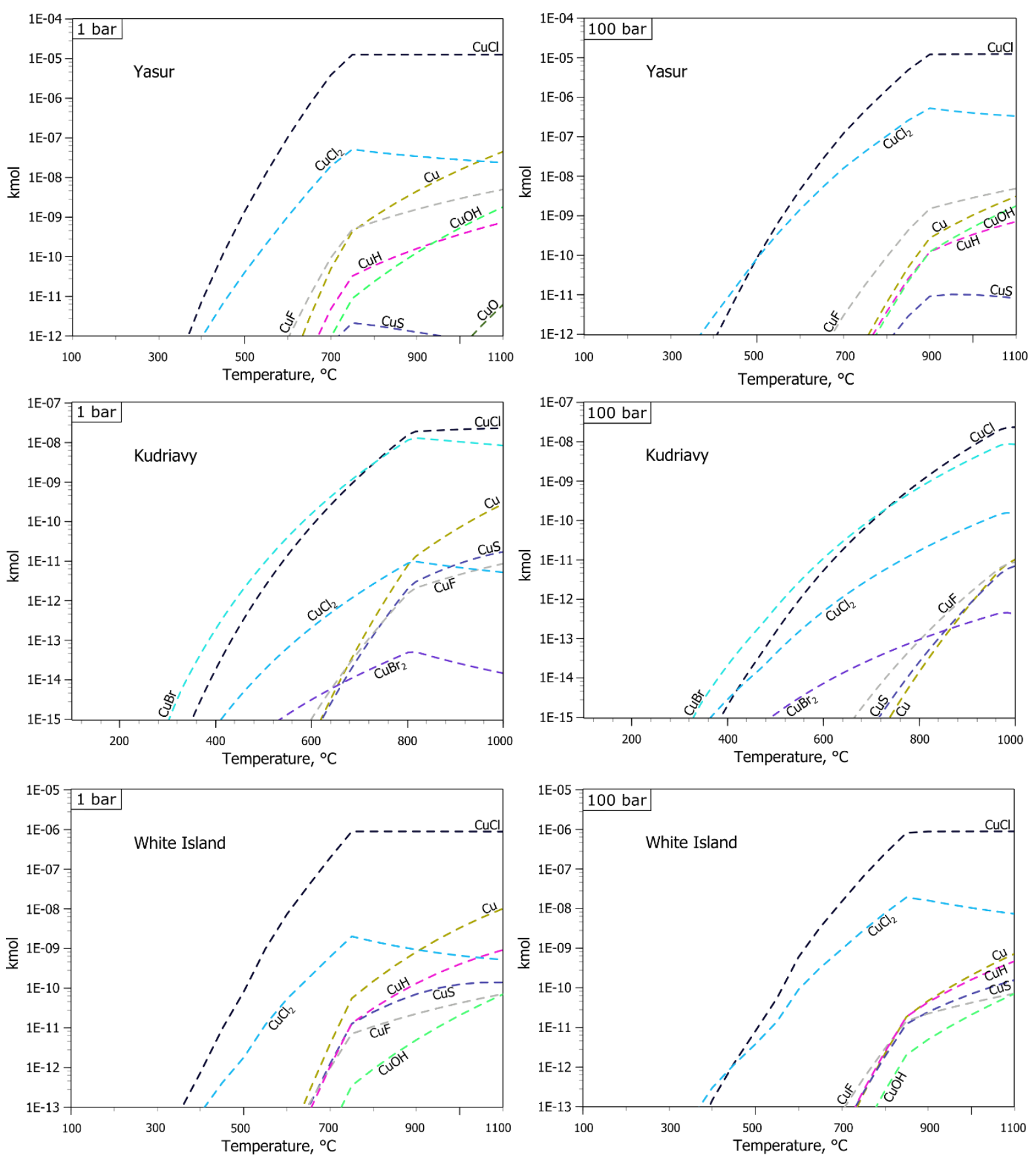

Figure 7-3: Distribution of gaseous $\mathrm{Cu}$ species in high-temperature gases from Kudriavy, Yasur and White Island volcanoes at 1 bar and 100 bar.

Nuccio et al. (1999) showed that high temperature fumaroles such as those recorded at Kudriavy, are the result of quasi-isenthalpic expansion. This assumption is realistic in the case of White Island, taking into account that the maximum temperature recorded in fumarolic gases was $772{ }^{\circ} \mathrm{C}$ in February 1984 (Giggenbach and Sheppard, 1989). Assuming that these gases were exsolved from the shallowly emplaced magma at $\sim 240$ bar and $900{ }^{\circ} \mathrm{C}$, the decompression path obtained in the $\mathrm{H}_{2} \mathrm{O}-\mathrm{NaCl}$ system is close to isenthalpic expansion (Figure 7-4). The lower temperatures recorded in periods of low activity are likely the result 
of interactions with hydrothermal fluids invading the magmatic conduit following cooling of the magmatic intrusion.

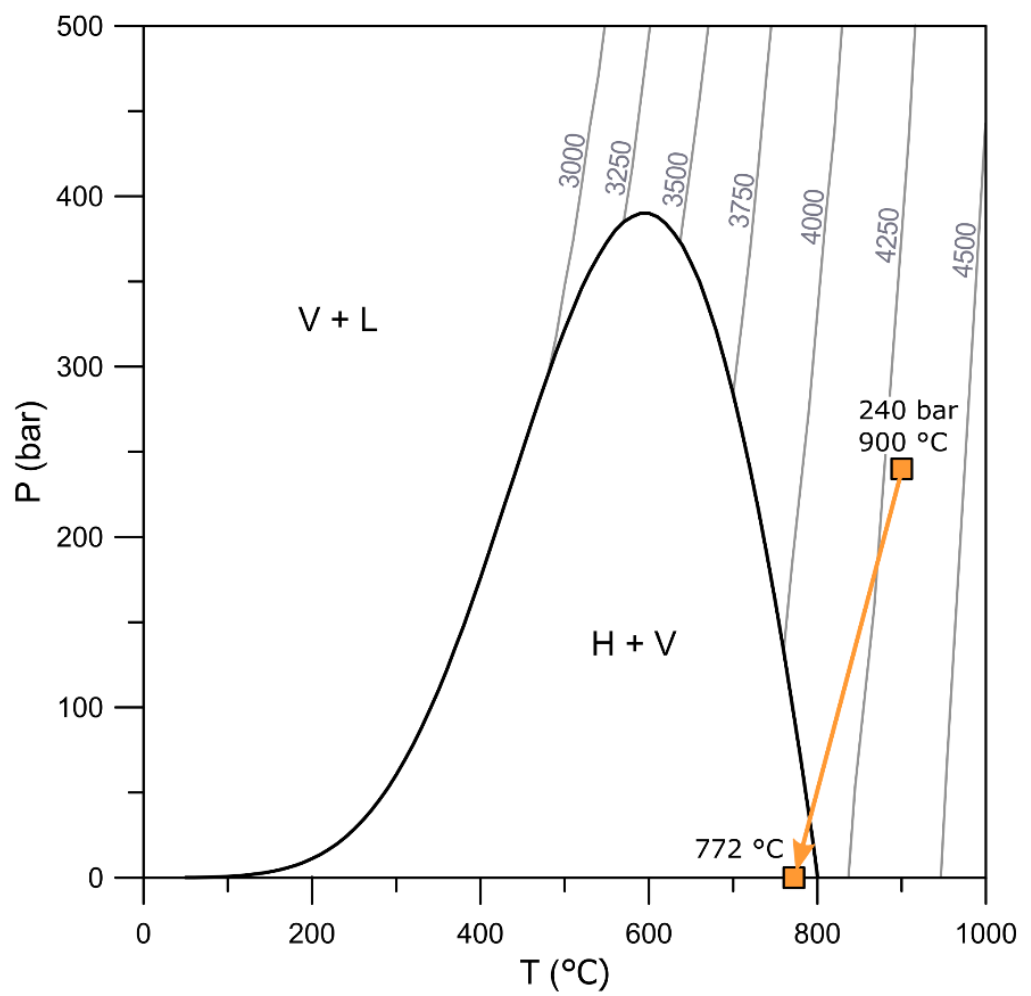

Figure 7-4: Pressure-temperature phase diagram of the $\mathrm{H}_{2} \mathrm{O}-\mathrm{NaCl}$ system. Isenthalpic expansion paths (in $\mathrm{kJ} . \mathrm{kg}^{-1}$ ) are shown. The decompression path for White Island magmatic gases from the shallow magma chamber at $900{ }^{\circ} \mathrm{C}$ and 240 bar, to their emission at the surface at $772{ }^{\circ} \mathrm{C}$ (Giggenbach and Sheppard, 1989) is close to isenthalpic. Constructed using the Sowat program (Driesner, 2007).

Many ore deposits are thought to form between 1 and $5 \mathrm{~km}$ from cooling intrusions emplaced at 5 to $15 \mathrm{~km}$ depth (Seedorff et al., 2005; Sillitoe, 2010, and references therein). The shallow depth (400-800 m) of White Island dacitic reservoirs is, in that regard, quite unusual. If we assume that the fluid exsolving from the magma in the dacitic reservoirs is ascending to the surface through a network of fractures, the confining pressure is that of the overlying groundwater column. Such hydrostatic pressure at a depth of $800 \mathrm{~m}$ corresponds to around 80 bar. The vapor phase exsolving at the base of this array of fractures open to the atmosphere, with a temperature around $900{ }^{\circ} \mathrm{C}$, would expand from 240 bar to 80 bar. Such expansion leads to a drop in gas density, destabilizing solvated complexes and driving precipitation (Rusk et al., 2008; Mavrogenes et al., 2010; Henley and Berger, 2011; Henley and Berger, 2013; Henley et al., 2015). This mechanism was, for instance, responsible for the formation of the Pascua high-sulfidation deposit (Chile-Argentina), in the previously altered vuggy silica environment underlying a crater lake (Chouinard et al., 2005).

The drop in halite solubility during quasi-isenthalpic expansion of magmatic vapor modelled by Henley and Berger (2011) is accompanied by sulfide and sulfosalt deposition. In a recent review, Taran and Zelenski (2015) observed the impact of halite precipitation on $\mathrm{Na}$ and $\mathrm{HCl}$ contents of volcanic gases at different temperatures. A similar scenario could be responsible 
for deposition of the $\mathrm{Cu}$ load carried by White Island low-density vapors exsolving from the shallow dacitic magma. This is especially relevant given the low pressure of exsolution, placing the magmatic vapor close to the halite + vapor field (Figure 7-4). Isenthalpic or quasiisenthalpic expansion, with loss of heat to the surrounding rocks, would result in the vapor intersecting the vapor + halite field. In turn, halite precipitation would destabilize chloridecomplexed metals, thus favoring metal deposition.

Other deposition mechanisms involve gas-rock reactions. The $\mathrm{SO}_{2}$ contained in the gas can react with Fe-bearing rock (Giggenbach, 1987):

$$
\mathrm{SO}_{2(g)}+6 \mathrm{FeO}+\mathrm{H}_{2} \mathrm{O}=\mathrm{H}_{2} \mathrm{~S}_{(g)}+6 \mathrm{FeO}_{1.5}
$$

and/or with Ca-bearing rock (Henley et al., 2015):

$$
3 \mathrm{CaAl}_{2} \mathrm{Si}_{2} \mathrm{O}_{8}+4 \mathrm{SO}_{2(g)}+\mathrm{H}_{2} \mathrm{O}=3 \mathrm{CaSO}_{4}+3 \mathrm{Al}_{2} \mathrm{SiO}_{5}+3 \mathrm{SiO}_{2}+\mathrm{H}_{2} \mathrm{~S}_{(\mathrm{g})}
$$

These two processes are quite relevant given the presence of Fe-rich and Ca-rich minerals in White Island dacitic lava and in the alteration assemblage. Both reactions lead to formation of $\mathrm{H}_{2} \mathrm{~S}$, further driving sulfide deposition. Moreover, the solubility of copper chloride complexes in vapor decreases dramatically between $400{ }^{\circ} \mathrm{C}$ and $300{ }^{\circ} \mathrm{C}$ (Crerar and Barnes, 1976; Bernard, 1985; Symonds et al., 1987; Hemley et al., 1992; Xiao et al., 1998; Landtwing et al., 2005; Klemm et al., 2007) most likely due to hydrolysis of $\mathrm{SO}_{2}$ into $\mathrm{H}_{2} \mathrm{~S}$ and $\mathrm{H}_{2} \mathrm{SO}_{4}$ at $\mathrm{T}<400{ }^{\circ} \mathrm{C}$ (Holland, 1965; Burnham, 1967; Sakai and Matsubaya, 1977; Kusakabe et al., 2000), leading to sulfide and sulfate (anhydrite) deposition.

\subsection{Thesis Conclusions}

- The 1976-2000 eruptive sequence of White Island was related to repeated injections of partly degassed mafic magma from $>5 \mathrm{~km}$ depth into more evolved reservoirs located at $\sim 400$ to $800 \mathrm{~m}$ depth. Convection within the deeper chamber is thought to be responsible for the efficient degassing of the less soluble $\mathrm{CO}_{2}, \mathrm{H}_{2} \mathrm{O}$ and $\mathrm{SO}_{2}$ without erupting large volumes of magma (see Figure 7-5). Crystallization of plagioclase and pyroxene in the shallow reservoirs led to chlorine exsolution from the silicate melt. The latter, in conjunction with deeper sulfur fluxing through the chamber, supplied ligands for metal degassing. Magnetite precipitation, in turn, may have triggered saturation of a sulfide melt, efficiently segregating $\mathrm{Fe}, \mathrm{Cu}, \mathrm{Ni}, \mathrm{Ag}$ and $\mathrm{Au}$ from the magma.

- $\quad$ The crater lake absorbs high enthalpy magmatic gases forming highly acidic and reactive fluids. Seeping underneath the lake and/or recirculation explains the intense alteration observed in ancient dissected volcanoes and at Kawah Ijen for example. As can be seen in Figure 7-5, elemental sulfur is forming at the bottom of the crater lake, efficiently scavenging metals either through saturation of metal sulfides in this reduced environment, or through adsorption on the positively charged surface of sulfur particles and subsequent 
reaction with $\mathrm{H}_{2} \mathrm{~S}$ produced by sulfur hydrolysis. The lake itself is a very active system, with thermal, redox and compositional gradients with depth. The speciation of metals is greatly affected by these variations, with $\mathrm{Cu}^{\mathrm{I}}, \mathrm{Fe}^{\mathrm{II}}$ chloride complexes and $\mathrm{As}(\mathrm{OH})_{3}$ present in the reduced waters at depth and $\mathrm{Cu}^{\mathrm{II}}, \mathrm{Fe}^{\mathrm{III}}$ chloride complexes and $\mathrm{H}_{3} \mathrm{AsO}_{4}$ in the oxidized surficial environment. $\mathrm{Zn}, \mathrm{Pb}$ and $\mathrm{Ag}$ chloride complexes are not affected by redox variations. Dissolution of host rock and precipitation of various secondary minerals (i.e. anhydrite, gypsum, alunite, sulfur, barite, silica) are occurring.

- Low temperature gases emitted at fumaroles have interacted with the twophase envelope surrounding the magmatic conduit described by Giggenbach (1987) and shown in Figure 7-5. The extent of these interactions is dependent on volcanic activity, due to retraction/expansion of the envelope. More metals are transported into the atmosphere during periods of heightened activity. Decreasing temperature leads to destabilization of metal complexes and subsequent deposition, at $\mathrm{T}<350{ }^{\circ} \mathrm{C}$ for metals such as $\mathrm{Bi}$ and $\mathrm{Pb}$. Copper deposition starts at higher temperature $\left(\sim 700^{\circ} \mathrm{C}\right)$ as evidenced by similarly low contents in present day $\sim 190{ }^{\circ} \mathrm{C}$ fumarolic gases and $495{ }^{\circ} \mathrm{C}$ gases sampled in 1988. Although the dominant ligand appears to be $\mathrm{Cl}$, sulfur is equally important given the control it exerts on redox conditions, further controlling gas speciation and saturated minerals. Cooling and oxidation as the gases approach the surface lead to precipitation of sublimates (dominated by various sulfates) and condensation of elemental sulfur, at White Island.

- $\quad$ The volcanic plume is more enriched in metals than the fumarolic gases, owing to the assumed higher temperature and decreased interactions with the hydrothermal system. $\mathrm{Cu}$ is nevertheless depleted in White Island's plume compared to other species such as $\mathrm{Bi}, \mathrm{Cd}, \mathrm{Tl}, \mathrm{Se}, \mathrm{Te}$ and $\mathrm{Sb}$. The aerosol fraction consists of halides, sulfates, oxides, silicates and sulfuric acid, formed through gas-to-particle reactions or erosion of the conduit wall. Changes in volcanic activity are reflected by the plume composition, not only in terms of major elements, but with potential insights from metal contents. The presence of gold in the White Island plume (i.e. aerosol), for example, is related to emissions of higher temperature gases with a magmatic signature (i.e. high $\mathrm{SO}_{2} / \mathrm{HCl}$ ratio). Fluxes of metals are significant, with an annual emission of $\sim 2$ tons of $\mathrm{Cu}, \mathrm{As}, \mathrm{Zn}, \sim 0.4$ tons of $\mathrm{Pb}$ and $\sim 16 \mathrm{~kg}$ of Au during quiescent degassing.

- Mass balance calculations predict that $51-55 \%$ of the total $\mathrm{Cu}$ is segregated at depth. $45 \%$ remains in the silicate melt and $<4 \%$ is emitted into the environment. Gold and silver may also be efficiently segregated at depth. These results support earlier assumptions that White Island is a favorable environment for ore deposition processes to occur. The segregated metals either accumulate at depth in a high-density and high-salinity aqueous liquid exsolving from the dacitic magma, and/or are deposited by low-density vapors on their way to the surface (Figure 7-5). The metal-transporting hydrothermal fluid will deposit metals (e.g. as sulfides) in response to: reactions with Fe- and/or Ca-bearing rocks, mixing with meteoric fluids, and rapid expansion during the transition from lithostatic to hydrostatic 
regime. A very small fraction of $\mathrm{Cu}$ may also be segregated by metal-rich sulfide blebs trapped within phenocrysts.

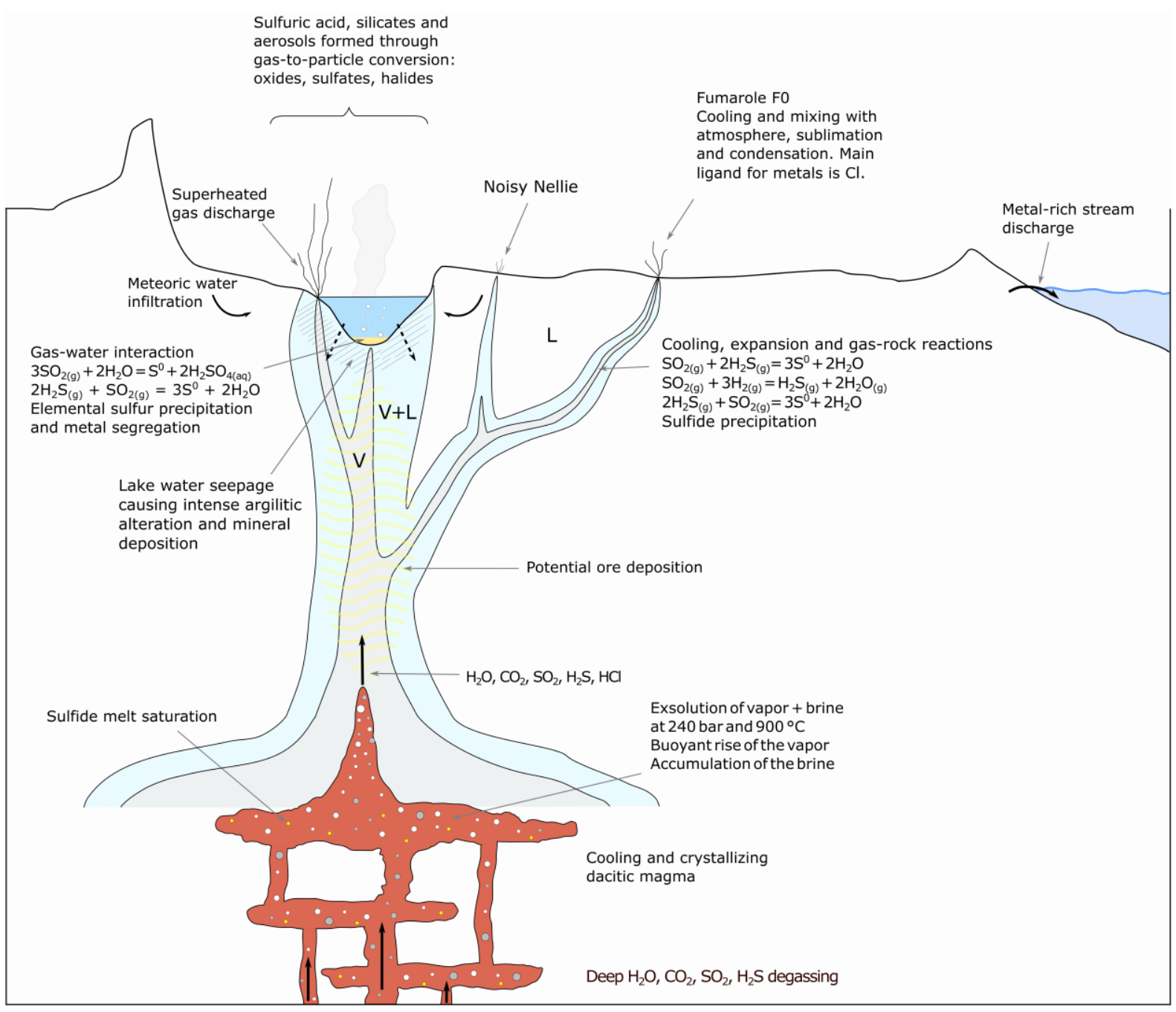

Figure 7-5: Sketch of White Island magmatic-hydrothermal system. The model for the two-phase hydrothermal envelope is taken from Giggenbach (1987).

This thesis has detailed the fate of metals in an active andesitic-dacitic magmatichydrothermal system. We constrained the transport of metals after their exsolution from the magma and showed that, despite significant emission at the surface, certain elements such as $\mathrm{Cu}, \mathrm{Au}$ and $\mathrm{Ag}$, are predominantly sequestered in the subsurface environment.

Questions nevertheless still arise. Further study, particularly in better constraining the depth and temperature of the magmatic reservoirs at White Island, is needed in order to gain more understanding on the processes occurring in an ore deposition environment. Similarly, petrologic studies and especially mineral analyses would help constraining the P-T conditions of crystallization, as well as trace metal partitioning between mineral/melt/volatile phase. The redox state of sulfur in matrix glass and melt inclusions would also help constraining the 
evolution of redox conditions in the silicate melt during crystallization, degassing and immiscible sulfide melt exsolution. Moreover, long term monitoring of White Island discharge features (fumarolic gases and volcanic plume) in terms of metals is required to define potential variations in composition related to shifts in volcanic activity. Such a monitoring tool would improve our ability to forecast changes in volcanic activity. Finally, the new drone sampling technique needs to be refined and improved in the view of developing a method for monitoring volcanic emissions that is not weather dependent. 


\section{References}

Africano, F., Van Rompaey, G., Bernard, A., Le Guern, F., (2002). Deposition of trace elements from high temperature gases of Satsuma-Iwojima volcano. Earth, Planets and Space 54(3), 275-286.

Agrinier, P., Jendrzejewski, N., (2000). Overcoming problems of density and thickness measurements in FTIR volatile determinations: a spectroscopic approach. Contributions to Mineralogy and Petrology 139(3), 265-272.

Aiuppa, A., Allard, P., D’Alessandro, W., Michel, A., Parello, F., Treuil, M., Valenza, M., (2000). Mobility and fluxes of major, minor and trace metals during basalt weathering and groundwater transport at Mt. Etna volcano (Sicily). Geochimica et Cosmochimica Acta 64(11), 1827-1841.

Aiuppa, A., Dongarrà, G., Valenza, M., Federico, C., Pecoraino, G., (2003). Degassing of Trace Volatile Metals During the 2001 Eruption of Etna. In: Volcanism and the Earth's Atmosphere. (Eds) A. Robock, C. Oppenheimer, Washington, D.C., American Geophysical Union, 41-54.

Aiuppa, A., Federico, C., Paonita, A., Pecoraino, G., Valenza, M., (2002). S, Cl and F degassing as an indicator of volcanic dynamics: The 2001 eruption of Mount Etna. Geophysical Research Letters 29(11), 54-5154-54.

Aiuppa, A., Moretti, R., Federico, C., Giudice, G., Gurrieri, S., Liuzzo, M., Papale, P., Shinohara, H., Valenza, M., (2007). Forecasting Etna eruptions by real-time observation of volcanic gas composition. Geology 35(12), 1115-1118.

Allard, P., (1997). Endogenous magma degassing and storage at Mount Etna. Geophysical Research Letters 24(17), 2219-2222.

Allard, P., Aiuppa, A., Bani, P., Métrich, N., Bertagnini, A., Gauthier, P. J., Shinohara, H., Sawyer, G., Parello, F., Bagnato, E., Pelletier, B., Garaebiti, E., (2015). Prodigious emission rates and magma degassing budget of major, trace and radioactive volatile species from Ambrym basaltic volcano, Vanuatu island Arc. Journal of Volcanology and Geothermal Research 304, 378-402.

Allard, P., Aiuppa, A., Loyer, H., Carrot, F., Gaudry, A., Pinte, G., Michel, A., Dongarrà, G., (2000). Acid gas and metal emission rates during long-lived basalt degassing at Stromboli Volcano. Geophysical Research Letters 27(8), 1207-1210.

Allen, A. G., Baxter, P. J., Ottley, C. J., (2000). Gas and particle emissions from Soufrière Hills Volcano, Montserrat, West Indies: characterization and health hazard assessment. Bulletin of Volcanology 62(1), 8-19.

Alletti, M., Baker, D. R., Freda, C., (2007). Halogen diffusion in a basaltic melt. Geochimica et Cosmochimica Acta 71(14), 3570-3580.

Alletti, M., Baker, D. R., Scaillet, B., Aiuppa, A., Moretti, R., Ottolini, L., (2009). Chlorine partitioning between a basaltic melt and H2O-CO2 fluids at Mount Etna. Chemical Geology 263(1-4), 37-50.

Anderson, A. T., (1976). Magma mixing: petrological process and volcanological tool. Journal of Volcanology and Geothermal Research 1(1), 3-33.

Anderson, A. T., Newman, S., Williams, S. N., Druitt, T. H., Skirius, C., Stolper, E., (1989). H2O, CO2, CI, and gas in Plinian and ash-flow Bishop rhyolite. Geology 17(3), 221-225.

Andres, R. J., Kyle, P. R., Chuan, R. L., (1993). Sulphur dioxide, particle and elemental emissions from Mount Etna, Italy during July 1987. Geologische Rundschau 82(4), 687-695.

Archibald, S. M., Migdisov, A. A., Williams-Jones, A. E., (2001). The stability of Au-chloride complexes in water vapor at elevated temperatures and pressures. Geochimica et Cosmochimica Acta 65(23), 44134423 .

Archibald, S. M., Migdisov, A. A., Williams-Jones, A. E., (2002). An experimental study of the stability of copper chloride complexes in water vapor at elevated temperatures and pressures. Geochimica et Cosmochimica Acta 66(9), 1611-1619.

Audétat, A., Günther, D., Heinrich, C. A., (1998). Formation of a Magmatic-Hydrothermal Ore Deposit: Insights with LA-ICP-MS Analysis of Fluid Inclusions. Science 279(5359), 2091-2094.

Audetat, A., Pettke, T., (2006). Evolution of a Porphyry-Cu Mineralized Magma System at Santa Rita, New Mexico (USA). Journal of Petrology 47(10), 2021-2046.

Bacon, C. R., (1989). Crystallization of accessory phases in magmas by local saturation adjacent to phenocrysts. Geochimica et Cosmochimica Acta 53(5), 1055-1066.

Badrudin, M., (1994). Kelut volcano monitoring: Hazards, mitigation and changes in water chemistry prior to the 1990 eruption. Geochemical Journal 28(3), 233-241.

Bagnato, E., Aiuppa, A., Parello, F., Allard, P., Shinohara, H., Liuzzo, M., Giudice, G., (2011). New clues on the contribution of Earth's volcanism to the global mercury cycle. Bulletin of Volcanology 73(5), 497510 . 
Bagnato, E., Aiuppa, A., Parello, F., Calabrese, S., D’Alessandro, W., Mather, T. A., McGonigle, A. J. S., Pyle, D. M., Wängberg, I., (2007). Degassing of gaseous (elemental and reactive) and particulate mercury from Mount Etna volcano (Southern Italy). Atmospheric Environment 41(35), 7377-7388.

Baker, R. G. A., Rehkämper, M., Hinkley, T. K., Nielsen, S. G., Toutain, J. P., (2009). Investigation of thallium fluxes from subaerial volcanism-Implications for the present and past mass balance of thallium in the oceans. Geochimica et Cosmochimica Acta 73(20), 6340-6359.

Baker, T., Van Achterberg, E., Ryan, C. G., Lang, J. R., (2004). Composition and evolution of ore fluids in a magmatic-hydrothermal skarn deposit. Geology 32(2), 117-120.

Balcone-Boissard, H., Baker, D. R., Villemant, B., Boudon, G., (2009). F and Cl diffusion in phonolitic melts: Influence of the $\mathrm{Na} / \mathrm{K}$ ratio. Chemical Geology 263(1-4), 89-98.

Bani, P., Lardy, M., (2007). Sulphur dioxide emission rates from Yasur volcano, Vanuatu archipelago. Geophysical Research Letters 34(20), n/a-n/a.

Bani, P., Oppenheimer, C., Varekamp, J. C., Quinou, T., Lardy, M., Carn, S., (2009). Remarkable geochemical changes and degassing at Voui crater lake, Ambae volcano, Vanuatu. Journal of Volcanology and Geothermal Research 188(4), 347-357.

Barnes, H. L., (1981). Measuring thermodynamically-interpretable solubilities at high pressures and temperatures. Physics and Chemistry of the Earth 13-14(C), 321-343.

Barnes, H. L., (1997). Geochemistry of hydrothermal ore deposits, John Wiley \& Sons.

Barnes, H. L., Kullerud, G., (1957). Relations between composition of ore minerals and ore solutions. Economic Geology 52(7), 825-830.

Bas, M. J. L., Maitre, R. W. L., Streckeisen, A., Zanettin, B., (1986). A Chemical Classification of Volcanic Rocks Based on the Total Alkali-Silica Diagram. Journal of Petrology 27(3), 745-750.

Baxter, P., Stoiber, R., Williams, S., (1982). Volcanic gases and health: Masaya volcano, Nicaragua. The Lancet 320(8290), 150-151.

Behrens, H., Ohlhorst, S., Holtz, F., Champenois, M., (2004). CO2 solubility in dacitic melts equilibrated with $\mathrm{H} 2 \mathrm{O}-\mathrm{CO} 2$ fluids: Implications for modeling the solubility of $\mathrm{CO} 2$ in silicic melts. Geochimica et Cosmochimica Acta 68(22), 4687-4703.

Bernard, A., (1985). Les mécanismes de condensation des gaz volcaniques. PhD dissertation, Université Libre de Bruxelles, Brussels.

Bernard, A., Symonds, R. B., Rose, W. I., (1990). Volatile transport and deposition of Mo, W and Re in high temperature magmatic fluids. Applied Geochemistry 5(3), 317-326.

Berner, Z. A., Puchelt, H., Noltner, T., Kramar, U. T. Z., (2013). Pyrite geochemistry in the Toarcian Posidonia Shale of south-west Germany: Evidence for contrasting trace-element patterns of diagenetic and syngenetic pyrites. Sedimentology 60(2), 548-573.

Best, M. G., (2003). Igneous and Metamorphic Petrology, Second Edition. Oxford, Blackwell Science Ltd.

Bethke, C. M., (2007). Geochemical and biogeochemical reaction modeling 2nd Edition. Cambridge, Cambridge University Press.

Black, P. M., (1970). Observations on White Island volcano, New Zealand. Bulletin Volcanologique 34(1), 158167.

Bloomberg, S., (2012). Looking for Permeability: Mass and Heat Flow Assessment Using High Resolution soil CO2 Flux Surveys within the Taupo Volcanic Zone, New Zealand. University of Canterbury, Christchurch.

Blundy, J., Cashman, K. V., Rust, A., Witham, F., (2010). A case for CO2-rich arc magmas. Earth and Planetary Science Letters 290(3-4), 289-301.

Blundy, J., Mavrogenes, J., Tattitch, B., Sparks, S., Gilmer, A., (2015). Generation of porphyry copper deposits by gas-brine reaction in volcanic arcs. Nature Geoscience 8(3), 235-240.

Bodnar, R. J., (1995). Fluid-inclusion evidence for a magmatic source for metals in porphyry copper deposits. Mineralogical Association of Canada Short Course Series 23(1), 139-152.

Bodnar, R. J., Beane, R. E., (1980). Temporal and spatial variations in hydrothermal fluid characteristics during vein filling in preore cover overlying deeply buried porphyry copper-type mineralization at Red Mountain, Arizona. Economic Geology 75(6), 876-893.

Bodnar, R. J., Burnham, C. W., Sterner, S. M., (1985). Synthetic fluid inclusions in natural quartz. III. Determination of phase equilibrium properties in the system $\mathrm{H} 2 \mathrm{O}-\mathrm{NaCl}$ to $1000^{\circ} \mathrm{C}$ and 1500 bars. Geochimica et Cosmochimica Acta 49(9), 1861-1873.

Brantley, S. L., Borgiatt, A., Rowe, G., Fernandez, J. F., Reynolds, J. R., (1987). Poas volcano crater lake acts as a condenser for acid metal-rich brine. Nature 330(6147), 470-472.

Brown, G. C., Rymer, H., Dowden, J., Kapadia, P., Stevenson, D., Barquero, J., Morales, L. D., (1989). Energy budget analysis for Poas crater lake: implications for predicting volcanic activity. Nature 339(6223), 370-373. 
Brown, G. C., Rymer, H., Stevenson, D., (1991). Volcano monitoring by microgravity and energy budget analysis. Journal of the Geological Society 148(3), 585-593.

Browne, P. R. L., Lawless, J. V., (2001). Characteristics of hydrothermal eruptions, with examples from New Zealand and elsewhere. Earth-Science Reviews 52(4), 299-331.

Buat-Ménard, P., Arnold, M., (1978). The heavy metal chemistry of atmospheric particulate matter emitted by Mount Etna Volcano. Geophysical Research Letters 5(4), 245-248.

Burnham, C. W., (1967). Hydrothermal fluids at the magmatic stage. In: Geochemistry of hydrothermal ore deposits. (Eds) H. L. Barnes, New York, Holt, Rinehart and Winston, 34-76.

Burnham, C. W., (1979). Magmas and hydrothermal fluids. In: Geochemistry of hydrothermal ore deposits, 2nd edition. (Eds) H. L. Barnes, New York, Wiley-Interscience, 71-136.

Burnham, C. W., (1997). Magmas and hydrothermal fluids. In: Geochemistry of hydrothermal ore deposits, 3rd edition. (Eds) H. L. Barnes, New York, Wiley and Sons, 63-123.

Cadle, R. D., (1980). A comparison of volcanic with other fluxes of atmospheric trace gas constituents. Reviews of Geophysics 18(4), 746-752.

Calabrese, S., Aiuppa, A., Allard, P., Bagnato, E., Bellomo, S., Brusca, L., D’Alessandro, W., Parello, F., (2011). Atmospheric sources and sinks of volcanogenic elements in a basaltic volcano (Etna, Italy). Geochimica et Cosmochimica Acta 75(23), 7401-7425.

Calabrese, S., D'Alessandro, W., (2015). Characterization of the Etna volcanic emissions through an active biomonitoring technique (moss-bags): Part 2 - Morphological and mineralogical features. Chemosphere 119, 1456-1464.

Caltabiano, T., Burton, M., Giammanco, S., Allard, P., Bruno, N., Murè, F., Romano, R., (2004). Volcanic Gas Emissions from the Summit Craters and Flanks of Mt. Etna, 1987-2000. In: Mt. Etna: Volcano Laboratory, American Geophysical Union, 111-128.

Candela, P. A., (1989). Magmatic Ore-Forming Fluids: Thermodynamic and Mass Transfer Calculations of Metal Concentrations. In: Ore deposition associated with magmas. (Eds) J. A. Whitney, A. J. Naldrett, Reviews in Economic Geology, Society of Economic Geologists. 4, 203-221.

Candela, P. A., Holland, H. D., (1986). A mass transfer model for copper and molybdenum in magmatic hydrothermal systems; the origin of porphyry-type ore deposits. Economic Geology 81(1), 1-19.

Candela, P. A., Piccoli, P. M., (1995a). An experimental-theoretical model of brine-vapor-silicate melt equilibria with applications to geothermal and ore-forming systems. Mineralogical Association of Canada Short Course Series 23, 101-127.

Candela, P. A., Piccoli, P. M., (1995b). Model ore-metal partitioning from melts into vapor and vapor/brine mixtures. In: Magmas, Fluids, and ore deposits. (Eds) J. F. H. Thompson, Victoria. 23, 101-127.

Candela, P. A., Piccoli, P. M., (2005). Magmatic processes in the development of porphyry-type ore systems. Economic Geology 100, 25-37.

Capasso, G., Dongarrà, G., Favara, R., Hauser, S., Valenza, M., (1992). Isotope composition of rain water, well water and fumarole steam on the island of Vulcano, and their implications for volcanic surveillance. Journal of Volcanology and Geothermal Research 49(1), 147-155.

Capasso, G., Favara, R., Francofonte, S., Inguaggiato, S., (1999). Chemical and isotopic variations in fumarolic discharge and thermal waters at Vulcano Island (Aeolian Islands, Italy) during 1996: evidence of resumed volcanic activity. Journal of Volcanology and Geothermal Research 88(3), 167-175.

Carroll, M. R., Rutherford, M. J., (1985). Sulfide and sulfate saturation in hydrous silicate melts. Journal of Geophysical Research: Solid Earth 90(S02), C601-C612.

Carroll, M. R., Rutherford, M. J., (1988). Sulfur speciation in hydrous experimental glasses of varying oxidation state; results from measured wavelength shifts of sulfur X-rays. American Mineralogist 73(7-8), 845849.

Carroll, M. R., Webster, J. D., (1994). Solubilities of sulfur, noble gases, nitrogen, chlorine, and fluorine in magmas. Reviews in Mineralogy and Geochemistry 30(1), 231-279.

Casadevall, T. J., Rose, W. I., Fuller, W. H., Hunt, W. H., Hart, M. A., Moyers, J. L., Woods, D. C., Chuan, R. L., Friend, J. P., (1984). Sulfur dioxide and particles in quiescent volcanic plumes from Poás, Arenal, and Colima Volcanos, Costa Rica and Mexico. Journal of Geophysical Research: Atmospheres 89(D6), 9633-9641.

Cashman, K. V., (1992). Groundmass crystallization of Mount St. Helens dacite, 1980-1986: a tool for interpreting shallow magmatic processes. Contributions to Mineralogy and Petrology 109(4), 431-449.

Cauzid, J., Philippot, P., Martinez-Criado, G., Ménez, B., Labouré, S., (2007). Contrasting Cu-complexing behaviour in vapour and liquid fluid inclusions from the Yankee Lode tin deposit, Mole Granite, Australia. Chemical Geology 246(1-2), 39-54.

Cervantes, P., Wallace, P. J., (2003). Magma degassing and basaltic eruption styles: a case study of 2000 year BP Xitle volcano in central Mexico. Journal of Volcanology and Geothermal Research 120(3-4), 249270. 
Chen, J. K., Taylor, F. W., Edwards, R. L., Cheng, H., Burr, G. S., (1995). Recent Emerged Reef Terraces of the Yenkahe Resurgent Block, Tanna, Vanuatu: Implications for Volcanic, Landslide and Tsunami Hazards. The Journal of Geology 103(5), 577-590.

Cheynet, B., Dall'Aglio, M., Garavelli, A., Grasso, M. F., Vurro, F., (2000). Trace elements from fumaroles at Vulcano Island (Italy): rates of transport and a thermochemical model. Journal of Volcanology and Geothermal Research 95(1-4), 273-283.

Chiodini, G., Cioni, R., Marini, L., (1993). Reactions governing the chemistry of crater fumaroles from Vulcano Island, Italy, and implications for volcanic surveillance. Applied Geochemistry 8(4), 357-371.

Chiodini, G., Cioni, R., Marini, L., Panichi, C., (1995). Origin of the fumarolic fluids of Vulcano Island, Italy and implications for volcanic surveillance. Bulletin of Volcanology 57(2), 99-110.

Chouinard, A., Williams-Jones, A. E., Leonardson, R. W., Hodgson, C. J., Silva, P., Téllez, C., Vega, J., Rojas, F., (2005). Geology and Genesis of the Multistage High-Sulfidation Epithermal Pascua Au-Ag-Cu Deposit, Chile and Argentina. Economic Geology 100(3), 463-490.

Christenson, B. W., (2000). Geochemistry of fluids associated with the 1995-1996 eruption of Mt. Ruapehu, New Zealand: signatures and processes in the magmatic-hydrothermal system. Journal of Volcanology and Geothermal Research 97(1-4), 1-30.

Christenson, B. W., Mroczek, E. K., (2003). Potential Reaction Pathways of Hg in Some New Zealand Hydrothermal Environments. Special Publication-Society of Economic Geologists 10, 111-132.

Christenson, B. W., Németh, K., Rouwet, D., Tassi, F., Vandemeulebrouck, J., Varekamp, J. C., (2015). Volcanic lakes. In: Volcanic Lakes. (Eds) D. Rouwet, B. Christenson, F. Tassi, J. Vandemeulebrouck, Berlin, Springer Heidelberg, 1-20.

Christenson, B. W., Reyes, A. G., Young, R., Moebis, A., Sherburn, S., Cole-Baker, J., Britten, K., (2010). Cyclic processes and factors leading to phreatic eruption events: Insights from the 25 September 2007 eruption through Ruapehu Crater Lake, New Zealand. Journal of Volcanology and Geothermal Research 191(1-2), 15-32.

Christenson, B. W., Tassi, F., (2015). Gases in Volcanic Lake Environments. In: Volcanic Lakes. (Eds) D. Rouwet, B. Christenson, F. Tassi, J. Vandemeulebrouck, Berlin, Advances in Volcanology, Springer Heidelberg, 125-153.

Christenson, B. W., Werner, C. A., Reyes, A. G., Sherburn, S., Scott, B. J., Miller, C., Rosenburg, M. J., Hurst, A. W., Britten, K., (2007). Hazards from hydrothermally sealed volcanic conduits. Eos, Transactions American Geophysical Union 88(5), 53-55.

Christenson, B. W., White, S., Britten, K., Scott, B. J., (2017). Hydrological Evolution and Chemical Structure of a Hyper-acidic Spring-lake System on Whakaari/White Island, NZ. Journal of Volcanology and Geothermal Research.

Christenson, B. W., Wood, C. P., (1993). Evolution of a vent-hosted hydrothermal system beneath Ruapehu Crater Lake, New Zealand. Bulletin of Volcanology 55(8), 547-565.

Chuan, R. L., Palais, J., Rose, W. I., Kyle, P. R., (1986). Fluxes, sizes, morphology and compositions of particles in the Mt. Erebus volcanic plume, December 1983. Journal of Atmospheric Chemistry 4(4), 467-477.

Cioni, R., D'Amore, F., (1984). A genetic model for the crater fumaroles of Vulcano island (Sicily, Italy). Geothermics 13(4), 375-384.

Clark, R. H., Cole, J. W., (1986). White Island. Royal Society of New Zealand Bulletin 23, 169-178.

Clark, R. H., Cole, J. W., (1989). Volcanic monitoring and surveillance at White Island before the 1976-82 eruption sequence. New Zealand Geological Survey Bulletin 103, 9-11.

Clark, R. H., Cole, J. W., Nairn, I. A., Wood, C. P., (1979). Magmatic eruption of White Island volcano, New Zealand, December 1976-April 1977. New Zealand Journal of Geology and Geophysics 22(2), 175190.

Cline, J. S., Bodnar, R. J., (1991). Can economic porphyry copper mineralization be generated by a typical calcalkaline melt? Journal of Geophysical Research: Solid Earth 96(B5), 8113-8126.

Cole, J. W., (1990). Structural control and origin of volcanism in the Taupo volcanic zone, New Zealand. Bulletin of Volcanology 52(6), 445-459.

Cole, J. W., Gamble, J. A., Burt, R. M., Carroll, L. D., Shelley, D., (2001). Mixing and mingling in the evolution of andesite-dacite magmas; evidence from co-magmatic plutonic enclaves, Taupo Volcanic Zone, New Zealand. Lithos 59(1-2), 25-46.

Cole, J. W., Graham, I. J., (1989). Petrology of strombolian and phreatomagmatic ejecta from the 1976-82 White Island eruption sequence. New Zealand Geological Survey Bulletin 103, 61-68.

Cole, J. W., Lewis, K. B., (1981). Evolution of the Taupo-Hikurangi subduction system. Tectonophysics 72(12), 1-21. 
Cole, J. W., Nairn, I. A., (1975). Part XXII, New Zealand: Catalogue of the active volcanoes of the world including solfatara fields. Rome, International Association of Volcanology and Chemistry of the Earth's Interior.

Cole, J. W., Thordarson, T., Burt, R. M., (2000). Magma Origin and Evolution of White Island (Whakaari) Volcano, Bay of Plenty, New Zealand. Journal of Petrology 41(6), 867-895.

Colvin, A., Rose, W. I., Varekamp, J. C., Palma, J. L., Escobar, D., Gutierrez, E., Montalvo, F., Maclean, A., (2013). Crater lake evolution at Santa Ana Volcano (El Salvador) following the 2005 eruption. Geological Society of America Special Papers 498, 23-43.

Cooke, D. R., Hollings, P., Walshe, J. L., (2005). Giant Porphyry Deposits: Characteristics, Distribution, and Tectonic Controls. Economic Geology 100(5), 801-818.

Core, D. P., Kesler, S. E., Essene, E. J., Dufresne, E. B., Clarke, R., Arms, D. A., Walko, D., Rivers, M. L., (2005). Copper and zinc in silicate and oxide minerals in igneous rocks from the Bingham - Park City Belt, Utah: Synchrotron X-Ray-fluorescence data. The Canadian Mineralogist 43(5), 1781-1796.

Craw, D., Falconer, D., Youngson, J. H., (2003). Environmental arsenopyrite stability and dissolution: theory, experiment, and field observations. Chemical Geology 199(1-2), 71-82.

Crerar, D. A., Barnes, H. L., (1976). Ore solution chemistry; V, Solubilities of chalcopyrite and chalcocite assemblages in hydrothermal solution at 200 degrees to 350 degrees C. Economic Geology 71(4), 772794.

Damman, A. H., Kars, S. M., Touret, J. L. R., Rieffe, E. C., Kramer, J. A. L. M., Vis, R. D., Pintea, I., (1996). PIXE and SEM analyses of fluid inclusions in quartz crystals from the K-alteration zone of the Rosia Poieni porphyry-Cu deposit, Apuseni Mountains, Rumania. European Journal of Mineralogy 8(5), 1081-1096.

Danyushevsky, L. V., Eggins, S. M., Falloon, T. J., Christie, D. M., (2000). H2O Abundance in Depleted to Moderately Enriched Mid-ocean Ridge Magmas; Part I: Incompatible Behaviour, Implications for Mantle Storage, and Origin of Regional Variations. Journal of Petrology 41(8), 1329-1364.

Delany, J., Lundeen, S., (1989). The LLNL thermochemical database. Lawrence Livermore National Laboratory Report UCRL-21658 150.

Delmelle, P., (2003). Environmental impacts of tropospheric volcanic gas plumes. Geological Society, London, Special Publications 213(1), 381-399.

Delmelle, P., Bernard, A., (1994). Geochemistry, mineralogy, and chemical modeling of the acid crater lake of Kawah Ijen Volcano, Indonesia. Geochimica et Cosmochimica Acta 58(11), 2445-2460.

Delmelle, P., Bernard, A., (2000). Volcanic lakes. In: Encyclopedia of volcanoes. (Eds) H. Sigurdsson, B. Houghton, H. Rymer, J. Stix, S. McNutt, San Diego, Academic Press, 877-895.

Delmelle, P., Bernard, A., (2015). The Remarkable Chemistry of Sulfur in Hyper-Acid Crater Lakes: A Scientific Tribute to Bokuichiro Takano and Minoru Kusakabe. In: Volcanic Lakes. (Eds) D. Rouwet, B. Christenson, F. Tassi, J. Vandemeulebrouck, Berlin, Advances in Volcanology, Springer Heidelberg, 239-259.

Delmelle, P., Henley, R. W., Opfergelt, S., Detienne, M., (2015). Summit acid crater lakes and flank instability in composite volcanoes. In: Volcanic Lakes. (Eds) D. Rouwet, B. Christenson, F. Tassi, J. Vandemeulebrouck, Berlin, Springer Heidelberg, 289-305.

Delmelle, P., Kusakabe, M., Bernard, A., Fischer, T., de Brouwer, S., del Mundo, E., (1998). Geochemical and isotopic evidence for seawater contamination of the hydrothermal system of Taal Volcano, Luzon, the Philippines. Bulletin of Volcanology 59(8), 562-576.

Demartin, F., Gramaccioli, C. M., Campostrini, I., (2010). Pyracmonite, (NH4)3Fe(SO4)3, a new ammonium iron sulfate from la fossa crater, vulcano, Aeolian islands, Italy. The Canadian Mineralogist 48(2), 307-313.

Di Muro, A., Pallister, J., Villemant, B., Newhall, C., Semet, M., Martinez, M., Mariet, C., (2008). Pre-1991 sulfur transfer between mafic injections and dacite magma in the Mt. Pinatubo reservoir. Journal of Volcanology and Geothermal Research 175(4), 517-540.

Dixon, J. E., Stolper, E. M., Delaney, J. R., (1988). Infrared spectroscopic measurements of CO2 and H2O in Juan de Fuca Ridge basaltic glasses. Earth and Planetary Science Letters 90(1), 87-104.

Dixon, J. E., Stolper, E. M., Holloway, J. R., (1995). An Experimental Study of Water and Carbon Dioxide Solubilities in Mid-Ocean Ridge Basaltic Liquids. Part I: Calibration and Solubility Models. Journal of Petrology 36(6), 1607-1631.

Driesner, T., (2007). The system H2O-NaCl. Part II: Correlations for molar volume, enthalpy, and isobaric heat capacity from 0 to $1000^{\circ} \mathrm{C}, 1$ to 5000bar, and 0 to $1 \mathrm{XNaCl}$. Geochimica et Cosmochimica Acta 71(20), 4902-4919.

Driesner, T., Heinrich, C. A., (2007). The system H2O-NaCl. Part I: Correlation formulae for phase relations in temperature-pressure-composition space from 0 to $1000{ }^{\circ} \mathrm{C}, 0$ to $5000 \mathrm{bar}$, and 0 to $1 \mathrm{XNaCl}$. Geochimica et Cosmochimica Acta 71(20), 4880-4901. 
Drummond, S. E., Ohmoto, H., (1985). Chemical evolution and mineral deposition in boiling hydrothermal systems. Economic Geology 80(1), 126-147.

Duncan, A. R., (1970). The petrology and petrochemistry of andesite and dacite volcanoes in eastern Bay of Plenty, New Zealand. PhD Thesis, Victoria University of Wellington, New Zealand.

Eastoe, C. J., (1978). A fluid inclusion study of the Panguna porphyry copper deposit, Bougainville, Papua New Guinea. Economic Geology 73(5), 721-748.

Eatough, D. J., Caka, F. M., Farber, R. J., (1994). The Conversion of SO2 to Sulfate in the Atmosphere. Israel Journal of Chemistry 34(3-4), 301-314.

Eichelberger, J. C., (1975). Origin of andesite and dacite: Evidence of mixing at Glass Mountain in California and at other circum-Pacific volcanoes. Geological Society of America Bulletin 86(10), 1381-1391.

Eichelberger, J. C., (1980). Vesiculation of mafic magma during replenishment of silicic magma reservoirs. Nature 288(5790), 446-450.

Ellis, A. J., (1979). Explored geothermal systems. In: Geochemistry of hydrothermal ore deposits, 2nd Edition. (Eds) H. L. Barnes, New York, Wiley and Sons, 632-683.

Ellis, A. J., Giggenbach, W. F., (1971). Hydrogen sulphide ionization and sulphur hydrolysis in high temperature solution. Geochimica et Cosmochimica Acta 35(3), 247-260.

Ellis, A. J., Mahon, W. A. J., (1964). Natural hydrothermal systems and experimental hot-water/rock interactions. Geochimica et Cosmochimica Acta 28(8), 1323-1357.

Esposito, R., Hunter, J., Schiffbauer, J. D., Shimizu, N., Bodnar, R. J., (2014). An assessment of the reliability of melt inclusions as recorders of the pre-eruptive volatile content of magmas. American Mineralogist 99(5-6), 976-998.

Etschmann, B. E., Liu, W., Testemale, D., Müller, H., Rae, N. A., Proux, O., Hazemann, J. L., Brugger, J., (2010). An in situ XAS study of copper(I) transport as hydrosulfide complexes in hydrothermal solutions $\left(25-592^{\circ} \mathrm{C}, 180-600 \mathrm{bar}\right)$ : Speciation and solubility in vapor and liquid phases. Geochimica et Cosmochimica Acta 74(16), 4723-4739.

Finnegan, D., Kotra, J., Hermann, D., Zoller, W., (1989). The use of7LiOH-impregnated filters for the collection of acidic gases and analysis by instrumental neutron activation analysis. Bulletin of Volcanology 51(2), 83-87.

Firth, C. W., Handley, H. K., Cronin, S. J., Turner, S. P., (2014). The eruptive history and chemical stratigraphy of a post-caldera, steady-state volcano: Yasur, Vanuatu. Bulletin of Volcanology 76(7), 837.

Fleischer, M., (1955). Minor elements in some sulfide minerals. Economic Geology 50th Anniversary Volume, 970-1024.

Floor, G. H., Calabrese, S., Román-Ross, G., D’Alessandro, W., Aiuppa, A., (2011). Selenium mobilization in soils due to volcanic derived acid rain: An example from Mt Etna volcano, Sicily. Chemical Geology 289(3-4), 235-244.

Fournier, R. O., (1999). Hydrothermal processes related to movement of fluid from plastic into brittle rock in the magmatic-epithermal environment. Economic Geology 94(8), 1193-1211.

Foustoukos, D. I., Seyfried Jr, W. E., (2007). Trace element partitioning between vapor, brine and halite under extreme phase separation conditions. Geochimica et Cosmochimica Acta 71(8), 2056-2071.

Frank, M. R., Simon, A. C., Pettke, T., Candela, P. A., Piccoli, P. M., (2011). Gold and copper partitioning in magmatic-hydrothermal systems at $800^{\circ} \mathrm{C}$ and $100 \mathrm{MPa}$. Geochimica et Cosmochimica Acta 75(9), 2470-2482.

Frezzotti, M.-L., (2001). Silicate-melt inclusions in magmatic rocks: applications to petrology. Lithos 55(1-4), 273-299.

Fulignati, P., Gioncada, A., Sbrana, A., (1998). Geologic model of the magmatic-hydrothermal system of Vulcano (Aeolian Islands, Italy). Mineralogy and Petrology 62(3), 195-222.

Fulignati, P., Gioncada, A., Sbrana, A., (1999). Rare-earth element (REE) behaviour in the alteration facies of the active magmatic-hydrothermal system of Vulcano (Aeolian Islands, Italy). Journal of Volcanology and Geothermal Research 88(4), 325-342.

Fulignati, P., Sbrana, A., Clocchiatti, R., Luperini, W., (2006). Environmental impact of the acid fumarolic plume of a passively degassing volcano (Vulcano Island, Italy). Environmental Geology 49(8), 11391155.

Gaetani, G. A., Grove, T. L., (1997). Partitioning of moderately siderophile elements among olivine, silicate melt, and sulfide melt: Constraints on core formation in the Earth and Mars. Geochimica et Cosmochimica Acta 61(9), 1829-1846.

Garavelli, A., Laviano, R., Vurro, F., (1997). Sublimate deposition from hydrothermal fluids at the Fossa Crater, Vulcano, Italy. European Journal of Mineralogy 9(2), 423-432.

Garavelli, A., Mitolo, D., Pinto, D., Vurro, F., (2013). Lucabindiite, (K,NH4)As4O6(Cl,Br), a new fumarole mineral from the "La Fossa" crater at Vulcano, Aeolian Islands, Italy. American Mineralogist 98(2-3), 470-477. 
Garcia, A. A., Druschel, G. K., (2014). Elemental sulfur coarsening kinetics. Geochemical Transactions 15(1), 11.

Gauthier, P.-J., Le Cloarec, M.-F., (1998). Variability of alkali and heavy metal fluxes released by Mt. Etna volcano, Sicily, between 1991 and 1995. Journal of Volcanology and Geothermal Research 81(3-4), 311-326.

Gauthier, P.-J., Sigmarsson, O., Gouhier, M., Haddadi, B., Moune, S., (2016). Elevated gas flux and trace metal degassing from the 2014-2015 fissure eruption at the Bárðarbunga volcanic system, Iceland. Journal of Geophysical Research: Solid Earth 121(3), 1610-1630.

Gemmell, J. B., (1987). Geochemistry of metallic trace elements in fumarolic condensates from Nicaraguan and Costa Rican volcanoes. Journal of Volcanology and Geothermal Research 33(1-3), 161-181.

GeoNet. (2001-2017). White Island Volcanic Alert Bulletins. GNS Science, from http://geonet.org.nz/volcano/info/whiteisland.

GeoNet. (2003-2017). White Island Volcanic Alert Bulletins. GNS Science, from http://geonet.org.nz/volcano/info/whiteisland.

GeoNet. (2004-2015). White Island Volcanic Alert Bulletins. GNS Science, from http://geonet.org.nz/volcano/info/whiteisland.

GeoNet. (2012-2013). White Island Volcanic Alert Bulletins. GNS Science, from http://geonet.org.nz/volcano/info/whiteisland.

GeoNet. (2016). White Island Volcanic Alert Bulletins. GNS Science, from http://geonet.org.nz/volcano/info/whiteisland.

Gerlach, D. C., Grove, T. L., (1982). Petrology of Medicine Lake Highland volcanics: Characterization of endmembers of magma mixing. Contributions to Mineralogy and Petrology 80(2), 147-159.

Getahun, A., Reed, M. H., Symonds, R., (1996). Mount St. Augustine volcano fumarole wall rock alteration: mineralogy, zoning, composition and numerical models of its formation process. Journal of Volcanology and Geothermal Research 71(2-4), 73-107.

Giggenbach, W. F., (1974). The chemistry of Crater Lake, Mt Ruapehu (New Zealand) during and after the 1971 active period. New Zealand Journal of Science 17(1), 33-46.

Giggenbach, W. F., (1975a). A simple method for the collection and analysis of volcanic gas samples. Bulletin volcanologique 39(1), 132-145.

Giggenbach, W. F., (1975b). Variations in the carbon, sulfur and chlorine contents of volcanic gas discharges from White Island, New Zealand. Bulletin Volcanologique 39(1), 15-27.

Giggenbach, W. F., (1982). The chemical and isotopic composition of gas discharges from New Zealand andesitic volcanoes. Bulletin Volcanologique 45(3), 253-255.

Giggenbach, W. F., (1983). Chemical surveillance of active volcanoes in New Zealand. In: Forecasting Volcanic Events. (Eds) H. Tazieff, J. C. Sabroux, Amsterdam, Elsevier, 311-322.

Giggenbach, W. F., (1987). Redox processes governing the chemistry of fumarolic gas discharges from White Island, New Zealand. Applied Geochemistry 2(2), 143-161.

Giggenbach, W. F., (1992a). Isotopic shifts in waters from geothermal and volcanic systems along convergent plate boundaries and their origin. Earth and Planetary Science Letters 113(4), 495-510.

Giggenbach, W. F., (1992b). Magma degassing and mineral deposition in hydrothermal systems along convergent plate boundaries. Economic Geology 87, 1927-1944.

Giggenbach, W. F., (1996). Chemical composition of volcanic gases. In: Monitoring and mitigation of volcano hazards. (Eds) R. Scarpa, R. I. Tilling, Berlin, Springer Berlin Heidelberg, 221-256.

Giggenbach, W. F., Glasby, G. P., (1977). The influence of thermal activity on the trace metal distribution in marine sediments around White Island, New Zealand. DSIR Bulletin 218, 121-126.

Giggenbach, W. F., Glover, R. B., (1975). The use of chemical indicators in the surveillance of volcanic activity affecting the Crater Lake on Mt Ruapehu, New Zealand. Bulletin Volcanologique 39(1), 70-81.

Giggenbach, W. F., Matsuo, S., (1991). Evaluation of results from Second and Third IAVCEI Field Workshops on Volcanic Gases, Mt Usu, Japan, and White Island, New Zealand. Applied Geochemistry 6(2), 125141.

Giggenbach, W. F., Sheppard, D. S., (1989). Variations in the temperature and chemistry of White Island fumarole discharges 1972-1985. New Zealand Geological Survey Bulletin 103, 119-126.

Giggenbach, W. F., Shinohara, H., Kusakabe, M., Ohba, T., (2003). Formation of acid volcanic brines through interaction of magmatic gases, seawater, and rock within the White Island volcanic-hydrothermal system, New Zealand. Special Publication-Society of Economic Geologists 10, 19-40.

Giggenbach, W. F., Soto, R. C., (1992). Isotopic and chemical composition of water and steam discharges from volcanic-magmatic-hydrothermal systems of the Guanacaste Geothermal Province, Costa Rica. Applied Geochemistry 7(4), 309-332.

Grace, R. V., (1975). White Island notes. Tane 21. 
Graham, I. J., Cole, J. W., (1991). Petrogenesis of andesites and dacites of White Island volcano, Bay of Plenty, New Zealand, in the light of new geochemical and isotopic data. New Zealand Journal of Geology and Geophysics 34(3), 303-315.

Grey, S. G., (1853). Ko Nga Moteatea me nga hakirara o Nga Maori. Wellington, Robert Stokes.

Griffin, W. L., Rama Murthy, V., (1969). Distribution of K, Rb, Sr and Ba in some minerals relevant to basalt genesis. Geochimica et Cosmochimica Acta 33(11), 1389-1414.

Gualda, G. A. R., Ghiorso, M. S., Lemons, R. V., Carley, T. L., (2012). Rhyolite-MELTS: a Modified Calibration of MELTS Optimized for Silica-rich, Fluid-bearing Magmatic Systems. Journal of Petrology 53(5), 875-890.

Gunther, D., Heinrich, C. A., (1999). Enhanced sensitivity in laser ablation-ICP mass spectrometry using helium-argon mixtures as aerosol carrier. Journal of Analytical Atomic Spectrometry 14(9), 1363-1368.

Halter, W. E., Heinrich, C. A., Pettke, T., (2005). Magma evolution and the formation of porphyry $\mathrm{Cu}-\mathrm{Au}$ ore fluids: evidence from silicate and sulfide melt inclusions. Mineralium Deposita 39(8), 845-863.

Halter, W. E., Pettke, T., Heinrich, C. A., (2002). The Origin of Cu/Au Ratios in Porphyry-Type Ore Deposits. Science 296(5574), 1844-1846.

Hamilton, W. M., Baumgart, I. L., (1959). White Island. DSIR Bulletin 127, 84.

Hammer, J. E., Cashman, K. V., Hoblitt, R. P., Newman, S., (1999). Degassing and microlite crystallization during pre-climactic events of the 1991 eruption of Mt. Pinatubo, Philippines. Bulletin of Volcanology $60(5), 355-380$.

Harris, A. C., Kamenetsky, V. S., White, N. C., van Achterbergh, E., Ryan, C. G., (2003). Melt Inclusions in Veins: Linking Magmas and Porphyry Cu Deposits. Science 302(5653), 2109-2111.

Harris, D. M., Anderson, A. T., (1983). Concentrations, sources, and losses of H2O, CO2, and S in Kilauean basalt. Geochimica et Cosmochimica Acta 47(6), 1139-1150.

Hattori, K. H., (1993). High-sulfur magma, a product of fluid discharge from underlying mafic magma: Evidence from Mount Pinatubo, Philippines. Geology 21(12), 1083-1086.

Hattori, K. H., Keith, J. D., (2001). Contribution of mafic melt to porphyry copper mineralization: evidence from Mount Pinatubo, Philippines, and Bingham Canyon, Utah, USA. Mineralium Deposita 36(8), 799-806.

Haughton, D. R., Roeder, P. L., Skinner, B. J., (1974). Solubility of Sulfur in Mafic Magmas. Economic Geology 69(4), 451-467.

Heap, M. J., Kennedy, B. M., Farquharson, J. I., Ashworth, J., Mayer, K., Letham-Brake, M., Reuschlé, T., Gilg, H. A., Scheu, B., Lavallée, Y., Siratovich, P., Cole, J., Jolly, A. D., Baud, P., Dingwell, D. B., (2017). A multidisciplinary approach to quantify the permeability of the Whakaari/White Island volcanic hydrothermal system (Taupo Volcanic Zone, New Zealand). Journal of Volcanology and Geothermal Research 332, 88-108.

Hedenquist, J. W., Aoki, M., Shinohara, H., (1994a). Flux of volatiles and ore-forming metals from the magmatic-hydrothermal system of Satsuma Iwojima volcano. Geology 22(7), 585-588.

Hedenquist, J. W., Arribas, A. R., Gonzalez-Urien, E., (2000). Exploration for epithermal gold deposits. Reviews in Economic Geology 13, 245-277.

Hedenquist, J. W., Lowenstern, J. B., (1994). The role of magmas in the formation of hydrothermal ore deposits. Nature 370, 519-527.

Hedenquist, J. W., Matsuhisa, Y., Izawa, E., White, N. C., Giggenbach, W. F., Aoki, M., (1994b). Geology, geochemistry, and origin of high sulfidation $\mathrm{Cu}-\mathrm{Au}$ mineralization in the Nansatsu District, Japan. Economic Geology 89(1), 1-30.

Hedenquist, J. W., Simmons, S. F., Giggenbach, W. F., Eldridge, C. S., (1993). White Island, New Zealand, volcanic-hydrothermal system represents the geochemical environment of high-sulfidation $\mathrm{Cu}$ and $\mathrm{Au}$ ore deposition. Geology 21(8), 731-734.

Heinrich, C. A., (2005). The physical and chemical evolution of low-salinity magmatic fluids at the porphyry to epithermal transition: a thermodynamic study. Mineralium Deposita 39(8), 864-889.

Heinrich, C. A., Driesner, T., Stefánsson, A., Seward, T. M., (2004). Magmatic vapor contraction and the transport of gold from the porphyry environment to epithermal ore deposits. Geology 32(9), 761-764.

Heinrich, C. A., Günther, D., Audétat, A., Ulrich, T., Frischknecht, R., (1999). Metal fractionation between magmatic brine and vapor, determined by microanalysis of fluid inclusions. Geology 27(8), 755-758.

Heinrich, C. A., Pettke, T., Halter, W. E., Aigner-Torres, M., Audétat, A., Günther, D., Hattendorf, B., Bleiner, D., Guillong, M., Horn, I., (2003). Quantitative multi-element analysis of minerals, fluid and melt inclusions by laser-ablation inductively-coupled-plasma mass-spectrometry. Geochimica et Cosmochimica Acta 67(18), 3473-3497.

Heinrich, C. A., Ryan, C. G., Mernagh, T. P., Eadington, P. J., (1992). Segregation of ore metals between magmatic brine and vapor; a fluid inclusion study using PIXE microanalysis. Economic Geology 87(6), 1566-1583. 
Helgeson, H. C., (1969). Thermodynamics of hydrothermal systems at elevated temperatures and pressures. American Journal of Science 267(7), 729-804.

Hemley, J. J., Cygan, G. L., Fein, J. B., Robinson, G. R., d'Angelo, W. M., (1992). Hydrothermal ore-forming processes in the light of studies in rock-buffered systems; I, Iron-copper-zinc-lead sulfide solubility relations. Economic Geology 87(1), 1-22.

Henley, R. W., (2015). Hyperacidic Volcanic Lakes, Metal Sinks and Magmatic Gas Expansion in Arc Volcanoes. In: Volcanic Lakes. (Eds) D. Rouwet, B. Christenson, F. Tassi, J. Vandemeulebrouck, Berlin, Advances in Volcanology, Springer Heidelberg, 155-178.

Henley, R. W., Berger, B. R., (2011). Magmatic-vapor expansion and the formation of high-sulfidation gold deposits: Chemical controls on alteration and mineralization. Ore Geology Reviews 39(1-2), 63-74.

Henley, R. W., Berger, B. R., (2013). Nature's refineries — Metals and metalloids in arc volcanoes. EarthScience Reviews 125, 146-170.

Henley, R. W., Ellis, A. J., (1983). Geothermal systems ancient and modern: a geochemical review. EarthScience Reviews 19(1), 1-50.

Henley, R. W., King, P. L., Wykes, J. L., Renggli, C. J., Brink, F. J., Clark, D. A., Troitzsch, U., (2015). Porphyry copper deposit formation by sub-volcanic sulphur dioxide flux and chemisorption. Nature Geoscience 8(3), 210-215.

Henley, R. W., McNabb, A., (1978). Magmatic vapor plumes and ground-water interaction in porphyry copper emplacement. Economic Geology 73(1), 1-20.

Hinkley, T. K., (1991). Distribution of metals between particulate and gaseous forms in a volcanic plume. Bulletin of Volcanology 53(5), 395-400.

Hinkley, T. K., Lamothe, P. J., Wilson, S. A., Finnegan, D. L., Gerlach, T. M., (1999). Metal emissions from Kilauea, and a suggested revision of the estimated worldwide metal output by quiescent degassing of volcanoes. Earth and Planetary Science Letters 170(3), 315-325.

Hinkley, T. K., Le Cloarec, M. F., Lambert, G., (1994). Fractionation of families of major, minor, and trace metals across the melt-vapor interface in volcanic exhalations. Geochimica et Cosmochimica Acta 58(15), 3255-3263.

Hobbs, P. V., Tuell, J. P., Hegg, D. A., Radke, L. F., Eltgroth, M. W., (1982). Particles and gases in the emissions from the 1980-1981 volcanic eruptions of Mt. St. Helens. Journal of Geophysical Research: Oceans 87(C13), 11062-11086.

Holland, H. D., (1965). Some applications of thermochemical data to problems of ore deposits; [Part] 2, Mineral assemblages and the composition of ore forming fluids. Economic Geology 60(6), 1101-1166.

Holloway, J. R., (1976). Fluids in the evolution of granitic magmas: Consequences of finite CO2 solubility. Geological Society of America Bulletin 87(10), 1513-1518.

Holzheid, A., Grove, T. L., (2002). Sulfur saturation limits in silicate melts and their implications for core formation scenarios for terrestrial planets. American Mineralogist 87(2-3), 227-237.

Houghton, B. F., Nairn, I. A., (1989a). The 1976-82 Eruption Sequence at White Island Volcano (Whakaari), Bay of Plenty, New Zealand. New Zealand Geological Survey Bulletin 103.

Houghton, B. F., Nairn, I. A., (1989b). A model for the 1976-82 phreatomagmatic and strombolian eruption sequence at White Island volcano, New Zealand. New Zealand Geological Survey Bulletin 103, 127136.

Houghton, B. F., Nairn, I. A., (1989c). The phreatomagmatic and strombolian eruption events at White Island volcano 1976-82: Eruption narrative. New Zealand Geological Survey Bulletin 103, 13-23.

Houghton, B. F., Scott, B. J., Nairn, I. A., Wood, C. P., (1983). Cyclic variation in eruption products, White Island volcano, New Zealand 1976-79. New Zealand Journal of Geology and Geophysics 26(2), 213216.

Huppert, H. E., Woods, A. W., (2002). The role of volatiles in magma chamber dynamics. Nature 420(6915), 493-495.

IGNS, (1986-2001). White Island Science Alert Bulletins. Institute of Geological and Nuclear Sciences, New Zealand Geological Survey.

Izawa, E., (1991). Hydrothermal Alteration Associated with Nansatsu-type Gold Mineralization in the Kasuga Area, Kagoshima Prefecture, Japan Geological Survey of Japan Report(277), 49-52.

Jarosewich, E., Nelen, J. A., Norberg, J. A., (1980). Reference Samples for Electron Microprobe Analysis*. Geostandards Newsletter 4(1), 43-47.

Jenner, F. E., O’Neill, H. S. C., Arculus, R. J., Mavrogenes, J. A., (2010). The Magnetite Crisis in the Evolution of Arc-related Magmas and the Initial Concentration of $\mathrm{Au}, \mathrm{Ag}$ and $\mathrm{Cu}$. Journal of Petrology 51(12), 2445-2464.

Jochum, K. P., Weis, U., Schwager, B., Stoll, B., Wilson, S. A., Haug, G. H., Andreae, M. O., Enzweiler, J., (2016). Reference Values Following ISO Guidelines for Frequently Requested Rock Reference Materials. Geostandards and Geoanalytical Research 40(3), 333-350. 
Jochum, K. P., Willbold, M., Raczek, I., Stoll, B., Herwig, K., (2005). Chemical Characterisation of the USGS Reference Glasses GSA-1G, GSC-1G, GSD-1G, GSE-1G, BCR-2G, BHVO-2G and BIR-1G Using EPMA, ID-TIMS, ID-ICP-MS and LA-ICP-MS. Geostandards and Geoanalytical Research 29(3), 285-302.

Johnson, A., Canil, D., (2011). The degassing behavior of Au, Tl, As, Pb, Re, Cd and Bi from silicate liquids: Experiments and applications. Geochimica et Cosmochimica Acta 75(7), 1773-1784.

Johnson, E. R., Kamenetsky, V. S., McPhie, J., (2013). The Behavior of Metals (Pb, Zn, As, Mo, Cu) During Crystallization and Degassing of Rhyolites from the Okataina Volcanic Center, Taupo Volcanic Zone, New Zealand. Journal of Petrology 54(8), 1641-1659.

Johnson, E. R., Wallace, P. J., Cashman, K. V., Delgado Granados, H., (2010). Degassing of volatiles (H2O, $\mathrm{CO} 2, \mathrm{~S}, \mathrm{Cl})$ during ascent, crystallization, and eruption at mafic monogenetic volcanoes in central Mexico. Journal of Volcanology and Geothermal Research 197(1-4), 225-238.

Johnson, E. R., Wallace, P. J., Cashman, K. V., Granados, H. D., Kent, A. J. R., (2008). Magmatic volatile contents and degassing-induced crystallization at Volcán Jorullo, Mexico: Implications for melt evolution and the plumbing systems of monogenetic volcanoes. Earth and Planetary Science Letters 269(3-4), 478-487.

Jugo, P. J., (2009). Sulfur content at sulfide saturation in oxidized magmas. Geology 37(5), 415-418.

Kavalieris, I., (1994). High Au, Ag, Mo, Pb, V and W content of fumarolic deposits at Merapi volcano, central Java, Indonesia. Journal of Geochemical Exploration 50(1), 479-491.

Kazahaya, K., Shinohara, H., Saito, G., (1994). Excessive degassing of Izu-Oshima volcano: magma convection in a conduit. Bulletin of Volcanology 56(3), 207-216.

Kazahaya, K., Shinohara, H., Saito, G., (2002). Degassing process of Satsuma-Iwojima volcano, Japan: Supply of volatile components from a deep magma chamber. Earth Planets and Space 54(3), 327-336.

Keith, J. D., Whitney, J. A., Hattori, K., Ballantyne, G. H., Christiansen, E. H., Barr, D. L., Cannan, T. M., Hook, C. J., (1997). The Role of Magmatic Sulfides and Mafic Alkaline Magmas in the Bingham and Tintic Mining Districts, Utah. Journal of Petrology 38(12), 1679-1690.

Kent, A. J. R., Darr, C., Koleszar, A. M., Salisbury, M. J., Cooper, K. M., (2010). Preferential eruption of andesitic magmas through recharge filtering. Nature Geoscience 3(9), 631-636.

Keppler, H., (1996). Constraints from partitioning experiments on the composition of subduction-zone fluids. Nature 380(6571), 237-240.

Kettler, R. M., Rye, R. O., Kesler, S. E., Meyers, P. A., Polanco, J., Russell, N., (1992). Gold deposition by sulfidation of ferrous Fe in the lacustrine sediments of the Pueblo Viejo district (Dominican Republic): The effect of $\mathrm{Fe}-\mathrm{C}-\mathrm{S}$ diagenesis on later hydrothermal mineralization in a Maar-Diatreme complex. Chemical Geology 99(1), 29-50.

Kilgour, G., Moune, S., Della-Pasqua, F., Christenson, B. W., (in prep). Petrological insights into the 1976-2000 eruption episode of White Island, New Zealand: an eruption fuelled by repeated mafic recharge.

Kilinc, I. A., Burnham, C. W., (1972). Partitioning of chloride between a silicate melt and coexisting aqueous phase from 2 to 8 kilobars. Economic Geology 67(2), 231-235.

King, P. L., Vennemann, T. W., Holloway, J. R., Hervig, R. L., Lowenstern, J. B., Forneris, J. F., (2002). Analytical techniques for volatiles: A case study using intermediate (andesitic) glasses. American Mineralogist 87(8-9), 1077-1089.

Klemm, L. M., Pettke, T., Heinrich, C. A., Campos, E., (2007). Hydrothermal Evolution of the El Teniente Deposit, Chile: Porphyry Cu-Mo Ore Deposition from Low-Salinity Magmatic Fluids. Economic Geology 102(6), 1021-1045.

Kling, G. W., Clark, M. A., Wagner, G. N., Compton, H. R., Humphrey, A. M., Devine, J. D., Evans, W. C., Lockwood, J. P., Tuttle, M. L., Koenigsberg, E. J., (1987). The 1986 Lake Nyos Gas Disaster in Cameroon, West Africa. Science 236(4798), 169-175.

Korzhinsky, M. A., Tkachenko, S. I., Shmulovich, K. I., Taran, Y. A., Steinberg, G. S., (1994). Discovery of a pure rhenium mineral at Kudriavy volcano. Nature 369(6475), 51-52.

Kouzmanov, K., Pokrovski, G. S., (2012). Hydrothermal Controls on Metal Distribution in Porphyry Cu (-MoAu) Systems. In: Geology and Genesis of Major Copper Deposits and Districts of the World: A Tribute to Richard H. Sillitoe. (Eds) J. W. Hedenquist, M. Harris, F. Camus, Special Publication, Society of Economic Geologists. 16, 573-618.

Krauskopf, K. B., (1957). The heavy metal content of magmatic vapor at 600 degrees C. Economic Geology 52(7), 786-807.

Krauskopf, K. B., (1964). The possible role of volatile metal compounds in ore genesis. Economic Geology 59(1), 22-45.

Krupp, R. E., Seward, T. M., (1987). The Rotokawa geothermal system, New Zealand; an active epithermal gold-depositing environment. Economic Geology 82(5), 1109-1129. 
Kusakabe, M., Komoda, Y., Takano, B., Abiko, T., (2000). Sulfur isotopic effects in the disproportionation reaction of sulfur dioxide in hydrothermal fluids: implications for the $\delta 34 \mathrm{~S}$ variations of dissolved bisulfate and elemental sulfur from active crater lakes. Journal of Volcanology and Geothermal Research 97(1-4), 287-307.

Kusakabe, M., Ohsumi, T., Aramaki, S., (1989). The Lake Nyos gas disaster: chemical and isotopic evidence in waters and dissolved gases from three Cameroonian crater lakes, Nyos, Monoun and Wum. Journal of Volcanology and Geothermal Research 39(2), 167-185.

Kyle, P. R., Meeker, K., Finnegan, D., (1990). Emission rates of sulfur dioxide, trace gases and metals from Mount Erebus, Antarctica. Geophysical Research Letters 17(12), 2125-2128.

Lambert, G., Le Cloarec, M. F., Ardouin, B., Le Roulley, J. C., (1985). Volcanic emission of radionuclides and magma dynamics. Earth and Planetary Science Letters 76(1), 185-192.

Landtwing, M. R., Furrer, C., Redmond, P. B., Pettke, T., Guillong, M., Heinrich, C. A., (2010). The Bingham Canyon Porphyry Cu-Mo-Au Deposit. III. Zoned Copper-Gold Ore Deposition by Magmatic Vapor Expansion. Economic Geology 105(1), 91-118.

Landtwing, M. R., Pettke, T., Halter, W. E., Heinrich, C. A., Redmond, P. B., Einaudi, M. T., Kunze, K., (2005). Copper deposition during quartz dissolution by cooling magmatic-hydrothermal fluids: The Bingham porphyry. Earth and Planetary Science Letters 235(1-2), 229-243.

Lange, R. A., (1997). A revised model for the density and thermal expansivity of K2O-Na2O-CaO-MgOAl2O3-SiO2 liquids from 700 to $1900 \mathrm{~K}$ : extension to crustal magmatic temperatures. Contributions to Mineralogy and Petrology 130(1), 1-11.

Lange, R. A., Carmichael, I. S. E., (1990). Thermodynamic properties of silicate liquids with emphasis on density, thermal expansion and compressibility. Reviews in Mineralogy and Geochemistry 24(1), 2564.

Larocque, A. C. L., Stimac, J. A., Keith, J. D., Huminicki, M. A. E., (2000). Evidence for open-system behavior in immiscible Fe-S-O liquids in silicate magmas: Implications for contributions of metals and sulfur to ore-forming fluids. The Canadian Mineralogist 38(5), 1233-1249.

Le Cloarec, M. F., Allard, P., Ardouin, B., Giggenbach, W. F., Sheppard, D. S., (1992). Radioactive isotopes and trace elements in gaseous emissions from White Island, New Zealand. Earth and Planetary Science Letters 108(1-3), 19-28.

Le Guern, F., (1988). Ecoulements gazeux reactifs a hautes temperatures, mesures et modelisation. PhD thesis, Universite de Paris VII, Paris.

Le Guern, F., Bernard, A., (1982). A new method for sampling and analyzing volcanic sublimates — application to Merapi volcano, Java. Journal of Volcanology and Geothermal Research 12(1-2), 133-146.

Leach, T., Corbett, G., (2008). Fluid mixing as a mechanism for bonanza grade epithermal gold formation. Paper presented at the Terry Leach Symposium.

Lefevre, R., Gaudichet, A., Billon-Galland, M. A., (1986). Silicate microspherules intercepted in the plume of Etna volcano. Nature 322(6082), 817-820.

Lepel, E. A., Stefansson, K. M., Zoller, W. H., (1978). The enrichment of volatile elements in the atmosphere by volcanic activity: Augustine volcano 1976. Journal of Geophysical Research: Oceans 83(C12), 62136220.

Lerchbaumer, L., Audétat, A., (2012). High $\mathrm{Cu}$ concentrations in vapor-type fluid inclusions: An artifact? Geochimica et Cosmochimica Acta 88, 255-274.

Lerchbaumer, L., Audétat, A., (2013). The Metal Content of Silicate Melts and Aqueous Fluids in Subeconomically Mo Mineralized Granites: Implications for Porphyry Mo Genesis. Economic Geology 108(5), 987-1013.

Lesne, P., Kohn, S. C., Blundy, J., Witham, F., Botcharnikov, R. E., Behrens, H., (2011). Experimental Simulation of Closed-System Degassing in the System Basalt-H2O-CO2-S-Cl. Journal of Petrology 52(9), 1737-1762.

Letham-Brake, M., (2013). Geological constraints on fluid flow at Whakaari volcano (White Island). MSc thesis, University of Canterbury, Christchurch.

Li, B., Xue, X., Yi, S., (1989). Discovery of Cu3Zn in Kalatongke intrusion, Xinjiang. Geol Lab 5(4), $239-241$.

Li, Y., Audétat, A., (2012). Partitioning of V, Mn, Co, Ni, Cu, Zn, As, Mo, Ag, Sn, Sb, W, Au, Pb, and Bi between sulfide phases and hydrous basanite melt at upper mantle conditions. Earth and Planetary Science Letters 355-356, 327-340.

Lindsley, D. H., Andersen, D. J., (1983). A two-pyroxene thermometer. Journal of Geophysical Research: Solid Earth 88(S02), A887-A906.

Lodders, K., Palme, H., (1991). On the chalcophile character of molybdenum: determination of sulfide/silicate partition coefficients of Mo and W. Earth and Planetary Science Letters 103(1-4), 311-324.

Löhr, A., Bogaard, T., Heikens, A., Hendriks, M., Sumarti, S., Van Bergen, M., Van Gestel, K. C., Van Straalen, N., Vroon, P., Widianarko, B., (2005). Natural Pollution Caused by the Extremely Acid 
Crater Lake Kawah Ijen, East Java, Indonesia (7 pp). Environmental Science and Pollution Research 12(2), 89-95.

Love, S. P., Goff, F., Schmidt, S. C., Counce, D., Pettit, D., Christenson, B. W., Siebe, C., (2000). Passive Infrared Spectroscopic Remote Sensing of Volcanic Gases: Ground-Based Studies at White Island and Ruapehu, New Zealand, and Popocatépetl, Mexico. In: Remote sensing of active volcanism. (Eds) P. J. Mouginis-Mark, J. A. Crisp, J. H. Fink, American Geophysical Union. 116, 117-138.

Lowenstern, J. B., (1993). Evidence for a copper-bearing fluid in magma erupted at the Valley of ten thousand smokes, Alaska. Contributions to Mineralogy and Petrology 114(3), 409-421.

Lowenstern, J. B., (1995). Applications of silicate-melt inclusions to the study of magmatic volatiles. Magmas, Fluids and Ore Deposits. Mineralogical Association of Canada Short Course 23, 71-99.

Lowenstern, J. B., (2003). Melt inclusions come of age: volatiles, volcanoes, and Sorby's legacy. Developments in Volcanology 5, 1-21.

Lowenstern, J. B., Mahood, G. A., Rivers, M. L., Sutton, S. R., (1991). Evidence for Extreme Partitioning of Copper into a Magmatic Vapor Phase. Science 252(5011), 1405-1409.

Luhr, J. F., (1990). Experimental Phase Relations of Water- and Sulfur-Saturated Arc Magmas and the 1982 Eruptions of El Chichón Volcano. Journal of Petrology 31(5), 1071-1114.

Luhr, J. F., (2008). Primary igneous anhydrite: Progress since its recognition in the 1982 El Chichón trachyandesite. Journal of Volcanology and Geothermal Research 175(4), 394-407.

Luke, J., (1959). History. In: White Island. (Eds) W. M. Hamilton, I. L. Baumgart, Wellington, New Zealand Department of Scientific and Industrial Research. 127, 14-24.

Macpherson, C. G., Hilton, D. R., Newman, S., Mattey, D. P., (1999). CO2, 13C/12C and H2O variability in natural basaltic glasses: a study comparing stepped heating and ftir spectroscopic techniques. Geochimica et Cosmochimica Acta 63(11-12), 1805-1813.

Manville, V., (2015). Volcano-hydrologic hazards from volcanic lakes. In: Volcanic Lakes. (Eds) D. Rouwet, B. Christenson, F. Tassi, J. Vandemeulebrouck, Berlin, Springer Heidelberg, 21-71.

Martin, R. S., Mather, T. A., Pyle, D. M., Power, M., Allen, A. G., Aiuppa, A., Horwell, C. J., Ward, E. P. W., (2008). Composition-resolved size distributions of volcanic aerosols in the Mt. Etna plumes. Journal of Geophysical Research 113(D17).

Martin, R. S., Mather, T. A., Pyle, D. M., Power, M., Tsanev, V. I., Oppenheimer, C., Allen, A. G., Horwell, C. J., Ward, E. P. W., (2009a). Size distributions of fine silicate and other particles in Masaya's volcanic plume. Journal of Geophysical Research: Atmospheres 114(D9).

Martin, R. S., Mather, T. A., Pyle, D. M., Watt, S. F. L., Day, J. A., Collins, S. J., Wright, T. E., Aiuppa, A., Calabrese, S., (2009b). Sweet chestnut (Castanea sativa) leaves as a bio-indicator of volcanic gas, aerosol and ash deposition onto the flanks of Mt Etna in 2005-2007. Journal of Volcanology and Geothermal Research 179(1-2), 107-119.

Martin, R. S., Sawyer, G. M., Day, J. A., LeBlond, J. S., Ilyinskaya, E., Oppenheimer, C., (2012). Highresolution size distributions and emission fluxes of trace elements from Masaya volcano, Nicaragua. Journal of Geophysical Research: Solid Earth 117(B8).

Martínez, M., Fernández, E., Valdés, J., Barboza, V., Van der Laat, R., Duarte, E., Malavassi, E., Sandoval, L., Barquero, J., Marino, T., (2000). Chemical evolution and volcanic activity of the active crater lake of Poás volcano, Costa Rica, 1993-1997. Journal of Volcanology and Geothermal Research 97(1-4), 127141.

Martínez, M., Mason, P., van Bergen, M., Fernández, E., Duarte, E., Malavassi, E., Barquero, J., Valdés, J., (2002). Chemistry of sulphur globules from the acid crater lake of Poás Volcano, Costa Rica. Proceedings of Colima volcano international meeting.

Mather, T. A., Allen, A. G., Oppenheimer, C., Pyle, D. M., McGonigle, A. J. S., (2003a). Size-Resolved Characterisation of Soluble Ions in the Particles in the Tropospheric Plume of Masaya Volcano, Nicaragua: Origins and Plume Processing. Journal of Atmospheric Chemistry 46(3), 207-237.

Mather, T. A., Pyle, D. M., Oppenheimer, C., (2003b). Tropospheric Volcanic Aerosol. Geophysical Monograph-American Geophysical Union 139, 189-212.

Mather, T. A., Witt, M. L. I., Pyle, D. M., Quayle, B. M., Aiuppa, A., Bagnato, E., Martin, R. S., Sims, K. W. W., Edmonds, M., Sutton, A. J., Ilyinskaya, E., (2012). Halogens and trace metal emissions from the ongoing 2008 summit eruption of Kīlauea volcano, Hawai'i. Geochimica et Cosmochimica Acta 83(0), 292-323.

Matsuo, S., (1962). Establishment of chemical equilibrium in the volcanic gas obtained from the lava lake of Kilauea, Hawaii. Bulletin Volcanologique 24(1), 59-71.

Mavrogenes, J., Henley, R. W., Reyes, A. G., Berger, B., (2010). Sulfosalt melts: Evidence of high-temperature vapor transport of metals in the formation of high-sulfidation Lode gold deposits. Economic Geology 105(2), 257-262. 
Mavrogenes, J. A., O’Neill, H. S. C., (1999). The relative effects of pressure, temperature and oxygen fugacity on the solubility of sulfide in mafic magmas. Geochimica et Cosmochimica Acta 63(7-8), 1173-1180.

Menard, G., Moune, S., Vlastélic, I., Aguilera, F., Valade, S., Bontemps, M., González, R., (2014). Gas and aerosol emissions from Lascar volcano (Northern Chile): Insights into the origin of gases and their links with the volcanic activity. Journal of Volcanology and Geothermal Research 287, 51-67.

Mengason, M. J., Candela, P. A., Piccoli, P. M., (2011). Molybdenum, tungsten and manganese partitioning in the system pyrrhotite-Fe-S-O melt-rhyolite melt: Impact of sulfide segregation on arc magma evolution. Geochimica et Cosmochimica Acta 75(22), 7018-7030.

Mengason, M. J., Piccoli, P. M., Candela, P. A., (2006). Partitioning of ore metals among Fe-S-O melt, rhyolite melt, and pyrrhotite. Geological Society of America Abstracts with Programs 38, 245.

Menyaylov, I. A., Nikitina, L. P., Vergasova, L. P., Guseva, R. V., Shapar, V. N., Rozhkov, A. M., (1983). Chemistry, metal content and reaction products of gases from the New Tolbachik Volcanoes of 1975. In: The Great Tolbachik Fissure Eruption: Geological and Geophysical Data 1975-1976. (Eds) S. A. Fedotov, Y. K. Markhinin, New York, 164-175.

Métrich, N., Allard, P., Aiuppa, A., Bani, P., Bertagnini, A., Shinohara, H., Parello, F., Di Muro, A., Garaebiti, E., Belhadj, O., Massare, D., (2011). Magma and Volatile Supply to Post-collapse Volcanism and Block Resurgence in Siwi Caldera (Tanna Island, Vanuatu Arc). Journal of Petrology 52(6), 10771105 .

Métrich, N., Bertagnini, A., Di Muro, A., (2010). Conditions of Magma Storage, Degassing and Ascent at Stromboli: New Insights into the Volcano Plumbing System with Inferences on the Eruptive Dynamics. Journal of Petrology 51(3), 603-626.

Metrich, N., Clocchiatti, R., (1989). Melt inclusion investigation of the volatile behaviour in historic alkali basaltic magmas of Etna. Bulletin of Volcanology 51(3), 185-198.

Metrich, N., Clocchiatti, R., (1996). Sulfur abundance and its speciation in oxidized alkaline melts. Geochimica et Cosmochimica Acta 60(21), 4151-4160.

Metrich, N., Rutherford, M. J., (1992). Experimental study of chlorine behavior in hydrous silicic melts. Geochimica et Cosmochimica Acta 56(2), 607-616.

Migdisov, A. A., Bychkov, A. Y., Williams-Jones, A. E., van Hinsberg, V. J., (2014). A predictive model for the transport of copper by HCl-bearing water vapour in ore-forming magmatic-hydrothermal systems: Implications for copper porphyry ore formation. Geochimica et Cosmochimica Acta 129, 33-53.

Mizutani, Y., Sugiura, T., (1966). The Chemical Equilibrium of the $2 \mathrm{H} 2 \mathrm{~S}+\mathrm{SO} 2=3 \mathrm{~S}+2 \mathrm{H} 2 \mathrm{O}$ Reaction in Solfataras of the Nasudake Volcano. Bulletin of the Chemical Society of Japan 39(11), 2411-2414.

Moon, V., Bradshaw, J., de Lange, W., (2009). Geomorphic development of White Island Volcano based on slope stability modelling. Engineering Geology 104(1-2), 16-30.

Moune, S., Gauthier, P.-J., Delmelle, P., (2010). Trace elements in the particulate phase of the plume of Masaya Volcano, Nicaragua. Journal of Volcanology and Geothermal Research 193(3-4), 232-244.

Moune, S., Holtz, F., Botcharnikov, R. E., (2009). Sulphur solubility in andesitic to basaltic melts: implications for Hekla volcano. Contributions to Mineralogy and Petrology 157(6), 691.

Muntean, J. L., Kesler, S. E., Russell, N., Polanco, J., (1990). Evolution of the Monte Negro acid-sulfate Au-Ag deposit, Pueblo Viejo, Dominican Republic; important factors in grade development. Economic Geology 85(8), 1738-1758.

Murphy, M. D., Sparks, R. S. J., Barclay, J., Carroll, M. R., Lejeune, A. M., Brewer, T. S., Macdonald, R., Black, S., Young, S., (1998). The role of magma mixing in triggering the current eruption at the Soufriere Hills Volcano, Montserrat, West Indies. Geophysical Research Letters 25(18), 3433-3436.

Nadeau, O., (2011). The Behaviour of Base Metals in Arc-Type Magmatic-Hydrothermal Systems-- Insights from Merapi Volcano, Indonesia. PhD thesis, McGill University, Montreal.

Nadeau, O., Stix, J., Williams-Jones, A. E., (2016). Links between arc volcanoes and porphyry-epithermal ore deposits. Geology 44(1), 11-14.

Nadeau, O., Williams-Jones, A. E., Stix, J., (2010). Sulphide magma as a source of metals in arc-related magmatic hydrothermal ore fluids. Nature Geoscience 3(7), 501-505.

Nagaseki, H., Hayashi, K.-i., (2008). Experimental study of the behavior of copper and zinc in a boiling hydrothermal system. Geology 36(1), 27-30.

Nairn, I. A., Houghton, B. F., (1989). Formation of collapse craters and morphological changes in the main crater of White Island volcano during the 1976-82 eruption sequence. New Zealand Geological Survey Bulletin 103, 25-34.

Nairn, I. A., Wood, C. P., (1986). International Volcanological Congress, New Zealand, 1986. Tour Guide C6: active volcanoes of Taupo Volcanic Zone. Unpublished tour guide New Zealand Geological Survey, Department of Scientific and Industrial Research, Rotorua.

Naughton, J. J., Lewis, V., Thomas, D., Finlayson, J. B., (1975). Fume compositions found at various stages of activity at Kilauea Volcano, Hawaii. Journal of Geophysical Research 80(21), 2963-2966. 
Nho, E.-Y., Le Cloarec, M.-F., Ardouin, B., Tjetjep, W. S., (1996). Source strength assessment of volcanic trace elements emitted from the Indonesian arc. Journal of Volcanology and Geothermal Research 74(1-2), 121-129.

Nichols, A. R. L., Wysoczanski, R. J., (2007). Using micro-FTIR spectroscopy to measure volatile contents in small and unexposed inclusions hosted in olivine crystals. Chemical Geology 242(3-4), 371-384.

Nilsson, K., Peach, C. L., (1993). Sulfur speciation, oxidation state, and sulfur concentration in backarc magmas. Geochimica et Cosmochimica Acta 57(15), 3807-3813.

Nriagu, J., Becker, C., (2003). Volcanic emissions of mercury to the atmosphere: global and regional inventories. Science of The Total Environment 304(1-3), 3-12.

Nriagu, J. O., (1989). A global assessment of natural sources of atmospheric trace metals. Nature 338(6210), 4749.

Nuccio, P. M., Paonita, A., Sortino, F., (1999). Geochemical modeling of mixing between magmatic and hydrothermal gases: the case of Vulcano Island, Italy. Earth and Planetary Science Letters 167(3), 321-333.

Obenholzner, J. H., Schroettner, H., Golob, P., Delgado, H., (2003). Particles from the plume of Popocatépetl volcano, Mexico — the FESEM/EDS approach. Geological Society, London, Special Publications 213(1), 123-148.

Ochs, A. F., Lange, A. R., (1997). The partial molar volume, thermal expansivity, and compressibility of H2O in NaAlSi3O8 liquid: new measurements and an internally consistent model. Contributions to Mineralogy and Petrology 129(2), 155-165.

Ohba, T., Hirabayashi, J., Nogami, K., (2000). D/H and 18O/16O ratios of water in the crater lake at KusatsuShirane volcano, Japan. Journal of Volcanology and Geothermal Research 97(1-4), 329-346.

Ohba, T., Hirabayashi, J., Nogami, K., (2008). Temporal changes in the chemistry of lake water within Yugama Crater, Kusatsu-Shirane Volcano, Japan: Implications for the evolution of the magmatic hydrothermal system. Journal of Volcanology and Geothermal Research 178(2), 131-144.

Okrugin, V., Favero, M., Liu, A., Etschmann, B., Plutachina, E., Mills, S., Tomkins, A. G., Lukasheva, M., Kozlov, V., Moskaleva, S., Chubarov, M., Brugger, J., (2017). Smoking gun for thallium geochemistry in volcanic arcs: Nataliyamalikite, TII, a new thallium mineral from an active fumarole at Avacha Volcano, Kamchatka Peninsula, Russia. American Mineralogist 102(8), 1736-1746.

Oppenheimer, C., (1993). Infrared surveillance of crater lakes using satellite data. Journal of Volcanology and Geothermal Research 55(1), 117-128.

Oppenheimer, C., Bani, P., Calkins, J. A., Burton, M. R., Sawyer, G. M., (2006). Rapid FTIR sensing of volcanic gases released by Strombolian explosions at Yasur volcano, Vanuatu. Applied Physics B 85(2), 453-460.

Papale, P., Moretti, R., Barbato, D., (2006). The compositional dependence of the saturation surface of $\mathrm{H} 2 \mathrm{O}+$ CO2 fluids in silicate melts. Chemical Geology 229(1-3), 78-95.

Parat, F., Holtz, F., Streck, M. J., (2011). Sulfur-bearing Magmatic Accessory Minerals. Reviews in Mineralogy and Geochemistry 73(1), 285-314.

Park, J.-W., Campbell, I. H., Kim, J., Moon, J.-W., (2015). The Role of Late Sulfide Saturation in the Formation of a Cu- and Au-rich Magma: Insights from the Platinum Group Element Geochemistry of NiuatahiMotutahi Lavas, Tonga Rear Arc. Journal of Petrology 56(1), 59-81.

Pasternack, G. B., Varekamp, J. C., (1994). The geochemistry of the Keli Mutu crater lakes, Flores, Indonesia. Geochemical Journal(28), 243-262.

Patterson, C. C., Settle, D. M., (1987). Magnitude of lead flux to the atmosphere from volcanoes. Geochimica et Cosmochimica Acta 51(3), 675-681.

Peach, C. L., Mathez, E. A., Keays, R. R., (1990). Sulfide melt-silicate melt distribution coefficients for noble metals and other chalcophile elements as deduced from MORB: Implications for partial melting. Geochimica et Cosmochimica Acta 54(12), 3379-3389.

Pennisi, M., Le Cloarec, M. F., Lambert, G., Le Roulley, J. C., (1988). Fractionation of metals in volcanic emissions. Earth and Planetary Science Letters 88(3-4), 284-288.

Pitzer, K. S., Pabalan, R. T., (1986). Thermodynamics of $\mathrm{NaCl}$ in steam. Geochimica et Cosmochimica Acta 50(7), 1445-1454

Pokrovski, G. S., Akinfiev, N. N., Borisova, A. Y., Zotov, A. V., Kouzmanov, K., (2014). Gold speciation and transport in geological fluids: Insights from experiments and physical-chemical modelling. In: GoldTransporting Hydrothermal Fluids in the Earth's Crust. (Eds) P. S. Garofalo, J. R. Ridley, London, Special Publications, Geological Society. 402, 9-70.

Pokrovski, G. S., Borisova, A. Y., Bychkov, A. Y., (2013). Speciation and Transport of Metals and Metalloids in Geological Vapors. Reviews in Mineralogy and Geochemistry 76(1), 165-218.

Pokrovski, G. S., Borisova, A. Y., Harrichoury, J.-C., (2008). The effect of sulfur on vapor-liquid fractionation of metals in hydrothermal systems. Earth and Planetary Science Letters 266(3-4), 345-362. 
Pokrovski, G. S., Roux, J., Harrichoury, J.-C., (2005). Fluid density control on vapor-liquid partitioning of metals in hydrothermal systems. Geology 33(8), 657-660.

Poulson, S. R., Ohmoto, H., (1990). An evaluation of the solubility of sulfide sulfur in silicate melts from experimental data and natural samples. Chemical Geology 85(1-2), 57-75.

Pudack, C., Halter, W. E., Heinrich, C. A., Pettke, T., (2009). Evolution of Magmatic Vapor to Gold-Rich Epithermal Liquid: The Porphyry to Epithermal Transition at Nevados de Famatina, Northwest Argentina. Economic Geology 104(4), 449-477.

Pyle, D. M., Mather, T. A., (2003). The importance of volcanic emissions for the global atmospheric mercury cycle. Atmospheric Environment 37(36), 5115-5124.

Quisefit, J. P., Toutain, J. P., Bergametti, G., Javoy, M., Cheynet, B., Person, A., (1989). Evolution versus cooling of gaseous volcanic emissions from Momotombo Volcano, Nicaragua: Thermochemical model and observations. Geochimica et Cosmochimica Acta 53(10), 2591-2608.

Quist, A. S., Marshall, W. L., Jolley, H. R., (1965). Electrical Conductances of Aqueous Solutions at High Temperature and Pressure. II. The Conductances and Ionization Constants of Sulfuric Acid-Water Solutions from 0 to $800^{\circ}$ and at Pressures up to 4000 Bars. The Journal of Physical Chemistry 69(8), 2726-2735.

Radke, L. F., (1982). Sulphur and sulphate from Mt Erebus. Nature 299(5885), 710-712.

Rapien, M. H., (1998). Geochemical Evolution at White Island, New Zealand. MSc Thesis, Virginia Polytechnic Institute and State University, Blacksburg, VA.

Rapien, M. H., Bodnar, R. J., Simmons, S. F., Szabo, C. S., Wood, C. P., Sutton, S. R., (2003). Melt inclusion study of the embryonic porphyry copper system at White Island, New Zealand. Society of Economic Geologists 10, 41-59.

Reed, M. H., (1997). Hydrothermal alteration and its relationship to ore fluid composition. In: Geochemistry of hydrothermal ore deposits, 3rd Edition. (Eds) H. L. Barnes, New York, Wiley \& Sons. 3, 303-365.

Reed, M. H., Palandri, J., (2006). Sulfide Mineral Precipitation from Hydrothermal Fluids. Reviews in Mineralogy and Geochemistry 61(1), 609-631.

Renggli, C. J., King, P. L., Henley, R. W., Norman, M. D., (2017). Volcanic gas composition, metal dispersion and deposition during explosive volcanic eruptions on the Moon. Geochimica et Cosmochimica Acta 206, 296-311.

Reubi, O., Blundy, J., (2009). A dearth of intermediate melts at subduction zone volcanoes and the petrogenesis of arc andesites. Nature 461(7268), 1269-1273.

Richards, J. P., (2011). Magmatic to hydrothermal metal fluxes in convergent and collided margins. Ore Geology Reviews 40(1), 1-26.

Ripley, E. M., Brophy, J. G., Li, C., (2002). Copper solubility in a basaltic melt and sulfide liquid/silicate melt partition coefficients of $\mathrm{Cu}$ and Fe. Geochimica et Cosmochimica Acta 66(15), 2791-2800.

Roberts, A. C., Venance, K. E., Seward, T. M., Grice, J. D., (2006). Lafossaite, a new mineral from the La Fossa Crater Vulcano, Italy. Mineralogical Record 37(2), 165-168.

Robie, R. A., Hemingway, B. S., (1995). Thermodynamic properties of minerals and related substances at $298.15 \mathrm{~K}$ and 1 bar (105 pascals) pressure and at higher temperatures. In: US Geological Survey Bulletin. 2131, 470.

Roedder, E., (1971). Fluid inclusion studies on the porphyry-type ore deposits at Bingham, Utah, Butte, Montana, and Climax, Colorado. Economic Geology 66(1), 98-118.

Roedder, E., (1984). Volume 12: Fluid inclusions, Mineralogical Society of America.

Roeder, P. L., Emslie, R. F., (1970). Olivine-liquid equilibrium. Contributions to Mineralogy and Petrology 29(4), 275-289.

Roggensack, K., Hervig, R. L., McKnight, S. B., Williams, S. N., (1997). Explosive Basaltic Volcanism from Cerro Negro Volcano: Influence of Volatiles on Eruptive Style. Science 277(5332), 1639-1642.

Romberger, S. B., Barnes, H. L., (1970). Ore solution chemistry III. Solubility of CuS in sulfide solutions. Economic Geology 65(8), 901-919.

Rose, W. I., Chuan, R. L., Giggenbach, W. F., Kyle, P. R., Symonds, R. B., (1986). Rates of sulfur dioxide and particle emissions from White Island volcano, New Zealand, and an estimate of the total flux of major gaseous species. Bulletin of Volcanology 48(4), 181-188.

Rose, W. I., Chuan, R. L., Woods, D. C., (1982). Small particles in plumes of Mount St. Helens. Journal of Geophysical Research: Oceans 87(C7), 4956-4962.

Rouwet, D., Tassi, F., (2011). Geochemical monitoring of volcanic lakes. A generalized box model for active crater lakes.

Rouwet, D., Tassi, F., Mora-Amador, R., Sandri, L., Chiarini, V., (2014). Past, present and future of volcanic lake monitoring. Journal of Volcanology and Geothermal Research 272, 78-97.

Rowe, G. L., (1994). Oxygen, hydrogen, and sulfur isotope systematics of the crater lake system of Poas Volcano, Costa Rica. Geochemical Journal 28(3), 263-287. 
Rowe, G. L., Brantley, S. L., (1993). Estimation of the dissolution rates of andesitic glass, plagioclase and pyroxene in a flank aquifer of Poás Volcano, Costa Rica. Chemical Geology 105(1-3), 71-87.

Rowe, G. L., Brantley, S. L., Fernandez, J. F., Borgia, A., (1995). The chemical and hydrologic structure of Poa's Volcano, Costa Rica. Journal of Volcanology and Geothermal Research 64(3-4), 233-267.

Rowe, G. L., Brantley, S. L., Fernandez, M., Fernandez, J. F., Borgia, A., Barquero, J., (1992a). Fluid-volcano interaction in an active stratovolcano: the crater lake system of Poás volcano, Costa Rica. Journal of Volcanology and Geothermal Research 49(1), 23-51.

Rowe, G. L., Ohsawa, S., Takano, B., Brantley, S. L., Fernandez, J. F., Barquero, J., (1992b). Using Crater Lake chemistry to predict volcanic activity at Poás Volcano, Costa Rica. Bulletin of Volcanology 54(6), 494503.

Ruaya, J. R., Seward, T. M., (1987). The ion-pair constant and other thermodynamic properties of $\mathrm{HCl}$ up to $350^{\circ}$ C. Geochimica et Cosmochimica Acta 51(1), 121-130.

Rusk, B. G., Reed, M. H., Dilles, J. H., (2008). Fluid Inclusion Evidence for Magmatic-Hydrothermal Fluid Evolution in the Porphyry Copper-Molybdenum Deposit at Butte, Montana. Economic Geology 103(2), 307-334.

Rye, R. O., Bethke, P. M., Wasserman, M. D., (1992). The stable isotope geochemistry of acid sulfate alteration. Economic Geology 87(2), 225-262.

Sakai, H., Matsubaya, O., (1977). Stable isotopic studies of japanese geothermal systems. Geothermics 5(1), 97 124.

Sakuyama, M., (1981). Petrological Study of the Myoko and Kurohime Volcanoes, Japan: Crystallization Sequence and Evidence for Magma Mixing. Journal of Petrology 22(4), 553-583.

Salerno, G. G., Burton, M. R., Oppenheimer, C., Caltabiano, T., Randazzo, D., Bruno, N., Longo, V., (2009). Three-years of SO2 flux measurements of Mt. Etna using an automated UV scanner array: Comparison with conventional traverses and uncertainties in flux retrieval. Journal of Volcanology and Geothermal Research 183(1-2), 76-83.

Sawkins, F. J., (1984). Metal deposits in relation to plate tectonics. Berlin, Springer-Verlag.

Scaillet, B., Pichavant, M., (2005). A model of sulphur solubility for hydrous mafic melts: application to the determination of magmatic fluid compositions of Italian volcanoes. Annals of Geophysics 48(4-5).

Schipper, C. I., Mandon, C., Maksimenko, A., Castro, J. M., Conway, C. E., Hauer, P., Kirilova, M., Kilgour, G., (2017). Vapor-phase cristobalite as a durable indicator of magmatic pore structure and halogen degassing: an example from White Island volcano (New Zealand). Bulletin of Volcanology 79(10), 74.

Scott, B. J., (1992). White Island volcano. Eruption observations, seismicity and crater geomorphology, 1991. Institute of Geological and Nuclear Sciences Report 92(7), 17-23.

Seedorff, E., Dilles, J. H., Proffett, J. M., Einaudi, M. T., Zurcher, L., Stavast, W. J. A., Johnson, D. A., Barton, M. D., (2005). Porphyry deposits: Characteristics and origin of hypogene features. Economic Geology 100th anniversary volume, 251-298.

Seo, J. H., Guillong, M., Heinrich, C. A., (2009). The role of sulfur in the formation of magmatic-hydrothermal copper-gold deposits. Earth and Planetary Science Letters 282(1-4), 323-328.

Seward, T. M., (1981). Metal complex formation in aqueous solutions at elevated temperatures and pressures. Physics and Chemistry of the Earth 13,113-132.

Seward, T. M., Williams-Jones, A. E., Migdisov, A. A., (2014). The Chemistry of Metal Transport and Deposition by Ore-Forming Hydrothermal Fluids. In: Treatise on Geochemistry (Second Edition). (Eds) K. K. Turekian, Oxford, Elsevier, 29-57.

Sherman, D. M., (2010). Metal complexation and ion association in hydrothermal fluids: insights from quantum chemistry and molecular dynamics. Geofluids 10(1-2), 41-57.

Shinohara, H., (1994). Exsolution of immiscible vapor and liquid phases from a crystallizing silicate melt: Implications for chlorine and metal transport. Geochimica et Cosmochimica Acta 58(23), 5215-5221.

Shinohara, H., Hedenquist, J. W., (1997). Constraints on Magma Degassing beneath the Far Southeast Porphyry $\mathrm{Cu}-\mathrm{Au}$ Deposit, Philippines. Journal of Petrology 38(12), 1741-1752.

Shinohara, H., Iiyama, J. T., Matsuo, S., (1989). Partition of chlorine compounds between silicate melt and hydrothermal solutions: I. Partition of NaCl-KCl. Geochimica et Cosmochimica Acta 53(10), 26172630.

Shinohara, H., Kazahaya, K., Lowenstern, J. B., (1995). Volatile transport in a convecting magma column: Implications for porphyry Mo mineralization. Geology 23(12), 1091-1094.

Shiraki, K., Saito, T., Kuroda, N., Urano, H., Tsutomu, S., Cole, J. W., (1994). Magnesian andesites from White Island, New Zealand: mineralogical evidence for mixing of high-magnesian basalt and dacite magma. Geoscience Reports of Shizuoka University 20,33-40.

Siebert, L., Simkin, T., Kimberly, P., (2010). Volcanoes of the World. Washington, D.C., Smithsonian Institution. 
Siegel, B. Z., Siegel, S. M., (1987). gHawaiian volcanoes and the biogeology of mercury. In: Volcanism in Hawaii. (Eds) R. W. Decker, T. L. Wright, P. H. Stauffer, U.S. Geological Survey Professional Paper 1350. 1, 827-839.

Sigurdsson, H., Devine, J. D., Tchua, F. M., Presser, F. M., Pringle, M. K. W., Evans, W. C., (1987). Origin of the lethal gas burst from Lake Monoun, Cameroun. Journal of Volcanology and Geothermal Research 31(1), 1-16.

Sillitoe, R. H., (1972). A Plate Tectonic Model for the Origin of Porphyry Copper Deposits. Economic Geology 67(2), 184-197.

Sillitoe, R. H., (1995). The influence of magmatic-hydrothermal models on exploration strategies for volcanoplutonic arcs. Mineralogical Association of Canada Short Course Series 23, 511-525.

Sillitoe, R. H., (2010). Porphyry Copper Systems. Economic Geology 105(1), 3-41.

Sillitoe, R. H., Bonham, H. F., (1984). Volcanic landforms and ore deposits. Economic Geology 79(6), 12861298.

Sillitoe, R. H., Hedenquist, J. W., (2003). Linkages between volcanotectonic settings, ore-fluid compositions, and epithermal precious metal deposits. Special Publication-Society of Economic Geologists 10, 315343.

Simkin, T., Siebert, L., (1994). Volcanoes of the World: A Regional Directory, Gazetteer, and Chronology of Volcanism During the Last 10,000 Years. Tucson, AZ, Geoscience.

Simon, A. C., Frank, M. R., Pettke, T., Candela, P. A., Piccoli, P. M., Heinrich, C. A., (2005). Gold partitioning in melt-vapor-brine systems. Geochimica et Cosmochimica Acta 69(13), 3321-3335.

Simon, A. C., Pettke, T., Candela, P. A., Piccoli, P. M., (2008). The partitioning behavior of silver in a vaporbrine-rhyolite melt assemblage. Geochimica et Cosmochimica Acta 72(6), 1638-1659.

Simon, A. C., Pettke, T., Candela, P. A., Piccoli, P. M., Heinrich, C. A., (2006). Copper partitioning in a meltvapor-brine-magnetite-pyrrhotite assemblage. Geochimica et Cosmochimica Acta 70(22), 5583-5600.

Simon, A. C., Pettke, T., Candela, P. A., Piccoli, P. M., Heinrich, C. A., (2007). The partitioning behavior of As and $\mathrm{Au}$ in S-free and S-bearing magmatic assemblages. Geochimica et Cosmochimica Acta 71(7), 1764-1782.

Simon, A. C., Ripley, E. M., (2011). The Role of Magmatic Sulfur in the Formation of Ore Deposits. Reviews in Mineralogy and Geochemistry 73(1), 513-578.

Smith, E. G. C., Stern, T., Reyners, M., (1989). Subduction and back-arc activity at the Hikurangi convergent Margin, New Zealand. Pure and applied geophysics 129(1), 203-231.

Smithsonian Institution. (1976-2000). Global Volcanism Program. White Island., from http://www.volcano.si.edu/volcano.cfm?vn=241040.

Sobolev, A. V., (1996). Melt inclusions in minerals as a source of principle petrological information. Petrology 4(3), 209-220.

Sobolev, A. V., Danyushevsky, L. V., (1994). Petrology and Geochemistry of Boninites from the North Termination of the Tonga Trench: Constraints on the Generation Conditions of Primary High-Ca Boninite Magmas. Journal of Petrology 35(5), 1183-1211.

Sourirajan, S., Kennedy, G. C., (1962). The system H 2 O-NaCl at elevated temperatures and pressures. American Journal of Science 260(2), 115-141.

Sparks, S. R. J., Marshall, L. A., (1986). Thermal and mechanical constraints on mixing between mafic and silicic magmas. Journal of Volcanology and Geothermal Research 29(1), 99-124.

Sparks, S. R. J., Sigurdsson, H., Wilson, L., (1977). Magma mixing: a mechanism for triggering acid explosive eruptions. Nature 267(5609), 315-318.

Spilliaert, N., Métrich, N., Allard, P., (2006). S-Cl-F degassing pattern of water-rich alkali basalt: Modelling and relationship with eruption styles on Mount Etna volcano. Earth and Planetary Science Letters 248(3-4), 772-786.

Spycher, N. F., Reed, M. H., (1989). Evolution of a broadlands-type epithermal ore fluid along alternative P-T paths; implications for the transport and deposition of base, precious, and volatile metals. Economic Geology 84(2), 328-359.

Sriwana, T., van Bergen, M. J., Sumarti, S., de Hoog, J. C. M., van Os, B. J. H., Wahyuningsih, R., Dam, M. A. C., (1998). Volcanogenic pollution by acid water discharges along Ciwidey River, West Java (Indonesia). Journal of Geochemical Exploration 62(1-3), 161-182.

Sriwana, T., van Bergen, M. J., Varekamp, J. C., Sumarti, S., Takano, B., van Os, B. J. H., Leng, M. J., (2000). Geochemistry of the acid Kawah Putih lake, Patuha Volcano, West Java, Indonesia. Journal of Volcanology and Geothermal Research 97(1-4), 77-104.

Stavast, W. J. A., Keith, J. D., Christiansen, E. H., Dorais, M. J., Tingey, D., Larocque, A., Evans, N., (2006). The Fate of Magmatic Sulfides During Intrusion or Eruption, Bingham and Tintic Districts, Utah. Economic Geology 101(2), 329-345. 
Stevenson, D. S., Blake, S., (1998). Modelling the dynamics and thermodynamics of volcanic degassing. Bulletin of Volcanology 60(4), 307-317.

Stewart, M. K., Hulston, J. R., (1975). Stable isotope ratios of volcanic steam from White Island, New Zealand. Bulletin Volcanologique 39(1), 28-46.

Stimac, J., Hickmott, D., Abell, R., Larocque, A. C. L., Broxton, D., Gardner, J., Chipera, S., Wolff, J., Gauerke, E., (1996). Redistribution of $\mathrm{Pb}$ and other volatile trace metals during eruption, devitrification, and vapor-phase crystallization of the Bandelier Tuff, New Mexico. Journal of Volcanology and Geothermal Research 73(3-4), 245-266.

Stock, M. J., Humphreys, M. C. S., Smith, V. C., Isaia, R., Pyle, D. M., (2016). Late-stage volatile saturation as a potential trigger for explosive volcanic eruptions. Nature Geoscience 9(3), 249-254.

Stoffregen, R. E., (1987). Genesis of acid-sulfate alteration and Au-Cu-Ag mineralization at Summitville, Colorado. Economic Geology 82(6), 1575-1591.

Stoiber, R. E., Rose, W. I., (1974). Fumarole incrustations at active central american volcanoes. Geochimica et Cosmochimica Acta 38(4), 495-516.

Symonds, R. B., Gerlach, T. M., Reed, M. H., (2001). Magmatic gas scrubbing: implications for volcano monitoring. Journal of Volcanology and Geothermal Research 108(1-4), 303-341.

Symonds, R. B., Reed, M. H., Rose, W. I., (1992). Origin, speciation, and fluxes of trace-element gases at Augustine volcano, Alaska: Insights into magma degassing and fumarolic processes. Geochimica et Cosmochimica Acta 56(2), 633-657.

Symonds, R. B., Rose, W. I., Bluth, G. J. S., Gerlach, T. M., (1994). Volcanic-gas studies: methods, results, and applications. In: Volatiles in magmas. (Eds) M. R. Carroll, J. R. Holloway, Reviews in Mineralogy, Mineralogical Society of America. 30, 1-66.

Symonds, R. B., Rose, W. I., Gerlach, T. M., Briggs, P. H., Harmon, R. S., (1990). Evaluation of gases, condensates, and SO2 emissions from Augustine volcano, Alaska: the degassing of a Cl-rich volcanic system. Bulletin of Volcanology 52(5), 355-374.

Symonds, R. B., Rose, W. I., Reed, M. H., Lichte, F. E., Finnegan, D. L., (1987). Volatilization, transport and sublimation of metallic and non-metallic elements in high temperature gases at Merapi Volcano, Indonesia. Geochimica et Cosmochimica Acta 51(8), 2083-2101.

Szramek, L., Gardner, J. E., Larsen, J., (2006). Degassing and microlite crystallization of basaltic andesite magma erupting at Arenal Volcano, Costa Rica. Journal of Volcanology and Geothermal Research $157(1-3), 182-201$.

Takano, B., (1987). Correlation of Volcanic Activity with Sulfur Oxyanion Speciation in a Crater Lake. Science 235(4796), 1633-1635.

Takano, B., Saitoh, H., Takano, E., (1994). Geochemical implications of subaqueous molten sulfur at Yugama crater lake, Kusatsu-Shirane volcano, Japan. Geochemical Journal 28(3), 199-216.

Takano, B., Watanuki, K., (1990). Monitoring of volcanic eruptions at Yugama crater lake by aqueous sulfur oxyanions. Journal of Volcanology and Geothermal Research 40(1), 71-87.

Takenouchi, S., Imai, H., (1975). Glass and fluid inclusions in acidic igneous rocks from some mining areas in Japan. Economic Geology 70(4), 750-769.

Taran, Y., Zelenski, M., (2015). Systematics of water isotopic composition and chlorine content in arc-volcanic gases. Geological Society, London, Special Publications 410(1), 237-262.

Taran, Y. A., Bernard, A., Gavilanes, J.-C., Africano, F., (2000). Native gold in mineral precipitates from hightemperature volcanic gases of Colima volcano, Mexico. Applied Geochemistry 15(3), 337-346.

Taran, Y. A., Bernard, A., Gavilanes, J.-C., Lunezheva, E., Cortés, A., Armienta, M. A., (2001). Chemistry and mineralogy of high-temperature gas discharges from Colima volcano, Mexico. Implications for magmatic gas-atmosphere interaction. Journal of Volcanology and Geothermal Research 108(1-4), 245-264.

Taran, Y. A., Hedenquist, J. W., Korzhinsky, M. A., Tkachenko, S. I., Shmulovich, K. I., (1995). Geochemistry of magmatic gases from Kudryavy volcano, Iturup, Kuril Islands. Geochimica et Cosmochimica Acta 59(9), 1749-1761.

Taran, Y. A., Pilipenko, V. P., Rozhkov, A. M., Vakin, E. A., (1992). A geochemical model for fumaroles of the Mutnovsky volcano, Kamchatka, USSR. Journal of Volcanology and Geothermal Research 49(3), 269283.

Tassi, F., Aguilera, F., Vaselli, O., Medina, E., Tedesco, D., Delgado Huertas, A., Poreda, R., Kojima, S., (2009). The magmatic- and hydrothermal-dominated fumarolic system at the Active Crater of Lascar volcano, northern Chile. Bulletin of Volcanology 71(2), 171-183.

Tassi, F., Vaselli, O., Capaccioni, B., Giolito, C., Duarte, E., Fernandez, E., Minissale, A., Magro, G., (2005). The hydrothermal-volcanic system of Rincon de la Vieja volcano (Costa Rica): A combined (inorganic and organic) geochemical approach to understanding the origin of the fluid discharges and its possible 
application to volcanic surveillance. Journal of Volcanology and Geothermal Research 148(3-4), 315333.

Tazieff, H., (1994). Permanent lava lakes: observed facts and induced mechanisms. Journal of Volcanology and Geothermal Research 63(1), 3-11.

Tedesco, D., Toutain, J.-P., (1991). Chemistry and emission rate of volatiles from White Island Volcano (New Zealand). Geophysical Research Letters 18(1), 113-116.

Toutain, J. P., Quisefit, J. P., Briole, P., Aloupogiannis, P., Blanc, P., Robaye, G., (1995). Mineralogy and chemistry of solid aerosols emitted from Mount Etna. Geochemical Journal 29(3), 163-173.

Ulrich, T., Gunther, D., Heinrich, C. A., (1999). Gold concentrations of magmatic brines and the metal budget of porphyry copper deposits. Nature 399(6737), 676-679.

Ulrich, T., Günther, D., Heinrich, C. A., (2001). The Evolution of a Porphyry Cu-Au Deposit, Based on LAICP-MS Analysis of Fluid Inclusions: Bajo de la Alumbrera, Argentina. Economic Geology 96(8), $1743-1774$.

Urabe, T., (1987). The effect of pressure on the partitioning ratios of lead and zinc between vapor and rhyolite melts. Economic Geology 82(4), 1049-1052.

van Hinsberg, V., Berlo, K., Sumarti, S., van Bergen, M., Williams-Jones, A., (2010a). Extreme alteration by hyperacidic brines at Kawah Ijen volcano, East Java, Indonesia: II: Metasomatic imprint and element fluxes. Journal of Volcanology and Geothermal Research 196(3-4), 169-184.

van Hinsberg, V., Berlo, K., van Bergen, M., Williams-Jones, A., (2010b). Extreme alteration by hyperacidic brines at Kawah Ijen volcano, East Java, Indonesia: I. Textural and mineralogical imprint. Journal of Volcanology and Geothermal Research 198(1-2), 253-263.

Varekamp, J. C., Ouimette, A. P., Herman, S. W., Bermúdez, A., Delpino, D., (2001). Hydrothermal element fluxes from Copahue, Argentina: A "beehive" volcano in turmoil. Geology 29(11), 1059-1062.

Varekamp, J. C., Ouimette, A. P., Herman, S. W., Flynn, K. S., Bermudez, A., Delpino, D., (2009). Naturally acid waters from Copahue volcano, Argentina. Applied Geochemistry 24(2), 208-220.

Varekamp, J. C., Thomas, E., Germani, M., Buseck, P. R., (1986). Particle geochemistry of volcanic plumes of Etna and Mount St. Helens. Journal of Geophysical Research: Solid Earth 91(B12), 12233-12248.

Varrica, D., Aiuppa, A., Dongarrà, G., (2000). Volcanic and anthropogenic contribution to heavy metal content in lichens from Mt. Etna and Vulcano island (Sicily). Environmental Pollution 108(2), 153-162.

Vaselli, O., Tassi, F., Montegrossi, G., Capaccioni, B., Giannini, L., (2006). Sampling and analysis of volcanic gases. Acta vulcanologica 18(1/2), 67.

Vié le Sage, R., (1983). Chemistry of the volcanic aerosol. In: Forecasting Volcanic Events. (Eds) H. Tazieff, J. C. Sabroux, Amsterdam, Elsevier, 445-474.

Vikre, P. G., (2007). Sinter-Vein Correlations at Buckskin Mountain, National District, Humboldt County, Nevada. Economic Geology 102(2), 193-224.

Wahrenberger, C., Seward, T. M., Dietrich, V., (2002). Volatile trace-element transport in high-temperature gases from Kudriavy volcano (Iturup, Kurile Islands, Russia). In: Water-Rock Interaction: a Tribute to David A. Crerar. (Eds) R. Hellmann, S. A. Wood, Geochemical Society Special Publication. 7, $307-$ 327.

Wahrenberger, C. M., (1997). Some aspects of the chemistry of volcanic gases. PhD thesis, ETH Zurich, Zurich.

Wallace, P. J., (2005). Volatiles in subduction zone magmas: concentrations and fluxes based on melt inclusion and volcanic gas data. Journal of Volcanology and Geothermal Research 140(1-3), 217-240.

Wallace, P. J., Carmichael, I. S. E., (1992). Sulfur in basaltic magmas. Geochimica et Cosmochimica Acta 56(5), 1863-1874.

Wallace, P. J., Edmonds, M., (2011). The Sulfur Budget in Magmas: Evidence from Melt Inclusions, Submarine Glasses, and Volcanic Gas Emissions. Reviews in Mineralogy and Geochemistry 73(1), 215-246.

Wallace, P. J., Kamenetsky, V. S., Cervantes, P., (2015). Melt inclusion CO2 contents, pressures of olivine crystallization, and the problem of shrinkage bubbles. American Mineralogist 100(4), 787-794.

Wardell, L. J., Kyle, P. R., Counce, D., (2008). Volcanic emissions of metals and halogens from White Island (New Zealand) and Erebus volcano (Antarctica) determined with chemical traps. Journal of Volcanology and Geothermal Research 177(3), 734-742.

Wardell, L. J., Kyle, P. R., Dunbar, N., Christenson, B. W., (2001). White Island volcano, New Zealand: carbon dioxide and sulfur dioxide emission rates and melt inclusion studies. Chemical Geology 177(1-2), 187200.

Watson, E. B., (1991). Diffusion of dissolved $\mathrm{CO} 2$ and $\mathrm{Cl}$ in hydrous silicic to intermediate magmas. Geochimica et Cosmochimica Acta 55(7), 1897-1902.

Watson, I. M., Oppenheimer, C., (2000). Particle size distributions of Mount Etna's aerosol plume constrained by Sun photometry. Journal of Geophysical Research: Atmospheres 105(D8), 9823-9829. 
Watts, R. B., de Silva, S. L., Jimenez de Rios, G., Croudace, I., (1999). Effusive eruption of viscous silicic magma triggered and driven by recharge: a case study of the Cerro Chascon-Runtu Jarita Dome Complex in Southwest Bolivia. Bulletin of Volcanology 61(4), 241-264.

Webster, J. D., (1992). Fluid-melt interactions involving Cl-rich granites: Experimental study from 2 to 8 kbar. Geochimica et Cosmochimica Acta 56(2), 659-678.

Webster, J. D., Botcharnikov, R. E., (2011). Distribution of Sulfur Between Melt and Fluid in S-O-H-C-ClBearing Magmatic Systems at Shallow Crustal Pressures and Temperatures. Reviews in Mineralogy and Geochemistry 73(1), 247-283.

Wells, N., (1967). Selenium content of soil-forming rocks. New Zealand Journal of Geology and Geophysics 10(1), 198-208.

Werner, C., Hurst, T., Scott, B. J., Sherburn, S., Christenson, B. W., Britten, K., Cole-Baker, J., Mullan, B., (2008). Variability of passive gas emissions, seismicity, and deformation during crater lake growth at White Island Volcano, New Zealand, 2002-2006. Journal of Geophysical Research: Solid Earth 113(B1).

Westervelt, W. D., (1916). Hawaiian legends of Volcanoes: (mythology) Collected and translated from the Hawaiian. Boston, Ellis Press.

White, N. C., Hedenquist, J. W., (1990). Epithermal environments and styles of mineralization: Variations and their causes, and guidelines for exploration. Journal of Geochemical Exploration 36(1), 445-474.

Wilkinson, J. J., (2013). Triggers for the formation of porphyry ore deposits in magmatic arcs. Nature Geoscience 6(11), 917-925.

Williams-Jones, A. E., Heinrich, C. A., (2005). Vapor Transport of Metals and the Formation of MagmaticHydrothermal Ore Deposits. Economic Geology 100(7), 1287-1312.

Williams-Jones, A. E., Migdisov, A. A., Archibald, S. M., Xiao, Z., (2002). Vapor-transport of ore metals. Water-rock interaction: a tribute to David A. Crerar: Geochemical Society Special Publication 7, 279305.

Wilson, L., (1980). Relationships between pressure, volatile content and ejecta velocity in three types of volcanic explosion. Journal of Volcanology and Geothermal Research 8(2), 297-313.

Witt, M. L. I., Mather, T. A., Pyle, D. M., Aiuppa, A., Bagnato, E., Tsanev, V. I., (2008). Mercury and halogen emissions from Masaya and Telica volcanoes, Nicaragua. Journal of Geophysical Research: Solid Earth 113(B6).

Witter, J. B., Kress, V. C., Newhall, C. G., (2005). Volcán Popocatépetl, Mexico. Petrology, Magma Mixing, and Immediate Sources of Volatiles for the 1994-Present Eruption. Journal of Petrology 46(11), 23372366.

Wood, C. P., (1977). Petrology of ejected lake sediments and the geochemical cycle in Ruapheu Crtaer Lake, New Zealand. DSIR Bulletin 218, 103-110.

Wood, C. P., (1994). Mineralogy at the magma-hydrothermal system interface in andesite volcanoes, New Zealand. Geology 22(1), 75-78.

Wood, C. P., Browne, P. R. L., (1996). Chlorine-rich pyrometamorphic magma at White Island volcano, New Zealand. Journal of Volcanology and Geothermal Research 72(1-2), 21-35.

Woods, A. W., Koyaguchi, T., (1994). Transitions between explosive and effusive eruptions of silicic magmas. Nature 370(6491), 641-644.

Wright, I. C., (1992). Shallow structure and active tectonism of an offshore continental back-arc spreading system: the Taupo Volcanic Zone, New Zealand. Marine Geology 103(1-3), 287-309.

Wysoczanski, R. J., Tani, K., (2006). Spectroscopic FTIR imaging of water species in silicic volcanic glasses and melt inclusions: An example from the Izu-Bonin arc. Journal of Volcanology and Geothermal Research 156(3-4), 302-314.

Wysoczanski, R. J., Wright, I. C., Gamble, J. A., Hauri, E. H., Luhr, J. F., Eggins, S. M., Handler, M. R., (2006). Volatile contents of Kermadec Arc-Havre Trough pillow glasses: Fingerprinting slab-derived aqueous fluids in the mantle sources of arc and back-arc lavas. Journal of Volcanology and Geothermal Research 152(1-2), 51-73.

Xiao, Z., Gammons, C. H., Williams-Jones, A. E., (1998). Experimental study of copper(I) chloride complexing in hydrothermal solutions at 40 to $300^{\circ} \mathrm{C}$ and saturated water vapor pressure. Geochimica et Cosmochimica Acta 62(17), 2949-2964.

Yamaguchi, K. E., Ohmoto, H., (2006). Evidence from sulfur isotope and trace elements in pyrites for their multiple post-depositional processes in uranium ores at the Stanleigh Mine, Elliot Lake, Ontario, Canada. Geological Society of America Memoirs 198, 143-156.

Yamashita, S., Kitamura, T., Kusakabe, M., (1997). Infrared spectroscopy of hydrous glasses of arc magma compositions. Geochemical Journal 31(3), 169-174.

Yardley, B. W. D., Manning, C. E., Garven, G., (2011). Frontiers in geofluids. Chichester, Wiley-Blackwell. 
Yeghicheyan, D., Carignan, J., Valladon, M., Le Coz, M. B., Cornec, F. L., Castrec-Rouelle, M., Robert, M., Aquilina, L., Aubry, E., Churlaud, C., Dia, A., Deberdt, S., Dupré, B., Freydier, R., Gruau, G., Hénin, O., de Kersabiec, A.-M., Macé, J., Marin, L., Morin, N., Petitjean, P., Serrat, E., (2001). A Compilation of Silicon and Thirty One Trace Elements Measured in the Natural River Water Reference Material SLRS-4 (NRC-CNRC). Geostandards Newsletter 25(2-3), 465-474.

Yudovskaya, M. A., Distler, V. V., Chaplygin, I. V., Mokhov, A. V., Trubkin, N. V., Gorbacheva, S. A., (2006). Gaseous transport and deposition of gold in magmatic fluid: evidence from the active Kudryavy volcano, Kurile Islands. Mineralium Deposita 40(8), 828.

Yudovskaya, M. A., Tessalina, S., Distler, V. V., Chaplygin, I. V., Chugaev, A. V., Dikov, Y. P., (2008). Behavior of highly-siderophile elements during magma degassing: A case study at the Kudryavy volcano. Chemical Geology 248(3-4), 318-341.

Yund, R. A., Kullerud, G., (1966). Thermal Stability of Assemblages in the $\mathrm{Cu}-\mathrm{Fe}-\mathrm{S}$ System. Journal of Petrology 7(3), 454-488.

Zajacz, Z., Halter, W., (2009). Copper transport by high temperature, sulfur-rich magmatic vapor: Evidence from silicate melt and vapor inclusions in a basaltic andesite from the Villarrica volcano (Chile). Earth and Planetary Science Letters 282(1-4), 115-121.

Zajacz, Z., Halter, W. E., Pettke, T., Guillong, M., (2008). Determination of fluid/melt partition coefficients by LA-ICPMS analysis of co-existing fluid and silicate melt inclusions: Controls on element partitioning. Geochimica et Cosmochimica Acta 72(8), 2169-2197.

Zajacz, Z., Seo, J. H., Candela, P. A., Piccoli, P. M., Tossell, J. A., (2011). The solubility of copper in hightemperature magmatic vapors: A quest for the significance of various chloride and sulfide complexes. Geochimica et Cosmochimica Acta 75(10), 2811-2827.

Zelenski, M., Bortnikova, S., (2005). Sublimate speciation at Mutnovsky volcano, Kamchatka. European Journal of Mineralogy 17(1), 107-118.

Zelenski, M., Fischer, T. P., de Moor, J. M., Marty, B., Zimmermann, L., Ayalew, D., Nekrasov, A. N., Karandashev, V. K., (2013). Trace elements in the gas emissions from the Erta Ale volcano, Afar, Ethiopia. Chemical Geology 357, 95-116.

Zellmer, G. F., Sakamoto, N., Matsuda, N., Iizuka, Y., Moebis, A., Yurimoto, H., (2016). On progress and rate of the peritectic reaction $\mathrm{Fo}+\mathrm{SiO} 2 \rightarrow \mathrm{En}$ in natural andesitic arc magmas. Geochimica et Cosmochimica Acta 185, 383-393.

Zoller, W. H., Gladney, E. S., Duce, R. A., (1974). Atmospheric Concentrations and Sources of Trace Metals at the South Pole. Science 183(4121), 198-200.

Zreda-Gostynska, G., Kyle, P. R., Finnegan, D., Prestbo, K. M., (1997). Volcanic gas emissions from Mount Erebus and their impact on the Antarctic environment. Journal of Geophysical Research: Solid Earth 102(B7), 15039-15055. 


\section{Appendix}

\section{A.1 LA-ICP-MS analytical precision and accuracy}

Table A-1: LA-ICP-MS analytical precision ( \pm 1 RSD) and accuracy (bias) estimated with certified reference material GSD-1 for the different spot sizes used.

\begin{tabular}{|c|c|c|c|c|c|c|}
\hline & $1 \%$ RSD & & & Bias (\%) & & \\
\hline Spot size & $25 \mu \mathrm{m}$ & $20 \mu \mathrm{m}$ & $15 \mu \mathrm{m}$ & $25 \mu \mathrm{m}$ & $20 \mu \mathrm{m}$ & $15 \mu \mathrm{m}$ \\
\hline $\mathrm{Li}$ & 3.15 & 2.44 & 2.32 & 1.35 & 0.54 & -4.22 \\
\hline B & 5.21 & 4.33 & 1.28 & 2.54 & 4.14 & 5.26 \\
\hline $\mathrm{Sc}$ & 4.00 & 5.36 & 3.99 & 9.42 & 11.11 & 5.49 \\
\hline $\mathrm{Ti}$ & 3.98 & 2.89 & 7.76 & 4.86 & 6.21 & -2.50 \\
\hline V & 4.70 & 2.94 & 11.33 & 0.00 & 1.33 & -6.41 \\
\hline $\mathrm{Cr}$ & 10.78 & 10.70 & 28.14 & 3.70 & 10.81 & 28.00 \\
\hline Mn & 3.87 & 2.61 & 6.37 & -0.59 & -0.79 & -3.90 \\
\hline Co & 3.21 & 2.97 & 3.48 & -2.73 & -2.00 & -6.94 \\
\hline $\mathrm{Ni}$ & 4.65 & 4.91 & 11.43 & -1.33 & -1.11 & 2.79 \\
\hline $\mathrm{Cu}$ & 4.15 & 6.01 & 9.17 & -0.86 & -2.61 & -2.40 \\
\hline $\mathrm{Zn}$ & 6.45 & 5.32 & 2.18 & -1.87 & -11.12 & -5.43 \\
\hline $\mathrm{Ga}$ & 2.29 & 2.79 & 2.12 & 3.57 & 4.74 & 4.35 \\
\hline As & 6.21 & 5.24 & 7.38 & -3.26 & -3.58 & -4.06 \\
\hline $\mathrm{Se}$ & 44.13 & 52.97 & - & 57.78 & 152.62 & 137.96 \\
\hline $\mathrm{Rb}$ & 4.28 & 6.85 & 7.56 & -2.65 & -3.13 & -8.60 \\
\hline $\mathrm{Sr}$ & 6.07 & 3.99 & 5.53 & -0.51 & -1.36 & -8.66 \\
\hline Mo & 3.73 & 4.30 & 8.16 & 0.72 & 0.45 & 2.04 \\
\hline $\mathrm{Ag}$ & 5.05 & 3.87 & 8.06 & -1.17 & -3.61 & -1.76 \\
\hline $\mathrm{Cd}$ & 9.57 & 15.56 & 6.99 & -0.99 & -8.16 & -20.95 \\
\hline $\mathrm{Sn}$ & 4.85 & 5.03 & 5.94 & -3.57 & -1.86 & -11.03 \\
\hline $\mathrm{Sb}$ & 4.96 & 2.98 & 9.01 & 2.91 & -0.11 & -2.27 \\
\hline $\mathrm{Ba}$ & 9.50 & 9.00 & 10.10 & 4.91 & 2.30 & -8.91 \\
\hline $\mathrm{Yb}$ & 6.57 & 5.44 & 7.25 & -1.04 & 2.65 & -11.59 \\
\hline W & 4.74 & 4.20 & 3.74 & -1.55 & -4.25 & -5.99 \\
\hline $\operatorname{Re}$ & 7.86 & 12.93 & 8.11 & - & - & - \\
\hline $\mathrm{Au}$ & 10.23 & 24.61 & 8.36 & 6.94 & 11.83 & -11.26 \\
\hline $\mathrm{Tl}$ & 13.14 & 21.94 & 21.78 & 4.37 & -7.77 & 23.79 \\
\hline $\mathrm{Pb}$ & 4.55 & 3.46 & 6.20 & -3.49 & -5.11 & -2.61 \\
\hline $\mathrm{Bi}$ & 4.50 & 6.40 & 6.78 & -8.20 & -6.87 & -10.57 \\
\hline $\mathrm{U}$ & 3.90 & 4.18 & 10.60 & 1.32 & 0.02 & -4.76 \\
\hline
\end{tabular}

Notes: - not determined

Bias: Deviation between the certified and measured values, in percent. 


\section{A.2 Melt inclusions and matrix glass compositions}

Table A-2: Melt inclusion and matrix glass compositions.

\begin{tabular}{|c|c|c|c|c|c|c|c|c|c|c|}
\hline & $\begin{array}{l}\text { WIDP6- } \\
\text { IN01 }\end{array}$ & $\begin{array}{l}\text { WIDP6- } \\
\text { IN02 }\end{array}$ & $\begin{array}{l}\text { WIDP6- } \\
\text { IN05 }\end{array}$ & $\begin{array}{l}\text { WIDP6- } \\
\text { IN06 }\end{array}$ & $\begin{array}{l}\text { WIDP6- } \\
\text { IN07 }\end{array}$ & $\begin{array}{l}\text { WIDP6- } \\
\text { IN09* }\end{array}$ & $\begin{array}{l}\text { WIDP6- } \\
\text { IN10 }\end{array}$ & $\begin{array}{l}\text { WIDP6- } \\
\text { IN12 }\end{array}$ & $\begin{array}{l}\text { WIDP6- } \\
\text { IN14 }\end{array}$ & $\begin{array}{l}\text { WIDP6- } \\
\text { IN15 }\end{array}$ \\
\hline \multicolumn{11}{|c|}{ Major elements (wt\%) } \\
\hline $\mathrm{SiO}_{2}$ & 64.49 & 64.01 & 68.26 & 67.53 & 68.39 & 65.34 & 64.69 & 64.06 & 63.19 & 65.14 \\
\hline $\mathrm{TiO}_{2}$ & 0.84 & 1.01 & 1.52 & 0.88 & 0.94 & 0.68 & 0.99 & 1.05 & 0.99 & 1.01 \\
\hline $\mathrm{Al}_{2} \mathrm{O}_{3}$ & 13.57 & 15.12 & 14.70 & 14.52 & 14.06 & 14.93 & 14.39 & 13.70 & 14.20 & 13.12 \\
\hline $\mathrm{FeO}_{\mathrm{t}}$ & 6.00 & 6.42 & 5.10 & 4.51 & 4.07 & 3.78 & 6.02 & 6.34 & 7.56 & 7.66 \\
\hline $\mathrm{MnO}$ & 0.14 & 0.11 & 0.07 & 0.12 & 0.07 & 0.09 & 0.09 & 0.11 & 0.11 & 0.11 \\
\hline $\mathrm{MgO}$ & 1.85 & 2.01 & 0.32 & 1.84 & 1.30 & 2.25 & 1.95 & 2.26 & 1.89 & 1.49 \\
\hline $\mathrm{CaO}$ & 5.09 & 5.52 & 2.09 & 4.54 & 4.15 & 4.69 & 5.28 & 4.23 & 5.46 & 4.74 \\
\hline $\mathrm{Na}_{2} \mathrm{O}$ & 3.27 & 3.26 & 3.41 & 3.46 & 3.17 & 3.40 & 3.17 & 3.37 & 3.25 & 3.19 \\
\hline $\mathrm{K}_{2} \mathrm{O}$ & 3.02 & 3.05 & 4.10 & 2.78 & 3.13 & 2.90 & 2.57 & 2.91 & 2.37 & 2.78 \\
\hline $\mathrm{P}_{2} \mathrm{O}_{5}$ & 1.28 & 0.01 & 0.11 & 0.01 & 0.06 & nd & 0.00 & 0.01 & 0.01 & 0.06 \\
\hline $\mathrm{Cr}_{2} \mathrm{O}_{3}$ & 0.02 & 0.00 & 0.01 & 0.02 & 0.02 & 0.00 & nd & 0.00 & 0.01 & 0.01 \\
\hline $\mathrm{Cl}(\mathrm{ppm})$ & 1460 & 820 & 1815 & 1013 & 1100 & 1283 & 1130 & 1010 & 1177 & 1050 \\
\hline S (ppm) & 72 & 60 & 90 & 128 & 152 & 461 & 108 & 147 & 382 & 400 \\
\hline $\mathrm{H}_{2} \mathrm{O}(\mathrm{wt} \%)$ & na & na & na & na & na & na & na & na & na & na \\
\hline Total & 99.74 & 100.62 & 99.88 & 100.32 & 99.49 & 98.23 & 99.28 & 98.15 & 99.18 & 99.47 \\
\hline $\begin{array}{l}\text { Hosting } \\
\text { phenocryst }\end{array}$ & Opx & Opx & Pla & Opx & Cpx & Opx & Opx & Pla & Opx & Opx \\
\hline \multicolumn{11}{|c|}{ Trace elements (ppm) } \\
\hline $\mathrm{Li}$ & 22.78 & 29.27 & na & 24.48 & 26.51 & 33.75 & 22.74 & 82.72 & 26.47 & 19.49 \\
\hline B & 45.40 & 39.29 & na & 43.84 & 40.33 & 38.43 & 40.94 & 40.15 & 33.67 & 36.22 \\
\hline $\mathrm{Sc}$ & 33.32 & 35.72 & na & 23.91 & 33.99 & 23.11 & 26.60 & 25.67 & 31.03 & 30.41 \\
\hline $\mathrm{Ti}$ & 5276.26 & 7052.29 & na & 5683.93 & 6206.96 & 4289.31 & 6026.12 & 6369.96 & 6241.30 & 6081.06 \\
\hline V & 165.08 & 295.37 & na & 230.11 & 240.14 & 238.97 & 252.30 & 239.95 & 291.61 & 341.33 \\
\hline $\mathrm{Cr}$ & 7.91 & 91.51 & na & 8.92 & 2.88 & 11.06 & nd & 17.55 & 10.60 & 6.21 \\
\hline $\mathrm{Mn}$ & 1197.63 & 900.51 & na & 690.45 & 764.11 & 707.16 & 708.49 & 749.98 & 876.96 & 860.93 \\
\hline Co & 12.27 & 22.73 & na & 10.11 & 11.07 & 11.54 & 11.79 & 16.56 & 18.56 & 15.93 \\
\hline $\mathrm{Ni}$ & nd & 44.74 & na & 5.17 & 7.39 & 6.30 & 2.92 & 27.59 & 22.79 & 9.89 \\
\hline $\mathrm{Cu}$ & 163.29 & 149.60 & na & 167.79 & 168.67 & 174.12 & 155.54 & 474.02 & 1004.12 & 375.27 \\
\hline $\mathrm{Zn}$ & 63.94 & 64.30 & na & 60.65 & 66.81 & 56.99 & 67.82 & 67.67 & 79.43 & 85.61 \\
\hline $\mathrm{Ga}$ & 240.64 & 163.31 & na & 207.40 & 249.15 & 213.01 & 204.19 & 200.56 & 185.74 & 200.39 \\
\hline As & 6.43 & 4.62 & na & 3.67 & 6.53 & 5.19 & 5.08 & 4.60 & 4.65 & 4.04 \\
\hline $\mathrm{Se}$ & nd & 1.65 & na & nd & nd & nd & nd & nd & nd & nd \\
\hline $\mathrm{Rb}$ & 94.77 & 88.17 & na & 90.89 & 111.91 & 84.92 & 86.24 & 90.15 & 70.27 & 81.93 \\
\hline $\mathrm{Sr}$ & 208.32 & 145.88 & na & 178.30 & 164.89 & 175.15 & 168.18 & 140.83 & 194.31 & 179.75 \\
\hline Mo & 1.69 & 1.68 & na & 1.13 & 2.15 & 1.37 & 1.75 & 1.45 & 1.31 & 1.58 \\
\hline $\mathrm{Ag}$ & 0.38 & 0.19 & na & nd & 0.25 & 0.17 & nd & 0.32 & 0.24 & nd \\
\hline $\mathrm{Cd}$ & nd & nd & na & nd & nd & 0.46 & 0.37 & nd & 0.52 & nd \\
\hline Sn & 1.60 & nd & na & 2.01 & 2.27 & nd & 1.69 & 0.86 & 2.45 & 1.86 \\
\hline $\mathrm{Sb}$ & 0.53 & 0.75 & na & 0.43 & nd & 0.46 & 0.81 & 0.36 & 0.44 & nd \\
\hline $\mathrm{Ba}$ & 1149.98 & 779.94 & na & 1150.62 & 1348.78 & 1140.74 & 1085.39 & 1003.17 & 981.50 & 1003.87 \\
\hline $\mathrm{Yb}$ & 6.27 & 3.61 & na & 3.51 & 4.74 & 2.77 & 3.07 & 2.71 & 3.30 & 2.63 \\
\hline W & 1.71 & 1.18 & na & 2.33 & 1.81 & 1.59 & 0.84 & 1.52 & 0.77 & 2.28 \\
\hline $\mathrm{Re}$ & nd & nd & na & nd & nd & nd & nd & nd & nd & nd \\
\hline $\mathrm{Au}$ & nd & nd & na & nd & nd & nd & nd & 0.34 & nd & nd \\
\hline $\mathrm{Tl}$ & 0.34 & 0.41 & na & 0.50 & 0.58 & 0.38 & 0.22 & 0.38 & 0.30 & 0.25 \\
\hline $\mathrm{Pb}$ & 16.51 & 13.40 & na & 13.58 & 12.66 & 14.99 & 13.23 & 12.14 & 13.61 & 13.20 \\
\hline $\mathrm{Bi}$ & 0.16 & 0.11 & na & 0.36 & 0.14 & 0.14 & 0.21 & 0.11 & 0.06 & nd \\
\hline U & 3.06 & 1.59 & na & 1.95 & 1.58 & 1.71 & 1.90 & 1.83 & 1.72 & 2.04 \\
\hline
\end{tabular}


Table A-2 (continued)

\begin{tabular}{|c|c|c|c|c|c|c|c|c|c|c|}
\hline & $\begin{array}{l}\text { WIDP6- } \\
\text { IN16 }\end{array}$ & $\begin{array}{l}\text { WIDP6- } \\
\text { IN17* }\end{array}$ & $\begin{array}{l}\text { WIDP6- } \\
\text { IN18* }\end{array}$ & $\begin{array}{l}\text { WIDP6- } \\
\text { IN19* }\end{array}$ & $\begin{array}{l}\text { WIDP6- } \\
\text { IN20* }\end{array}$ & $\begin{array}{l}\text { WIDP6- } \\
\text { IN21 }\end{array}$ & $\begin{array}{l}\text { WIDP6- } \\
\text { IN23 }\end{array}$ & $\begin{array}{l}\text { WIDP6- } \\
\text { IN24 }\end{array}$ & $\begin{array}{l}\text { WIDP6- } \\
\text { IN25 }\end{array}$ & $\begin{array}{l}\text { WIDP6- } \\
\text { IN26 }\end{array}$ \\
\hline \multicolumn{11}{|c|}{ Major elements (wt\%) } \\
\hline $\mathrm{SiO}_{2}$ & 61.54 & 67.77 & 64.68 & 64.44 & 64.43 & 62.20 & 66.32 & 66.48 & 65.98 & 63.72 \\
\hline $\mathrm{TiO}_{2}$ & 0.75 & 0.78 & 0.55 & 0.63 & 0.62 & 0.95 & 1.19 & 1.06 & 1.15 & 1.06 \\
\hline $\mathrm{Al}_{2} \mathrm{O}_{3}$ & 19.21 & 15.07 & 17.52 & 15.85 & 16.66 & 14.88 & 14.42 & 14.14 & 13.68 & 14.20 \\
\hline $\mathrm{FeO}_{\mathrm{t}}$ & 4.14 & 4.26 & 3.65 & 4.55 & 3.70 & 7.85 & 6.15 & 6.30 & 6.51 & 5.90 \\
\hline $\mathrm{MnO}$ & 0.06 & 0.09 & 0.05 & 0.06 & 0.08 & 0.14 & 0.05 & 0.08 & 0.11 & 0.09 \\
\hline $\mathrm{MgO}$ & 1.36 & 1.62 & 2.05 & 2.29 & 2.09 & 2.15 & 0.93 & 1.00 & 1.62 & 2.24 \\
\hline $\mathrm{CaO}$ & 7.70 & 4.17 & 5.07 & 5.84 & 5.16 & 6.19 & 4.71 & 4.69 & 3.73 & 4.99 \\
\hline $\mathrm{Na}_{2} \mathrm{O}$ & 3.34 & 3.48 & 4.05 & 3.18 & 3.67 & 3.39 & 2.70 & 3.10 & 3.25 & 3.67 \\
\hline $\mathrm{K}_{2} \mathrm{O}$ & 1.77 & 3.26 & 3.31 & 2.72 & 3.24 & 1.83 & 2.76 & 2.83 & 3.00 & 2.90 \\
\hline $\mathrm{P}_{2} \mathrm{O}_{5}$ & nd & 0.01 & 0.01 & nd & nd & nd & 0.07 & 0.09 & 0.03 & 0.03 \\
\hline $\mathrm{Cr}_{2} \mathrm{O}_{3}$ & 0.01 & 0.01 & 0.01 & 0.00 & 0.01 & 0.01 & 0.01 & 0.01 & 0.02 & 0.00 \\
\hline $\mathrm{Cl}(\mathrm{ppm})$ & 713 & 937 & 980 & 970 & 967 & 787 & 1043 & 1003 & 1007 & 963 \\
\hline $\mathrm{S}(\mathrm{ppm})$ & 89 & 127 & 499 & 279 & 535 & 427 & 36 & 93 & 112 & 56 \\
\hline $\mathrm{H}_{2} \mathrm{O}(\mathrm{wt} \%)$ & na & na & na & na & na & na & na & na & na & na \\
\hline Total & 99.96 & 100.63 & 101.10 & 99.68 & 99.80 & 99.71 & 99.41 & 99.89 & 99.18 & 98.90 \\
\hline $\begin{array}{l}\text { Hosting } \\
\text { phenocryst }\end{array}$ & Cpx & Opx & Opx & Opx & Opx & Opx & Opx & Opx & Cpx & $\mathrm{Pla}$ \\
\hline \multicolumn{11}{|c|}{ Trace elements (ppm) } \\
\hline $\mathrm{Li}$ & 27.17 & 27.29 & 29.95 & 16.58 & 31.63 & 27.75 & 24.26 & 20.74 & 26.65 & 35.25 \\
\hline B & 37.64 & 41.65 & 26.11 & 15.76 & 34.92 & 27.51 & 39.64 & 39.90 & 42.44 & 13.71 \\
\hline $\mathrm{Sc}$ & 26.88 & 24.54 & 20.48 & 42.19 & 18.27 & 29.89 & 27.27 & 32.24 & 31.07 & 12.06 \\
\hline $\mathrm{Ti}$ & 6772.54 & 4836.82 & 3159.07 & 2741.91 & 3697.51 & 5491.68 & 7059.10 & 6519.46 & 7082.17 & 1853.63 \\
\hline V & 305.15 & 145.72 & 111.00 & 153.13 & 116.09 & 271.92 & 266.72 & 276.40 & 318.61 & 72.65 \\
\hline $\mathrm{Cr}$ & nd & 109.79 & 325.53 & 777.15 & 16.88 & 7.00 & 38.23 & 122.01 & 45.17 & 7.31 \\
\hline Mn & 769.22 & 1012.25 & 772.18 & 1740.31 & 454.20 & 898.90 & 772.28 & 954.48 & 809.11 & 216.54 \\
\hline Co & 12.06 & 20.46 & 26.17 & 64.59 & 11.46 & 18.79 & 17.63 & 22.89 & 15.75 & 4.87 \\
\hline $\mathrm{Ni}$ & 2.67 & 59.56 & 127.80 & 410.89 & 22.87 & 15.54 & 40.69 & 51.48 & 10.66 & 8.76 \\
\hline $\mathrm{Cu}$ & 172.15 & 137.72 & 234.26 & 48.78 & 151.67 & 212.11 & 158.40 & 139.91 & 184.42 & 155.61 \\
\hline $\mathrm{Zn}$ & 76.12 & 83.87 & 57.18 & 90.76 & 35.35 & 79.57 & 72.71 & 82.91 & 80.78 & 26.59 \\
\hline $\mathrm{Ga}$ & 194.60 & 235.53 & 148.01 & 82.13 & 172.58 & 140.24 & 185.98 & 204.53 & 216.52 & 91.17 \\
\hline As & 4.03 & 12.69 & 3.17 & 2.81 & 5.37 & 2.70 & 5.22 & 4.26 & 6.29 & nd \\
\hline $\mathrm{Se}$ & nd & nd & nd & nd & nd & nd & nd & nd & nd & nd \\
\hline $\mathrm{Rb}$ & 77.51 & 91.89 & 65.59 & 47.74 & 86.57 & 54.83 & 83.87 & 85.51 & 94.64 & 25.30 \\
\hline $\mathrm{Sr}$ & 161.25 & 171.57 & 231.87 & 118.76 & 248.76 & 186.99 & 158.22 & 154.25 & 163.89 & 391.75 \\
\hline Mo & 1.21 & 1.63 & 0.71 & 0.49 & 1.01 & 0.47 & 1.52 & 2.10 & 1.51 & nd \\
\hline $\mathrm{Ag}$ & nd & nd & nd & nd & nd & 0.21 & nd & nd & nd & 0.39 \\
\hline $\mathrm{Cd}$ & nd & nd & nd & nd & nd & nd & 0.72 & nd & nd & nd \\
\hline $\mathrm{Sn}$ & 0.93 & 2.29 & nd & nd & nd & 2.63 & nd & nd & 1.19 & nd \\
\hline $\mathrm{Sb}$ & 0.59 & 1.04 & 0.01 & 0.06 & nd & 0.44 & 1.06 & 1.04 & 0.51 & 0.62 \\
\hline $\mathrm{Ba}$ & 1076.47 & 1268.31 & 823.15 & 407.59 & 881.71 & 737.96 & 1018.05 & 1043.66 & 1171.13 & 431.80 \\
\hline $\mathrm{Yb}$ & 3.52 & 2.27 & 0.94 & 1.65 & 1.29 & 3.24 & 1.71 & 5.09 & 3.32 & nd \\
\hline $\mathrm{W}$ & 1.91 & 1.70 & 1.73 & 0.46 & 1.22 & 0.69 & 1.50 & 1.14 & 1.71 & nd \\
\hline $\operatorname{Re}$ & nd & 0.75 & nd & nd & nd & nd & nd & nd & 0.27 & nd \\
\hline $\mathrm{Au}$ & nd & nd & nd & 0.29 & nd & nd & nd & nd & nd & nd \\
\hline $\mathrm{Tl}$ & 0.46 & 0.37 & 0.45 & nd & 0.32 & 0.45 & 0.29 & 0.34 & 0.37 & nd \\
\hline $\mathrm{Pb}$ & 13.36 & 19.84 & 15.94 & 5.69 & 14.03 & 8.99 & 12.71 & 9.81 & 14.51 & 4.98 \\
\hline $\mathrm{Bi}$ & 0.20 & 0.37 & 0.16 & nd & 0.18 & 0.11 & nd & nd & 0.11 & nd \\
\hline $\mathrm{U}$ & 1.90 & 1.87 & 1.50 & 0.82 & 1.57 & 1.14 & 1.97 & 2.19 & 1.87 & 0.47 \\
\hline
\end{tabular}


Table A-2 (continued)

\begin{tabular}{|c|c|c|c|c|c|c|c|c|c|c|}
\hline & $\begin{array}{c}\text { WIDP6- } \\
\text { IN28 }\end{array}$ & $\begin{array}{c}\text { WIDP6- } \\
\text { IN29 }\end{array}$ & $\begin{array}{c}\text { WIDP6- } \\
\text { IN30 }\end{array}$ & $\begin{array}{c}\text { WIDP6- } \\
\text { IN31 }\end{array}$ & $\begin{array}{c}\text { WIDP6- } \\
\text { IN32 }\end{array}$ & $\begin{array}{c}\text { WIDP6- } \\
\text { IN33 }\end{array}$ & $\begin{array}{c}\text { WIDP6- } \\
\text { IN34 }\end{array}$ & $\begin{array}{l}\text { WIDP6- } \\
\text { Matrix } \\
\text { glass } 1\end{array}$ & $\begin{array}{l}\text { WIDP6- } \\
\text { Matrix } \\
\text { glass } \\
\text { enclave }\end{array}$ & $\begin{array}{l}\text { WIDP6- } \\
\text { Matrix } \\
\text { Glass } 2\end{array}$ \\
\hline \multicolumn{11}{|c|}{ Major elements (wt\%) } \\
\hline $\mathrm{SiO}_{2}$ & 64.40 & 65.09 & 65.86 & 64.60 & 63.80 & 65.13 & 64.93 & 62.99 & 73.22 & 63.51 \\
\hline $\mathrm{TiO}_{2}$ & 0.58 & 1.02 & 1.05 & 1.06 & 1.19 & 1.04 & 1.11 & 0.97 & 0.78 & 0.93 \\
\hline $\mathrm{Al}_{2} \mathrm{O}_{3}$ & 15.69 & 13.49 & 13.65 & 13.85 & 13.98 & 13.95 & 13.90 & 14.81 & 12.21 & 14.72 \\
\hline $\mathrm{FeO}_{\mathrm{t}}$ & 4.78 & 6.34 & 5.80 & 5.95 & 6.37 & 5.89 & 6.00 & 6.29 & 3.54 & 5.70 \\
\hline $\mathrm{MnO}$ & 0.07 & 0.09 & 0.12 & 0.10 & 0.13 & 0.09 & 0.11 & 0.14 & 0.07 & nd \\
\hline $\mathrm{MgO}$ & 2.23 & 1.72 & 1.70 & 2.22 & 2.51 & 2.09 & 2.12 & 3.08 & 0.73 & 2.49 \\
\hline $\mathrm{CaO}$ & 5.45 & 4.61 & 4.69 & 4.90 & 5.19 & 4.78 & 4.73 & 6.01 & 1.99 & 6.24 \\
\hline $\mathrm{Na}_{2} \mathrm{O}$ & 3.58 & 3.20 & 3.11 & 3.50 & 3.51 & 3.25 & 3.34 & 3.39 & 3.04 & 3.20 \\
\hline $\mathrm{K}_{2} \mathrm{O}$ & 2.28 & 2.81 & 3.02 & 2.78 & 2.78 & 2.84 & 2.81 & 2.39 & 3.55 & 2.47 \\
\hline $\mathrm{P}_{2} \mathrm{O}_{5}$ & 0.01 & 0.08 & 0.01 & 0.03 & 0.05 & 0.01 & nd & nd & nd & nd \\
\hline $\mathrm{Cr}_{2} \mathrm{O}_{3}$ & 0.01 & 0.02 & 0.01 & 0.01 & 0.01 & 0.00 & 0.01 & 0.12 & 0.12 & nd \\
\hline $\mathrm{Cl}$ (ppm) & 1173 & 933 & 1077 & 887 & 920 & 960 & 990 & 698 & 690 & 691 \\
\hline $\mathrm{S}(\mathrm{ppm})$ & 171 & 100 & 96 & 76 & 112 & 67 & 155 & 105 & 76 & 28 \\
\hline $\mathrm{H}_{2} \mathrm{O}(\mathrm{wt} \%)$ & na & na & na & na & na & na & na & na & na & na \\
\hline Total & 99.22 & 98.56 & 99.14 & 99.09 & 99.63 & 99.17 & 99.15 & 100.22 & 99.26 & 99.33 \\
\hline $\begin{array}{l}\text { Hosting } \\
\text { phenocryst } \\
\text { Trace elem }\end{array}$ & $\begin{array}{l}\text { Cpx } \\
\text { (ppm) }\end{array}$ & Opx & Opx & Pla & Pla & Pla & Pla & & & \\
\hline $\mathrm{Li}$ & 26.30 & 23.47 & 25.59 & 109.77 & 89.08 & 74.04 & 70.23 & 22.54 & na & na \\
\hline B & 33.94 & 44.96 & 46.00 & 42.78 & 44.82 & 41.65 & 38.33 & 39.44 & na & na \\
\hline $\mathrm{Sc}$ & 24.36 & 25.57 & 27.09 & 27.71 & 23.46 & 27.21 & 25.21 & 32.85 & na & na \\
\hline $\mathrm{Ti}$ & 3554.12 & 6179.52 & 6213.83 & 6754.00 & 7124.35 & 6475.37 & 5898.24 & 5918.48 & na & na \\
\hline V & 124.91 & 253.37 & 253.09 & 265.57 & 283.50 & 263.97 & 251.29 & 260.33 & na & na \\
\hline $\mathrm{Cr}$ & 5.85 & 8.95 & nd & 12.30 & 19.71 & 16.48 & 12.42 & 137.27 & na & na \\
\hline $\mathrm{Mn}$ & 632.70 & 715.06 & 734.11 & 727.71 & 775.56 & 738.15 & 692.81 & 911.40 & na & na \\
\hline Co & 14.08 & 13.74 & 13.38 & 15.39 & 18.24 & 15.95 & 16.21 & 20.45 & na & na \\
\hline $\mathrm{Ni}$ & 15.38 & 12.25 & 7.08 & 29.51 & 32.60 & 12.11 & 13.33 & 43.38 & na & na \\
\hline $\mathrm{Cu}$ & 173.73 & 161.33 & 168.92 & 826.65 & 634.86 & 333.15 & 336.06 & 141.67 & na & na \\
\hline $\mathrm{Zn}$ & 55.67 & 67.06 & 61.54 & 70.77 & 66.04 & 65.55 & 56.72 & 67.43 & na & na \\
\hline $\mathrm{Ga}$ & 169.61 & 197.57 & 205.56 & 202.94 & 203.04 & 202.23 & 187.30 & 160.12 & na & na \\
\hline As & 4.09 & 6.56 & 7.24 & 5.26 & 4.95 & 4.59 & 3.61 & 4.73 & na & na \\
\hline $\mathrm{Se}$ & nd & nd & nd & 1.07 & nd & nd & nd & 2.21 & na & na \\
\hline $\mathrm{Rb}$ & 75.71 & 97.43 & 97.95 & 90.99 & 91.27 & 85.34 & 82.45 & 69.63 & na & na \\
\hline $\mathrm{Sr}$ & 239.43 & 142.43 & 137.22 & 142.32 & 144.21 & 144.68 & 131.20 & 167.07 & na & na \\
\hline Mo & 1.35 & 1.67 & 1.87 & 1.20 & 1.99 & 1.41 & 1.46 & 1.02 & na & na \\
\hline $\mathrm{Ag}$ & nd & nd & nd & nd & 0.37 & nd & 0.34 & 0.40 & na & na \\
\hline $\mathrm{Cd}$ & 0.30 & nd & 0.71 & nd & nd & nd & 0.33 & nd & na & na \\
\hline $\mathrm{Sn}$ & 1.73 & 1.43 & 1.93 & 2.61 & 1.11 & 1.72 & 2.17 & 1.67 & na & na \\
\hline $\mathrm{Sb}$ & 0.72 & 0.68 & 0.31 & 0.42 & 0.52 & 0.30 & 0.56 & 0.53 & na & na \\
\hline $\mathrm{Ba}$ & 868.48 & 1058.62 & 1073.74 & 1043.44 & 989.72 & 1081.53 & 1009.78 & 857.40 & na & na \\
\hline $\mathrm{Yb}$ & 1.74 & 2.37 & 2.67 & 3.20 & 2.95 & 2.70 & 2.93 & 2.75 & na & na \\
\hline W & 1.34 & 1.59 & 1.63 & 0.97 & 1.60 & 1.74 & 2.01 & 1.26 & na & na \\
\hline $\operatorname{Re}$ & nd & nd & nd & nd & nd & nd & nd & 0.23 & na & na \\
\hline $\mathrm{Au}$ & nd & nd & nd & nd & 0.22 & nd & nd & 0.43 & na & na \\
\hline $\mathrm{Tl}$ & 0.31 & 0.34 & 0.37 & 0.43 & 0.29 & 0.27 & nd & 0.32 & na & na \\
\hline $\mathrm{Pb}$ & 9.03 & 12.98 & 13.93 & 12.45 & 12.51 & 11.03 & 11.29 & 9.74 & na & na \\
\hline $\mathrm{Bi}$ & nd & 0.17 & 0.18 & nd & 0.27 & 0.12 & nd & 0.14 & na & na \\
\hline $\mathrm{U}$ & 1.67 & 2.14 & 2.31 & 2.05 & 2.12 & 1.86 & 1.89 & 1.57 & na & na \\
\hline
\end{tabular}


Table A-2 (continued)

\begin{tabular}{|c|c|c|c|c|c|c|c|c|c|c|}
\hline & $\begin{array}{l}\text { WIDP18 } \\
\text {-Ctx21- } \\
\text { IN01 }\end{array}$ & $\begin{array}{l}\text { WIDP18 } \\
\text {-Ctx21- } \\
\text { IN02 }\end{array}$ & $\begin{array}{l}\text { WIDP18 } \\
\text {-Ctx01- } \\
\text { IN01 }\end{array}$ & $\begin{array}{l}\text { WIDP18 } \\
\text {-Ctx23- } \\
\text { IN02 }\end{array}$ & $\begin{array}{l}\text { WIDP18 } \\
\text { - Ctx03- } \\
\text { IN02-R2 }\end{array}$ & $\begin{array}{l}\text { WIDP18 } \\
\text { - Ctx03- } \\
\text { IN03-R2 }\end{array}$ & $\begin{array}{l}\text { WIDP18 } \\
\text { - Ctx03- } \\
\text { IN04-R2 }\end{array}$ & $\begin{array}{l}\text { WIDP18 } \\
\text { - Ctx20- } \\
\text { IN01-R2 }\end{array}$ & $\begin{array}{l}\text { WIDP18 } \\
\text { - Matrix } \\
\text { glass }\end{array}$ & $\begin{array}{c}\text { WIDP10 } \\
\text {-IN01 }\end{array}$ \\
\hline \multicolumn{11}{|c|}{ Major elements (wt\%) } \\
\hline $\mathrm{SiO}_{2}$ & 67.18 & 65.17 & 63.64 & 66.75 & 53.02 & 51.58 & 55.53 & 48.20 & 61.73 & 63.45 \\
\hline $\mathrm{TiO}_{2}$ & 0.83 & 0.81 & 0.83 & 0.84 & 0.16 & 0.92 & 0.85 & 0.85 & 0.96 & 0.99 \\
\hline $\mathrm{Al}_{2} \mathrm{O}_{3}$ & 13.98 & 14.00 & 14.16 & 16.21 & 24.98 & 19.89 & 18.19 & 19.64 & 15.25 & 14.56 \\
\hline $\mathrm{FeO}_{\mathrm{t}}$ & 5.09 & 6.42 & 6.70 & 3.47 & 2.10 & 3.52 & 4.05 & 4.72 & 5.75 & 5.82 \\
\hline $\mathrm{MnO}$ & 0.06 & 0.09 & 0.08 & 0.06 & 0.06 & 0.06 & 0.07 & 0.10 & 0.08 & 0.10 \\
\hline $\mathrm{MgO}$ & 1.07 & 1.25 & 1.74 & 0.98 & 5.29 & 4.46 & 4.81 & 4.45 & 2.42 & 2.55 \\
\hline $\mathrm{CaO}$ & 4.18 & 4.76 & 4.74 & 4.95 & 11.68 & 14.78 & 11.98 & 15.27 & 6.28 & 5.61 \\
\hline $\mathrm{Na}_{2} \mathrm{O}$ & 1.70 & 2.25 & 3.56 & 2.20 & 2.99 & 2.50 & 2.00 & 2.27 & 3.41 & 3.08 \\
\hline $\mathrm{K}_{2} \mathrm{O}$ & 3.11 & 2.86 & 2.61 & 2.69 & 0.39 & 0.93 & 1.44 & 0.63 & 2.37 & 2.78 \\
\hline $\mathrm{P}_{2} \mathrm{O}_{5}$ & 0.03 & 0.04 & 0.03 & nd & nd & nd & nd & nd & 0.04 & nd \\
\hline $\mathrm{Cr}_{2} \mathrm{O}_{3}$ & 0.05 & 0.04 & 0.05 & nd & 0.04 & 0.04 & 0.07 & 0.05 & 0.04 & nd \\
\hline $\mathrm{Cl}(\mathrm{ppm})$ & 1175 & 1260 & 1140 & 1487 & 257 & 1703 & 1583 & 2027 & 616 & 1245 \\
\hline $\mathrm{S}(\mathrm{ppm})$ & 203 & 150 & 108 & 4 & 72 & 1030 & 713 & 1179 & 62 & 57 \\
\hline $\begin{array}{l}\mathrm{H}_{2} \mathrm{O} \\
(\mathrm{wt} \%)\end{array}$ & 0.21679 & na & 0.28651 & na & 0.97 & na & 0.21 & 0.32 & na & na \\
\hline Total & 97.41 & 97.83 & 98.28 & 98.29 & 100.71 & 98.68 & 98.99 & 96.18 & 98.39 & 99.08 \\
\hline $\begin{array}{l}\text { Hosting } \\
\text { phenocrys } \\
\text { t } \\
\text { Trace elen }\end{array}$ & nts (ppm) & Opx & Opx & Opx & $\mathrm{Ol}$ & $\mathrm{Ol}$ & $\mathrm{Ol}$ & $\mathrm{Ol}$ & & Pla \\
\hline $\mathrm{Li}$ & 22.43 & 21.00 & 35.91 & na & 13.90 & 5.17 & 21.52 & 7.46 & na & 25.03 \\
\hline B & 43.10 & 43.15 & 35.90 & na & 11.95 & 13.46 & 16.72 & 12.82 & na & 37.96 \\
\hline $\mathrm{Sc}$ & 23.35 & 21.87 & 21.23 & na & 25.23 & 44.64 & 41.96 & 60.79 & na & 28.59 \\
\hline $\mathrm{Ti}$ & 5231.22 & 4776.72 & 5336.80 & na & 2184.32 & 4522.82 & 3662.79 & 4580.30 & na & 5864.93 \\
\hline $\mathrm{V}$ & 256.30 & 251.63 & 231.44 & na & 120.53 & 278.58 & 243.93 & 370.73 & na & 231.78 \\
\hline $\mathrm{Cr}$ & 25.43 & nd & 4.17 & na & 327.27 & 343.59 & 389.47 & 88.43 & na & 35.80 \\
\hline $\mathrm{Mn}$ & 675.33 & 644.65 & 731.44 & na & 1655.63 & 861.53 & 1138.64 & 724.38 & na & 736.70 \\
\hline Co & 17.57 & 14.39 & 13.86 & na & 115.99 & 57.90 & 63.09 & 19.01 & na & 17.53 \\
\hline $\mathrm{Ni}$ & 25.00 & 17.57 & 5.05 & na & 1776.84 & 939.29 & 926.68 & 173.04 & na & 31.83 \\
\hline $\mathrm{Cu}$ & 150.45 & 160.68 & 264.60 & na & 643.79 & 91.81 & 153.17 & 6.49 & na & 156.97 \\
\hline $\mathrm{Zn}$ & 64.00 & 54.69 & 71.57 & na & 117.27 & 33.85 & 50.96 & 42.76 & na & 61.89 \\
\hline $\mathrm{Ga}$ & 191.91 & 193.50 & 199.19 & na & 55.25 & 73.53 & 78.44 & 66.34 & na & 183.41 \\
\hline As & 5.86 & 4.32 & 4.63 & na & 2.64 & 3.48 & 6.52 & nd & na & 3.77 \\
\hline $\mathrm{Se}$ & nd & nd & nd & na & nd & 9.49 & 17.08 & nd & na & nd \\
\hline $\mathrm{Rb}$ & 97.01 & 90.29 & 81.55 & na & 24.25 & 19.99 & 18.78 & 14.65 & na & 83.27 \\
\hline $\mathrm{Sr}$ & 145.51 & 161.54 & 173.23 & na & 48.08 & 169.31 & 170.17 & 206.49 & na & 165.87 \\
\hline Mo & 0.85 & 2.25 & 1.29 & na & nd & nd & 2.25 & 1.44 & na & 1.32 \\
\hline $\mathrm{Ag}$ & nd & 0.46 & nd & na & nd & nd & 1.26 & nd & na & 0.28 \\
\hline $\mathrm{Cd}$ & 1.31 & nd & nd & na & 2.18 & nd & 5.86 & 5.35 & na & nd \\
\hline $\mathrm{Sn}$ & 2.16 & nd & 2.29 & na & nd & nd & 7.43 & nd & na & 0.97 \\
\hline $\mathrm{Sb}$ & 1.87 & nd & $\mathrm{nd}$ & na & nd & nd & nd & nd & na & 0.43 \\
\hline $\mathrm{Ba}$ & 1031.08 & 985.89 & 1078.72 & na & 256.42 & 340.39 & 326.27 & 302.16 & na & 932.99 \\
\hline $\mathrm{Yb}$ & 3.14 & 3.26 & 2.52 & na & 0.63 & 3.74 & 4.41 & nd & na & 2.45 \\
\hline $\mathrm{W}$ & 1.49 & 3.12 & 1.59 & na & nd & nd & nd & nd & na & 1.39 \\
\hline $\operatorname{Re}$ & 0.63 & nd & nd & na & nd & nd & nd & nd & na & nd \\
\hline $\mathrm{Au}$ & nd & nd & nd & na & nd & nd & nd & nd & na & nd \\
\hline $\mathrm{Tl}$ & 0.51 & nd & 0.34 & na & nd & nd & nd & nd & na & 0.29 \\
\hline $\mathrm{Pb}$ & 13.27 & 13.96 & 12.89 & na & 1.99 & 3.54 & 7.60 & 4.97 & na & 10.91 \\
\hline $\mathrm{Bi}$ & nd & nd & 0.28 & na & nd & nd & 0.56 & nd & na & 0.14 \\
\hline $\mathrm{U}$ & 2.03 & 1.81 & 1.97 & na & 0.69 & nd & 0.72 & 0.57 & na & 1.58 \\
\hline
\end{tabular}


Table A-2(continued)

\begin{tabular}{|c|c|c|c|c|c|c|c|c|c|c|}
\hline & $\begin{array}{l}\text { WIDP1 } \\
0 \text {-IN02 }\end{array}$ & $\begin{array}{l}\text { WIDP10 } \\
\text {-IN03 }\end{array}$ & $\begin{array}{l}\text { WIDP10 } \\
\text {-IN04 }\end{array}$ & $\begin{array}{l}\text { WIDP10 } \\
\text {-IN05 }\end{array}$ & $\begin{array}{l}\text { WIDP10 } \\
\text {-IN06 }\end{array}$ & $\begin{array}{l}\text { WIDP10 } \\
\text {-IN07 }\end{array}$ & $\begin{array}{c}\text { WIDP10 } \\
\text {-IN08 }\end{array}$ & $\begin{array}{l}\text { WIDP10 } \\
\text {-IN09 }\end{array}$ & $\begin{array}{c}\text { WIDP10 } \\
\text {-IN10 }\end{array}$ & $\begin{array}{l}\text { WIDP10 } \\
\text {-IN11 }\end{array}$ \\
\hline \multicolumn{11}{|c|}{ Major elements (wt\%) } \\
\hline $\mathrm{SiO}_{2}$ & 67.14 & 63.10 & 64.69 & 65.76 & 65.46 & 65.23 & 63.80 & 64.93 & 64.31 & 64.33 \\
\hline $\mathrm{TiO}_{2}$ & 0.85 & 1.06 & 1.28 & 0.91 & 0.97 & 1.40 & 1.01 & 0.86 & 0.92 & 1.08 \\
\hline $\mathrm{Al}_{2} \mathrm{O}_{3}$ & 13.51 & 14.40 & 13.15 & 13.77 & 13.91 & 13.83 & 14.09 & 14.07 & 14.15 & 13.46 \\
\hline $\mathrm{FeO}_{\mathrm{t}}$ & 5.82 & 6.01 & 7.63 & 6.42 & 6.45 & 6.49 & 6.81 & 6.81 & 6.56 & 6.53 \\
\hline $\mathrm{MnO}$ & 0.10 & 0.09 & 0.12 & 0.12 & 0.10 & 0.11 & 0.13 & 0.11 & 0.11 & 0.11 \\
\hline $\mathrm{MgO}$ & 1.64 & 2.59 & 1.99 & 1.76 & 2.10 & 2.23 & 2.24 & 2.21 & 2.26 & 2.04 \\
\hline $\mathrm{CaO}$ & 4.09 & 5.84 & 5.10 & 4.99 & 4.96 & 5.06 & 5.46 & 5.15 & 5.41 & 5.21 \\
\hline $\mathrm{Na}_{2} \mathrm{O}$ & 1.47 & 3.06 & 1.90 & 2.29 & 2.55 & 2.36 & 2.48 & 2.26 & 2.83 & 2.24 \\
\hline $\mathrm{K}_{2} \mathrm{O}$ & 3.59 & 2.63 & 2.78 & 2.82 & 2.89 & 2.99 & 2.53 & 2.63 & 2.70 & 2.71 \\
\hline $\mathrm{P}_{2} \mathrm{O}_{5}$ & 0.02 & nd & 0.01 & 0.01 & nd & 0.02 & nd & nd & 0.00 & nd \\
\hline $\mathrm{Cr}_{2} \mathrm{O}_{3}$ & 0.01 & 0.03 & 0.01 & 0.01 & 0.02 & 0.04 & 0.01 & 0.02 & 0.01 & 0.04 \\
\hline $\mathrm{Cl}(\mathrm{ppm})$ & 1490 & 1340 & 1283 & 1283 & 1274 & 1340 & 1321 & 1611 & 1340 & 1340 \\
\hline $\mathrm{S}(\mathrm{ppm})$ & 100 & 84 & 35 & 84 & 96 & 51 & 318 & 356 & 266 & 152 \\
\hline $\mathrm{H}_{2} \mathrm{O}(\mathrm{wt} \%)$ & na & na & na & na & na & na & na & na & na & na \\
\hline Total & 98.39 & 98.94 & 98.81 & 99.01 & 99.56 & 99.89 & 98.71 & 99.25 & 99.43 & 97.90 \\
\hline $\begin{array}{l}\text { Hosting } \\
\text { phenocryst }\end{array}$ & Cpx & $\mathrm{Cpx}$ & Cpx & Opx & Opx & Opx & Opx & Opx & Opx & Opx \\
\hline \multicolumn{11}{|c|}{ Trace elements (ppm) } \\
\hline $\mathrm{Li}$ & nd & 24.75 & 17.15 & 22.40 & 27.06 & 23.20 & 22.88 & 25.18 & 24.66 & 22.12 \\
\hline B & nd & 38.92 & 33.09 & 32.75 & 41.85 & 36.21 & 33.11 & 32.01 & 31.71 & 31.38 \\
\hline $\mathrm{Sc}$ & nd & 31.56 & 78.23 & 30.34 & 30.51 & 34.67 & 34.80 & 30.26 & 29.83 & 36.38 \\
\hline $\mathrm{Ti}$ & nd & 6216.19 & 7366.77 & 4519.55 & 5810.20 & 6950.62 & 7005.89 & 5371.21 & 5524.57 & 6054.79 \\
\hline $\mathrm{V}$ & nd & 251.26 & 444.41 & 223.25 & 251.14 & 276.51 & 303.42 & 263.91 & 260.89 & 276.99 \\
\hline $\mathrm{Cr}$ & nd & 43.90 & 157.70 & 150.53 & 14.58 & 167.75 & 34.63 & 9.74 & 17.82 & 183.46 \\
\hline $\mathrm{Mn}$ & nd & 733.43 & 1504.96 & 1018.13 & 766.30 & 1353.95 & 891.77 & 811.69 & 810.58 & 1249.13 \\
\hline Co & nd & 16.79 & 30.99 & 31.53 & 16.18 & 34.61 & 17.55 & 17.16 & 17.14 & 34.60 \\
\hline $\mathrm{Ni}$ & nd & 29.46 & 78.66 & 87.43 & 15.94 & 100.28 & 19.93 & 16.36 & 15.90 & 89.86 \\
\hline $\mathrm{Cu}$ & nd & 158.24 & 107.70 & 129.02 & 155.71 & 125.54 & 141.90 & 79.44 & 166.25 & 118.70 \\
\hline $\mathrm{Zn}$ & nd & 60.75 & 63.41 & 74.00 & 72.99 & 88.73 & 72.20 & 74.63 & 51.80 & 80.09 \\
\hline $\mathrm{Ga}$ & nd & 180.75 & 160.44 & 155.80 & 203.89 & 165.23 & 201.48 & 219.39 & 177.37 & 165.62 \\
\hline As & nd & 3.56 & 4.91 & 2.80 & 4.94 & 5.19 & 2.81 & 5.33 & 4.96 & 2.83 \\
\hline $\mathrm{Se}$ & nd & nd & nd & nd & nd & nd & nd & nd & nd & nd \\
\hline $\mathrm{Rb}$ & nd & 76.82 & 63.00 & 73.15 & 88.74 & 77.25 & 69.22 & 82.18 & 82.78 & 73.22 \\
\hline $\mathrm{Sr}$ & nd & 173.16 & 125.91 & 125.08 & 156.54 & 128.91 & 251.65 & 222.65 & 191.26 & 148.56 \\
\hline Mo & nd & 1.27 & 1.56 & 1.20 & 1.43 & 0.66 & 1.65 & 1.14 & 1.02 & 1.40 \\
\hline $\mathrm{Ag}$ & nd & nd & nd & nd & nd & nd & nd & nd & 0.45 & 0.33 \\
\hline $\mathrm{Cd}$ & nd & nd & nd & nd & nd & 0.13 & nd & nd & nd & nd \\
\hline $\mathrm{Sn}$ & nd & 1.90 & 3.42 & 1.55 & 0.99 & nd & nd & 3.27 & 0.04 & nd \\
\hline $\mathrm{Sb}$ & nd & 0.29 & 0.27 & nd & 0.75 & nd & 0.76 & nd & nd & $\mathrm{nd}$ \\
\hline $\mathrm{Ba}$ & nd & 895.04 & 843.48 & 809.64 & 1032.51 & 898.91 & 1020.01 & 1136.88 & 875.98 & 890.52 \\
\hline $\mathrm{Yb}$ & nd & 2.79 & 3.37 & 2.18 & 2.76 & 2.83 & 4.37 & 3.90 & 4.60 & 3.77 \\
\hline $\mathrm{W}$ & nd & 1.74 & 1.62 & 1.57 & 1.34 & 1.08 & 1.48 & 1.59 & 1.28 & 1.72 \\
\hline $\operatorname{Re}$ & nd & nd & nd & nd & nd & nd & 0.95 & nd & nd & nd \\
\hline $\mathrm{Au}$ & nd & 0.45 & nd & nd & nd & nd & nd & nd & nd & nd \\
\hline $\mathrm{Tl}$ & nd & 0.30 & 0.02 & nd & 0.39 & 0.34 & 0.45 & 0.33 & 0.36 & nd \\
\hline $\mathrm{Pb}$ & nd & 10.72 & 9.17 & 10.43 & 12.71 & 11.29 & 13.51 & 13.18 & 12.03 & 9.70 \\
\hline $\mathrm{Bi}$ & nd & 0.16 & nd & nd & nd & 0.16 & nd & 0.09 & 0.18 & nd \\
\hline $\mathrm{U}$ & nd & 1.84 & 1.46 & 1.53 & 2.18 & 1.90 & 1.75 & 2.06 & 1.97 & 2.18 \\
\hline
\end{tabular}


Table A-2 (continued)

\begin{tabular}{|c|c|c|c|c|c|c|c|c|c|c|}
\hline & $\begin{array}{l}\text { WIDP1 } \\
\text { 0-IN12 }\end{array}$ & $\begin{array}{c}\text { WIDP10 } \\
\text {-IN13 }\end{array}$ & $\begin{array}{l}\text { WIDP10 } \\
\text {-IN14 }\end{array}$ & $\begin{array}{l}\text { WIDP10 } \\
\text {-IN15 }\end{array}$ & $\begin{array}{c}\text { WIDP10 } \\
\text {-IN16 }\end{array}$ & $\begin{array}{l}\text { WIDP10 } \\
\text {-IN18 }\end{array}$ & $\begin{array}{c}\text { WIDP10 } \\
\text {-IN19 }\end{array}$ & $\begin{array}{l}\text { WIDP10 } \\
\text {-IN20 }\end{array}$ & $\begin{array}{c}\text { WIDP10 } \\
\text {-IN21 }\end{array}$ & $\begin{array}{c}\text { WIDP10 } \\
\text {-IN22 }\end{array}$ \\
\hline \multicolumn{11}{|c|}{ Major elements (wt\%) } \\
\hline $\mathrm{SiO}_{2}$ & 65.05 & 65.56 & 65.96 & 65.20 & 63.59 & 63.92 & 64.27 & 63.34 & 63.58 & 64.35 \\
\hline $\mathrm{TiO}_{2}$ & 0.91 & 0.92 & 0.86 & 0.86 & 1.29 & 1.32 & 1.35 & 0.88 & 0.91 & 1.04 \\
\hline $\mathrm{Al}_{2} \mathrm{O}_{3}$ & 13.74 & 13.84 & 13.60 & 13.93 & 14.41 & 14.47 & 14.38 & 13.80 & 13.62 & 14.14 \\
\hline $\mathrm{FeO}_{\mathrm{t}}$ & 6.48 & 6.39 & 6.21 & 6.69 & 6.02 & 5.91 & 6.00 & 7.29 & 7.43 & 6.42 \\
\hline $\mathrm{MnO}$ & 0.12 & 0.10 & 0.10 & 0.12 & 0.10 & 0.12 & 0.09 & 0.12 & 0.12 & 0.09 \\
\hline $\mathrm{MgO}$ & 2.03 & 1.97 & 1.89 & 1.97 & 2.11 & 2.22 & 2.35 & 2.29 & 2.29 & 2.01 \\
\hline $\mathrm{CaO}$ & 4.85 & 4.75 & 4.56 & 4.98 & 5.40 & 5.33 & 5.33 & 5.97 & 5.84 & 5.32 \\
\hline $\mathrm{Na}_{2} \mathrm{O}$ & 2.44 & 2.45 & 2.56 & 2.09 & 2.71 & 2.15 & 1.68 & 2.59 & 2.58 & 2.94 \\
\hline $\mathrm{K}_{2} \mathrm{O}$ & 2.91 & 2.97 & 3.14 & 2.85 & 2.77 & 2.86 & 2.87 & 2.26 & 2.24 & 2.92 \\
\hline $\mathrm{P}_{2} \mathrm{O}_{5}$ & 0.06 & 0.01 & 0.08 & 0.01 & 0.12 & 0.16 & 0.09 & nd & nd & nd \\
\hline $\mathrm{Cr}_{2} \mathrm{O}_{3}$ & 0.02 & 0.01 & 0.00 & 0.00 & 0.00 & 0.02 & 0.03 & 0.01 & 0.04 & 0.01 \\
\hline $\mathrm{Cl}(\mathrm{ppm})$ & 1269 & 1226 & 1250 & 1345 & 1350 & 1264 & 1283 & 1521 & 1559 & 1440 \\
\hline $\mathrm{S}(\mathrm{ppm})$ & 182 & 184 & 119 & 298 & 97 & 85 & 96 & 375 & 467 & 120 \\
\hline $\mathrm{H}_{2} \mathrm{O}(\mathrm{wt} \%)$ & na & na & na & na & na & na & na & na & na & na \\
\hline Total & 98.75 & 99.11 & 99.10 & 98.86 & 98.67 & 98.63 & 98.58 & 98.73 & 98.86 & 99.40 \\
\hline $\begin{array}{l}\text { Hosting } \\
\text { phenocryst }\end{array}$ & Opx & Opx & Opx & Opx & $\mathrm{Pla}$ & Pla & Pla & Cpx & Cpx & Opx \\
\hline \multicolumn{11}{|c|}{ Trace elements (ppm) } \\
\hline $\mathrm{Li}$ & 24.59 & 24.54 & 25.33 & 24.86 & 24.39 & 21.57 & 23.06 & 25.83 & 24.60 & 23.18 \\
\hline $\mathrm{B}$ & 41.98 & 38.15 & 44.12 & 40.15 & 48.91 & 41.73 & 37.81 & 32.83 & 32.01 & 42.51 \\
\hline $\mathrm{Sc}$ & 31.35 & 27.88 & 24.16 & 26.89 & 28.66 & 26.22 & 25.86 & 33.38 & 34.07 & 27.84 \\
\hline $\mathrm{Ti}$ & 6114.09 & 5436.94 & 4922.05 & 4727.33 & 7387.82 & 7007.24 & 7530.31 & 4967.95 & 5299.68 & 6086.04 \\
\hline V & 248.51 & 234.51 & 204.26 & 218.83 & 279.20 & 266.59 & 267.06 & 191.89 & 222.00 & 248.25 \\
\hline $\mathrm{Cr}$ & 12.36 & 15.66 & 8.67 & 24.37 & 16.85 & 8.46 & 11.69 & 16.61 & 11.15 & 91.14 \\
\hline $\mathrm{Mn}$ & 797.05 & 815.32 & 699.58 & 795.36 & 730.02 & 661.04 & 701.76 & 874.22 & 900.64 & 823.32 \\
\hline Co & 16.14 & 20.04 & 15.79 & 17.94 & 16.28 & 15.05 & 15.18 & 17.24 & 17.44 & 22.06 \\
\hline $\mathrm{Ni}$ & 14.87 & 25.72 & 12.81 & 26.59 & 28.45 & 26.92 & 22.49 & 15.45 & 12.68 & 55.55 \\
\hline $\mathrm{Cu}$ & 122.03 & 135.59 & 151.14 & 141.00 & 155.48 & 144.42 & 142.27 & 118.27 & 73.12 & 161.58 \\
\hline $\mathrm{Zn}$ & 69.02 & 77.75 & 65.95 & 79.04 & 64.77 & 59.05 & 56.29 & 71.31 & 88.33 & 72.59 \\
\hline $\mathrm{Ga}$ & 228.47 & 199.51 & 194.12 & 194.07 & 187.57 & 185.11 & 195.56 & 140.06 & 157.71 & 182.25 \\
\hline As & 4.40 & 5.04 & 5.49 & 4.48 & 6.37 & 4.90 & 4.94 & 4.96 & 3.38 & 4.62 \\
\hline $\mathrm{Se}$ & nd & nd & nd & nd & $\mathrm{nd}$ & nd & nd & nd & nd & nd \\
\hline $\mathrm{Rb}$ & 85.38 & 88.43 & 92.68 & 80.33 & 72.58 & 71.74 & 69.90 & 61.92 & 56.47 & 84.79 \\
\hline $\mathrm{Sr}$ & 176.82 & 179.32 & 144.08 & 159.39 & 158.16 & 169.69 & 198.79 & 156.70 & 172.97 & 141.17 \\
\hline Mo & 1.34 & 1.81 & 0.93 & 1.40 & 1.64 & 1.53 & 1.72 & 0.91 & 1.78 & 1.35 \\
\hline $\mathrm{Ag}$ & nd & nd & nd & nd & nd & nd & nd & nd & 0.34 & nd \\
\hline $\mathrm{Cd}$ & nd & nd & nd & nd & 0.88 & nd & nd & nd & nd & nd \\
\hline Sn & 3.67 & 1.25 & nd & 2.00 & 0.58 & nd & nd & 2.90 & 1.69 & 2.19 \\
\hline $\mathrm{Sb}$ & nd & 0.37 & nd & nd & nd & 0.33 & nd & nd & 1.55 & nd \\
\hline $\mathrm{Ba}$ & 1247.29 & 1041.62 & 991.23 & 1008.91 & 972.79 & 930.38 & 971.18 & 710.33 & 748.24 & 929.36 \\
\hline $\mathrm{Yb}$ & 2.64 & 2.60 & 2.15 & 2.61 & 4.06 & 2.71 & 2.58 & 2.75 & 3.47 & 3.26 \\
\hline W & 0.94 & 1.39 & 1.33 & 1.30 & 1.50 & 2.46 & 1.44 & 1.04 & 1.20 & 2.05 \\
\hline $\mathrm{Re}$ & nd & nd & nd & nd & 0.20 & nd & nd & 0.83 & nd & nd \\
\hline $\mathrm{Au}$ & nd & nd & 0.44 & nd & $\mathrm{nd}$ & nd & 0.32 & 0.33 & nd & nd \\
\hline $\mathrm{Tl}$ & 0.21 & 0.72 & 0.17 & 0.45 & 0.61 & 0.49 & nd & nd & nd & 0.29 \\
\hline $\mathrm{Pb}$ & 14.13 & 11.72 & 12.30 & 11.76 & 12.60 & 11.53 & 11.94 & 9.37 & 11.13 & 11.15 \\
\hline $\mathrm{Bi}$ & nd & 0.07 & 0.04 & 0.16 & nd & 0.17 & 0.22 & 0.36 & nd & 0.31 \\
\hline $\mathrm{U}$ & 2.13 & 1.89 & 2.07 & 2.09 & 2.47 & 2.27 & 2.55 & 1.98 & 1.67 & 1.69 \\
\hline
\end{tabular}


Table A-2 (continued)

\begin{tabular}{|c|c|c|c|c|c|c|c|c|c|c|}
\hline & $\begin{array}{l}\text { WIDP1 } \\
0-I N 23\end{array}$ & $\begin{array}{c}\text { WIDP10 } \\
\text {-IN24 }\end{array}$ & $\begin{array}{l}\text { WIDP10 } \\
\text {-IN25 }\end{array}$ & $\begin{array}{l}\text { WIDP10 } \\
\text {-IN26- } \\
\text { R2 }\end{array}$ & $\begin{array}{l}\text { WIDP10 } \\
\text { - Matrix } \\
\text { glass }\end{array}$ & $\begin{array}{l}\text { WIDP10 } \\
\text { _ Glass } \\
\text { around } \\
\text { Sulfide }\end{array}$ & $\begin{array}{c}\text { WIDP11 } \\
\text {-IN01 }\end{array}$ & $\begin{array}{l}\text { WIDP11 } \\
\text {-IN02 }\end{array}$ & $\begin{array}{l}\text { WIDP11 } \\
\text {-IN03 }\end{array}$ & $\begin{array}{l}\text { WIDP11 } \\
\text {-IN05 }\end{array}$ \\
\hline \multicolumn{11}{|c|}{ Major elements (wt\%) } \\
\hline $\mathrm{SiO}_{2}$ & 63.79 & 63.10 & 62.91 & 54.88 & 63.38 & 63.39 & 65.51 & 65.13 & 67.43 & 63.35 \\
\hline $\mathrm{TiO}_{2}$ & 0.89 & 1.32 & 1.33 & 2.52 & 1.04 & 0.89 & 0.94 & 0.79 & 0.83 & 1.17 \\
\hline $\mathrm{Al}_{2} \mathrm{O}_{3}$ & 14.34 & 14.28 & 14.21 & 14.95 & 14.62 & 14.47 & 14.53 & 14.56 & 13.61 & 13.12 \\
\hline $\mathrm{FeO}_{\mathrm{t}}$ & 6.93 & 6.90 & 6.70 & 9.05 & 5.95 & 5.94 & 5.44 & 5.70 & 5.57 & 8.51 \\
\hline $\mathrm{MnO}$ & 0.09 & 0.11 & 0.10 & 0.16 & 0.09 & na & 0.10 & 0.08 & 0.07 & 0.15 \\
\hline $\mathrm{MgO}$ & 2.19 & 2.56 & 2.49 & 4.45 & 2.75 & 2.65 & 1.86 & 1.81 & 1.60 & 1.98 \\
\hline $\mathrm{CaO}$ & 5.64 & 5.32 & 5.24 & 8.01 & 5.87 & 5.89 & 4.93 & 5.07 & 4.09 & 5.38 \\
\hline $\mathrm{Na}_{2} \mathrm{O}$ & 2.12 & 2.36 & 2.28 & 2.41 & 3.21 & 3.12 & 2.98 & 2.82 & 2.17 & 2.62 \\
\hline $\mathrm{K}_{2} \mathrm{O}$ & 2.69 & 2.78 & 2.82 & 2.29 & 2.66 & 2.39 & 2.90 & 2.81 & 3.56 & 2.49 \\
\hline $\mathrm{P}_{2} \mathrm{O}_{5}$ & 0.00 & 0.03 & 0.06 & 1.39 & 0.04 & na & 0.05 & nd & 0.01 & nd \\
\hline $\mathrm{Cr}_{2} \mathrm{O}_{3}$ & 0.00 & 0.01 & nd & 0.00 & 0.03 & na & 0.03 & 0.01 & 0.02 & 0.06 \\
\hline $\mathrm{Cl}$ (ppm) & 1347 & 1606 & 1502 & 3938 & 998 & 825 & 1117 & 1226 & 1768 & 1202 \\
\hline S (ppm) & 110 & 111 & 69 & 630 & 71 & 27 & 92 & 29 & 147 & 290 \\
\hline $\mathrm{H}_{2} \mathrm{O}(\mathrm{wt} \%)$ & na & na & na & na & na & na & na & na & na & na \\
\hline Total & 98.84 & 98.94 & 98.30 & 98.71 & 99.76 & 98.83 & 99.40 & 98.92 & 99.15 & 98.99 \\
\hline $\begin{array}{l}\text { Hosting } \\
\text { phenocryst }\end{array}$ & Opx & Pla & Pla & $\mathrm{Ol}$ & & & Pla & Pla & Opx & $\mathrm{Cpx}$ \\
\hline \multicolumn{11}{|c|}{ Trace elements (ppm) } \\
\hline $\mathrm{Li}$ & 22.02 & 23.77 & 24.06 & 24.68 & 25.21 & na & 23.08 & 23.24 & 25.45 & 23.61 \\
\hline B & 32.60 & 46.40 & 46.34 & 192.77 & 37.49 & na & 35.63 & 22.78 & 42.01 & 36.42 \\
\hline $\mathrm{Sc}$ & 41.12 & 31.64 & 32.65 & 30.73 & 27.42 & na & 20.20 & 33.83 & 26.47 & 36.51 \\
\hline $\mathrm{Ti}$ & 5029.04 & 7195.51 & 8017.61 & $\begin{array}{r}13364.0 \\
7\end{array}$ & 6203.33 & na & 5775.49 & 5042.34 & 5167.94 & 7566.55 \\
\hline $\mathrm{V}$ & 258.61 & 323.62 & 322.66 & 338.11 & 250.73 & na & 176.25 & 281.76 & 207.11 & 353.31 \\
\hline $\mathrm{Cr}$ & 282.61 & 3.87 & 17.84 & 87.08 & 37.16 & na & 11.02 & 14.25 & 14.04 & 11.45 \\
\hline $\mathrm{Mn}$ & 1280.92 & 829.14 & 796.15 & 1027.05 & 749.26 & na & 679.62 & 768.17 & 670.38 & 1090.64 \\
\hline Co & 32.65 & 18.19 & 17.74 & 24.36 & 17.52 & na & 13.17 & 17.19 & 14.86 & 18.87 \\
\hline $\mathrm{Ni}$ & 99.90 & 24.50 & 26.60 & 63.46 & 29.93 & na & 22.63 & 22.02 & 22.27 & 8.42 \\
\hline $\mathrm{Cu}$ & 137.30 & 171.60 & 160.31 & 110.31 & 150.88 & na & 136.87 & 155.96 & 128.86 & 64.86 \\
\hline $\mathrm{Zn}$ & 87.27 & 71.51 & 72.35 & 82.98 & 80.44 & na & 60.91 & 72.45 & 61.72 & 98.45 \\
\hline $\mathrm{Ga}$ & 175.03 & 196.01 & 204.61 & 374.43 & 171.37 & na & 190.52 & 185.59 & 180.71 & 170.85 \\
\hline As & 3.75 & 6.84 & 6.64 & 20.98 & 4.18 & na & 4.94 & 2.10 & 5.08 & 5.48 \\
\hline $\mathrm{Se}$ & nd & nd & nd & nd & nd & na & nd & nd & nd & nd \\
\hline $\mathrm{Rb}$ & 62.26 & 87.26 & 86.83 & 138.76 & 79.81 & na & 58.15 & 70.25 & 107.27 & 83.59 \\
\hline $\mathrm{Sr}$ & 165.86 & 156.32 & 164.51 & 200.51 & 169.99 & na & 181.13 & 172.38 & 132.91 & 166.80 \\
\hline Mo & 1.06 & 1.29 & 1.86 & 10.17 & 1.40 & na & 1.73 & 0.39 & 1.22 & 1.10 \\
\hline $\mathrm{Ag}$ & 0.18 & nd & 0.60 & nd & nd & na & nd & 0.74 & 0.26 & 0.13 \\
\hline $\mathrm{Cd}$ & nd & nd & nd & nd & nd & na & nd & nd & nd & nd \\
\hline Sn & 3.18 & 1.16 & nd & nd & 1.73 & na & 0.22 & 2.24 & nd & 2.08 \\
\hline $\mathrm{Sb}$ & 0.56 & nd & nd & 2.72 & 2.68 & na & 0.31 & 0.65 & 0.49 & 0.63 \\
\hline $\mathrm{Ba}$ & 1016.24 & 1019.16 & 1113.67 & 1952.98 & 932.75 & na & 1080.52 & 1008.91 & 1010.83 & 981.22 \\
\hline $\mathrm{Yb}$ & 4.44 & 2.88 & 4.17 & 4.59 & 2.50 & na & 4.11 & 3.73 & 2.79 & 5.41 \\
\hline W & 1.50 & 2.16 & 2.42 & 10.41 & 1.23 & na & 1.42 & 0.65 & 2.40 & 1.44 \\
\hline $\operatorname{Re}$ & nd & 0.16 & nd & nd & 0.24 & na & nd & nd & nd & nd \\
\hline $\mathrm{Au}$ & nd & nd & nd & nd & nd & na & nd & nd & nd & nd \\
\hline $\mathrm{Tl}$ & 0.63 & 0.20 & 0.23 & 0.36 & 0.36 & na & 0.36 & 0.27 & 0.43 & 0.25 \\
\hline $\mathrm{Pb}$ & 12.03 & 11.99 & 12.29 & 17.91 & 10.52 & na & 11.14 & 11.41 & 12.45 & 12.15 \\
\hline $\mathrm{Bi}$ & 0.28 & 0.21 & 0.26 & 0.58 & 0.11 & na & 0.16 & 0.16 & 0.10 & nd \\
\hline $\mathrm{U}$ & 2.19 & 2.75 & 2.39 & 8.84 & 1.69 & na & 2.56 & 1.09 & 2.10 & 2.09 \\
\hline
\end{tabular}


Table A-2 (continued)

\begin{tabular}{|c|c|c|c|c|c|c|c|c|c|c|}
\hline & $\begin{array}{l}\text { WIDP1 } \\
\text { 1-IN06 }\end{array}$ & $\begin{array}{l}\text { WIDP11 } \\
\text {-IN07 }\end{array}$ & $\begin{array}{c}\text { WIDP11 } \\
\text {-IN08 }\end{array}$ & $\begin{array}{l}\text { WIDP11 } \\
\text {-IN09 }\end{array}$ & $\begin{array}{l}\text { WIDP11 } \\
\text {-IN10 }\end{array}$ & $\begin{array}{c}\text { WIDP11 } \\
\text {-IN11 }\end{array}$ & $\begin{array}{l}\text { WIDP11 } \\
\text {-IN13 }\end{array}$ & $\begin{array}{l}\text { WIDP11 } \\
\text {-IN14 }\end{array}$ & $\begin{array}{l}\text { WIDP11 } \\
\text {-IN15 }\end{array}$ & $\begin{array}{l}\text { WIDP11 } \\
\text { - Matrix } \\
\text { glass }\end{array}$ \\
\hline \multicolumn{11}{|c|}{ Major elements (wt\%) } \\
\hline $\mathrm{SiO}_{2}$ & 63.91 & 63.64 & 64.00 & 63.33 & 63.97 & 64.60 & 64.55 & 64.91 & 65.14 & 63.18 \\
\hline $\mathrm{TiO}_{2}$ & 1.19 & 1.12 & 1.08 & 1.14 & 0.99 & 1.24 & 0.98 & 1.30 & 1.05 & 0.96 \\
\hline $\mathrm{Al}_{2} \mathrm{O}_{3}$ & 13.55 & 13.47 & 14.40 & 14.32 & 14.41 & 13.48 & 14.45 & 12.74 & 13.79 & 14.62 \\
\hline $\mathrm{FeO}_{\mathrm{t}}$ & 7.93 & 8.03 & 6.28 & 6.29 & 6.26 & 7.48 & 5.91 & 7.30 & 6.50 & 6.15 \\
\hline $\mathrm{MnO}$ & 0.13 & 0.15 & 0.11 & 0.12 & 0.08 & 0.13 & 0.12 & 0.15 & 0.11 & 0.11 \\
\hline $\mathrm{MgO}$ & 1.92 & 1.93 & 2.17 & 2.20 & 2.13 & 1.88 & 1.94 & 1.93 & 1.97 & 2.55 \\
\hline $\mathrm{CaO}$ & 5.23 & 5.47 & 5.27 & 5.38 & 5.26 & 5.56 & 5.00 & 5.19 & 4.86 & 5.95 \\
\hline $\mathrm{Na}_{2} \mathrm{O}$ & 2.55 & 2.92 & 2.38 & 2.44 & 2.96 & 1.70 & 3.15 & 2.75 & 1.96 & 3.18 \\
\hline $\mathrm{K}_{2} \mathrm{O}$ & 2.52 & 2.53 & 2.70 & 2.58 & 2.67 & 2.45 & 2.72 & 2.49 & 2.72 & 2.42 \\
\hline $\mathrm{P}_{2} \mathrm{O}_{5}$ & nd & nd & nd & nd & 0.03 & 0.00 & 0.05 & 0.02 & 0.02 & 0.07 \\
\hline $\mathrm{Cr}_{2} \mathrm{O}_{3}$ & 0.03 & 0.01 & 0.00 & nd & 0.05 & nd & 0.04 & 0.02 & 0.03 & 0.03 \\
\hline $\mathrm{Cl}(\mathrm{ppm})$ & 1255 & 1112 & 1402 & 1393 & 1426 & 1433 & 1260 & 1219 & 1450 & 977 \\
\hline $\mathrm{S}$ (ppm) & 124 & 83 & 108 & 125 & 59 & 268 & 52 & 166 & 37 & 55 \\
\hline $\mathrm{H}_{2} \mathrm{O}(\mathrm{wt} \%)$ & na & na & na & na & na & na & na & na & na & na \\
\hline Total & 99.09 & 99.39 & 98.54 & 97.95 & 98.96 & 98.69 & 99.05 & 98.94 & 98.29 & 99.33 \\
\hline $\begin{array}{l}\text { Hosting } \\
\text { phenocryst }\end{array}$ & Cpx & Cpx & Pla & Pla & $\mathrm{Pla}$ & Cpx & Pla & Cpx & Cpx & \\
\hline \multicolumn{11}{|c|}{ Trace elements (ppm) } \\
\hline $\mathrm{Li}$ & 25.05 & 26.04 & 25.02 & 21.32 & 23.84 & 24.71 & 23.41 & 23.71 & 25.13 & 24.93 \\
\hline B & 37.20 & 35.75 & 46.02 & 46.05 & 42.69 & 37.49 & 36.97 & 36.77 & 43.84 & 38.85 \\
\hline $\mathrm{Sc}$ & 36.92 & 37.25 & 30.59 & 35.67 & 29.38 & 28.74 & 22.85 & 43.98 & 33.16 & 28.09 \\
\hline $\mathrm{Ti}$ & 7243.94 & 7314.96 & 6368.33 & 7562.12 & 6502.85 & 8292.01 & 6534.22 & 8336.20 & 6835.10 & 6143.42 \\
\hline V & 353.38 & 338.73 & 269.42 & 312.72 & 267.77 & 342.72 & 235.69 & 365.93 & 284.20 & 253.88 \\
\hline $\mathrm{Cr}$ & 38.14 & 4.89 & 20.60 & 20.49 & 17.09 & 14.74 & 18.38 & 5.17 & 6.15 & 41.22 \\
\hline $\mathrm{Mn}$ & 981.36 & 959.32 & 770.41 & 813.89 & 759.29 & 848.15 & 744.62 & 914.75 & 787.15 & 756.24 \\
\hline Co & 19.08 & 17.51 & 16.92 & 15.97 & 17.49 & 15.78 & 14.77 & 18.20 & 16.01 & 17.64 \\
\hline $\mathrm{Ni}$ & 17.72 & 8.83 & 31.33 & 25.83 & 29.03 & 6.31 & 26.37 & 11.38 & 11.74 & 31.36 \\
\hline $\mathrm{Cu}$ & 139.09 & 154.82 & 146.86 & 147.86 & 150.24 & 57.58 & 145.23 & 87.85 & 122.28 & 142.53 \\
\hline $\mathrm{Zn}$ & 90.33 & 89.06 & 62.48 & 65.78 & 70.56 & 69.68 & 66.53 & 76.50 & 69.44 & 64.72 \\
\hline $\mathrm{Ga}$ & 170.32 & 168.81 & 172.94 & 193.68 & 185.87 & 180.32 & 178.57 & 173.90 & 202.59 & 164.18 \\
\hline As & 5.16 & 4.70 & 5.20 & 6.03 & 5.86 & 4.18 & 5.40 & 4.98 & 5.60 & 4.27 \\
\hline $\mathrm{Se}$ & nd & nd & nd & nd & $\mathrm{nd}$ & nd & nd & nd & nd & 2.18 \\
\hline $\mathrm{Rb}$ & 75.31 & 77.43 & 98.01 & 96.85 & 97.26 & 82.18 & 77.25 & 85.02 & 87.73 & 77.38 \\
\hline $\mathrm{Sr}$ & 155.82 & 162.50 & 148.90 & 162.17 & 161.13 & 197.60 & 161.62 & 135.62 & 182.82 & 172.68 \\
\hline Mo & 1.36 & 1.32 & 1.27 & 1.38 & 1.25 & 1.45 & 1.63 & 1.10 & 1.47 & 1.22 \\
\hline $\mathrm{Ag}$ & nd & nd & 0.43 & nd & nd & nd & nd & nd & nd & nd \\
\hline $\mathrm{Cd}$ & nd & nd & nd & nd & nd & nd & 0.47 & nd & nd & 0.21 \\
\hline Sn & 1.19 & 2.09 & nd & 0.98 & 2.19 & 1.27 & nd & 2.84 & 4.31 & 1.69 \\
\hline $\mathrm{Sb}$ & 0.79 & nd & 0.99 & 0.57 & 0.43 & 0.62 & 0.40 & 0.40 & 0.38 & 0.57 \\
\hline $\mathrm{Ba}$ & 943.19 & 947.31 & 1016.10 & 1133.09 & 1016.82 & 1019.70 & 1031.05 & 977.84 & 1203.25 & 924.30 \\
\hline $\mathrm{Yb}$ & 3.49 & 4.38 & 2.93 & 3.76 & 4.08 & 5.12 & 2.95 & 5.98 & 2.29 & 3.03 \\
\hline W & 1.43 & 1.14 & 1.74 & 1.17 & 1.28 & 1.17 & 1.57 & 1.40 & 1.41 & 1.24 \\
\hline $\mathrm{Re}$ & nd & nd & nd & nd & nd & nd & nd & 0.27 & nd & 0.17 \\
\hline $\mathrm{Au}$ & nd & nd & nd & nd & 0.48 & nd & nd & nd & nd & 0.30 \\
\hline $\mathrm{Tl}$ & 0.36 & 0.46 & 0.42 & 0.26 & 0.20 & 0.44 & 0.27 & 0.47 & 0.48 & 0.33 \\
\hline $\mathrm{Pb}$ & 13.01 & 11.91 & 12.36 & 14.20 & 13.88 & 14.85 & 11.34 & 11.68 & 14.48 & 10.99 \\
\hline $\mathrm{Bi}$ & nd & 0.14 & nd & 0.29 & nd & 0.16 & nd & 0.15 & 0.17 & 0.15 \\
\hline $\mathrm{U}$ & 2.00 & 1.95 & 1.87 & 1.89 & 1.92 & 2.58 & 2.45 & 2.06 & 2.75 & 1.62 \\
\hline
\end{tabular}


Table A-2 (continued)

\begin{tabular}{|c|c|c|c|c|c|c|c|c|c|c|}
\hline & $\begin{array}{l}\text { WIDP1 } \\
\text { 3-IN03 }\end{array}$ & $\begin{array}{c}\text { WIDP13 } \\
\text {-IN04 }\end{array}$ & $\begin{array}{l}\text { WIDP13 } \\
\text {-IN05 }\end{array}$ & $\begin{array}{l}\text { WIDP13 } \\
\text {-IN06 }\end{array}$ & $\begin{array}{c}\text { WIDP13 } \\
\text {-IN07 }\end{array}$ & $\begin{array}{l}\text { WIDP13 } \\
\text {-IN08 }\end{array}$ & $\begin{array}{c}\text { WIDP13 } \\
\text {-IN09 }\end{array}$ & $\begin{array}{l}\text { WIDP13 } \\
\text {-IN10 }\end{array}$ & $\begin{array}{c}\text { WIDP13 } \\
\text {-IN13 }\end{array}$ & $\begin{array}{c}\text { WIDP13 } \\
\text {-IN14 }\end{array}$ \\
\hline \multicolumn{11}{|c|}{ Major elements (wt\%) } \\
\hline $\mathrm{SiO}_{2}$ & 67.03 & 66.11 & 66.07 & 66.56 & 62.58 & 65.68 & 66.17 & 64.94 & 65.14 & 65.26 \\
\hline $\mathrm{TiO}_{2}$ & 1.00 & 1.08 & 1.02 & 1.02 & 1.66 & 1.00 & 1.04 & 1.08 & 1.02 & 0.91 \\
\hline $\mathrm{Al}_{2} \mathrm{O}_{3}$ & 14.25 & 13.83 & 14.40 & 14.41 & 12.45 & 14.38 & 14.66 & 12.65 & 14.22 & 13.31 \\
\hline $\mathrm{FeO}_{\mathrm{t}}$ & 5.08 & 5.87 & 5.21 & 5.48 & 7.88 & 5.64 & 5.43 & 6.82 & 5.68 & 6.53 \\
\hline $\mathrm{MnO}$ & 0.13 & 0.13 & 0.07 & 0.11 & 0.16 & 0.10 & 0.09 & 0.12 & 0.11 & 0.13 \\
\hline $\mathrm{MgO}$ & 1.14 & 1.32 & 1.39 & 1.25 & 2.71 & 1.42 & 1.25 & 2.35 & 1.65 & 2.21 \\
\hline $\mathrm{CaO}$ & 4.90 & 4.37 & 4.38 & 4.07 & 4.89 & 4.72 & 4.63 & 4.62 & 5.09 & 4.26 \\
\hline $\mathrm{Na}_{2} \mathrm{O}$ & 3.31 & 2.42 & 2.54 & 1.80 & 2.00 & 2.42 & 2.52 & 2.44 & 2.67 & 1.89 \\
\hline $\mathrm{K}_{2} \mathrm{O}$ & 1.98 & 2.58 & 2.61 & 2.70 & 2.70 & 2.63 & 2.60 & 2.89 & 2.58 & 2.98 \\
\hline $\mathrm{P}_{2} \mathrm{O}_{5}$ & 0.03 & nd & nd & 0.03 & 0.25 & 0.03 & 0.03 & 0.01 & 0.03 & nd \\
\hline $\mathrm{Cr}_{2} \mathrm{O}_{3}$ & 0.04 & 0.02 & 0.03 & 0.01 & 0.04 & 0.01 & nd & nd & 0.04 & 0.03 \\
\hline $\mathrm{Cl}(\mathrm{ppm})$ & 1683 & 1645 & 1483 & 1473 & 1804 & 1336 & 1435 & 1533 & 1412 & 1416 \\
\hline $\mathrm{S}(\mathrm{ppm})$ & 1391 & 371 & 113 & 97 & 88 & 67 & 85 & 100 & 87 & 39 \\
\hline $\mathrm{H}_{2} \mathrm{O}(\mathrm{wt} \%)$ & na & na & na & na & na & na & na & na & na & na \\
\hline Total & 99.22 & 97.94 & 97.89 & 97.60 & 97.50 & 98.17 & 98.57 & 98.08 & 98.37 & 97.66 \\
\hline $\begin{array}{l}\text { Hosting } \\
\text { phenocryst }\end{array}$ & Cpx & Cpx & Cpx & Cpx & $\mathrm{Pla}$ & Opx & Opx & Pla & Opx & $\mathrm{Pla}$ \\
\hline \multicolumn{11}{|c|}{ Trace elements (ppm) } \\
\hline $\mathrm{Li}$ & 21.68 & 29.00 & 29.67 & 30.40 & 28.91 & na & na & 35.59 & 24.84 & 33.99 \\
\hline B & 46.68 & 37.21 & 40.01 & 43.24 & 57.73 & na & na & 37.39 & 41.82 & 28.86 \\
\hline $\mathrm{Sc}$ & 33.03 & 37.26 & 27.47 & 28.43 & 37.72 & na & na & 28.64 & 24.65 & 20.61 \\
\hline $\mathrm{Ti}$ & 9575.07 & 6562.68 & 6949.38 & 7262.77 & 9777.56 & na & na & 5963.52 & 6239.37 & 5530.54 \\
\hline V & 353.80 & 295.86 & 266.94 & 264.47 & 401.97 & na & na & 251.32 & 241.43 & 188.44 \\
\hline $\mathrm{Cr}$ & nd & 43.34 & nd & 7.10 & 15.84 & na & na & 23.45 & nd & 21.90 \\
\hline $\mathrm{Mn}$ & 980.29 & 889.13 & 674.62 & 666.38 & 918.61 & na & na & 712.95 & 763.13 & 751.06 \\
\hline Co & 21.08 & 14.65 & 10.46 & 9.23 & 18.77 & na & na & 14.77 & 11.90 & 15.78 \\
\hline $\mathrm{Ni}$ & 57.93 & 15.33 & 4.27 & 1.22 & 34.52 & na & na & 25.90 & 3.89 & 25.49 \\
\hline $\mathrm{Cu}$ & 317.39 & 271.54 & 178.20 & 216.69 & 199.08 & na & na & 205.45 & 162.60 & 284.68 \\
\hline $\mathrm{Zn}$ & 96.19 & 67.10 & 65.23 & 63.48 & 77.66 & na & na & 56.21 & 68.37 & 64.17 \\
\hline $\mathrm{Ga}$ & 203.29 & 179.13 & 205.08 & 212.19 & 201.25 & na & na & 181.96 & 175.36 & 187.51 \\
\hline As & 5.98 & 5.53 & 6.00 & 6.28 & 9.42 & na & na & 4.48 & 4.86 & 3.96 \\
\hline $\mathrm{Se}$ & nd & nd & nd & nd & nd & na & na & nd & nd & nd \\
\hline $\mathrm{Rb}$ & 76.87 & 85.75 & 94.45 & 93.06 & 97.40 & na & na & 86.21 & 90.24 & 68.63 \\
\hline $\mathrm{Sr}$ & 219.43 & 155.23 & 193.24 & 196.61 & 161.42 & na & na & 201.71 & 162.21 & 160.98 \\
\hline Mo & 1.33 & 1.35 & 1.92 & 1.93 & 2.24 & na & na & 0.26 & 1.52 & 0.95 \\
\hline $\mathrm{Ag}$ & nd & nd & nd & 0.78 & $\mathrm{nd}$ & na & na & nd & nd & nd \\
\hline $\mathrm{Cd}$ & nd & nd & nd & nd & nd & na & na & 0.59 & 0.53 & nd \\
\hline $\mathrm{Sn}$ & 2.60 & nd & 2.20 & nd & 2.01 & na & na & nd & 1.45 & nd \\
\hline $\mathrm{Sb}$ & 1.19 & $\mathrm{nd}$ & nd & nd & $\mathrm{nd}$ & na & na & 0.29 & 0.34 & 0.58 \\
\hline $\mathrm{Ba}$ & 1327.59 & 1025.28 & 1144.86 & 1258.62 & 1131.71 & na & na & 994.60 & 924.08 & 1063.56 \\
\hline $\mathrm{Yb}$ & 8.09 & 3.66 & 3.60 & 4.12 & 4.03 & na & na & 3.20 & 3.87 & 2.05 \\
\hline $\mathrm{W}$ & 1.03 & 1.62 & 1.44 & 2.27 & 2.65 & na & na & 0.93 & 1.36 & 1.35 \\
\hline $\mathrm{Re}$ & nd & nd & nd & nd & nd & na & na & nd & nd & nd \\
\hline $\mathrm{Au}$ & nd & 0.15 & nd & 0.21 & nd & na & na & nd & nd & nd \\
\hline $\mathrm{Tl}$ & 0.27 & 0.80 & 0.51 & 0.43 & 0.23 & na & na & 0.30 & 0.23 & 0.37 \\
\hline $\mathrm{Pb}$ & 17.49 & 11.44 & 14.92 & 17.04 & 14.73 & na & na & 11.59 & 12.76 & 11.95 \\
\hline $\mathrm{Bi}$ & nd & nd & nd & nd & 0.17 & na & na & 0.09 & nd & nd \\
\hline $\mathrm{U}$ & 3.29 & 2.09 & 2.16 & 2.67 & 3.31 & na & na & 1.76 & 1.93 & 1.46 \\
\hline
\end{tabular}


Table A-2 (continued)

\begin{tabular}{|c|c|c|c|c|c|c|c|c|c|c|}
\hline & $\begin{array}{l}\text { WIDP1 } \\
\text { 3-IN17 }\end{array}$ & $\begin{array}{l}\text { WIDP13 } \\
\text {-IN18 }\end{array}$ & $\begin{array}{l}\text { WIDP13 } \\
\text { - Matrix } \\
\text { glass }\end{array}$ & $\begin{array}{l}\text { WIDP9- } \\
\text { IN01 }\end{array}$ & $\begin{array}{c}\text { WIDP9- } \\
\text { IN02 }\end{array}$ & $\begin{array}{l}\text { WIDP9- } \\
\text { IN03 }\end{array}$ & $\begin{array}{l}\text { WIDP9- } \\
\text { IN04 }\end{array}$ & $\begin{array}{l}\text { WIDP9- } \\
\text { IN05 }\end{array}$ & $\begin{array}{l}\text { WIDP9- } \\
\text { IN06 }\end{array}$ & $\begin{array}{l}\text { WIDP9- } \\
\text { IN08 }\end{array}$ \\
\hline \multicolumn{11}{|c|}{ Major elements (wt\%) } \\
\hline $\mathrm{SiO}_{2}$ & 65.40 & 65.80 & 66.90 & 65.66 & 66.38 & 63.88 & 66.32 & 65.51 & 64.96 & 67.96 \\
\hline $\mathrm{TiO}_{2}$ & 1.15 & 1.08 & 1.23 & 1.02 & 0.94 & 1.04 & 1.04 & 0.92 & 0.97 & 0.93 \\
\hline $\mathrm{Al}_{2} \mathrm{O}_{3}$ & 14.72 & 14.63 & 13.62 & 14.59 & 15.02 & 15.25 & 14.93 & 14.98 & 14.77 & 14.95 \\
\hline $\mathrm{FeO}_{\mathrm{t}}$ & 6.04 & 6.05 & 6.02 & 5.80 & 5.85 & 6.42 & 6.78 & 5.83 & 6.62 & 5.34 \\
\hline $\mathrm{MnO}$ & 0.07 & 0.13 & 0.08 & 0.10 & 0.11 & 0.11 & 0.11 & 0.11 & 0.10 & 0.10 \\
\hline $\mathrm{MgO}$ & 1.22 & 1.26 & 1.38 & 1.62 & 1.37 & 1.72 & 1.36 & 1.74 & 1.45 & 0.88 \\
\hline $\mathrm{CaO}$ & 4.86 & 4.92 & 3.78 & 5.08 & 5.10 & 4.94 & 3.85 & 4.88 & 5.09 & 4.18 \\
\hline $\mathrm{Na}_{2} \mathrm{O}$ & 3.11 & 1.58 & 3.10 & 3.28 & 2.65 & 3.39 & 3.16 & 3.06 & 3.43 & 3.00 \\
\hline $\mathrm{K}_{2} \mathrm{O}$ & 2.63 & 2.44 & 3.15 & 2.71 & 2.65 & 3.11 & 2.70 & 2.72 & 2.59 & 3.31 \\
\hline $\mathrm{P}_{2} \mathrm{O}_{5}$ & nd & 0.04 & 0.07 & nd & 0.00 & 0.02 & nd & 0.01 & nd & 0.03 \\
\hline $\mathrm{Cr}_{2} \mathrm{O}_{3}$ & 0.05 & 0.04 & 0.01 & 0.00 & 0.01 & 0.02 & 0.01 & 0.01 & 0.02 & 0.01 \\
\hline $\mathrm{Cl}$ (ppm) & 1435 & 1554 & 1135 & 990 & 965 & 980 & 1133 & 963 & 1067 & 1137 \\
\hline $\mathrm{S}(\mathrm{ppm})$ & 127 & 116 & 41 & 60 & 16 & 112 & 136 & 230 & 235 & 119 \\
\hline $\mathrm{H}_{2} \mathrm{O}(\mathrm{wt} \%)$ & na & na & na & na & na & na & na & na & na & na \\
\hline Total & 99.41 & 98.14 & 97.93 & 99.97 & 100.19 & 100.01 & 100.38 & 99.89 & 100.12 & 100.82 \\
\hline $\begin{array}{l}\text { Hosting } \\
\text { phenocryst } \\
\text { Trace eleme }\end{array}$ & ts (ppm) & Opx & & Cpx & Opx & Cpx & Cpx & Cpx & Opx & Opx \\
\hline $\mathrm{Li}$ & 30.70 & 21.15 & 26.49 & 23.78 & 15.18 & 44.64 & 33.43 & 28.21 & 21.34 & 10.65 \\
\hline B & 41.19 & 39.77 & 39.93 & 41.18 & 21.82 & 43.59 & 43.42 & 38.61 & 35.42 & 11.56 \\
\hline $\mathrm{Sc}$ & 25.47 & 25.41 & 25.64 & 28.35 & 49.28 & 23.53 & 27.29 & 24.76 & 28.19 & 61.75 \\
\hline $\mathrm{Ti}$ & 7479.72 & 6922.56 & 6025.13 & 7004.86 & 3872.89 & 6206.79 & 6308.41 & 5294.71 & 6189.64 & 3972.66 \\
\hline V & 291.67 & 267.07 & 241.28 & 272.83 & 239.86 & 231.02 & 263.35 & 203.59 & 302.93 & 320.86 \\
\hline $\mathrm{Cr}$ & 9.02 & 37.48 & 33.61 & 7.21 & 579.34 & 3.30 & 37.17 & 7.00 & 4.70 & 674.17 \\
\hline $\mathrm{Mn}$ & 633.85 & 721.53 & 688.46 & 739.10 & 2199.82 & 753.59 & 668.97 & 721.70 & 720.36 & 3204.91 \\
\hline $\mathrm{Co}$ & 14.16 & 17.58 & 16.29 & 12.06 & 61.16 & 15.39 & 13.54 & 12.82 & 14.04 & 99.49 \\
\hline $\mathrm{Ni}$ & 12.53 & 32.46 & 23.23 & 8.48 & 219.82 & 6.18 & 14.80 & 5.47 & 9.12 & 363.95 \\
\hline $\mathrm{Cu}$ & 137.55 & 151.65 & 131.56 & 165.44 & 78.84 & 244.76 & 209.53 & 186.13 & 212.41 & 52.53 \\
\hline $\mathrm{Zn}$ & 106.36 & 77.42 & 64.68 & 68.91 & 121.80 & 75.42 & 75.70 & 60.43 & 76.45 & 195.63 \\
\hline $\mathrm{Ga}$ & 198.81 & 185.96 & 173.90 & 211.56 & 122.03 & 197.67 & 197.16 & 177.48 & 188.92 & 75.51 \\
\hline As & 4.13 & 6.51 & 5.12 & 6.35 & 2.81 & 5.42 & 4.55 & 6.15 & 5.62 & nd \\
\hline $\mathrm{Se}$ & nd & nd & 3.31 & nd & nd & nd & nd & nd & nd & 2.89 \\
\hline $\mathrm{Rb}$ & 81.33 & 87.46 & 82.62 & 84.47 & 43.20 & 93.82 & 90.00 & 87.79 & 81.22 & 34.60 \\
\hline $\mathrm{Sr}$ & 205.25 & 187.34 & 194.39 & 202.09 & 88.10 & 181.30 & 162.93 & 151.38 & 194.79 & 57.08 \\
\hline Mo & 1.83 & 0.82 & 1.22 & 1.32 & 0.38 & 2.10 & 1.03 & 1.74 & 1.51 & nd \\
\hline $\mathrm{Ag}$ & nd & nd & 0.37 & nd & nd & 0.23 & 0.43 & nd & nd & 0.31 \\
\hline $\mathrm{Cd}$ & nd & nd & 0.63 & nd & nd & nd & nd & nd & nd & nd \\
\hline Sn & 2.78 & nd & 2.25 & 1.79 & 1.94 & 1.01 & nd & 1.08 & nd & 2.44 \\
\hline $\mathrm{Sb}$ & 5.36 & 0.35 & 0.70 & $\mathrm{nd}$ & nd & 0.04 & 1.12 & 0.22 & 0.94 & nd \\
\hline $\mathrm{Ba}$ & 1114.16 & 1025.43 & 970.87 & 1192.63 & 514.43 & 1049.28 & 968.49 & 932.31 & 998.51 & 410.48 \\
\hline $\mathrm{Yb}$ & 5.86 & 4.02 & 2.58 & 2.73 & 2.84 & 4.86 & 3.13 & 2.40 & 4.32 & 2.34 \\
\hline W & 2.00 & 1.10 & 1.41 & 1.66 & 0.63 & 1.34 & 1.21 & 1.28 & 2.05 & 0.49 \\
\hline $\mathrm{Re}$ & nd & 0.72 & nd & nd & nd & nd & nd & nd & nd & nd \\
\hline $\mathrm{Au}$ & nd & nd & 0.27 & nd & 0.87 & 0.25 & nd & nd & nd & nd \\
\hline $\mathrm{Tl}$ & 0.58 & nd & 0.28 & 0.27 & 0.15 & 0.56 & 0.27 & 0.38 & 0.41 & 0.29 \\
\hline $\mathrm{Pb}$ & 13.29 & 14.27 & 11.48 & 14.37 & 5.95 & 14.87 & 14.87 & 11.56 & 11.75 & 3.96 \\
\hline $\mathrm{Bi}$ & nd & nd & 0.17 & 0.20 & 0.09 & 0.31 & 0.30 & nd & 0.18 & nd \\
\hline $\mathrm{U}$ & 2.58 & 2.31 & 1.86 & 2.74 & 1.12 & 1.96 & 2.52 & 1.74 & 1.69 & 0.57 \\
\hline
\end{tabular}


Table A-2 (continued)

\begin{tabular}{|c|c|c|c|c|c|c|c|c|c|c|}
\hline & $\begin{array}{l}\text { WIDP9 } \\
\text {-IN09 }\end{array}$ & $\begin{array}{l}\text { WIDP9- } \\
\text { IN11 }\end{array}$ & $\begin{array}{l}\text { WIDP9- } \\
\text { IN12 }\end{array}$ & $\begin{array}{l}\text { WIDP9- } \\
\text { IN13 }\end{array}$ & $\begin{array}{l}\text { WIDP9- } \\
\text { IN14 }\end{array}$ & $\begin{array}{l}\text { WIDP9- } \\
\text { IN15 }\end{array}$ & $\begin{array}{l}\text { WIDP9- } \\
\text { IN16 }\end{array}$ & $\begin{array}{l}\text { WIDP9- } \\
\text { IN17 }\end{array}$ & $\begin{array}{c}\text { WIDP9- } \\
\text { IN18 }\end{array}$ & $\begin{array}{c}\text { WIDP9_- } \\
\text { Matrix } \\
\text { glass }\end{array}$ \\
\hline \multicolumn{11}{|c|}{ Major elements (wt\%) } \\
\hline $\mathrm{SiO}_{2}$ & 67.03 & 64.55 & 64.95 & 65.35 & 67.76 & 63.52 & 64.59 & 65.77 & 66.03 & 65.92 \\
\hline $\mathrm{TiO}_{2}$ & 1.11 & 0.94 & 0.99 & 0.98 & 0.93 & 1.08 & 0.87 & 0.99 & 0.78 & 1.20 \\
\hline $\mathrm{Al}_{2} \mathrm{O}_{3}$ & 14.40 & 13.43 & 13.54 & 13.96 & 14.06 & 15.66 & 14.99 & 14.44 & 14.85 & 13.91 \\
\hline $\mathrm{FeO}_{\mathrm{t}}$ & 5.63 & 6.33 & 7.36 & 6.98 & 6.03 & 7.22 & 6.38 & 7.02 & 6.42 & 6.18 \\
\hline $\mathrm{MnO}$ & 0.12 & 0.12 & 0.11 & 0.07 & 0.06 & 0.15 & 0.13 & 0.12 & 0.13 & 0.09 \\
\hline $\mathrm{MgO}$ & 1.55 & 3.17 & 1.78 & 1.48 & 1.18 & 1.56 & 1.76 & 1.39 & 1.26 & 1.74 \\
\hline $\mathrm{CaO}$ & 4.46 & 6.32 & 5.26 & 5.28 & 4.33 & 5.38 & 5.16 & 5.38 & 4.88 & 4.68 \\
\hline $\mathrm{Na}_{2} \mathrm{O}$ & 3.31 & 2.84 & 3.37 & 2.81 & 2.58 & 2.59 & 3.32 & 2.60 & 3.15 & 3.19 \\
\hline $\mathrm{K}_{2} \mathrm{O}$ & 2.64 & 2.49 & 2.32 & 2.68 & 3.10 & 2.27 & 2.44 & 2.61 & 2.60 & 3.10 \\
\hline $\mathrm{P}_{2} \mathrm{O}_{5}$ & 0.00 & 0.01 & 0.03 & 0.05 & nd & 0.03 & 0.03 & 0.05 & 0.01 & 0.02 \\
\hline $\mathrm{Cr}_{2} \mathrm{O}_{3}$ & 0.00 & 0.02 & nd & 0.01 & 0.01 & 0.01 & 0.02 & nd & 0.02 & 0.04 \\
\hline $\mathrm{Cl}(\mathrm{ppm})$ & 1060 & 922 & 1013 & 1297 & 940 & 1460 & 1018 & 1120 & 1117 & 647 \\
\hline $\mathrm{S}$ (ppm) & 49 & 107 & 834 & 709 & 60 & 941 & 569 & 66 & 398 & 43 \\
\hline $\mathrm{H}_{2} \mathrm{O}(\mathrm{wt} \%)$ & na & na & na & na & na & na & na & na & na & na \\
\hline Total & 100.38 & 100.34 & 99.90 & 99.86 & 100.15 & 99.72 & 99.85 & 100.49 & 100.27 & 100.14 \\
\hline $\begin{array}{l}\text { Hosting } \\
\text { phenocryst }\end{array}$ & Cpx & Pla & Opx & Opx & Opx & Cpx & Cpx & Opx & Opx & \\
\hline \multicolumn{11}{|c|}{ Trace elements (ppm) } \\
\hline $\mathrm{Li}$ & 30.20 & 53.60 & 29.89 & 21.04 & 15.57 & 24.36 & 27.65 & 21.92 & 20.42 & 33.49 \\
\hline B & 44.01 & 51.23 & 39.76 & 37.52 & 19.61 & 29.95 & 34.04 & 38.06 & 27.68 & 43.07 \\
\hline $\mathrm{Sc}$ & 28.11 & 64.42 & 29.07 & 34.33 & 51.49 & 61.29 & 28.40 & 29.36 & 36.99 & 29.46 \\
\hline $\mathrm{Ti}$ & 7018.49 & $\begin{array}{r}10335.0 \\
1\end{array}$ & 6534.07 & 6109.26 & 4329.95 & 5500.31 & 5552.66 & 5832.76 & 4582.31 & 6873.64 \\
\hline V & 315.55 & 587.51 & 323.23 & 296.68 & 277.99 & 319.78 & 207.63 & 254.20 & 254.07 & 273.01 \\
\hline $\mathrm{Cr}$ & nd & 1.23 & 5.67 & 74.16 & 487.10 & 251.54 & 12.32 & 189.80 & 137.65 & 32.30 \\
\hline $\mathrm{Mn}$ & 847.69 & 806.15 & 897.46 & 1140.43 & 2326.51 & 1350.54 & 818.38 & 1169.45 & 1497.24 & 834.30 \\
\hline Co & 11.77 & 14.08 & 16.37 & 24.92 & 68.47 & 26.61 & 14.91 & 29.34 & 39.20 & 18.55 \\
\hline $\mathrm{Ni}$ & 2.16 & 8.39 & 17.29 & 70.95 & 230.58 & 63.87 & 9.31 & 81.92 & 106.95 & 27.99 \\
\hline $\mathrm{Cu}$ & 190.04 & 345.66 & 38.65 & 626.61 & 75.72 & 892.47 & 587.69 & 139.97 & 239.78 & 152.41 \\
\hline $\mathrm{Zn}$ & 83.61 & 48.65 & 81.75 & 85.94 & 118.72 & 81.89 & 72.54 & 93.11 & 88.97 & 68.92 \\
\hline $\mathrm{Ga}$ & 188.45 & 236.08 & 214.59 & 210.22 & 125.82 & 140.43 & 185.36 & 167.96 & 163.90 & 195.53 \\
\hline As & 5.21 & 7.79 & 4.71 & 5.89 & 2.99 & 3.68 & 3.65 & 2.09 & 2.05 & 4.99 \\
\hline $\mathrm{Se}$ & 3.13 & nd & nd & nd & nd & nd & nd & 2.24 & 4.05 & nd \\
\hline $\mathrm{Rb}$ & 83.96 & 85.78 & 83.04 & 76.85 & 56.21 & 46.32 & 78.27 & 70.17 & 64.50 & 90.16 \\
\hline $\mathrm{Sr}$ & 173.57 & 161.87 & 184.67 & 159.58 & 94.41 & 168.66 & 199.77 & 152.42 & 164.23 & 150.81 \\
\hline Mo & 1.62 & 2.36 & 1.43 & 1.55 & 0.96 & 1.15 & 1.25 & 1.11 & 0.97 & 1.55 \\
\hline $\mathrm{Ag}$ & 0.33 & 0.23 & nd & nd & 0.47 & 0.26 & 0.31 & 0.68 & nd & 0.27 \\
\hline $\mathrm{Cd}$ & nd & nd & nd & nd & nd & nd & nd & nd & nd & 0.58 \\
\hline $\mathrm{Sn}$ & nd & 2.97 & 1.47 & 1.81 & 2.15 & 1.32 & 2.26 & nd & nd & 1.74 \\
\hline $\mathrm{Sb}$ & 0.42 & 0.99 & nd & 0.42 & 0.37 & 0.78 & 0.12 & nd & 0.67 & 0.72 \\
\hline $\mathrm{Ba}$ & 1045.95 & 1326.64 & 1171.80 & 1154.78 & 712.40 & 748.57 & 979.20 & 849.39 & 898.40 & 1046.48 \\
\hline $\mathrm{Yb}$ & 4.05 & 4.37 & 3.97 & 4.21 & 2.51 & 2.67 & 3.22 & 4.16 & 4.49 & 3.13 \\
\hline W & 1.62 & 3.21 & 1.16 & 1.39 & 1.95 & 2.50 & 1.44 & 0.95 & 1.96 & 1.38 \\
\hline $\operatorname{Re}$ & nd & nd & nd & nd & nd & nd & nd & nd & nd & nd \\
\hline $\mathrm{Au}$ & nd & nd & 0.48 & 0.44 & 0.40 & nd & nd & 0.38 & 0.55 & 0.36 \\
\hline $\mathrm{Tl}$ & 0.29 & 0.23 & 0.54 & 0.58 & 0.25 & 0.39 & 0.57 & nd & 0.36 & 0.29 \\
\hline $\mathrm{Pb}$ & 13.72 & 16.26 & 13.32 & 11.96 & 6.88 & 11.19 & 11.90 & 9.98 & 6.59 & 11.86 \\
\hline $\mathrm{Bi}$ & 0.16 & nd & 0.22 & 0.38 & nd & 0.17 & 0.07 & 0.16 & 0.18 & 0.22 \\
\hline U & 2.12 & 3.21 & 1.95 & 1.57 & 1.59 & 2.27 & 2.19 & 1.44 & 1.09 & 2.07 \\
\hline
\end{tabular}


Table A-2 (continued)

\begin{tabular}{|c|c|c|c|c|c|c|c|c|c|c|}
\hline & $\begin{array}{l}\text { WIDP8 } \\
\text {-IN02 }\end{array}$ & $\begin{array}{l}\text { WIDP8- } \\
\text { IN03 }\end{array}$ & $\begin{array}{l}\text { WIDP8- } \\
\text { IN04 }\end{array}$ & $\begin{array}{l}\text { WIDP8- } \\
\text { IN05 }\end{array}$ & $\begin{array}{l}\text { WIDP8- } \\
\text { IN06 }\end{array}$ & $\begin{array}{c}\text { WIDP8- } \\
\text { IN07 }\end{array}$ & $\begin{array}{l}\text { WIDP8- } \\
\text { IN08 }\end{array}$ & $\begin{array}{l}\text { WIDP8- } \\
\text { IN09 }\end{array}$ & $\begin{array}{l}\text { WIDP8- } \\
\text { IN10 }\end{array}$ & $\begin{array}{l}\text { WIDP8- } \\
\text { IN11 }\end{array}$ \\
\hline \multicolumn{11}{|c|}{ Major elements (wt\%) } \\
\hline $\mathrm{SiO}_{2}$ & 66.36 & 59.96 & 64.40 & 65.05 & 66.86 & 65.37 & 64.71 & 64.69 & 65.26 & 64.87 \\
\hline $\mathrm{TiO}_{2}$ & 0.56 & 2.09 & 1.19 & 1.29 & 1.02 & 1.26 & 1.02 & 1.06 & 1.12 & 1.12 \\
\hline $\mathrm{Al}_{2} \mathrm{O}_{3}$ & 15.00 & 12.98 & 13.33 & 13.49 & 13.60 & 13.53 & 14.33 & 14.35 & 14.05 & 13.32 \\
\hline $\mathrm{FeO}_{\mathrm{t}}$ & 5.59 & 7.73 & 6.64 & 6.27 & 5.97 & 5.86 & 6.32 & 6.54 & 6.25 & 6.32 \\
\hline $\mathrm{MnO}$ & 0.07 & 0.15 & 0.10 & 0.09 & 0.09 & 0.11 & 0.12 & 0.08 & 0.10 & 0.11 \\
\hline $\mathrm{MgO}$ & 1.46 & 3.21 & 2.58 & 1.56 & 1.34 & 1.63 & 1.61 & 1.61 & 1.55 & 2.49 \\
\hline $\mathrm{CaO}$ & 4.64 & 5.54 & 4.72 & 4.36 & 3.92 & 4.29 & 4.67 & 4.63 & 4.58 & 4.60 \\
\hline $\mathrm{Na}_{2} \mathrm{O}$ & 3.59 & 2.68 & 3.04 & 3.36 & 3.27 & 3.32 & 3.36 & 3.28 & 3.19 & 3.07 \\
\hline $\mathrm{K}_{2} \mathrm{O}$ & 2.49 & 2.40 & 2.74 & 2.93 & 2.75 & 3.00 & 2.70 & 2.68 & 2.76 & 2.79 \\
\hline $\mathrm{P}_{2} \mathrm{O}_{5}$ & nd & 0.55 & 0.11 & 0.08 & 0.02 & 0.06 & 0.01 & 0.01 & 0.03 & 0.02 \\
\hline $\mathrm{Cr}_{2} \mathrm{O}_{3}$ & 0.00 & 0.00 & 0.01 & 0.03 & 0.01 & 0.01 & 0.01 & 0.02 & 0.01 & 0.01 \\
\hline $\mathrm{Cl}$ (ppm) & 1340 & 1350 & 1080 & 1173 & 877 & 1187 & 973 & 1023 & 913 & 1140 \\
\hline $\mathrm{S}(\mathrm{ppm})$ & 247 & 267 & 147 & 230 & 88 & 48 & 113 & 124 & 103 & 56 \\
\hline $\mathrm{H}_{2} \mathrm{O}(\mathrm{wt} \%)$ & na & na & na & na & na & na & na & na & na & na \\
\hline Total & 99.94 & 97.46 & 98.99 & 98.65 & 98.93 & 98.55 & 98.97 & 99.07 & 98.99 & 98.85 \\
\hline $\begin{array}{l}\text { Hosting } \\
\text { phenocryst }\end{array}$ & Opx & Pla & Pla & Pla & Cpx & Pla & Cpx & Cpx & Cpx & Pla \\
\hline \multicolumn{11}{|c|}{ Trace elements (ppm) } \\
\hline $\mathrm{Li}$ & 20.34 & 30.30 & 34.51 & 36.35 & 22.25 & 25.72 & 23.02 & 23.86 & 24.63 & 26.56 \\
\hline B & 22.74 & 43.04 & 42.97 & 45.03 & 30.34 & 45.78 & 41.12 & 40.41 & 42.04 & 37.55 \\
\hline $\mathrm{Sc}$ & 42.81 & 44.47 & 34.17 & 29.90 & 21.79 & 31.06 & 24.52 & 26.75 & 27.43 & 26.62 \\
\hline $\mathrm{Ti}$ & 2541.10 & $\begin{array}{r}11813.4 \\
8\end{array}$ & 7766.27 & 7663.25 & 4796.59 & 8446.95 & 6308.04 & 6805.22 & 6845.24 & 6556.49 \\
\hline $\mathrm{V}$ & 233.55 & 492.52 & 324.22 & 343.05 & 178.74 & 307.89 & 244.30 & 261.50 & 275.28 & 257.88 \\
\hline $\mathrm{Cr}$ & 816.46 & nd & 5.62 & 4.82 & 4.05 & 6.51 & nd & nd & nd & 23.69 \\
\hline Mn & 2271.66 & 931.32 & 855.27 & 707.43 & 529.67 & 758.20 & 719.30 & 775.74 & 740.96 & 739.53 \\
\hline Co & 60.89 & 20.75 & 19.81 & 15.14 & 10.99 & 14.46 & 14.93 & 14.04 & 14.76 & 17.56 \\
\hline $\mathrm{Ni}$ & 201.86 & 17.15 & 13.74 & 13.31 & 6.14 & 13.98 & 9.06 & 6.63 & 12.35 & 11.03 \\
\hline $\mathrm{Cu}$ & 41.93 & 248.92 & 189.39 & 210.08 & 114.65 & 144.71 & 157.78 & 166.37 & 154.37 & 132.73 \\
\hline $\mathrm{Zn}$ & 156.57 & 92.32 & 81.40 & 75.02 & 59.10 & 62.79 & 71.19 & 87.05 & 70.15 & 65.53 \\
\hline $\mathrm{Ga}$ & 130.89 & 192.31 & 199.07 & 196.61 & 162.83 & 240.52 & 189.57 & 199.90 & 195.05 & 189.00 \\
\hline As & 3.14 & 8.24 & 4.67 & 5.93 & 3.68 & 5.41 & 5.71 & 6.97 & 4.83 & 5.55 \\
\hline $\mathrm{Se}$ & nd & nd & nd & nd & nd & nd & nd & nd & 2.42 & nd \\
\hline $\mathrm{Rb}$ & 39.83 & 62.86 & 86.81 & 91.37 & 77.26 & 91.64 & 88.01 & 89.57 & 88.29 & 81.77 \\
\hline $\mathrm{Sr}$ & 106.92 & 163.10 & 151.03 & 146.69 & 210.57 & 163.38 & 155.04 & 174.49 & 150.58 & 144.67 \\
\hline Mo & 0.90 & 3.97 & 1.73 & 1.79 & 1.52 & 1.84 & 1.14 & 1.98 & 2.11 & 1.67 \\
\hline $\mathrm{Ag}$ & nd & 0.40 & nd & nd & nd & 0.47 & 0.39 & nd & nd & nd \\
\hline $\mathrm{Cd}$ & 1.50 & nd & nd & nd & nd & 1.69 & 1.31 & nd & nd & nd \\
\hline $\mathrm{Sn}$ & nd & nd & 2.44 & 2.02 & 2.35 & 0.01 & 2.33 & 0.73 & nd & 2.71 \\
\hline $\mathrm{Sb}$ & nd & nd & nd & nd & nd & 1.02 & 0.43 & 0.64 & 1.29 & nd \\
\hline $\mathrm{Ba}$ & 629.75 & 918.06 & 1059.51 & 1016.94 & 874.56 & 1341.72 & 972.00 & 1044.42 & 1081.51 & 1036.52 \\
\hline $\mathrm{Yb}$ & 2.67 & 6.17 & 4.66 & 4.06 & 2.32 & 5.59 & 3.94 & 3.14 & 3.27 & 2.67 \\
\hline $\mathrm{W}$ & nd & 4.73 & 1.56 & 1.92 & 0.59 & 1.47 & 1.41 & 1.07 & 1.55 & 1.75 \\
\hline $\mathrm{Re}$ & 0.40 & nd & nd & nd & nd & nd & nd & nd & nd & nd \\
\hline $\mathrm{Au}$ & nd & nd & nd & 0.47 & nd & 0.12 & nd & nd & nd & nd \\
\hline $\mathrm{Tl}$ & nd & nd & 0.32 & 0.36 & nd & 0.69 & 0.57 & 0.32 & 0.40 & 0.21 \\
\hline $\mathrm{Pb}$ & 9.14 & 12.82 & 13.62 & 13.28 & 8.76 & 14.49 & 12.20 & 12.91 & 13.42 & 13.64 \\
\hline $\mathrm{Bi}$ & 0.17 & nd & nd & nd & 0.06 & nd & 0.31 & nd & nd & 0.25 \\
\hline $\mathrm{U}$ & 1.00 & 5.45 & 1.77 & 2.34 & 1.39 & 2.32 & 2.15 & 2.39 & 1.82 & 1.73 \\
\hline
\end{tabular}


Table A-2 (continued)

\begin{tabular}{|c|c|c|c|c|c|c|c|c|c|c|}
\hline & $\begin{array}{l}\text { WIDP8 } \\
\text {-IN15 }\end{array}$ & $\begin{array}{l}\text { WIDP8- } \\
\text { IN16 }\end{array}$ & $\begin{array}{l}\text { WIDP8- } \\
\text { IN17 }\end{array}$ & $\begin{array}{l}\text { WIDP8- } \\
\text { IN18 }\end{array}$ & $\begin{array}{l}\text { WIDP8- } \\
\text { IN19 }\end{array}$ & $\begin{array}{c}\text { WIDP8_ } \\
\text { Matrix } \\
\text { glass }\end{array}$ & $\begin{array}{c}\text { WIDP17 } \\
\text {-IN01 }\end{array}$ & $\begin{array}{l}\text { WIDP17 } \\
\text {-IN02 }\end{array}$ & $\begin{array}{c}\text { WIDP17 } \\
\text {-IN03 }\end{array}$ & $\begin{array}{l}\text { WIDP17 } \\
\text {-IN04 }\end{array}$ \\
\hline \multicolumn{11}{|c|}{ Major elements (wt\%) } \\
\hline $\mathrm{SiO}_{2}$ & 65.48 & 63.33 & 60.89 & 70.21 & 71.47 & 67.68 & 64.52 & 64.40 & 63.05 & 64.04 \\
\hline $\mathrm{TiO}_{2}$ & 1.10 & 1.52 & 2.21 & 0.44 & 0.45 & 1.07 & 0.95 & 1.10 & 0.95 & 1.04 \\
\hline $\mathrm{Al}_{2} \mathrm{O}_{3}$ & 13.29 & 13.49 & 13.31 & 11.24 & 11.57 & 13.34 & 14.77 & 14.78 & 13.91 & 15.03 \\
\hline $\mathrm{FeO}_{\mathrm{t}}$ & 5.93 & 6.56 & 7.55 & 5.58 & 5.45 & 5.45 & 5.67 & 5.31 & 6.84 & 5.64 \\
\hline $\mathrm{MnO}$ & 0.10 & 0.13 & 0.11 & 0.13 & 0.09 & 0.08 & 0.08 & 0.02 & 0.10 & 0.07 \\
\hline $\mathrm{MgO}$ & 2.19 & 2.30 & 2.50 & 1.13 & 0.79 & 1.39 & 2.25 & 2.29 & 2.55 & 2.01 \\
\hline $\mathrm{CaO}$ & 4.55 & 5.03 & 5.45 & 3.11 & 2.60 & 3.95 & 5.28 & 5.39 & 5.29 & 5.03 \\
\hline $\mathrm{Na}_{2} \mathrm{O}$ & 3.05 & 2.70 & 2.73 & 2.71 & 2.73 & 3.10 & 2.76 & 2.49 & 2.73 & 3.19 \\
\hline $\mathrm{K}_{2} \mathrm{O}$ & 2.84 & 2.75 & 2.51 & 2.74 & 2.82 & 3.09 & 2.72 & 2.84 & 2.61 & 2.81 \\
\hline $\mathrm{P}_{2} \mathrm{O}_{5}$ & 0.01 & 0.14 & 0.30 & nd & nd & 0.01 & 0.15 & 0.18 & 0.15 & 0.15 \\
\hline $\mathrm{Cr}_{2} \mathrm{O}_{3}$ & 0.00 & 0.01 & 0.01 & 0.02 & 0.02 & 0.03 & 0.05 & 0.03 & nd & 0.04 \\
\hline $\mathrm{Cl}(\mathrm{ppm})$ & 1003 & 1270 & 1260 & 1477 & 1593 & 1066 & 440 & 540 & 410 & 603 \\
\hline $\mathrm{S}$ (ppm) & 156 & 242 & 247 & 99 & 77 & 58 & 122 & 28 & 103 & 109 \\
\hline $\mathrm{H}_{2} \mathrm{O}(\mathrm{wt} \%)$ & na & na & na & na & na & na & na & na & na & na \\
\hline Total & 98.66 & 98.12 & 97.72 & 97.47 & 98.15 & 99.30 & 99.25 & 98.90 & 98.24 & 99.10 \\
\hline $\begin{array}{l}\text { Hosting } \\
\text { phenocryst }\end{array}$ & Pla & Pla & Pla & Cpx & Cpx & & Pla & Pla & Opx & Pla \\
\hline \multicolumn{11}{|c|}{ Trace elements (ppm) } \\
\hline $\mathrm{Li}$ & 26.19 & 22.86 & 24.90 & 41.80 & 35.40 & 29.60 & 21.49 & 24.23 & 24.14 & 45.78 \\
\hline B & 40.70 & 49.69 & 44.48 & 32.75 & 15.15 & 44.75 & 35.10 & 39.18 & 35.49 & 38.97 \\
\hline $\mathrm{Sc}$ & 28.68 & 32.16 & 34.62 & 41.71 & 178.68 & 24.83 & 25.54 & 28.57 & 27.29 & 24.76 \\
\hline $\mathrm{Ti}$ & 7167.83 & 8346.95 & 8488.09 & 2504.11 & 3093.12 & 6800.67 & 5659.44 & 7563.77 & 5597.69 & 6162.02 \\
\hline V & 262.46 & 316.33 & 375.35 & 129.69 & 270.26 & 234.97 & 237.20 & 301.67 & 258.83 & 246.55 \\
\hline $\mathrm{Cr}$ & 24.99 & nd & 14.36 & 3.08 & nd & 6.86 & 17.54 & 31.71 & 48.96 & 12.19 \\
\hline $\mathrm{Mn}$ & 768.92 & 756.33 & 614.86 & 940.74 & 2598.39 & 655.11 & 666.10 & 777.98 & 832.20 & 714.81 \\
\hline Co & 15.62 & 15.18 & 12.70 & 9.46 & 27.81 & 11.59 & 15.04 & 16.32 & 16.99 & 14.63 \\
\hline $\mathrm{Ni}$ & 10.36 & 11.26 & 6.46 & nd & 4.71 & 7.23 & 23.54 & 36.07 & 34.61 & 23.18 \\
\hline $\mathrm{Cu}$ & 139.46 & 190.68 & 94.49 & 85.32 & 38.48 & 131.71 & 134.62 & 136.44 & 137.35 & 184.73 \\
\hline $\mathrm{Zn}$ & 66.92 & 61.54 & 53.95 & 66.53 & 107.63 & 62.74 & 57.04 & 63.44 & 77.44 & 60.36 \\
\hline $\mathrm{Ga}$ & 202.68 & 213.03 & 176.57 & 169.67 & 104.95 & 214.72 & 171.98 & 205.86 & 170.51 & 164.43 \\
\hline As & 7.18 & 6.06 & 9.05 & 4.71 & 4.30 & 5.77 & 4.04 & 6.38 & 4.69 & 3.66 \\
\hline $\mathrm{Se}$ & nd & nd & nd & 0.33 & nd & nd & nd & nd & nd & nd \\
\hline $\mathrm{Rb}$ & 94.00 & 92.23 & 63.59 & 92.70 & 50.28 & 100.25 & 78.79 & 86.77 & 76.07 & 86.41 \\
\hline $\mathrm{Sr}$ & 159.98 & 189.86 & 333.08 & 88.70 & 71.69 & 151.39 & 181.70 & 203.95 & 168.75 & 152.60 \\
\hline Mo & 1.61 & 2.27 & 1.42 & 1.25 & 0.61 & 1.28 & 1.05 & 1.03 & 1.14 & 1.13 \\
\hline $\mathrm{Ag}$ & nd & nd & nd & nd & nd & 0.41 & nd & 0.60 & 0.25 & nd \\
\hline $\mathrm{Cd}$ & nd & 0.24 & nd & nd & nd & nd & nd & nd & nd & nd \\
\hline Sn & 1.85 & 3.50 & 1.07 & 2.16 & 3.23 & 2.22 & 3.30 & nd & 3.09 & 1.99 \\
\hline $\mathrm{Sb}$ & 0.72 & 0.19 & nd & 0.87 & nd & 0.28 & 0.53 & nd & nd & 0.43 \\
\hline $\mathrm{Ba}$ & 1136.28 & 1028.73 & 914.60 & 917.53 & 511.98 & 1198.65 & 975.96 & 1357.18 & 962.39 & 993.89 \\
\hline $\mathrm{Yb}$ & 3.02 & 3.13 & 4.86 & 4.89 & 7.20 & 3.26 & 2.69 & 2.89 & 2.25 & 2.85 \\
\hline W & 1.21 & 2.52 & 2.29 & 2.03 & nd & 1.64 & 1.11 & 2.13 & 1.78 & 1.53 \\
\hline $\mathrm{Re}$ & 0.12 & nd & nd & nd & nd & nd & nd & nd & nd & nd \\
\hline $\mathrm{Au}$ & nd & nd & nd & nd & nd & 0.45 & nd & nd & nd & nd \\
\hline $\mathrm{Tl}$ & 0.38 & nd & 0.35 & 0.34 & 0.48 & 0.37 & 0.26 & nd & nd & 0.31 \\
\hline $\mathrm{Pb}$ & 11.08 & 13.30 & 9.68 & 13.36 & 7.45 & 13.28 & 11.62 & 13.74 & 11.45 & 11.45 \\
\hline $\mathrm{Bi}$ & nd & nd & nd & 0.21 & nd & 0.11 & nd & nd & nd & 0.09 \\
\hline $\mathrm{U}$ & 2.35 & 2.29 & 3.39 & 1.92 & 1.06 & 2.29 & 1.54 & 2.41 & 1.80 & 1.70 \\
\hline
\end{tabular}


Table A-2 (continued)

\begin{tabular}{|c|c|c|c|c|c|c|c|c|c|c|}
\hline & $\begin{array}{l}\text { WIDP1 } \\
\text { 7-IN05 }\end{array}$ & $\begin{array}{l}\text { WIDP17 } \\
\text {-IN06 }\end{array}$ & $\begin{array}{l}\text { WIDP17 } \\
\text {-IN07 }\end{array}$ & $\begin{array}{c}\text { WIDP17 } \\
\text {-IN08 }\end{array}$ & $\begin{array}{c}\text { WIDP17 } \\
\text {-IN09 }\end{array}$ & $\begin{array}{c}\text { WIDP17 } \\
\text {-IN10 }\end{array}$ & $\begin{array}{c}\text { WIDP17 } \\
\text {-IN11 }\end{array}$ & $\begin{array}{l}\text { WIDP17 } \\
\text {-IN12 }\end{array}$ & $\begin{array}{c}\text { WIDP17 } \\
\text {-IN13 }\end{array}$ & $\begin{array}{l}\text { WIDP17 } \\
\text {-IN14 }\end{array}$ \\
\hline \multicolumn{11}{|c|}{ Major elements (wt\%) } \\
\hline $\mathrm{SiO}_{2}$ & 64.15 & 65.07 & 64.84 & 63.42 & 65.34 & 64.76 & 65.55 & 63.53 & 63.38 & 63.87 \\
\hline $\mathrm{TiO}_{2}$ & 1.29 & 1.13 & 1.15 & 1.06 & 1.11 & 0.80 & 0.85 & 0.97 & 0.97 & 0.94 \\
\hline $\mathrm{Al}_{2} \mathrm{O}_{3}$ & 13.30 & 13.03 & 13.41 & 13.80 & 13.77 & 13.99 & 13.97 & 14.36 & 14.34 & 14.61 \\
\hline $\mathrm{FeO}_{\mathrm{t}}$ & 7.44 & 7.24 & 6.66 & 7.54 & 6.08 & 6.16 & 5.90 & 6.12 & 6.85 & 6.15 \\
\hline $\mathrm{MnO}$ & 0.16 & 0.15 & 0.10 & 0.12 & 0.20 & 0.10 & 0.08 & 0.19 & 0.11 & 0.21 \\
\hline $\mathrm{MgO}$ & 2.08 & 2.15 & 2.51 & 2.41 & 2.37 & 2.13 & 2.07 & 2.85 & 2.71 & 2.57 \\
\hline $\mathrm{CaO}$ & 5.29 & 4.98 & 5.22 & 5.41 & 4.94 & 5.24 & 4.97 & 5.82 & 5.78 & 5.24 \\
\hline $\mathrm{Na}_{2} \mathrm{O}$ & 3.00 & 2.28 & 2.43 & 2.04 & 1.96 & 2.54 & 2.97 & 3.31 & 2.61 & 2.95 \\
\hline $\mathrm{K}_{2} \mathrm{O}$ & 2.62 & 2.65 & 2.63 & 2.50 & 2.87 & 3.26 & 3.29 & 2.54 & 2.50 & 2.64 \\
\hline $\mathrm{P}_{2} \mathrm{O}_{5}$ & 0.14 & 0.12 & 0.15 & 0.17 & 0.15 & 0.18 & 0.16 & 0.12 & 0.11 & 0.16 \\
\hline $\mathrm{Cr}_{2} \mathrm{O}_{3}$ & 0.02 & 0.02 & 0.07 & 0.01 & 0.03 & 0.07 & 0.02 & 0.05 & 0.01 & 0.10 \\
\hline $\mathrm{Cl}(\mathrm{ppm})$ & 440 & 527 & 530 & 567 & 550 & 507 & 603 & 510 & 580 & 535 \\
\hline $\mathrm{S}(\mathrm{ppm})$ & 28 & 174 & 172 & 368 & 36 & 88 & 129 & 142 & 126 & 26 \\
\hline $\mathrm{H}_{2} \mathrm{O}(\mathrm{wt} \%)$ & na & na & na & na & na & na & na & na & na & na \\
\hline Total & 99.53 & 98.88 & 99.24 & 98.56 & 98.86 & 99.28 & 99.91 & 99.94 & 99.43 & 99.49 \\
\hline $\begin{array}{l}\text { Hosting } \\
\text { phenocryst }\end{array}$ & Cpx & Cpx & Opx & Opx & $\mathrm{Cpx}$ & Cpx & Cpx & Opx & Opx & Opx \\
\hline \multicolumn{11}{|c|}{ Trace elements (ppm) } \\
\hline $\mathrm{Li}$ & 23.83 & 19.87 & 22.06 & 25.17 & 24.56 & 25.87 & 23.98 & 28.16 & 22.59 & 23.68 \\
\hline B & 37.11 & 33.01 & 37.23 & 33.39 & 38.03 & 38.77 & 39.26 & 38.37 & 31.91 & 39.91 \\
\hline $\mathrm{Sc}$ & 39.73 & 62.28 & 29.23 & 28.81 & 34.15 & 25.64 & 26.98 & 28.07 & 28.07 & 26.46 \\
\hline $\mathrm{Ti}$ & 8015.75 & 7012.89 & 7909.38 & 6035.91 & 7609.33 & 4759.33 & 5108.65 & 6445.56 & 5165.62 & 5488.67 \\
\hline V & 315.04 & 420.32 & 319.83 & 282.36 & 306.36 & 180.35 & 191.83 & 263.14 & 228.41 & 205.57 \\
\hline $\mathrm{Cr}$ & 14.12 & 290.57 & 17.61 & 6.92 & 36.06 & 20.32 & 9.57 & 22.91 & 149.93 & 96.52 \\
\hline $\mathrm{Mn}$ & 914.60 & 1408.56 & 817.14 & 832.41 & 741.86 & 777.31 & 718.27 & 747.24 & 905.08 & 813.06 \\
\hline Co & 17.71 & 28.85 & 15.96 & 16.00 & 17.02 & 13.68 & 14.12 & 15.03 & 28.70 & 20.96 \\
\hline $\mathrm{Ni}$ & 11.05 & 55.65 & 19.72 & 16.09 & 24.10 & 10.41 & 11.65 & 18.96 & 89.68 & 51.89 \\
\hline $\mathrm{Cu}$ & 125.48 & 110.18 & 151.80 & 52.57 & 151.52 & 141.57 & 144.91 & 162.56 & 135.01 & 146.10 \\
\hline $\mathrm{Zn}$ & 82.81 & 82.16 & 73.41 & 91.77 & 61.94 & 75.24 & 64.54 & 67.39 & 74.97 & 71.49 \\
\hline $\mathrm{Ga}$ & 165.81 & 136.96 & 192.53 & 157.88 & 183.85 & 189.41 & 205.40 & 172.96 & 140.62 & 169.39 \\
\hline As & 4.73 & 4.57 & 3.97 & 2.86 & 5.50 & 5.46 & 5.41 & 6.16 & 4.58 & 3.53 \\
\hline $\mathrm{Se}$ & nd & nd & nd & nd & $\mathrm{nd}$ & nd & nd & nd & nd & nd \\
\hline $\mathrm{Rb}$ & 80.04 & 69.43 & 79.89 & 71.33 & 84.26 & 101.69 & 103.25 & 81.03 & 73.32 & 79.83 \\
\hline $\mathrm{Sr}$ & 155.55 & 133.09 & 188.13 & 193.59 & 164.65 & 127.45 & 140.20 & 190.11 & 141.35 & 153.63 \\
\hline Mo & 1.19 & 1.00 & 2.74 & 1.15 & 1.11 & 2.39 & 1.55 & 2.13 & 0.98 & 1.54 \\
\hline $\mathrm{Ag}$ & 0.13 & 0.59 & nd & 0.29 & $\mathrm{nd}$ & 0.39 & nd & 0.40 & nd & nd \\
\hline $\mathrm{Cd}$ & nd & 1.05 & 0.19 & nd & nd & nd & nd & nd & nd & nd \\
\hline $\mathrm{Sn}$ & 3.80 & 1.36 & 3.51 & 2.25 & 7.24 & 2.50 & 1.28 & nd & nd & 1.57 \\
\hline $\mathrm{Sb}$ & nd & nd & 0.92 & 0.25 & 0.64 & 0.02 & 0.59 & 0.12 & 0.50 & 0.40 \\
\hline $\mathrm{Ba}$ & 966.42 & 800.04 & 1136.15 & 872.25 & 1027.86 & 1136.74 & 1234.41 & 985.33 & 790.09 & 998.76 \\
\hline $\mathrm{Yb}$ & 4.19 & 4.46 & 3.24 & 2.98 & 3.45 & 3.21 & 2.45 & 3.33 & 2.32 & 2.85 \\
\hline $\mathrm{W}$ & 1.41 & 0.92 & 2.02 & 1.08 & 1.20 & 0.84 & 1.78 & 0.95 & 1.06 & 1.20 \\
\hline $\mathrm{Re}$ & 0.41 & nd & nd & nd & nd & nd & nd & nd & nd & nd \\
\hline $\mathrm{Au}$ & nd & nd & nd & nd & 0.50 & nd & 0.09 & nd & nd & nd \\
\hline $\mathrm{Tl}$ & 0.33 & 0.30 & 0.47 & 0.30 & $\mathrm{nd}$ & 0.29 & 0.51 & 0.23 & 0.25 & 0.47 \\
\hline $\mathrm{Pb}$ & 12.41 & 9.36 & 11.97 & 11.45 & 12.40 & 12.52 & 12.71 & 12.81 & 9.30 & 11.48 \\
\hline $\mathrm{Bi}$ & nd & $\mathrm{nd}$ & nd & nd & $\mathrm{nd}$ & nd & nd & nd & nd & 0.13 \\
\hline $\mathrm{U}$ & 1.81 & 1.51 & 1.76 & 1.95 & 1.89 & 1.73 & 1.80 & 1.87 & 1.48 & 1.62 \\
\hline
\end{tabular}


Table A-2 (continued)

\begin{tabular}{|c|c|c|c|c|c|c|c|c|c|c|}
\hline & $\begin{array}{c}\text { WIDP1 } \\
7- \\
\text { Matrix } \\
\text { glass } \\
\end{array}$ & $\begin{array}{l}\text { WIDP4- } \\
\text { IN01 }\end{array}$ & $\begin{array}{l}\text { WIDP4- } \\
\text { IN02 }\end{array}$ & $\begin{array}{l}\text { WIDP4- } \\
\text { IN03 }\end{array}$ & $\begin{array}{l}\text { WIDP4- } \\
\text { IN24-R2 }\end{array}$ & $\begin{array}{l}\text { WIDP4- } \\
\text { IN25-R2 }\end{array}$ & $\begin{array}{c}\text { WIDP4- } \\
\text { IN04 }\end{array}$ & $\begin{array}{l}\text { WIDP4- } \\
\text { IN05 }\end{array}$ & $\begin{array}{l}\text { WIDP4- } \\
\text { IN06 }\end{array}$ & $\begin{array}{l}\text { WIDP4- } \\
\text { IN07-R2 }\end{array}$ \\
\hline \multicolumn{11}{|c|}{ Major elements (wt\%) } \\
\hline $\mathrm{SiO}_{2}$ & 62.94 & 64.68 & 62.97 & 66.29 & 57.14 & 56.71 & 62.83 & 65.84 & 65.75 & 56.65 \\
\hline $\mathrm{TiO}_{2}$ & 0.99 & 1.11 & 0.99 & 1.16 & 0.87 & 0.79 & 2.00 & 1.18 & 1.14 & 0.73 \\
\hline $\mathrm{Al}_{2} \mathrm{O}_{3}$ & 14.73 & 14.30 & 15.42 & 13.80 & 15.13 & 15.93 & 14.01 & 14.38 & 14.28 & 16.33 \\
\hline $\mathrm{FeO}_{\mathrm{t}}$ & 5.94 & 5.99 & 7.57 & 5.91 & 7.94 & 7.01 & 6.76 & 6.54 & 6.33 & 5.59 \\
\hline $\mathrm{MnO}$ & 0.08 & 0.08 & 0.12 & 0.09 & 0.15 & 0.14 & 0.10 & 0.12 & 0.08 & 0.11 \\
\hline $\mathrm{MgO}$ & 2.89 & 1.95 & 2.01 & 1.67 & 4.89 & 3.54 & 2.46 & 1.71 & 1.74 & 2.85 \\
\hline $\mathrm{CaO}$ & 5.78 & 5.03 & 5.99 & 4.73 & 9.10 & 11.03 & 5.45 & 4.79 & 4.79 & 12.17 \\
\hline $\mathrm{Na}_{2} \mathrm{O}$ & 3.58 & 2.75 & 2.17 & 2.25 & 2.12 & 2.52 & 2.23 & 1.77 & 2.04 & 2.28 \\
\hline $\mathrm{K}_{2} \mathrm{O}$ & 2.57 & 2.77 & 2.04 & 2.94 & 1.85 & 1.58 & 2.53 & 2.68 & 2.69 & 1.18 \\
\hline $\mathrm{P}_{2} \mathrm{O}_{5}$ & 0.16 & nd & nd & 0.01 & nd & nd & 0.31 & 0.02 & 0.02 & nd \\
\hline $\mathrm{Cr}_{2} \mathrm{O}_{3}$ & 0.05 & 0.01 & 0.01 & 0.04 & 0.02 & 0.00 & 0.01 & 0.01 & nd & 0.04 \\
\hline $\mathrm{Cl}(\mathrm{ppm})$ & 429 & 1173 & 998 & 1325 & 1520 & 1118 & 1321 & 1270 & 1344 & 1022 \\
\hline $\mathrm{S}(\mathrm{ppm})$ & 53 & 44 & 383 & 302 & 297 & 548 & 84 & 93 & 92 & 733 \\
\hline $\mathrm{H}_{2} \mathrm{O}(\mathrm{wt} \%)$ & na & na & na & na & na & na & na & na & na & na \\
\hline Total & 99.72 & 98.78 & 99.41 & 99.05 & 99.21 & 99.26 & 98.83 & 99.17 & 99.01 & 97.94 \\
\hline Hosting phe & cryst & Cpx & Cpx & Opx & $\mathrm{Ol}$ & $\mathrm{Ol}$ & Pla & Cpx & Cpx & $\mathrm{Ol}$ \\
\hline \multicolumn{11}{|c|}{ Trace elements (ppm) } \\
\hline $\mathrm{Li}$ & 24.47 & 39.03 & 30.15 & 25.94 & 22.29 & 57.89 & 27.09 & 27.22 & 29.45 & 29.17 \\
\hline B & 38.94 & 41.07 & 22.32 & 40.89 & 12.45 & 24.46 & 67.93 & 37.99 & 40.95 & 11.96 \\
\hline $\mathrm{Sc}$ & 27.60 & 24.35 & 30.17 & 26.04 & 30.12 & 42.89 & 38.55 & 31.98 & 27.24 & 28.51 \\
\hline $\mathrm{Ti}$ & 5966.68 & 6389.82 & 5650.74 & 7085.99 & 2346.23 & 4346.09 & $\begin{array}{r}12791.4 \\
1\end{array}$ & 7797.08 & 7420.35 & 2145.62 \\
\hline V & 248.41 & 242.88 & 268.00 & 293.77 & 129.15 & 258.93 & 474.93 & 302.55 & 235.61 & 133.60 \\
\hline $\mathrm{Cr}$ & 39.39 & 13.72 & 79.14 & 10.56 & 445.03 & 167.86 & 30.21 & 51.33 & nd & 615.66 \\
\hline $\mathrm{Mn}$ & 747.04 & 729.05 & 914.61 & 714.85 & 2087.23 & 1130.80 & 905.27 & 820.68 & 753.42 & 1362.24 \\
\hline Co & 17.98 & 15.75 & 22.82 & 14.86 & 140.68 & 35.15 & 19.61 & 15.75 & 16.27 & 103.84 \\
\hline $\mathrm{Ni}$ & 31.22 & 14.34 & 29.26 & 9.99 & 1507.37 & 191.98 & 13.63 & 21.34 & 10.79 & 1850.01 \\
\hline $\mathrm{Cu}$ & 150.96 & 149.81 & 90.17 & 23.79 & 42.88 & 227.00 & 191.15 & 176.26 & 169.38 & 101.96 \\
\hline $\mathrm{Zn}$ & 64.55 & 65.03 & 93.92 & 65.62 & 136.42 & 72.61 & 83.59 & 63.03 & 75.48 & 73.46 \\
\hline $\mathrm{Ga}$ & 160.06 & 189.49 & 149.49 & 255.05 & 73.09 & 121.08 & 210.34 & 210.40 & 204.41 & 57.67 \\
\hline As & 4.64 & 4.79 & 2.04 & 5.85 & 1.72 & 3.04 & 8.62 & 5.46 & 5.00 & nd \\
\hline $\mathrm{Se}$ & 3.44 & nd & nd & nd & nd & nd & 3.10 & nd & nd & nd \\
\hline $\mathrm{Rb}$ & 77.62 & 89.24 & 64.41 & 93.77 & 29.14 & 40.41 & 79.01 & 85.32 & 86.61 & 16.53 \\
\hline $\mathrm{Sr}$ & 167.66 & 165.68 & 198.41 & 165.82 & 77.70 & 194.25 & 183.77 & 183.44 & 186.08 & 97.70 \\
\hline Mo & 1.22 & 1.05 & 1.05 & 1.58 & 0.67 & 1.32 & 2.98 & 1.51 & 1.30 & nd \\
\hline $\mathrm{Ag}$ & 0.20 & 0.43 & nd & nd & 0.67 & nd & nd & nd & nd & 0.82 \\
\hline $\mathrm{Cd}$ & 0.56 & nd & nd & nd & nd & nd & nd & nd & nd & nd \\
\hline Sn & 1.13 & 2.19 & nd & 2.21 & nd & nd & 1.95 & nd & 1.94 & 1.76 \\
\hline $\mathrm{Sb}$ & 0.60 & 0.56 & 0.28 & 1.54 & 0.95 & 0.78 & 0.82 & 0.40 & 0.44 & nd \\
\hline $\mathrm{Ba}$ & 932.22 & 932.85 & 801.43 & 1324.50 & 378.14 & 553.14 & 1096.89 & 1056.82 & 1045.48 & 289.25 \\
\hline $\mathrm{Yb}$ & 3.04 & 3.00 & 5.29 & 2.92 & 0.57 & 1.64 & 7.67 & 5.22 & 3.80 & 2.42 \\
\hline W & 1.26 & 1.23 & 1.22 & 1.91 & nd & nd & 3.76 & 2.36 & 2.05 & 0.51 \\
\hline $\mathrm{Re}$ & 0.19 & nd & nd & nd & 0.69 & nd & nd & 0.53 & nd & nd \\
\hline $\mathrm{Au}$ & 0.29 & nd & nd & nd & nd & nd & 0.37 & 0.48 & nd & nd \\
\hline $\mathrm{Tl}$ & 0.35 & 0.45 & nd & 0.61 & 0.24 & nd & nd & 0.24 & 0.13 & nd \\
\hline $\mathrm{Pb}$ & 11.30 & 11.82 & 10.20 & 13.94 & 7.11 & 9.78 & 12.84 & 14.10 & 13.22 & 3.25 \\
\hline $\mathrm{Bi}$ & 0.24 & 0.22 & 0.24 & nd & nd & 0.18 & nd & 0.17 & nd & 0.17 \\
\hline $\mathrm{U}$ & 1.65 & 2.09 & 1.29 & 2.26 & 0.37 & 0.99 & 5.14 & 2.13 & 2.10 & 0.53 \\
\hline
\end{tabular}


Table A-2 (continued)

\begin{tabular}{|c|c|c|c|c|c|c|c|c|c|c|}
\hline & $\begin{array}{c}\text { WIDP4 } \\
\text {-IN08- } \\
\text { R2 }\end{array}$ & $\begin{array}{l}\text { WIDP4- } \\
\text { IN09-R2 }\end{array}$ & $\begin{array}{l}\text { WIDP4- } \\
\text { IN10 }\end{array}$ & $\begin{array}{l}\text { WIDP4- } \\
\text { IN13 }\end{array}$ & $\begin{array}{c}\text { WIDP4- } \\
\text { IN14 }\end{array}$ & $\begin{array}{l}\text { WIDP4- } \\
\text { IN15-R2 }\end{array}$ & $\begin{array}{l}\text { WIDP4- } \\
\text { IN15b- } \\
\text { R2 }\end{array}$ & $\begin{array}{l}\text { WIDP4- } \\
\text { IN16 }\end{array}$ & $\begin{array}{l}\text { WIDP4- } \\
\text { IN17 }\end{array}$ & $\begin{array}{l}\text { WIDP4- } \\
\text { IN18-R2 }\end{array}$ \\
\hline \multicolumn{11}{|c|}{ Major elements (wt\%) } \\
\hline $\mathrm{SiO}_{2}$ & 55.30 & 56.72 & 66.31 & 63.46 & 62.61 & 52.44 & 53.04 & 65.37 & 64.23 & 55.60 \\
\hline $\mathrm{TiO}_{2}$ & 0.65 & 0.73 & 0.85 & 1.70 & 1.80 & 0.64 & 0.82 & 0.94 & 0.92 & 0.71 \\
\hline $\mathrm{Al}_{2} \mathrm{O}_{3}$ & 15.05 & 16.17 & 13.97 & 13.99 & 13.74 & 16.13 & 18.05 & 14.21 & 14.30 & 15.29 \\
\hline $\mathrm{FeO}_{\mathrm{t}}$ & 6.84 & 6.96 & 5.65 & 6.52 & 7.08 & 4.86 & 4.68 & 6.36 & 6.86 & 6.61 \\
\hline $\mathrm{MnO}$ & 0.14 & 0.14 & 0.09 & 0.10 & 0.11 & 0.08 & 0.10 & 0.10 & 0.10 & 0.12 \\
\hline $\mathrm{MgO}$ & 6.12 & 3.43 & 1.90 & 2.34 & 2.59 & 7.06 & 4.00 & 1.75 & 1.80 & 6.89 \\
\hline $\mathrm{CaO}$ & 11.14 & 9.70 & 4.58 & 5.65 & 5.76 & 12.16 & 13.99 & 5.34 & 5.62 & 10.88 \\
\hline $\mathrm{Na}_{2} \mathrm{O}$ & 2.54 & 2.72 & 2.30 & 2.87 & 2.62 & 2.07 & 2.46 & 1.82 & 2.43 & 1.84 \\
\hline $\mathrm{K}_{2} \mathrm{O}$ & 1.21 & 1.72 & 2.88 & 2.51 & 2.59 & 0.81 & 0.91 & 2.61 & 2.43 & 1.22 \\
\hline $\mathrm{P}_{2} \mathrm{O}_{5}$ & nd & nd & nd & 0.11 & 0.28 & nd & nd & nd & nd & nd \\
\hline $\mathrm{Cr}_{2} \mathrm{O}_{3}$ & 0.07 & 0.03 & 0.02 & nd & 0.02 & 0.03 & 0.00 & 0.00 & 0.01 & 0.06 \\
\hline $\mathrm{Cl}(\mathrm{ppm})$ & 987 & 1068 & 1076 & 1193 & 1297 & 1310 & 1516 & 1092 & 1033 & 1038 \\
\hline $\mathrm{S}$ (ppm) & 592 & 296 & 51 & 61 & 119 & 826 & 977 & 148 & 107 & 612 \\
\hline $\mathrm{H}_{2} \mathrm{O}(\mathrm{wt} \%)$ & na & na & na & na & na & na & na & na & na & na \\
\hline Total & 99.06 & 98.32 & 98.67 & 99.39 & 99.35 & 96.28 & 98.05 & 98.62 & 98.81 & 99.20 \\
\hline $\begin{array}{l}\text { Hosting } \\
\text { phenocryst }\end{array}$ & $\mathrm{Ol}$ & $\mathrm{Ol}$ & Pla & Pla & Pla & $\mathrm{Ol}$ & $\mathrm{Ol}$ & Cpx & Cpx & $\mathrm{Ol}$ \\
\hline \multicolumn{11}{|c|}{ Trace elements (ppm) } \\
\hline $\mathrm{Li}$ & 33.02 & 34.36 & 27.26 & 27.20 & 24.81 & 4.78 & 7.85 & 24.52 & 27.90 & 21.98 \\
\hline B & 14.11 & 15.17 & 27.48 & 44.79 & 42.07 & 12.68 & 14.75 & 38.32 & 35.82 & 9.87 \\
\hline $\mathrm{Sc}$ & 27.87 & 32.42 & 21.69 & 61.06 & 48.20 & 32.41 & 39.29 & 24.11 & 25.67 & 27.16 \\
\hline $\mathrm{Ti}$ & 2087.20 & 2885.68 & 5470.39 & $\begin{array}{r}10672.1 \\
1\end{array}$ & 11201.71 & 2474.21 & 2562.37 & 5716.61 & 5699.86 & 2054.45 \\
\hline V & 125.54 & 169.14 & 190.25 & 616.61 & 462.82 & 197.90 & 187.17 & 245.29 & 272.33 & 134.45 \\
\hline $\mathrm{Cr}$ & 410.53 & 387.29 & 12.91 & 19.40 & 33.93 & 518.03 & 362.71 & 9.61 & 15.23 & 528.64 \\
\hline Mn & 1624.33 & 1604.98 & 695.18 & 826.95 & 882.37 & 1135.62 & 1163.08 & 733.71 & 800.63 & 1681.35 \\
\hline Co & 113.09 & 94.62 & 15.31 & 18.23 & 19.43 & 105.83 & 87.14 & 15.05 & 16.76 & 138.23 \\
\hline $\mathrm{Ni}$ & 1447.69 & 949.41 & 19.05 & 23.99 & 27.11 & 1564.10 & 1264.47 & 12.72 & 8.23 & 1933.66 \\
\hline $\mathrm{Cu}$ & 114.80 & 134.89 & 152.07 & 179.54 & 187.32 & 45.40 & 35.93 & 161.22 & 157.96 & 78.95 \\
\hline $\mathrm{Zn}$ & 98.36 & 98.72 & 59.68 & 75.55 & 76.39 & 58.09 & 59.57 & 68.26 & 75.69 & 88.12 \\
\hline $\mathrm{Ga}$ & 50.42 & 83.55 & 199.36 & 219.79 & 220.90 & 46.02 & 47.58 & 188.29 & 184.90 & 51.08 \\
\hline As & 2.45 & 2.74 & 3.42 & 7.94 & 8.75 & nd & nd & 5.41 & 4.45 & 1.01 \\
\hline $\mathrm{Se}$ & 3.28 & nd & nd & nd & nd & nd & nd & nd & 4.20 & nd \\
\hline $\mathrm{Rb}$ & 16.25 & 27.76 & 78.40 & 69.19 & 76.25 & 11.59 & 11.07 & 83.60 & 76.67 & 12.55 \\
\hline $\mathrm{Sr}$ & 105.26 & 141.88 & 141.40 & 183.64 & 177.80 & 122.98 & 123.76 & 166.77 & 181.02 & 102.16 \\
\hline Mo & 1.02 & 1.95 & 0.97 & 2.99 & 4.19 & nd & nd & 1.05 & 0.90 & 1.35 \\
\hline $\mathrm{Ag}$ & nd & nd & nd & nd & nd & nd & nd & nd & nd & nd \\
\hline $\mathrm{Cd}$ & nd & nd & nd & nd & nd & nd & nd & nd & 1.34 & nd \\
\hline $\mathrm{Sn}$ & nd & nd & 3.03 & 1.81 & nd & nd & nd & 1.52 & 2.07 & nd \\
\hline $\mathrm{Sb}$ & 1.10 & nd & 0.25 & 0.55 & 0.50 & nd & nd & 0.44 & 0.16 & nd \\
\hline $\mathrm{Ba}$ & 220.02 & 391.33 & 1076.76 & 1181.28 & 1188.28 & 197.21 & 227.28 & 968.42 & 923.58 & 283.12 \\
\hline $\mathrm{Yb}$ & 0.76 & 2.49 & 2.35 & 5.94 & 5.11 & nd & 5.92 & 3.17 & 2.68 & 1.65 \\
\hline W & 0.51 & 1.67 & 0.87 & 2.51 & 4.32 & nd & 1.92 & 1.38 & 1.60 & 2.22 \\
\hline $\operatorname{Re}$ & 0.71 & nd & nd & nd & nd & nd & nd & nd & nd & nd \\
\hline $\mathrm{Au}$ & nd & 0.66 & nd & nd & 0.29 & 1.63 & 0.92 & nd & nd & 0.37 \\
\hline $\mathrm{Tl}$ & nd & nd & 0.26 & 0.33 & 0.42 & 0.59 & nd & 0.20 & 0.82 & nd \\
\hline $\mathrm{Pb}$ & 2.85 & 4.21 & 12.32 & 13.03 & 16.00 & 3.88 & 2.21 & 12.23 & 11.93 & 4.13 \\
\hline $\mathrm{Bi}$ & nd & nd & nd & 0.32 & nd & nd & 0.57 & nd & 0.11 & nd \\
\hline U & 0.48 & 0.51 & 1.40 & 3.47 & 4.66 & 0.42 & 0.12 & 1.55 & 2.22 & 0.20 \\
\hline
\end{tabular}


Table A-2 (continued)

\begin{tabular}{|c|c|c|c|c|c|c|c|c|c|c|}
\hline & $\begin{array}{c}\text { WIDP4 } \\
\text {-IN18b- } \\
\text { R2 }\end{array}$ & $\begin{array}{l}\text { WIDP4- } \\
\text { IN19 }\end{array}$ & $\begin{array}{l}\text { WIDP4- } \\
\text { IN20-R2 }\end{array}$ & $\begin{array}{l}\text { WIDP4- } \\
\text { IN21 }\end{array}$ & $\begin{array}{c}\text { WIDP4- } \\
\text { IN22 }\end{array}$ & $\begin{array}{l}\text { WIDP4- } \\
\text { IN23 }\end{array}$ & $\begin{array}{l}\text { WIDP4- } \\
\text { Ctx18- } \\
\text { IN01 }\end{array}$ & $\begin{array}{l}\text { WIDP4- } \\
\text { Ctx18- } \\
\text { IN02 }\end{array}$ & $\begin{array}{l}\text { WIDP4- } \\
\text { Ctx15- } \\
\text { IN01 }\end{array}$ & $\begin{array}{l}\text { WIDP4- } \\
\text { Ctx15- } \\
\text { IN02 }\end{array}$ \\
\hline \multicolumn{11}{|c|}{ Major elements (wt\%) } \\
\hline $\mathrm{SiO}_{2}$ & 57.23 & 65.67 & 52.18 & 67.70 & 63.53 & 65.54 & 67.31 & 65.23 & 64.88 & 65.16 \\
\hline $\mathrm{TiO}_{2}$ & 0.78 & 1.01 & 0.75 & 1.14 & 1.42 & 0.88 & 0.78 & 0.88 & 0.96 & 0.96 \\
\hline $\mathrm{Al}_{2} \mathrm{O}_{3}$ & 16.04 & 14.35 & 18.06 & 13.04 & 13.82 & 14.51 & 14.08 & 14.21 & 14.16 & 14.20 \\
\hline $\mathrm{FeO}_{\mathrm{t}}$ & 6.92 & 6.70 & 5.18 & 6.51 & 6.91 & 6.17 & 5.63 & 6.37 & 6.20 & 5.94 \\
\hline $\mathrm{MnO}$ & 0.14 & 0.09 & 0.10 & 0.12 & 0.12 & 0.10 & 0.07 & 0.09 & 0.11 & 0.11 \\
\hline $\mathrm{MgO}$ & 4.37 & 1.79 & 3.51 & 1.58 & 2.48 & 1.71 & 1.39 & 1.88 & 2.03 & 1.66 \\
\hline $\mathrm{CaO}$ & 10.37 & 5.50 & 14.67 & 4.27 & 5.26 & 5.31 & 4.42 & 5.21 & 5.17 & 5.04 \\
\hline $\mathrm{Na}_{2} \mathrm{O}$ & 2.57 & 1.19 & 1.91 & 1.68 & 2.27 & 2.18 & 2.08 & 2.63 & 2.71 & 2.39 \\
\hline $\mathrm{K}_{2} \mathrm{O}$ & 1.61 & 2.45 & 0.81 & 3.03 & 2.66 & 2.69 & 3.25 & 2.97 & 2.92 & 3.00 \\
\hline $\mathrm{P}_{2} \mathrm{O}_{5}$ & 0.00 & 0.00 & nd & 0.01 & 0.11 & 0.03 & 0.03 & 0.04 & 0.00 & 0.01 \\
\hline $\mathrm{Cr}_{2} \mathrm{O}_{3}$ & 0.04 & nd & 0.02 & 0.02 & 0.00 & 0.00 & 0.02 & 0.04 & 0.06 & 0.00 \\
\hline $\mathrm{Cl}$ (ppm) & 1078 & 1200 & 1580 & 983 & 1243 & 1243 & 1816 & 1275 & 1181 & 1230 \\
\hline S (ppm) & 339 & 176 & 1020 & 107 & 100 & 131 & 231 & 247 & 81 & 95 \\
\hline $\mathrm{H}_{2} \mathrm{O}(\mathrm{wt} \%)$ & na & na & na & na & na & na & 0.30 & 0.49 & 0.33 & 0.63 \\
\hline Total & 100.06 & 98.88 & 97.19 & 99.20 & 98.72 & 99.26 & 99.28 & 99.70 & 99.33 & 98.61 \\
\hline $\begin{array}{l}\text { Hosting } \\
\text { phenocryst }\end{array}$ & $\mathrm{Ol}$ & Opx & $\mathrm{Ol}$ & Cpx & Pla & Opx & Opx & Opx & Cpx & Cpx \\
\hline \multicolumn{11}{|c|}{ Trace elements (ppm) } \\
\hline $\mathrm{Li}$ & 39.44 & 26.24 & 9.25 & 26.72 & 20.91 & 25.63 & 27.29 & 28.27 & 26.09 & 26.50 \\
\hline B & 17.80 & 37.31 & 13.36 & 38.39 & 47.21 & 42.08 & 41.96 & 38.56 & 39.99 & 41.92 \\
\hline $\mathrm{Sc}$ & 31.02 & 24.84 & 46.65 & 35.73 & 27.16 & 26.22 & 21.97 & 24.21 & 23.97 & 25.42 \\
\hline $\mathrm{Ti}$ & 3338.01 & 5807.08 & 3625.96 & 6924.44 & 7298.41 & 5270.61 & 4811.83 & 5798.24 & 6183.35 & 6606.36 \\
\hline V & 194.71 & 258.38 & 258.65 & 265.47 & 292.55 & 225.98 & 205.43 & 249.52 & 261.57 & 260.14 \\
\hline $\mathrm{Cr}$ & 236.06 & 15.44 & 460.89 & 14.68 & 16.07 & 8.11 & 13.24 & 26.88 & 11.54 & 3.13 \\
\hline Mn & 1315.64 & 753.19 & 1165.09 & 823.61 & 763.05 & 738.37 & 643.79 & 784.43 & 765.17 & 748.62 \\
\hline Co & 76.53 & 16.95 & 65.26 & 14.01 & 16.37 & 15.03 & 15.38 & 15.10 & 15.00 & 15.58 \\
\hline $\mathrm{Ni}$ & 666.76 & 14.75 & 867.60 & 6.49 & 20.14 & 11.78 & 15.43 & 8.81 & 13.71 & 9.22 \\
\hline $\mathrm{Cu}$ & 51.68 & 172.05 & 31.33 & 108.41 & 139.59 & 156.87 & 76.65 & 77.06 & 151.23 & 144.39 \\
\hline $\mathrm{Zn}$ & 94.29 & 66.46 & 72.06 & 69.02 & 59.44 & 65.18 & 63.55 & 73.23 & 69.63 & 68.18 \\
\hline $\mathrm{Ga}$ & 99.71 & 175.44 & 68.74 & 188.02 & 185.22 & 218.67 & 216.13 & 195.46 & 192.33 & 201.27 \\
\hline As & 3.73 & 5.08 & 3.06 & 4.48 & 4.97 & 7.03 & 5.79 & 3.99 & 5.05 & 5.67 \\
\hline $\mathrm{Se}$ & nd & nd & nd & nd & nd & nd & nd & nd & nd & nd \\
\hline $\mathrm{Rb}$ & 41.18 & 78.38 & 19.12 & 104.61 & 85.34 & 88.60 & 103.89 & 85.72 & 89.64 & 89.79 \\
\hline $\mathrm{Sr}$ & 147.52 & 172.54 & 175.16 & 134.79 & 172.39 & 175.10 & 150.53 & 159.13 & 167.21 & 174.45 \\
\hline Mo & 0.78 & 1.48 & 0.03 & 1.49 & 2.10 & 1.45 & 1.29 & 0.75 & 1.25 & 1.04 \\
\hline $\mathrm{Ag}$ & nd & nd & nd & nd & nd & 0.40 & nd & nd & 0.36 & nd \\
\hline $\mathrm{Cd}$ & nd & nd & 3.06 & nd & nd & nd & nd & 0.65 & nd & nd \\
\hline $\mathrm{Sn}$ & nd & nd & nd & nd & 4.08 & nd & 2.29 & 4.15 & 1.93 & 1.42 \\
\hline $\mathrm{Sb}$ & 0.92 & nd & nd & 0.48 & 0.59 & 0.28 & $\mathrm{nd}$ & $\mathrm{nd}$ & nd & 0.75 \\
\hline $\mathrm{Ba}$ & 512.82 & 887.41 & 265.20 & 1023.63 & 867.27 & 1119.19 & 1138.34 & 1012.82 & 1054.08 & 1054.89 \\
\hline $\mathrm{Yb}$ & 0.66 & 2.96 & 0.47 & 4.12 & 3.98 & 2.15 & 2.46 & 2.99 & 3.86 & 2.98 \\
\hline $\mathrm{W}$ & nd & 1.51 & 0.43 & 2.55 & 2.69 & 2.61 & 1.41 & 0.94 & 1.48 & 1.12 \\
\hline $\mathrm{Re}$ & 1.17 & nd & nd & nd & nd & nd & nd & nd & nd & nd \\
\hline $\mathrm{Au}$ & 0.82 & nd & nd & 0.38 & nd & 0.12 & nd & nd & nd & nd \\
\hline $\mathrm{Tl}$ & nd & 0.21 & nd & 0.37 & 0.50 & 0.21 & 0.47 & 0.73 & 0.18 & 0.23 \\
\hline $\mathrm{Pb}$ & 8.78 & 11.29 & 3.44 & 12.48 & 11.93 & 15.72 & 13.47 & 14.14 & 12.40 & 12.95 \\
\hline $\mathrm{Bi}$ & 0.24 & nd & nd & nd & 0.16 & nd & nd & nd & nd & nd \\
\hline $\mathrm{U}$ & 0.85 & 1.56 & 0.39 & 1.90 & 1.96 & 2.04 & 1.93 & 2.07 & 2.15 & 1.86 \\
\hline
\end{tabular}


Table A-2 (continued)

\begin{tabular}{|c|c|c|c|c|c|c|c|c|c|c|}
\hline & $\begin{array}{c}\text { WIDP4 } \\
\text {-Ctx13- } \\
\text { IN03 }\end{array}$ & $\begin{array}{l}\text { WIDP4- } \\
\text { Ctx13- } \\
\text { IN02 }\end{array}$ & $\begin{array}{l}\text { WIDP4- } \\
\text { Ctx17- } \\
\text { IN01 }\end{array}$ & $\begin{array}{l}\text { WIDP4- } \\
\text { Ctx17- } \\
\text { IN02 }\end{array}$ & $\begin{array}{l}\text { WIDP4- } \\
\text { Ctx9- } \\
\text { IN01 }\end{array}$ & $\begin{array}{l}\text { WIDP4- } \\
\text { Ctx9- } \\
\text { IN03 }\end{array}$ & $\begin{array}{l}\text { WIDP4- } \\
\text { Ctx9- } \\
\text { IN04 }\end{array}$ & $\begin{array}{l}\text { WIDP4- } \\
\text { Ctx4- } \\
\text { IN01 }\end{array}$ & $\begin{array}{l}\text { WIDP4- } \\
\text { Ctx2- } \\
\text { IN01 }\end{array}$ & $\begin{array}{l}\text { WIDP4- } \\
\text { Ctx16b- } \\
\text { IN01 }\end{array}$ \\
\hline \multicolumn{11}{|c|}{ Major elements (wt\%) } \\
\hline $\mathrm{SiO}_{2}$ & 63.12 & 64.96 & 64.56 & 64.05 & 63.73 & 62.80 & 63.92 & 64.17 & 65.85 & 62.53 \\
\hline $\mathrm{TiO}_{2}$ & 1.01 & 0.82 & 0.89 & 0.88 & 1.25 & 1.31 & 1.06 & 1.07 & 0.93 & 1.34 \\
\hline $\mathrm{Al}_{2} \mathrm{O}_{3}$ & 14.11 & 14.26 & 13.95 & 13.65 & 13.95 & 13.72 & 13.88 & 14.06 & 14.06 & 14.02 \\
\hline $\mathrm{FeO}_{\mathrm{t}}$ & 6.23 & 6.19 & 6.13 & 6.26 & 6.11 & 6.06 & 5.78 & 6.28 & 5.79 & 7.55 \\
\hline $\mathrm{MnO}$ & 0.09 & 0.09 & 0.10 & 0.08 & 0.09 & 0.11 & 0.08 & 0.09 & 0.08 & 0.13 \\
\hline $\mathrm{MgO}$ & 1.67 & 1.39 & 1.96 & 1.90 & 2.24 & 2.26 & 2.15 & 1.66 & 1.81 & 1.97 \\
\hline $\mathrm{CaO}$ & 5.71 & 5.10 & 5.08 & 4.93 & 4.92 & 4.75 & 4.69 & 4.91 & 4.90 & 5.49 \\
\hline $\mathrm{Na}_{2} \mathrm{O}$ & 2.56 & 2.32 & 2.83 & 2.54 & 2.61 & 2.69 & 2.72 & 2.43 & 2.48 & 2.71 \\
\hline $\mathrm{K}_{2} \mathrm{O}$ & 2.82 & 2.89 & 2.75 & 2.73 & 2.76 & 2.73 & 2.83 & 2.68 & 2.82 & 2.34 \\
\hline $\mathrm{P}_{2} \mathrm{O}_{5}$ & nd & 0.05 & 0.00 & 0.05 & 0.06 & 0.08 & nd & nd & 0.00 & 0.01 \\
\hline $\mathrm{Cr}_{2} \mathrm{O}_{3}$ & 0.03 & nd & 0.06 & 0.08 & 0.00 & 0.04 & 0.01 & 0.03 & nd & nd \\
\hline $\mathrm{Cl}(\mathrm{ppm})$ & 1415 & 1510 & 1049 & 1420 & 1326 & 1284 & 1249 & 1091 & 1207 & 1474 \\
\hline $\mathrm{S}$ (ppm) & 78 & 332 & 188 & 290 & 60 & 119 & 80 & 31 & 51 & 535 \\
\hline $\mathrm{H}_{2} \mathrm{O}(\mathrm{wt} \%)$ & 0.47 & 0.34 & 0.71 & 0.93 & 0.59 & na & na & 0.76 & 0.29 & 0.80 \\
\hline Total & 97.49 & 98.26 & 98.43 & 97.32 & 97.86 & 96.67 & 97.26 & 97.48 & 98.85 & 98.30 \\
\hline $\begin{array}{l}\text { Hosting } \\
\text { phenocryst }\end{array}$ & Opx & Opx & Opx & Opx & Pla & Pla & Pla & Cpx & Opx & Opx \\
\hline \multicolumn{11}{|c|}{ Trace elements (ppm) } \\
\hline $\mathrm{Li}$ & 20.71 & 29.01 & 27.40 & 21.83 & 22.28 & 21.89 & 21.15 & 27.17 & 25.19 & 26.61 \\
\hline B & 33.70 & 45.24 & 37.01 & 39.66 & 42.34 & 44.04 & 39.17 & 39.91 & 36.94 & 36.36 \\
\hline $\mathrm{Sc}$ & 26.23 & 24.24 & 24.05 & 24.92 & 26.29 & 27.72 & 24.61 & 26.00 & 22.88 & 31.60 \\
\hline $\mathrm{Ti}$ & 5767.32 & 4887.97 & 5715.15 & 5756.64 & 6862.57 & 7977.22 & 6270.83 & 6902.33 & 5736.15 & 8111.71 \\
\hline V & 236.83 & 240.22 & 239.29 & 245.31 & 283.72 & 320.27 & 259.35 & 256.43 & 245.43 & 339.62 \\
\hline $\mathrm{Cr}$ & 191.00 & 16.67 & 14.11 & 13.23 & 15.14 & 10.86 & 12.81 & nd & 9.00 & 10.13 \\
\hline $\mathrm{Mn}$ & 998.72 & 751.46 & 764.38 & 766.38 & 725.74 & 792.03 & 745.75 & 792.46 & 709.15 & 971.42 \\
\hline Co & 32.17 & 15.68 & 15.41 & 15.07 & 16.89 & 16.01 & 14.84 & 15.49 & 12.67 & 19.60 \\
\hline $\mathrm{Ni}$ & 114.60 & 8.57 & 10.80 & 13.59 & 22.72 & 24.32 & 19.92 & 9.80 & 9.08 & 11.61 \\
\hline $\mathrm{Cu}$ & 140.54 & 20.95 & 124.74 & 234.23 & 156.46 & 158.96 & 145.66 & 159.22 & 148.23 & 23.16 \\
\hline $\mathrm{Zn}$ & 78.91 & 73.80 & 69.24 & 72.22 & 58.35 & 73.18 & 57.83 & 70.94 & 76.87 & 90.44 \\
\hline $\mathrm{Ga}$ & 151.51 & 168.27 & 195.54 & 196.34 & 182.01 & 187.07 & 190.13 & 188.54 & 190.98 & 176.08 \\
\hline As & 6.03 & 5.16 & 4.55 & 5.10 & 6.07 & 5.96 & 4.69 & 5.07 & 4.65 & 3.93 \\
\hline $\mathrm{Se}$ & nd & nd & nd & nd & 0.02 & nd & nd & nd & nd & nd \\
\hline $\mathrm{Rb}$ & 73.12 & 86.39 & 89.01 & 91.09 & 83.95 & 83.02 & 81.96 & 87.77 & 89.12 & 70.97 \\
\hline $\mathrm{Sr}$ & 134.77 & 156.28 & 174.89 & 167.31 & 132.95 & 138.54 & 130.74 & 168.32 & 160.70 & 182.43 \\
\hline Mo & 1.68 & 0.14 & 1.34 & 1.81 & 1.79 & 1.27 & 1.15 & 1.05 & 1.55 & 1.20 \\
\hline $\mathrm{Ag}$ & nd & nd & 0.60 & nd & nd & nd & nd & nd & nd & nd \\
\hline $\mathrm{Cd}$ & nd & nd & nd & nd & nd & nd & nd & nd & nd & nd \\
\hline $\mathrm{Sn}$ & 2.45 & 3.37 & nd & 1.48 & 1.28 & nd & nd & nd & nd & 1.91 \\
\hline $\mathrm{Sb}$ & nd & nd & nd & 0.40 & 0.53 & 0.54 & 0.36 & 0.72 & nd & 0.51 \\
\hline $\mathrm{Ba}$ & 688.62 & 903.83 & 1046.31 & 1062.75 & 938.54 & 964.61 & 1020.52 & 1034.51 & 1004.46 & 942.68 \\
\hline $\mathrm{Yb}$ & 1.76 & 2.64 & 2.66 & 3.10 & 2.73 & 3.79 & 3.26 & 3.33 & 2.60 & 3.85 \\
\hline W & 0.79 & 1.99 & 1.26 & 1.07 & 1.68 & 2.52 & 1.73 & 1.58 & 2.51 & 0.89 \\
\hline $\mathrm{Re}$ & 0.81 & nd & 0.33 & nd & nd & nd & nd & nd & nd & nd \\
\hline $\mathrm{Au}$ & nd & nd & 0.15 & nd & nd & nd & nd & 0.24 & nd & nd \\
\hline $\mathrm{Tl}$ & 0.47 & 0.25 & 0.35 & 0.37 & nd & 0.44 & 0.31 & 0.36 & 0.55 & 0.43 \\
\hline $\mathrm{Pb}$ & 13.52 & 12.58 & 11.08 & 12.95 & 12.51 & 13.39 & 12.40 & 12.33 & 12.73 & 11.89 \\
\hline $\mathrm{Bi}$ & nd & 0.31 & nd & 0.19 & nd & 0.09 & nd & nd & nd & nd \\
\hline U & 1.34 & 2.16 & 2.02 & 1.85 & 2.19 & 2.30 & 1.56 & 1.63 & 1.69 & 1.69 \\
\hline
\end{tabular}


Table A-2 (continued)

\begin{tabular}{|c|c|c|c|c|c|c|c|c|c|c|}
\hline & $\begin{array}{c}\text { WIDP4 } \\
\text {-Ctx16- } \\
\text { IN01 }\end{array}$ & $\begin{array}{l}\text { WIDP4- } \\
\text { Ctx16- } \\
\text { IN02 }\end{array}$ & $\begin{array}{l}\text { WIDP4- } \\
\text { Ctx14- } \\
\text { IN01 }\end{array}$ & $\begin{array}{l}\text { WIDP4- } \\
\text { Ctx14- } \\
\text { IN03 }\end{array}$ & $\begin{array}{c}\text { WIDP4_- } \\
\text { Matrix } \\
\text { glass }\end{array}$ & $\begin{array}{l}\text { WIDP4 _ } \\
\text { Matrix } \\
\text { glass } \\
\text { enclave }\end{array}$ & $\begin{array}{l}\text { WIDP7- } \\
\text { IN06 }\end{array}$ & $\begin{array}{l}\text { WIDP7- } \\
\text { IN24 }\end{array}$ & $\begin{array}{l}\text { WIDP7- } \\
\text { IN08 }\end{array}$ & $\begin{array}{l}\text { WIDP7- } \\
\text { IN08b }\end{array}$ \\
\hline \multicolumn{11}{|c|}{ Major elements (wt\%) } \\
\hline $\mathrm{SiO}_{2}$ & 64.31 & 61.45 & 64.95 & 65.12 & 61.44 & 61.73 & 67.61 & 67.38 & 69.55 & 71.38 \\
\hline $\mathrm{TiO}_{2}$ & 1.08 & 1.20 & 0.85 & 0.86 & 0.92 & 0.92 & 0.69 & 1.03 & 1.14 & 1.07 \\
\hline $\mathrm{Al}_{2} \mathrm{O}_{3}$ & 14.33 & 14.39 & 13.84 & 13.78 & 15.15 & 14.77 & 15.03 & 16.93 & 15.81 & 15.99 \\
\hline $\mathrm{FeO}_{\mathrm{t}}$ & 6.35 & 8.40 & 6.05 & 5.99 & 5.89 & 5.13 & 1.55 & 3.80 & 1.24 & 1.57 \\
\hline $\mathrm{MnO}$ & 0.10 & 0.16 & 0.09 & 0.09 & 0.09 & 0.11 & 0.03 & 0.04 & 0.04 & 0.03 \\
\hline $\mathrm{MgO}$ & 1.81 & 2.44 & 1.96 & 1.75 & 2.91 & 2.39 & 0.29 & 0.40 & 0.20 & 0.36 \\
\hline $\mathrm{CaO}$ & 4.91 & 6.34 & 4.69 & 4.74 & 6.32 & 6.20 & 2.87 & 4.79 & 2.78 & 3.05 \\
\hline $\mathrm{Na}_{2} \mathrm{O}$ & 2.88 & 2.58 & 3.12 & 2.97 & 4.56 & 5.62 & 2.61 & 3.68 & 2.96 & 3.34 \\
\hline $\mathrm{K}_{2} \mathrm{O}$ & 2.72 & 1.79 & 2.61 & 2.70 & 2.55 & 1.93 & 3.43 & 3.14 & 5.56 & 3.38 \\
\hline $\mathrm{P}_{2} \mathrm{O}_{5}$ & nd & nd & 0.01 & 0.05 & 0.04 & 0.02 & 0.01 & 0.04 & 0.01 & 0.02 \\
\hline $\mathrm{Cr}_{2} \mathrm{O}_{3}$ & 0.02 & 0.04 & 0.03 & 0.00 & 0.05 & 0.03 & 0.01 & 0.01 & 0.00 & 0.03 \\
\hline $\mathrm{Cl}(\mathrm{ppm})$ & 1291 & 1154 & 1342 & 1619 & 1918 & 3659 & 1585 & 1189 & 1445 & 1499 \\
\hline $\mathrm{S}(\mathrm{ppm})$ & 164 & 513 & 304 & 310 & 52 & 79 & 112 & 87 & 104 & 75 \\
\hline $\mathrm{H}_{2} \mathrm{O}(\mathrm{wt} \%)$ & 0.75 & na & 0.33 & 0.47 & na & na & na & na & na & na \\
\hline Total & 98.64 & 98.95 & 98.37 & 98.23 & 100.09 & 99.23 & 94.31 & 101.39 & 99.48 & 100.37 \\
\hline $\begin{array}{l}\text { Hosting } \\
\text { phenocryst }\end{array}$ & Opx & Opx & Opx & Opx & & & Opx & Cpx & Opx & Opx \\
\hline \multicolumn{11}{|c|}{ Trace elements (ppm) } \\
\hline $\mathrm{Li}$ & 27.40 & 29.16 & 26.62 & 26.22 & 32.58 & na & 12.25 & 16.13 & 44.56 & 25.91 \\
\hline B & 40.59 & 29.67 & 41.09 & 40.46 & 34.51 & na & 19.24 & 0.21 & 48.27 & 49.31 \\
\hline $\mathrm{Sc}$ & 25.11 & 37.24 & 23.69 & 23.66 & 31.33 & na & 49.23 & 8.06 & 14.11 & 23.26 \\
\hline $\mathrm{Ti}$ & 6147.87 & 7708.03 & 5414.87 & 5529.71 & 5837.59 & na & 3701.14 & 533.94 & 6339.55 & 7321.92 \\
\hline $\mathrm{V}$ & 235.98 & 370.24 & 228.25 & 237.53 & 248.98 & na & 253.34 & 6.12 & 172.09 & 258.08 \\
\hline $\mathrm{Cr}$ & 26.41 & 0.05 & 16.05 & 5.80 & 89.25 & na & 660.53 & nd & nd & nd \\
\hline $\mathrm{Mn}$ & 723.31 & 1104.02 & 721.67 & 707.23 & 873.79 & na & 2600.73 & 75.40 & 290.48 & 504.96 \\
\hline Co & 31.41 & 21.20 & 15.02 & 14.41 & 20.99 & na & 73.15 & 2.58 & 0.36 & 6.29 \\
\hline $\mathrm{Ni}$ & 9.38 & 13.69 & 13.53 & 10.46 & 31.10 & na & 292.00 & nd & 3.85 & nd \\
\hline $\mathrm{Cu}$ & 214.32 & 9.33 & 72.70 & 53.65 & 81.44 & na & 24.46 & 3.72 & 21.26 & 130.44 \\
\hline $\mathrm{Zn}$ & 63.17 & 94.74 & 61.96 & 67.20 & 66.22 & na & 145.59 & 14.54 & 22.46 & 31.09 \\
\hline $\mathrm{Ga}$ & 182.19 & 145.66 & 200.67 & 202.01 & 155.96 & na & 95.73 & 77.77 & 212.98 & 256.44 \\
\hline As & 4.52 & 3.67 & 5.05 & 4.26 & 4.11 & na & 1.53 & nd & 2.66 & 4.58 \\
\hline $\mathrm{Se}$ & 1.86 & nd & nd & nd & nd & na & nd & nd & nd & nd \\
\hline $\mathrm{Rb}$ & 86.13 & 59.31 & 92.47 & 87.90 & 71.50 & na & 39.87 & 4.36 & 116.80 & 105.93 \\
\hline $\mathrm{Sr}$ & 157.31 & 206.56 & 165.35 & 160.56 & 177.18 & na & 80.07 & 427.98 & 205.30 & 229.30 \\
\hline Mo & 1.57 & 1.09 & 1.93 & 1.45 & 1.22 & na & 0.66 & 1.41 & 1.16 & 1.17 \\
\hline $\mathrm{Ag}$ & nd & nd & nd & nd & 0.34 & na & nd & nd & nd & 0.20 \\
\hline $\mathrm{Cd}$ & nd & nd & nd & nd & nd & na & nd & 1.57 & nd & nd \\
\hline $\mathrm{Sn}$ & 2.44 & nd & nd & 2.68 & 1.43 & na & 3.94 & 10.04 & nd & nd \\
\hline $\mathrm{Sb}$ & 0.73 & 0.32 & 0.19 & 0.27 & 0.71 & na & 0.84 & 0.40 & nd & nd \\
\hline $\mathrm{Ba}$ & 1006.28 & 794.40 & 1054.74 & 1047.37 & 822.11 & na & 489.98 & 277.18 & 1232.50 & 1375.07 \\
\hline $\mathrm{Yb}$ & 2.70 & 3.15 & 2.61 & 2.46 & 2.82 & na & 1.65 & nd & 4.39 & 3.13 \\
\hline W & 1.23 & 1.20 & 1.34 & 1.49 & 1.19 & na & 1.03 & 0.45 & 2.48 & 1.64 \\
\hline $\mathrm{Re}$ & nd & nd & nd & nd & nd & na & nd & nd & nd & nd \\
\hline $\mathrm{Au}$ & nd & nd & nd & nd & 0.19 & na & nd & nd & nd & 0.13 \\
\hline $\mathrm{Tl}$ & 0.56 & 0.25 & 0.50 & 0.32 & 0.15 & na & nd & nd & 0.97 & 0.68 \\
\hline $\mathrm{Pb}$ & 13.67 & 10.23 & 12.76 & 13.06 & 9.77 & na & 4.77 & 3.42 & 12.99 & 14.82 \\
\hline $\mathrm{Bi}$ & nd & nd & 0.15 & 0.33 & 0.14 & na & nd & 0.74 & 0.14 & nd \\
\hline $\mathrm{U}$ & 2.35 & 1.56 & 1.98 & 1.79 & 1.44 & na & 0.67 & nd & 2.64 & 2.88 \\
\hline
\end{tabular}


Table A-2 (continued)

\begin{tabular}{|c|c|c|c|c|c|c|c|c|c|c|}
\hline & $\begin{array}{l}\text { WIDP7 } \\
\text {-IN13b }\end{array}$ & $\begin{array}{l}\text { WIDP7- } \\
\text { IN14b }\end{array}$ & $\begin{array}{l}\text { WIDP7- } \\
\text { IN15b }\end{array}$ & $\begin{array}{l}\text { WIDP7- } \\
\text { IN16 }\end{array}$ & $\begin{array}{l}\text { WIDP7- } \\
\text { IN20 }\end{array}$ & $\begin{array}{c}\text { WIDP7_- } \\
\text { Matrix } \\
\text { glass }\end{array}$ & $\begin{array}{l}\text { WIDP3- } \\
\text { IN01 }\end{array}$ & $\begin{array}{l}\text { WIDP3- } \\
\text { IN02 }\end{array}$ & $\begin{array}{l}\text { WIDP3- } \\
\text { IN04 }\end{array}$ & $\begin{array}{l}\text { WIDP3- } \\
\text { IN05 }\end{array}$ \\
\hline \multicolumn{11}{|c|}{ Major elements (wt\%) } \\
\hline $\mathrm{SiO}_{2}$ & 70.96 & 70.82 & 71.00 & 71.55 & 70.81 & 64.36 & 65.41 & 66.12 & 65.39 & 65.14 \\
\hline $\mathrm{TiO}_{2}$ & 1.10 & 1.29 & 1.10 & 1.22 & 1.14 & 1.03 & 0.76 & 0.88 & 1.07 & 1.30 \\
\hline $\mathrm{Al}_{2} \mathrm{O}_{3}$ & 15.59 & 15.89 & 15.52 & 15.49 & 15.77 & 15.47 & 14.09 & 13.65 & 13.81 & 13.85 \\
\hline $\mathrm{FeO}_{\mathrm{t}}$ & 1.33 & 1.34 & 1.35 & 1.38 & 1.22 & 5.54 & 6.64 & 6.16 & 6.54 & 7.08 \\
\hline $\mathrm{MnO}$ & 0.03 & 0.04 & 0.05 & 0.04 & 0.04 & 0.07 & 0.09 & 0.08 & 0.10 & 0.10 \\
\hline $\mathrm{MgO}$ & 0.10 & 0.17 & 0.15 & 0.15 & 0.15 & 2.18 & 1.11 & 1.35 & 1.23 & 1.47 \\
\hline $\mathrm{CaO}$ & 1.82 & 2.84 & 2.32 & 2.40 & 2.62 & 5.98 & 4.61 & 4.64 & 5.12 & 5.09 \\
\hline $\mathrm{Na}_{2} \mathrm{O}$ & 3.35 & 3.07 & 3.09 & 2.95 & 3.04 & 3.39 & 2.34 & 2.40 & 1.67 & 1.16 \\
\hline $\mathrm{K}_{2} \mathrm{O}$ & 6.09 & 5.84 & 6.02 & 5.67 & 5.44 & 2.70 & 2.64 & 3.26 & 3.06 & 2.60 \\
\hline $\mathrm{P}_{2} \mathrm{O}_{5}$ & nd & nd & 0.01 & 0.03 & 0.03 & 0.02 & nd & 0.03 & 0.01 & 0.00 \\
\hline $\mathrm{Cr}_{2} \mathrm{O}_{3}$ & 0.01 & 0.01 & 0.01 & 0.01 & 0.01 & 0.05 & 0.03 & 0.02 & nd & 0.04 \\
\hline $\mathrm{Cl}(\mathrm{ppm})$ & 1402 & 1519 & 1402 & 1371 & 1433 & 873 & 1531 & 1278 & 1165 & 1231 \\
\hline $\mathrm{S}$ (ppm) & 93 & 196 & 135 & 105 & 220 & 50 & 359 & 299 & 81 & 290 \\
\hline $\mathrm{H}_{2} \mathrm{O}(\mathrm{wt} \%)$ & na & na & na & na & na & na & na & na & na & na \\
\hline Total & 100.53 & 101.48 & 100.77 & 101.03 & 100.43 & 100.88 & 97.91 & 98.72 & 98.11 & 97.98 \\
\hline $\begin{array}{l}\text { Hosting } \\
\text { phenocryst }\end{array}$ & Opx & Opx & Opx & Opx & Opx & & Opx & Opx & Opx & Opx \\
\hline \multicolumn{11}{|c|}{ Trace elements (ppm) } \\
\hline $\mathrm{Li}$ & 39.65 & 34.62 & 30.09 & 38.63 & 43.57 & 18.53 & 24.44 & 19.68 & 24.90 & 25.12 \\
\hline B & 48.66 & 40.62 & 44.58 & 46.59 & 40.11 & 40.86 & 36.12 & 42.64 & 40.51 & 38.64 \\
\hline $\mathrm{Sc}$ & 15.76 & 19.94 & 16.63 & 17.93 & 28.83 & 26.84 & 25.94 & 24.71 & 25.09 & 29.54 \\
\hline $\mathrm{Ti}$ & 7884.00 & 7541.43 & 6560.22 & 7645.37 & 7776.43 & 6195.91 & 4241.34 & 5762.77 & 6393.22 & 7703.93 \\
\hline V & 287.17 & 261.44 & 229.62 & 250.45 & 310.93 & 258.07 & 249.00 & 240.58 & 270.29 & 302.93 \\
\hline $\mathrm{Cr}$ & nd & 80.10 & nd & 1.78 & nd & 39.37 & 20.87 & 26.76 & 22.20 & 20.01 \\
\hline $\mathrm{Mn}$ & 308.38 & 814.66 & 382.33 & 356.45 & 891.82 & 772.56 & 698.76 & 644.10 & 724.28 & 761.12 \\
\hline Co & 3.21 & 22.82 & 3.49 & 2.81 & 12.64 & 19.10 & 13.24 & 13.25 & 10.51 & 14.41 \\
\hline $\mathrm{Ni}$ & 1.58 & 48.69 & 4.98 & nd & 10.04 & 34.30 & 4.74 & 4.19 & 2.90 & 1.19 \\
\hline $\mathrm{Cu}$ & 91.61 & 292.13 & 126.64 & 71.38 & 77.76 & 14.35 & 169.98 & 68.53 & 85.54 & 77.08 \\
\hline $\mathrm{Zn}$ & 43.12 & 77.70 & 41.07 & 25.59 & 43.55 & 63.81 & 60.74 & 68.03 & 74.74 & 69.96 \\
\hline $\mathrm{Ga}$ & 226.28 & 222.19 & 281.60 & 253.63 & 191.03 & 171.57 & 180.72 & 209.51 & 181.59 & 193.13 \\
\hline As & 5.11 & 5.79 & 6.65 & 6.99 & 3.48 & 4.15 & 4.20 & 6.57 & 4.68 & 4.37 \\
\hline $\mathrm{Se}$ & nd & nd & 3.28 & nd & nd & 1.52 & nd & nd & nd & 3.42 \\
\hline $\mathrm{Rb}$ & 174.77 & 160.79 & 201.87 & 156.50 & 107.37 & 85.48 & 72.04 & 98.15 & 95.54 & 79.35 \\
\hline $\mathrm{Sr}$ & 201.23 & 209.60 & 182.85 & 199.98 & 195.37 & 178.29 & 225.47 & 148.03 & 163.00 & 182.58 \\
\hline Mo & 1.55 & 1.32 & 1.16 & 2.25 & 0.17 & 1.00 & 0.59 & 1.30 & 1.07 & 1.39 \\
\hline $\mathrm{Ag}$ & nd & 0.32 & nd & nd & 0.30 & 0.11 & nd & 0.57 & nd & nd \\
\hline $\mathrm{Cd}$ & nd & nd & nd & 0.89 & 1.36 & nd & nd & nd & nd & 1.69 \\
\hline Sn & nd & 0.08 & 1.84 & 5.05 & nd & 2.07 & 1.04 & 1.08 & 1.49 & 3.05 \\
\hline $\mathrm{Sb}$ & nd & 0.54 & nd & nd & nd & 0.72 & nd & 0.04 & nd & 0.71 \\
\hline $\mathrm{Ba}$ & 1217.14 & 1224.68 & 1665.69 & 1399.28 & 982.30 & 907.35 & 1001.56 & 980.71 & 961.83 & 996.42 \\
\hline $\mathrm{Yb}$ & 2.81 & 2.20 & 2.86 & 2.63 & 5.83 & 2.85 & 4.02 & 2.07 & 2.38 & 4.09 \\
\hline W & 1.18 & 2.08 & 2.26 & 1.81 & 1.85 & 1.25 & 0.92 & 2.03 & 2.53 & 1.57 \\
\hline $\mathrm{Re}$ & nd & nd & nd & nd & nd & nd & 0.14 & nd & nd & 1.28 \\
\hline $\mathrm{Au}$ & nd & nd & nd & nd & nd & nd & nd & 0.62 & 0.46 & nd \\
\hline $\mathrm{Tl}$ & 1.84 & 1.15 & 1.49 & 1.18 & 1.95 & 0.52 & 0.77 & 0.67 & & 0.37 \\
\hline $\mathrm{Pb}$ & 22.62 & 16.43 & 17.95 & 12.92 & 12.44 & 10.20 & 13.41 & 19.54 & 14.31 & 14.17 \\
\hline $\mathrm{Bi}$ & nd & 0.07 & 0.59 & nd & nd & 0.26 & 0.31 & nd & 0.21 & nd \\
\hline $\mathrm{U}$ & 2.19 & 2.46 & 3.11 & 2.38 & 2.01 & 1.83 & 2.08 & 2.05 & 1.52 & 2.32 \\
\hline
\end{tabular}


Table A-2 (continued)

\begin{tabular}{|c|c|c|c|c|c|c|c|c|c|c|}
\hline & $\begin{array}{l}\text { WIDP3 } \\
\text {-IN06 }\end{array}$ & $\begin{array}{l}\text { WIDP3- } \\
\text { IN07 }\end{array}$ & $\begin{array}{l}\text { WIDP3- } \\
\text { IN08 }\end{array}$ & $\begin{array}{l}\text { WIDP3- } \\
\text { IN09 }\end{array}$ & $\begin{array}{l}\text { WIDP3- } \\
\text { IN10 }\end{array}$ & $\begin{array}{c}\text { WIDP3- } \\
\text { IN11 }\end{array}$ & $\begin{array}{l}\text { WIDP3- } \\
\text { IN12 }\end{array}$ & $\begin{array}{c}\text { WIDP3- } \\
\text { IN13 }\end{array}$ & $\begin{array}{c}\text { WIDP3- } \\
\text { IN14 }\end{array}$ & $\begin{array}{l}\text { WIDP3- } \\
\text { IN15 }\end{array}$ \\
\hline \multicolumn{11}{|c|}{ Major elements (wt\%) } \\
\hline $\mathrm{SiO}_{2}$ & 63.54 & 65.06 & 66.25 & 67.02 & 63.47 & 65.08 & 66.38 & 60.63 & 64.74 & 65.72 \\
\hline $\mathrm{TiO}_{2}$ & 1.17 & 0.94 & 1.05 & 1.11 & 1.17 & 1.09 & 1.07 & 2.27 & 1.14 & 1.12 \\
\hline $\mathrm{Al}_{2} \mathrm{O}_{3}$ & 14.28 & 14.20 & 13.95 & 14.09 & 13.76 & 14.13 & 13.61 & 13.66 & 14.20 & 13.87 \\
\hline $\mathrm{FeO}_{\mathrm{t}}$ & 6.13 & 6.02 & 6.55 & 6.47 & 7.49 & 5.69 & 6.56 & 7.26 & 5.79 & 6.49 \\
\hline $\mathrm{MnO}$ & 0.09 & 0.08 & 0.10 & 0.10 & 0.09 & 0.09 & 0.09 & 0.12 & 0.09 & 0.09 \\
\hline $\mathrm{MgO}$ & 2.28 & 2.32 & 1.36 & 1.14 & 1.92 & 2.05 & 1.40 & 3.00 & 2.20 & 1.34 \\
\hline $\mathrm{CaO}$ & 5.14 & 5.05 & 5.06 & 4.88 & 5.76 & 4.92 & 4.93 & 5.98 & 5.13 & 5.19 \\
\hline $\mathrm{Na}_{2} \mathrm{O}$ & 2.53 & 1.68 & 2.16 & 1.37 & 1.73 & 2.88 & 1.66 & 1.67 & 2.26 & 1.49 \\
\hline $\mathrm{K}_{2} \mathrm{O}$ & 3.05 & 3.19 & 2.95 & 2.88 & 2.31 & 2.84 & 2.77 & 2.57 & 2.75 & 2.53 \\
\hline $\mathrm{P}_{2} \mathrm{O}_{5}$ & 0.04 & 0.01 & 0.02 & 0.04 & 0.01 & 0.00 & 0.04 & 0.51 & 0.01 & nd \\
\hline $\mathrm{Cr}_{2} \mathrm{O}_{3}$ & 0.04 & 0.00 & 0.00 & 0.03 & 0.03 & 0.02 & 0.03 & 0.02 & 0.00 & 0.01 \\
\hline $\mathrm{Cl}(\mathrm{ppm})$ & 1041 & 1150 & 1274 & 1220 & 1228 & 1022 & 1181 & 1398 & 963 & 1313 \\
\hline $\mathrm{S}(\mathrm{ppm})$ & 81 & 80 & 69 & 89 & 296 & 76 & 111 & 123 & 32 & 63 \\
\hline $\mathrm{H}_{2} \mathrm{O}(\mathrm{wt} \%)$ & na & na & na & na & na & na & na & na & na & na \\
\hline Total & 98.38 & 98.66 & 99.58 & 99.27 & 97.90 & 98.90 & 98.66 & 97.85 & 98.42 & 97.99 \\
\hline $\begin{array}{l}\text { Hosting } \\
\text { phenocryst }\end{array}$ & Pla & Pla & Opx & Opx & Opx & Pla & Opx & Pla & Pla & Opx \\
\hline \multicolumn{11}{|c|}{ Trace elements (ppm) } \\
\hline $\mathrm{Li}$ & 24.28 & 31.06 & 28.34 & 17.46 & 23.43 & 24.90 & 25.49 & 17.56 & 20.46 & 24.47 \\
\hline B & 39.58 & 36.67 & 41.88 & 43.78 & 35.66 & 43.24 & 38.13 & 43.78 & 42.69 & 37.83 \\
\hline $\mathrm{Sc}$ & 27.22 & 24.98 & 26.28 & 26.74 & 27.37 & 22.74 & 25.51 & 47.93 & 24.80 & 25.46 \\
\hline $\mathrm{Ti}$ & 6884.28 & 5650.00 & 6184.67 & 6837.40 & 6833.89 & 6375.33 & 6626.43 & 13271.3 & 6954.82 & 6674.72 \\
\hline V & 280.09 & 245.95 & 275.34 & 282.95 & 302.57 & 234.71 & 267.24 & 481.23 & 270.83 & 271.02 \\
\hline $\mathrm{Cr}$ & 23.28 & 8.14 & 1.72 & 4.28 & 19.78 & 14.04 & 3.06 & 21.80 & 16.83 & 18.93 \\
\hline $\mathrm{Mn}$ & 776.96 & 781.14 & 754.37 & 675.10 & 831.25 & 742.36 & 715.22 & 909.11 & 721.84 & 774.46 \\
\hline Co & 16.41 & 17.72 & 13.28 & 12.12 & 16.15 & 14.89 & 12.61 & 20.04 & 14.77 & 15.01 \\
\hline $\mathrm{Ni}$ & 24.48 & 28.36 & 3.14 & 2.87 & 9.92 & 19.58 & 4.03 & 34.92 & 23.67 & 19.94 \\
\hline $\mathrm{Cu}$ & 140.21 & 150.72 & 105.96 & 88.21 & 44.01 & 160.09 & 45.80 & 147.49 & 148.75 & 107.34 \\
\hline $\mathrm{Zn}$ & 72.99 & 73.56 & 66.85 & 77.32 & 79.33 & 66.68 & 61.73 & 83.03 & 60.33 & 82.23 \\
\hline $\mathrm{Ga}$ & 198.94 & 204.38 & 203.89 & 220.23 & 158.07 & 198.73 & 196.86 & 220.97 & 188.23 & 199.79 \\
\hline As & 5.75 & 5.55 & 4.14 & 5.07 & 4.95 & 4.96 & 4.09 & 15.24 & 4.28 & 3.59 \\
\hline $\mathrm{Se}$ & nd & nd & nd & nd & nd & 4.52 & nd & 2.72 & nd & nd \\
\hline $\mathrm{Rb}$ & 86.35 & 89.77 & 88.11 & 100.91 & 68.02 & 86.93 & 90.31 & 66.30 & 82.52 & 86.03 \\
\hline $\mathrm{Sr}$ & 152.03 & 142.71 & 164.26 & 174.80 & 178.73 & 150.22 & 154.36 & 193.04 & 149.10 & 158.34 \\
\hline Mo & 1.23 & 1.68 & 1.50 & 1.12 & 1.10 & 1.20 & 1.06 & 5.91 & 0.96 & 1.35 \\
\hline $\mathrm{Ag}$ & 0.37 & nd & nd & nd & nd & nd & nd & nd & nd & nd \\
\hline $\mathrm{Cd}$ & nd & nd & nd & nd & nd & 1.48 & nd & nd & nd & 0.59 \\
\hline $\mathrm{Sn}$ & nd & nd & 2.55 & 2.35 & nd & 1.68 & 1.17 & nd & nd & 1.53 \\
\hline $\mathrm{Sb}$ & 0.80 & 0.84 & 0.26 & 0.48 & 0.73 & 0.53 & 0.28 & 0.72 & 1.29 & 0.67 \\
\hline $\mathrm{Ba}$ & 980.63 & 1063.31 & 1053.13 & 1209.16 & 824.53 & 1080.40 & 1075.41 & 1164.17 & 1008.15 & 960.86 \\
\hline $\mathrm{Yb}$ & 3.66 & 3.09 & 2.91 & 2.68 & 3.67 & 2.62 & 1.81 & 6.41 & 4.39 & 3.20 \\
\hline $\mathrm{W}$ & 1.56 & 1.14 & 1.06 & 1.38 & 0.66 & 1.33 & 1.22 & 6.77 & 1.75 & 1.49 \\
\hline $\operatorname{Re}$ & nd & nd & nd & nd & nd & 0.52 & nd & nd & nd & nd \\
\hline $\mathrm{Au}$ & nd & nd & nd & nd & nd & nd & nd & 0.31 & nd & nd \\
\hline $\mathrm{Tl}$ & 0.60 & 0.48 & 0.36 & 0.30 & 0.44 & 0.41 & 0.39 & 0.06 & 0.43 & 0.45 \\
\hline $\mathrm{Pb}$ & 11.89 & 12.20 & 14.11 & 15.18 & 14.07 & 11.98 & 17.09 & 13.10 & 10.38 & 14.13 \\
\hline $\mathrm{Bi}$ & nd & 0.21 & nd & 0.20 & 0.19 & 0.22 & 0.26 & 0.24 & nd & 0.23 \\
\hline $\mathrm{U}$ & 2.20 & 2.01 & 2.28 & 2.70 & 2.34 & 1.86 & 1.75 & 8.53 & 1.92 & 1.91 \\
\hline
\end{tabular}


Table A-2 (continued)

\begin{tabular}{|c|c|c|c|c|c|c|c|c|c|}
\hline & $\begin{array}{l}\text { WIDP3 } \\
\text {-IN16 }\end{array}$ & $\begin{array}{c}\text { WIDP3- } \\
\text { IN17 }\end{array}$ & $\begin{array}{l}\text { WIDP3- } \\
\text { IN18 }\end{array}$ & $\begin{array}{l}\text { WIDP3- } \\
\text { IN19 }\end{array}$ & $\begin{array}{l}\text { WIDP3- } \\
\text { IN21-R2 }\end{array}$ & $\begin{array}{l}\text { WIDP3- } \\
\text { Ctx17- } \\
\text { IN01 }\end{array}$ & $\begin{array}{l}\text { WIDP3- } \\
\text { Ctx2- } \\
\text { IN01 }\end{array}$ & $\begin{array}{l}\text { WIDP3- } \\
\text { Ctx2- } \\
\text { IN02 }\end{array}$ & $\begin{array}{c}\text { WIDP3_- } \\
\text { Matrix } \\
\text { glass }\end{array}$ \\
\hline \multicolumn{10}{|c|}{ Major elements (wt\%) } \\
\hline $\mathrm{SiO}_{2}$ & 63.62 & 64.35 & 64.33 & 64.98 & 59.89 & 66.80 & 66.93 & 65.66 & 64.04 \\
\hline $\mathrm{TiO}_{2}$ & 1.35 & 1.16 & 1.21 & 1.19 & 1.34 & 1.12 & 0.95 & 0.94 & 1.04 \\
\hline $\mathrm{Al}_{2} \mathrm{O}_{3}$ & 14.24 & 14.25 & 13.75 & 13.73 & 15.55 & 15.08 & 15.11 & 14.49 & 14.58 \\
\hline $\mathrm{FeO}_{\mathrm{t}}$ & 6.16 & 6.11 & 6.65 & 7.44 & 6.39 & 5.25 & 4.66 & 5.84 & 5.95 \\
\hline $\mathrm{MnO}$ & 0.09 & 0.11 & 0.11 & 0.11 & 0.10 & 0.07 & 0.06 & 0.08 & 0.09 \\
\hline $\mathrm{MgO}$ & 2.34 & 2.24 & 2.06 & 1.76 & 2.38 & 0.73 & 0.72 & 1.21 & 2.64 \\
\hline $\mathrm{CaO}$ & 5.29 & 5.07 & 5.10 & 4.68 & 7.09 & 3.02 & 4.22 & 5.00 & 5.78 \\
\hline $\mathrm{Na}_{2} \mathrm{O}$ & 2.11 & 2.82 & 2.76 & 1.64 & 1.16 & 1.55 & 1.38 & 1.86 & 3.05 \\
\hline $\mathrm{K}_{2} \mathrm{O}$ & 2.76 & 2.77 & 2.54 & 2.49 & 3.51 & 3.58 & 3.06 & 2.98 & 2.63 \\
\hline $\mathrm{P}_{2} \mathrm{O}_{5}$ & 0.08 & 0.03 & 0.05 & 0.01 & 0.70 & 0.05 & nd & 0.01 & nd \\
\hline $\mathrm{Cr}_{2} \mathrm{O}_{3}$ & 0.03 & nd & 0.00 & 0.01 & 0.04 & 0.04 & nd & nd & 0.03 \\
\hline $\mathrm{Cl}(\mathrm{ppm})$ & 1103 & 1057 & 1053 & 1173 & 4388 & 1671 & 1386 & 1365 & 1048 \\
\hline $\mathrm{S}$ (ppm) & 97 & 89 & 112 & 183 & 559 & 129 & 162 & 139 & 47 \\
\hline $\mathrm{H}_{2} \mathrm{O}(\mathrm{wt} \%)$ & na & na & na & na & na & 0.94 & 0.42 & 0.34 & na \\
\hline Total & 98.19 & 99.03 & 98.68 & 98.19 & 97.44 & 97.47 & 97.25 & 98.23 & 99.94 \\
\hline $\begin{array}{l}\text { Hosting } \\
\text { phenocryst }\end{array}$ & Pla & Pla & Cpx & Cpx & $\mathrm{Ol}$ & Opx & Opx & Opx & \\
\hline \multicolumn{10}{|c|}{ Trace elements (ppm) } \\
\hline $\mathrm{Li}$ & 21.51 & 18.65 & 25.28 & 26.27 & 24.43 & 21.56 & 26.92 & 26.31 & 19.76 \\
\hline B & 51.19 & 41.08 & 41.04 & 41.99 & 197.90 & 28.48 & 42.49 & 39.74 & 39.41 \\
\hline $\mathrm{Sc}$ & 27.33 & 25.79 & 30.41 & 28.54 & 25.36 & 81.94 & 22.71 & 24.10 & 26.52 \\
\hline $\mathrm{Ti}$ & 8223.73 & 6834.16 & 7478.77 & 7428.61 & 6519.01 & 7150.71 & 5631.52 & 5578.22 & 6267.02 \\
\hline V & 332.98 & 259.00 & 291.60 & 282.39 & 268.18 & 484.08 & 242.89 & 243.49 & 249.91 \\
\hline $\mathrm{Cr}$ & 19.28 & 16.85 & 23.40 & 11.24 & 2.81 & 408.32 & 2.99 & 20.19 & 54.35 \\
\hline Mn & 810.53 & 733.39 & 880.39 & 829.42 & 1571.58 & 1569.99 & 648.90 & 713.84 & 771.71 \\
\hline Co & 18.48 & 16.04 & 16.21 & 16.06 & 106.63 & 39.62 & 13.52 & 13.61 & 18.39 \\
\hline $\mathrm{Ni}$ & 26.74 & 28.56 & 11.14 & 6.01 & 987.73 & 97.51 & 7.49 & 3.12 & 34.84 \\
\hline $\mathrm{Cu}$ & 151.09 & 159.66 & 78.13 & 110.94 & 183.96 & 138.85 & 168.81 & 127.20 & 44.11 \\
\hline $\mathrm{Zn}$ & 67.77 & 56.62 & 73.03 & 77.97 & 150.30 & 93.59 & 64.84 & 82.52 & 66.88 \\
\hline $\mathrm{Ga}$ & 198.66 & 191.03 & 189.94 & 190.75 & 426.61 & 184.03 & 188.96 & 184.91 & 176.87 \\
\hline As & 5.68 & 5.22 & 4.27 & 4.58 & 15.52 & 3.69 & 5.17 & 5.38 & 5.38 \\
\hline $\mathrm{Se}$ & nd & nd & nd & nd & nd & nd & nd & nd & 2.60 \\
\hline $\mathrm{Rb}$ & 76.24 & 80.46 & 81.73 & 88.47 & 141.19 & 59.06 & 94.36 & 83.77 & 84.81 \\
\hline $\mathrm{Sr}$ & 144.94 & 132.18 & 168.23 & 158.79 & 240.03 & 140.93 & 157.96 & 159.65 & 168.24 \\
\hline Mo & 2.10 & 1.25 & 1.20 & 0.98 & 10.21 & 1.97 & 2.03 & 2.01 & 1.53 \\
\hline $\mathrm{Ag}$ & nd & nd & nd & 0.66 & nd & 0.62 & nd & nd & nd \\
\hline $\mathrm{Cd}$ & nd & nd & nd & nd & nd & 0.65 & nd & nd & nd \\
\hline $\mathrm{Sn}$ & nd & 3.58 & 1.61 & nd & nd & 2.65 & nd & 3.39 & 1.99 \\
\hline $\mathrm{Sb}$ & 0.50 & nd & 0.69 & 0.64 & 3.32 & nd & nd & 0.14 & 0.75 \\
\hline $\mathrm{Ba}$ & 1072.10 & 1073.17 & 979.15 & 1004.59 & 2304.92 & 1020.52 & 993.09 & 969.10 & 967.10 \\
\hline $\mathrm{Yb}$ & 4.43 & 3.08 & 3.87 & 2.81 & 3.93 & 4.08 & 2.58 & 3.94 & 3.09 \\
\hline W & 1.87 & 2.13 & 1.55 & 1.37 & 6.16 & 1.37 & 1.25 & 1.81 & 1.20 \\
\hline $\mathrm{Re}$ & nd & nd & nd & nd & nd & nd & nd & nd & nd \\
\hline $\mathrm{Au}$ & nd & nd & nd & nd & nd & nd & nd & nd & nd \\
\hline $\mathrm{Tl}$ & 0.84 & nd & 0.24 & 0.25 & nd & nd & 0.88 & 0.01 & 0.33 \\
\hline $\mathrm{Pb}$ & 13.07 & 11.50 & 13.67 & 15.22 & 25.80 & 12.72 & 11.71 & 13.33 & 11.44 \\
\hline $\mathrm{Bi}$ & 0.15 & 0.11 & 0.30 & 0.11 & nd & 0.26 & 0.23 & nd & 0.20 \\
\hline $\mathrm{U}$ & 2.35 & 2.13 & 1.82 & 2.20 & 8.84 & 2.11 & 2.00 & 2.15 & 1.79 \\
\hline
\end{tabular}

Notes: na: Not analyzed. nd: Below detection limit. Pla: Plagioclase. Cpx: Clinopyroxene. Ol: Olivine. Opx: Orthopyroxene. 


\section{A.3 Cu-Fe sulphide composition maps}

a) WIDP 13 _ 12-25 March 1977 _ Sulfide 2

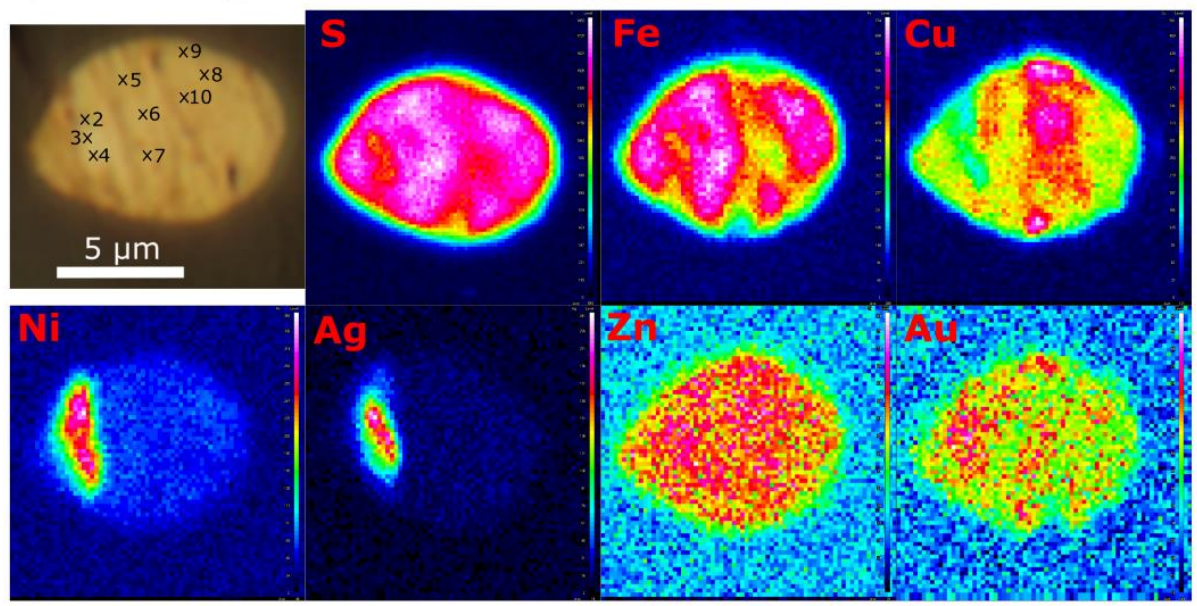

b) WIDP 8 _ 27 July-3 August 1977 _ Sulfide 1

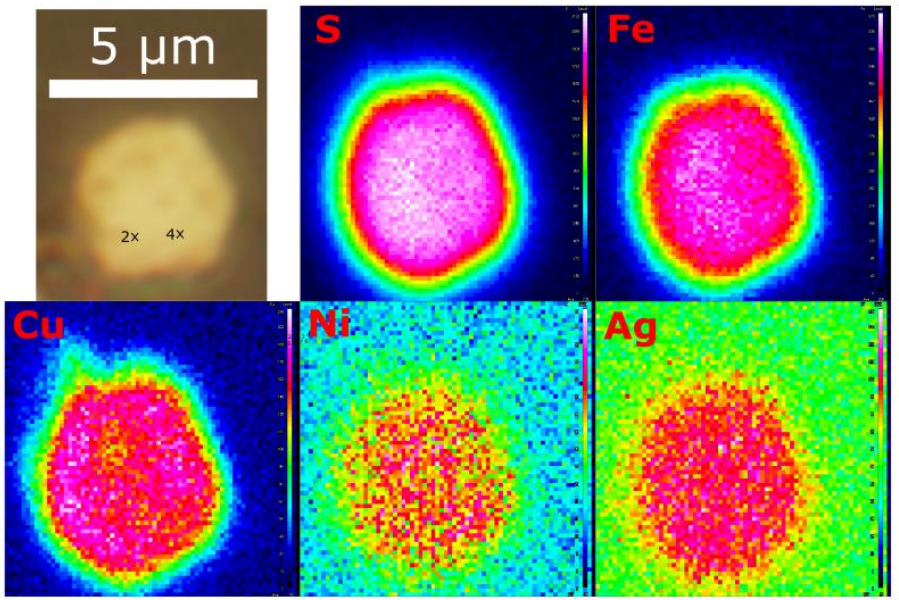

c) WIDP 8 _ 27 July-3 August 1977 _ Sulfide 3

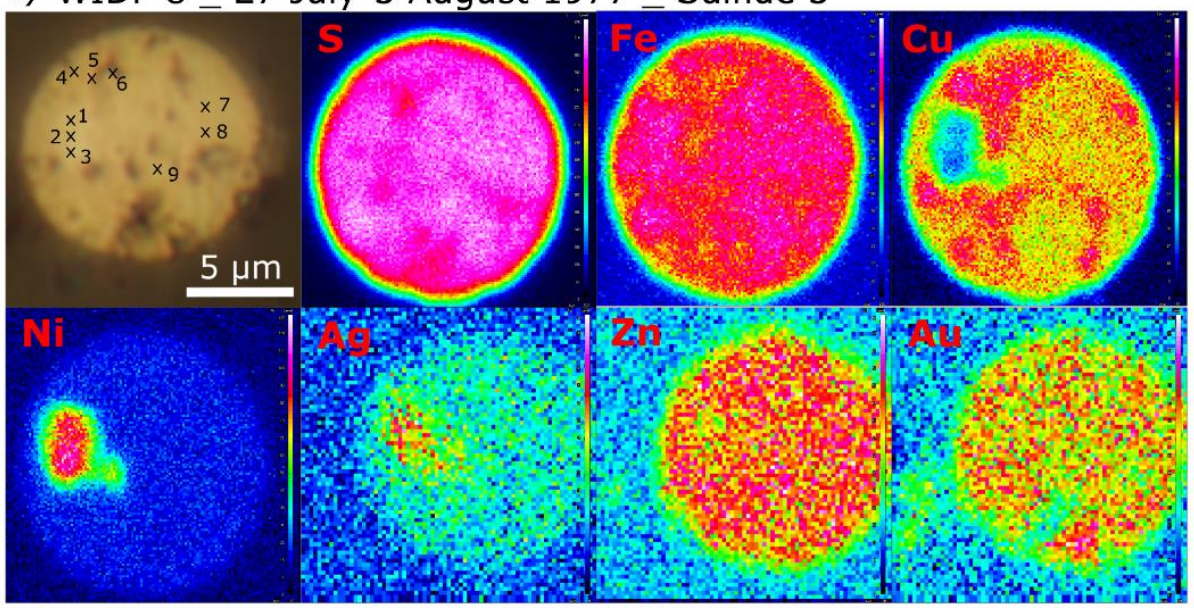

Figure A-1: $\mathrm{Cu}-\mathrm{Fe}$ sulphide composition maps 2. The reflected light image on top left corner shows the position of quantitative point analyses. The other images are composition maps acquired using WDS detectors and show the distribution of each species within the sulphide. a) Sulphide in plagioclase phenocryst from WIDP 13, March 1977. b) Sulphide in plagioclase phenocryst from WIDP 8, JulyAugust 1977. c) Sulphide in plagioclase phenocryst from WIDP 8, July-August 1977. 
a) WIDP 4 _ 19 Octobre 1977

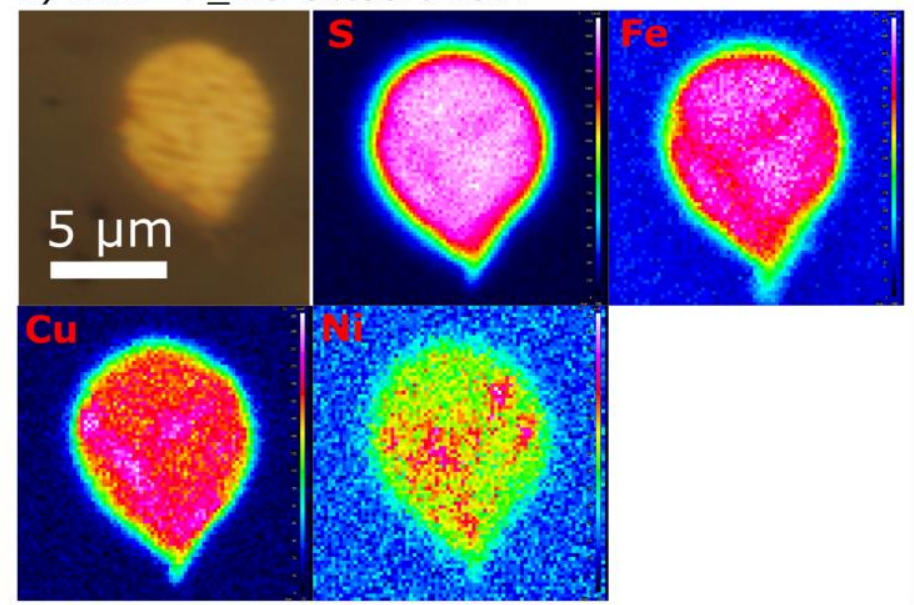

b) WIDP $3_{\text {_ }} 27$ July $2000_{\text {_ Sulfide } 2}$

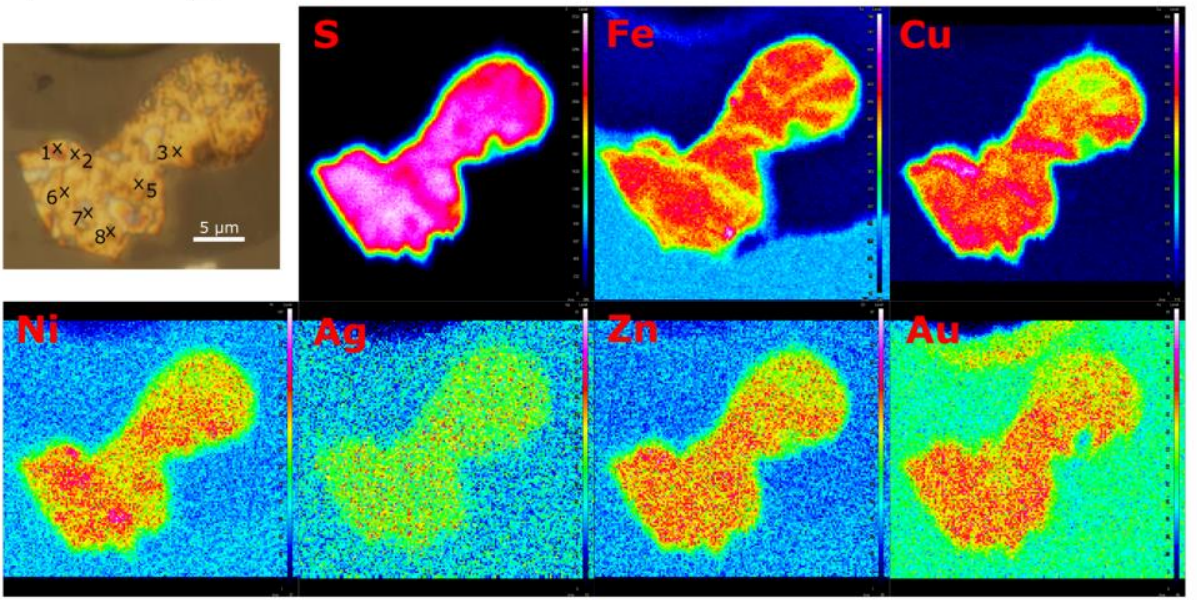

c) WIDP 3_ 27 July 2000 _ Sulfide 3

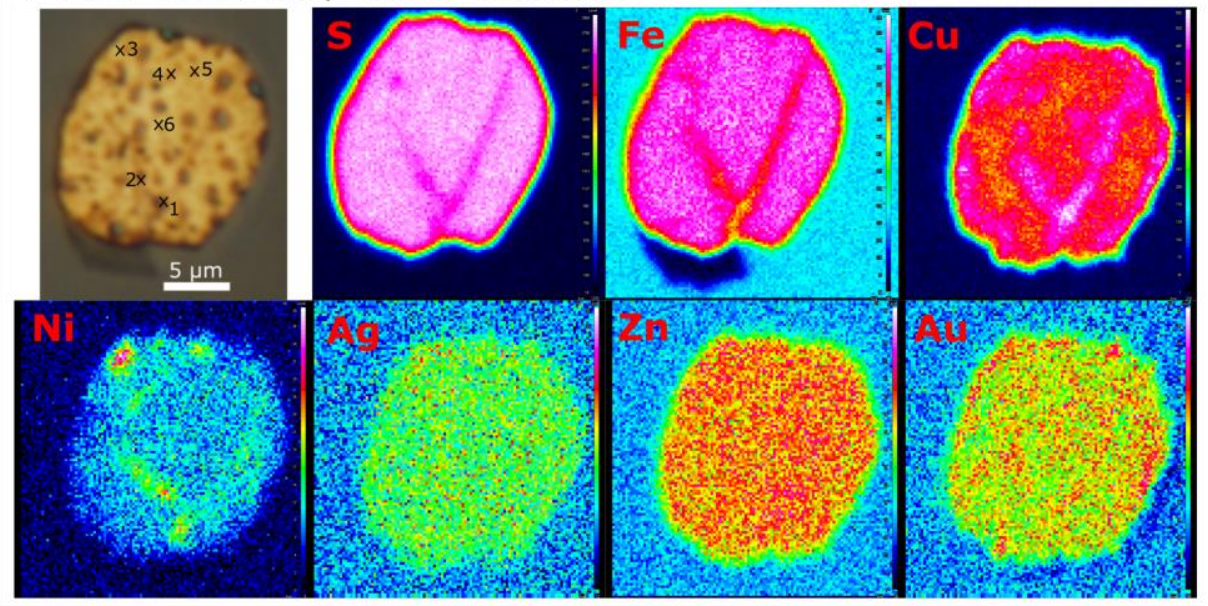

Figure A-2: Cu-Fe sulphide composition maps 3. The reflected light image on top left corner shows the position of quantitative point analyses. The other images are composition maps acquired using WDS detectors and show the distribution of each species within the sulphide. a) Sulphide in a melt inclusion hosted in an orthopyroxene phenocryst from WIDP 4, October 1993. b) Sulphide in a melt inclusion hosted in an orthopyroxene phenocryst from WIDP 3, July 2000. c) Sulphide in an orthopyroxene phenocryst from WIDP 3, July 2000. 


\section{A.4 Sediment core and sulfur globule compositions}

Table A-3: Sediment cores composition, black and yellow sulfur globules composition.

\begin{tabular}{|c|c|c|c|c|c|c|c|c|}
\hline & Core $1 a-1$ & Core $1 a-2$ & Core $1 a-3$ & Core 1a-4 & Core $1 a-5$ & Core $1 a-6$ & $\begin{array}{l}\text { Sulfur } \\
\text { globules } \\
\text { yellow }\end{array}$ & $\begin{array}{c}\text { Sulfur } \\
\text { globules } \\
\text { black }\end{array}$ \\
\hline Date & $5 / 06 / 15$ & $5 / 06 / 15$ & $5 / 06 / 15$ & $5 / 06 / 15$ & $5 / 06 / 15$ & $5 / 06 / 15$ & $5 / 06 / 15$ & $5 / 06 / 15$ \\
\hline $\mathrm{Na}$ (ppm) & 10061 & 4745 & 8280 & 4780 & 4380 & 5005 & 326.4 & 91.93 \\
\hline $\mathrm{Ca}$ & 150820 & 172908 & 50801 & 35399 & 62259 & 53901 & 609.8 & 553.7 \\
\hline Mg & 5401 & 2286 & 9352 & 3164 & 2603 & 3103 & 158.2 & 36.70 \\
\hline Al & 12641 & 7197 & 28442 & 19739 & 19656 & 22098 & 268.3 & 82.83 \\
\hline $\mathrm{Fe}$ & 6799 & 2914 & 17364 & 11693 & 11741 & 11946 & 442.1 & 20582 \\
\hline K & 4235 & 2223 & 10338 & 6311 & 6479 & 7160 & 91.71 & 32.51 \\
\hline B & 45.56 & 5.21 & 78.91 & 11.63 & 36.44 & 10.03 & 4.51 & 1.68 \\
\hline $\mathrm{Rb}$ & 14.55 & 8.46 & 39.81 & 32.33 & 29.95 & 33.99 & 0.26 & 0.06 \\
\hline $\mathrm{Sr}$ & 313.4 & 295.0 & 217.6 & 131.9 & 191.4 & 175.0 & 0.83 & 0.67 \\
\hline $\mathrm{Zr}$ & 10.67 & 14.39 & 91.96 & 106.1 & 85.07 & 96.11 & 0.24 & 0.41 \\
\hline Mo & 0.48 & 0.46 & 1.38 & 1.50 & 1.50 & 1.40 & 0.37 & 1.40 \\
\hline $\mathrm{Ba}$ & 62.97 & 181.6 & 531.1 & 604.6 & 545.6 & 605.9 & 0.52 & 1.57 \\
\hline $\mathrm{TI}$ & 7.05 & 2.61 & 4.08 & 3.59 & 2.58 & 2.50 & 0.17 & 1.31 \\
\hline $\mathrm{Pb}$ & 16.36 & 6.94 & 20.54 & 11.15 & 10.43 & 11.04 & 0.35 & 3.30 \\
\hline $\mathrm{Bi}$ & 5.86 & 2.00 & 2.01 & 1.59 & 1.52 & 1.45 & 0.15 & 1.71 \\
\hline Sc & 20.68 & 26.94 & 12.79 & 7.18 & 6.82 & 7.78 & 0.05 & 0.07 \\
\hline $\mathrm{Ti}$ & 498.8 & 792.1 & 3468 & 4288 & 3365 & 3703 & 4.71 & 30.06 \\
\hline V & 38.19 & 20.87 & 88.48 & 59.56 & 55.77 & 63.45 & 0.43 & 0.64 \\
\hline $\mathrm{Cr}$ & 44.20 & 26.23 & 132.8 & 65.16 & 55.77 & 59.25 & 0.69 & 6.29 \\
\hline $\mathrm{Mn}$ & 356.7 & 63.69 & 249.0 & 125.2 & 102.3 & 122.5 & 3.59 & 2.59 \\
\hline Co & 3.17 & 1.45 & 8.31 & 6.05 & 5.27 & 5.31 & 0.20 & 27.14 \\
\hline $\mathrm{Ni}$ & 9.38 & 4.86 & 25.36 & 15.75 & 13.56 & 12.73 & 0.34 & 62.20 \\
\hline $\mathrm{Cu}$ & 14.56 & 7.34 & 31.86 & 80.00 & 34.51 & 36.52 & 0.79 & 98.97 \\
\hline $\mathrm{Zn}$ & 24.74 & 8.43 & 17.17 & 10.44 & 10.52 & 11.78 & 0.51 & 1.37 \\
\hline Ga & 2.64 & 1.41 & 6.64 & 4.59 & 4.53 & 4.99 & 0.03 & 0.03 \\
\hline As & 47.83 & 31.89 & 26.74 & 21.98 & 17.73 & 18.14 & na & 345.0 \\
\hline Se & nd & nd & 39.15 & 26.12 & 25.88 & 21.82 & 305.8 & 701.2 \\
\hline $\mathrm{Ag}(\mathrm{ppb})$ & 263.1 & 140.2 & 817.7 & 975.5 & 764.6 & 1088 & 8.52 & 96.09 \\
\hline $\mathrm{Cd}$ & 245.9 & 124.5 & 160.3 & 128.8 & 129.6 & 124.7 & 7.34 & 32.48 \\
\hline In & 165.6 & 69.13 & 76.44 & 51.25 & 50.16 & 48.31 & 4.61 & 9.26 \\
\hline Sn & 984.3 & 507.8 & 1057 & 929.1 & 920.6 & 904.9 & 138.0 & 96.71 \\
\hline $\mathrm{Sb}$ & 2410 & 1067 & 2394 & 1768 & 1594 & 1713 & 151.3 & 315.3 \\
\hline $\mathrm{Te}$ & nd & nd & 120.99 & 66.89 & 74.16 & 63.63 & 186982 & 128643 \\
\hline $\mathrm{Sm}$ & 2692 & 2993 & 3350 & 1678 & 2285 & 2152 & 4.01 & 5.58 \\
\hline $\mathrm{Yb}$ & 533.6 & 480.2 & 1345 & 732.7 & 771.0 & 848.1 & 5.92 & 3.27 \\
\hline W & 360.2 & 460.8 & 1436 & 1482 & 1417 & 1228 & 103.7 & 145.6 \\
\hline $\mathrm{Re}$ & 8.31 & 8.36 & 11.79 & 18.52 & 22.79 & 23.62 & 3.12 & 294.0 \\
\hline $\mathrm{Au}$ & 19.62 & 36.94 & 124.5 & 158.7 & 192.7 & 167.3 & 9.99 & 124.4 \\
\hline $\mathrm{Hg}$ & 21.91 & nd & 28.87 & nd & nd & nd & nd & 59.39 \\
\hline
\end{tabular}


Table A-3 (continued)

\begin{tabular}{|c|c|c|c|c|c|c|c|c|}
\hline & $\begin{array}{l}\text { Core } 1 b- \\
1\end{array}$ & $\begin{array}{l}\text { Core } 1 b- \\
2\end{array}$ & $\begin{array}{l}\text { Core } 1 b- \\
3\end{array}$ & $\begin{array}{l}\text { Core 1b- } \\
4\end{array}$ & $\begin{array}{l}\text { Core } 1 b- \\
5\end{array}$ & $\begin{array}{l}\text { Core } 1 b- \\
6\end{array}$ & $\begin{array}{l}\text { Core } 1 b- \\
7\end{array}$ & $\begin{array}{l}\text { Core } 1 b- \\
8\end{array}$ \\
\hline Date & $5 / 06 / 15$ & $5 / 06 / 15$ & $5 / 06 / 15$ & $5 / 06 / 15$ & $5 / 06 / 15$ & $5 / 06 / 15$ & $5 / 06 / 15$ & $5 / 06 / 15$ \\
\hline $\begin{array}{l}\mathrm{Na} \\
(\mathrm{ppm})\end{array}$ & 9516 & 6718 & 6866 & 5352 & 5308 & 3614 & 5780 & 4982 \\
\hline $\mathrm{Ca}$ & 137766 & 157499 & 35770 & 164527 & 147374 & 39832 & 30364 & 24188 \\
\hline Mg & 4795 & 3231 & 8137 & 2861 & 3072 & 3672 & 3000 & 3360 \\
\hline Al & 13335 & 9455 & 24468 & 8339 & 7821 & 8227 & 31878 & 22850 \\
\hline $\mathrm{Fe}$ & 6887 & 3833 & 14254 & 4004 & 4008 & 9792 & 15693 & 15226 \\
\hline K & 4266 & 2878 & 2857 & 2637 & 2287 & 2757 & 2573 & 7269 \\
\hline B & 27.37 & 86.93 & 125.63 & 49.65 & 18.80 & 12.27 & 85.58 & $\mathrm{nd}$ \\
\hline $\mathrm{Rb}$ & 14.50 & 10.79 & 34.69 & 9.28 & 10.32 & 11.87 & 32.94 & 36.48 \\
\hline $\mathrm{Sr}$ & 264.8 & 272.1 & 118.5 & 272.6 & 220.6 & 75.94 & 134.3 & 107.4 \\
\hline $\mathrm{Zr}$ & 16.12 & 15.80 & 91.37 & 12.40 & 17.83 & 27.84 & 98.86 & 89.83 \\
\hline Mo & 0.64 & 0.58 & 1.23 & 0.34 & 0.46 & 0.85 & 1.67 & 1.41 \\
\hline $\mathrm{Ba}$ & 120.8 & 175.6 & 314.2 & 224.0 & 256.4 & 225.1 & 531.4 & 527.5 \\
\hline $\mathrm{TI}$ & 6.28 & 3.43 & 3.93 & 2.97 & 3.18 & 1.93 & 2.77 & 2.65 \\
\hline $\mathrm{Pb}$ & 14.71 & 9.88 & 11.23 & 9.06 & 8.57 & 5.15 & 13.48 & 10.67 \\
\hline $\mathrm{Bi}$ & 5.19 & 2.74 & 1.84 & 2.32 & 2.66 & 1.63 & 1.48 & 1.34 \\
\hline Sc & 20.25 & 21.34 & 10.64 & 10.95 & 16.38 & 4.13 & 10.21 & 7.61 \\
\hline $\mathrm{Ti}$ & 753.3 & 811.0 & 3171 & 572.0 & 904.4 & 1097 & 3651 & 3412 \\
\hline v & 40.69 & 27.17 & 70.54 & 25.69 & 23.54 & 26.49 & 92.46 & 63.49 \\
\hline $\mathrm{Cr}$ & 49.50 & 33.66 & 88.44 & 32.67 & 26.97 & 35.33 & 116.2 & 62.46 \\
\hline $\mathrm{Mn}$ & 141.4 & 89.12 & 198.3 & 79.76 & 86.11 & 88.76 & 108.8 & 126.4 \\
\hline Co & 3.48 & 1.77 & 6.72 & 1.75 & 1.83 & 6.54 & 7.58 & 6.38 \\
\hline $\mathrm{Ni}$ & 10.33 & 5.81 & 20.34 & 5.46 & 5.23 & 17.12 & 18.08 & 16.13 \\
\hline $\mathrm{Cu}$ & 17.16 & 8.98 & 35.49 & 8.08 & 8.85 & 27.47 & 43.68 & 38.49 \\
\hline $\mathrm{Zn}$ & 24.11 & 12.32 & 18.81 & 9.07 & 9.78 & 7.43 & 11.63 & 12.05 \\
\hline $\mathrm{Ga}$ & 2.90 & 1.90 & 5.10 & 1.94 & 1.56 & 1.72 & 7.07 & 4.97 \\
\hline As & 52.26 & 33.60 & 16.70 & 17.78 & 19.26 & 138.4 & 17.71 & 45.67 \\
\hline Se & nd & nd & 17.32 & nd & nd & 296.3 & 34.41 & 73.89 \\
\hline $\mathrm{Ag}(\mathrm{ppb})$ & 180.6 & 236.3 & 829.9 & 127.9 & 166.5 & 225.8 & 892.5 & 734.7 \\
\hline $\mathrm{Cd}$ & 229.1 & 162.5 & 144.7 & 108.4 & 123.5 & 66.46 & 125.5 & 115.8 \\
\hline In & 148.4 & 92.32 & 65.45 & 77.02 & 90.73 & 43.25 & 55.24 & 46.58 \\
\hline Sn & 977.6 & 706.2 & 989.0 & 570.7 & 573.3 & 484.1 & 805.5 & 902.3 \\
\hline $\mathrm{Sb}$ & 2246 & 1540 & 2214 & 1354 & 1480 & 1016 & 1777 & 1655 \\
\hline Te & nd & nd & 49.37 & nd & nd & 1229 & 67.78 & 244.9 \\
\hline $\mathrm{Sm}$ & 2398 & 2538 & 1512 & 2502 & 2526 & 1025 & 1352 & 1178 \\
\hline $\mathrm{Yb}$ & 478.2 & 442.2 & 860.3 & 381.2 & 448.6 & 378.7 & 655.9 & 668.8 \\
\hline w & 495.2 & 448.8 & 1303 & 313.7 & 497.1 & 533.8 & 1275 & 1193 \\
\hline $\mathrm{Re}$ & 9.91 & 5.88 & 14.09 & 4.45 & 8.58 & 29.62 & 30.52 & 19.13 \\
\hline $\mathrm{Au}$ & 43.47 & 25.96 & 136.7 & 10.21 & 17.66 & 28.05 & 112.6 & 138.8 \\
\hline $\mathrm{Hg}$ & 13.62 & 13.92 & 17.82 & 16.06 & nd & nd & nd & nd \\
\hline
\end{tabular}


Table A-3 (continued)

\begin{tabular}{|c|c|c|c|c|c|c|c|c|}
\hline & Core $1 b-9$ & Core 2-1 & Core 2-2 & Core 2-3 & Core 2-4 & Core 2-5 & Core 2-6 & Core 2-7 \\
\hline $\begin{array}{l}\text { Sampling } \\
\text { date }\end{array}$ & $5 / 06 / 15$ & $23 / 12 / 15$ & $23 / 12 / 15$ & $23 / 12 / 15$ & $23 / 12 / 15$ & $23 / 12 / 15$ & $23 / 12 / 15$ & $23 / 12 / 15$ \\
\hline $\mathrm{Na}$ (ppm) & 5596 & 3525 & 2405 & 3332 & 1158 & 4107 & 4445 & 4568 \\
\hline $\mathrm{Ca}$ & 35178 & 22008 & 16304 & 5193 & 1295 & 9618 & 30663 & 36802 \\
\hline Mg & 4006 & 1842 & 1119 & 1708 & 531.1 & 2014 & 2232 & 2307 \\
\hline Al & 24378 & 5785 & 4339 & 5300 & 1800 & 7666 & 11878 & 13498 \\
\hline $\mathrm{Fe}$ & 13100 & 15594 & 21186 & 15167 & 11713 & 12825 & 8695 & 8569 \\
\hline K & 7115 & 1570 & 1268 & 1411 & 625.7 & 1896 & 2953 & 3377 \\
\hline B & 89.30 & nd & nd & nd & nd & nd & nd & nd \\
\hline $\mathrm{Rb}$ & 33.05 & 6.08 & 5.83 & 5.92 & 2.08 & 10.62 & 20.45 & 24.83 \\
\hline $\mathrm{Sr}$ & 131.2 & 285.0 & 315.3 & 213.0 & 52.08 & 313.1 & 492.1 & 548.2 \\
\hline $\mathrm{Zr}$ & 91.10 & 22.04 & 20.74 & 19.93 & 5.11 & 30.79 & 56.74 & 69.51 \\
\hline Mo & 1.36 & 1.15 & 1.25 & 1.24 & 0.60 & 1.11 & 1.13 & 1.23 \\
\hline $\mathrm{Ba}$ & 508.4 & 300.8 & 283.1 & 252.3 & 102.3 & 479.0 & 563.6 & 919.1 \\
\hline TI & 2.32 & 3.10 & 2.83 & 3.11 & 1.30 & 3.48 & 3.81 & 4.11 \\
\hline $\mathrm{Pb}$ & 10.52 & 5.43 & 4.77 & 5.16 & 2.00 & 5.31 & 5.29 & 5.52 \\
\hline $\mathrm{Bi}$ & 1.30 & 3.01 & 2.63 & 2.83 & 1.44 & 2.98 & 2.39 & 2.27 \\
\hline Sc & 8.66 & 2.48 & 1.89 & 2.36 & 0.80 & 3.19 & 4.81 & 5.32 \\
\hline $\mathrm{Ti}$ & 3474 & 967.1 & 873.0 & 891.8 & 254.7 & 1515 & 3006 & 3707 \\
\hline V & 70.05 & 17.60 & 13.00 & 16.01 & 5.56 & 21.24 & 31.91 & 36.11 \\
\hline $\mathrm{Cr}$ & 71.99 & 23.28 & 17.14 & 21.49 & 9.01 & 24.61 & 29.02 & 30.23 \\
\hline $\mathrm{Mn}$ & 143.4 & 64.00 & 43.41 & 60.09 & 20.18 & 78.83 & 105.7 & 117.4 \\
\hline Co & 5.87 & 13.20 & 17.65 & 12.01 & 9.11 & 8.93 & 5.99 & 5.66 \\
\hline $\mathrm{Ni}$ & 14.34 & 34.35 & 44.24 & 31.81 & 24.46 & 23.20 & 14.40 & 13.65 \\
\hline $\mathrm{Cu}$ & 36.30 & 76.18 & 117.3 & 79.52 & 49.60 & 49.17 & 37.73 & 38.90 \\
\hline $\mathrm{Zn}$ & 12.09 & 18.43 & 6.62 & 8.04 & 2.84 & 10.44 & 10.78 & 11.90 \\
\hline $\mathrm{Ga}$ & 5.27 & 1.21 & 0.85 & 1.04 & 0.37 & 1.42 & 2.06 & 2.37 \\
\hline As & 21.07 & 549.5 & 431.3 & 692.5 & 257.1 & 737.2 & 333.3 & 187.3 \\
\hline $\mathrm{Se}$ & 29.61 & 540.4 & 558.9 & 534.5 & 709.8 & 424.1 & 169.3 & 84.27 \\
\hline $\mathrm{Ag}(\mathrm{ppb})$ & 795.3 & 214.0 & 233.7 & 205.0 & 73.4 & 320.2 & 644.2 & 860.5 \\
\hline $\mathrm{Cd}$ & 125.1 & 94.22 & 82.71 & 89.28 & 35.50 & 83.81 & 103.2 & 129.8 \\
\hline In & 50.39 & 74.76 & 53.44 & 67.11 & 25.91 & 81.98 & 81.17 & 85.49 \\
\hline Sn & 879.3 & 868.0 & 639.6 & 898.5 & 299.2 & 1093 & 8855 & 1557 \\
\hline $\mathrm{Sb}$ & 1819 & 1211 & 1025 & 1161 & 397.3 & 1283 & 1753 & 2103 \\
\hline Te & 147.5 & 52974 & 52724 & 49866 & 54683 & 40153 & 15100 & 7585 \\
\hline Sm & 1338 & 599.2 & 704.7 & 481.9 & 141.2 & 752.1 & 1389 & 1493 \\
\hline $\mathrm{Yb}$ & 700.5 & 248.2 & 243.5 & 250.8 & 82.2 & 375.7 & 659.8 & 766.2 \\
\hline W & 1139 & 290.1 & 291.7 & 301.5 & 117.1 & 422.1 & 854.8 & 1034 \\
\hline $\mathrm{Re}$ & 20.96 & 221.9 & 274.2 & 243.4 & 160.0 & 198.8 & 124.0 & 107.4 \\
\hline $\mathrm{Au}$ & 99.38 & 22.99 & 34.06 & 46.55 & 11.86 & 25.54 & 31.92 & 41.42 \\
\hline $\mathrm{Hg}$ & nd & 6.83 & 10.27 & 4.94 & 5.60 & 42.45 & 49.65 & 11.31 \\
\hline
\end{tabular}


Table A-3 (continued)

\begin{tabular}{|c|c|c|c|c|c|c|}
\hline & Core 2-8 & Core 2-9 & Core 2-10 & Core 2-11 & Core $2-12$ & Core $2-13$ \\
\hline Sampling date & $23 / 12 / 15$ & $23 / 12 / 15$ & $23 / 12 / 15$ & $23 / 12 / 15$ & $23 / 12 / 15$ & $23 / 12 / 15$ \\
\hline $\mathrm{Na}(\mathrm{ppm})$ & 2883 & 4000 & 4498 & 3280 & 3552 & 3512 \\
\hline $\mathrm{Ca}$ & 6238 & 6415 & 4224 & 2745 & 3116 & 8999 \\
\hline Mg & 1721 & 2048 & 2153 & 1754 & 1892 & 1863 \\
\hline Al & 12143 & 10280 & 16298 & 8560 & 9322 & 10833 \\
\hline $\mathrm{Fe}$ & 11074 & 8988 & 12747 & 11471 & 8955 & 8984 \\
\hline K & 3126 & 2546 & 4543 & 2106 & 2254 & 2499 \\
\hline B & nd & nd & nd & nd & nd & $\mathrm{nd}$ \\
\hline $\mathrm{Rb}$ & 24.36 & 17.33 & 30.35 & 15.43 & 16.32 & 18.46 \\
\hline $\mathrm{Sr}$ & 156.6 & 232.6 & 147.5 & 239.6 & 229.5 & 186.0 \\
\hline $\mathrm{Zr}$ & 60.16 & 48.15 & 66.64 & 42.17 & 40.33 & 43.64 \\
\hline Mo & 0.98 & 1.27 & 1.07 & 1.27 & 1.12 & 1.25 \\
\hline $\mathrm{Ba}$ & 435.6 & 619.6 & 384.6 & 1102 & 823.7 & 597.1 \\
\hline TI & 2.47 & 3.72 & 4.48 & 3.41 & 3.50 & 3.22 \\
\hline $\mathrm{Pb}$ & 4.30 & 4.69 & 5.73 & 4.29 & 4.11 & 3.83 \\
\hline $\mathrm{Bi}$ & 1.81 & 2.51 & 2.08 & 2.40 & 2.37 & 1.89 \\
\hline Sc & 3.78 & 3.68 & 4.91 & 3.09 & 3.23 & 3.52 \\
\hline $\mathrm{Ti}$ & 3130 & 2907 & 3269 & 2666 & 2738 & 3196 \\
\hline V & 29.16 & 27.65 & 37.95 & 23.88 & 24.86 & 28.07 \\
\hline $\mathrm{Cr}$ & 20.53 & 25.92 & 26.99 & 22.47 & 21.85 & 25.17 \\
\hline $\mathrm{Mn}$ & 89.92 & 85.51 & 126.0 & 72.39 & 80.17 & 86.92 \\
\hline Co & 7.67 & 6.72 & 9.72 & 8.67 & 6.86 & 6.17 \\
\hline $\mathrm{Ni}$ & 19.25 & 17.06 & 24.48 & 22.28 & 16.61 & 14.98 \\
\hline $\mathrm{Cu}$ & 42.03 & 38.39 & 54.41 & 46.29 & 45.22 & 47.88 \\
\hline $\mathrm{Zn}$ & 9.56 & 9.18 & 12.35 & 8.74 & 8.24 & 9.27 \\
\hline $\mathrm{Ga}$ & 2.11 & 1.74 & 2.88 & 1.53 & 1.57 & 1.77 \\
\hline As & 101.7 & 465.5 & 86.11 & 344.2 & 310.8 & 238.2 \\
\hline $\mathrm{Se}$ & 341.9 & 239.0 & 227.1 & 320.6 & 257.5 & 202.6 \\
\hline $\mathrm{Ag}(\mathrm{ppb})$ & 777.0 & 654.8 & 965.3 & 587.0 & 593.2 & 696.7 \\
\hline $\mathrm{Cd}$ & 98.95 & 104.3 & 125.5 & 103.2 & 89.26 & 89.17 \\
\hline In & 53.17 & 79.57 & 64.36 & 67.30 & 71.48 & 62.81 \\
\hline Sn & 2221 & 1238 & 1290 & 1211 & 1095 & 1106 \\
\hline $\mathrm{Sb}$ & 1227 & 1695 & 1727 & 1472 & 1550 & 1622 \\
\hline Te & 31452 & 23161 & 21514 & 31590 & 26600 & 16756 \\
\hline $\mathrm{Sm}$ & 812.3 & 567.7 & 926.2 & 407.6 & 430.0 & 527.0 \\
\hline $\mathrm{Yb}$ & 623.4 & 436.4 & 845.8 & 369.3 & 378.3 & 429.2 \\
\hline W & 844.9 & 856.5 & 969.4 & 799.8 & 790.4 & 896.7 \\
\hline $\mathrm{Re}$ & 119.8 & 157.3 & 106.2 & 193.5 & 145.0 & 123.9 \\
\hline $\mathrm{Au}$ & 43.63 & 38.46 & 52.98 & 29.94 & 31.30 & 29.61 \\
\hline $\mathrm{Hg}$ & 8.46 & 31.30 & 29.25 & 8.00 & 10.67 & 12.27 \\
\hline
\end{tabular}

Notes: nd: Note determined.

Core 1a and 1b were collected on 5 June 2015. Core 2 was collected on 23 December 2015. 


\section{A.5 XRD diffractograms}

28 April Ash

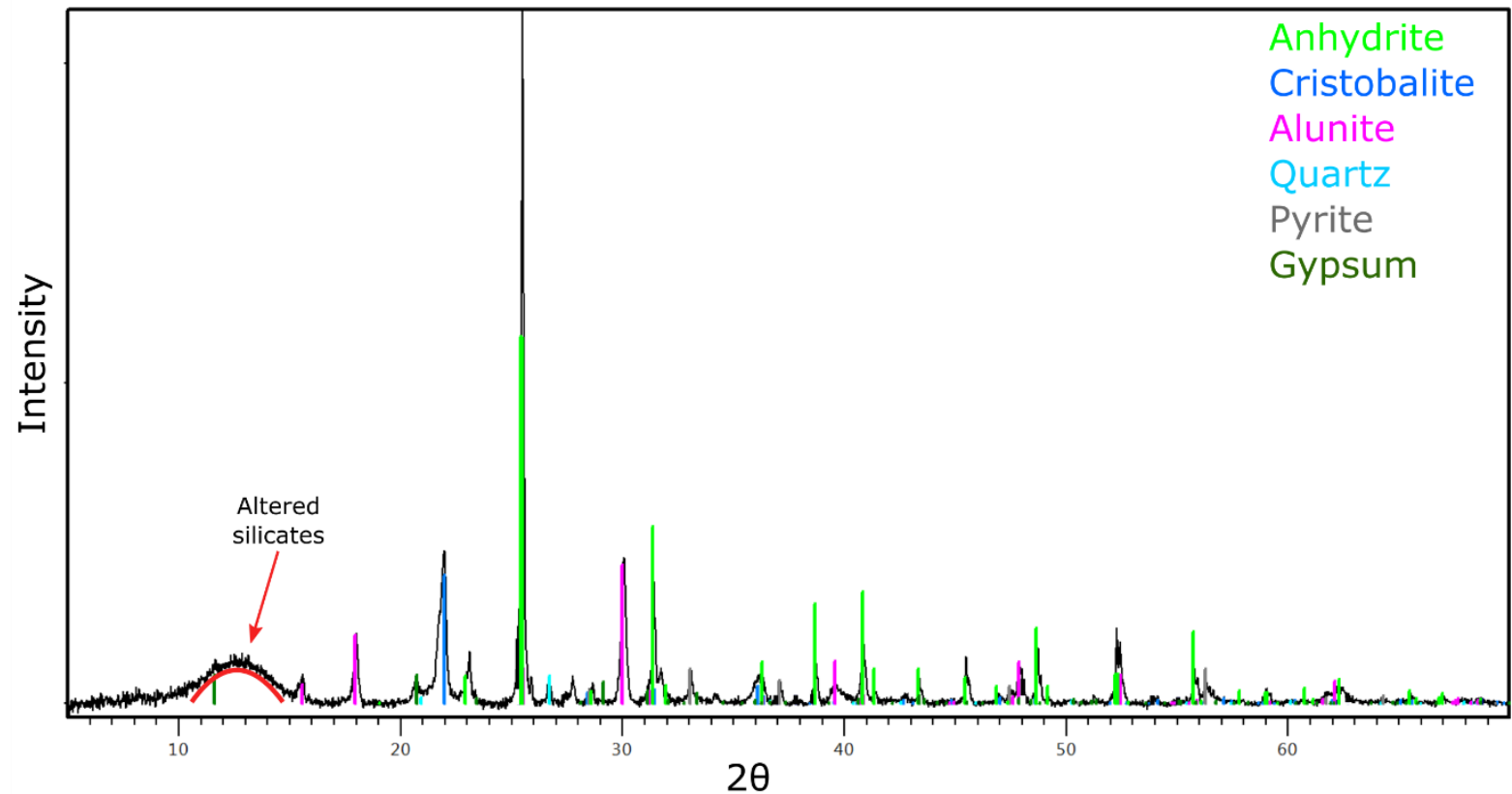

Suspended particles 23/12/15

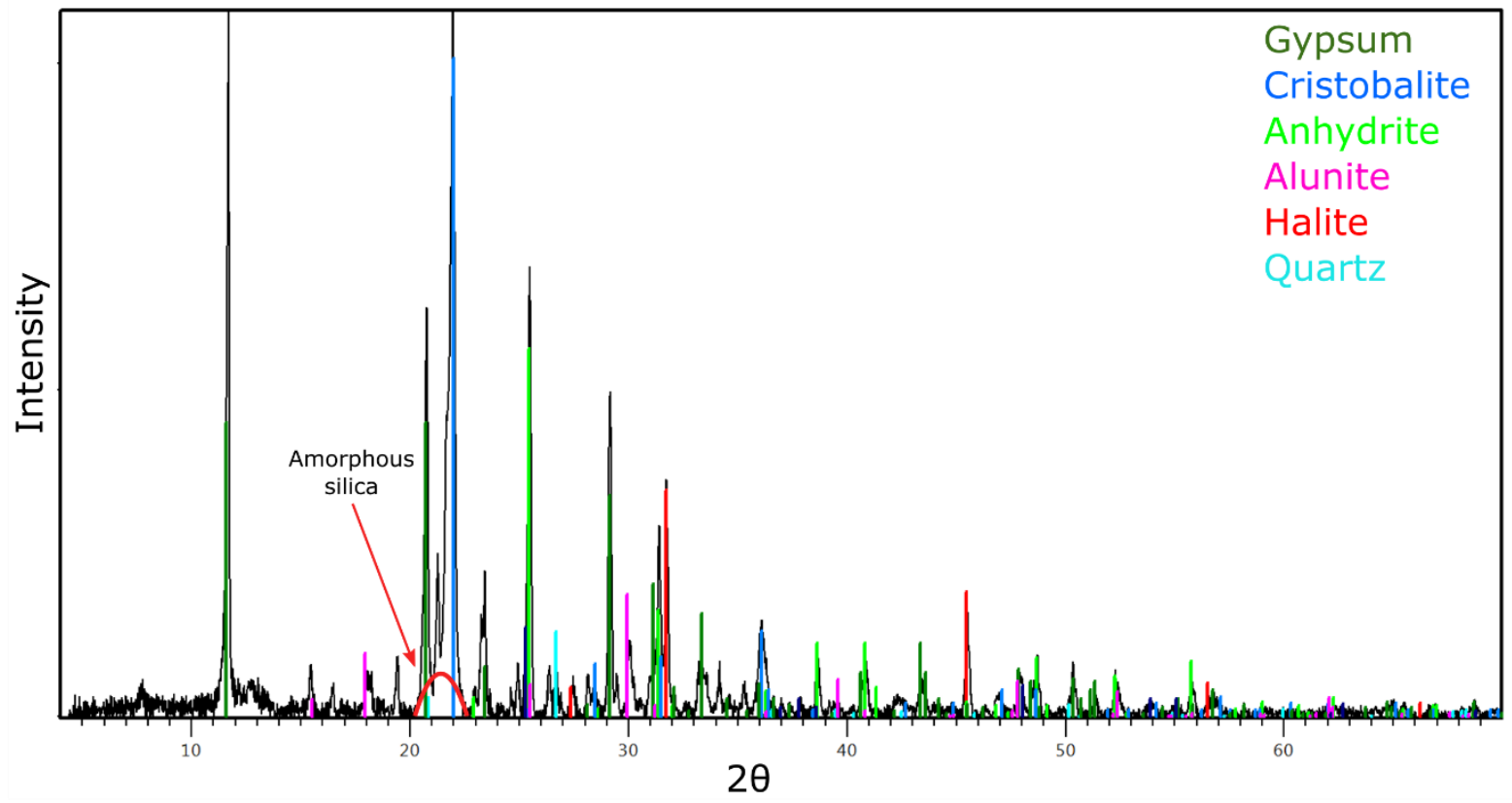

Figure A-3: XRD diffractograms of ash and suspended particles. 


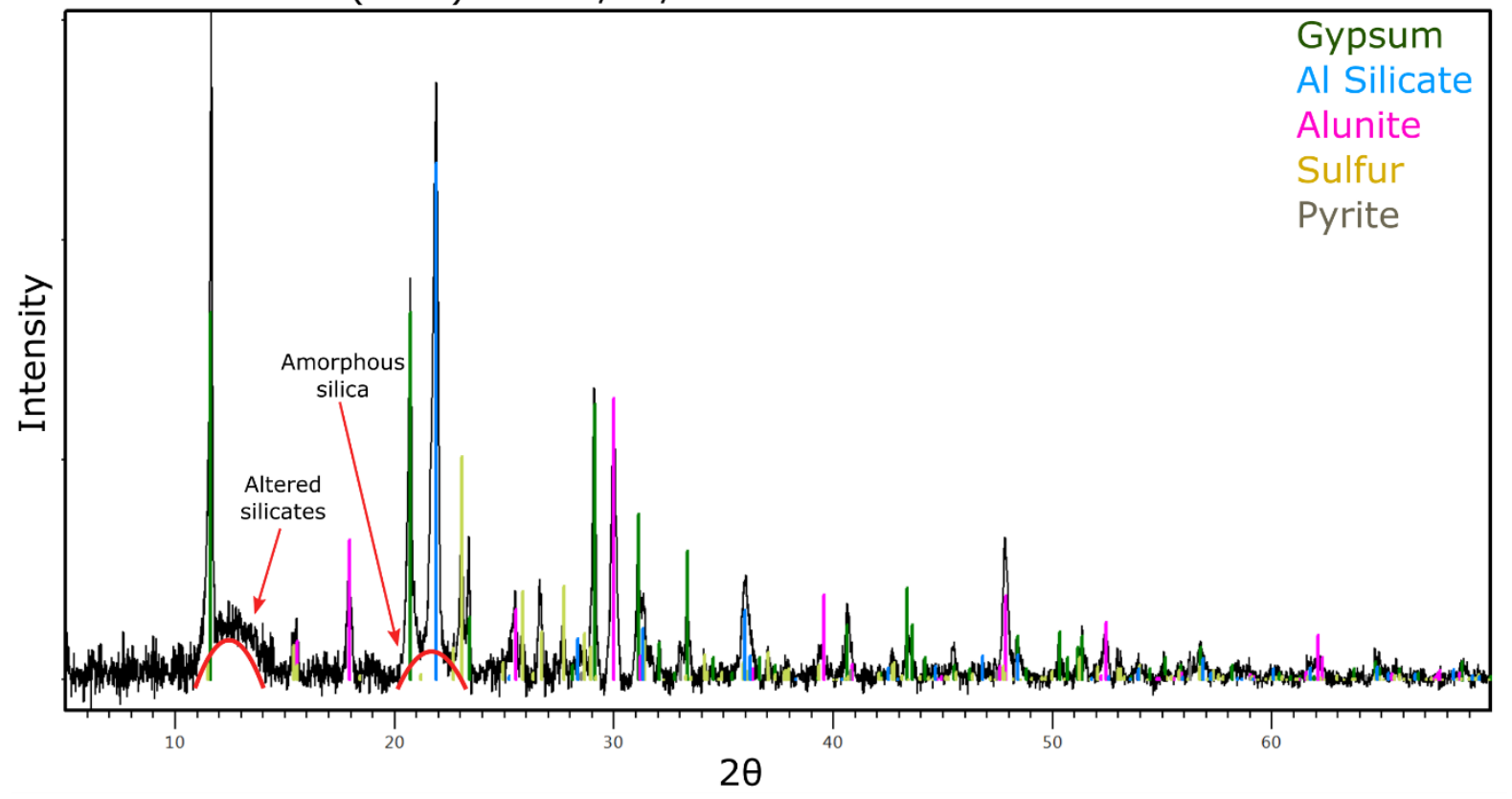

Sediment core (2-6) from 23/12/15

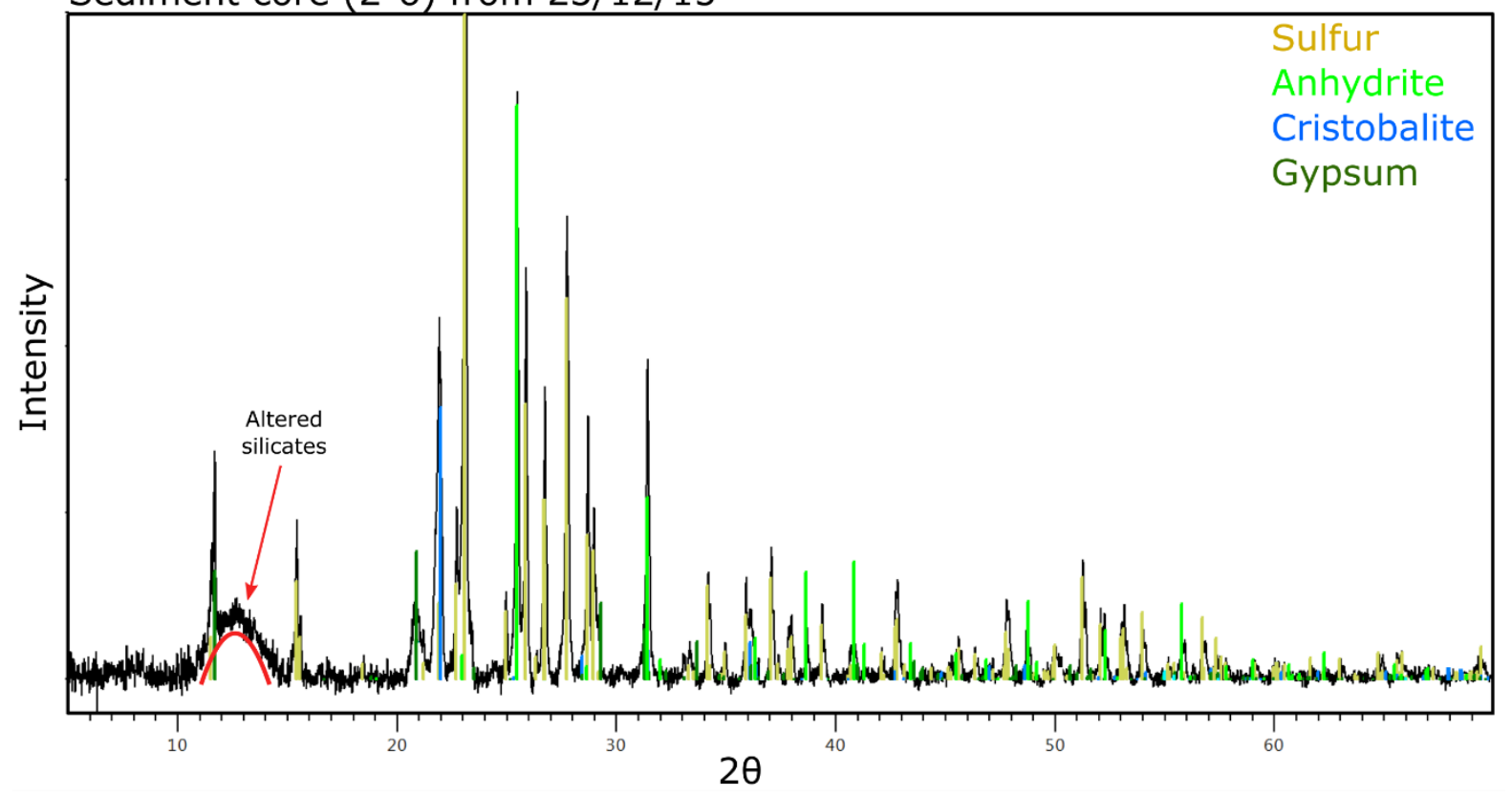

Figure A-4: XRD diffractograms of sediment cores. Layer $1 \mathrm{~b}-8$ was analysed in the sediment core collected on 5 June 2015. Layer 2-6 was analysed in the sediment core collected on 23 December 2015. 


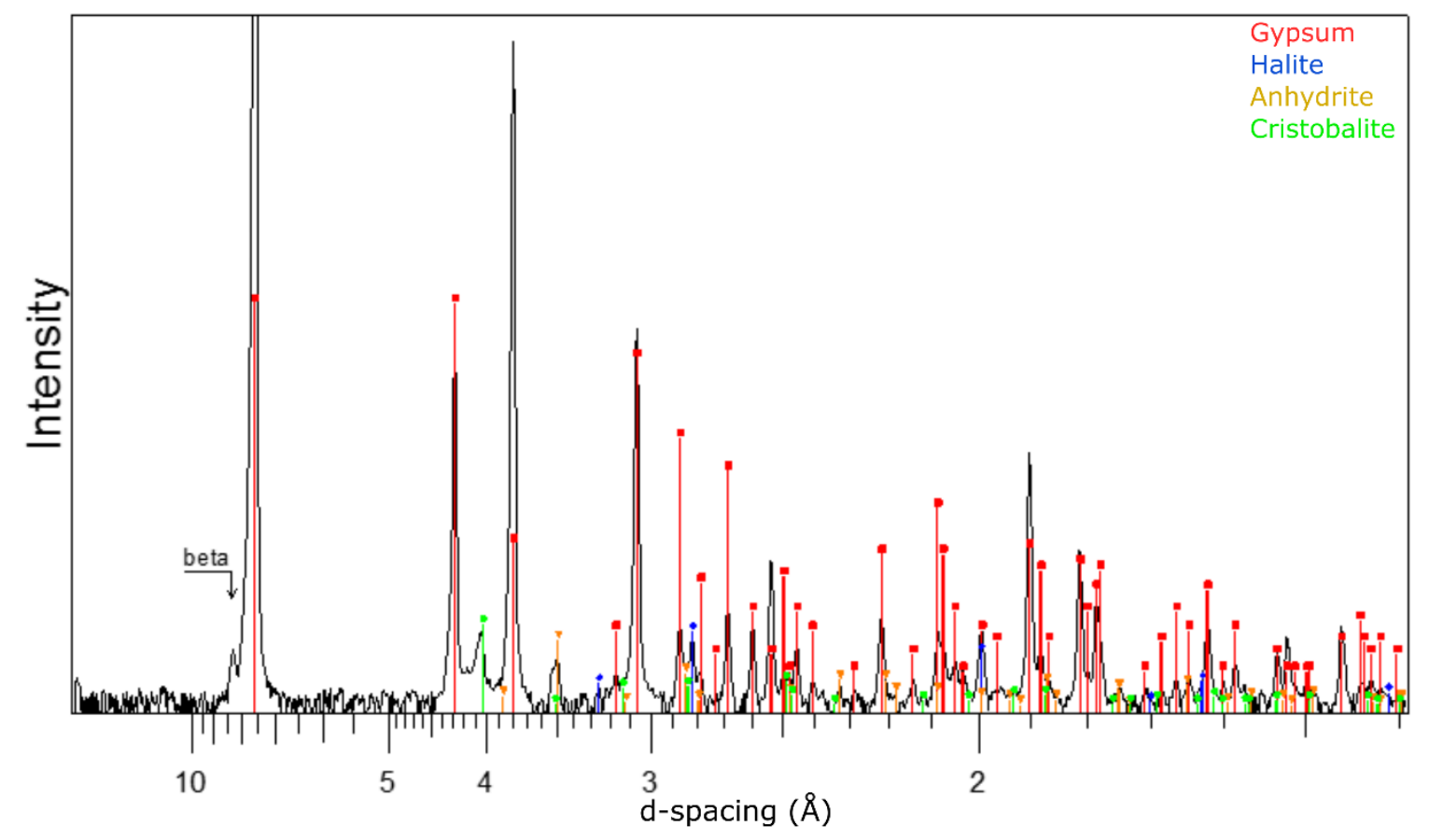

Figure A-5: XRD diffractogram of Core 1b-1. Analysis performed at Callaghan Innovation, Lower Hutt, New Zealand. 


\section{A.6 Sediment core 1a collected on 5 June 2015}

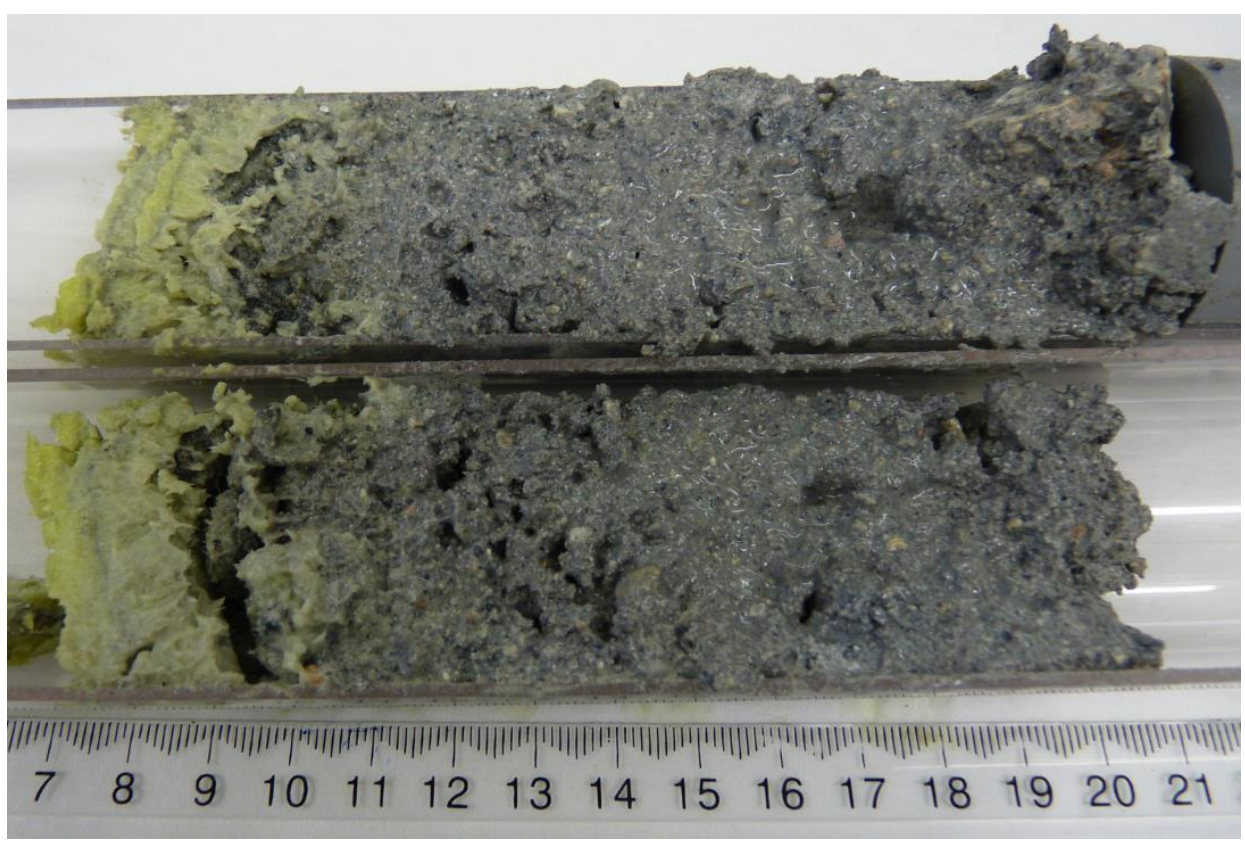

Figure A-6: Picture of one of the core sediments collected on 5 June 2015, Core 1a. 


\section{A.7 ICP-MS detection limit, accuracy and precision}

Table A-4: ICP-MS detection limit (3 SD), secondary standards (SLRS-4, JB1, BIR-1) measurement values, errors (1 SD) and bias.

\begin{tabular}{|c|c|c|c|c|c|c|c|c|c|c|}
\hline & \multirow{2}{*}{$\begin{array}{l}\mathrm{DL} \\
\text { (ng/g) }\end{array}$} & \multicolumn{3}{|l|}{ SLRS-4 } & \multicolumn{3}{|l|}{ JB1 } & \multicolumn{3}{|l|}{ BIR-1 } \\
\hline & & CRM $(\mu \mathrm{g} / \mathrm{l})$ & $\mathrm{MV}(\mu \mathrm{g} / \mathrm{l})$ & Bias (\%) & CRM $(\mu \mathrm{g} / \mathrm{g})$ & $\mathrm{MV}(\mu \mathrm{g} / \mathrm{g})$ & Bias (\%) & CRM $(\mu \mathrm{g} / \mathrm{g})$ & $\mathrm{MV}(\mu \mathrm{g} / \mathrm{g})$ & Bias (\%) \\
\hline B & 0.84 & $5.95^{*}$ & $6.15 \pm 0.67$ & 3.3 & & & & & & \\
\hline $\mathrm{Na}$ & 1.66 & $2400 \pm 200$ & $3083 \pm 1169$ & 28.5 & $20393 \pm 490$ & $22048 \pm 506$ & 8.1 & $13591 \pm 1632$ & 14082 & 3.6 \\
\hline $\mathrm{Ca}$ & 15.15 & $6200 \pm 200$ & $6309 \pm 364.7$ & 1.8 & $66681 \pm 1144$ & $63840 \pm 1066$ & -4.3 & $94983 \pm 429$ & $126506 \pm 98$ & 33.2 \\
\hline $\mathrm{Rb}$ & 0.006 & $1.53^{*} \pm 0.05$ & $1.61 \pm 0.14$ & 5.5 & $39.8 \pm 1.1$ & $36.3 \pm 0.9$ & -8.8 & $0.21 \pm 0.0081$ & $0.18 \pm 0.03$ & -12.1 \\
\hline $\mathrm{Sr}$ & 0.21 & $26.3 \pm 3.2$ & $27.39 \pm 0.72$ & 4.1 & $440.5 \pm 5.9$ & $409.3 \pm 0.9$ & -7.1 & $108.6 \pm 0.7$ & $108.7 \pm 0.4$ & 0.1 \\
\hline $\mathrm{Zr}$ & 0.001 & $0.12 * \pm 0.015$ & $0.1 \pm 0.01$ & -15.2 & $137.9 \pm 4.3$ & $130.3 \pm 2.7$ & -5.5 & $14.8 \pm 0.22$ & $15.7 \pm 0.7$ & 6.3 \\
\hline Mo & 0.006 & $0.21 \pm 0.02$ & $0.22 \pm 0.02$ & 6.3 & $31.6 \pm 2.6$ & $23 \pm 1.6$ & -27.3 & $0.068 \pm 0.021$ & $0.49 \pm 0.1$ & 621.1 \\
\hline $\mathrm{Ag}$ & 0.0004 & $0.035^{*}$ & $0.001 \pm 0.0003$ & -96.8 & 0.049 & $1.1 \pm 0.1$ & 2148.5 & 0.041 & $0.006 \pm 0.002$ & -84.3 \\
\hline $\mathrm{Cd}$ & 0.002 & 0.012 & $0.014 \pm 0.002$ & 18.3 & 0.11 & 0.22 & 97.2 & $0.077 \pm 0.017$ & $0.067 \pm 0.03$ & -12.5 \\
\hline In & 0.0002 & & & & $0.054 \pm 0.007$ & $0.049 \pm 0.037$ & -9.3 & $0.0576 \pm 0.0028$ & $0.044 \pm 0.008$ & -23.2 \\
\hline Sn & 0.019 & $0.008-0.01 *$ & $0.013 \pm 0.008$ & & 2 & $4.1 \pm 3.4$ & 103.4 & $0.701 \pm 0.067$ & $0.65 \pm 0.06$ & -7.6 \\
\hline $\mathrm{Sb}$ & 0.002 & $0.23 \pm 0.04$ & $0.28 \pm 0.04$ & 20.7 & $0.295 \pm 0.027$ & $0.31 \pm 0.07$ & 6.1 & $0.462 \pm 0.032$ & $0.45 \pm 0.03$ & -2.1 \\
\hline Te & 0.008 & $0.004^{*}$ & $0.008 \pm 0.006$ & 98.3 & 0.0018 & $2.9 \pm 4$ & 159735.4 & $0.0057 \pm 0.0024$ & 0.0003 & -95.0 \\
\hline $\mathrm{Ba}$ & 0.035 & $12.22 \pm 0.6$ & $13.33 \pm 1.12$ & 9.1 & $501.2 \pm 7.2$ & $445.3 \pm 24.7$ & -11.2 & $6.75 \pm 0.13$ & $6.96 \pm 0.67$ & 3.1 \\
\hline Sm & 0.0002 & $0.0574 * \pm 0.0028$ & $0.059 \pm 0.004$ & 2.8 & $5.08 \pm 0.1$ & $4.7 \pm 0.3$ & -7.7 & $1.113 \pm 0.018$ & $1.08 \pm 0.02$ & -2.8 \\
\hline $\mathrm{Yb}$ & 0.00004 & $0.012^{*} \pm 0.0004$ & $0.013 \pm 0.001$ & 7.9 & $2.108 \pm 0.052$ & $2 \pm 0.2$ & -6.5 & $1.631 \pm 0.015$ & $1.58 \pm 0.1$ & -3.1 \\
\hline W & 0.002 & $0.0133^{*} \pm 0.001$ & $0.011 \pm 0.004$ & -16.2 & 18 & $10.5 \pm 0.8$ & -41.8 & $0.027 \pm 0.015$ & $1.27 \pm 0.78$ & 4585.4 \\
\hline $\operatorname{Re}$ & 0.0001 & $0.0072^{*}$ & $0.007 \pm 0.001$ & 0.3 & 0.0038 & $0.01 \pm 0.006$ & 161.4 & 0.00065 & $0.001 \pm 0.000004$ & 85.1 \\
\hline $\mathrm{Au}$ & 0.001 & $0.0009-0.00277^{*}$ & $0.009 \pm 0.003$ & & 0.00079 & $0.96 \pm 0.36$ & 121317.8 & 0.0025 & $0.0001 \pm 0.0001$ & -95.9 \\
\hline $\mathrm{Hg}$ & 0.006 & $0.032-0.051^{*}$ & $0.022 \pm 0.025$ & & 0.0299 & $0.23 \pm 0.13$ & 670.1 & 0.0073 & 0.001 & -81.2 \\
\hline TI & 0.001 & $0.0068^{*} \pm 0.0013$ & $0.008 \pm 0.002$ & 13.6 & 0.1 & $0.13 \pm 0.09$ & 31.7 & $0.0021 \pm 0.0007$ & 0.002 & -18.5 \\
\hline $\mathrm{Pb}$ & 0.001 & $0.086 \pm 0.007$ & $0.092 \pm 0.011$ & 6.4 & $7.13 \pm 0.33$ & $9.2 \pm 1.5$ & 29.4 & $3.037 \pm 0.049$ & $2.89 \pm 0.11$ & -4.7 \\
\hline $\mathrm{Bi}$ & 0.0001 & $0.0021 * \pm 0.0001$ & $0.002 \pm 0.0004$ & 2.0 & 0.03 & $0.03 \pm 0.009$ & 0.2 & $0.0051 \pm 0.0014$ & $0.014 \pm 0.009$ & 168.9 \\
\hline $\mathrm{Mg}$ & 0.22 & $1600 \pm 100$ & $1629 \pm 172$ & 1.8 & $47081 \pm 531$ & $57622 \pm 537$ & 22.4 & $58431 \pm 314$ & $59926 \pm 1938$ & 2.6 \\
\hline
\end{tabular}


Table A-4 (continued)

\begin{tabular}{|c|c|c|c|c|c|c|c|c|c|c|}
\hline & $\mathrm{DL}$ & SLRS-4 & & & JB1 & & & BIR-1 & & \\
\hline & (ng/g) & CRM ( $\mu \mathrm{g} / \mathrm{l})$ & $\mathrm{MV}(\mu \mathrm{g} / \mathrm{l})$ & Bias (\%) & CRM $(\mu \mathrm{g} / \mathrm{g})$ & $\mathrm{MV}(\mu \mathrm{g} / \mathrm{g})$ & Bias (\%) & CRM $(\mu \mathrm{g} / \mathrm{g})$ & $\mathrm{MV}(\mu \mathrm{g} / \mathrm{g})$ & Bias (\%) \\
\hline $\mathrm{Al}$ & 0.26 & $54 \pm 4$ & $57.59 \pm 4.73$ & 6.7 & $76899 \pm 741$ & $67679 \pm 822$ & -12.0 & $82085 \pm 370$ & 85124 & 3.7 \\
\hline Sc & 0.0002 & $0.0113^{*} \pm 0.0006$ & $0.011 \pm 0.002$ & 1.3 & $27.3 \pm 3.8$ & $25.8 \pm 0.4$ & -5.3 & $43.21 \pm 0.59$ & $43.7 \pm 1.2$ & 1.2 \\
\hline $\mathrm{Ti}$ & 0.11 & $1.46^{*} \pm 0.08$ & $1.33 \pm 0.19$ & -9.1 & $7787 \pm 126$ & $7649 \pm 74$ & -1.8 & $5747 \pm 40$ & $6033 \pm 35$ & 5.0 \\
\hline V & 0.001 & $0.32 \pm 0.03$ & $0.35 \pm 0.03$ & 10.5 & $213 \pm 13$ & $201 \pm 3$ & -5.5 & $320.6 \pm 2.9$ & $346.4 \pm 1.4$ & 8.0 \\
\hline $\mathrm{Cr}$ & 0.013 & $0.33 \pm 0.02$ & $0.33 \pm 0.03$ & 1.2 & $430 \pm 31$ & $459 \pm 4$ & 6.8 & $392.9 \pm 3.9$ & $392.8 \pm 5.9$ & 0.0 \\
\hline $\mathrm{Mn}$ & 0.030 & $3.37 \pm 0.18$ & $3.72 \pm 0.29$ & 10.4 & $1157 \pm 45$ & $1153 \pm 55$ & -0.4 & $1341 \pm 12$ & $1420 \pm 33$ & 5.9 \\
\hline $\mathrm{Fe}$ & 0.10 & $103 \pm 5$ & $105.2 \pm 8$ & 2.1 & $62880 \pm 909$ & $58152 \pm 559$ & -7.5 & $79737 \pm 350$ & $83229 \pm 2297$ & 4.4 \\
\hline Co & 0.001 & $0.033 \pm 0.006$ & $0.037 \pm 0.003$ & 12.5 & $37.8 \pm 2.4$ & $36 \pm 1.2$ & -4.7 & $52.22 \pm 0.57$ & $53.7 \pm 1.5$ & 2.8 \\
\hline $\mathrm{Ni}$ & 0.041 & $0.67 \pm 0.08$ & $0.74 \pm 0.06$ & 9.9 & $138.6 \pm 5.9$ & $133 \pm 8$ & -3.7 & $168.9 \pm 1.9$ & $181.5 \pm 8.1$ & 7.5 \\
\hline $\mathrm{Cu}$ & 0.006 & $1.81 \pm 0.08$ & $1.93 \pm 0.13$ & 6.4 & $54.9 \pm 1.3$ & $50.5 \pm 3.6$ & -8.0 & $120.7 \pm 1.6$ & $132 \pm 10$ & 9.4 \\
\hline $\mathrm{Zn}$ & 0.054 & $0.93 \pm 0.1$ & $1.58 \pm 0.16$ & 69.7 & $83.7 \pm 5.4$ & $89.8 \pm 13.4$ & 7.3 & $70.4 \pm 1.1$ & $75.5 \pm 34.5$ & 7.2 \\
\hline Ga & 0.0003 & $0.0119 * \pm 0.0004$ & $0.01 \pm 0.001$ & -14.8 & $17.3 \pm 1.8$ & $17.4 \pm 1$ & 0.8 & $15.46 \pm 0.23$ & $16 \pm 0.3$ & 3.5 \\
\hline K & 1.28 & $680 \pm 20$ & $708.3 \pm 67$ & 4.2 & $11788 \pm 224$ & $11181 \pm 309$ & -5.2 & $241 \pm 25$ & $233.1 \pm 62.4$ & -3.3 \\
\hline As & 0.012 & $0.68 \pm 0.06$ & $0.81 \pm 0.06$ & 19.1 & $2.5 \pm 0.5$ & $2.1 \pm 0.1$ & -14.4 & $0.17 \pm 0.14$ & $0.094 \pm 0.066$ & -45.0 \\
\hline Se & 0.15 & $0.23 * \pm 0.03$ & $0.27 \pm 0.11$ & 19.0 & 0.02 & $1.4 \pm 1.3$ & 7144.1 & $0.019 \pm 0.012$ & $0.12 \pm 0.16$ & 545.4 \\
\hline
\end{tabular}

Notes: DL: Detection Limit (3 standard deviations $1 \% \mathrm{HNO}_{3}$ ). CRM: Certified Reference Material. MV: Measured value and standard deviation. Bias: Deviation between the certified and measured values. * Compiled values. 
A.8 Plume enrichment factors, rock compositions (White Island, Yasur, Etna)

Table A-5: Enrichment factors in the aerosol and rock composition for White Island, Yasur and Etna

\begin{tabular}{|c|c|c|c|c|c|c|c|c|}
\hline & \multicolumn{5}{|c|}{ Enrichment factors } & \multicolumn{3}{|c|}{ Rock composition $\left(\mu \mathrm{g} \cdot \mathrm{g}^{-1}\right)$} \\
\hline & $\begin{array}{l}\text { White } \\
\text { Island }\end{array}$ & $\begin{array}{l}\text { White } \\
\text { Island }\end{array}$ & $\begin{array}{l}\text { White } \\
\text { Island }\end{array}$ & Yasur & Etna & $\begin{array}{l}\text { White } \\
\text { Island }\end{array}$ & Yasur & Etna \\
\hline & $26 / 06 / 15$ & $17 / 06 / 16$ & 20/12/16 & $18 / 10 / 16$ & $3 / 08 / 16$ & Andesite & Ash & Lava \\
\hline B & 214.2 & & 325.5 & & & 25 & 39 & na \\
\hline $\mathrm{Na}$ & & 2.8 & 0.3 & 2.0 & 86.9 & 16988 & 23534 & 27100 \\
\hline $\mathrm{Ca}$ & 3.1 & 5.8 & 2.0 & 2.0 & & 57819 & 55131 & 74200 \\
\hline $\mathrm{Rb}$ & 0.5 & 1.5 & 0.2 & 1.9 & 295.7 & 47 & 40 & 40 \\
\hline $\mathrm{Sr}$ & 1.0 & 12.7 & & & & 161 & na & 1270 \\
\hline $\mathrm{Zr}$ & 0.4 & & 1.6 & 0.7 & 2.2 & 98 & 107 & 210 \\
\hline Mo & 204.7 & & 160.5 & 28.1 & 971.6 & 1.0 & 3.0 & 3.7 \\
\hline $\mathrm{Ag}$ & 281.5 & & 1280.6 & 9.5 & 5.8 & 0.04 & 0.7 & 0.9 \\
\hline $\mathrm{Cd}$ & 143.1 & 1410.0 & & 1196.5 & 8175.8 & 0.05 & 0.12 & 0.9 \\
\hline In & 41.3 & & & 4107.1 & & 0.05 & 0.04 & 0.08 \\
\hline Sn & 43.2 & & & & & 1.5 & 1.1 & 1.5 \\
\hline $\mathrm{Sb}$ & 1063.6 & 13878.6 & 200.1 & 66.0 & 8382.7 & 0.19 & 0.19 & 0.12 \\
\hline Te & 312451.2 & 1271470.7 & & & 8707.6 & 0.0011 & - & 1.9 \\
\hline $\mathrm{Ba}$ & 0.4 & 7.6 & 1.2 & 1.0 & 5.5 & 510 & 531 & 680 \\
\hline $\mathrm{Sm}$ & 0.4 & 1.5 & 1.8 & 0.9 & 2.5 & 2.4 & 4.7 & 9.2 \\
\hline $\mathrm{Yb}$ & 0.2 & 1.0 & 0.6 & 0.9 & 3.6 & 2.0 & 2.6 & 1.3 \\
\hline W & 269.5 & 1.5 & & 29.9 & & 1.3 & 0.33 & 1.0 \\
\hline $\operatorname{Re}$ & 1044.9 & & & & 298103.4 & 0.0012 & - & 0.0004 \\
\hline $\mathrm{Au}$ & 62128.0 & & 37709.7 & & & 0.0001 & 0.05 & 0.10 \\
\hline $\mathrm{Tl}$ & 2372.6 & 11988.7 & 78.7 & 3830.8 & 253601.5 & 0.19 & 0.05 & 0.09 \\
\hline $\mathrm{Pb}$ & 100.1 & 703.6 & 5.1 & 82.6 & 7369.7 & 7.7 & 11.8 & 8.0 \\
\hline $\mathrm{Bi}$ & 382.2 & 449.1 & 47.8 & 2433.7 & 390531.2 & 0.76 & 0.02 & 0.02 \\
\hline $\mathrm{Mg}$ & 0.1 & 0.6 & 0.1 & 3.7 & & 48185 & 16284 & 30700 \\
\hline Al & 1.0 & 1.0 & 1.0 & 1.0 & 1.0 & 69966 & 84172 & 96000 \\
\hline Sc & 0.3 & 0.6 & 0.3 & 0.7 & 1.1 & 30 & 20 & 20 \\
\hline $\mathrm{Ti}$ & 0.4 & 0.8 & 0.5 & 1.7 & 8.0 & 3657 & 4808 & 6300 \\
\hline V & 0.4 & 1.4 & 0.1 & 0.9 & 10.4 & 211 & 254 & 305 \\
\hline $\mathrm{Cr}$ & 23.6 & & 40.7 & 0.7 & & 356 & 27 & 32 \\
\hline $\mathrm{Mn}$ & & & 0.2 & 0.8 & 0.5 & 929 & 1285 & 1000 \\
\hline $\mathrm{Fe}$ & 0.4 & 0.5 & 0.1 & 0.9 & 3.9 & 56096 & 55783 & 77200 \\
\hline Co & 0.2 & 1.5 & 0.2 & 0.9 & 26.1 & 32 & 19 & 30 \\
\hline $\mathrm{Ni}$ & 0.4 & & 3.1 & 2.7 & & 114 & 17 & 54 \\
\hline $\mathrm{Cu}$ & 4.4 & 17.6 & 9.1 & 16.5 & 2746.7 & 81 & 277 & 90 \\
\hline $\mathrm{Zn}$ & 21.6 & 6847.4 & & 7.4 & 2225.6 & 47 & 98 & 110 \\
\hline Ga & 1.0 & 5.6 & 1.4 & 1.0 & 3.4 & 13 & 19 & 16 \\
\hline K & 0.6 & 5.8 & 0.6 & 12.9 & 128.0 & 11871 & 3582 & 15400 \\
\hline As & 855.7 & 7222.4 & 13.2 & 378.2 & 38502.5 & 4.8 & 2.9 & 1.0 \\
\hline $\mathrm{Se}$ & 1524.9 & 74031.8 & & 418.1 & 2159524.3 & $0.9 *$ & 0.9 & 0.05 \\
\hline
\end{tabular}

White Island 1977 andesite (this study), Yasur ash (this study), Etna lava (Aiuppa et al., 2003)

*: Se value for White Island andesite from Wells (1967). 


\section{A.9 HSC input files}

Table A-6: Gas composition in mol\% used as input for HSC thermochemical modeling

\begin{tabular}{|c|c|c|c|c|c|c|c|}
\hline Sample & $\begin{array}{l}\text { Donald } \\
\text { Mound }\end{array}$ & F0 & F0 & F0 & Yasur $^{b}$ & Kudriavy $^{b}$ & $\begin{array}{l}\text { White } \\
\text { Island d }^{d}\end{array}$ \\
\hline Date & Feb 1988 & $\begin{array}{c}23 \mathrm{Dec} \\
2014\end{array}$ & $\begin{array}{l}5 \text { Jun } \\
2015\end{array}$ & $\begin{array}{c}30 \text { Sep } \\
2015\end{array}$ & Oct 2007 & 1995 & Feb 1984 \\
\hline$\left({ }^{\circ} \mathrm{C}\right)$ & 495 & 160.7 & 160 & 174 & na & 984 & 772 \\
\hline $\log f_{\mathrm{O}_{2}}(\mathrm{bar})^{1}$ & -20.53 & -53 & -45.95 & -44.07 & na & -10.99 & -13.18 \\
\hline$\Delta \mathrm{NNO}^{1}$ & +2.56 & -4.90 & +2.25 & +2.32 & na & -0.52 & +1.31 \\
\hline $\log f_{\mathrm{O}_{2}}(\mathrm{bar})^{2}$ & -20.74 & -48.72 & -47.83 & -39.48 & & & \\
\hline$\triangle \mathrm{NNO}^{2}$ & +2.35 & -0.62 & +0.36 & +6.91 & & & \\
\hline $\mathrm{H}_{2} \mathrm{O}$ & 94.44 & 92.22 & 89.18 & 85.47 & 97.17 & 94.79 & 94.50 \\
\hline $\mathrm{CO}_{2}$ & 4.00 & 6.18 & 8.78 & 12.34 & 1.50 & 1.72 & 3.85 \\
\hline $\mathrm{SO}_{2}$ & 0.59 & 0.074 & 0.82 & 1.47 & 0.83 & 1.83 & $0.86^{*}$ \\
\hline $\mathrm{H}_{2} \mathrm{~S}$ & 0.17 & 0.35 & 0.24 & 0.12 & $4.16 \mathrm{E}-03$ & 0.19 & na \\
\hline $\mathrm{HCl}$ & 0.60 & 0.82 & 0.80 & 0.52 & 0.36 & 0.17 & 0.63 \\
\hline $\mathrm{HF}$ & $9.80 \mathrm{E}-03$ & $3.65 \mathrm{E}-04$ & $1.42 \mathrm{E}-04$ & 6.07E-04 & 0.097 & 0.075 & 0.03 \\
\hline $\mathrm{NH}_{3}$ & na & 8.37E-05 & $3.32 \mathrm{E}-05$ & $1.85 \mathrm{E}-04$ & na & na & 0.003 \\
\hline $\mathrm{H}_{2}$ & 0.025 & 0.32 & 0.10 & $5.3 \mathrm{E}-05$ & 0.042 & 1.17 & 0.23 \\
\hline $\mathrm{N}_{2}$ & 0.017 & 0.033 & 0.077 & 0.084 & na & na & 0.02 \\
\hline $\mathrm{CH}_{4}$ & 4.60E-04 & $1.50 \mathrm{E}-03$ & $8.96 \mathrm{E}-04$ & $7.50 \mathrm{E}-04$ & na & $8.15 \mathrm{E}-12$ & 0.001 \\
\hline $\mathrm{CO}$ & $1.50 \mathrm{E}-04$ & $5.82 \mathrm{E}-03$ & $2.48 \mathrm{E}-06$ & 4.17E-06 & na & 0.033 & 0.004 \\
\hline $\mathrm{HBr}$ & na & 4.91E-05 & $1.23 \mathrm{E}-04$ & 2.37E-04 & na & $1.54 \mathrm{E}-04$ & na \\
\hline TI & $6.62 \mathrm{E}-07$ & $8.64 \mathrm{E}-11$ & $9.11 \mathrm{E}-11$ & $2.2 \mathrm{E}-09$ & $8.82 \mathrm{E}-08$ & $6.69 \mathrm{E}-07$ & $6.50 \mathrm{E}-07$ \\
\hline $\mathrm{Pb}$ & $1.68 \mathrm{E}-06$ & $9.05 \mathrm{E}-09$ & $1.5 \mathrm{E}-08$ & $2.4 \mathrm{E}-07$ & $5.45 \mathrm{E}-07$ & $6.76 \mathrm{E}-06$ & $1.65 \mathrm{E}-06$ \\
\hline $\mathrm{Bi}$ & $6.48 \mathrm{E}-07$ & $3.48 \mathrm{E}-09$ & $5.82 \mathrm{E}-09$ & $5.5 \mathrm{E}-08$ & 3.07E-08 & $5.46 \mathrm{E}-07$ & $6.36 \mathrm{E}-07$ \\
\hline $\mathrm{Fe}$ & $3.29 \mathrm{E}-05$ & $2.11 \mathrm{E}-06$ & $3.26 \mathrm{E}-07$ & $2.2 \mathrm{E}-05$ & $2.64 \mathrm{E}-05$ & $1.52 \mathrm{E}-04$ & $3.23 \mathrm{E}-05$ \\
\hline $\mathrm{Cu}$ & $9.13 \mathrm{E}-07$ & $1.53 \mathrm{E}-07$ & $1.37 \mathrm{E}-07$ & $3.2 \mathrm{E}-06$ & $1.27 \mathrm{E}-05$ & $1.52 \mathrm{E}-06$ & 8.97E-07 \\
\hline $\mathrm{Zn}$ & $3.55 \mathrm{E}-05$ & $1.48 \mathrm{E}-06$ & 2.66E-07 & $8.4 \mathrm{E}-06$ & $2.58 \mathrm{E}-06$ & 3.46E-05 & $3.49 \mathrm{E}-05$ \\
\hline As & $6.97 \mathrm{E}-05$ & $3.22 \mathrm{E}-06$ & 3.01E-05 & $1.4 \mathrm{E}-05$ & $1.94 \mathrm{E}-06$ & 4.39E-05 & $6.84 \mathrm{E}-05$ \\
\hline
\end{tabular}

Note: na: Not analysed.

a: From Tedesco \& Toutain, 1991

${ }^{\mathrm{b}}$ : Major elements from Metrich et al., 2011, trace metals from our filter pack study

c: From Wahrenberg et al., 2002

d: Major elements from Giggenbach \& Sheppard, 1989, trace metals from Tedesco \& Toutain, 1991

*: sulfur total

1: $f_{\mathrm{O}_{2}}$ calculated from $\mathrm{CO} / \mathrm{CO}_{2}$

: $f_{\mathrm{O}_{2}}$ calculated from $\mathrm{H}_{2} / \mathrm{H}_{2} \mathrm{O}$ 